\title{
A RECONSTRUCTION OF PROTO-NORTHERN ADELBERT PHONOLOGY AND LEXICON
}

\author{
A dissertation submitted to the Graduate Division of the University of Hawai'i at Mānoa
} in partial fulfillment of the requirements for the degree of

\section{DOCTOR OF PHILOSOPHY IN LINGUISTICS}

December 2020

\author{
Andrew Pick
}

Dissertation Committee:

Robert Blust, Chair

Lyle Campbell

Alex Golub

Gary Holton

Don Daniels 


\section{Acknowledgments}

First and foremost, I would like to express my deepest gratitude to the people in Madang who have supported this research, either by working with me on their languages, or by helping me with practical matters during my stays in Gildipasi. Thank you to Mathew Lawun, whose passion for his language led to the inception of this project. Thank you to Agustin, Veronica, Tobi, Judith, and the rest of the Talim family, for inviting me into your home and family. Thank you to Josepa Wak for the many hours you patiently spent answering my questions about Qkuan Kambuar. To Yat Paol, thank you for your help with arranging practicalities and for introducing me to the Gildipasi community. Thank you for everyone who took the time to share with me their knowledge of their languages. There are too many of you to name here, but I would like to give thanks in particular to John Paol, Guwat Pepetua, Philip Yabop, Regina Tamagara, Francis Balang, Joe Anuwai, Barbara Mek, Martin Marap, Josep Taran, John Sangabor, (for Waskia), the Kamuang family Lukas, Collins, Stanley, and Bangar, Orawin Ivura, Melchior Matti, and Ben Yavis (for Barem), Paul Lawoi, Andrew Ilom, Josep Yal, Otwin Langbank and his family, and John Bii (for Manep), James Kitter (for Yamben), Anton Ake (for Karian), and Gabriel Lamuk Sr., Gabriel Lamuk Jr., and Valentine Laut (for Gavak). Special thanks to Ernest Gidaget for all the funny stories.

I would also like to thank Bob Blust and the other members of my doctoral committee: Don Daniels, Lyle Campbell, Gary Holton, and Alex Golub. Thank you also to all the other teachers at UH who have guided and encouraged me over the course of my academic career.

Thank you to the Bilinski Educational Foundation, the University of Hawai'i at Mānoa department of linguistics, and the Endangered Languages Documentation Programme (Grant SG0529), who provided financial support for this research. 


\section{Abstract}

This dissertation concerns the Northern Adelbert languages, a group of 23 Papuan languages spoken in Madang province, Papua New Guinea. The dissertation has two main components, .synchronic descriptions of Northern Adelbert languages, and an investigation of the diachronic changes in these languages. The synchronic descriptions outline the basics of each languages' phonology and verb morphology, with a focus on several languages which were previously poorly documented: Barem (ISO 639-3: buq), Manep (mkr), Mokati (wnb), Karian (bql), and Gavak (dmc). The diachronic component of the dissertation presents a reconstruction of Proto-Northern Adelbert phonology and lexicon, the ancestral language of the Northern Adelbert languages, as well as reconstructions of interstage proto-languages for various subgroups of Northern Adelbert., and presents a tree-structure classification for the family based on shared innovations. 


\section{Table of Contents}

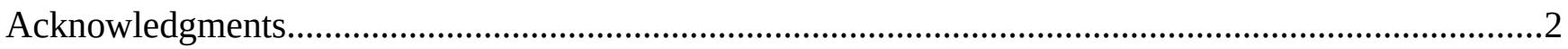

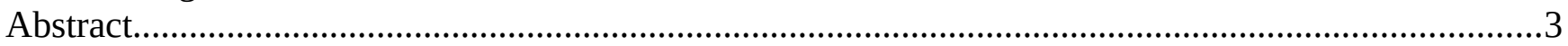

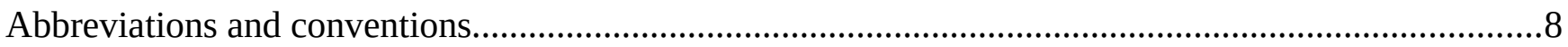

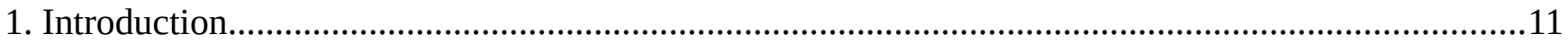

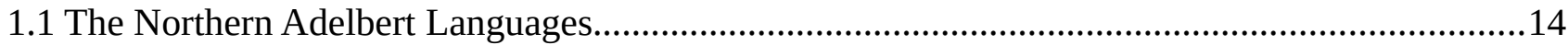

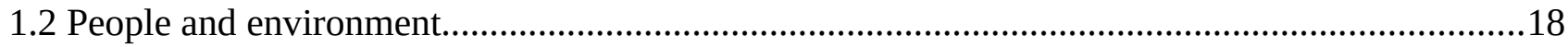

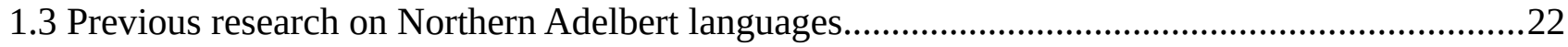

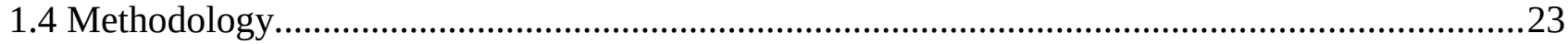

1.5 Overview of common traits in Northern Adelbert languages.................................................26

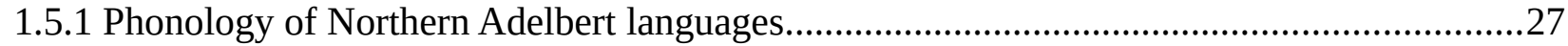

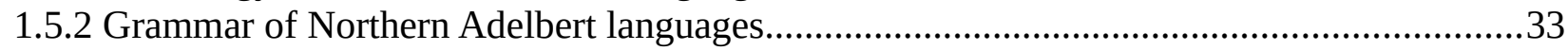

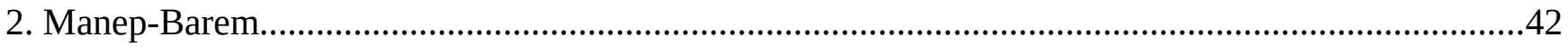

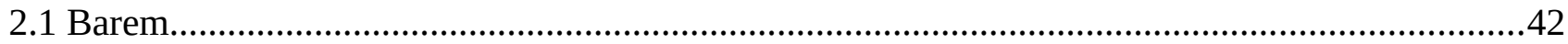

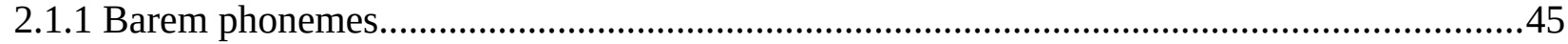

2.1.2 Barem syllable and word structure........................................................................50

2.1.3. Morphophonological processes in Barem..................................................................54

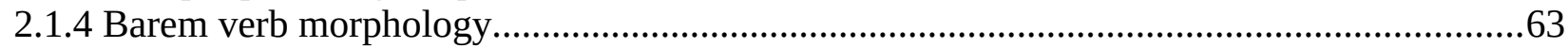

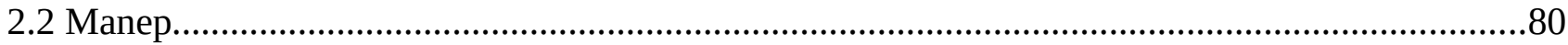

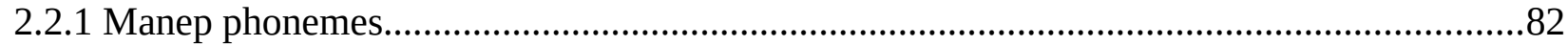

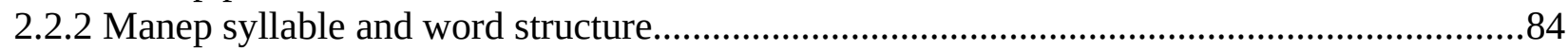

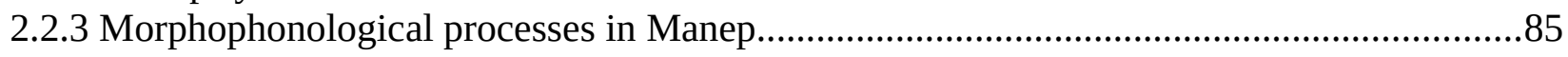

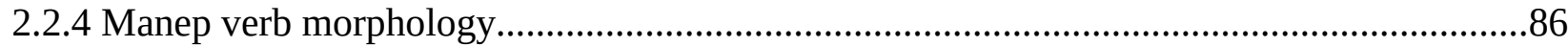

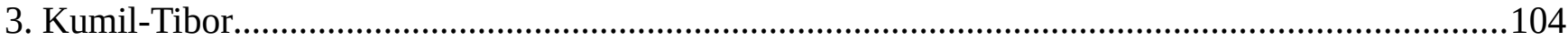

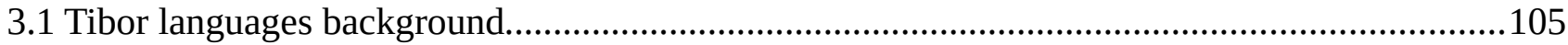

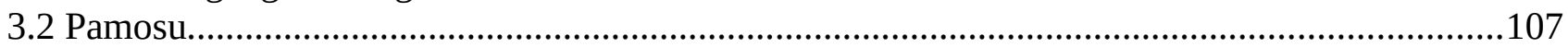

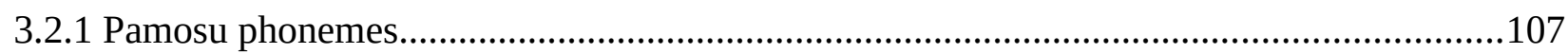

3.2.2 Pamosu verb morphology................................................................................... 108

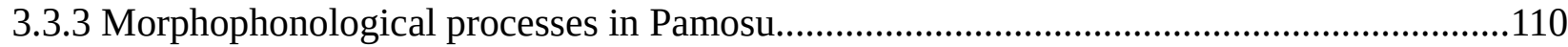

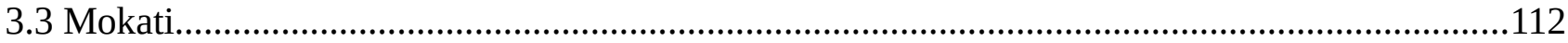

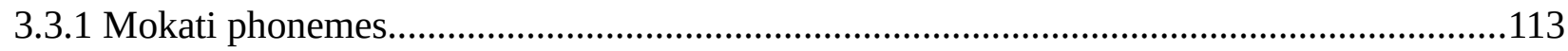

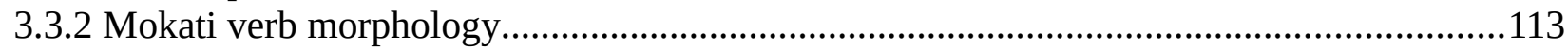

3.3.3 Morphophonological processes in Mokati.................................................................116

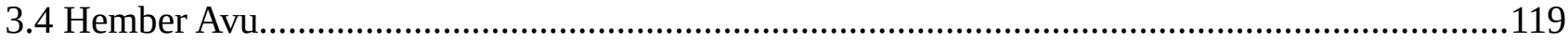

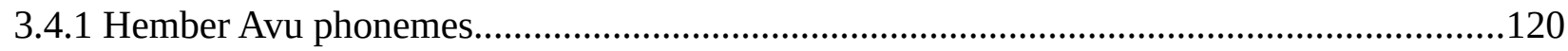

3.4.2 Hember Avu verb morphology..............................................................................121

3.4.3 Morphophonological processes in Hember Avu........................................................123

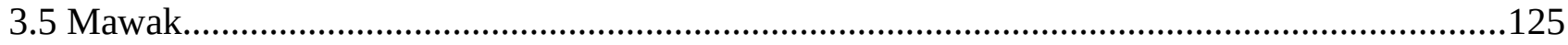

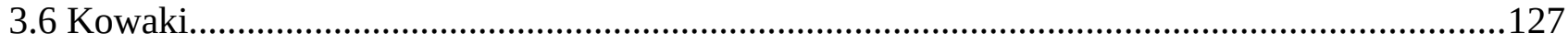

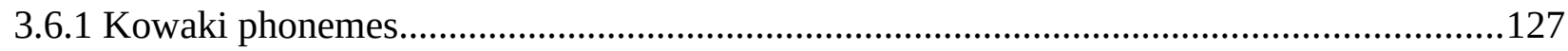

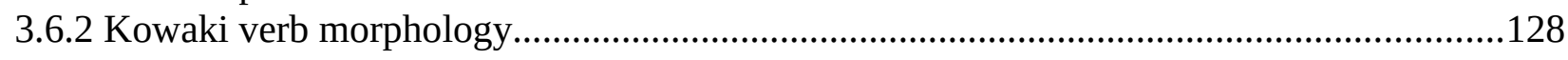

3.6.3 Morphophonological processes in Kowaki............................................................129

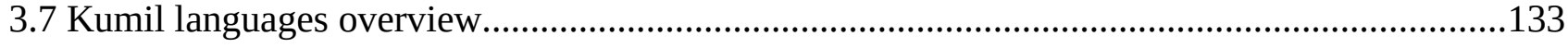

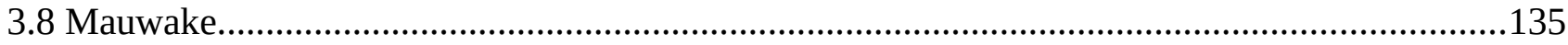

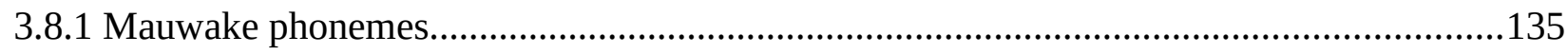

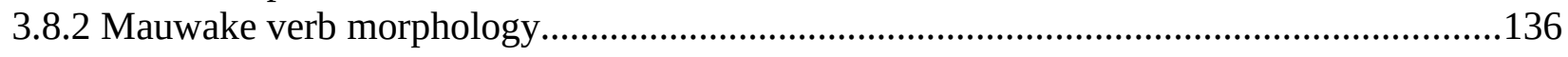


3.8.3 Morphophonological processes in Mauwake..................................................................137

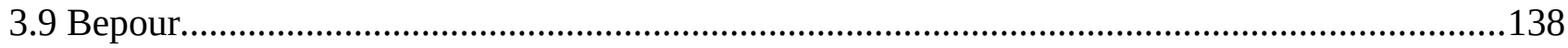

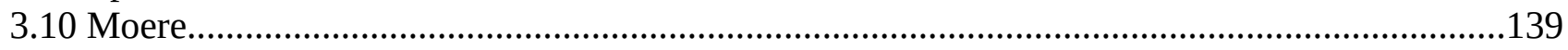

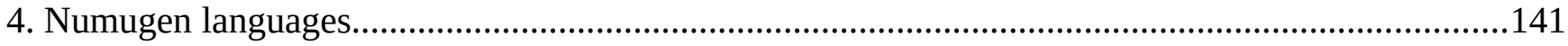

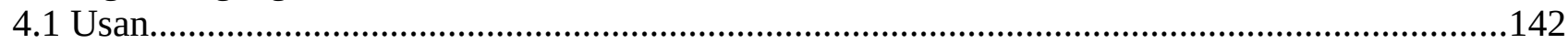

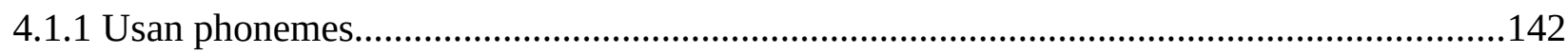

4.1.2 Usan verbal morphology.................................................................................................144

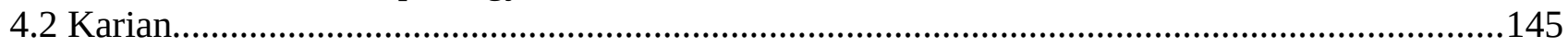

4.2.1 Karian phonemes........................................................................................................146

4.2.2 Morphophonological processes in Karian.......................................................................148

4.2.3 Karian verb morphology...............................................................................................149

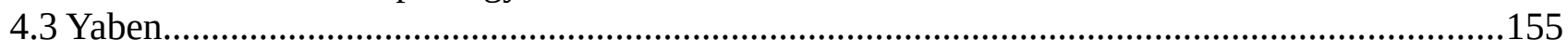

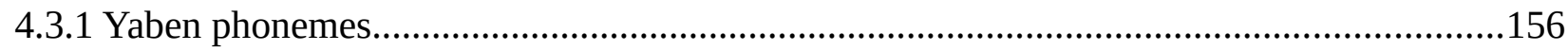

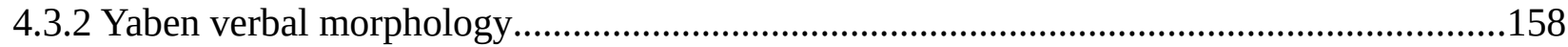

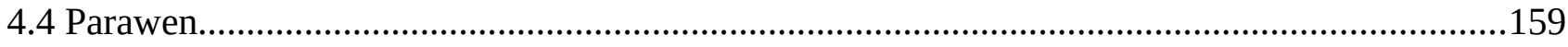

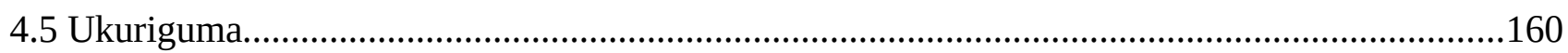

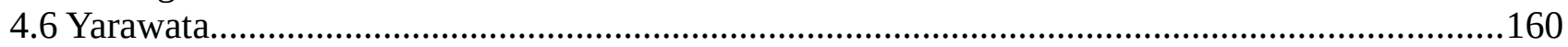

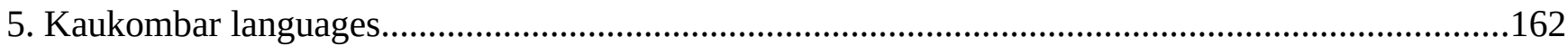

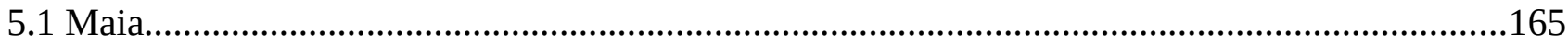

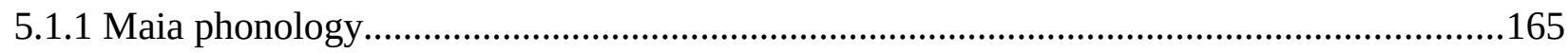

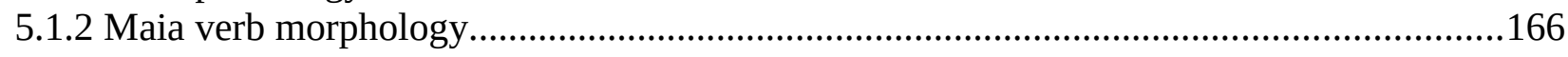

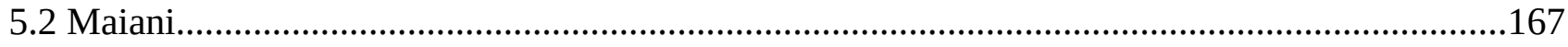

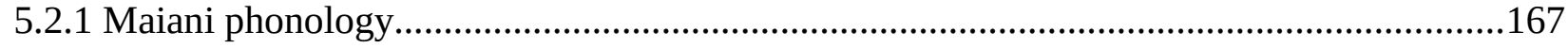

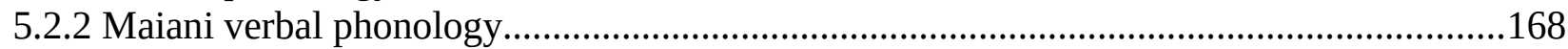

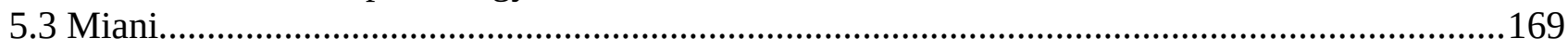

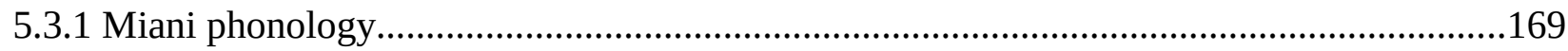

5.3.2 Miani verb morphology .......................................................................................170

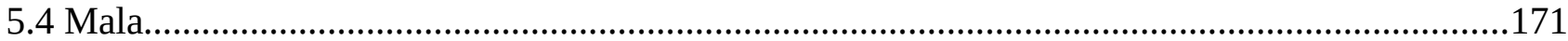

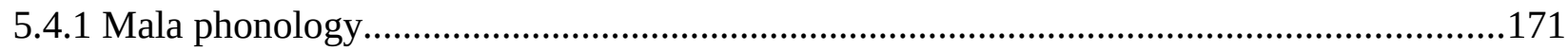

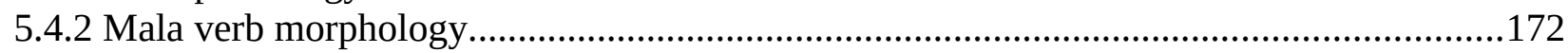

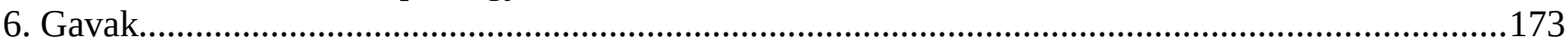

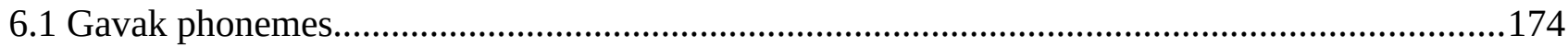

6.2 Gavak syllable and word structure.....................................................................................176

6.3 Morphophonoligical processes in Gavak................................................................................177

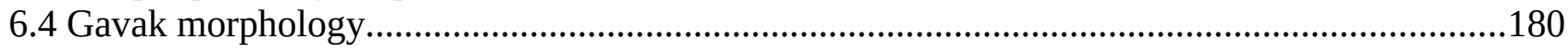

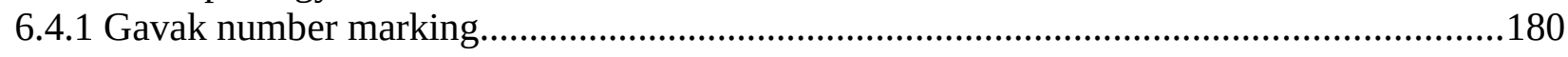

6.4.2 Gavak verb morphology..............................................................................................186

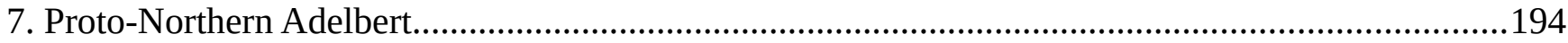

7.1 Papuan historical linguistics......................................................................................................194

7.2 A new classification of Northern Adelbert languages....................................................................199

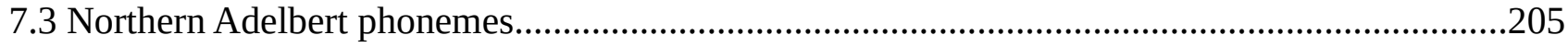

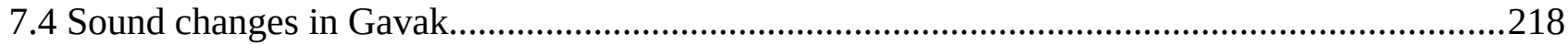

7.5 Proto-Northern Adelbert lexical reconstructions........................................................................221

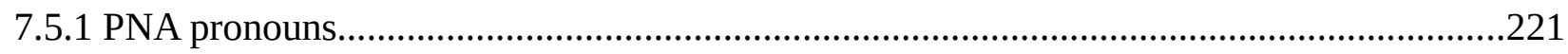

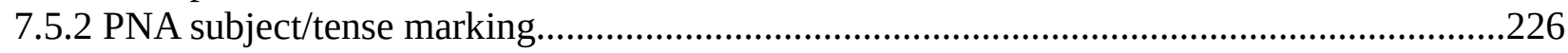

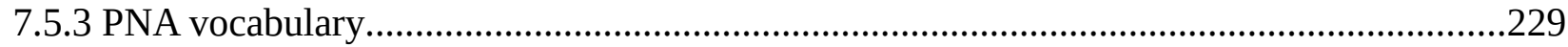

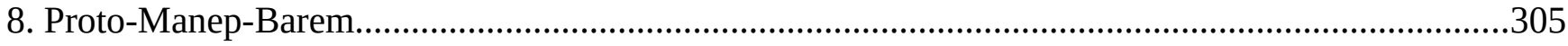




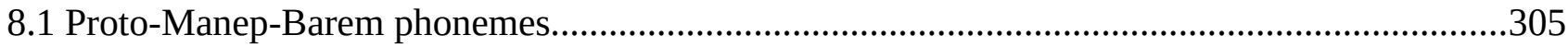

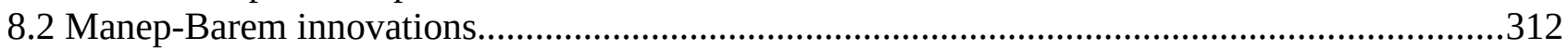

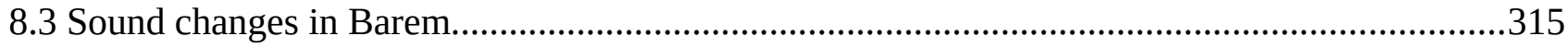

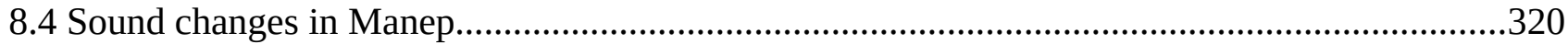

8.5 Proto-Manep-Barem grammatical morphemes..................................................................324

8.6 Proto-Manep-Barem vocabulary lexical reconstructions....................................................335

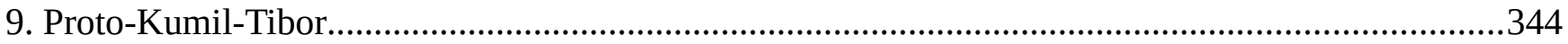

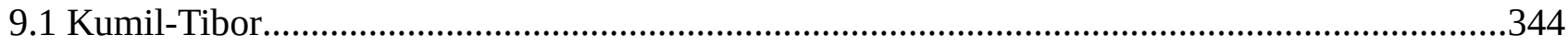

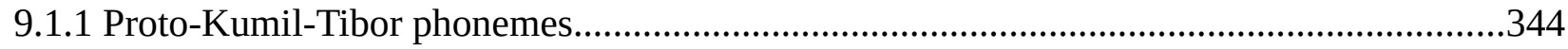

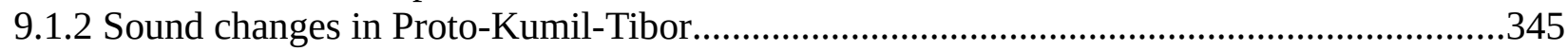

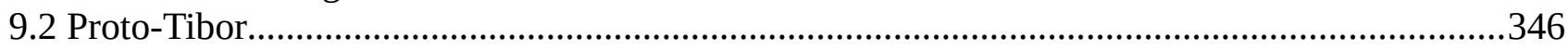

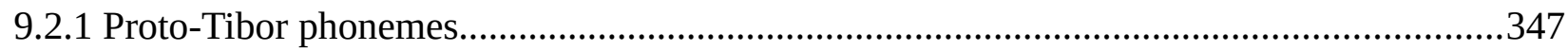

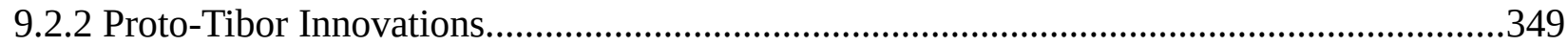

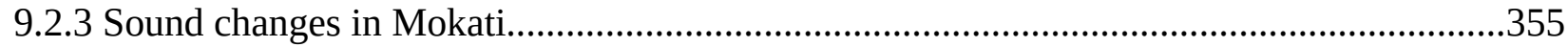

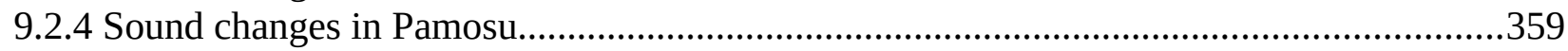

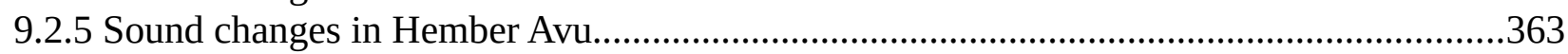

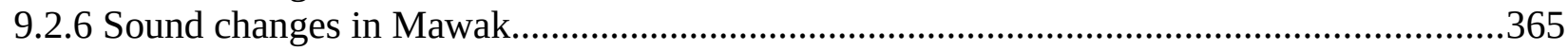

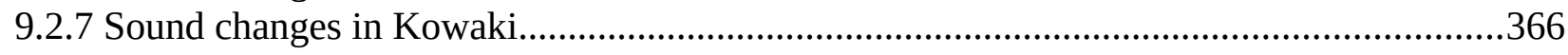

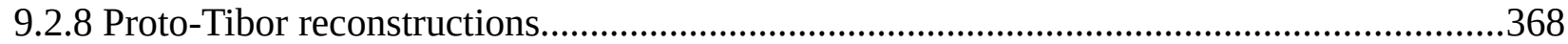

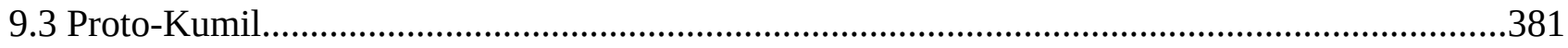

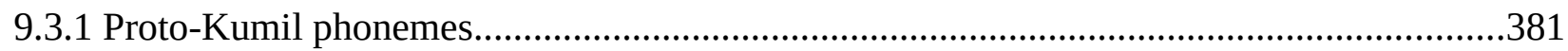

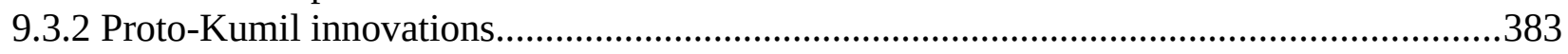

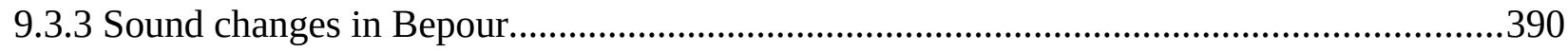

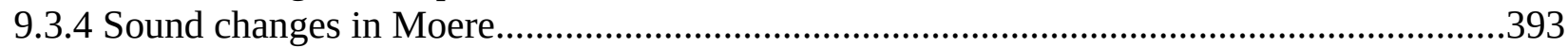

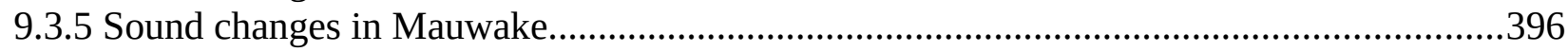

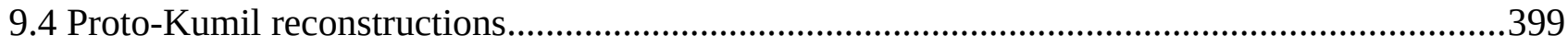

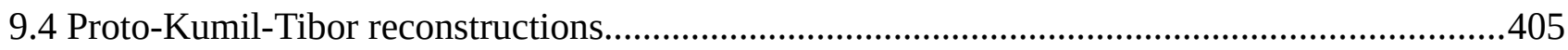

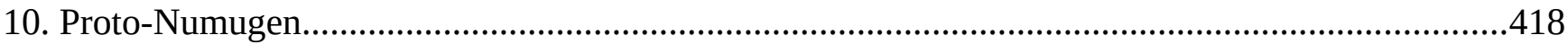

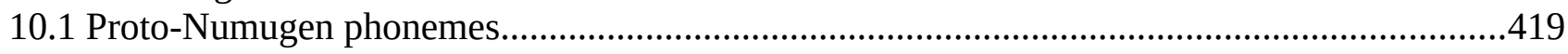

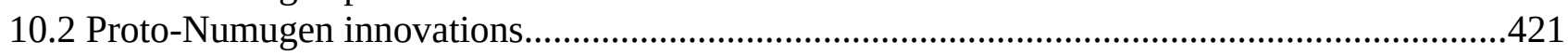

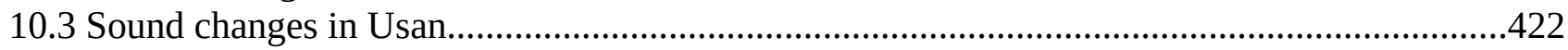

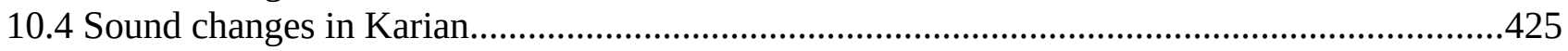

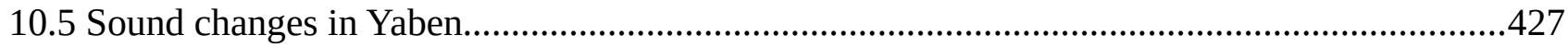

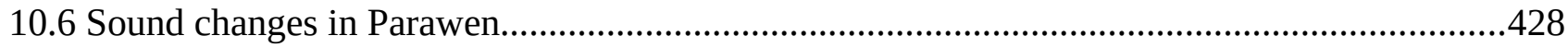

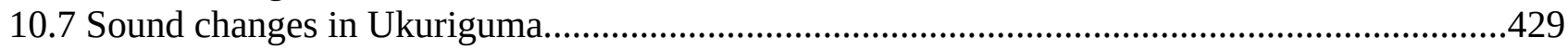

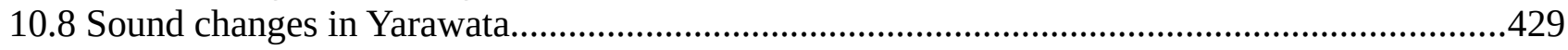

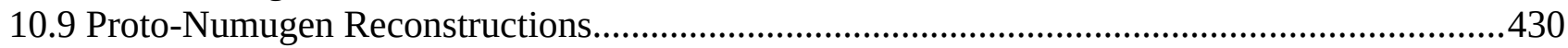

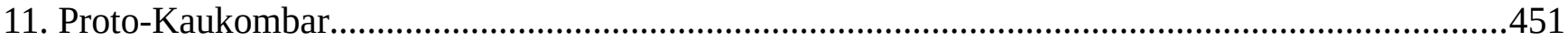

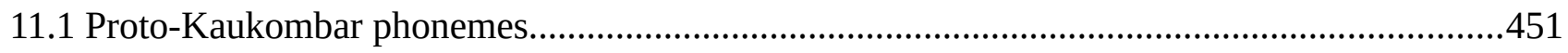

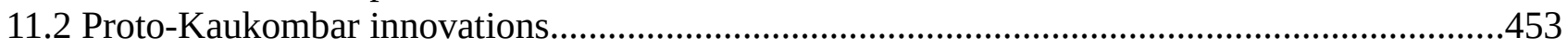

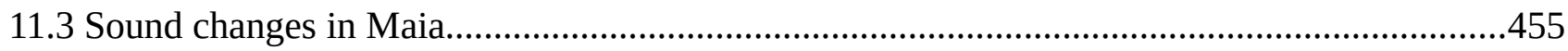

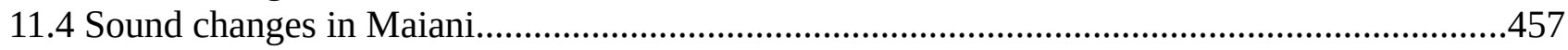

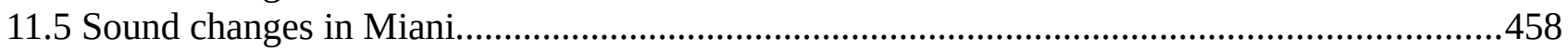

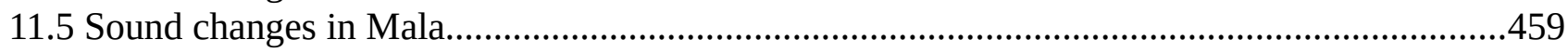

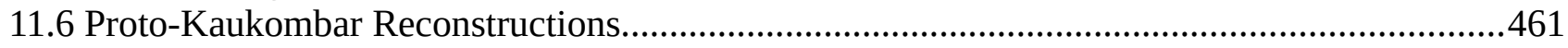

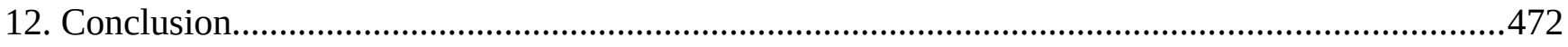

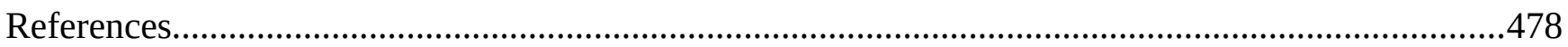




\section{Abbreviations and conventions}

$\begin{array}{ll}1 & \text { first person } \\ 2 & \text { second person } \\ 3 & \text { third person } \\ \text { COM } & \text { commitative } \\ \text { D } & \text { voiced obstruent } \\ \text { DEM } & \text { demonstrative } \\ \text { DES } & \text { desiderative } \\ \text { DS } & \text { different subject } \\ \text { DU } & \text { dual } \\ \text { FUT } & \text { future } \\ \text { INST } & \text { instrumental } \\ \text { IPFV } & \text { imperfective } \\ \text { IRR } & \text { irrealis } \\ \text { HOD } & \text { hodiernal } \\ \text { N } & \text { nasal } \\ \text { NEG } & \text { negator } \\ \text { NFUT } & \text { nonfuture } \\ \text { NMLZ } & \text { nominalizer/gerund } \\ \text { PFV } & \text { perfective } \\ \text { PL } & \text { plural } \\ \text { PRG } & \text { present progressive } \\ \text { PROS } & \text { prospective aspect } \\ \text { PST } & \text { past } \\ \text { Q } & \text { question particle } \\ \text { R } & \text { realis } \\ \text { REM } & \text { remote past } \\ \text { SG } & \text { singular } \\ \text { SS } & \text { same subject } \\ \text { T } & \text { voiceless obstruent } \\ \text { V } & \text { vowel } \\ & \end{array}$

In example sentences, brackets [] are used for words in other languages (usually Tok Pisin or English).

Reconstructed proto-forms are marked with a single asterisk *, and unattested or unacceptable forms are marked with a double asterisk **.

In reconstructions, parentheses $(x)$ indicate it is not clear whether a segment was present. $(x / y)$ indicates either $x$ or $y$ was present, but it is not clear which. 


\section{Orthographic conventions}

Most Northern Adelbert languages are not commonly written by their speakers, although orthographies have been developed for some languages. For those languages with grammars and dictionaries, I adopt the orthographies used in them. Most of the Northern Adelbert languages have similar phonemic inventories, and are for the most part easily represented by the same orthography used for Tok Pisin. Orthographic choices have therefore usually been fairly obvious, and the orthographies developed by different groups for different languages are often similar. For languages that have not had an orthography developed, I try to adopt as uniform a representation as possible, although for some languages it has been necessary to use some special symbols, such as the digraph $<\mathrm{qk}>$ in Barem (see Chapter 2). The table below lists the orthographic symbols used for Northern Adelbert languages throughout this dissertation, with the approximate IPA equivalent of the sounds they represent. Any additional special symbols are discussed in the chapters for those individuals languages.

This orthography is meant to be relatively shallow. The use of an orthographic symbol does not necessarily mean that particular sound or contrast is phonemic in the language. For example, in many Northern Adelbert languages, $[\mathrm{b}]$ and $[\mathrm{mb}]$ are allophones of an underlying prenasalized voiced bilabial stop $/{ }^{\mathrm{m}} \mathrm{b} /$, while in others these sounds are contrastive. In both cases, $<\mathrm{b}>$ and $<\mathrm{mb}>$ are used. The chapters on individual languages and language groups give more information on how surface forms relate to underlying phonemic representations in each language. 


\begin{tabular}{|c|c|}
\hline Sound & Orthographic symbol \\
\hline [i] & $<\mathrm{i}>$ \\
\hline$[\mathrm{e}, \varepsilon]$ & $<\mathrm{e}>$ \\
\hline$[\mathrm{u}]$ & $<\mathrm{u}\rangle$ \\
\hline [o] & $<_{\mathrm{o}}>$ \\
\hline [a] & $<\mathrm{a}>$ \\
\hline [ə] & $<\partial>$ \\
\hline [p] & $<\mathrm{p}>$ \\
\hline [b] & $<\mathrm{b}>$ \\
\hline$[\mathrm{t}]$ & $<\mathrm{t}>$ \\
\hline [d] & $<\mathrm{d}>$ \\
\hline$[\mathrm{k}]$ & $<\mathrm{k}>$ \\
\hline [?] & $<>$ \\
\hline [g] & $<\mathrm{g}>$ \\
\hline [m] & $<\mathrm{m}>$ \\
\hline [n] & $<\mathrm{n}>$ \\
\hline$[\mathrm{y}]$ & $<\mathrm{ng}>$ \\
\hline [d] $]$ & $<\mathrm{j}>$ \\
\hline$[\phi]$ & $<\mathrm{f}>$ \\
\hline$[\beta]$ & $<\mathrm{v}>$ \\
\hline [s] & $<\mathrm{s}>$ \\
\hline$[\mathrm{r}]$ & $<\mathrm{r}>$ \\
\hline$[\mathrm{w}]$ & $<\mathrm{w}>$ \\
\hline [j], [3] & $<\mathrm{y}>$ \\
\hline
\end{tabular}

The languages for which I adopt another author's orthography are Pamosu (Tupper 2012), Mauwake (Berghäll), Waskia (Ross \& Paol 1978, Barker \& Lee 1985), Maia (Hardin et al 2007), and Usan (Reesink 1987). The differences between the orthographic symbols shown above and the orthographies used in these works are small, so they can be summarized here. Tupper (2012) uses $<$ ng $>$ to represent the sequence [ng], as this does not contrast with a velar nasal in Pamosu. As some other Northern Adelbert languages do contrast these, I use $<\mathrm{ng}>$ for [n], and $<\mathrm{ngg}>$ for [ng]. Mauwake has long vowels, which are written as digraphs $<\mathrm{ii}>$, $<\mathrm{aa}>$, etc. For Usan, $<\hat{\mathrm{a}}>$ represents schwa, and $<\mathrm{q}$ $>$ represents a glottal stop. For other languages, I use $<_{\partial}>$ and $<^{\prime}>$, respectively. 


\section{Introduction}

This dissertation concerns the Northern Adelbert languages, a group of twenty-one Papuan languages spoken in Madang Province, Papua New Guinea. In this dissertation, I apply the comparative method to reconstruct the phonology and lexicon of Proto-Northern Adelbert, the ancestral language from which all the modern Northern Adelbert languages descend. I outline the sound changes that have taken place in each of the Northern Adelbert languages, and classify them into subgroups based on shared innovations. My goal is to reconstruct as much of Proto-Northern Adelbert phonology, lexicon, and verbal morphology as possible, given current understanding of these languages.

In working towards this goal, it has been necessary to do much of the research from the ground up. While the Northern Adelbert languages have been included in previous large-scale classifications of Madang languages, this project is the first to focus exclusively on the Northern Adelbert languages, to use the comparative method to identify regular sound correspondences among them, and to propose a classification based on shared innovations. Since McElhanon \& Voorhoeve (1970), it has been widely assumed that the languages of Madang, which include Northern Adelbert, are a branch of the large Trans-New Guinea phylum, a hypothesized language family that encompasses hundreds of languages throughout New Guinea. However, this classification is based on lexical similarities and areal traits, rather than rigorous application of the comparative method. The reconstruction of Northern Adelbert presented in this dissertation provides a more solid basis for examining hypotheses about putative higher order subgroups such as Madang and Trans-New Guinea.

In addition to the reconstruction of Proto-Northern Adelbert, a second goal of this dissertation is to contribute to the documentation of Northern Adelbert languages, most of which are in danger of no longer being spoken within the next few generations. With this goal in mind, I have included sketches 
of the synchronic phonology and verbal morphology of several Northern Adelbert languages for which data was previously very limited.

Although the New Guinea region is one of the most linguistically diverse in the world, Papuan languages are underrepresented in all fields of linguistics. As the Northern Adelbert languages are all severely understudied, I hope that this dissertation will be an important step for the documentation and study of languages of Madang and New Guinea. For the languages Mokati, Karian, Manep, Barem, and Gavak, this dissertation contains the most thorough description of these languages to date. Additionally, the audio and video recordings created over the course of my dissertation research include elicitation sessions, narratives, and conversations of at least eleven different languages, providing valuable documentation. These recordings are archived in the Kaipuleohone Language Archive and the Endangered Languages Archive (ELAR), and it is my hope that speakers of Northern Adelbert languages, as well as other researchers, will find them to be of value.

This dissertation touches upon various phenomena in Northern Adelbert languages that will be of interest not only to historical linguists and Papuanists, but researchers working in other fields as well. In my descriptions of Northern Adelbert languages my goal has been to present the data in as theory-neutral a manner as possible. However, I touch on several topics that I believe will be of value in furthering linguistic theory in different areas. Here are two examples, both from Barem. First, Barem hast preaspirated or prespirantized velar stops, a typologically rare feature. While preaspiration is rare to begin with, Barem [ $\left.{ }^{\mathrm{h}} \mathrm{k}\right]$ is found almost exclusively in word-initial position, a perhaps unique distribution, as most other languages with preaspiration limit it to word-medial or word-final position (Silverman 2003). Clayton (2010) suggests that the relative rarity of preaspiration cross-linguistically, especially word-initially, is partly due to a limited number of diachronic processes that may give rise to it. Clayton proposes that voiceless geminates are one of the only three identified sources of preaspirated stops crosslinguistically. I demonstrate in this dissertation that Barem [ $\mathrm{h}$ ] does indeed 
derive from historic ${ }^{*} \mathrm{kk}$, to my knowledge the first time that this process has been shown to have occurred word-initially. Another example of a typologically interesting phenomenon discussed in Barem is that indirect objects, but not direct objects, are marked for agreement on the verb, which is cross-linguistically uncommon (Comrie 2003, Siewierska 2003). Especially unusual is that this occurs with several verbs of physical or mental transfer ("ask, "tell", etc), whereas crosslinguistically this feature is usually limited to the verb "give". A number of other interesting phenomena from other Northern Adelbert languages are described for the first time in this dissertation.

Section 1.1 of this chapter provides further background on the Northern Adelbert languages, and section 1.2 discusses the speakers of Northern Adelbert languages and their physical environment and society. Section 1.3 gives an overview of some of the previous research on Northern Adelbert languages, and in Section 1.4 I discuss my methodology for this study. Section 1.5 describes some common traits seen in Northern Adelbert languages, in order to orient the reader for the synchronic descriptions of individual languages. These descriptions are the subject of chapters 2-6, with one chapter dedicated to each branch of Northern Adelbert. The focus of these descriptions is on phonology and verbal morphology, and they vary in the depth of description, depending on the quality and amount of data available for particular languages.

In Chapters 7-11, I present my reconstructions of Proto-Northern Adelbert (PNA), and the proto-languages for each subgroup. Chapter 7 first gives some background on previous historical linguistic research in the area, including some of the classifications that have been proposed for languages of Madang that include the Northern Adelbert languages. I then present my own classification of the Northern Adelbert languages, the reconstructed PNA phonology and lexicon, and illustrate the changes that have taken place in each subgroup relative to PNA. Chapters 8-11 present the reconstructed lexicon for the proto-languages of each of the Northern Adelbert subgroups, and 
outline the sound changes that have taken place in individual languages. Chapter 12 concludes by suggesting some wider connections between Northern Adelbert and other Madang languages.

\subsection{The Northern Adelbert Languages}

The Northern Adelbert languages are spoken in a contiguous area in the Northern part of Madang Province, Papua New Guinea. This region is home to both Papuan and Austronesian languages. The label "Papuan" does not presuppose that these language are all genetically related, but is simply a convenient label for the non-Austronesian languages of the region. The Northern Adelbert languages are Papuan, and are widely considered to belong to the Madang branch of the Trans New Guinea phylum (see Chapter 7).

The Northern Adelbert family can be divided into five main branches, each branch composed of a group of languages that are more closely related to each other than to the other Northern Adelbert languages.. In some cases, these branches can be further divided into subgroups. The Gavak language is the smallest branch, with only one language. The largest branch is Kumil-Tibor, with eight languages. The branches of Northern Adelbert and their constituent languages are:

Manep-Barem: Manep, Barem

Kumil-Tibor:

Kumil: Mauwake, Bepour, Moere

Tibor: Pamosu, Hember Avu, Mokati, Mawak, Kowaki

Numugen: $\quad$ Usan, Karian, Yaben, Yarawata, Parawen, Ukuriguma

Kaukombar: Maia, Mala, Miani, Maiani

Gavak

\section{Diversity and endangerment}

The New Guinea area is one of the most linguistically diverse in the world, and in Madang Province alone there are over 100 languages (Pawley \& Hammarström 2018). New Guinea is also 
linguistically one of the least documented regions, as only a small fraction of these languages have been the subject of more than preliminary linguistic study. For several Northern Adelbert languages, the only documentation is a wordlist of basic vocabulary (Z'graggen 1980b).

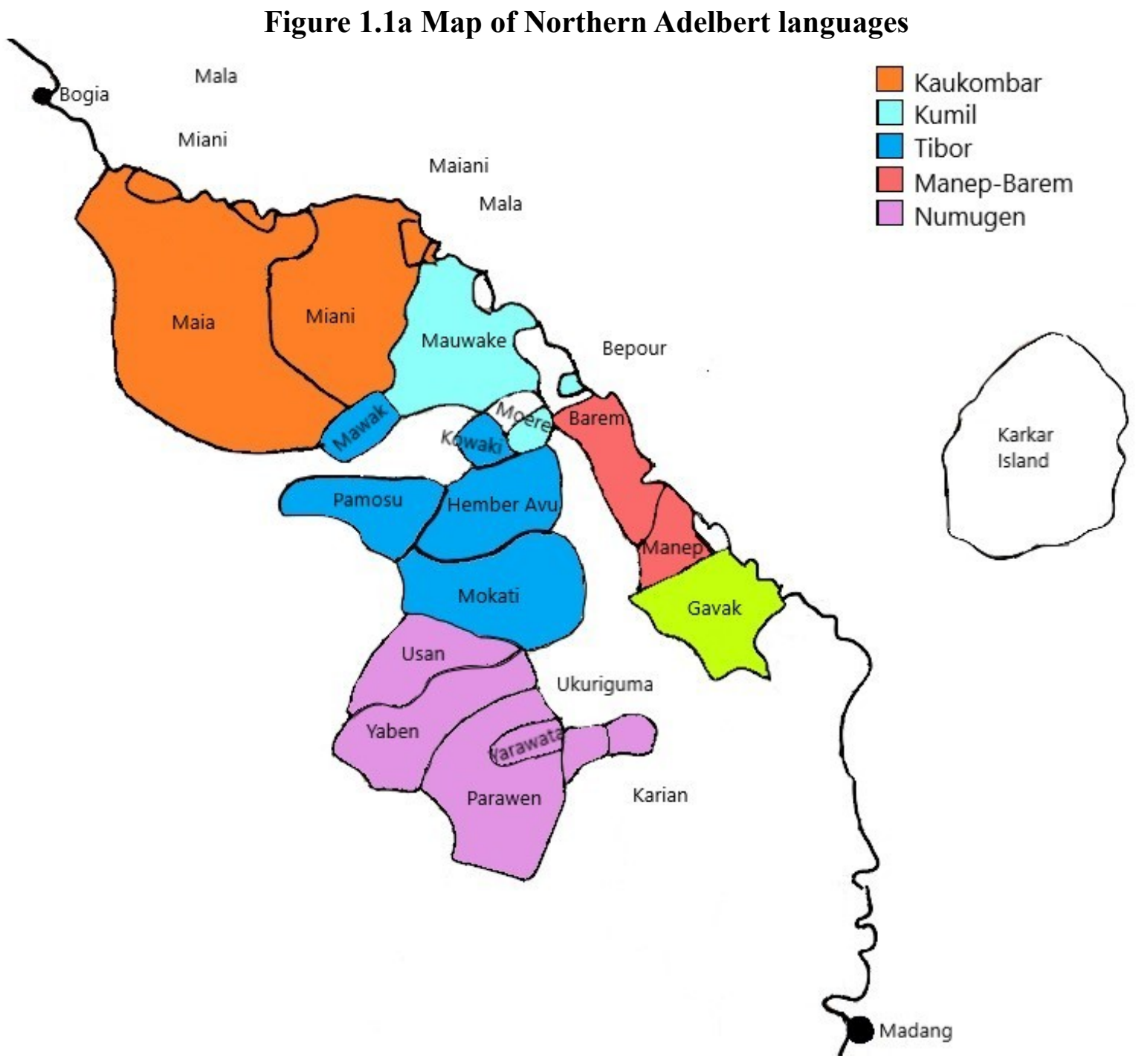

All of the Northern Adelbert languages are facing pressures which may lead to them no longer being spoken in the next few generations. The biggest of these pressures is the growing use of Tok Pisin, one of the national languages of Papua New Guinea, and the lingua franca of the area. Most children in the area use Tok Pisin as their primary language. In my visits to various communities, I 
rarely heard children speaking any of the indigenous languages, and parents usually spoke to their children in Tok Pisin. In many communities, Tok Pisin is the primary language for people of all ages.

\section{A note on language names}

The issue of language names requires some explanation. For most Northern Adelbert languages, the names listed in Ethnologue (Simons \& Fennig 2020) are based upon the work of John Z'graggen, who refers to most of the languages he worked on by the name of one of the villages where it is spoken. Z'graggen explains that he chose this method because the people in Madang often do not have names for their languages (Z'graggen 1971a: 11). In a later publication, Z'graggen (1975a: 5) acknowledges that speakers dislike the use of village names as language names, and invites speakers to give their own language names to replace the village names he has designated as labels for languages. Many speakers I worked with echoed this sentiment, and rejected Z'graggen's labels, stating that those were the names of places, not languages. I, and other researchers working in the area in recent years, have found that people often do have agreed-upon names for their languages ${ }^{1}$. Although Z'graggen's names are common in the literature, I opt to use the language names provided by speakers themselves, a practice followed in recent work on Madang languages, including Daniels (2020), Tupper (2012), Berghäll (2015).

Table 1.1b lists the names I use for Northern Adelbert languages, as well as other languages in the region which do not belong to Northern Adelbert but are mentioned in this dissertation. The second column shows the name used to refer to the language in Z'graggen's publications, or other publications where relevant, and the ISO 639-3 code is listed in the third column. For consistency's sake, the updated language names are used throughout the remainder of the dissertation, even when referencing works which used Z'graggen's names. For branches of Northern Adelbert, I have retained most of

1 This may be a relatively recent development that was not as common at the time Z'graggen conducted his surveys. Although most speakers I worked with readily provided a label for their language, others hesitated to give it a name. 
Z'graggen's labels when these groups more or less correspond with mine. ${ }^{2}$ The exception to this is the Manep-Barem branch, which I have opted to simply name after its two members.

Table 1.1b Northern Adelbert language names

\begin{tabular}{|c|c|c|}
\hline Language name & name per Z'graggen (1980) & ISO 639-3 \\
\hline Amako & Korak & koz \\
\hline Barem & $\begin{array}{l}\text { Bunabun (Z'graggen 1980) } \\
\text { Bunubun (Capell 1952) }\end{array}$ & buq \\
\hline Bargam & Mugil & $\mathrm{mlp}$ \\
\hline Bepour & Bepour & bie \\
\hline Gavak & Dimir & $\mathrm{dmc}$ \\
\hline Hember Avu & $\begin{array}{l}\text { Musar (Z'graggen 1980) } \\
\text { Amben (Petir et al 1996) } \\
\text { Vanembere (Capell 1952) }\end{array}$ & $\mathrm{mmi}$ \\
\hline Karian & Bilakura & bql \\
\hline Kobol & Koguman & kgu \\
\hline Kowaki & Kowaki & xow \\
\hline Maia & Pila, Saki & sks \\
\hline Maiani & Tani & tnh \\
\hline Mala & Pay & ped \\
\hline Miani & \begin{tabular}{|l|} 
Tani (Z'graggen 1980) \\
Banar (Capell 1952)
\end{tabular} & pla \\
\hline Manep & Malas & $\mathrm{mkr}$ \\
\hline Mauwake & Ulingan & $\mathrm{mhl}$ \\
\hline Mawak & Mawak & $\mathrm{mjj}$ \\
\hline Moere & Moere & $\mathrm{mvq}$ \\
\hline Mokati & Wanambre & wnb \\
\hline Pal & Abasakur & abw \\
\hline Pamosu & Hinihon & hih \\
\hline Parawen & Parawen & prw \\
\hline Ukuriguma & Ukuriguma & ukg \\
\hline Usan & Wanuma & wnu \\
\hline Waskia & Waskia & wsk \\
\hline Yaben & Yaben & ybm \\
\hline Yarawata & Yarawata & yrw \\
\hline
\end{tabular}

2 Although, like Ross (2000), I have removed the -an suffix from these names (i.e. Tibor, rather than Tiboran). 


\subsection{People and environment}

Northern Adelbert languages occupy a relatively small geographic area, and while the various Northern Adelbert speech communities share many cultural traits, they are not culturally uniform. The biggest divide is between communities in inland mountain areas, who tend toward a more traditional way of life, and those that live closer to the coast, who have more access to infrastructure and tend to participate more heavily in the cash economy.

\section{Geography and climate}

The Northern Adelbert languages are spoken in Madang Province, Papua New Guinea, in an area stretching along the coast from Cape Croisilles in the southeast, nearly reaching the city of Bogia in the northwest, and reaching inland to encompass the northern section of the Adelbert Mountains.

Much of the coastline is comprised of long, sandy beaches, with offshore coral reef that provide a source of fish. The land along the coast remains flat for a short distance before turning into the foothills, which in turn transition into Adelbert Mountains, characterized by steep slopes, narrow ridges, and numerous cliffs and gorges. Forest covers most of the mountainous areas, as well as some parts of the foothills and flat coastal areas (Haantjens et al 1976, Löffler 1977). The hills and coastal areas are otherwise comprised of large swaths of tall swordgrass (kunai in Tok Pisin) or more managed terrain, such plantations, gardens, and villages.

The climate is tropical, with relatively steady and warm temperatures throughout the year. Temperatures along the coast are usually in the range of $20-30^{\circ} \mathrm{C}\left(68-89^{\circ} \mathrm{F}\right)$, while the mountainous inland areas are cooler, with a range of $15-22^{\circ} \mathrm{C}\left(59-72^{\circ} \mathrm{F}\right)$ (Short, 1976). The wet season begins in December and ends around April. Rain can fall for days at a time, and flash floods are not uncommon in coastal communities, sometimes reaching catastrophic levels that can destroy entire areas. 


\section{Infrastructure}

Travel along the coast is relatively easy, and is facilitated by a highway which traverses the entire length of the coast in the area where speakers of Northern Adelbert languages live, from Bogia to Madang. Residents of coastal areas consequently have easier access to the facilities in these cities, such as shopping centers and health services. In the town of Tokain, where I stayed during my fieldwork, people commonly took day trips by PMV ("private motor vehicle") to Madang city for shopping and other errands, typically leaving in the morning and returning around sundown.

PMVs are the most common mode of medium-distance travel for the vast majority of people living along the coast highway who don't have their own vehicle. They are large privately owned vehicles, such as a vans or cargo trucks, that run semi-regular routes and schedules between their home village and one of the major cities, charging a flat rate for the journey. The comings and goings of PMVs are a frequent topic of conversation.

For residents in the mountainous inland areas, travel to one of the larger cities is considerably more of an ordeal, as most inland communities are not accessible by road, and the only way to get to the coast is to walk. Depending on how far inland one lives, this journey could take up to two to three days. In Gildipasi, there are several communities of people who came from inland areas but have resettled near the coast in order to have easier access to infrastructure. My fieldwork on Mokati, Hember Avu, Pamosu, and Karian took place in these coastal communities, with speakers who hadn't regularly lived in their home territories for decades.

\section{Demographics}

There is great variation in the populations of various language groups. At the upper end are languages such as Mauwake and Maia, with populations over 4,000. In the middle range are languages 
with between 1,000 and 2,000 speakers, such as Barem, Usan, and Pamosu. The smallest languages have only a few dozen speakers or less. These include Karian, Bepour, and Moere. In all languages, the number of speakers of the native language is much smaller than the community population, as Tok Pisin is the primary language for most younger speakers.

\section{Economy}

Traditionally, speakers of Northern Adelbert languages have relied on subsistence agriculture, and many still do so today. Most people today grow and hunt most of their own food, but supplement this with purchased groceries. The main crops are yams, banana, and taro, and other crops include sago, cassava, sweet potato, and Singapore taro, as well as the leafy green vegetables know as aibika and aupa in Tok Pisin ${ }^{3}$. Betel nut is a ubiquitous crop that is important economically, culturally, and socially. Betel nut is exchanged and chewed together at all important gatherings, as well as everyday casual meetings with acquaintances. Exchanging betel nut is a key part of building and maintaining relationships and resolving conflicts (Sharp 2012).

Protein is provided by hunting small game such as bandicoots, wallabies, flying foxes, and larger game such as wild pigs and cassowaries. Coastal communities fish in the ocean, while both mountain and coastal communities collect crayfish from rivers. Sea turtles are also a traditional source of meat for coastal communities, and are highly prized. However, sea turtle populations have declined, and turtles are rarely eaten now. Domestic pigs and chickens are raised by some families, although pigs are generally only sold for cash or killed for feasts on special occasions. Berghäll (2015) writes that hunting is becoming less significant for the coastal Mauwake people, as game becomes increasingly scarce, while Tupper (2012) reports that wild game remains a central part of the diet of Pamosu speakers, who live in a mountanous inland region where game is plentiful. From my own

3 Abelmoschus manihot and Amaranthus tricolor, respectively. 
observations of coastal Manep, Barem, and Gavak communities, most families rely only partly on hunting and fishing for their protein sources, supplementing this with tinned fish and meat.

Many people's participation in the cash economy is minimal, and few have regular paid jobs. Most people's need for cash is also minimal, since they grow their own food, and build their homes out of timber and other materials collected in the forest. In addition to its cultural importance, betel nut is also an important source of cash for lowland Northern Adelbert communities. Many families grow betel nut to sell it in the highlands, where betel nut doesn't grow, at a substantial markup. In Madang Province in 2000, over half of rural households reported selling betel nut to earn income (Sharp 2012: 68). Some people also grow coconuts, coffee, cocoa, and vanilla as cash crops, or sell food and other items at local markets.

\subsection{Previous research on Northern Adelbert languages}

The earliest mentions in print of Northern Adelbert language are German publications containing short wordlists of some languages in the Kaukombar subgroup (Hollrung 1887, Zöller 1890, Schmidt 1900). Chinnery (1923) also contains a short wordlist of the Saki dialect of Maia. Capell (1952) wrote brief sketches of several languages in the region, including the Northern Adelbert Languages Miani, Mauwake, Barem, and Hember Avu.

The most in-depth survey of Madang languages so far is that conducted by John Z'graggen, a missionary working at the Catholic Mission Station at Mugil, near Cape Croisilles. From 1964 to 1973, he did firsthand research on nearly every language in the province. The results of this research are summarized in his PhD thesis (Z'graggen 1969), and several later publications (Z'graggen 1971a, 1975a-b, 1980a-d). The most important of these for this dissertation is Z'graggen (1980b), which contains comparative wordlists of around 300 items for nearly all of the Northern Adelbert languages 
(as well as several other languages outside the Northern Adelbert group). For several of the Northern Adelbert languages, Z'graggen's publications are still the only primary published data available. In addition to his written publications, some of Z'graggen's recordings of elicitation sessions with speakers of various Northern Adelbert languages have been digitized and are available online at the Pacific and Regional Archive for Digital Sources in Endangered Cultures (PARADISEC) (Z'graggen 1971b).

In the decades following Z'graggen's survey, various researchers affiliated with academic institutions or the missionary organization SIL have worked in depth on individual Northern Adelbert languages, and have produced larger wordlists, grammatical and phonological descriptions, and dictionaries. May and Loeweke (1982a, 1982) are sketches of the phonology and grammar of the Kaukombar languages Maia, Maiani, Miani, and Mala. Hardin builds on their work with a more indepth description of Maia grammar (2002), and a Maia dictionary (Harden et al 2007). Berghäll produced a Mauwake grammar (2015) and dictionary (Järvinen (= Berghäll) Kwan, \& Aduna, 2001). Tupper (2012) is a grammar of Pamosu with an extensive wordlist, and Reesink (1987) is a grammar of Usan. With the addition of my own work on Manep, Barem, and Gavak, there is now at least one relatively well-described language for each branch of Northern Adelbert.

There have been a number of comparative studies which have proposed different classifications of the languages of Madang Province, including Z'graggen (1971), Ross (2000), and Pawley and Hammarström (2018). These classifications all agree that the Northern Adelbert languages are related, and belong to the Madang branch of the Trans New Guinea phylum. However, none of these classifications treat the Northern Adelbert languages as a coherent subgroup. These classifications are discussed in more detail and compared with my own in Chapter 7. 


\subsection{Methodology}

This dissertation relies heavily on data gathered during primary fieldwork in Madang Province during the summers of 2016-2019. My fieldwork began at the invitation of the Gildipasi Konsevesen Komiti, a grassroots cultural revitalization organization started by a group of several communities, including Manep, Barem, Karian, Mokati, Yamben, and Waskia speaker communities. This Gildipasi Konsevesen Komiti is concerned with threats to the environment, culture, and languages of their member communities. Beginning in 2000, they initiated environmental conservation projects, founding marine and forest conservation zones. In 2013, their work expanded to cultural conservation, and in 2016, to language conservation, with the initiation of the language documentation project that has led to this dissertation (Gildipasi Konseven Komiti, 2016).

In 2013, I spent a month working with speakers of the Qkuan Kambuar dialect of Barem, and became acquainted with other language communities in the area. I returned every summer from 20142016 for two to three months, and worked with speakers of seven different Northern Adelbert languages: Barem, Manep, Karian, Mokati, Hember Avu, Pamosu, and Mala (as well as a number of other languages in the area that don't belong to Northern Adelbert). I worked with speakers of some of these languages for only a single afternoon, while others were the focus of many months' work over the course of a few years. We investigated their languages in a variety of ways. Sometimes we worked one-on-one in targeted elicitation sessions to investigate the phonology and verbal morphology of their languages. Other times we worked in small groups to collect extended vocabulary lists. We also made audio and video recordings of conversations and narratives, which were then transcribed and translated.

The analysis of the recordings and field notes produced during these trips form the backbone of the Barem, Manep, Karian, and Mokati descriptions presented in my dissertation. The descriptions of 
some other languages are based on my analysis of Z'graggen's recordings and wordlists, while others summarize the most relevant points from publications that describe these languages in greater depth.

The lexical data used to reconstruct PNA and the proto-languages for each subgroup come from a variety of sources, listed in Table 1.4a.

Table 1.4a: Sources of lexical data for this study

\begin{tabular}{|c|c|}
\hline Amako & author's fieldwork \\
\hline Barem & $\begin{array}{l}\text { author's fieldwork } \\
\text { Capell (1952) }\end{array}$ \\
\hline Bargam & Hepner 2006, Hepner 2007 \\
\hline Bepour & Z'graggen (1971b) \\
\hline Gavak & author's fieldwork \\
\hline Hember Avu & $\begin{array}{l}\text { author's fieldwork } \\
\text { Capell (1952) } \\
\text { Petir et al (1996) }\end{array}$ \\
\hline Karian & author's fieldwork \\
\hline Kowaki & Z'graggen (1971b) \\
\hline Maia & $\begin{array}{l}\text { Hardin et al (2007), Hardin (2002), May \& } \\
\text { Loeweke (1982a-b) }\end{array}$ \\
\hline Maiani & $\begin{array}{l}\text { May \& Loeweke (1982a-b), May (1994a), } \\
\text { "Maiani" (1975) }\end{array}$ \\
\hline Mala & author's fieldwork, May \& Loeweke (1982a-b) \\
\hline Miani & $\begin{array}{l}\text { May \& Loeweke (1982a-b), May (1994b), "Miani" } \\
\text { (1975), Capell (1952) }\end{array}$ \\
\hline Manep & author's fieldwork \\
\hline Mauwake & Berghäll (2015), Järvinen \& Kwan (2007) \\
\hline Moere & Z'graggen (1971b) \\
\hline Mokati & author's fieldwork \\
\hline Pamosu & Tupper (2012), author's fieldwork \\
\hline Usan & Reesink (1987) \\
\hline Waskia & $\begin{array}{l}\text { author's fieldwork, Ross \& Paol (1978), Barker \& } \\
\text { Lee (1985) }\end{array}$ \\
\hline Yaben & Z'graggen (1971b) \\
\hline
\end{tabular}

I rely on lexical data found in previous publications, such as Z'graggen's (1980a-d) wordlists, as well as other dictionaries and descriptions of Northern Adelbert languages, and data collected during my own fieldwork. I also consulted Z'graggen's recordings of various Northern Adelbert languages archived at 
PARADISEC (Z'graggen 1971b) which contain much information that is not available in his published books, including additional lexical data. Table 1.4a lists the sources of lexical data for each language in this study in addition to Z'graggen's (1980a-d) published wordlists, which were consulted for each language $\mathrm{e}^{4}$

The comparative method is the primary tool I rely upon for my reconstruction of the PNA lexicon and phonology. In theory, the comparative method is a straightforward process: one identifies regular sound correspondences, and posits a proto-phoneme for each unique correspondence. This process relies on the assumption that the data are clean and reliable. For many of the Northern Adelbert languages, this is often decidedly not the case, and the only data available are phonetically transcribed wordlists or scratchy recordings. Even when applying the comparative method to relatively well-documented languages, there are bound to be unexplained exceptions and irregularities. This is even more the case when working with poorly documented languages. The data for any given word in a language may be the record of just a single token from a single speaker. Such data will inevitably contain speech errors, speaker idiosyncrasies, transcription errors, mistranslations, and so on. These errors can be difficult to identify, especially for languages without multiple sources of data to check against each other.

On the whole, I am confident that I have been reasonably rigorous with the sound correspondences and reconstructions I present in this dissertation. However, I have tolerated occassional irregularities in correspondences, especially for languages with poorer quality data. In the notes for each reconstruction, I call attention to reflexes which don't fit the correspondence exactly, so that readers may judge for themselves the strength any particular reconstruction.

4 This includes some languages which are excluded from the Northern Adelbert group, but are more distantly related, discussed in Chapters 7 and 12. For languages not listed in Table 1.4a, Z'graggen (1980b) was the only source of data. 
On some occasions, I have used evidence from languages outside the Northern Adelbert group in reconstructing a particular form. In all cases, this evidence comes from the languages Waskia and Amako, which are sister languages that are more distantly related to the Northern Adelbert languages ${ }^{5}$

\subsection{Overview of common traits in Northern Adelbert languages}

In this section I provide an overview of some phonological and grammatical traits that are commonly found in Northern Adelbert languages, and which recur in many of the descriptions of individual languages in Chapters 2-6. The section ends with a discussion of the widespread practice of name taboo, and its potential effects on language change.

\subsubsection{Phonology of Northern Adelbert languages.}

In terms of phonology, the Northern Adelbert languages are, as a whole, typical of Trans New Guinea languages. Pawley \& Hammarström (2018) and Foley (2000) characterize a typical TNG consonant phoneme inventory as having two stops series and a nasal series, with three contrasting points of articulation (bilabial, alveolar/dental, and velar), and small numbers of fricatives, liquids, and glides. A five-vowel system (/i, u, e, o, a/) is the most common vowel system in TNG languages, and is found in most of the Northern Adelbert languages.

\section{Stops}

Pawley \& Hammarström (2018) note that TNG languages most commonly have two stop series: a voiceless series, and either a plain voiced series, or a prenasalized voiced series (single segments with

5 In Pick (), I included Amako-Waskia as a branch of Northern Adelbert. I discuss the reasons why I do not now consider them to be part of Northern Adelbert proper in Chapter 7. However, they are demonstrably related to the Northern Adelbert languages, and in Pick (2012) I outline regular correspondences which demonstrate this. 
multiple articulatory gestures, where the stop portion is preceded by a homorganic nasal gesture). A smaller number of TNG languages either have only a voiceless series, or have a three-way distinction between voiceless, voiced, and prenasalized voiced stops.

This characterization of TNG as a whole also fits the Northern Adelbert languages in particular. Fifteen of the twenty-one Northern Adelbert languages have two series of stops. The languages in the Tibor subgroup all have a voiceless series and prenasalized voiced series, while the Kumil language Mauwake has a voiceless series and plain voiced series. In Gavak, as well as some of the languages of the Kaukombar subgroup, voiced stops are sometimes realized with prenasalization, and sometimes without, and this seems to be a matter of free variation. The Kumil language Moere also has two series of stops, but is unusual in that it contrasts plain voiceless stops with prenasalized voiceless stops.

Only two Northern Adelbert languages, Bepour and Miani, have a single (voiceless) stop series. Four languages, Manep, Barem, Usan, and Karian, have a distinction between voiceless, plain voiced, and prenasalized voiced stops (or nasal-stop sequences) ${ }^{6}$. However, in these four languages, the contrast between plain voiced and prenasalized-voiced is marginal, and probably a recent development ${ }^{7}$. In Barem and Manep, for example, there is only a two-way distinction (voiceless vs. prenasalized voiced) in vocabulary inherited from PNA.

For most Northern Adelbert languages with two series of stops, the voiced stops have both plain voiced and prenasalized voiced allophones, and these allophones are also reconstructed for PNA (see Chapter 7). For some languages, like Gavak, plain voiced and prenasalized voiced stops are in free variation in at least some positions. In other languages, plain voiced and prenasalized voiced allophones are in complementary distribution according to a predictable pattern: plain voiced

6 Reesink (1987) analyzes prenasalized voiced stops in Usan as unitary phonemes, while in my descriptions of Barem, Manep, and Karian, I consider homorganic nasal-stop sequences to be two phonemes, a nasal followed by a stop.

7 It is probably no coincidence that these four languages are relatively well-documented compared to other Northern Adelbert languages. If the distinction between plain voiced and prenasalized voiced stops exists only marginally in other, more poorly documented languages, it would likely not be evident in the available data. 
allophones are found word-initially, while prenasalized voiced allophones are found postvocalically. For example, Tupper (2012) analyzes Pamosu as having underlying prenasalized voiced stops, which lose their nasalization in word-initial position. Word-medially and word-finally, they surface with prenasalization. This pattern is also followed by the other languages in the Tibor subgroup as well. In Gavak, Mala, and Maiani, post-vocalic voiced stops freely vary between plain and prenasalized allophones, but only plain voiced allophones are found word-initially.

In a number of Northern Adelbert languages, the phonetic realization of voiced stops is also affected by another voiced stop in the environment. If two voiced stops are separated by only a vowel, they are both realized as plain voiced. For example, in Barem, nd is found in the words kindor 'breadfruit' and umund 'child', as there is no other voiced stop in the environment. However, in the words badar 'roots' and gaid 'sky', where there are two voiced stops in a row, we find $d$ rather than $n d$. This same pattern is also found in Manep and Mala, although loanwords have introduced exceptions.

This pattern is also evident in diachronic changes that have taken place in some languages. For example, in Mawak, PNA $* \mathrm{~b}, * \mathrm{~d}$, and $*_{\mathrm{g}}$ are reflected as voiceless stops word-initially, as in PNA * gemay 'liver' > kema, and in sequences of two historically voiced stops, as in PNA *bug- 'to sit'> Mawak pok-. Elsewhere, historically voiced stops are reflected as prenasalized voiced, as in *kuduruk 'fly' > kunduruk. The voiceless stop reflexes in Mawak were historically plain voiced allophones of PNA $* \mathrm{~b} * \mathrm{~d}$, and $* \mathrm{~g}$, whereas the prenasalized voiced stop reflexes in Mawak were historically prenasalized voiced allophones of $* \mathrm{~b}, * \mathrm{~d}$, and $* \mathrm{~g}$.

This pattern of avoidance of multiple nasal-stop sequences in a single word in Northern Adelbert languages may reflect a wider cross-linguistic tendency. Blust (2012) gives examples of several Austronesian and Australian languages which disallow two nasal-stop sequences in the same word, and which use different strategies to resolve these sequences when they arise ${ }^{8}$. One strategy,

8 The particulars of the restriction on multiple NC sequences in a word vary across these languages, and can also depend on place of articulation and voicing of the stop. 
adopted by the Austronesian language Timugon Murut, is to delete the nasal portion of one nasal-stop sequence, so that /CVN-CVNCV(C)/ surfaces as $\mathrm{CV}-\underline{\mathrm{CVNCV}}(\mathrm{C})$. Another Austronesian language Ngaju Dayak resolves these disallowed sequences using a different strategy, through coalescence of

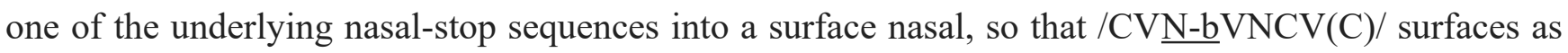
CV-mVNCV(C). Blust connects these processes with a cross-linguistic tendency (discussed in MacEachern $(1999,2002))$ for languages to avoid multiple 'marked' sequences, such as geminates, aspirated stops, or ejectives, within the same word, and suggests this tendency may be one of the driving forces behind processes of dissimilation. The Northern Adelbert languages, however, resolve

these disfavored sequences through loss of nasalization in both nasal-stop sequences, which usually results in surface segments which are phonetically more similar than they otherwise would have been. This may lend support to Blust's suggestion that dissimilation may in some cases be driven by an avoidance of consecutive marked segments, rather than avoidance of consecutive elements which share a featural identity, as suggested by the Obligatory Contour Principle.

Most Northern Adelbert languages follow the tendency of TNG languages to have three place distinctions for the stops: bilabial, alveolar, and velar. Several languages (Hember Avu, Barem, and most of the Numugen languages) have /b/ but lack/p/, or have /p/ only in borrowed vocabulary. Usan and Moere also have glottal stops in addition to velars, while Bepour and Kowaki have a glottal stop but no velar stops.

\section{Nasals}

Pawley and Hammarström (2018) note that TNG languages commonly have three nasals, /m, n, $\mathrm{y} /$, although many languages lack /y/, and for those which do have a velar nasal, it is often disallowed in word-initial position. A small number of TNG languages also have a palatal nasal /n/. The Northern Adelbert languages fit these generalizations quite well. All Northern Adelbert languages have /m/ 
and /n/, while only four of them (Barem, Manep, Maiani, and Gavak) have phonemic /y/, although in some languages, such as Hember Avu and Moere, a velar nasal is found as a word-final allophone of /g/. Of the four languages with phonemic /y/, only Gavak allows it in word-initial position. ${ }^{9}$ Phonemic /n/ is only found in Karian, and possibly other Numugen languages

\section{Fricatives}

TNG languages typically have only one or two fricatives, usually /s/ or /h/, though /f/ and /v/ are not uncommon (Pawley \& Hammarström 2018, Foley 2000). Most Northern Adelbert languages have /s/, and many have a bilabial fricative as well. Several Kumil-Tibor languages have a glottal fricative, either as an allophone of $/ \mathrm{k} /$ or as a distinct phoneme. A number of Northern Adelbert languages also have a voiced palatal affricate. Some Kaukombar languages appear to have no phonemic fricatives, though $s$ is found as an allophone of $/ \mathrm{t} /$.

\section{Liquids}

TNG languages typically have one lateral and one rhotic phoneme. This is the case for several Northern Adelbert languages, including Manep, Mauwake, and Gavak. Other Northern Adelbert languages have only one liquid, either a rhotic or a lateral, having merged PNA *r and *1.

\section{Glides}

Almost every Northern Adelbert language has two glides, a labiovelar /w/ and a palatal /y/, which is the pattern seen in many TNG languages. Mala, which only has /w/, is an exception. In many Northern Adelbert languages, phonemic glides have both glide and fricative allophones. In Barem, for

9 Gavak is also the only language which regularly retains $/ \mathrm{y} /$ as a reflex of PNA * $\mathrm{y}$. In Barem and Manep, $/ \mathrm{y} /$ developed from ${ }^{*} \mathrm{~g}$ in certain environments, or is found in borrowed vocabulary, while Mala $/ \mathrm{y} /$ is a reflex of word-initial PNA * $\mathrm{k}$. 
example, /w/ is realized as a voiced bilabial fricative $[\beta]$ word-finally or adjacent to a high front vowel. In Mauwake, $/ \mathrm{w} /$ can be realized as $[\mathrm{v}]$ or $[\beta]$, depending on the quality of adjacent vowels.

\section{Vowels}

Five vowel systems of /i, e, $\mathrm{u}, \mathrm{o}, \mathrm{a} /$ are the most predominant vowel systems in TNG languages. It is not uncommon for TNG languages to have an additional mid-central vowel as well. With the exception of languages in the Numugen subgroup, all Northern Adelbert languages have the common five vowel system. In the Numugen subgroup, Usan has a six vowel system, with an added mid-central vowel. Although it is rare for TNG languages to have a vowel system with less than five vowels (Pawley \& Hammarström, 2018), four vowel systems are found in the other Numugen languages. Karian, Yaben, Parawen, and Yarawata lack the mid vowels /e/ and /o/, but have a mid-central/ə/, while Ukuriguma has a vowel inventory of $/ \mathrm{i}, \mathrm{u}, \mathrm{o}, \mathrm{a} /{ }^{10} \mathrm{~A}$ few languages, such as Mauwake and Usan, have a length distinction in their vowels.

\section{Stress}

Suprasegmental phonology, including stress, has only been described for a small number of Northern Adelbert languages. According to Berghäll (2015: 42), stress is predictable in Mauwake, falling on the second syllable (in words of two syllables or longer). In Pamosu as well, stress is mostly predictable, and depends on the length of a word, its morphological makeup, and the structure of the final syllable (open or closed). Generally speaking, there is final stress on words with closed final syllables, and antepenultimate stress on words with open final syllables (Tupper 2012: 99-102).

10 My analyses of Parawen, Ukuriguma, and Yarawata phonology are based solely on the phonetic transcriptions of Z'graggen's wordlists, so are extremely tentative. Although these Numugen languages do not have phonemic mid vowels, mid vowels can appear in surface forms. For example, Karian and Yaben have surface [o], which seems to be in free variation with [aw], and is probably best analyzed as underlying /aw/. In Parawen and Yarawata, /a/ is usually realized as a front mid vowel [e] before /i/. 
However, Tupper notes that there are numerous exceptions, for example itu 'flower' [i. 'tu], which has an open final syllable but nonetheless has final stress. On the other hand, Reesink (1987: 39-40) characterizes stress in Usan as phonemic, and illustrates this with minimal pairs that differ only in stress, such as [go.'bi] 'a tree', and ['go.bi] 'taro seedling'. ${ }^{11}$

In the pages that follow, I have little else to say about stress in Northern Adelbert languages, or in Proto-Northern Adelbert. This is not because I have deemed it unimportant-- on the contrary, I suspect that stress may be relevant in resolving some of the unexplained or irregular changes that have taken place in certain Northern Adelbert languages. For example, the difference seen in the reflexes of Barem $k s i k$ 'wild' < PNA *kasik and kain 'mosquito' < PNA *kasin could potentially be explained by a difference in stress placement in the reconstructed forms. Unfortunately, the available data on stress in most languages are minimal or nonexistent, and if stress plays a role in the reconstruction of ProtoNorthern Adelbert, this must await future research.

\subsubsection{Grammar of Northern Adelbert languages}

Below I provide an overview of some of the common grammatical characteristics shared by Northern Adelbert languages.

\section{Word order}

In all Northern Adelbert languages, the unmarked order of major constituents is SOV. This is unsurprising, as all TNG languages have SOV as the basic word order (Pawley \& Hammarström 2018). Northern Adelbert languages also follow the usual ordering of agreement affixes on the verb, with

11 Reesink does not make clear whether in Usan stress placement generally follows certain patterns, but has exceptions, as in Pamosu, or whether it is completely unpredictable. 
objects marked by prefixes on the verb, and subjects marked by suffixes. However not all languages mark objects with affixes on the verb.

Northern Adelbert languages typically have postpositions, rather than prepositions, and adjective and other modifiers typically follow the noun phrase they modify.

\section{Northern Adelbert verbs}

Figure 1.5a shows the common ordering of verb affixes in Northern Adelbert languages.

Figure 1.5a: Northern Adelbert verb affix ordering

\begin{tabular}{|l|l|l|l|}
\hline obj- & root & -aspect & -tense/subject \\
\hline
\end{tabular}

In all Northern Adelbert languages, tense- and subject- marking affixes follow the verb root. In those languages which have aspectual markers on the verb, these always follow the verb root and precede the tense and subject markers.

Not all Northern Adelbert languages mark direct objects on the verb, but some mark objects with verb prefixes. Manep and Mauwake are examples of languages which do not mark direct objects on the verb. In some languages, objects are only marked on a subset of transitive verbs. For example, Barem does not usually use object-marking prefixes, but does for the verbs 'to see' and 'to show' (see Chapter 3). Additionally, as described below, in most Northern Adelbert languages some verb stems have the person and/or number of a direct object included in the meaning of the verb stem.

Individual languages may of course have other kinds of affixes which don't fit into the template in Figure 1.5a. For example, Pamosu (Tupper 2012: 347) and Mauwake (Berghäll 2015: 140) both have a distributive suffix which immediately follows the verb root. 
A common Northern Adelbert trait is that verbs are inflected with fusional suffixes that mark tense and subject. This is illustrated by the Gavak and Mokati verbs below, where in the 3SG.PST suffixes, the meanings of 3SG and past tense are conveyed by the same form.

$\begin{array}{lll}\text { (101) } & \begin{array}{l}\text { unggur-er } \\ \text { die-3SG.PST } \\ \text { 'he died' }\end{array} & \text { (Gavak) } \\ \text { (102) } & \begin{array}{l}\text { um-end } \\ \text { die-3SG.PST } \\ \text { 'he died' }\end{array} & \text { (Mokati) }\end{array}$

In a few languages, such as Mauwake and Karian, some inflected verbs are less fusional, with separate morphemes for the subject and tense. This is illustrated by the Mauwake verb below, where the past tense morpheme is separable from the $3 \mathrm{SG}$ subject marker.

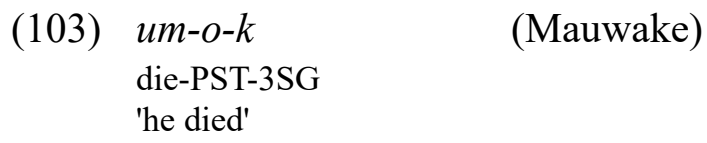

However, even in these languages, there are some conjugations where the semantic components of tense and subject are not entirely separable into two morphemes. In a few languages, including Maia and the Qkuan Kambuar dialect of Barem, the final suffix on the verb may be better analyzed as marking realis or irrealis mood, rather than tense.

\section{Verb classes}

In many Northern Adelbert languages, verbs can be divided into different classes, which follow different conjugational patterns. Usan, for exampe has seven major classes of verbs, some with smaller subclasses that behave slightly differently (Reesink 1987). Between the classes there are numerous differences in the conjugational paradigms that they follow. Mauwake, on the other hand, has only two verb classes, and the differences in the conjugational patterns followed by the two classes are small, mostly depending on whether the past tense marker takes the form - $e$ or $-a$. Furthermore, in Mauwake, 
the verb class is largely, but not entirely, predictable from the phonological shape of the stem. Barem is similar to Mauwake, in that there are few affixes whose vowel is either $-e$ or $-a$, depending on the verb class (Berghäll 2015). As in Mauwake, verb class often correlates with the phonological shape of the verb stem, but this correlation is not perfect.

A phenomenon tied in with verb class is that in most Northern Adelbert languages, at least some verbs have multiple related stems, with different stems used with different sets of conjugational affixes. For example, in Pamosu, the verb 'to sit' has four different stems: pukam- (used with the past tense), puk- (used with the present tense) pukem-, and puka- (used with various other conjugations). Similarly, Manep has two verb stems for 'to sit': bung- is used with past and present tense, and bungom- is used with future tense and imperatives and other conjugations, as illustrated below.

bung-an

sit-2/3SG.PST

'you/he sat'

(105) bungom-inden

sit-2/3SG.FUT

'you/he will sit'
(Manep)

(Manep)

In the Tibor languages, there are numerous verbs with multiple stems, and verbs can be divided into classes depending on the patterns they follow for how the stems are formed, and how they are distributed across the conjugational paradigm. The forms of these stems are often related to each other (as with the Pamosu stems for 'to sit' listed above), but not always in a predictable way (see Chapter 3). Again, Mauwake is one of the languages with more regularity. Mauwake verb stems are largely invariant, with the possible exception of a few irregular verbs like $i k$ - 'to be', whose cognates in other Northern Adelbert languages have the largest number of stems of any verb.

For some verbs, the different stems depend on the person and number of the direct object. The verbs which behave this way tend to be drawn from the same small set, which includes 'to see', 'to hit/shoot', 'to chase/follow', 'to give', and 'to tell'. For example, Gavak has four stems for 'to hit': ur- 'hit 
3SG', inggar- 'hit 1SG', nanggar- 'hit 2SG', and gar- 'hit PL'. Manep follows the same pattern as Gavak, with four stems for 'to hit', a plural stem, and one for each person in the singular. In most cases, these verb stems are clearly derived from fossilized object-marking prefixes that are not productive. All verbs which behave this way are transitive verbs in which suppletion indicates person and number of the direct object. This is in line with Durie's (1986: 357) observation that cross-linguistically verb stem suppletion seems to invariably select for the number of the absolutive argument.

\section{Clause chains and switch reference}

In most Northern Adelbert languages there is a distinction between medial verbs and final verbs, which combine to form clause chains. The number of medial verbs in a clause chain is in theory unlimited, but each clause chain has only one final verb. The inflectional suffixes available to medial verbs and final verbs are often different. Final verbs are typically inflected with suffixes indicating subject and tense, according to the template in Figure 1.5a above, while medial verbs are inflected with switch reference markers that indicate whether the subject of the following verb is the same or different as the subject of the verb it is marked on.

Switch reference systems are prevalent in TNG languages, which are known to have some of the most elaborate switch reference systems that have been described (Pawley \& Hammarström 2018). Haiman and Munro (1983: x) define switch reference in the following way: "Canonical switchreference is an inflectional category of the verb, which indicates whether or not its subject is identical with the subject of some other verb."

In Northern Adelbert languages, switch reference markers often also mark the subject of the medial verb they appear on. In Usan, the suffix -ine indicates that the subject of the medial verb it appears on is $1 \mathrm{SG}$, and that the following verb has a different subject, while the suffix $-a$ indicates that the medial verb it appears on has a 2/3SG subject and that the subject of the following verb is different. 
Switch reference markers often make fewer distinctions than the subject/tense markers on final verbs. For example, the Karian different subject marker -arz marks both second and third person, which are kept distinct in the subject/tense markers on final verbs.

Not all Northern Adelbert languages mark switch reference with verbal suffixes. Manep uses conjunctions that are independent words to mark switch reference (see Chapter 2). Conjunctions marking switch reference are also found in Waskia (Ross \& Paol, 1978), one of Manep's neighboring languages, which is related to the Northern Adelbert languages.

\section{Name Taboos}

A common cultural practice throughout many Melanesian societies is name taboo, whereby individuals are prohibited from uttering the names of certain relatives. This practice is found in both Austronesian and Papuan languages throughout the region (Simons 1982, Holzknecht 1988, Foley 1986: 42). For some communities, the name taboo extends to any homophonous words or associated linguistic forms. Since names in Melanesian societies are often derived from meaningful words in the language, there are many words which are tabooed for any particular individual. I worked with speakers of Northern Adelbert languages who were prohibited from saying common words such as 'knife', 'hand', and 'mouth', for example.

The practice of name taboos has been observed in several Northern Adelbert languages, including all of those that are relatively well documented. Reesink (1987: 11) states that the use of one's in-laws' names is prohibited in Usan, and I have observed this is also the case in Barem, Manep, and Gavak ${ }^{12}$. In Mauwake, also, it is forbidden to use the names of one's in-laws. In Mauwake families, parents give their child the name of one of their relatives, and children may be given multiple

12 What counts as an 'in-law' for taboos includes Ego's spouse's siblings and parents, as well as the Ego's siblings' spouses. In the kinship systems of most Northern Adelbert languages, the notion 'sibling' also includes a paternal uncle's children and a maternal aunt's children. In small communities, the result is that a large fraction of the community that one interacts with are in-laws. 
other names as well. A name assigned by one parent is taboo for the other parent, since it refers to one of their in-laws. Once that child is married, it will be taboo for anyone who is the child's in-law as well, along with all of their other names (Berghäll 2015). Since a married Mauwake speaker will have multiple in-laws, each with multiple names, some of which will be passed down over generations, it is easy to see how in this way, a particular word can persist as taboo for a large number of people over time. Meinerzag (2015) writes that Pamosu speakers are prohibited from saying the names of one's maternal uncles, as well as their children. In addition to these strict taboos, Pamosu speakers find the use of personal names in general, even one's own, to be embarrassing and cause for discomfort. As in Mauwake, personal names are often transferred across generations.

Name taboos raise the question of what strategies speakers use to refer to something (or someone) without being able to name it directly. Holzknecht (1988) discusses strategies that speakers of Markham languages (a group of Austronesian languages spoken in Morobe and Madang Provinces) use to avoid tabooed words. These strategies include the use of synonyms, the use of a semantically related word (for example 'light' to refer to taboo 'fire'), or borrowing from a neighboring language or Tok Pisin. She notes that a word borrowed in this way can become nativized, and for many speakers, its origin may be forgotten, or an incorrect origin may be attributed to it. She gives an example from Adzera, an Austronesian language. Speakers of the Sangang area of Adzera often use the word tati if the usual word for fire, dzaf, is taboo. They claim that tati is from the Guruf dialect of Adzera, when in actuality it is from Taap, a Papuan language.

In my own fieldwork, I encountered a few instances where some speakers were unaware that a word was borrowed, while others explicitly stated that the word was borrowed to avoid name taboos. An illustrative example comes from Waskia, which is located along the coast between the Northern Adelbert languages Gavak and Manep. ${ }^{13}$ I had only ever heard Waskia speakers use the word bamban

13 Waskia and its sister language Amako are not Northern Adelbert languages, but are related. 
for 'fish', which is identical to the word for fish in both Gavak and Manep. I asked the couple I lived with, Veronica and Agustin Talim (both native Waskia speakers), if they knew a word wal, which is the form that Z'graggen lists for 'fish' in his Waskia wordlist (1980b). Veronica informed me that wal meant fish, and was more commonly used in the past. However, it was taboo for many people, as it was also the name of a prominent community member that had passed away many years prior. Agustin expressed surprise at this, but conceded that Veronica was correct, and that he had forgotten all about the word wal, having not heard it in so long. This was all completely new information to their son Tobi, in his twenties, who although a proficient Waskia speaker, told me he had never heard the word wal before.

This anecdote illustrates why name taboos may be important for historical linguistics, as they can potentially be mechanisms of language change. If Veronica's assessment is correct, the native Waskia word for 'fish' was almost completely replaced over the course of a couple generations, and this change was driven by name taboo. ${ }^{14}$

The comparative method traditionally relies on the comparison of basic vocabulary, which is crosslinguistically less prone to borrowing (Tadmore et al. 2010). It has been noted that in Papuan languages, however, borrowing of basic vocabulary is not uncommon (Foley 1986, 2000). It is an open question whether name taboos cause core vocabulary to be borrowed at a higher rate, but this has been argued to be the case for some Austronesian languages in Melanesia (Chowning 1985, Simons 1982). Simons (1982) suggests there are three mechanisms of change caused by taboos: borrowing, deliberate phonological modification of a word, and semantic innovation within the language. These mechanisms should be kept in mind when examining language change in Papuan languages, particularly with regard to the application of the comparative method. If Papuan languages do borrow basic vocabulary at a

14 It is clear that wal is the native Waskia word, as it has a cognate wa in Waskia's sister language Amako. Barker \& Lee (2008) list wal, but not bamban, in their Waskia dictionary, which is based on the variety of Waskia spoken on Karkar island. I worked with Waskia speakers on the mainland, who generally are not in frequent contact with Waskia speakers on Karkar. 
higher rate, this is potentially a problem for the application of the comparative method, which relies on the assumption that the items being compared are all directly inherited from a common proto-form. Simons (1982) and Holzknecht (1988) bring up the consideration that multiple borrowings may result in regular sound correspondences due to borrowing, and not direct inheritance, resulting in too many phonemes being reconstructed for a proto-language. If reconstructions for a higher-order protolanguage are available for comparison, this is one method for identifying these spurious correspondences, but these reconstructions are generally not available for Papuan languages. As Pawley \& Hammarström (2018) note, the reconstruction of Proto-TNG is still in its beginning stages.

Another mechanism listed by Simons, semantic innovation, can complicate the application of the comparative method in another way. If some languages shift the meaning of certain words due to name taboo, this would results in a word set of regularly corresponding forms whose meanings do not correspond precisely. Potential cognate sets should therefore not be dismissed out of hand because of discrepancies in meaning.

As Pawley \& Hammarström (2018) point out, higher levels of borrowing in Papuan languages do not present challenges qualitatively different from those faced by historical linguists working in any other part of the world. There are methods for distinguishing true cognate forms from spurious correspondences. Borrowed items may sometimes be identifiable because they do not fit the regular phonotactic patterns of the language. For example, Waskia bamban stands out because Waskia generally lacks nasal-stop sequences (or prenasalized stops) in native vocabulary. On the other hand, borrowed words can be adapted to fit native phonology, in which case they can be harder to detect. With regard to potential cognates whose meanings do not correspond, it is useful to look at patterns of polysemy in related languages. For example, Barem ivor 'rain' appears to be the reflex of PNA *iper 'salt, ocean'. While a connection between 'rain' and 'salt, ocean' initially seems tenuous, it seems more 
likely once we consider that in some other Northern Adelbert languages there is polysemy between 'ocean' and 'water', or between 'water' and 'rain'. 


\section{Manep-Barem}

This chapter gives an overview of the synchronic phonology and verb morphology of two Northern Adelbert languages, Manep and Barem, which together form a subgroup of Northern Adelbert. This provides the background necessary for the reconstruction of Proto-Manep-Barem, and for understanding the sound changes that have taken place in both languages, which is the subject of Chapter 8 .

\subsection{Barem}

The Barem people live on the northwest coast of Madang Province, and are centrally located within the Northern Adelbert group. Their neighbors are Manep speaking communities to the southwest, across the Dibor river, and Korak speakers to the northwest. The homeland of the Barem people is Masor mountain, north and inland of the Dibor river. While many Barem speakers still reside inland near Masor mountain, a greater number now live along the coast, from the area around the Dibor in the south, to Bunabun village, the largest Barem-speaking settlement, in the north. There are at least four distinct dialects: Bunabun (spoken north of the Dibor near the coast), Asumbin (spoken in inland areas), Qkuan Kambuar (with only a few speakers, residing around the Dibor river and in Tokain village to the south), and Kimbu Kambuar (now extinct; the Kimbu people live inland from Tokain village). According to Ethnologue (Eberhard, Simons \& Fenig 2020) there were 1,190 speakers as of 2003.

The Qkuan Kambuar dialect is severely endangered. The few remaining speakers are middleaged or older, and are not in daily contact with each other. When they do meet, they usually speak to 
each other in Waskia or Tok Pisin. All Qkuan Kambuar speakers are conversant in the Bunabun dialect as well, and will often switch between the two dialects. Bunabun speakers, on the other hand, generally have little or no knowledge of Qkuan Kambuar.

The Bunabun dialect is less endangered, and more vital than most other languages in the area. Its speakers comprise the biggest part of the Barem population. From what I observed in 2019, Barem is the primary language of the community. Adults speak to each other in Barem most of the time, and I observed children speaking to each other in Barem. Tok Pisin is also in daily use, but I encountered a few adults who were uncomfortable speaking Tok Pisin, which is unusual for the region.

The Kimbu Kambuar community no longer speak Barem, and their primary language is now Tok Pisin. The middle-aged adults I met with told me that even their grandparents' generation no longer spoke Kimbu Kambuar, but had switched to Qkuan Kambuar. They state that the dialect spoken by their ancestors was distinct from other Barem dialects, and Laurence Kimbu, one of the Kimbu clan leaders, was able to recall a few short words and phrases that support this. Table 2.1a lists the Kimbu Kambuar expressions that Laurence recalled to me, alongside the Qkuan Kambuar and Bunabun cognates. These phrases provide some potentially valuable information for understanding Barem's history (see Chapter 8).

Table 2.1a: Kimbu Kambuar expressions

\begin{tabular}{|l|l|l|l|}
\hline Kimbu Kambuar & Qkuan Kambuar & Bunabun & gloss \\
\hline gamang & gaman & gaman & 'liver' \\
\hline ombe & ombek & ombek & 'branch' \\
\hline mata urampkan & matav oramkan & matav orakan & 'you're talking' \\
\hline aragarag & -- & -- & 'hurry up!' \\
\hline
\end{tabular}

I did not work with any speakers of the Asumbin dialect, but was told that it is similar to Bunabun. 
This description of Barem is based primarily on data collected during my 2016-2018 fieldwork, working with speakers of the Qkuan Kambuar and Bunabun dialects. Most of the data on Qkuan Kambuar comes from elicitation sessions with Josepa Wok, the oldest and most fluent speaker, along with a few recordings of more naturalistic speech. The Bunabun data comes mainly from recordings of conversations and narratives collected in 2019, which were transcribed and translated into Tok Pisin by myself, Collins Kumuang, and Lukas Kumuang, and can be accessed online at the Endangered Languages Archive. I also consulted the Barem wordlist in Z'graggen (1980b), as well as Capell (1952), which includes a short wordlist and two and half page description of Bunabun. For Qkuan Kambuar, I also consulted a handbook of short stories collected by Qkuan Kambuar youth sometime in the 1990's as part of a literacy project headed by Nicholas Faraclas (Stories). In this project, young members of the community interviewed their elders and wrote stories they were told in Qkuan Kambuar. The orthography used in this book also forms the basis of the orthography I use here, with a few adaptations.

The Qkuan Kambuar and Bunabun dialects have many differences in their vocabulary, phonology, and inflectional verb morphology. When a statement in this chapter refers to "Barem", it applies to both dialects unless otherwise noted. Where a description applies to only one dialect, this is made clear. Most of the example sentences are from the Bunabun dialect. Those drawn from Qkuan Kambuar are noted with $(\mathrm{QK})$ on the first line.

The structure of the remainder of the section is as follows. In Section 2.1.1, I give the Barem phoneme inventory, discuss the major allophones of each phoneme, and outline the Barem orthography, and Section 2.1.2 discusses syllable structure and word structure. In Section 2.1.3, I discuss morphophonological processes that apply in the inflection of Barem verbs. Section 2.1.4 gives an overview of Barem verbal morphology, including the marking of subject, object, and indirect object on the verb, TAM marking, and switch reference. 


\subsubsection{Barem phonemes}

Tables 2.1.1a-2.1.1b show the Barem phoneme inventory. In many respects, this inventory is typical of Papuan languages. Barem, like many Papuan languages, has a small number of place distinctions, a two-way distinction between voiceless and voiced oral stops (with the voiced series often realized with prenasalization), and a small number of fricatives and liquids. (Foley 2000). Barem also has the five-vowel system that is typical of many Papuan languages (Foley 2000). In the sections below, I discuss the major allophones for each phoneme and the environments which condition them.

Table 2.1.1a: Barem vowel phonemes

\begin{tabular}{|l|l|l|}
\hline & front & back \\
\hline high & /i/ & $/ \mathrm{u} /$ \\
\hline mid & /e/ & $/ \mathrm{o} /$ \\
\hline low & & $/ \mathrm{a} /$ \\
\hline
\end{tabular}

Table 2.1.1b: Barem consonant phonemes

\begin{tabular}{|c|c|c|c|c|}
\hline & labial & alveolar & palatal & velar \\
\hline stop & $/ \mathrm{p} /, / \mathrm{b} /$ & $/ \mathrm{t} /, / \mathrm{d} /$ & & $/ \mathrm{k} /, / \mathrm{d} /$ \\
\hline nasal & $/ \mathrm{m} /$ & $/ \mathrm{n} /$ & & $/ \mathrm{ng} /$ \\
\hline affricate & & & $/ \mathrm{j} /$ & \\
\hline fricative & $/ \mathrm{f} /$ & $/ \mathrm{s} /$ & & \\
\hline trill & & $/ \mathrm{r} /$ & & \\
\hline glide & $/ \mathrm{w} /$ & & $/ \mathrm{y} /$ & \\
\hline
\end{tabular}

\section{Vowels}

Phonetically, /e/ is usually pronounced as a lax vowel $[\varepsilon]$ when followed by a consonant. /i/ often lowers to /e/ word-initially in the Bunabun dialect, as in /in+me/ > inume enume 'I slept'. Common vowel sequences are /ai/, /au/, /ia/, /ua/, and /ie/, and /io/ and /uo/ are attested in a small number of words. 


\section{Voiceless stops}

Barem has three voiceless stops, $/ \mathrm{p} /, / \mathrm{t} /$, and $/ \mathrm{k} /$. Voiceless stops are sometimes realized as fricatives word-initially when preceding another voiceless stop, for example /tkun/ 'moon' > $[\theta$ kun tkun skun], /ptiw/ 'sago' $>[\phi$ ti $\beta \sim$ pti $\beta]$ and $/ \mathrm{kta} /$ 'coconut' $>[\mathrm{xta} \sim \mathrm{kta}]$. It is not quite clear whether $/ \mathrm{t} /$ and $/ \mathrm{s} /$ contrast before $/ \mathrm{k} /$. Variation has been recorded for some words, as just shown with /tkun/ 'moon', while others, such as /skar/ 'rock, reef', have only been recorded with [s]. I have assumed that lack of variation indicates underlying /sk/, while variation indicates underlying/tk/.

For $/ \mathrm{k} /$, the fricative allophone is mandatory when preceding another $/ \mathrm{k} /$, as in $/ \mathrm{kka} /, \operatorname{dog}^{\prime}>$ $[\mathrm{xka}]$. Speakers seem to regard this $[\mathrm{xk}]$ sequence as a distinct sound from both plain voiceless $/ \mathrm{k} /$ and the fricative allophone $[\mathrm{x}]$ which may appear before $/ \mathrm{t} /$, and many have expressed pride in it as a characteristic sound of Barem which is not found in neighboring languages. They've chosen to represent this sequence orthographically as $\langle\mathrm{qk}\rangle$, although the most parsimonious analysis would regard this as underlying $/ \mathrm{kk} /$ rather than a distinct prespirantized stop phoneme.

A voiceless stop may also spirantize word-medially if the cluster of two voiceless stops straddles a morpheme boundary, for example /iyok+ke/ 'I disliked it' > [ijoxke] (see Section 5). If the word-medial cluster is within the same morpheme, spirantization does not occur, for example /atkaw/ 'just' > [atkaß], but not $*[a \theta k a \beta]$.

\section{Voiced stops}

Barem has three voiced stops /b/, /d/, and /g/, and one voiced affricate $/ \mathrm{j} /$.

With some exceptions, discussed below, voiced stops and their corresponding homorganic nasal-stop clusters are in complementary distribution. In general, plain voiced stops are found wordinitially and in consonant clusters, while homorganic nasal-stop clusters are found intervocalically and 
word-finally. There are two further caveats: first, instead of word-final [yg] we find [y]. Second, when two voiced stops are separated by only a vowel, they are both plain voiced, no matter their position in the word. So, for example, we find medial /b/ in words such as dabuw- 'to shine', where it is preceded by another voiced stop, but $/ \mathrm{mb} /$ in words such as kambuar 'speech', where there is no other voiced stop in the environment. In most words with two voiced obstruents, one of them is word-initial. However, there are words with two medial (plain) voiced consonants, such as kidiban 'lizard' and magubem 'eagle'. Such words indicate that the lack of prenasalization is due to both voiced obstruents affecting each other, rather than a 'spread' of plain voicing from an initial plain voiced consonant to the following medial one. Table 2.1.1c illustrates this distribution of voiced stops and nasal-stop sequences.

Table 2.1.1c: distribution of Barem voiced stops and homorganic nasal-stop clusters

\begin{tabular}{|c|c|c|c|c|}
\hline & $\begin{array}{l}\text { word-initial: } \\
\text { plain voiced }\end{array}$ & $\begin{array}{l}\text { intervocalic: } \\
\text { nasal-stop }\end{array}$ & $\begin{array}{l}\text { word-final: } \\
\text { nasal-stop }\end{array}$ & $\begin{array}{l}\text { two voiced stops in } \\
\text { sequence: } \\
\text { plain voiced }\end{array}$ \\
\hline$/ \mathrm{b} /$ & [baram] 'hornbill' & $\begin{array}{l}\text { [kumbum] 'stinging } \\
\text { nettle' }\end{array}$ & [imb] 'feces' & [kidiban] 'lizard' \\
\hline$/ \mathrm{d} /$ & [dur] 'tail' & [kindor] 'breadfruit' & [фond] 'wall' & [badar] 'roots' \\
\hline /g/ & [gaman] 'liver' & [kingur] 'shadow' & [jay] 'water' & [dagok] 'throat' \\
\hline$/ \mathrm{j} /$ & 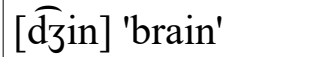 & [inḑzin] 'smell' & [nandิ3] 'pole' & [A] ibug] 'mouth' \\
\hline
\end{tabular}

The distribution of plain voiced stops and homorganic nasal-stop clusters described above applies to most of the Barem lexicon, including all the vocabulary items that can be traced to PNA and Proto-Manep-Barem (except for some inflectional affixes). However, there are some words that do not fit the pattern. Words such as wagi 'cuscus' and ked- 'to love' have plain-voiced segments intervocalically, where nasal-stop clusters are expected. Other words, such as ganggar 'bad' and embugan 'thigh', have nasal-stop clusters in an environment where plain voiced stops typically occur. Some of these exceptional items can be identified as probable loans, such as wagi 'cuscus' and kanagiv 
'knife', which closely resemble the Simbukanam dialect of Manep, wagi 'cuscus' and kanagip 'knife'. The provenance of other exceptional items, such as ked- 'to love' and ganggar 'bad' is unclear. Furthermore, many inflectional affixes and function words do not fit the pattern, such as the Bunabun inflectional affixes -mid '3PL.REM', -kid ' 3PL.REC', and -Vd '3SG.REM', and the plural pronoun indugo.

It is likely that at an earlier point in Barem's history, plain-voiced stops and prenasalized-voiced stops were predictable allophonic variants. In contemporary Barem, however, there is synchronically a phonemic distinction between, for example, /nd/ and /d/. For this reason, I analyze homorganic nasalstop sequences as clusters, rather than as allophones of the voiced stops, since this prenasalization is no longer predictable. Loans such as wagi 'cuscus' and kanagip 'knife' have created a contrast between $[\mathrm{yg}]$ and $[\mathrm{g}]$ where there previously was none. This has effectively created a new phoneme $/ \mathrm{y} / .^{15}$

\section{Fricatives}

Barem has two voiceless fricative phonemes, bilabial /f/ and alveolar /s/. Glides also have voiced fricative allophones, discussed in the section on glides below.

For much of Barem vocabulary, $/ \mathrm{p} /$ and $/ \mathrm{f} /$ are in either complementary distribution or free variation. /f/ is found word-initially and intervocalically, as in /fen/ 'navel', and /wafur/ 'far', while /p/ is found in clusters with /s/, such as /psuw-/ 'to carry around the neck', and /spakur/ 'chief'. As mentioned above, in word-initial voiceless stop clusters, there is variation between a fricative and a stop, as in $[\phi \mathrm{ti} \beta \sim \mathrm{pti} \beta]$ 'sago', or $[\phi \mathrm{k}-\sim \mathrm{pk}-]$ 'to sharpen, carve'. So far, then, $[\phi]$ and $[\mathrm{p}]$ could be analyzed as allophones of a single phoneme, with $[\mathrm{p}]$ found in clusters with $/ \mathrm{s} /,[\mathrm{p}]$ and $[\phi]$ in free variation in word-initial clusters with $/ \mathrm{t} /$ and $/ \mathrm{k} /$, and $[\phi]$ found elsewhere.

15 Alternately, we could say a contrast has developed between plain voiced $/ \mathrm{g} /$ and prenasalized $/{ }^{\mathrm{p}} \mathrm{g} /$, rather than between $/ \mathrm{g} /$ and $/ \mathrm{y} /$. In either case, word-final [ $\mathrm{y}$ ], which developed from ${ }^{\mathrm{k}} \mathrm{g}$, could still be considered an allophone of $/ \mathrm{g} /$. 
However, a number of words do not fit this pattern, such as piropir 'butterfly', sarupe 'serving spoon', pon 'sea turtle' and par 'platform', (the last two are loans from Waskia ${ }^{16}$ ). Therefore, /p/ and /f/ must synchronically be treated as separate phonemes, which seem to have become distinct through the introduction of loanwords or other innovated vocabulary.

\section{Sonorants}

Barem has three nasals, $/ \mathrm{m} /$ and $/ \mathrm{n} /$ and $/ \mathrm{y} /$. As mentioned above, $/ \mathrm{y} /$ developed phonemic status through the introduction of loanwords that contain $[\mathrm{g}]$ without prenasalization. $/ \mathrm{y} /$ is therefore contrastive only before /g/. In the Qkuan Kambuar dialect, /y/ contrasts only with its absence. The Bunabun dialect allows heterorganic nasal-clusters, so $/ \mathrm{y} /$ also contrasts with the other nasals before $/ \mathrm{g} /$, for example /munguan/ 'bird' vs. /mungurun/ 'laughter'. Word-finally, we find [y], but not [g], so there is no contrast in this position.

Barem has one liquid, which I refer to here as an alveolar trill. However, speakers of the Qkuan Kambuar and Bunabun dialects state that the pronunciation of this liquid is different in the two dialects. Further research is needed on the phonetics of this liquid across dialects.

\section{Glides}

Barem has a labiovelar glide $/ \mathrm{w} /$ and a palatal glide $/ \mathrm{j} /$. /w/ has glide and voiced bilabial fricative allophones, with the fricative occurring adjacent to /i/ (/wi/ 'rope' $\rightarrow[\beta \mathrm{i}])$, and syllable-finally (/uyaw/ 'spear' $\rightarrow$ [ujaß], /buwdum/ 'earthquake' $\rightarrow$ [bußdum]). The glide and fricative allophones are in free variation adjacent to mid-vowels and /u/, (/kawet/ 'fishing net bag' $\rightarrow$ [kawet $\sim$ kaßst], /uwute/ 'many' $\rightarrow$ [uwute $\sim \mathrm{u} \beta$ ute].

16 The ultimate source of pon 'sea turtle' is Austronesian, and likely entered into Waskia from Takia, an Austronesian language which is in close contact with Waskia. Barem/Waskia par 'platform' may also ultimately be an Austronesian loan (Proto-Oceanic *paRa 'storage rack above the hearth'), although Barem par typically refers to a bench or platform for sitting, not for storage. 
The palatal glide also has a palatal fricative allophone, which can occur adjacent to /i/, as in /iyat/ 'young' $\rightarrow$ [ijat izat]. In the Bunabun dialect, word-initial /j/ deleted preceding /i/, although this is only attested in one word: /yik/ 'sore' $\rightarrow$ [ik] (Bun.), [jik zik] (QK).

\section{Barem orthography}

There is no standard Barem orthography. The orthography used here is based on the one developed in a literacy project headed by Nicholas Faraclas, that is used in a book of Qkuan Kambuar stories (Stories). It is shallow in the sense that in several cases, different symbols are used for predictable allophones of a single phoneme. For example, $<\mathrm{w}>$ and $<\mathrm{v}>$ are both used to represent underlying /w/. The Barem orthography is similar to that adopted for other Northern Adelbert languages in this dissertation, but with the addition of two special symbols, $<\mathrm{qk}>$ and $<_{-}>$. Underlying $/ \mathrm{kk} /$ clusters are pronounced as a preaspirated velar stop [ $\left.{ }^{\mathrm{h}} \mathrm{k}\right]$ or prespirantized $\mathrm{stop}$ [xk], and represented orthographically as $<\mathrm{qk}>$. Another special symbol is the dash $<->$, which is used to differentiate the sequence $/ \mathrm{ng} /<\mathrm{n}-\mathrm{g}>$ from $/ \mathrm{y} /<\mathrm{ng}>$ and $/ \mathrm{ng} /<\mathrm{ngg}>$.

\subsubsection{Barem syllable and word structure}

In this section I discuss Barem syllable and word structure, including restrictions on the distribution of individual phonemes.

\section{Barem syllables}

Barem syllables have a $(\mathrm{C})(\mathrm{C}) \mathrm{V}(\mathrm{N})(\mathrm{C})$ structure: onsets contain from zero to two segments, while codas may contain zero to two segments. 


\section{Barem syllable onsets}

If a Barem syllable has a single-segment onset, this may be any consonant, although only one $r$ initial word has been identified so far. Complex onsets contain only voiceless obstruents. Complex onsets may be phonologically stop-stop, fricative-stop, or stop-fricative. No fricative-fricative onsets have been identified. Historically these complex onsets derive from words which began with two voiceless obstruents separated by a vowel which was later lost, leaving a cluster of two adjacent voiceless obstruents.

In $t k$ - and $k t$ - onsets, the first stop in the cluster may be realized as a fricative, (/tkun/ 'moon' $\rightarrow$ [ $\theta \mathrm{kun}], / \mathrm{kta} /$ 'coconut' $\rightarrow[\mathrm{xta}])$ or as a sequence of two stops separated only by the release of the first stop, but no vowel. Figures 2.1.2a-b are spectrograms of two tokens of kta 'coconut', both spoken by Josepa Wok, a Qkuan Kambuar speaker. In Figure 2.1.2a, the initial velar stop is realized as a fricative [x] , and the alveolar stop is realized as a stop [t]. In Figure 2.1.2b, both $/ \mathrm{k} /$ and $/ \mathrm{t} /$ are realized as stops.

Note that in both Figures 2.1.2a and 2.1.2b there is no vowel between the stops. This is characteristic of complex onsets in Barem: the initial stop burst is followed immediately by the closure of the second stop, with no epenthetic vowel. Speakers sometimes describe this type of onset as "silent $p$ " or "silent $t$ ", although it is usually audible. 
Figure 2.1.2a: $k t a$ 'coconut' with stop lenition

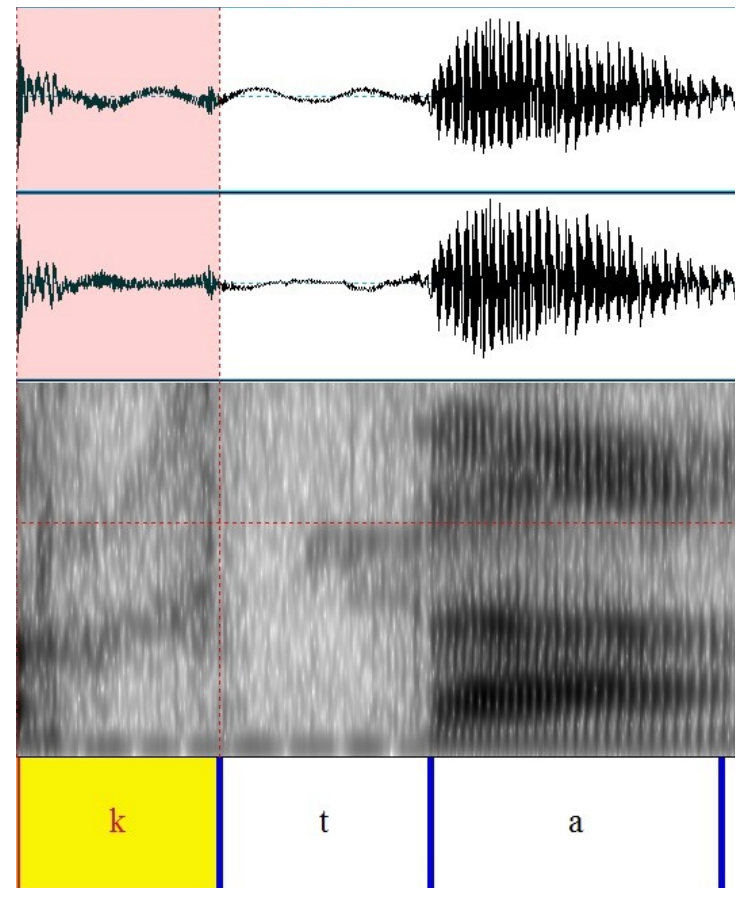

Figure 2.1.2b: kta 'coconut' with no lenition

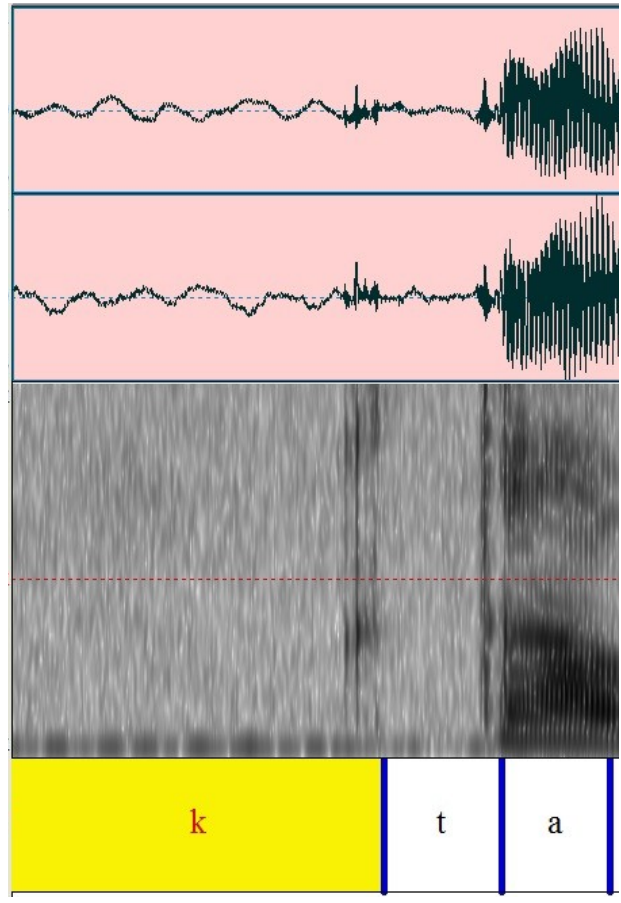

As discussed above, there are a number of words with onsets represented orthographically as $<\mathrm{ft}>$ whose initial labial can be phonetically realized as either a stop or fricative, as in ftiv, 'sago', $[p t i \beta \sim, \phi \mathrm{ti} \beta]$. These derive historically from ${ }^{*} p \mathrm{Vt}$-, but whether to consider the initial segment as 
underlyingly $/ \mathrm{p} /$ or /f/ synchronically is a matter of personal preference, as $[\mathrm{p}]$ and $[\phi]$ were allophones of a single phoneme until the system was disrupted by loanwords with /p/ as an independent phoneme contrasting with /f/.

Another complex onset, represented orthographically as $<\mathrm{qk}>$, can be analyzed as an underlying sequence of two velar stops, but is realized as either a prespirantized or preaspirated velar stop, $[\mathrm{xk}]$ or $\left[{ }^{\mathrm{h}} \mathrm{k}\right]$. Although $q k$ - onsets are always phonetically $[\mathrm{xk}]$ or $\left[{ }^{\mathrm{h}} \mathrm{k}\right]$, there are several reasons to consider them to be phonemically a $/ \mathrm{kk} /$ cluster. First, they derive historically from $* \mathrm{kVk}$ sequences, from example $q k a$ 'dog' from Proto-Manep-Barem *kakas (Manep: kakas). Second, the initial velar in $k t$ - onsets may also be realized as a fricative. Third, synchronically, two adjacent velar stops separated by a word or morpheme boundary may also be realized as [xk], for example /uyek\#ki/ 'or not?' > [ujexki].

Fricative-stop onsets consist of an alveolar fricative /s/ followed by any one of the voiceless stops $/ \mathrm{p} /, / \mathrm{t} /$ or $/ \mathrm{k} /$. For example: spuam 'rattle', stiri 'chicken', skov 'sand'. Stop-fricative onsets consist of either a voiceless labial or alveolar stop followed by an alveolar fricative /s/, as in psak'tree sp.' and ksim 'gnat'.

\section{Barem syllable codas}

Barem codas contain either a single segment, or a homorganic nasal-voiced stop sequence. As mentioned above, these nasal-stop sequences were historically a single phoneme. The palatal glide /y/ and the bilabial fricative /f/ do not occur in coda position. /s/ appears in coda position only after /a/ in native Barem vocabulary, but is found after other vowels in loanwords. Some /s/ codas can be shown to derive historically from *t, as in babaras 'year' < PNA *barat, which suggests that Pre-Barem lacked fricative codas altogether. All other types of segments are found in coda position. 


\section{Barem word structure}

Most Barem monomorphemic words are of one or two syllables, and three syllable words are not uncommon. Only one apparently monomorphemic word longer than three syllables has been identified: isiweka $(\mathrm{QK})$ 'slow, quiet'. Many three-syllable words have been derived by a process of reduplication. For example: ararer 'two', babaras 'year', didigen 'straight', gigiruk 'crooked', mamunjir 'ants'. Other three-syllable words are monomorphemic, such as magubem 'eagle', kunduruk 'flies', kamandim 'bow'. In the Murukanam dialect, the medial vowel in most three syllable words has been lost. Compare, for example, Qkuan Kambuar urumik to Murukanam urmik 'fish' (See Chapter 8). In most Qkuan Kambuar disyllabic words, only the final syllable may have a coda, although there are exceptions (QK: buvdum 'earthquake', makten 'behind'). In Bunabun, the loss of medial vowels in three-syllable words has led to many two syllable words with codas in the initial syllable.

\subsubsection{Morphophonological processes in Barem}

This section outlines morphophonological processes that apply when a verb root is affixed with inflectional morphology. Some of these processes apply only when select morphemes are involved. For example, $e$-rounding (rule 4 below), in which $e$ becomes $o$ following a labial, applies to some $e$ initial suffixes, but not others, and does not apply in monomorphemic words, such as kawet 'fishing bag'. Other processes apply to all sequences of the relevant type, for example, $w-m$ coalescence (rule 1 below). Sequences of underlying $/ \mathrm{w}+\mathrm{m} /$ are always realized on the surface as $[\mathrm{b}]$, and $/ \mathrm{wm} /$ sequences are not found in monomorphemic words.

Some of the processes described here are general phonological processes that apply not just at morpheme boundaries, but also within a morpheme. For example, Bunabun vowel insertion (rule 5 below) applies to non-high vowels after a high vowel and a single consonant, as in /in + ed/ $\rightarrow$ [inicd] 
'he slept'. The same process has applied to monomorphemic words, as in Proto-Manep-Barem *kibem 'hand drum' > (Bun.) kimbiem, (QK) kimbem. Vowel insertion is clearly a synchronically active process, but its application in kimbiem 'hand drum' can be viewed as a historical change, since the sequence /ie/ in this word does not alternate with a /e/ under any circumstance. Processes like this are discussed both in this section, and again in the section on sound change in Barem in Chapter 8 .

\section{1. $w-m$ coalescence: $/ w+m / \rightarrow b$}

When a $w$-final root is suffixed with an $m$-initial suffix, the resulting /wm/ cluster is realized as $[\mathrm{b}]^{17}$.

$$
\begin{aligned}
& / \mathrm{kaw}+\mathrm{me} / \rightarrow \text { kabe } \\
& \text { open+1SG.REM } \\
& \text { 'I opened it' }
\end{aligned}
$$

Recall that when two voiced stop phonemes are separated only by a vowel, both stops are realized without prenasalization. When such a sequence is created by the $w-m$ coalescence, the first voiced stop may be realized with or without prenasalization:

$$
\begin{aligned}
& \text { /iduw }+ \text { me/ } \rightarrow \text { indube idube } \\
& \text { go+1SG.REM } \\
& \text { 'I went' }
\end{aligned}
$$

\section{2. r-deletion}

Verb root-final $/ \mathrm{r} /$ deletes before a number of different suffixes. Four different rules are necessary to account for all cases of $r$-deletion. These are outlined below.

2a. $/ \mathrm{r} / \rightarrow \varnothing /+\mathrm{N}$

Verb root-final /r/ deletes before suffixes beginning with a nasal.

17 This is always realized without prenasalization. 
(203)

/or+minbi/ $\rightarrow$ ominbi

hit+2SG.PFV.SS

'you hit it'

$/$ tanar + mid $/ \rightarrow$ tanmid $^{18}$

talk+1PL.REM

'they talked'

(205)

$/$ kawar $+\mathrm{n}+$ ombin/ $\rightarrow$ kawanombin

wash+2SG+1PL.IRR

'We will wash it for you'

Note that clusters of $/ \mathrm{r} /$ followed by a nasal are permitted in monomorphemic words, for example irnua 'ringworm type' and yarm- 'to wear'.

2b. $/ \mathrm{r} / \rightarrow \varnothing / \mathrm{d}$

Verb root-final /r/ deletes before suffixes beginning with $/ \mathrm{d} /$.

(206) $\quad$ or $+\mathrm{di} / \rightarrow$ odi

hit+3PL.PFV.SS

'they hit'

(207) /ambar $+\mathrm{da} / \rightarrow$ ambada

come+3SG.PFV.SS

'he came'

2c. $/ \mathrm{r} / \rightarrow \varnothing /+\mathrm{V}$

Verb root-final /r/ deletes before the suffixes -Vn '2SG.REM' and -Vd '3SG.REM'. The vowel takes different forms depending on the root these suffixes attach to (see Section 2.1.4). For $r$-final roots, they take the forms -an and -ad.

$\begin{array}{ll}\text { (208) } & \text { kur }+ \text { an } / \rightarrow \text { kuan } \\ \text { come+2SG.REM } \\ \text { 'you came' }\end{array}$

18 This example, as well as (212) below, also show medial vowel deletion, described later in the section (rule 8). 
$/$ tanar $+\mathrm{ad} / \rightarrow$ tanad

say+3SG.REM

'he said'

$2 \mathrm{~d} . / \mathrm{r} / \rightarrow \varnothing /[$ R-markers $]$

Barem has a set of suffixes I call $R$-markers which mark several types of arguments on the verb, including indirect objects and beneficiaries (Section 2.1.4). These are $-i$ '1SG.IDO', $n$ '2SG.IDO', $-t$ '3SG.IDO' and -ind 'PL.IDO'. In polysyllabic $r$-final verb roots, /r/ is deleted when followed by an Rmarker.

$/ \mathrm{kawar}+\mathrm{i}+\mathrm{am}+\mathrm{ko} / \rightarrow$ kawayamko

$(\mathrm{QK})$

wash+1SG+IPFV+3SG.R

'he's washing it for me'

(211) /kawar+ind $+\mathrm{am}+\mathrm{ko} / \rightarrow$ kawaindamko

$(\mathrm{QK})$

wash+PL+IPFV+3SG.R

'he's washing it for us'

(212) $/$ tanar $+\mathrm{t}+\mathrm{ed} / \rightarrow$ tanted

say+3SG+3SG.REM

'he said to him'

In monosyllabic $r$-final verb roots, $r$-deletion is optional. Although the number of relevant examples in the corpus is small, it seems that $r$ is usually retained in these cases.
(213) $\quad /$ or $+\mathrm{t}+\mathrm{ed} / \rightarrow$ oted $\sim$ orted
hit+3SG+3SG.REM
'he hit it for him'

Note that $r$-deletion triggered by $-n$ '2SG.IDO' and $-t$ '3SG.IDO' could be covered by rules $2 \mathrm{a}$ and $2 \mathrm{~b}$, respectively. However, $-i$ '1SG.IDO' and -ind '1PL.IDO' are the only $i$-initial suffixes which trigger $r$ deletion. 


\section{3. vowel epenthesis: $\varnothing \rightarrow \mathrm{V} /[$-continuant $]+\mathbf{m}$ (optional)}

An epenthetic vowel is often inserted between morpheme-final stops, nasals and alveolar trill, and a following $/ \mathrm{m} /$ within the same word. The quality of this vowel varies, and $[\varepsilon],[\mathrm{o}],[\mathrm{a}]$ and $[\mathrm{u}]$ have all been recorded.

(214) /usund + mind/ $\rightarrow$ usundumind

chase+1PL.REM

'we chased it'

\section{4. e-rounding:}

4a. e $\rightarrow \mathrm{o} /[+$ labial $]+$

In some suffixes, an initial /e/ surfaces as [o] when attached to a root with a final labial consonant. This rule applies to the Qkuan Kambuar suffixes -eme '1SG.R', -eko '3SG.R', -ema '2PL.R', -engamba '2PL.IRR', -em '2PL.IMP', and -era '3SG.SS'. In the examples below, a suffix-initial $e$ rounds when following the labial-final verb roots $u m$ - 'die' and taw- 'cut', while it does not round following the verb roots angg- 'see' and tanar- 'talk'.

/um+eko/ $\rightarrow$ umoko

die+3SG.R

'he died'

(216) $/$ taw + em $/ \rightarrow$ tawom cut+2PL.IMP

'cut it!'

(217) lang+eko/ $\rightarrow$ anggeko

see+3SG.R

'he saw'

(218) $/$ tanar $+\mathrm{em} / \rightarrow$ tanarem

talk+2PL.IMP

'talk!' 
This rule does not apply to two Qkuan Kambuar e-initial suffixes, -engambin '2SG.IRR' and -enggara '3SG.IRR'.

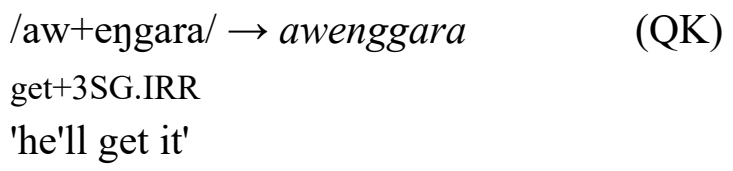

The $e$-rounding rule is not present in the Bunabun dialect, which has only two $e$-initial suffixes, -embin '2SG.IRR' and -emda '3SG.IRR'. Like their Qkuan Kambuar counterparts -engambin and -enggara, these Bunabun irrealis suffixes do not undergo rounding.

However, there is some indication that rounding applied in Bunabun in the past. The Qkuan Kambuar 2PL.IMP suffix has the allomorphs -om (after labials) and -em (elsewhere). In Bunabun, the 2PL.IMP suffix is -om, which likely used to alternate as in Qkuan Kambuar, but the -om allomorph was generalized to be used with all verb roots.

Since all of the $e$-initial suffixes which do not undergo rounding are irrealis suffixes, it is almost possible to say that irrealis suffixes are exempt from e-rounding. However, there is an exception to this generalization in that Qkuan Kambuar -engamba '2PL.IRR' does round.

(221) /aw+engamba/ $\rightarrow$ awonggamba

do+2PL.IRR

'you will do it'

(222) /an+engamba/ $\rightarrow$ anenggamba eat+2PL.IRR

'you will eat' 
4b. $\mathrm{e} \rightarrow \mathrm{o} / \mathrm{uC}$

The suffix $-e$, used in serial verb constructions, rounds to $o$ (with subsequent vowel insertion resulting in $u o$ in Bunabun, according to rule 5 below) when the preceding vowel is high and back. In (223) below, the serial verb suffix has the form $-e$ when attached to $a w$ - 'do', but rounds to $-o$ when attached to kur- 'come' and tun- 'cook'.

$\begin{array}{llll}\text { inuo biga } & \text { na betem-kuo-na } & \text { aw-e aw-e kur-uo } & \text { kur-uo } \\ \text { 1PL ocean } & \text { TOP throw-3SG.HOD-DS.IPFV } & \text { get-SER get-SER come-SER } & \text { come-SER } \\ \text { tun-uo } & \text { tun-uo an- } \text {-kin. } & & \\ \text { cook-SER cook-SER en } & \text { eat.IPFV-1PL.HOD } \\ \text { 'The ocean throws them up and we go and get them and come and cook and eat them.' }\end{array}$

This $e$-rounding is also triggered by the sequences $u a$ and $a u$.

$\begin{array}{ll}\text { omben } & \text { auw-o } \\ \text { hand burn-SER } & \text { finish-od. }\end{array}$

'His hand was completely burned.'

Unlike the $e$-initial suffixes that undergo rounding according to rule $4 \mathrm{a}$, labial final consonants do not trigger rounding on the serial verb suffix $-e$.

$\begin{array}{lll}\text { (225) } \begin{array}{l}\text { muang } \\ \text { eye } \\ \text { 'He threw open his eyes.' } \\ \text { open-SER }\end{array} & \begin{array}{l}\text { tam-od. } \\ \text { throw-3SG.REM }\end{array} \\ \text { (226) } & \begin{array}{l}\text { dokom-e } \\ \text { run-SER }\end{array} & \begin{array}{l}\text { indu-bid. } \\ \text { go-3PL.REM }\end{array}\end{array}$

\section{Vowel insertion: V[+high]CV[-high] > V[+high]CV[+high]V[-high] (Bun.)}

In Bunabun, when a non-high vowel follows a high vowel with one intervening consonant (or a homorganic nasal-stop sequence), a high vowel is inserted before the non-high vowel. The quality of the high vowel depends on the conditioning high vowel and the non-high vowel it affects. If the nonhigh vowel is /a/ or /o/, then a copy of the conditioning high vowel is created. So if the conditioning 
high vowel is $/ \mathrm{i} /$, then $i$ is inserted before the non-high vowel, as in (227) and (228). If the conditioning high vowel is /u/, then $u$ is inserted., as in (229) and (230).

(227) $/ \varnothing+\mathrm{i}+\mathrm{kan} / \rightarrow$ ikian give+1SG+2SG.R

'I gave it to you'

(228) /ingid+omdi/ $\rightarrow$ inggidiomdi

stay+3PL.IRR

'they will stay'

(229) $/ \varnothing+\mathrm{u}+\mathrm{kan} / \rightarrow$ ukuan

give+1SG+2SG.R

'he gave it to you'

(230) /um+ombin/ $\rightarrow$ umuombin

die+1PL.IRR

'we will die'

If the affected vowel is /e/, then $i$ is inserted, regardless of whether the conditioning vowel is $/ \mathrm{i} /$, as in (231) or /u/, as in (232) and (233).

(231) $/$ in + ed/ $\rightarrow$ inied

sleep+3SG.REM

'he slept'

(232) $/ \varnothing+\mathrm{u}+\mathrm{me} / \rightarrow$ umie

give+1SG+3SG.REM

'I gave it to him'

(233) /urum+embin/ $\rightarrow$ urumiembin

kill+2SG.IRR

'you will kill'

The /u/ also acts as a conditioning high vowel, even when immediately followed by /a/, as in (234-235).

This suggests that the sequence /ua/ should perhaps be considered a single phoneme with the value [+high].

(234) /induan + omdi/ $\rightarrow$ iduanuomdi

hear+3PL.IRR

'they will hear' 
(235) /kumduan+ombin/ $\rightarrow$ kumduanuombin

hide+1PL.IRR

'we will hide it'

\section{6. stop devoicing D $>$ [-voice]/_T (optional)}

Voiced obstruents may devoice before a voiceless stop. In the case of nasal-stop sequences, devoicing may also entail the loss of the nasal, as in (238).

/babad $+\mathrm{kid} / \rightarrow$ babatkid

cut_up+3PL.HOD

'they cut them up'

(237) $/ \mathrm{ked}+\mathrm{kin} / \rightarrow$ ketkin

love+1PL.HOD

'we loved it'

(238) /akumb+kin/ $\rightarrow$ akupkin

walk+1PL.HOD

'we walk'

7. $\mathbf{k}>\mathbf{x} /$ _k

A cluster of an underlying velar stop followed by a voiceless velar stop may be realized as a preaspirated [hk] or prespirantized $[\mathrm{xk}]$ velar stop $(<q k>$ in orthography).

(239) /uyek+ki/ $\rightarrow$ uyeqki

$\mathrm{NEG}+\mathrm{Q}$

'or not'

This may also apply to underlying /g/ which devoices before $/ \mathrm{k} /$ :

(240) /bug+kan/ $\rightarrow$ buqkan

sit+2SG.HOD

'you sat'

\section{8. medial vowel deletion $\mathrm{V}>\varnothing / \mathrm{VC} \_\mathrm{CV}$ (Bunabun)}

In Bunabun, medial vowels in words of three syllables usually delete or reduce to schwa.

(241) /induw + mba/ $\rightarrow$ edba eduba

go+1SG.SS.IRR

'I will go and...' 


\subsubsection{Barem verb morphology}

Barem has a rich system of inflectional verbal morphology that includes fusional subject and tense/mood-marking suffixes, markers for the direct object, markers for the indirect object (which I refer to as R-markers, as they have a number of other functions as well), and switch reference markers. Barem, like many Papuan languages, makes extensive use of clause chains, in which the final verb in a clause chain is inflected with a different set of markers than medial (non-final) verbs. There are a number of important differences between the Qkuan Kambuar and Bunabun dialects in their verbal morphology, discussed in the relevant sections below.

Table 2.1.4a shows the ordering of Barem affixes on the verb root. Only one affix from each cell can appear on a single verb. Only the verb root and the affixes which occur in the final position are mandatory.

Table 2.1.4a. Barem affix ordering

\begin{tabular}{|l|l|l|l|l|}
\hline OBJ & root & R-markers & IPFV & subject + tense/mood \\
& & & SR \\
& & & SER \\
& & & \\
& & & \\
\hline
\end{tabular}

\section{Barem subject and tense/mood markers}

Final verbs in a Barem clause chain are marked with a fusional marker that expresses both the person/number of the subject and tense/mood. These are the final suffix on the verb. The Bunabun and Qkuan Kambuar dialects have different systems for these markers, so they are discussed separately.

\section{Bunabun subject and tense/mood markers}

The Bunabun dialect has four sets of markers which indicate the person and number of the subject, as well as give information on tense/mood. These are the remote past markers, hodiernal markers, irrealis markers, and imperative markers. 


\section{Bunabun remote past}

Table 2.1.4b gives the Bunabun remote past markers, which also indicate the person and number of the subject.

Table 2.1.4b: Bunabun remote past marke
\begin{tabular}{|l|l|}
\hline $1 \mathrm{Sg}$ & $-m e$ \\
\hline $2 \mathrm{Sg}$ & - an, -en, -on \\
\hline $3 \mathrm{Sg}$ & $-a d,-e d,-o d$ \\
\hline $1 \mathrm{Pl}$ & - min \\
\hline $2 \mathrm{Pl}$ & $-m a$ \\
\hline $3 \mathrm{Pl}$ & - mid \\
\hline
\end{tabular}

Remote past markers are used for events that have taken place anytime before the current day, which ranges from the distant past, as in (242), up to the day before the current day, as in (243).

$\begin{array}{llllllll}\text { [nineteen ninetyseven }] & \text { te, } & \text { gin } & \text { onde } & \text { te } & \text { ono } & \text { [submission] } & \text { didub-min. } \\ \text { nineteen ninety seven } & \text { LOC } & \text { day } & \text { that } & \text { LOC } & 3 S G & \text { submission } & \text { write-1PL-REM }\end{array}$
'In 1997, at that time we wrote him a submission.'

$\begin{array}{lll}\text { noknav } & \text { nawu } & \text { a-bin. } \\ \text { yesterday } & \text { 2SG.OBJ } & \text { get-1PL.REM }\end{array}$

'We got you yesterday.'

The Bunabun 2SG.REM and 3SG.REM suffixes each have three allomorphs. Which one is used depends on the consonant that precedes it. After an alveolar (except $r$ ) or palatal, these suffixes take the forms -en and -ed, respectively (244). After a velar, they take the forms -an and -ad (245), and after a labial, they are -on and -od (246). For $r$-final verb stems, $r$ deletes, and the suffixes take the forms - an and -ad (247) (see section 5). 
(244)

an-ed

eat-3SG.REM

'He ate'

(245) angg-ad

see-3SG.REM

'She saw'

(246) banm-od

go_down-3SG.REM

'She went down'

(247) $/$ tanar-ad/ $\rightarrow$ tan-ad

talk-3SG.REM

'He talked'

Since other $a$ - or $e$ - initial suffixes do not alternate in this way, there is no obvious candidate that one could propose as an underlying vowel. However, a case could be made that the $o$ allomorphs are underlyingly /e/, since some other $e$-initial suffixes round to $o$ after a labial.

\section{Bunabun hodiernal}

Bunabun hodiernal markers indicate hodiernal tense and the person and number of the subject.

Table 2.1.4c: Bunabun hodiernal markers

\begin{tabular}{|l|l|}
\hline $1 \mathrm{Sg}$ & $-k e$ \\
\hline $2 \mathrm{Sg}$ & $-k a n$ \\
\hline $3 \mathrm{Sg}$ & $-k o,-k a$ \\
\hline $1 \mathrm{P} 1$ & $-k i n$ \\
\hline $2 \mathrm{P} 1$ & $-k a$ \\
\hline $3 \mathrm{P} 1$ & $-k i d$ \\
\hline
\end{tabular}

Hodiernal marking indicates that the time of the event is the current day, whether that event is in the past or currently taking place. In (248), the hodiernal is used for an event earlier that day, where tanarke 'I spoke' refers to the speaker's telling of a story earlier that afternoon. The hodiernal can also 
be used for events just prior to the moment of speech, as in (249), where tanarke 'I spoke' refers to something the speaker just said a moment before.

$\begin{array}{llll}\text { go gie tanar-ke, andav gie tanar-imba. } & \text { gie } \\ \text { DEM one speak-1SG.HOD now one speak-1SG.IRR }\end{array}$

'I told one (story), now I'll tell another.'

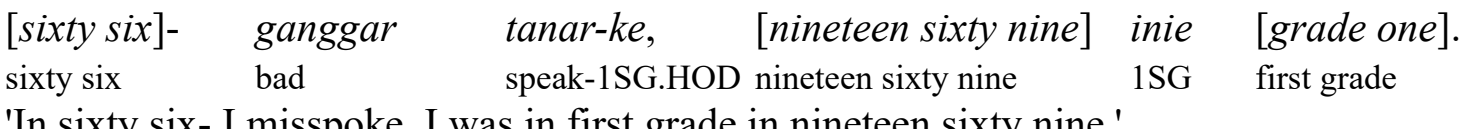

'In sixty six- I misspoke, I was in first grade in nineteen sixty nine.'

A hodiernal-marked verb can also refer to something taking place at the present moment, as in (250).

$\begin{array}{llll}\text { siria } & \text { go } & \text { me } & \text { ked-kin } \\ \text { behavior } & \text { DEM } & \text { NEG } & \text { like-1PL.HOD }\end{array}$

'We don't like that behavior.'

In languages with a hodiernal, the cutoff point for what counts as the "current day" varies depending on a culture's or an individual's conception of when one day ends and a new one begins (Comrie 1985: 89-90). In Barem, hodiernal tense is generally used for events that took place anytime from the previous sundown up to and including the present moment ${ }^{19}$. (251) is from a story in which avkan 'you did' refers to events of the previous night, and in (252) the speaker says kurkan 'you came' referring to my arrival at his home the previous day at dusk.

$\begin{array}{lllllll}\text { (251) ye avi, nene urun ma ge } & \text { wa } a v-k a n ? \\ \text { hey father } 2 \text { SG night what one } & \text { work do-2SG.HOD }\end{array}$

'Hey father, what were you doing at night?'

(252) onor ko usiv nene kur-kan.

so good 2SG come-2SG.HOD

'So it's good you came.'

The 3SG.HOD suffix has two allomorphs: $-k a$ is used after an alveolar or velar (253-254), and $k o$ is used after a labial (255).

(253) $k u r-k a$

come-3SG.HOD

'He came'

19 In Pamosu, another Northern Adelbert languages with hodiernal tense, the cutoff point is also around sundown of the previous day (Tupper 2012). 
'He held it'

$a v-k o$

get-3SG.HOD

'He got it'

Although the basic function of the remote past and hodiernal affixes is to mark remote past and hodiernal tense, respectively, they also have other functions when used in conjunction with different affixes, namely the past imperfective $-i$, and the different subject markers $-k o$ and $-n a$ (see below).

\section{Qkuan Kambuar realis}

Qkuan Kambuar marks subject and tense/mood differently from Bunabun, both in the forms of the markers and their patterns of use. A major difference is that while Bunabun distinguishes between remote past and hodiernal, Qkuan Kambuar seems to be in the end stages of losing this distinction. Cognates with both the Bunabun remote past and hodiernal markers are present in QK. However, speakers use both sets of markers for events that have taken place at any time in the past, or are currently taking place. Furthermore, for most person/number combinations, QK speakers have one generally agreed-upon marker, with the other having mostly fallen into disuse ${ }^{20}$. For example, the $1 \mathrm{SG}$ marker -eme (derived historically from the remote past) is used much more frequently than -ke (derived historically from the hodiernal), which appears only a handful of times in the Qkuan Kambuar corpus.

Since both sets of markers have the same function in Qkuan Kambuar, covering any time in the past, as well as the present moment, I refer to them as realis markers. Table 2.1.4d shows both sets of Qkuan Kambuar realis markers, with infrequently used markers in parentheses. Note that Qkuan Kambuar also differs from Bunabun in that 1PL and 3PL are not distinguished.

20 These simplifications in verb morphology may be related to language obsolescence. Qkuan Kambuar is very endangered, with only a handful of speakers remaining, and obsolescing languages have been known to undergo changes that may otherwise be unexpected (Palosaari \& Campbell, 2011). 
Table 2.1.4d: Qkuan Kambuar subject and tense/mood markers

\begin{tabular}{|l|l|l|}
\hline & $\begin{array}{l}\text { Realis (historically } \\
\text { remote past) }\end{array}$ & $\begin{array}{l}\text { Realis (historically } \\
\text { realis) }\end{array}$ \\
\hline $1 \mathrm{Sg}$ & - -me & $(-k e)$ \\
\hline $2 \mathrm{Sg}$ & $(-\mathrm{V} n)$ & $-k a n$ \\
\hline $3 \mathrm{Sg}$ & $(-\mathrm{V} r)$ & -eko \\
\hline $1 / 3 \mathrm{Pl}$ & - mind & -gind \\
\hline $2 \mathrm{Pl}$ & - -ema & -- \\
\hline
\end{tabular}

The examples below show the use of -eme '1SG.R' for events in the remote past (256), the previous day (257), earlier the same day (258), and the present moment (259, illustrating the loss of the remote past/hodiernal distinction.

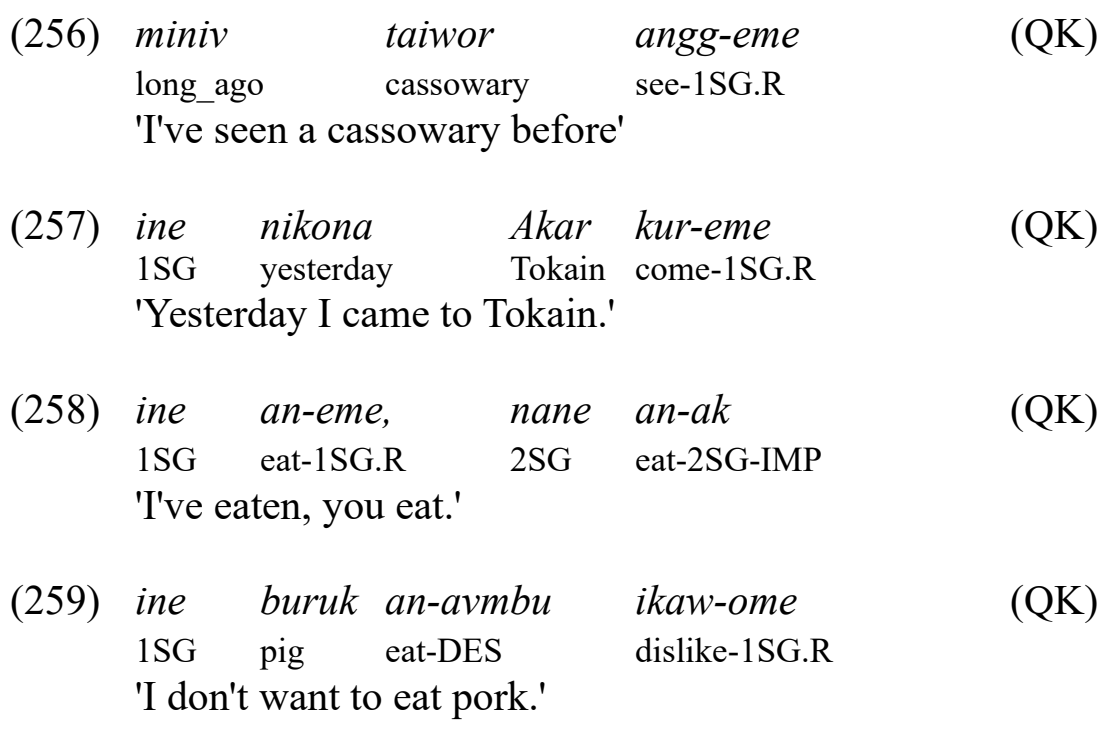

\section{Bunabun imperfective}

In Bunabun, there are two imperfective affixes that are always used in conjunction with the hodiernal to express habitual or ongoing action. The present imperfective affix $-a$ is used together with the hodiernal to express actions that are currently ongoing (260) or habitual (261). 
kambuar awa tanar-a-ke

speech this speak-IPFV.PRS-1SG.HOD

'I'm telling this story'

(261) yam me wa aw-a-kid

nothing NEG work do-IPFV.PRS-3PL.HOD

'They don't work for nothing'

The past imperfective affix $-i$ is also used in conjunction with the hodiernal markers. Together, they indicate that an action was ongoing or habitual in the past. Note that despite the use of hodiernal suffixes, verbs marked in this way can refer to events in the remote past.

$\begin{array}{llll}\text { bokmav } & \text { naqkia } & \text { te } & \text { tanar-i-kid } \\ \text { ancestors } & \text { long_ago } & \text { LOC } & \text { speak-IPFV.PST-3PL.HOD }\end{array}$

'The ancestors used to tell it (a story) in the past'

$\begin{array}{llllllllll}\text { naqkia } & \text { go } & \text { ono wam } & \text { kanam te, } & \text { skar } & \text { kanam te, } & \text { o } & \text { dos } \\ \text { long_ago } & \text { DEM } & \text { 3PL tree base LOC } & \text { rock } & \text { base LOC } & \text { or } & \text { wherever }\end{array}$

te omde induguanu-i-kid.

LOC thus PL.OBJ leave-IPFV.PST-3PL.HOD

'In the past, they'd leave them at the base of a tree, or the foot of a rock, or wherever.'

(264) inie nem siria
1SG also behavior
'I too didn't like that bad

Whereas Bunabun has two IPFV markers $-a$ and $-i$, QK has only one imperfective marker, with the allomorphs -amba and -am (the latter used only before $k$ ). The QK imperfective expresses that an action is currently taking place, as in (265) and (266), or habitual, as in (267).

(265) kurake wa awa nananor omben te un-amba-me. (QK) so work this 2PL.POSS hand LOC put-IPFV-1SG.R

'So I'm putting this job in your hands.'

(266) yu kima-t-am-kan, ine ye? who tell-3SG-IPFV-2SG.R 1SG EXCL

'Who are you talking to, me?' 
(267) mambu komte in-am-kan

why always sleep-IPFV-2SG.R

$(\mathrm{QK})$

'Why are you always sleeping?'

\section{Barem irrealis}

The Barem irrealis endings are used for actions that have not yet taken place. Bunabun and Qkuan Kambuar have different forms for some irrealis endings, but they are functionally equivalent.

Table 2.1.4e: Barem irrealis markers

\begin{tabular}{|l|l|l|}
\hline & Bunabun & Qkuan Kambuar \\
\hline $1 \mathrm{Sg}$ & -imba & -imba \\
\hline $2 \mathrm{Sg}$ & -embin & -engambin \\
\hline $3 \mathrm{Sg}$ & -emda & -enggara \\
\hline $1 \mathrm{P} 1$ & -ombin & -ombin \\
\hline $2 \mathrm{P1}$ & -emba & -engamba \\
\hline $3 \mathrm{P} 1$ & -omdi & -omdi \\
\hline
\end{tabular}

An irrealis-marked verb can refer to an action that is expected to take place, as in (268), where the speaker is expressing his intentions for the next day with the irrealis-marked iruimba 'I'll go up'. Irrealis-marked verbs can also refer to hypothetical or generic actions, as in (269), where the speaker used the irrealis-marked iruembin 'you'll go up' to give me directions to a place he knew I wouldn't in fact be going. ${ }^{21}$
inie matinia
nawu
a-mbua
iru-imba.
1SG tomorrow 2SG.OBJ leave-SS.IRR go_up-1SG.IRR

'Tomorrow I'll leave you and go up (the mountain).'

(269) bubua iru-embin go inuo onde i-kin.

hill go_up-2SG.IRR DEM 1PL there stay-1PL.HOD

'If you go up the hill, that's where we stay.'

21 The irrealis also has a similar function in other Northern Adelbert languages, including Manep, Barem's sister language. In Mauwake, the 2SG future tense is used in a similar way, to refer to generic or habitual situations, or instructions (Berghäll 2015: 150-151) 


\section{Barem imperatives}

Imperative markers are used for commands or suggestions. Only forms for 2SG, 2PL, and 1PL have been recorded.

Table 2.1.4f: Barem imperative markers

\begin{tabular}{|lll|}
\hline & Bunabun & Qkuan Kambuar \\
\hline $2 \mathrm{SG}$ & $-a k$ & $-a k$ \\
\hline $2 \mathrm{PL}$ & $-o m$ & $-e m$ \\
\hline $1 \mathrm{PL}$ & $-a v m b o$ & -amnor \\
\hline
\end{tabular}

(270) tanar-ak

speak-2SG.IMP

'Speak!'

(271) ande kuwur-om

here come-2PL.IMP

'Come here!'

\section{Barem direct object marking}

Direct objects are not marked on most Barem verbs, as in the verb gur- 'bite' in (272):

$\begin{array}{llll}q k a & (\text { ivo }) & \text { gur-eko } & (\mathrm{QK}) \\ \operatorname{dog} & 1 \mathrm{SG} & \text { bite-3SG.R }\end{array}$

'The dog bit me'

In (272), the 3rd person singular subject $q k a$ 'dog' is marked on the verb, but the first person singular direct object is not. The first direct object pronoun ivo is optional, and speakers usually only include it when the direct object is not clear from context.

There are, however, two verbs on which the direct object is obligatorily marked: angg- 'see' and anggar- 'teach/show ${ }^{22}$. For these verbs, object-marking prefixes are obligatory, and can be used in conjunction with independent object pronouns. While the singular objects markers are clearly related

22 anggar- 'show/teach' is probably historically derived from angg- 'see' plus ar- 'become', so it is therefore not surprising that these two verbs exceptionally mark direct objects in the same way. 
to the independent object pronouns ivo, nawo, and $u w o$, the plural object marker imb- does not resemble the plural object pronoun indugu.

A 3SG direct object is marked in different ways for angg- 'to see' and anggar- 'teach/show'. anggar- uses the 3SG object marker $u w$-, but for angg-, a 3SG direct object is not overtly marked. Table 2.1.4g shows the Barem direct object markers, which are the same for Bunabun and Qkuan Kambuar. ${ }^{23}$

Table 2.1.4g: Barem direct object markers

\begin{tabular}{|l|l|l|l|}
\hline & $1 \mathrm{st}$ & 2nd & $3 \mathrm{rd}$ \\
\hline Singular & $i v-$ & $n a w-$ & $\begin{array}{l}u w \text { - (for anggar-) } \\
\varnothing-(\text { for angg-) }\end{array}$ \\
\hline Plural & \multicolumn{4}{|c|}{$i m b-$} \\
\hline
\end{tabular}

Examples of direct object marking for angg- 'to see':

(273) mambute iv-angg-am-kan? (QK) why 1SG-see-IPFV-2SG.R

'Why are you looking at me?

(274) $\varnothing$-angg-mind $\quad(\mathrm{QK})$ 3SG-see-1/3.R

'We saw him'

Examples of anggar- 'to teach, show':

(275) ivo iv-anggar-ak!

1SG 1SG-teach-2SG.IMP

'teach me!'

(276)

$\begin{array}{lllll}\text { imb-angg-ad aka inuo me } & \text { wa } & \text { aw-a-kin. } \\ \text { PL.OBJ-show-3SG.REM but } 1 \text { PL NEG work } & \text { make-IPFV.PRS-1PL.R } \\ \text { 'She showed us how, but we don't make them.' }\end{array}$

23 An alternate analysis would be to posit different stems for different direct objects, for example ivangg- 'to see 1SG' and imbangg- 'to see PL', as I have done for Barem's sister language Manep. However, since these verbs are more easily segmentable in Barem than in Manep, I have opted for analysis of object prefixes in Barem. 


\section{R-markers}

A third set of markers are used for the indirect object, which in Barem I consider to be any argument that is marked in the same way that the recipient is marked on the verb 'give'. However, these markers can mark a number of other kinds of arguments beyond indirect objects. For this reason, I refer to them with the term 'R-markers' (the R can stand for 'recipient'). R-markers are used to mark (1) the recipient on verbs of physical or mental transfer, such as 'give', kanaw- 'ask' and kima- 'tell', (2) beneficiaries and maleficiaries, and (3) the experiencer of bodily state verbs such as dagok fa- 'to be thirsty' and siriri ma- 'to ache'. These three uses are discussed below.

Table 2.1.4h shows the R-agreement markers, which are the same in both Qkuan Kambuar and Bunabun. There are two forms for the 3SG R-marker: $-w$ is used only on the verb 'give', while $-t$ is used on all other verbs.

Table 2.1.4h: Barem R-markers

\begin{tabular}{|l|l|l|l|}
\hline R-agreement & $1 \mathrm{st}$ & $2 \mathrm{nd}$ & $3 \mathrm{rd}$ \\
\hline Singular & $-i$ & $-n$ & $\begin{array}{l}-w \text { (for “give") } \\
-t \text { (for other verbs) }\end{array}$ \\
\hline Plural & \multicolumn{2}{|c|}{-ind } \\
\hline
\end{tabular}

\section{'Give' in Barem}

The verb 'give' in Barem is special in that there is no overt verb root. The verb forms for 'give' consist of the R-marker, indicating the recipient, and the subject marker, indicating the giver, without a separate root for the meaning of "give". Another way to think of this is that give has a "zero root" which is not pronounced. ${ }^{24}$ This unpronounced verb root is indicated with the symbol $<\varnothing>$ in the

24 An alternate analysis to a zero root for 'give' would be to posit several different roots for 'give', with multiple different forms depending on the person and number of the recipient, ror example $i$ - 'give to 1sg' and $n$ - 'give to 2SG'. Multiple verbs for give are found in several related languages, such as Waskia (Ross \& Paol, 1978) and Usan (Reesink, 1987). However, it would still be necessary to posit a set of R-markers that are used as affixes on other verbs, and these would essentially be homophonous with the different verbs stems for 'give' (except for the 3SG). Fedden (2010) analyzes Mian, another Papuan language, as also having a zero root for 'give'. 
examples below. In (277), the $1 \mathrm{SG}$ recipient of 'give' is marked with the R-marker $-i$, and the $3 \mathrm{SG}$ subject is marked with the final suffix -eko (which also indicates realis). 'Give' in (278) has both a 3SG recipient, marked by $-w$, and a 3 SG subject, marked by -oko.

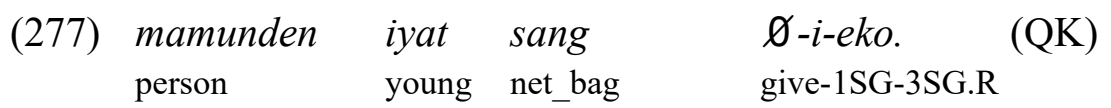

'The boy gave me a net bag.'

(278) une kundi $\quad \varnothing_{\text {-w-oko. }}$ (QK)
3SG banana give-3SG-3SG.R
'He gave him bananas.'

\section{kanaw- 'ask' and kima- 'tell'}

R-markers also appear on the verbs kanaw- 'ask' and kima- 'tell'. The person being asked or told something can be considered the recipient of the question or statement. In this sense, the function of Rmarkers on these verbs is similar to how R-markers indicate the recipient for the verb "give".

(279) kanav-n-ume (QK)

ask-2SG-1SG.R

'I asked you.'

(280) Anggi kima-t-ume ine Akar induv-imba (QK) Anggi tell-3SG-1SG.R 1Sg Tokain go-1SG.FUT

'I told Anggi I will to go Tokain.'

\section{Beneficiaries and maleficiaries.}

The R-markers are also used to mark the beneficiary or maleficiary of an action. Note that the beneficiary/maleficiary can be referred to with possessive pronoun forms (as with inor in (281)).
(281) inor $^{25}$
umbav-i-eko
1SG.POSS
cook-1SG-3SG.R
$(\mathrm{QK})$
'She cooked it for me.'

25 The most common use of 1SG inor (and other pronouns in this paradigm) is to express a possessor, but it is also used to refer to beneficiaries. 
(282)

kta ge kivk-n-imba (QK)

coconut one break_open-2SG-1SG.IRR

'I'll open a coconut for you.'

R-markers are also used to mark the maleficiary of an action, as in (283).

$\begin{array}{llrl}\text { Kuwur } & \text { yam } & \text { bim-ind-eko } & \text { (QK) } \\ \text { Kuwur } & \text { for_nothing } & \text { lie-PL-3SG.R } & \\ \text { 'Kuwur lied to us.' } & \end{array}$

\section{Bodily state expression}

Bodily state expressions describe someone experiencing or undergoing a mental or bodily state.

The grammatical subject of these expressions is always a 3SG body part creating or related to the bodily state, as indicated by the subject/tense marker on the verb. Although the independent pronouns used for the experiencer are the forms normally used for the subject, the experiencer is marked by Rmarkers on the verb.

$$
\begin{array}{llll}
\text { nane dagok fa-n-am-ko } & e ? & (\mathrm{QK}) \\
2 \mathrm{SG} & \text { throat dry-2SG-IPFV-3SG.R } & \mathrm{Q} &
\end{array}
$$

'Are you thirsty?' (lit: 'Is your throat drying to you?')

(285) muang in-t-am-ko (QK)

eyes sleep-IPFV-3SG-3SG.R

'She's feeling sleepy.'

\section{Barem clause chains and switch reference}

Like many Papuan languages, including other Northern Adelbert languages, Barem verbs can be linked together in a clause chain. Barem clause chains consist of one or more medial verbs, and one final verb. The set of suffixes available to medial verbs is different than the set of suffixes available to final verbs. The suffixes used on final verbs are discussed in the first part of this section. The remainder of this section describes the inflection of medial verbs.

Barem medial verbs are inflected with switch-reference markers that indicate whether or not the subject of a verb has the same referent as the subject of the following verb. A medial verb is marked as 
same subject if its subject and the subject of the following verb have the same referent. A medial verb is marked as different subject when its subject and the subject of the following verb have different referents (though there are exceptions to this generalization, discussed at the end of the section).

\section{Barem same-subject marking}

In Barem, same-subject medial verbs are not marked with the fusional subject and tense/moodmarking suffixes that are used on final verbs, but with a different set of suffixes used only on medial verbs. These same-subject suffixes can mark the person and number of the subject, as well as perfective and imperfective aspect or irrealis mood. Table 2.1.4i lists the Barem same-subject suffixes. Where Bunabun and Qkuan Kambuar have different forms, the dialect is given in parentheses.

Table 2.1.4i: Barem same-subject markers

\begin{tabular}{|c|c|c|c|}
\hline & PFV.SS & IPFV.SS & SS.IRR \\
\hline $1 \mathrm{Sg}$ & -memba & \multirow{3}{*}{-omada } & $-m b a$ \\
\hline $2 \mathrm{Sg}$ & $-m i n b i$ & & $-m b i$ \\
\hline $3 \mathrm{Sg}$ & $\begin{array}{l}\text { - da (Bun.) } \\
\text {-era (QK) }\end{array}$ & & \multirow{4}{*}{$-m b a$} \\
\hline 1P1 & $-m i n b i$ & \multirow{3}{*}{-omadi } & \\
\hline $2 \mathrm{Pl}$ & $-m a m b a$ & & \\
\hline $3 \mathrm{P} 1$ & $\begin{array}{l}\text {-di (Bun.) } \\
\text {-minda }(\mathrm{QK})\end{array}$ & & \\
\hline
\end{tabular}

The examples below illustrate the use of some of the same-subject perfective suffixes. (286) illustrates the 1SG.SS marker -memba, (287) illustrates the 3SG.SS marker -da, and (288) illustrates the 3PL.SS marker -di. (288) is also an example of a longer clause chain, with five medial verbs.

\begin{tabular}{|c|c|c|c|c|}
\hline (286) & $\begin{array}{ll}{[\text { skul }]} & a w-a v \\
\text { school } & \text { do-NMLZ }\end{array}$ & $\begin{array}{l}\text { iyok-memba } \\
\text { dislike-1SG.PFV.SS }\end{array}$ & $\begin{array}{l}\text { dokm-memba teka } \\
\text { run-1SG. PFV.SS again }\end{array}$ & $\begin{array}{l}\text { kove } \\
\text { village.DAT }\end{array}$ \\
\hline
\end{tabular}
1SG.REM

'I didn't like school and ran away and came back to the village' 


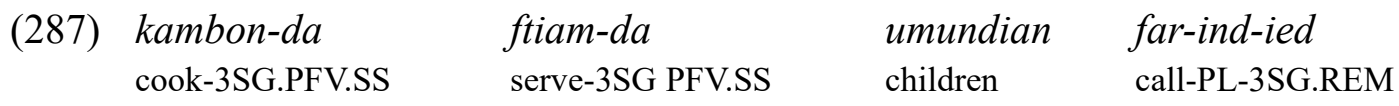

'She cooked it and served it and called to the children'

(288)

$\begin{array}{lllllll}\text { ko-di } & \text { bugum-di } & \text { iniar } & \text { [blok }] & \text { go } & {[k a k a o]} & \text { stamb-di } \\ \text { come-3PL.PFV.SS } & \text { sit-3PL.PFV.SS } & \text { 1SG.POSS } & \text { parcel } & \text { DEM } & \text { cacao } & \text { cut-3PL.PFV.SS } \\ \text { tu-di } & a v-d i, & \text { arav karen } & & \text { wa } & \text { a-bid. } & \end{array}$

burn-3PL.PFV.SSget-3PL.PFV.SS alright new_garden work make-3PL.REM

'They came and settled and cut down my cacao orchard and burned it and took it, alright, and made new gardens.'

Imperfective same-subject markers indicate imperfective aspect on the medial verb, and indicate whether the subject is singular (289) or plural (290).

in-iomada amin gaman wa aw-od.

sleep-SG.IPFV.SS mind liver work do-3SG.REM

'He was sleeping and had an idea'
ono ekar-omadi
dardi
kimb-et-mid
3 laugh-PL.IPFV.SS get_up-3PL.PFV.SS
say-3SG-3PL.REM

'They were laughing and got up and said to her...'

There are two same-subject irrealis markers: - $m b i$, used for 2SG subjects, and -mba, used for all other person/number subjects. These markers indicate that the action of the medial verb has not taken place. They are often followed with a final verb that is either imperative-marked, as in (291) and (292), or irrealis-marked, as in (293) and (294).
$(291)$
nene fofov induguba-bi
2SG quick PL.OBJ collect-2SG.SS.IRR
'Hurry up and collect them and go.'
induw-ak
go-2SG.IMP
gaman un-umba
misor an-em
$(\mathrm{QK})$
liver put-SS.IR betel nut eat-2PL.IMP
'Relax and chew betel nut.'

$\begin{array}{lllllll}\text { (293) } & \text { me } & \text { ko-mbi inie } & \text { duruang } & \text { umund awa nakor te } & \text { a-y-embin } \\ \text { NEG } & \text { come-2SG.SS.IRR 1SG } & \text { fish.sp } & \text { child this basket LOC put-1SG-2SG.IRR }\end{array}$

'You won't come and put the duruang fish in my basket for me.'

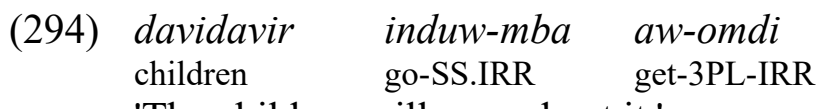

'The children will go and get it.' 


\section{Different-subject marking}

Similar to same subject markers, different subject markers indicate either perfective aspect, imperfect aspect, or irrealis mood. The imperfective different subject marker -na follows a medial verb that is inflected with a hodiernal marker. If a medial verb is marked in this way, this indicates that the action is either habitual, as in (295), or was ongoing when the action of the final verb occurred, as in (296) and (297). Although an imperfective-marked medial verb includes a hodiernal suffix, here it does not mark hodiernal tense.

$\begin{array}{lllll}\text { (295) inuo biga na betem-kuo-na } & \text { aw-e aw-e kur-uo } & \text { kur-uo } \\ \text { 1PL ocean } & \text { TOP throw-3SG.HOD-DS.IPFV } & \text { get-SER get-SER come-SER } & \text { come-SER } \\ \text { tun-uo } & \text { tun-uo } & & \\ \text { cook-SER } & \text { cook-SER an-a-kin. } & & \end{array}$

$\begin{array}{llllll}\text { (296) } & \text { bugum-da } & \text { ing-guo-na } & \text { par } & \text { yam nem } & \text { to-di idu-bid. } \\ \text { sit-3SG.SS } & \text { be-3SG.HOD-DS.IPFV } & \text { bed } & \text { nothing with } & \text { get-3PL.SS } & \text { go.3PL.REM }\end{array}$

'He was sitting down and they took the empty bed and left.'

(297) induv-kid-na iviskaka anda dokm-od.
go-3PL.HOD-DS.IPFV quiet
'They were leaving and he ran away quietly.'

A different subject medial verb is marked for perfective aspect with a remote past marker, followed by the perfective different subject marker $-k o$. Although perfective different subject medial verbs are inflected with the remote past markers, this does not mean that the action of the medial verb took place in the remote past. Rather, the tense of the medial verb is unspecified. In (2100), for example, the action of the medial verb took place moments before the speaker made the statement. In (2101), also, the action of the medial verb took place within the same time as the final verb, which is marked with hodiernal tense, while in (298) and (299), the action of the medial verb did indeed take place in the remote past.

(298) yarm-av asiv $\varnothing$-w-od-ko yarm-od. 
wear-NMLZ new give-3SG-3SG.REM-PFV.DS

wear-3SG.REM

'He gave her new clothes and she wore them.'

(299)

$\begin{array}{llrlll}\text { bin digidien } & \text { ta-ind-ied-ko } & \text { makimun } & \text { awa } & \text { inuo te } & \\ \text { problem straight } & \text { make-PL-3SG.REM-PFV.DS } & \text { land } & & \text { this } 1 \text { PL LOC }\end{array}$

akumb-kin.

walk-1PL.HOD

'He straightened out this problem for us and now we walk this land.'

(2100) bugum-od-ko inie andav gumun arawav tarimba.

sit-3SG.REM-PFV.DS 1SG now plate front put-1SG.IRR

'She's seated and I'll put a plate in front of her now.'

(2101) oo, omde wa aw-on-ko inuo kuriw-kin

yes thus work do-2SG.REM-PFV.DS 1PL startle-1PL.HOD

'Yeah, you did that and we got startled.'

The suffix -are is used to mark different subject and irrealis mood on a medial verb.

(2102) skar garan $\varnothing$-ind-iemda, $\varnothing$-ind-are [kakao $] \quad$ umbuomba.

money give-PL-3G.IRR give-PL-DS.IRR cacao plant-2PL.IRR

'He'll give you money, he'll give it to you and you'll plant cacao.'

There are two types of situation where same subject marking can be used even though there is a change in grammatical subject. This can happen when one of the subjects is non-agentive subject, or when there is overlapping reference between the subjects of the two clauses. In (2103), there is a change in grammatical subject between the medial clause enda 'she slept' and the final clause, which has the non-agentive subject bagen 'light'. Since no new agentive subject is introduced, same-subject marking is used.

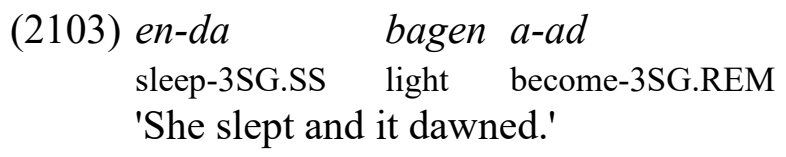

Same subject marking can also be used when there is overlapping reference in the subjects of two clauses. For example, in (2104), erdi 'they climbed' uses same-subject marking, even though the subject of the following clause refers to only one of the two men who climbed. 


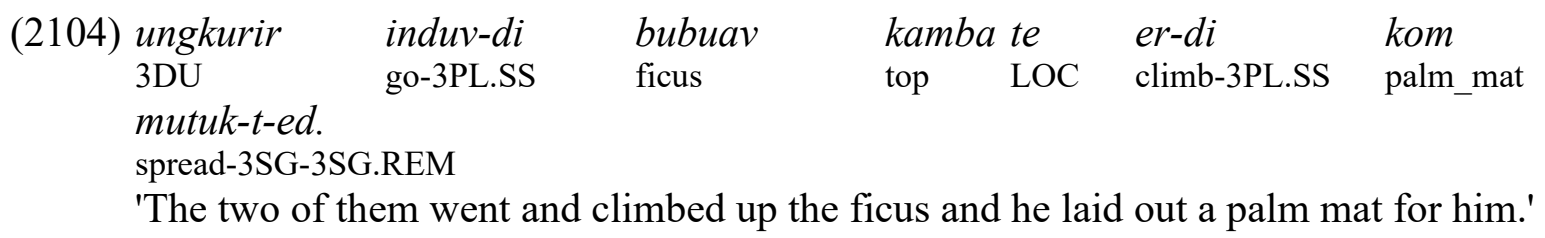

\section{Nominalizer $-a v$}

The suffix $-a v$ attaches to a verb stem to form a noun or a gerund. The meanings of nouns formed with $-a v$ are not predictable. Examples are $a n-a v$ 'eat-NMLZ' 'food', in-iav 'sleep-NMLZ' 'dream', and yarm- $a v$ 'wear-NMLZ' 'clothes'. The - $a v$ suffix is also used productively to form gerunds. The sentences in (2105) and (2106) show - $a v$ on same root inggid- 'stay' to form a gerund with the meaning 'staying' in (2105) and to form a noun with a fixed meaning, 'residents' in (2106). ${ }^{26}$

(2105) yam inggid-iav usiv uyeq-ko, Biga Birim. nothing stay-NMLZ good NEG-DS.IPFV Biga_Birim. 'Staying and doing nothing wasn't good, at Biga Birim.'

\begin{tabular}{|c|c|c|c|c|c|}
\hline $\begin{array}{l}\text { (2106) Rem } \\
\text { Rem }\end{array}$ & $\begin{array}{l}\text { inggid-iav } \\
\text { stay-NMLZ }\end{array}$ & $\begin{array}{l}\text { kove } \\
\text { village.DAT }\end{array}$ & $\begin{array}{l}\text { inggid-iomadi, aa, } \\
\text { stay PL.IPFV.SS ah }\end{array}$ & $\begin{array}{l}\text { naqkia ambuak } \\
\text { before very }\end{array}$ & $\begin{array}{l}g o, \\
\text { DEM }\end{array}$ \\
\hline & gar-av & nambek. & & & \\
\hline DEM & be_angry-NI & big & & & \\
\hline
\end{tabular}

'The residents of Rem lived in the village and, ah, a very long time ago there was a big war.'

\subsection{Manep}

Manep is spoken in two areas, each with its own dialect. One is a series of small hamlets strung along a road going into the mountains from the Waskia-speaking coastal village of Tokain, ending near the Yamben-speaking village of Yambarik. One of these is Simbukanam village, where Andrew Ilom and Paul Lawoi, my two primary Manep consultants, both live. Manep speakers living in this area have heavy contact with both Waskia and Yamben speakers, and there are many Yamben loanwords in Manep.

26 vowel insertaion applies to make the form of the suffix -iav (see Section 2.1.4). 
The second Manep-speaking area is Malas village, located near the coast, a short distance southeast of the Dibor river, and northwest of Tokain. While Manep is the main indigenous language of Malas, there are also small Karian and Mokati-speaking communities living in this area as well.

In both Manep-speaking areas, Tok Pisin is the primary language of the community. I have not observed anyone in their twenties or younger using Manep with any frequency, although parents sometimes speak to their children in Manep. Prior to my own fieldwork, Manep was extremely poorly documented, with the only published information being Z'graggen's (1980b) wordlist, collected in Malas village. In previous literature, this language has been called Malas, but several of my consultants made it emphatically clear that Malas is not the name of the language, it is Manep. However, most non-Manep speaking people in the area, as well as some Manep speakers in Malas village, do refer to the language as Malas.

The information I present on Manep is based primarily on my own fieldwork conducted from 2016-2019 with consultants from both Simbukanam and Malas. An annotated corpus of Manep recordings can be accessed online at the Endangered Languages Archive (Pick 2019). The only other published data on Manep of which I am aware is the wordlist in Z'graggen (1980b), and recordings of Z'graggen's Malas elicitation sessions (1971b).

The remainder of this describes the essentials of Manep synchronic phonology and verbal morphology. Section 2.2.1 describes the Manep phoneme inventory. Section 2.2.2 discusses Manep syllable and word structure. Section 2.2.3 discusses some of the phonological processes that are synchronically active in Manep, and Section 2.2.4 outlines Manep verbal morphology. 


\subsubsection{Manep phonemes}

Tables 2.2.1a-b list the Manep phonemes.

Table 2.2.1a: Manep vowel phonemes

\begin{tabular}{|l|l|l|}
\hline & front & back \\
\hline high & /i/ & /u/ \\
\hline mid & $/ \mathrm{e} /$ & $/ \mathrm{o} /$ \\
\hline low & & $/ \mathrm{a} /$ \\
\hline
\end{tabular}

Table 2.2.1b: Manep consonant phonemes

\begin{tabular}{|c|c|c|c|c|}
\hline & labial & alveolar & palatal & velar \\
\hline stop & $/ \mathrm{p} / / \mathrm{b} /$ & $/ \mathrm{t} / / \mathrm{d} /$ & & $/ \mathrm{k} / \mathrm{g} /$ \\
\hline nasal & $/ \mathrm{m} /$ & $/ \mathrm{n} /$ & & $/ \mathrm{g} /$ \\
\hline affricate & & & $/ \mathrm{j} /$ & \\
\hline fricative & & $/ \mathrm{s} /$ & & \\
\hline trill & & $/ \mathrm{r} / / \mathrm{l} /$ & & \\
\hline glide & $/ \mathrm{w} /$ & & $/ \mathrm{y} /$ & \\
\hline
\end{tabular}

\section{Vowels and Glides}

Manep has five vowels /i, $\mathrm{u}, \mathrm{e}, \mathrm{o}, \mathrm{a} /$ and two glides, $/ \mathrm{w} /$ and $/ \mathrm{y} /$. Similar to Barem, the front mid vowel /e/ is usually lax $[\varepsilon]$ before a consonant. The vowel sequences /ia/, /ai/, /ua/, and /au/ are most common, but other sequences are found as well.

\section{Stops}

Synchronically, voiced stops contrast with homorganic nasal-stop sequences. Compare, for example, abal 'far' and ambor 'good'. However, in vocabulary inherited from Proto-Manep-Barem, voiced stops and homorganic nasal-stop sequences are in complementary distribution, in a pattern similar to that in Manep's sister language Barem (see section 2.1.1). Proto-Manep-Barem voiced stops are reflected in Manep as plain voiced stops word-initially, or when the preceding or following 
consonant is another voiced stop. PMB voiced stops are reflected as nasal-stop sequences following a vowel. ${ }^{27}$ Word-final $* \mathrm{~g}$ is reflected as a nasal $/ \mathrm{y} /{ }^{28}$

The phonetic realization of the affricate / j/ varies widely. Variants that have been observed

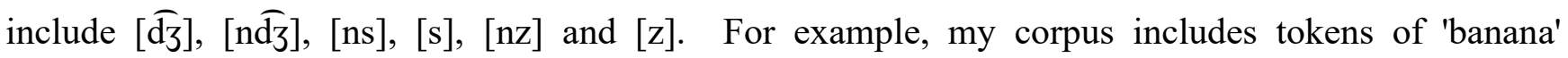

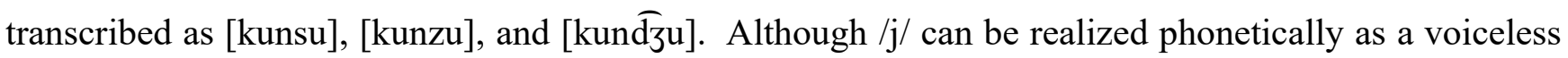
alveolar fricative [s], it contrasts phonologically with the fricative phoneme /s/. Since the [s] variant of $/ \mathrm{j} /$ is not uncommon, this makes $/ \mathrm{j} /$ potentially confusable with /s/, and can cause difficulty for deciding whether any given instance of $[\mathrm{s}]$ is underlyingly $/ \mathrm{j} /$ or $/ \mathrm{s} /$. The same can be said of any particular token of [ns], which is potentially ambiguous between underlying $/ \mathrm{j} /$ and $/ \mathrm{ns} /$. I have assumed that any morpheme that has been recorded only with $[\mathrm{s}]$ (and none of the other potential variants of $/ \mathrm{j} /$ ) contains an underlying /s/, and that any morpheme that has only been observed pronounced as [ns] is underlyingly /ns/. In some cases, top-down comparison can help to confirm this, since Manep /j/ derives from Proto-Manep-Barem *d, while /s/ derives from Proto-Manep-Barem *s. ${ }^{29}$

\section{Fricatives}

Manep has a single fricative, /s/. As mentioned above, the affricate $/ \mathrm{j} /$ is also sometimes realized as a fricative.

27 While this pattern holds for directly inherited vocabulary, exceptions are found in loanwords, such as bamban 'meat', a borrowing from Gavak.

28 The reflexes of most PMB word-final voiced stops are no longer word-final in Manep, since Manep underwent a change in which monosyllabic content words added final $-u$ (see Chapter 8). Although polysyllabic words were not subject to this change, no polysyllabic words with final *b or *d have been reconstructed for Proto-Manep-Barem. However, the reflex of word-final $*_{\mathrm{g}}$ in polysyllabic reconstructed words is $n g$, as in PMB *musag 'eye' > Manep musang, and *nanag 'tooth' > nanang.

29 There is only one instance of underlying /ns/ that has a clear origin. This is the 2SG indirect object marker -ans, which derives historically from $\mathrm{PMB} *$ nas- 'give to $2 \mathrm{SG}$ '. 


\section{Sonorants}

Manep has three nasals, $/ \mathrm{n} /, / \mathrm{m} /$, and $/ \mathrm{y} /$. Most instances of $/ \mathrm{y} /$ derive from PMB $* \mathrm{~g}$, but $/ \mathrm{y} /$ is also found in some morphemes of unclear origin, such as the imperfective affix -eng. Manep has two liquids, $/ \mathrm{r} /$ and $/ 1 /$.

\subsubsection{Manep syllable and word structure}

This section outlines what constitutes a possible Manep syllable and word, including restrictions on the distribution of particular phonemes.

\section{Manep syllables}

Manep syllables have the structure $(\mathrm{C}) \mathrm{V}(\mathrm{C})$, with the minimal syllable being $\mathrm{V}$ and the maximal syllable being CVC.

\section{Manep syllable onsets}

Manep syllables either have a single segment onset or no onset. There are no attested words with $/ \mathrm{y} /$ or $/ 1 /$ as the onset of an initial syllable.

\section{Manep syllable codas}

Manep syllables may have a single segment coda, or no coda. Glides are not found as syllable codas, and voiced stops generally do not appear as the coda of a final syllable (the only word with a final voiced stop so far identified is gaid 'sky'). In the Malas dialect, /k/ does not appear as a coda on final syllables (final $-k$ is retained in Simbukanam cognates). 


\section{Manep word structure}

Monomorphemic words (excluding names) have at most three syllables. Polymorphemic words, such as inflected verbs or compound words, may have more than three syllables. The maximal structure of monomorphemic words is CVCCVCCVC, exemplified by ganjimbap 'door'. Word-medial consonant clusters are allowed only if they are composed of a homorganic nasal-obstruent sequence.

Vowel hiatus is allowed in the Malas dialect, as in kusier 'papaya' (/ku.si.er/). Where Malas has vowel hiatus, the Simbukanam dialect has an intervening /g/ (kusiger 'papaya').

\subsubsection{Morphophonological processes in Manep}

This section outlines phonological processes in Manep that apply at morpheme boundaries, and which are synchronically active. Historical sound changes in Manep are discussed in Chapter 8 .

In addition to the phonological processes outlined in this section, Section 2.2.4 describes nonstandard verb conjugations which could also be considered to be the result of phonological processes, such as deletion or assimilation, which apply only to particular verb classes. For example, the final $r$ in the verb potar- 'to shut' deletes in certain conjugations, while the final $r$ in imbar- 'to fly', which belongs to a different verb class from potar-, does not. Furthermore, it is not always easy to draw a boundary between stem and suffix for some conjugations. For this reason, I have found it more convenient to describe these non-standard conjugations in terms of different groups of verbs patterning in different ways, rather than proposing sets of phonological rules which apply only to particular stem+suffix combinations. 


\section{Final consonant deletion in compounds}

In compound words, the final consonant of the first element of the compound deletes if it would create a disallowed consonant cluster (anything other than a homorganic nasal-obstruent sequence).

$$
\begin{aligned}
& \text { /pipir+janger/ } \rightarrow \text { pipijangger } \\
& \text { side+bone } \\
& \text { 'rib' } \\
& \text { /kasap+gunu/ } \rightarrow \text { kasagunu } \\
& \text { spirit+skin } \\
& \text { 'clothes' }
\end{aligned}
$$

\section{Vowel rounding}

There are four suffixes whose initial vowel becomes [o] when attached to a verb root which ends in a labial consonant. These are the 2/3SG.PST suffixes $-e n$ and $-i n^{30}$, the nominalizing suffix $-e p$, and the serial verb affix $-e$.

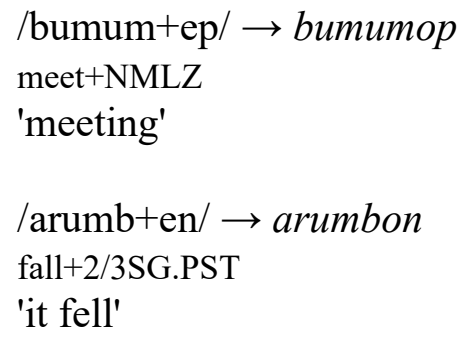

This rounding is not a general phonological rule, since it does not apply to other suffixes beginning with /e/ or /i/, only those outlined above.

\subsubsection{Manep verb morphology}

This section outlines the basics of Manep verb morphology. Like other Northern Adelbert languages, Manep is a synthetic language, with verb roots suffixed with fusional tense/subject markers. Manep verb roots are obligatorily bound, meaning they cannot stand alone as independent words. 
Manep verbs may also be marked with suffixes that mark the person and number of an indirect object or oblique argument. Manep also uses switch reference markers which indicate if the subjects of two adjacent clauses are the same or different.

\section{Manep verb classes}

Manep verbs can be divided into two major conjugation classes, which I call -an verbs and -en verbs, based on the forms used for the second person plural imperative suffix. While most inflectional and derivational suffixes are the same for both classes, there are a handful of suffixes which have different forms depending for each verb class. Within these two large classes, there are also groups of irregular verbs that follow somewhat different conjugation patterns. There are also a handful of irregular verbs that have their own unique conjugational paradigms, and cannot be classified as either -an or -en verbs. Table 2.2.4a lists the suffixes that take different forms for -an and -en verbs.

Table 2.2.4a: suffixes with differing forms for - an and -en verbs

\begin{tabular}{|l|l|l|}
\hline & $-a n$ verbs & -en verbs \\
\hline 2/3SG.PST & $-e n$ & $-i n$ \\
\hline 2PL.IMP & $-a n$ & $-e n$ \\
\hline NMLZ & $-a p$ & $-e p$ \\
\hline Serial verb & $-a$ & $-e$ \\
\hline
\end{tabular}

The second person plural imperative form is a convenient diagnostic for conjugation class, since it is always -en for all -en verbs, and -an for all -an verbs, while the other suffixes can have different forms for irregular verbs, or are subject to morphophonological processes which can alter their surface forms.

While there are some rough correspondences between the final phoneme of the verb root and its class, verb class is in general not predictable from phonological form. For example, most verb roots 
ending in velars are -en verbs, and most verbs ending in $/ \mathrm{r} /$ are -an verbs, but there are roughly equal numbers of -en verbs and -an verbs ending in labials.

Table 2.2.4b illustrates the ordering of affixes on a Manep verb. All verbs are obligatorily suffixed with one of the suffixes in the final cell, and these can not co-occur on the same verb. Rmarkers and the imperfective marker are both optional.

Table 2.2.4b: Manep affix ordering

\begin{tabular}{|l|l|l|l|}
\hline root & R-markers & IPFV & subject/tense \\
& & & IMP \\
& & NMLZ \\
& & SER \\
\hline pakin- & -as & -eng & -an \\
\hline
\end{tabular}

\section{Fusional subject/tense markers}

Finite Manep verbs are suffixed with fusional markers that indicate person and number of the subject, as well as tense (or imperative mood). Manep has a three-way distinction between past, present, and future tense. Manep does not mark a distinction between remote and recent past/hodiernal, as Barem and some other Northern Adelbert languages do.

Table 2.2.4c below shows the Manep subject/tense markers used for regular verbs, as well as the nominalizing and serial verb suffixes. Where different forms are used for -an and -en verbs, both forms are listed in the same cell, with the verb class in parentheses. Some suffixes have different forms in the Malas and Simbukanam dialects. For these, the dialect is given in parentheses as well. Irregular verbs which follow a different conjugation paradigm than the one in Table $2.2 .4 \mathrm{c}$ are discussed later in this section. 
Table 2.2.4c: Manep subject/tense markers

\begin{tabular}{|c|c|c|c|c|c|}
\hline & $1 \mathrm{SG}$ & $2 \mathrm{SG}$ & $3 \mathrm{SG}$ & $1 / 3 \mathrm{PL}$ & $2 \mathrm{PL}$ \\
\hline Past & $\begin{array}{l}\text {-umi (Sim.) } \\
\text {-umoi (Malas) }\end{array}$ & \multicolumn{2}{|c|}{$\begin{array}{l}\text {-en (-an verbs) } \\
\text {-in (-en verbs) }\end{array}$} & -umin & -uman \\
\hline Present & $\begin{array}{l}\text {-ikimi (Sim.) } \\
\text {-ikamoi (Malas) }\end{array}$ & -ian & $\begin{array}{l}\text {-egan (Sim.) } \\
\text {-ean (Malas) }\end{array}$ & -ikimin & -ikaman \\
\hline Future & -indi & \multicolumn{2}{|c|}{-inden } & -indun & -indan \\
\hline Imperative & $-i$ & $-a$ & & $-u(1 \mathrm{pl})$ & $\begin{array}{l}\text {-an (-an verbs) } \\
\text {-en (-en verbs) }\end{array}$ \\
\hline Gerund & \multicolumn{5}{|l|}{$\begin{array}{l}-a p(-a n \text { verbs) } \\
-e p(-e n \text { verbs) }\end{array}$} \\
\hline Serial verb & \multicolumn{5}{|l|}{$\begin{array}{l}-a(-a n \text { verbs }) \\
-e(-e n \text { verbs })\end{array}$} \\
\hline
\end{tabular}

Tables 2.2.4d and 2.2.4e illustrate the suffixes in Table 2.2.4c with conjugations of ukus- 'to shoot', representative of a regular -en verb, and in- 'to sleep', representative of a regular -an verb (forms shown are the Malas dialect).

Table 2.2.4d: Conjugation of -en verb ukus- 'to shoot'

\begin{tabular}{|c|c|c|c|c|c|}
\hline & $1 \mathrm{Sg}$ & $2 \mathrm{Sg}$ & $3 \mathrm{Sg}$ & $1 / 3 \mathrm{Pl}$ & 2P1 \\
\hline Past & ukusumoi & \multicolumn{2}{|l|}{ ukusin } & ukusumin & ukusuman \\
\hline Present & ukusikimoi & ukusian & ukusean & ukusikimin & ukusikaman \\
\hline Future & ukusindi & \multicolumn{2}{|l|}{ ukusinden } & ukusindun & ukusindan \\
\hline Imperative & & ukusa & & ukusu (1pl) & ukusen \\
\hline Gerund & \multicolumn{5}{|l|}{ ukusep } \\
\hline Serial verb & \multicolumn{5}{|l|}{ ukuse } \\
\hline
\end{tabular}

Table 2.2.4e: Conjugation of - $a n$ verb in- 'to sleep'

\begin{tabular}{|c|c|c|c|c|c|}
\hline & $1 \mathrm{Sg}$ & $2 \mathrm{Sg}$ & $3 \mathrm{Sg}$ & $1 / 3 \mathrm{Pl}$ & $2 \mathrm{Pl}$ \\
\hline Past & inumoi & \multicolumn{2}{|l|}{ inen } & inumin & inuman \\
\hline Present & inikimoi & inian & inean & inikimin & inikaman \\
\hline Future & inindi & \multicolumn{2}{|c|}{ ininden } & inindun & inindan \\
\hline Imperative & & ina & & іпи (1Pl) & inan \\
\hline Gerund & \multicolumn{5}{|l|}{ inap } \\
\hline Serial verb & \multicolumn{5}{|l|}{ ina } \\
\hline
\end{tabular}




\section{Irregular verb conjugations}

As mentioned above, many Manep verbs follow conjugation patterns that are different from the standard. Irregular conjugations generally involve loss of material from the right edge of the verb stem, a change in the initial vowel of a suffix, or both. For this reason, it is not always clear where to draw the boundary between verb stem and suffix. I therefore do not indicate morpheme boundaries in the irregular verb paradigms presented below.

\section{$r$-final verbs}

The large majority of $r$-final verbs are -an verbs. These can end in either/ar/ (such as potar- 'to shut, cover') or /ur/ (such as patapur- 'to throw'). Both groups have irregular past tense conjugations, but they follow different patterns. Irregular conjugations of $r$-final verbs generally involve the deletion of the final $/ \mathrm{r} /$ and deletion or a change in quality of the following vowel. There are also a small number of $r$-final -en verbs, which follow the standard conjugational pattern for -en verbs.

\section{-an verbs ending in /ar/}

-an verbs which end in /ar/ have irregular past tense conjugations (other tenses follow the regular conjugation pattern). Table 2.2.4f illustrates this pattern for ar- 'to become', alongside the expected (but unattested) conjugations if it were to follow the standard conjugation pattern for -an verbs, marked with a double asterisk. ${ }^{31}$

31 The verb bembar- 'to come' is the only -an verb ending in /ar/ that does not follow this pattern. bembar- follows the conjugation pattern for standard -an verbs, except for the irregular 2/3Sg.PST form bembarin, rather than the expected *bembaren. 
Table 2.2.4f: conjugation of - an verbs ending in /ar/

\begin{tabular}{|l|l|l|l|l|}
\hline & 1 Sg.PST & $2 / 3$ Sg.PST & $1 / 3$ P1.PST & 2P1.PST \\
\hline Actual conjugation & amoi & amun & amin & aman \\
\hline Unattested conjugation & $* *$ arumoi & $* *$ aren & $* *$ arumin & $* *$ aruman \\
\hline
\end{tabular}

Many verbs ending in /ar/ derive historically from independent words used in conjunction with ar- 'to become' as a light verb, for example, gadawar- 'to strengthen', from Proto-Manep-Barem *gadaw 'strength' + *ar- 'become'.

-an verbs ending in /ur/

All -an verbs which end in /ur/ also have irregular past tense conjugations. The conjugation pattern for the two monosyllabic verbs $u r$ - 'to hit' and pur- 'to call' is slightly different from the pattern followed by polysyllabic -an verbs ending /ur/. Tables $2.2 .4 \mathrm{~g}$ and $2.2 .4 \mathrm{~h}$ model the conjugation of monosyllabic and polysyllabic -an verbs ending in /ur/, respectively.

Table 2.2.4g: past tense conjugation of $u r$ - 'to hit'

\begin{tabular}{|l|l|l|l|l|}
\hline & 1 Sg.PST & $2 / 3$ Sg.PST & $1 / 3$ P1.PST & 2 P1.PST \\
\hline Actual conjugation & wamoi & wan & wamin & waman \\
\hline Unattested conjugation & $* *$ urumoi & $* *$ uren & $* *$ urumin & $* *$ uruman \\
\hline
\end{tabular}

Table 2.2.4h: past tense conjugation of pasapur- 'to run'

\begin{tabular}{|l|l|l|l|l|}
\hline & $1 \mathrm{Sg} . \mathrm{PST}$ & $2 / 3 \mathrm{Sg} . \mathrm{PST}$ & $1 / 3 \mathrm{P} 1 . \mathrm{PST}$ & 2P1.PST \\
\hline Actual conjugation & pasapumoi & pasapuan & pasapumin & pasapuman \\
\hline Expected conjugation & $* *$ pasapurumoi & $* *$ pasapuren & $* *$ pasapurumin & $* *$ pasapuruman \\
\hline
\end{tabular}

-en verbs ending in $/ \mathbf{r} /$

As mentioned above, unlike $r$-final -an verbs, $r$-final -en verbs conjugate regularly. An illustrative example is the pair of homophonous verb stems purur- 'to hide' (an -an verb) and purur- 'to shine' (an -en verb). While purur- 'to hide' has irregular past tense conjugations which delete the 
final /r/ (as in puruan 'it hid'), purur- 'to shine' has standard past tense conjugations, without /r/ deletion (pururin 'it shined').

Only a handful of $r$-final -en verbs have been identified. Of these, imbar- 'to fly', bisir- 'to laugh', and purur- 'to shine' follow the standard past tense conjugations for -en verbs, without deletion of $/ \mathrm{r} /$. The verbs inggar- 'to shoot' (and related verbs, see section below) and kambor- 'to know, say' have unique conjugational paradigms which also involve deletion of the final $/ \mathrm{r} /$ in the verb stem.

\section{Irregular future tense conjugations for $r$-final verbs}

Some $r$-final verbs have been observed to use shortened forms for future tense conjugations. These verbs can also follow the standard future tense conjugation pattern, and the two forms seem to be completely interchangeable. The shortened forms delete $/ \mathrm{r} /$ from the stem and the $/ \mathrm{n} /$ from the future tense suffix. It is not clear whether the shortened forms can be used for all $/ \mathrm{r} /$ final verbs, or only some. The two future tense paradigms are illustrated in Table 2.2.4i with the verb bembar- 'to come'.

Table 2.2.4i: standard and irregular future tense conjugations of bembar- 'to come'

\begin{tabular}{|l|l|l|l|l|}
\hline & $1 \mathrm{Sg} . \mathrm{FUT}$ & $2 / 3 \mathrm{Sg} . \mathrm{FUT}$ & $1 / 3 \mathrm{P} 1 . \mathrm{FUT}$ & 2P1.FUT \\
\hline Standard conjugation & bembarindi & bembarinden & bembarindun & bembarindan \\
\hline Shortened conjugation & bembidi & bembiden & bembidun & bemidan \\
\hline
\end{tabular}

\section{$w$-final verbs}

Polysyllabic verb roots ending in /w/ have irregular present and past tense conjugations, in which the final /w/ of the stem is lost, along with either the vowel preceding the final /w/ of the stem, or the initial vowel of the suffix. ${ }^{32}$ Table $2.2 .4 \mathrm{j}$ models the irregular conjugation of $w$-final verbs with the verb unew- 'to draw water'.

32 Which of these vowels is lost seems to depend on the quality of both vowels, but no clear pattern been worked out. 
Table 2.2.4j Conjugation of -en verb unew- 'to draw water'

\begin{tabular}{|l|l|l|l|l|l|}
\hline & $1 \mathrm{Sg}$ & 2Sg & 3Sg & $1 / 3 \mathrm{P} 1$ & $2 \mathrm{P} 1$ \\
\hline Past & unemoi & unen & unemin & uneman \\
\hline Present & unikimoi & unian & unean & unikimin & unikaman \\
\hline Future & unewindi & unewinden & unewindun & unewindan \\
\hline Imperative & & unewa & & unewen \\
\hline Gerund & unewop & & & \\
\hline Serial verb & unewo & & & \\
\hline
\end{tabular}

In addition to the irregular conjugations in Table $2.2 .4 \mathrm{j}$, forms which follow the standard conjugation have also been attested for some verbs. For example, both munen and munewon have been recorded for the 2/3SG.PST conjugation of munew- 'to swallow'. For some verbs, only the irregular forms have been recorded. It is therefore not clear whether the standard conjugations are available for all $w$-final verbs.

\section{bungom- 'to sit' \& darem- 'to stand'}

The verbs bungom- 'to sit' and darem- 'to stand' share an irregular conjugation pattern. Both use a shorter form for the stem in past and present tense conjugations (bung- and dar-, respectively). The past tense conjugations also differ from the standard in that they use /a/ rather than $/ \mathrm{u} /$ as the initial vowel of the past tense suffixes (for example, daramin 'we stood', rather than expected **darumin). The 2/3.PRES form for bungom- 'to sit' is also irregular, bungoan, rather than expected **bungean.

Table 2.2.4k Conjugation of -an verb darem- 'to stand'

\begin{tabular}{|l|l|l|l|l|l|}
\hline & $1 \mathrm{Sg}$ & $2 \mathrm{Sg}$ & $3 \mathrm{Sg}$ & $1 / 3 \mathrm{Pl}$ & $2 \mathrm{Pl}$ \\
\hline Past & daramoi & daran & daramin & daraman \\
\hline Present & darikimoi & darian & darean & darikimin & darikaman \\
\hline Future & daremindi & dareminden & & daremindun & daremindan \\
\hline Imperative & & darema & & & daremen \\
\hline Gerund & daremop & & & \\
\hline Serial verb & daremo & & & \\
\hline
\end{tabular}




\section{Irregular past tense conjugations of 'to give'}

In Manep, there are several different verb stems for 'to give', depending on the person and number of the recipient (see section on 'to give' below). These all follow the same irregular pattern for past tense conjugations, with a vowel change from $u$ to $e$ in the past tense suffixes. The 'to give' verbs otherwise conjugate like standard -an verbs. Their conjugation pattern is modeled in Table 2.2.41 with us- 'give to $3 \mathrm{SG}$ '.

Table 2.2.41 Conjugation of -en verb us- 'give to $3 \mathrm{SG}^{\prime}$

\begin{tabular}{|c|c|c|c|c|c|}
\hline & $1 \mathrm{Sg}$ & $2 \mathrm{Sg}$ & $3 \mathrm{Sg}$ & $1 / 3 \mathrm{Pl}$ & $2 \mathrm{P} 1$ \\
\hline Past & usemoi & \multicolumn{2}{|l|}{ usen } & usemin & useman \\
\hline Present & usikimoi & usian & usean & usikimin & usikaman \\
\hline Future & usindi & \multicolumn{2}{|c|}{ usinden } & usindun & usindan \\
\hline Imperative & & $u s a$ & & & usan \\
\hline Gerund & \multicolumn{5}{|l|}{ usap } \\
\hline Serial verb & \multicolumn{5}{|l|}{ usa } \\
\hline
\end{tabular}

\section{Other irregular verbs}

Beyond the groups of irregular verbs outlined above, there are also several verbs which follow their own unique conjugational paradigms. These include frequent verbs such as bembar- 'to come', anggew- 'to see', ir- 'to go up', and ingg- 'to be'.

\section{Manep imperfective}

Imperfective aspect is marked by the suffix -eng. It indicates ongoing action, as in (2111) or habitual action, as in (2112). There is no tense distinction for verbs marked with -eng. Verbs inflected with -eng always take present tense suffixes for $1 \mathrm{SG}$ or plural subjects, and the past tense suffix -an for 2/3SG subjects, regardless of whether the event is past or present. 
(2111) gaman pakin-as-eng-an ne amum-eng-an.

liver ache-3SG-IPFV-2/3.PST 3.SS cry-IPFV-2/3.PST

'her heart was aching and she was crying.'

(2112) uwomandeng kuling kuling und-eng-kimin si ta un money small small give_3PL-IPFV-1/3PL.PRS DS father 3PL kambor-eng-kimin, uwomandeng kase inind-ikimin uwomandeng ambor. think-IPFV-1/3PL.PRS money this give_1PL-1/3.PRS money gpod 'They'd give them a little bit of money and our fathers would think, "this money they give us is good money."'

\section{Verbs with different stems for different objects}

Direct objects are not marked on Manep verbs. A direct object may be indicated by a pronoun preceding the verb, but these may also be omitted. However a number of verbs have different stems depending on the person and number of the direct object. Some verbs have two stems, one for singular direct objects and one for plural, while others have separate stems for $1 \mathrm{SG}, 2 \mathrm{SG}, 3 \mathrm{SG}$, and plural direct objects. Some of the more frequently used of these verbs are discussed below.

The verb 'to tell' has different stems for use with singular and plural objects. takan- or takang- ${ }^{33}$ 'tell.SG' and takanjim- 'tell.PL'.

(2113) umansi husband takan-e weget 'She didn't tell her husband.' $\begin{array}{llll}\text { (2114) naik taik takanjim-a } & \text { weget } \\ \text { mother father tell.PL-SER } & \text { NEG }\end{array}$ 'She didn't tell her parents.'

Similarly, the verb 'to chase, follow' has different stems for singular and plural direct objects, uworum'follow/chase.SG' and imberum- 'follow/chase.PL', as does 'to see': anggew- 'see.SG' and imbensim-

33 All the Manep speakers I worked with consistently use takan-, while the speaker in Z'graggen's recordings consistently uses takang-. 
'see.PL'. While anggew- can be used with any singular direct object, there is another stem, naweng-, that is used specifically with $2 \mathrm{SG}$ direct objects. ${ }^{34}$

The verb 'to hit' has four different stems: nar- 'hit 1SG', nanar- 'hit 2SG', ur- 'hit 3SG', and inggar- 'hit PL'.

(2115) $u \quad i \quad$ nar-ean

3SG $1 \mathrm{SG}$ hit_1SG-3SG.PRS

'He hits me.'

(2116) siwir, wagi, usu ka uninte inggar-eng-kimin.

bandicoot cuscus wallaby DET 3.DAT hit_PL-IPFV-1/3PL.PRS

'They'd shoot bandicoots, cuscus, and wallabies.'

Similarly, the verb 'to teach/show' has four stems: iwansar- 'teach/show 1SG', nawansar'teach/show 2SG', uwansar- 'teach/show 3SG', and imbandar- 'teach/show.PL'.

Several of the verb stems with the included meaning of a specific person and number of the direct object share common elements, for example the beginning sequence /imb/ for verbs with a plural direct object. Comparative evidence with Barem suggests that these elements are object-marking prefixes that have become fossilized in Manep (see Chapter 8).

\section{'Give' in Manep}

There are six different verb stems with the meaning 'to give', which depend on the person and number of the recipient: is- 'give to $1 \mathrm{SG}^{\prime}$ ', nas- 'give to $2 \mathrm{SG}$ ', $u s$ - 'give to $3 \mathrm{SG}$ ', inind- 'give to $1 \mathrm{PL}$ ', nanind- 'give to $2 \mathrm{PL}$ ', and und- 'give to $3 \mathrm{PL}$ '.

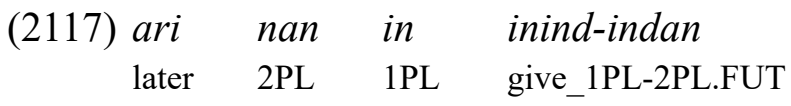

'You'll give it to us later'

(2118) ari $i \quad$ us-indi

later 1SG give_3SG-1SG.FUT

'I'll give it to him later'

34 Comparative evidence with Barem suggests that iweng- 'see 1SG' should exist as well, but this is not attested in the Manep corpus. 

(2119) ta un na un uwomandeng ninika und-a weget.
father 3PL mother 3PL money great give_PL-SER NEG
'They didn't give our fathers and mothers lots of money'

\section{R-markers}

Like its sister language, Barem, Manep verbs can be inflected with suffixes, which I refer to as R-markers, that mark several different kinds of indirect object or oblique arguments. Types of arguments that are marked by R-markers include beneficiaries, maleficiaries, experiencers in bodily or mental state verbs, and indirect objects in general. Often the argument indicated by the R-marker semantically has the flavor of a subject or direct object. For example, with the verb 'to sweat', the person sweating is marked with the R-marker, and in the verb 'to bathe', it is the person being bathed. Grammatically, however, an argument marked by an R-marker is either an indirect object (a core argument) or an oblique (an optional argument). R-markers do not mark direct objects in canonical transitive verbs, such as 'hit' or 'bite'. Manep R-markers are illustrated in Table 2.2.4m, and their various functions are outlined below.

Table 2.2.4m: Manep R-mark
\begin{tabular}{|l|l|}
\hline 1SG & -is \\
\hline $2 \mathrm{SG}$ & -ans \\
\hline 3SG & -as \\
\hline PL & -and \\
\hline
\end{tabular}

\section{Indirect objects}

R-markers can be used to mark an indirect object that is a core argument of the verb. For example, with the verb ind- 'to ask', the R-markers mark the recipient of the question. In is- 'to bathe', it marks the person being bathed, and in sirir- 'tell', it marks the person being told something. Examples (2120-2122) below illustrate R-markers for plural, 3SG, and 1SG indirect objects on the verb ind- 'ask'. 
(2120) naik taik ind-and-in

mother father ask-PL-2/3SG.PST

'she asked her mother and father'

(2121) $i \quad$ Yal ind-as-epte

1SG Yal ask-3SG-DES

'I want to ask Yal'

(2122) yawarap ne ind-ans-indi

again 2SG ask-2SG-1SG.FUT

'I'm going to ask you again'

\section{Beneficiaries and maleficiaries.}

R-markers can also mark beneficiaries and maleficiaries, in other words, parties who are effected either positively or negatively by the action of the verb.

(2123) ban-is-a

put-1SG-2SG.IMP

'put it for me'

(2124) samer usum-as-in

grass_skirt tie-3SG-2/3SG.PST

'she tied the grass skirt for her'

(2125) ne bim-ons-ian ${ }^{35}$

2SG trick-2SG-3SG.PRS

'she's tricking you'

\section{Bodily state verbs}

R-markers are also used in many very which describe a bodily or mental state such as pakin'ache', karim- 'swell' urir um- 'be hungry', bumu kaker- 'be thirsty', guad- 'sweat', koleleng ar- 'fear', and andamar- 'forget'. The grammatical subject of these verbs is a 3SG body part, evidenced by the fact that the verb inflects with a $3 \mathrm{SG}$ subject/tense marker. The experiencer of the bodily or mental state is indicated with the R-marker. A free translation of (2126) is 'I'm sweating', while a more literal translation would be something like 'skin is sweating on me'.

35 bim- 'trick, lie' is an irregular verb, which changes the vowel of the R-marker to $o$. 
(2126) karu guad-is-ean

skin sweat-1SG-3SG.PRS

'I'm sweating'

(2127) karu guad-ans-ean

skin sweat-2SG-3SG.PRS

'you're sweating'

(2128) ke

$\begin{array}{llllll}\text { ke } & \text { dimbingam } & \text { pakin-is-ean } & \text { ne } & \text { dimbingam } & \text { usuaw-eng-kimi } \\ \text { this } & \text { knee } & \text { ache-1SG.-3SG.PRS } & \text { 3.SS } & \text { knee } & \text { burn-IPFV-1SG.PRS }\end{array}$

'my knees ache so I'm heating them'

(2129) gaman pakin-as-eng-an

liver ache-3SG-IPFV-2/3SG.PST 3.SS cry-IPFV-2/3SG.PST

'her heart was aching and she was crying'

R-markers are not obligatory on bodily state verbs. These verbs may be used without them when there is not a specific experiencer. For example, pakinep, the nominative form of 'ache' in (2130), refers to aches in general, so is not inflected with an R-marker.

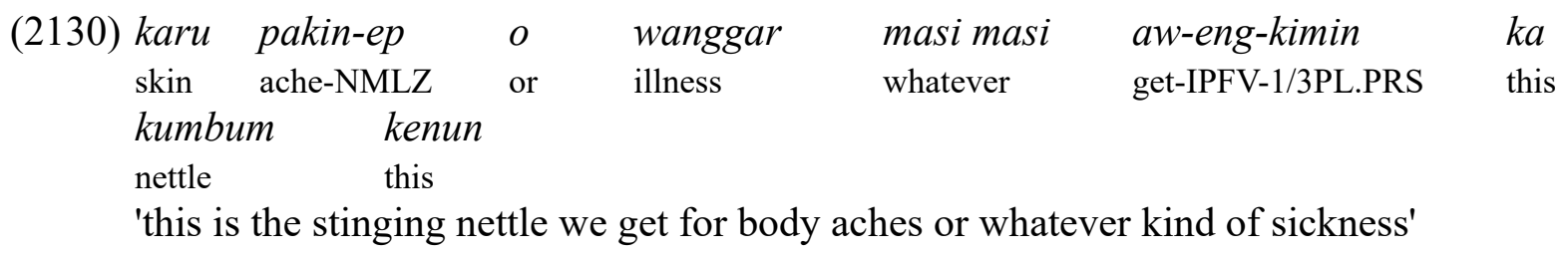

When a verb stem is suffixed with an R-marker, it conjugates like a standard -en verb, regardless of the verb class it belongs to. Compare the 2/3PST conjugation of the irregular -an verb pirunsur- 'to cut open' in (2131) to its conjugation in (2132), where piruns- is suffixed with an R-markers and the 2/3PST form used with -en verbs.

(2131) $u \quad$ mutur pirunsu-an 3SG coconut break_open-2/3SG-PST 'he broke open a coconut'

(2132) $u \quad$ mutur pirunsur-ans-in 3SG coconut break_open-2SG-2/3SG.PST 'he broke open a coconut for you' 


\section{Manep switch reference}

Manep switch reference markers indicate whether the referent of the subject of two adjacent clauses is the same or different. Switch reference markers in Manep are independent words which always follow an inflected verb. They are clearly independent words, and not suffixes on the verb, since speakers often pause between a verb and a switch reference marker, and speakers will sometimes begin a sentence with a switch reference marker, even after a very long pause. Manep same-subject markers make more distinctions than the different-subject markers, a trait that Manep shares with its sister language Barem, although there is little else in common between the switch reference systems of the two languages.

Manep has two same-subject markers: ne '3.SS' is used to link two clauses that have the same third person subject, as in (2134), and $m o$ '1/2.SS' is used to link two clauses with the same first or second person subject, as in (2135) and (2136).

(2134) irum ne imas-umin ne kuamb-umin woman TOP peel-1/3PL.PST 3.SS cook_in_pot-1/3.PL 'the women peeled the yams and cooked them'

(2135) imas-umin mo kuamb-umin peel-1/3PL.PST 1/2.SS cook_in_pot-1/3.PL 'we peeled them and cooked them'

(2136) nan imas-uman mo kuamb-uman i? 2PL peel-2PL.PST 1/2.SS cook_in_pot-1/3.PL Q 'did you guys peel the yams and cook them?'

There is only one different subject marker, si, which is used to link two clauses with different subjects, as in (2137).

(2137) munen matap w-aman $\quad$ si $\quad$ kambin-and-in
devil speech say-1/3PL.PST DS hear-PL-3SG.PST
'the were speaking devil language and he heard them.'

It is also possible to juxtapose two related clauses without a switch reference marker, as in (2138). 


(2138) Ameng uniner $\quad$ uwuk a-umin, $\quad$ Munigiwin uniner
Ameng 3PL.POSS
The Ameng made their group, and the Munigiwin made their group.'

There are some cases where either a same subject or a different subject marker are both acceptable. This can happen when there is a non-agentive subject, or when there is overlapping reference between the subjects of the two clauses.

Both same subject and different subject markers are acceptable when one of the clauses has a non-agentive subject, even if there is a change in grammatical subject. For example, in (2139), since both the subject of the first clause, bangen 'light', and the subject of the second clause, timbik 'rain', are non-agentive, and both clauses are talking about the weather in general, the same subject marker $n e$ is acceptable.

$\begin{array}{llll}\text { (2139) bangen } & \begin{array}{l}\text { andan } \\ \text { dawn-3SG.PST }\end{array} & \text { ne } & \text { timbik sag-ean. } \\ \text { light } & \text { r.SS } & \text { rain } & \text { come_down-3SG.PRS } \\ \text { 'It's dawned and it's raining.' } & & & \end{array}$

Likewise, in (2140) the third person same subject marker ne is used after inumin 'they slept', even though the subject of the following clause has a different grammatical subject, bangen 'light'. And again following bangen andan 'it dawned', ne is used to link the following clause, which reintroduces the 1PL subject of the initial clause. Since no new agentive subject was introduced in the clause bangen andan 'it dawned', the same subject marker ne is acceptable.

$\begin{array}{llllll}\text { (2140) } \begin{array}{l}\text { in-umin } \\ \text { sleep-1/3PL }\end{array} \text { 3.SS light } & \text { and-an } & \text { ne } & \text { musang } & \text { banumin } \\ \text { 'they slept, it dawned, and they looked' } & & & \text { put-1/3PL.PST }\end{array}$

The sentence in (2141) shows that the different subject marker is also acceptable in such contexts. Just as in (2140), inumin 'we slept' is followed by the clause bangen andan 'it dawned'. In (2141) however, the two clauses are linked with the different subject marker si. 


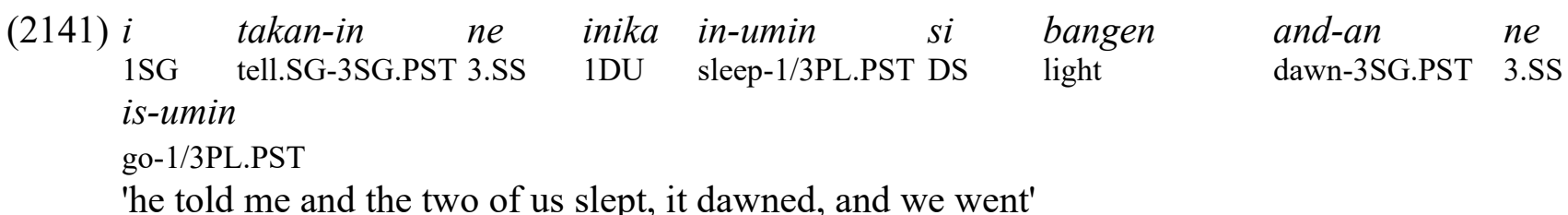

The sentence in (2141) also illustrates a case of overlapping reference, the second type of case where same subject and different subject markers are both acceptable. The initial clause, $i$ takanin 'he told me', has a 3SG subject. The subject of the following clause, inika '1.DU' refers to both the speaker and the man who is the subject of the initial clause. While there is a change in grammatical subject between the two clauses, the 3SG same subject marker ne is acceptable because the subjects overlap in reference. The sentence in (2142) below contains another example of overlapping reference, where the referent of the subject of angami 'I saw' is also one of the referents of the subject of the following verb, injiwindun 'we'll go'. These two clauses are linked by mo, the same subject marker for first and second person subjects.

\begin{tabular}{|c|c|c|c|c|c|c|c|}
\hline $\begin{array}{l}\text { (2142) andata-mun } \\
\text { finish-3SG.PST }\end{array}$ & $\begin{array}{l}n e \\
\text { 3.SS }\end{array}$ & $\begin{array}{l}\text { ang-ami } \\
\text { see-1SG.PST }\end{array}$ & $\begin{array}{l}m o \\
1 / 2 . S S\end{array}$ & $\begin{array}{l}\text { kanana } \\
\text { so }\end{array}$ & $\begin{array}{l}\text { inika } \\
1 \mathrm{DU}\end{array}$ & $\begin{array}{l}\text { injiw-indun, } \\
\text { go-1/3PL.FUT }\end{array}$ & $\begin{array}{l}\text { mitan. } \\
\text { tomorrow }\end{array}$ \\
\hline
\end{tabular}

More research is needed on how switch reference works for subjects that have overlapping reference, but it seems that in such cases the choice of third person or first/second person same subject marker depends on the subject of the first clause. This is evident in (2141), where the third person same subject marker ne, rather than the first/second person same subject marker mo, is used to link an initial clause with a $3 \mathrm{SG}$ subject to a following clause with a 1PL subject. It is not clear whether the different subject marker si would also be acceptable in such contexts. 


\section{Kumil-Tibor}

This chapter describes the synchronic phonology and verbal morphology of the Kumil-Tibor languages. Kumil-Tibor is a subgroup of Northern Adelbert that is further divided into two branches: the five Tibor languages Mokati, Pamosu, Hember Avu, Mawak, and Kowaki, and the three Kumil languages Mauwake, Bepour, and Moere.

Sections 3.1-3.6 deal with the Tibor languages. In 3.1, I provide background on the Tibor group as a whole, with an overview of how verbs work in Tibor languages. Sections 3.2-3.7 describe the phonology and verb morphology of individual Tibor languages. For each language, I present the consonant phoneme inventories, and make note of major allophonic alternations for each language. Vowel phonemes are not presented, as all five languages have the same five vowel system $(/ \mathrm{i} /, / \mathrm{u} /$, /a/, /e/, /o/), with the possible exception of Hember Avu (see section 3.4). When possible, I also illustrate the TAM-marking suffixes for each language, and discuss morphophonemic processes active in the individual languages that are relevant to the reconstruction of Proto-Tibor and PNA. Many of the morphophonemic processes that Tupper (2012) describes for Pamosu have parallels in the other Tibor languages, and I have relied heavily on Chapter 2 of Tupper (2012) for the analyses of these languages. Sections 3.7-3.10 describe the languages of the Kumil subgroup, first with a brief overview of the Kumil group in 3.7, followed by a section for each of the three Kumil languages in 3.83.10 .

The level of detail in the descriptions of each language naturally depends on the amount and quality of available data. Pamosu and Mauwake are relatively well-documented, each with a grammar and a dictionary. For Mawak, Kowaki, Bepour, and Moere, the only data available are Z'graggen's wordlists and recordings $(1980 \mathrm{~b}, 1971 \mathrm{~b})$. Data on the Kumil languages Bepour and Moere in particular 
are more limited. Some aspects of the analyses of these languages will no doubt need to be refined should additional data become available.

\subsection{Tibor languages background}

The Tibor languages are spoken in inland areas, south of Mauwake, and west of Barem. They are named after the Tibor (or Timper) river, which runs through their territory. The Pamosu, Hember Avu, and Mokati areas all border each other, and Tupper (2012) writes that Pamosu have strong ties with the Hember Avu community, and links with Mokati as well. As rugged terrain separates Pamosu from Mawak and Kowaki, these communities do not typically interact. Tupper (2012) estimates a population of 1700-1800 for the Pamosu community. A 2000 census listed 1,500 population for Hember Avu, 590 for Mokati, and 25 for both Mawak and Kowaki (Eberhard, Simons \&Fennig, 2020).

\section{Verb morphology in Tibor languages}

As with other Northern Adelbert languages, verbs are the most morphologically complex words in the Tibor languages. Finite verbs are composed of, minimally, a verb root suffixed with a fusional tense/subject marker. Verbs may also be inflected with object-marking prefixes and aspectual markers which occur after the verb root and before the tense/subject marker. This ordering, illustrated in Figure $3.1 \mathrm{a}^{36}$, is found in all Tibor languages for which data on verb inflection is available.

Figure 3.1a: Tibor verb template.

\begin{tabular}{|l|l|l|l|}
\hline obj- & root & -aspect & -tense/subject \\
\hline
\end{tabular}

36 Figure 3.1 illustrates the ordering of only those affixes which I compare across the Tibor languages. Tupper (2012) presents a more detailed template for Pamosu verbs which includes additional slots for other kinds suffixes, such as a distributive suffix and a 'remoteness' suffix. 
Tibor languages distinguish hodiernal, past, and future tense. Hodiernal tense is used for events of the current day, while past tense is used for events of the previous day or earlier. ${ }^{37}$ The different tenses are expressed with different sets of fusional tense/subject markers.

Determining the underlying form of a verb root in Tibor languages can sometimes be difficult, for two reasons. First, morphophonemic processes can obscure the relationship between underlying and surface forms. Second, many verbs have multiple stems, with different stems used with different sets of affixes. For example, for Proto-Tibor *bugum- 'to sit', reflexes of the full root are used in irrealis/future tense conjugations, while reflexes of a shorter root *bug- are used for hodiernal conjugations. In Pamosu, verbs can have between one and five different stems. Mokati verbs have between one and four. One stem can be considered the base, to which segments are added or subtracted to form the other stems. For example. the Pamosu verb 'to be' has five stems: ik-, ikuam-, ikua-, ikot-, and ikut-. Mokati 'to be' has four stems: ik-, ikam-, ika-, and ikel-.

These alternating verb stems are not distributed according to the same pattern for every verb. Tupper (2012) identifies eleven different conjugation classes in Pamosu, based on the number and formation of alternating verbs stems, and how these stems are distributed across conjugational paradigms. For the Tibor languages other than Pamosu, it is not possible to work out the patterns of stem distribution for every verb based on the data available. However, many of the alternating verb stems in these languages mirror the patterns seen in their Pamosu cognates, so that comparison with Pamosu greatly facilitates the analysis of conjugated verb forms in these languages. For other verbs, individual languages each have somewhat different patterns of alternating stem formation and distribution across the conjugational paradigm. In the sections on individual languages below, I do not discuss the formation and distribution of alternating verb stems, since a full picture is not possible for

37 Pamosu also has a remote past, formed by addition of the prefix $k a$ - to a verb inflected with past tense markers (Tupper 2012: 433). There is no counterpart to the Pamosu remote past evident in the data for other Tibor languages. 
most verbs. Where possible, this information on the distribution of different roots is presented in the section on Proto-Tibor reconstructed vocabulary, under the listing for individual Proto-Tibor verbs.

\subsection{Pamosu}

Pamosu is the best documented Tibor language. It is the only Tibor language which has a published grammar (Tupper 2012), which also includes an extensive wordlist. The summary of Pamosu phonology presented below is based entirely on Tupper (2012), and all examples are taken from this text $^{38}$. Rather than restate all of the morphophonological processes outlined by Tupper, I focus here only on the points that are most relevant for comparison with the other Tibor languages and the reconstruction of Proto-Tibor and Proto-Kumil-Tibor, which is the subject of Chapter 9.

\subsubsection{Pamosu phonemes}

The Pamosu consonant phoneme inventory is presented in Table 3.2.1a

Table 3.2.1a: Pamosu consonant phonemes

\begin{tabular}{|l|c|c|l|l|l|}
\hline & labial & alveolar & palatal & velar & glottal \\
\hline stop & $/ \mathrm{p} /, / \mathrm{m} \mathrm{b} /$ & $/ \mathrm{t} /, / \mathrm{n} \mathrm{d} /$ & & $/ \mathrm{k} /, /{ }^{\mathrm{n}} \mathrm{g} /$ & \\
\hline nasal & $/ \mathrm{m} /$ & $/ \mathrm{n} /$ & & & \\
\hline fricative & $/ \mathrm{f} /, / \mathrm{v} /$ & $/ \mathrm{s} /$ & & & $/ \mathrm{h} /$ \\
\hline liquid & & $/ \mathrm{l} /$ & & & \\
\hline glide & $\mathrm{w}$ & & $/ \mathrm{y} /$ & & \\
\hline
\end{tabular}

The voiceless stop series contrasts with prenasalized voiced stops. Prenasalized voiced stops

are realized with prenasalization in intervocalic and word-final positions, and as plain voiced stops word-initially. In some other Northern Adelbert languages, such as, Barem, when two prenasalized

38 In this section (and throughout the dissertation), I adopt the Pamosu orthography used in Tupper (2012). The only difference between Tupper's Pamosu orthography and the one I use for other Northern Adelbert languages is that in Pamosu, $<$ ng $>$ represents a prenasalized voiceled velar stop $\left[{ }^{\mathrm{n}} \mathrm{g}\right]$, whereas in the orthography for other languages, $<$ ng $>$ represents a velar nasal [y], and the $<$ ngg $>$ represents $\left[{ }^{\mathrm{g}} \mathrm{g}\right]$. 
voiced stops occurred in a row (separated by a vowel), both lost prenasalization (see Chapter 1). This is not a synchronic constraint in Pamosu, as word-medial prenasalized voiced stops are always realized as prenasalized, even when preceded by another voiced stop, as illustrated by $/{ }^{\mathrm{m}} \mathrm{ba}^{\mathrm{n}} \mathrm{guve} / \rightarrow\left[\mathrm{b} \Lambda \mathrm{ggu} \mathrm{\prime}^{\prime} \beta \varepsilon\right]$ 'black palm'. However, historically (prenasalized) voiced stops have both devoiced and lost prenasalization in a number of different environments, as is discussed in Chapter 9.

Pamosu is unusual among Northern Adelbert languages in that it has a contrast between two bilabial fricatives $f$ and $v$, as well as a glide $w$. Tupper notes, however, that the distribution of $f$ and $v$ is nearly complementary, as $f$ does not occur word-finally, and $v$ does not occur word-initially. As I demonstrate in Chapter 9, Proto-Tibor intervocalic and word-final ${ }^{*} \mathrm{f}$ and ${ }^{*} \mathrm{w}$ merged as $v$ in Pamosu. It is therefore not clear how the contrast between $f, v$, and $w$ developed.

Here I adopt the Pamosu orthography used in Tupper (2012), which differs slightly from the orthography I adopt for the other Tibor languages. In the Pamosu orthography, $<$ ng $>$ represents [yg], and not [y]. As some other Tibor languages have both [yg] and [y] as allophones of /g/, I use $<$ ngg $>$ and $<$ ng $>$, respectively, for representing these sounds in the other Tibor languages. The orthography I use for Pamosu and the other Tibor languages otherwise follows the conventions outlined in Chapter 1.

\subsubsection{Pamosu verb morphology}

Table 3.2.2a below presents the Pamosu TAM/subject markers.

Table 3.2.2a: Pamosu TAM/subject markers

\begin{tabular}{|c|c|c|c|c|c|}
\hline & $1 \mathrm{SG}$ & $2 \mathrm{SG}$ & 3 & 1PL & $2 \mathrm{PL}$ \\
\hline Past & -om & -on & $-o t$ & \multirow{3}{*}{-eming } & \multirow{3}{*}{-omong } \\
\hline Hodiernal & -hom & $-i k$ & $-o k /-e k /-a k$ & & \\
\hline Pres. Prog. & -hem -hom & $-i k$ & $-e k$ & & \\
\hline Irrealis & - ina & $-i n i$ & $-i n$ & $-u h u$ & $-u a$ \\
\hline Imperative & \multicolumn{5}{|l|}{$-a$} \\
\hline
\end{tabular}

Pamosu does not mark number in the third person. There are three forms of the 3.HOD suffix, 
$-o k$, -ek, and -ak. Which allomorph of 3.HOD is used is lexically determined, and in general not predictable from the phonological shape of the verb stem. However, stems of the shape $i \mathrm{C}$ - and $u \mathrm{C}$ - $(\mathrm{a}$ high vowel followed by a consonant) always take the suffix -ak (Tupper 2012: 296-297). Similar vowel alternations are seen in the other Tibor languages in the 3.HOD (as well as in Mauwake, Manep, and Barem 2SG and 3SG past tense markers).

The hodiernal tense markers can be used in conjunction with a progressive aspect marker $-u \sim-i$ to form a present progressive conjugation. In this case, some hodiernal tense markers have slightly different forms, illustrated in Table 3.2.2.a. The 1SG variant -hem is only used with the present progressive, and the form of the 3.HOD in the present progressive is always -ek, and never -ok or -ak.

The 1PL and 2PL affixes are identical for the past and hodiernal tense. However, this does not mean that past and hodiernal tense conjugations will necessarily be identical for $1 \mathrm{PL}$ and $2 \mathrm{PL}$ conjugations, since some verbs use different stems for these tenses. For example, 'to sit' uses the stem $p u k a$ - for the plural past tense conjugations, and puk- for all hodiernal conjugations.

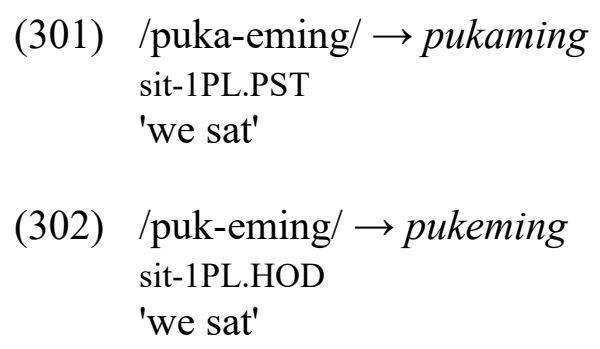

The Irrealis suffixes are used for future tense conjugations, among other modal uses outlined in Tupper (2012). I refer to their counterparts in the other Tibor languages as future tense markers, as this is their most evident use.

Pamosu has a single imperative suffix, $-a$, which is used for both $2 \mathrm{SG}$ and $2 \mathrm{PL}$ imperatives. It thus differs from most other Northern Adelbert languages, including the Tibor languages Hember Avu and Mokati,which have different forms for 2SG and 2PL imperative. 


\subsubsection{Morphophonological processes in Pamosu}

Below I summarize some of the Pamosu morphophonological processes described in Tupper (2012) which are most relevant for a comparison with the other Tibor languages.

\section{Nasal spreading}

In Pamosu there is a process of nasal spreading, whereby voiceless stops become prenasalized and voiced when the following conditions are met: "(i) the preceding consonant is a nasal; (ii) there is an intervening morpheme boundary; and (iii) there is not an intervening phonological word boundary." (Tupper 2012: 114). Compare the following examples from Tupper (2012: 116) which illustrate nasal spreading with the third person hodiernal suffix -ok. In (303), it is suffixed to a verb ending in a nasal, so the final stop in the inflectional suffix becomes voiced and prenasalized. In (304), where the final consonant on the stem is not a nasal, -ok takes its usual form.

(303) /pitim-ok/ $\rightarrow$ pitimong $\left[\right.$ pitimo $\left.{ }^{\mathrm{g}} \mathrm{g}\right]$ close-3.HOD

'he/she closed it'

(304) $/ \mathrm{mu}^{\mathrm{n}} \mathrm{d}-\mathrm{ok} / \rightarrow$ mundok $\left[\mathrm{mu}^{\mathrm{n}} \mathrm{d} \mathrm{ok}\right]$ pierce-3.HOD 'he/she has speared'

Nasal spreadking does not apply in monomorphemic words, as is clear in (305).

(305) /nemak/ $\rightarrow$ nemak' 'grandchild'

As Tupper notes, nasal spreading can be a useful diagnostic for identifying morpheme boundaries. This is true from a diachronic perspective as well, as it can indicate that there was historically a morpheme boundary present in words that are not necessarily divisible into separate morphemes in the modern language. For example, nanduhum 'walking stick' looks related to PNA 
*tukum 'stick', but there is extra syllable $n a$ at the beginning. In Pamosu, na means 'tree', but tuhum is apparantly not a independent word (nor is duhum). Although the usual reflex of intervocalic $*_{\mathrm{t}}$ is $t$, the reflex of *na+*tuhum would be nanduhum, due to the application of nasal spreading across a morpheme boundary. It is therefore likely that nanduhum is, at least historically, a compound word, and reflects Proto-Kumil-Tibor *tukum.

\section{Epenthetic o}

If verb affixation creates a sequence of two consonants, these are broken up with epenthetic $o$.

(306) /itiv-hom/ $\rightarrow$ itivohom go-1SG.HOD

'I went'

\section{Deletion of mid vowels following $a$}

The mid vowels $e$ and $o$ delete following stem-final $a$.

(307) /iva-ek/ $\rightarrow$ ivak

wash-3.HOD

'he/she/they washed'

/iva-omong/ $\rightarrow$ ivamong

wash-2PL.HOD

'you washed'

\section{e-rounding}

Tupper (2012: 113-114) describes a process of vowel assimilation in Pamosu, whereby e rounds to $o$ when the following vowel is $o$, as illustrated in (308).

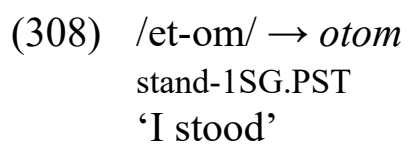

It is clear that the vowel in et- 'stand' is underlying $e$, since there are other conjugations where it does not round. However, this same process has resulted in a merger between Proto-Tibor *e and *o in 
lexical items where there is no alternation (see Chapter 9). Note that $e$-rounding can also be triggered by a following epenthetic $o$.

\subsection{Mokati}

The only previously published primary data on Mokati is Z'graggen's wordlist (1980b). Recordings of Z'grggen's Mokati elicitation sessions can be found online at PARADISEC (Z'graggen 1971b). These recordings contain information not in the published wordlist, including additional vocabulary and verb paradigms. The Mokati data presented here also come from my brief fieldwork in 2016 and 2018 with a Mokati-speaking community living near Malas (a Manep speaking village). My main Mokati consultants were Peter Mindebel and Belom Atul. I worked with these speakers for only one afternoon each of these years, recording lexical data and verb paradigms.

According to Peter Mindebel and Belom Atul, there are at least two distinct varieties of Mokati. The villages of Wanambre and Mawet speak one variety, and the villages of Tinami and Kotakot speak another. There are occasional lexical differences, such as Tinami nokalol 'louse' and Wanambre wena 'louse', but the vocabularies are largely the same. The most notable differences are in the TAM/subject markers, as outlined below. The speaker in Z'graggen's recordings seems to be a speaker of the Tinami/Kotakot variety (however, Z'graggen refers to the language as 'Wanambre' in his publications) ${ }^{39}$.

\subsubsection{Mokati phonemes}

Table 3.3.1a presents the Mokati consonant phoneme inventory. The inventory is the same for both the Mokati and Tinami dialects.

39 Capell's (1952) description of what is clearly Hember Avu is also labeled Vanembere. 
Table 3.3.1a: Mokati consonant phonemes

\begin{tabular}{|l|c|c|c|c|}
\hline & labial & alveolar & palatal & velar \\
\hline stop & $/ \mathrm{p} /, / \mathrm{m} \mathrm{b} /$ & $/ \mathrm{t} /, / \mathrm{n} \mathrm{d} /$ & & $/ \mathrm{k} /, / \mathrm{n} \mathrm{g} /$ \\
\hline nasal & $/ \mathrm{m} /$ & $/ \mathrm{n} /$ & & \\
\hline fricative & $/ \mathrm{f} /$ & $/ \mathrm{s} /$ & & \\
\hline liquid & & $/ \mathrm{l} /$ & & \\
\hline glide & $/ \mathrm{w} /$ & & $/ \mathrm{y} /$ & \\
\hline
\end{tabular}

The prenasalized voiced stops are realized as plain voiced stops word-initially. In the Tinami dialect, they also also lose prenasalization when the preceding consonant in the word is also a voiced stop. $^{40}$ In the Wanambre dialect, $/{ }^{\mathrm{p}} \mathrm{g} /$ has the word-final allophone [y].

In both dialects, intervocalic $/ \mathrm{k} /$ is sometimes pronounced as a glottal fricative $[\mathrm{h}]$. The Wanambre hodiernal suffixes are only recorded with $h$, and have not been observed with a stop $k$. However, [h] and [k] do not appear to be contrastive, and I analyze them as allophones of $/ \mathrm{k} /$.

\subsubsection{Mokati verb morphology}

Tables 3.3.2a and 3.3.2b below present the tense/subject marking affixes for the Tinami and Wanambre dialects. Like Pamosu, Mokati distinguishes hodiernal tense, which covers completed or ongoing events on the current day, from past tense, which covers events that took place prior to the current day, and future tense. There are several differences between the TAM markers in the two dialects. In Tinami, the same markers are used for plural subjects in the past and hodiernal tenses. These come historically from the past tense markers. Wanambre maintains separate markers for the 1PL and 3PL past and hodiernal, but has also extended the 2PL.PST marker for use in the hodiernal as well. The two dialects also have different forms for the 1SG.HOD and 1SG.PST markers. Wanambre 1SG.PST /-em/ has the form -om after a labial final root, and -em otherwise. It is likely that Tinami

40 In the Wanambre dialect, voiced stops became voiceless stops in this position (see section 9.2.3). 
reanalzyed the -om allomorph as the basic form, similar to a change of $* \mathrm{e}>o$ that took place in some Pamosu past tense affixes (see Chapter 9).

Table 3.3.2a: Tinami Mokati TAM/subject markers

\begin{tabular}{|c|c|c|c|c|c|c|}
\hline & $1 \mathrm{SG}$ & $2 \mathrm{SG}$ & $3 \mathrm{SG}$ & $1 \mathrm{PL}$ & $2 \mathrm{PL}$ & 3PL \\
\hline Past & $-o m$ & -en & $-e t$ & \multirow{2}{*}{-emik } & \multirow[b]{2}{*}{-omak } & \multirow[b]{2}{*}{-emit } \\
\hline Hodiernal & $-e m$ & $-i k$ & $-a k /-a u k \sim-o k$ & & & \\
\hline Future & -inumbon & $\begin{array}{l}\text {-ini } \\
\text {-inivon } \\
\text {-ini-ve }\end{array}$ & $\begin{array}{l}-i n \\
-i n e p\end{array}$ & $\begin{array}{l}-u n \\
-u v o n\end{array}$ & $\begin{array}{l}\text {-uwavon } \\
\text {-uwa-ve } \\
\text {-uwak }\end{array}$ & $\begin{array}{l}-u t \\
-u t u v o n\end{array}$ \\
\hline Imperative & & $-a$ & & & -eita & \\
\hline
\end{tabular}

Table 3.3.2b: Wanambre Mokati TAM/subject markers

\begin{tabular}{|c|c|c|c|c|c|c|}
\hline & $1 \mathrm{SG}$ & $2 \mathrm{SG}$ & $3 \mathrm{SG}$ & $1 \mathrm{PL}$ & $2 \mathrm{PL}$ & $3 \mathrm{PL}$ \\
\hline Past & -em & -en & -et & -eming & \multirow[b]{2}{*}{-omang } & -emind \\
\hline Hodiernal & -ehem & $-i k$ & $-a k /-o k$ & -ehing & & -ehind \\
\hline Future & -inumbon & $\begin{array}{l}\text {-ini } \\
\text {-inivon } \\
\text {-ini-ve }\end{array}$ & $\begin{array}{l}-i n \\
-i n e p\end{array}$ & $\begin{array}{l}-u n \\
-u v o n\end{array}$ & $\begin{array}{l}\text {-uwavon } \\
\text {-uwa-ve } \\
\text {-uwak }\end{array}$ & $\begin{array}{l}-u t \\
-u t u v o n\end{array}$ \\
\hline Imperative & & $-a$ & & & -eita & \\
\hline
\end{tabular}

The examples in (309-311) illustrate the use of past, hodiernal, and future tense marking in the

Tinami dialect on the same verb root, im- 'to cook'.

(309) inok

yesterday taro cook-1SG.PST

'I cooked taro yesterday'

(310)

sovokalu ma im-em (Tinami)

morning taro cook-1SG.HOD

'I cooked taro this morning'

(311) ma im-inumbom

(Tinami)

'I will cook taro'

Although the Tinami dialect uses the same forms for the plural hodiernal and past tense suffixes, plural conjugated verb forms in the past and hodiernal tense are not always identical, since 
some verbs use a different stem for the past than for the hodiernal, as illustrated in (312). This is similar to the verb stems illustrated for Pamosu above.

/wew-emit/ $\rightarrow$ wevemit $\quad$ (Tinami)

come-3PL.HOD

'they came/they are coming'

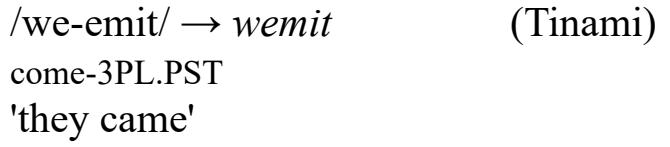

In both dialects, multiple endings have been recorded used to express future events for most person/number combinations. In most cases, there seems to be a base form, shown in the top line of the future tense cells in Tables 3.3.2a-b, which can be used either on its own or with additional elements attached to the right edge. There is no clear difference in the functions of the various future forms, other than that the element -ve is added only on 2SG and 2PL questions, as in (314).

\section{Imperfective aspect}

The Mokati imperfective aspect marker $-y$ is only used in the hodiernal tense, and indicates an ongoing action. It has a vowel allomorph $-i$ following a consonant.
'Where are you going?'
$\begin{array}{lll}\text { nik } & \text { gono } & \text { ya-y-omang } \\ \text { 2PL } & \text { where } & \text { go-IPFV-2PL.HOD }\end{array}$
ali ma im-i-em
now taro cook-IPFV-1SG.HOD
(Tinami)
'I'm cooking taro now'
(Wanambre) 


\subsubsection{Morphophonological processes in Mokati}

Below I outline some of the phonological processes which apply synchronically in Mokati.

Unless otherwise noted, these behave the same in both the Tinami and Wanambre dialects.

\section{Nasal spreading}

The Wanambre dialect of Mokati has essentially the same nasal spreading rule as Pamosu. The sentences in (317-318) show Wanambre Mokati verb stems with non-nasal final consonants suffixed with -ik'2SG.HOD' and -et '3SG.PST', which have final voiceless stops. Compare these to the inflected verbs in (319-320), in which the same suffixes are attached to verb stems with a final nasal consonant, and nasal spreading applies. ${ }^{41}$

/uw-ik/ $\rightarrow$ uvik $\quad$ (Wanambre) plant-2SG.HOD

'you planted'

(318) /yak-et/ $\rightarrow$ yaket (Wanambre) go-3SG.PST

'he went'

(319) /en-ik/ $\rightarrow$ ening [enin](Wanambre) eat-2SG.HOD

'you ate'

$$
\text { /um-et/ } \rightarrow \text { umend }\left[\text { ume }^{\mathrm{n}} \mathrm{d}\right] \quad \text { (Wanambre) }
$$
die-3SG.PST

'he died'

In the Tinami dialect, nasal spreading does not apply, as illustrated in (321-322). This is not surprising, as historically prenasalized voiced stops lost nasalization and devoiced in Tinami (see Chapter 9).
(321) /en-ik/ $\rightarrow$ enik
(Tinami)
eat-2SG.HOD
'you ate'

41 Mokati is slightly different from Pamosu in that the word-final allophone of $/ \mathrm{g} g / \mathrm{is}[\mathrm{\eta}]$, rather than [ng] 
(322) $/$ um-et/ $\rightarrow$ umet (Tinami) die-3SG.PST

'he died'

\section{Vowel sequence modification rules}

Sequences of certain vowels result in vowel coalesence or deletion of one of the vowels.

\section{Coalesence of $\boldsymbol{e}$ and back vowels}

Underyling /e/ followed by either of the back vowels /o/ or $/ \mathrm{u} /$ is realized as $o$.

/we+omak $\rightarrow$ womak $\quad$ (Tinami)

come-2PL.PST

'you came'

(324)
/we+uvon/ $\rightarrow$ wovon
(Tinami)

come-1PL.FUT

'we will come'

An underlying sequence of $/ \mathrm{ue} /$ is also realized as $o$.
(325) /iku+ehing/ $\rightarrow$ ikohing $\quad$ (Wanambre)
stay+1PL.HOD
'We stayed'

$/ \mathbf{a}+\mathbf{e} / \rightarrow a$

As in Pamosu, /e/ deletes following /a/. ${ }^{42}$
/ila + ep/ $\rightarrow$ ilap
(Tinami)

go_up+SS

'go up and...'

(327)
leka+em/ $\rightarrow$ ekam
(Tinami)

see+1SG.HOD

'I saw him'
(328) /na-eka-em/ $\rightarrow$ inakam (Wanambre) 2SG-see+1SG.PST
'I saw you'

42 In Pamosu, this rule applies to both mid vowels $e$ and o, but there is no evidence for it applying to $o$ in Mokati. 


\section{i-lowering}

A high front vowel $i$ lowers to $e$ after the present progressive suffix $-y$. While this may be a more general rule, the underlying sequence /yi/ has not been observed with any other morpheme.

(329)

yaka-y-ik/ $\rightarrow$ yakayek go-IPFV-2SG.HOD'

'You're going'
/en-y-ik/ $\rightarrow$ eniek
(Tinami) eat-IPFV-2SG.HOD'

'You're eating'
(Tinami)

\section{Assimilation of $\boldsymbol{e}$ to mid vowels}

In a regressive vowel assimilation in Pamosu, $e$ becomes $o$ when the next vowel is $o$. There is a similar rule in Mokati, but it applies optionally.

$/$ men-om/ $\rightarrow$ menom $\sim$ monom $\quad$ (Tinami) feed-1SG.PST

'I fed him'

$$
\text { /we-y-ok/ } \rightarrow \text { weyok woyok } \quad \text { (Tinami) }
$$
come-3SG.HOD

'He's coming'

This rule also applies progressively in Mokati, as $e$ assimilates to preceding $o$, as in (333).
(333) /iku-ekem/ $\rightarrow$ ikohom
(Wanambre)
stay-1SG.HOD
'I stay'

\section{e-rounding (Wanambre)}

As mentioned in 3.2.2, the Wanambre 1SG.PST suffix -em is realized as -om when suffixed to a labial-final root.

$$
\begin{aligned}
& \text { /uw-em/ } \rightarrow \text { uvom } \\
& \text { plant-1SG.PST } \\
& \text { 'I planted' }
\end{aligned}
$$

\section{(Wanambre)}

Rounding does not apply to other e-initial suffixes, such as -en 2SG.PST, or -et 3SG.PST. 
/uw-en/ $\rightarrow$ uvom $\quad$ (Wanambre)

plant-2SG.PST

'I planted'

\section{Glide insertion}

When the 2SG.IMP suffix $-a$ is attached to an $e$ - or $a$-final stem, a glide $y$ is inserted.

/we-a/ $\rightarrow$ weya $\quad$ (Wanambre)

come-2SG.IMP

'come!'

(337) /ila-a/ $\rightarrow$ ilaya

(Wanambre)

go_up-2SG.IMP

'go up!'

\subsection{Hember Avu}

Hember Avu (also known as Amben ${ }^{43}$ ) is spoken in seven villages: Salemben, Erinduk, Sevan, Erek Erek, Nagemak, Kumbu, and Embor. In addition to Z'graggen's publications and recordings in PARADISEC, I also consulted Petir et al (1996), a guide to the plants of Salemben village, which provides additional lexical data (most, but not all, of it plant-related). In 2016, I met with a small community of Hember Avu speakers that live near Malas, and worked with them for an afternoon to collect a Hember Avu wordlist. SIL has produced some short manuscripts related to orthography development which contain information on Hember Avu phonology and vocabulary, and some narrative texts (Easton 2000, Fam, Jombo, \& Nembenian 2000, Kenikos \& Pisen 2000).

43 Petir et al (1996) call the language Amben, and I also heard this name used by non-Hember Avu-speaking people in the area. As some of the authors of Petir et al (1996) are Amben speakers, it is clear that this is indeed a correct name for the language. However, as the speakers I worked with preferred the name Hember Avu, that is the one I adopt here. 


\subsubsection{Hember Avu phonemes}

Table 3.4.1a: Hember Avu consonant phonemes

\begin{tabular}{|l|c|c|l|l|}
\hline & labial & alveolar & palatal & velar \\
\hline stop & $/ \mathrm{p} /, /{ }^{\mathrm{m}} \mathrm{b} /$ & $/ \mathrm{t} /, / \mathrm{n} \mathrm{d} /$ & & $/ \mathrm{k} /, /{ }^{\mathrm{n}} \mathrm{g} /$ \\
\hline nasal & $/ \mathrm{m} /$ & $/ \mathrm{n} /$ & & \\
\hline fricative & $/ \mathrm{f} /$ & $/ \mathrm{s} /$ & & \\
\hline liquid & & $/ \mathrm{r} /$ & & \\
\hline glide & $/ \mathrm{w} /$ & & $/ \mathrm{y} /$ & \\
\hline
\end{tabular}

Similar to Mokati, the realization of word-initial prenasalized voiced stops in Hember Avu varies between voiced and voiceless (both without prenasalization), as in /mbaner/ $\rightarrow$ baner paner. Although the voiceless variants seem to be much more frequent, these stops are analyzed as underlyingly voiced. Since Proto-Tibor did not have *p, and word-initial *k lenited to $h$ in Hember Avu, there is no ambiguity in the underlying form of word-initial $[\mathrm{p}]$ and $[\mathrm{k}]$. These are realizations of $/{ }^{\mathrm{m}} \mathrm{b} /$ and $/{ }^{\mathrm{n}} \mathrm{g} /$, respectively. PNA initial $*_{\mathrm{t}}$ became $*_{\mathrm{s}}$ in most Proto-Tibor forms, but may have been preserved as *t before back vowels (see Chapter 9 ). Word-initial [t] is therefore potentially ambiguous between $/{ }^{\mathrm{n}} \mathrm{d} /$ and $/ \mathrm{t} /$ in Hember Avu. Devoicing of initial stops in Pamosu appears to be a change in progress that is well underway, but not yet complete. Since there are usually only a few tokens, at most, recorded for any individual lexical item, it is not clear whether this variation is present in every lexical item with initial voiced stops, or if the change can be considered complete for some items.

If an initial voiced stop is pronounced as devoiced, it also causes a following $/{ }^{\mathrm{n}} \mathrm{d} /$ or $/{ }^{\mathrm{n}} \mathrm{g} /$ to devoice and lose prenasalization, for example /mbegi/ 'light' $\rightarrow$ [peki]. However, if an initial stop is pronounced as voiced, the following voiced stop is pronounced as voiced, but without prenasalization $(/$ mbug-/ 'sit' $\rightarrow$ [bug- $\sim$ puk- $])^{44}$. /mb/ is not affected in this way, and is always pronounced as [ $\left.{ }^{\mathrm{m} b}\right]$ postvocalically (/mbimbik-/ 'be afraid' $\rightarrow\left[\right.$ bi $\left.\left.^{\mathrm{m}} \mathrm{bik}-\right]\right)$.

44 The loss of prenasalization in the environment of another voiced stop is common in Northern Adelbert languages, and is discussed in Chapter 1. 
Word-final $/{ }^{\mathrm{n}} \mathrm{g} /$ is realized as a nasal, for example $/$ ine $^{\mathrm{n}} \mathrm{g} /$ 'tomorrow' $^{\mathrm{t}} \rightarrow$ [inen].

Phonemic voiceless velar stops only appear intervocalically and word-finally, while $h$ only appears word-initially. [k] and [h] are therefore in complementary distribution, and are analyzed as allophones of a single phoneme $/ \mathrm{k} /$. However, as noted above, word-initial voiced stops are often realized as voiceless, which leads to a surface contrast between word-initial [k] (underlying /g/) and [h] (underlying /k/).

In describing their orthography Petir et al (1996) write: "The vowel "o" is pronounced in two different ways. In order to preserve this distinction, we have differentiated between these two sounds by using " $O$ " and "ö"." Providing English examples for the vowels, they write that $<_{0}>$ is like the vowel in forest, while $<_{0}>$ is like the vowel in hello. ${ }^{45}$ I interpret this as $<_{0}>$ representing [o], and $<\ddot{o}$ $>$ representing [o]. However, $<_{0}>$ is typically found in closed syllables (including homorganic nasalstop sequences), for example $<$ gongon hetar $>$, and $<$ mambur ombos $>$. On the other hand, $<\ddot{\text { o }}>$ is usually found in open syllables, as in $<$ hönem $>$, < göfar höte $>$, and < $<$ gömugömu $>{ }^{46}$. This complementary distribution suggests that these two sounds are both allophones of /o/. In vocabulary taken from Petir et al (1996), I have adapted their orthography to be consistent with the one I use for other Tibor languages, and represent both sounds with $<_{0}>$.

\subsubsection{Hember Avu verb morphology}

Table 3.4.2a presentes Hember Avu TAM/subject-marking affixes.

45 Presumably they mean the second vowel in hello, since they refer to both these sounds as "the vowel "o"'".

46 These are all names of plants. 
Table 3.4.2a: Hember Avu TAM/subject markers

\begin{tabular}{|l|l|l|l|l|l|l|}
\hline & 1SG & 2SG & 3SG & 1PL & 2PL & 3PL \\
\hline Past & -em & & - -en & -emin & -eman & -emin \\
\hline Hodiernal & -ekem & $-i k$ & $\begin{array}{l}\text {-ak/-ek } \\
\text { (allomorph -ok } \\
\text { after labial) }\end{array}$ & -ekemin & $\begin{array}{l}\text {-ekoman } \\
\text {-ekaman }\end{array}$ & -ekemin \\
\hline Future I & -av-okom & -av-ik & -avaron & -av-okomin & -av-okoman & -av-okomin \\
\hline Future II & -inarin & -inyerin & & & & -unerin \\
\hline Imperative & & $-a$ & & & -andik & \\
\hline
\end{tabular}

The Hember Avu hodiernal markers are formed by adding the element -ek before the past tense markers. The exceptions are 2SG.HOD $-i k$ and 3SG.HOD -ak/-ek, which are not derived from the 2/3SG.PST marker -en. Additionally, there is a vowel change in the 2PL.HOD marker, which has the variants -ekoman ekaman.

As with Mokati, there are multiple conjugational paradigms related to future events, and the semantic distinction between them (if there is one) is not clear from the available data, as they are both used in response to the same types of Tok Pisin prompts. The most frequently used future tense endings are listed in Table 3.4.2a as Future I. These future tense endings are formed by adding $-a v$ before the hodiernal markers, with rounding of /e/ to $o$ in the $1 \mathrm{SG}$ and plural forms. The exception is the 3SG.FUT -avaron, which does not resemeble the 3SG.HOD -ak/-ek. Although these endings use the hodiernal markers, they can be used to refer to future events past the current day.

The suffixes listed as Future II in Table 3.4.2a are less frequent in Z'graggen's recordings, and no 3SG, 1PL, or 2PL suffixes for this paradigm have been identified. 


\subsubsection{Morphophonological processes in Hember Avu}

\section{Nasal spreading}

Unlike other Tibor languages, nasal spreading does not seem to be an active phonological process in Hember Avu. The speaker in Z'graggen's recordings does not exhibit nasal spreading on conjugations of nasal-final verb roots where it appears in the other Tibor languages. Compare the realization of the 3SG hodiernal suffix $-e k$ on $u w o k$ 'he gave to him' in (338) with the same surface realization on umok 'he died' in (339). ${ }^{47}$ If nasal spreading were to apply, the surface form **[umong] would be expected. However, there is some evidence that nasal spreading may have applied in Hember Avu in the past (see Section 3.5 below).

/uw-ek/ $\rightarrow$ uwok give_3SG-3SG.HOD

'she gave it to him'

(339) /um-ek/ $\rightarrow$ umok die-3SG.HOD

'he died'

\section{e-rounding}

The initial $e$ in some Hember Avu suffixes rounds to $o$ when attached to a stem ending in a labial consonant. This rule applies to -em '1SG.PST', -en '2/3.PST' and -ek'3SG.HOD'. Compare the forms in (339-341), where the suffixes are attached to a stem ending in a velar, to those in (342-344) where they are attached to a stem ending in labial, triggering rounding of $e$ to $o$.

$$
\begin{array}{ll}
\text { (339) } \begin{array}{l}
\text { /ak-en/ } \rightarrow \text { aken } \\
\text { go-2/3.PST } \\
\text { 'He went' }
\end{array} \\
\text { (340) } \begin{array}{l}
\text { /ak-ek/ } \rightarrow \text { akek } \\
\text { go-3SG.HOD } \\
\text { 'He died' }
\end{array}
\end{array}
$$

47 On both verbs, -ek rounds to -ok following a root-final labial. 
(341)

/ak-em/ $\rightarrow$ akem

go-1SG.PST

'I went'

(342) /um-en/ $\rightarrow$ umon

die-2/3.PST

'He died'

(343) /um-ek/ $\rightarrow$ umok

die-3SG.HOD

'He died'

(344) $/ i^{\natural}$ gam-em/ $\rightarrow$ inggamom

stay-1SG.PST

'I stayed'

e-rounding does not apply to the plural past or hodiernal suffixes, or to 1SG.HOD -ekem, as illustrated in (345-347). Although $e$-rounding does not typically apply to the hodiernal suffixes, it has applied in the formation of the Future I suffixes, which are formed by attaching the hodiernal to labial-final -av.

(345) /um-emin/ $\rightarrow$ umemin.

die-1/3PL.PST

'He died'

(346) /um-ekemin/ $\rightarrow$ umekemin.

die-1/3PL.HOD

'He died'

(347) $/$ w-ekem/ $\rightarrow$ wekem

give-1SG.HOD

'I gave it to him'

$/ \mathbf{a}+\mathbf{e} / \rightarrow a$

As in Mokati and Pamosu, in an underlying sequence of $/ \mathrm{a}+\mathrm{e} /, e$ deletes.

(348) $/ \mathrm{i}^{\mathrm{i}} \mathrm{ga}$-emin/ $\rightarrow$ inggamin

stay-1/3PL.PST

'We stayed'

(349) /aka-ekem/ $\rightarrow$ akakem

go-1SG.HOD

'I go' 
$/ \mathbf{u}+\mathbf{e} / \rightarrow \boldsymbol{o}$

An underlying sequence of $/ \mathrm{u}+\mathrm{e} /$ coalesces to $o$.

(350) $/ \mathbf{i}^{\text {}}$ gu-ekem/ $\rightarrow$ inggokom

stay-1SG.HOD

'I stay'

\section{Vowel assimilation}

Hember Avu has two progressive vowel assimilation rules. First, $e$ becomes $a$ when the preceding vowel is a. This rule applies optionally, as illustrated in (351).

/a-ekemin/ $\rightarrow$ akamin $\sim$ akemin

become-1/3PL.HOD

'They became'

Second, $e$ becomes $o$ when the preceding vowel is $o$. This is illustrated in (352) below, as well as (350) above. A similar process is found in Mokati.

(352) /igu-ekemin/ $\rightarrow$ inggokomin stay-1/3PL.HOD

'We stay'

\subsection{Mawak}

For Mawak, the only lexical data come from Z'graggen's published work (1980b). Unfortunately, Mawak has not been identified in any of the digitized recordings in his PARADISEC collection. ${ }^{48}$ The description below is therefore based only on the phonetic transcriptions in Z'graggen's wordlist and should be considered tentative.

Table 3.5a: Mawak consonant phonemes

\begin{tabular}{|l|c|c|l|l|c|}
\hline & labial & alveolar & palatal & velar & glottal \\
\hline stop & $/ \mathrm{p} /$ & $/ \mathrm{t} /, / \mathrm{n} \mathrm{d} /$ & & $/ \mathrm{k} /, / \mathrm{n} \mathrm{g} /$ & \\
\hline nasal & $/ \mathrm{m} /$ & $/ \mathrm{n} /$ & & & \\
\hline fricative & $/ \mathrm{f} /$ & $/ \mathrm{s} /$ & & & $/ \mathrm{h} /$ \\
\hline liquid & & $/ \mathrm{r} /$ & & & \\
\hline glide & $/ \mathrm{w} /$ & & $/ \mathrm{y} /$ & & \\
\hline
\end{tabular}

48 There is a file in the collection titled Lg F09 Mawak Word List and Vocabulary but it is actually a recording of Pamosu. 
The prenasalized voiced stops /d/ and /g/ are not found word-initially, and /f/ is only found word-initially. Word-final $/ \mathrm{g} /$ is sometimes realized as a velar nasal, with no stop portion. The glottal fricative $/ \mathrm{h} /$ is only found intervocalically. $[\mathrm{h}],[\mathrm{k}]$, and $\left[{ }^{\mathrm{g}} \mathrm{g}\right]$ are very nearly in a complicated pattern of complementary distribution, where $[\mathrm{h}]$ and $[\mathrm{k}]$ could be analyzed as allophones of /k/ (with [h] occuring intervocalically and $[\mathrm{k}]$ occuring word-finally), and $[\mathrm{k}]$ and $\left[{ }^{\mathrm{p}} \mathrm{g}\right]$ analyzed as allophones of $/{ }^{\mathrm{p}} \mathrm{g} /$ (with [k ] found word-initially, immediately following a word-inital vowel, or following $p$ or another $k$, and $\left[{ }^{\mathrm{g}} \mathrm{g}\right]$ found elsewhere. $)^{49}$ However, a small number of words do not follow this pattern, for example tukum 'stick'. Such words are likely borrowings, but have created a phonemic contrast between $k$ and $h$.

Since the only data available for Mawak is the wordlist in Z'graggen (1980b), there is no information on its verb morphology, and not much can be said about morphophonemic processes. However, there is at least one example of nasal spreading having applied on reflexes of the adjectiveforming suffix *-at in Mawak (as well as the other Tibor languages). Table 3.5b shows the Tibor reflexes of Proto-Tibor *ket-at 'red', derived from *ket 'blood' and the adjective-forming suffix *-at. The reflex of final *t in all the Tibor languages is voiceless $t$. Compare this with the reflexes of *bin-at 'heavy', derived from *bin 'heavy, weight' plus *-at, where nasal spreading appears to have applied in all five languages, and the final *t is reflected as a prenasalized stop (or in the case of Hember Avu, a nasal). Note also that nasal spreading has applied here in Hember Avu, even though nasal spreading is not synchronically active in that language.

Table 3.5b: nasal spreading in Tibor reflexes of *-at

\begin{tabular}{|l|l|l|l|l|l|}
\hline Proto-Tibor & Mokati & Pamosu & Hember Avu & Mawak & Kowaki \\
\hline *ket-at 'red' & ketat & etat & hetat & etat & etat \\
\hline *bin-at 'heavy' & binant & pinand & pinan & pinant & pinant \\
\hline
\end{tabular}

49 See Chapter 9 for a discussion of the sound changes which led to this distribution. 


\subsection{Kowaki}

The only data available on Kowaki come from Z'graggen, which includes his published wordlist (Z'graggen 1980b), as well as a recording of a Kowaki elicitation session (Z'graggen 1971b), which contains additional vocabulary and verb paradigms not found in his books. The description of Kowaki verbal morphology and morphonemic processes I present below is based on the data found in this recording.

\subsubsection{Kowaki phonemes}

Table 3.6.1a presents the Kowaki consonant phoneme inventory.

Table 3.6.1a: Kowaki consonant phonemes

\begin{tabular}{|l|c|c|l|c|}
\hline & labial & alveolar & palatal & glottal \\
\hline stop & $/ \mathrm{p} /$ & $/ \mathrm{t} /, / \mathrm{n} \mathrm{d} /$ & & $/ \mathrm{T} /$ \\
\hline nasal & $/ \mathrm{m} /$ & $/ \mathrm{n} /$ & & \\
\hline fricative & $/ \mathrm{f} /$ & $/ \mathrm{s} /$ & & $/ \mathrm{h} /$ \\
\hline liquid & & $/ \mathrm{r} /$ & & \\
\hline glide & $/ \mathrm{w} /$ & & $/ \mathrm{y} /$ & \\
\hline
\end{tabular}

Kowaki is unique among the Tibor languages in that there are no velar consonants, as * $\mathrm{k}$ and $* \mathrm{~g}$ have become either $/ \mathrm{h} /$ or $/ \mathrm{R} /$ in all environments. The only voiced stop is $/{ }^{\mathrm{n}} \mathrm{d} /$, which contrasts with $/ \mathrm{t} /$ only after a vowel. The phonetic realization of $/{ }^{\mathrm{n}} \mathrm{d} /$ is usually a prenasalized voiceless stop [nt], although it is sometimes realized voiced. It could therefore be argued that there is no phonemic $/{ }^{\mathrm{n}} \mathrm{d} / \mathrm{but}$ rather a contrast between voiceless $/ \mathrm{t} /$ and nasal stop sequences $/ \mathrm{nt} /$. An argument for analyzing $/{ }^{\mathrm{n}} \mathrm{d} / \mathrm{as}$ a unitary phoneme (rather than a sequence of two phonemes /nd/) is that there are otherwise no phonological consonant clusters in the language, and there are synchronic processes which break up consonant clusters when they are formed through affixation (see below). ${ }^{50}$

50 In any case, $/{ }^{\mathrm{n}} \mathrm{d} /$ is the only prenasalized phoneme, or, if analyzed as $/ \mathrm{nd} / \mathrm{then} / \mathrm{d} /$ is the only (plain) voiced phoneme. 


\subsubsection{Kowaki verb morphology}

Table 3.6.2a shows the Kowaki TAM-marking morphology.

Table 3.6.2a: Kowaki TAM-marking morphology ${ }^{51}$

\begin{tabular}{|c|c|c|c|c|c|}
\hline & $1 \mathrm{SG}$ & $2 \mathrm{SG}$ & 3 & $1 \mathrm{PL}$ & $2 \mathrm{PL}$ \\
\hline Past & -om & -uan & $-e t$ & -emin & -eman \\
\hline Hodiernal & -ehem & $-i^{\prime}$ & $-e^{\prime}$ & $-e m i^{\prime}$ & $-e m a^{\prime}$ \\
\hline Irrealis & -ina(re) & -ini(re) & $-i n$ & -ihi(re) & -uane(re) \\
\hline Imperfective & \multicolumn{5}{|l|}{$-u$} \\
\hline Perfective & \multicolumn{5}{|l|}{$-p a$} \\
\hline
\end{tabular}

The Kowaki TAM morphology is similar to Pamosu's, both in the distinctions made and the forms of the affixes, which are almost all cognate. Like Pamosu, there is no distinction between singular and plural for the third person.

The irrealis suffixes sometimes appear with the element $r e$ as the last syllable, and sometimes without. There is no clear difference in meaning between the two forms.

A notable difference between Kowaki and Pamosu is the perfective apsect marker - $p a$, which has no counterpart in Pamosu ${ }^{52}$. It occurs in the same slot as the imperfective aspect marker $-u$, following the verb root and preceding the tense/subject marker. The examples below illustrate conjugations of the verb 'come' in hodiernal tense, with and without the perfective marker.

$$
\begin{array}{ll}
\text { wo } & \text { fo-pa-ha }{ }^{\prime 53} \\
\text { 3SG } & \text { come-PFV-3.HOD }
\end{array}
$$

'He came'

51 This table does not include imperative forms, as these are not known. Z'graggen's Kowaki recording archived at PARADISEC doesn't contain any imperative forms.

52 In the Kowaki data, verbs inflected with - $p a$ were given as a response almost exclusively to Tok Pisin prompts where the Tok Pisin verb was followed by pinis, which markes perfective aspect in Tok Pisin (Mühlhäusler 1985). For this reason, it is analyzed as a perfective marker in Kowaki.

53 The verbs in the examples in this section are subject to a number of phonological processes outlined in 3.6.2. 
(354) mante fo-'

man come-3.HOD

'The man is coming'

Kowaki imperfective $-u$, has only been recorded on verbs in hodiernal tense, as in (355).
(355) i'e pu'um-u-mi'
1PL sit-IPFV-1PL.HOD
'We're sitting'

According to Tupper (2012), Pamosu aspectual morphology does not appear in the past tense. This is true also of Kowaki imperfective $-u$. However, this is not the case for all Kowaki aspectual morphology, as the perfective aspect marker - $p a$, which Pamosu lacks, can be used with both hodiernal tense, as in (356), and past tense, as in (357-358).

$\begin{array}{lll}\text { (356) } & \begin{array}{l}\text { i'e in-impa-mi' } \\ \text { 1PL sleep-PFV-1PL.HOD }\end{array} \\ & \text { 'We slept' } \\ \text { (357) } & \begin{array}{l}\text { henina' } \\ \text { yesterday } \\ \text { 'We slept' }\end{array} & \begin{array}{l}\text { in-impa-min } \\ \text { sleep-PFV-1PL.PST }\end{array} \\ \text { (358) } & \begin{array}{l}\text { ohi'a } \\ \text { long_ago }\end{array} & \begin{array}{l}\text { fo-pa-hat } \\ \text { come-PFV-3.PST }\end{array} \\ & \text { 'He came long ago' }\end{array}$

\subsubsection{Morphophonological processes in Kowaki}

Below I outline the morphophonological processes present in Kowaki.

\section{Nasal spreading}

The nasal spreading process found in other Tibor languages applies also in Kowaki, with the difference that the contrast is between voiceless and prenasalized-voiceless, rather than prenasalizedvoiced. The examples in (359-360), show that the suffix -et '3.PST' undergoes nasal spreading when 
suffixed to a nasal-final stem, whereas in (361-362), it is realized with a plain voiceless stop. Nasal spreading applying to $p$ is illustrated in (363). ${ }^{54}$

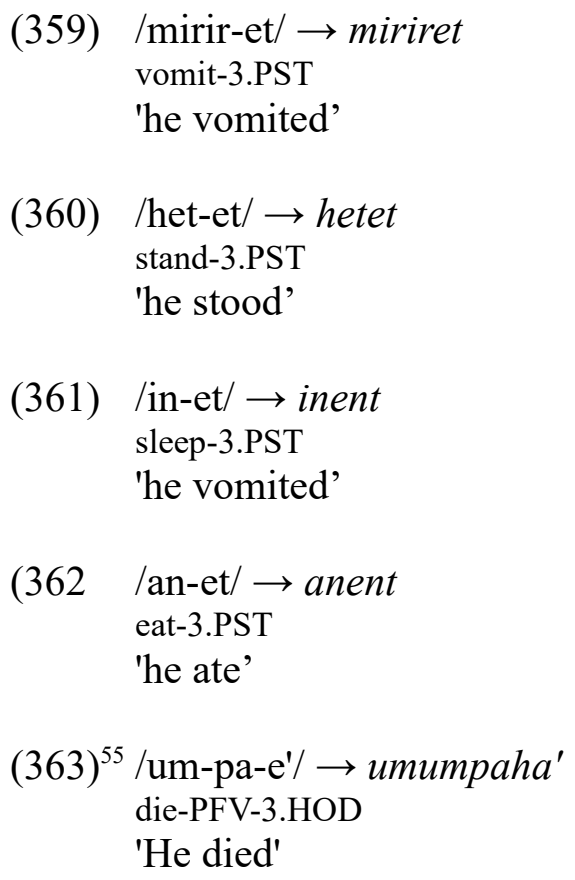

\section{$h$ epenthesis}

Epenthetic $h$ is inserted after the perfective marker - $p a$ and before a monosyllabic vowel-initial affix:

/e-pa-i'/ $\rightarrow$ epahi' become-PFV-2SG.HOD

'You have become'56

(365) /pu'-pa-et/ $\rightarrow$ pu'upahat sit-PFV-3.PST 'They sat down'

54 This example also illustrates the insertion of epenthetic $e$, and regressive assimilation of $e$ to $a$, which are described below.

55 This example also illustrates vowel epenthesis and vowel assimilation, described below.

56 This example is taken from the elicited phrase ne ta'er herere epahi' 'you're thirsty', literally 'you have become dry in the neck'. 
It seems that $h$-epenthesis only applies following -pa. Sequences of adjacent vowels created from inflection with the imperfective aspect marker $-u$ do not trigger $h$-epenthesis (366), nor do vowel-final verb stems (367).

/sop-u-i'/ $\rightarrow$ sopui

drink-IPFV-2SG.HOD

'You're drinking'

(367) /ira-et/ $\rightarrow$ irat

climb-3.PST

'He climbed'

\section{Vowel assimilation}

$e \rightarrow a / a(h)$

In Kowaki, $e$ assimilates to a preceding $a$ either when they are directly adjacent, or when there is an intervening $h$, as in (368-369). This applies also to epenthetic $h$, as in (365) above. If they are directly adjacent, this results in a sequence of two of the same vowel $a$, which coalescence into a single segment $a$, as with all sequences of identical vowels.

(368) /fo-pa-ehem/ $\rightarrow$ fopaham come-PFV-1SG.HOD

'I came'

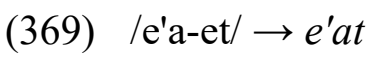
see-3.PST

'He saw'

$\boldsymbol{e} \rightarrow \boldsymbol{o} / \mathbf{o}(\boldsymbol{h})$

$e$ assimilates to a preceding $o$. As with $e \rightarrow a$, this rule also applies across an intervening $h$. Again, when assimilation results in a sequence of two identical vowels, they coalesce into a single segment, as for $e \rightarrow o$ by (371) below.

(370) $/$ fo-ehem $/ \rightarrow$ fohom come-1SG.HOD

'I come' 
(371) $/$ fo-e' $/ \rightarrow$ fo $^{\prime}$

come-3.HOD

'He came'

\section{e-rounding}

In the suffixes -et '3PST', $-e^{\prime}$ '3HOD', suffix-initial $e$ becomes $o$ following a labial consonant, as in (372).

(372) $/$ tiv-et/ $\rightarrow$ tivot go-3.PST

'He went'

(373) /pu'um-e'/ $\rightarrow$ pu'umo' sit-3.HOD

'They sat'

This does not apply to the plural past and hodiernal suffixes, or to 1SG.HOD -ehem.

(374) $/$ tiv-ehem/ $\rightarrow$ tivehem go-1SG.HOD

'I went'

(375) /sop-eman/ $\rightarrow$ sopeman

drink-2PL.PST

'You drank'

$/ \mathbf{u}+\mathbf{e} /$

Sequences of underlying $/ \mathrm{u}+\mathrm{e} / \mathrm{resolve}$ in three different ways, depending on the elements involved. If a $u$-final verb root is followed by an $e$-initial suffix $/ \mathrm{u}+\mathrm{e} /$ coalesces as $o$, as illustrated in (376).

$$
\begin{aligned}
& \text { /'u-ehem/ } \rightarrow \text { 'ohom } \\
& \text { stay-1SG.HOD }
\end{aligned}
$$

'I stay'

When a polysyllabic $e$-initial suffix follows the imperfective marker $-u, e$ deletes.

(377) $/$ in-u-emi'/ $\rightarrow$ tivumi'
sleep-IPFV-1PL.HOD
'We're sleeping' 
/tiv-u-ehem/ $\rightarrow$ tivuhom

stay-IPFV-1PL.HOD

'We're going'

When the monosyllabic suffix -ek'3.HOD' follows the imperfective marker $-u$, it rounds to $o$.

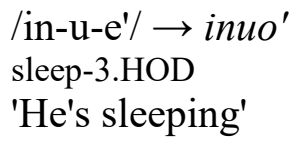

'He's sleeping'

\section{Vowel epenthesis}

If the perfective marker - $p a$ is attached to a consonant-final verb root, an epenthetic vowel is inserted as well, but the quality of the vowel depends on the preceding vowel in the verb root. If it is a high vowel, then the epenthetic vowel copies the preceding high vowel, as in (379-380). If the preceding vowel is non-high, then $a$ is inserted, as in (381)

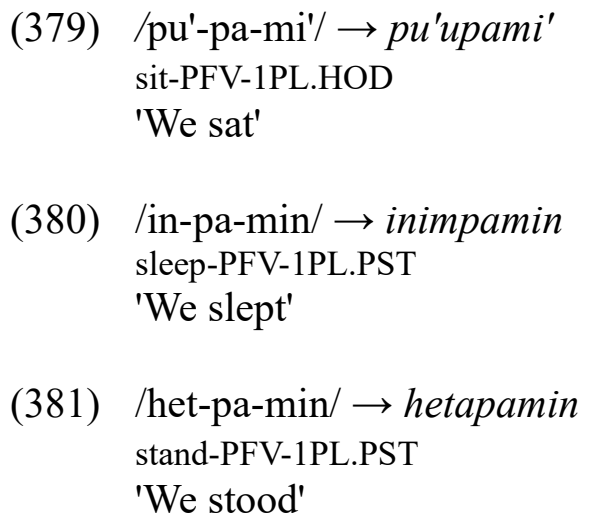

'We stood'

\subsection{Kumil languages overview}

The three Kumil languages, Mauwake, Bepour, and Moere, are spoken on the coast north of the Tibor languages, in an area surrounding the Kumil river. They are northwest of Barem-speaking territory, and southwest of the Kaukombar languages. Mauwake covers the largest area of the three languages, and is spoken as the main languages in fifteen villages over an area of about 100 square kilometers, with a population of around 4,000 (Berghäll 2015). The main Mauwake centers are Malala 
and Ulingan. The latter is also the name that Z'graggen and Capell use to refer to the language. Bepour and Moere are both much smaller than Mauwake, with around 50 speakers each in 2000 (Eberhard, Simons \&Fennig, 2020). Bepour is spoken in a small enclave within the Amako ${ }^{57}$-speaking area on the coast, and Moere is spoken inland from this, bordering the Kowaki and Musar areas on its southern side, and Barem to the east.

Mauwake is one of the best documented Northern Adelbert (and Papuan) languages, having been researched extensively by Liisa Berghäll and Kwan Poh San, who have produced a grammar (Berghäll 2015) and a dictionary (Järvinen (=Berghäll), Kwan \& Aduna 2001), as well as numerous manuscripts and articles, (Järvinen 1980, 1988, 1988b, 1989, 1990, 1991; Kwan 1980, 1983, 1988, 1989, 2002). Prior to the work of Berghäll and Kwan, the only primary data on Mauwake are from a short description in Capell (1952) and Z'graggen's work (1971a, 1975a 1980b). For Bepour and Moere, Z'graggen's work is the only published data available. Z'graggen's recordings of elicitation sessions with Bepour and Moere speakers have been digitized and made available online (1971b), and include more data than was published in the Bepour and Moere wordlists in Z'graggen (1980b), including additional vocabulary. Unfortunately, these recordings do not contain elicitations of full verb paradigms, so not much information can be gleaned on verbal morphology or the tense distinctions that are made in these languages.

In the rest of this section, I summarize the basics of phonology and verbal morphology for Mauwake, followed by a look at the phonology of Bepour and Moere. These sections are relatively short compared to the Tibor languages, for two reasons. First, there is less complex morphophonology in the Kumil languages, so it is usually readily apparant how surface forms relate to underlying forms. Second, a detailed description of verbal morphology in Bepour and Moere is not possible from the data available. In Z'graggen's (1971b) recordings of Bepour and Moere elicitation sessions, most of the

57 While not a northern Adelbert language, Amako is more distantly related. 
conjugated verb forms are in 3SG past or present, so unfortunately a more detailed analysis of the verb morphology of these languages is not possible. All of the Mauwake data and examples presented here are from Berghäll (2015).

\subsection{Mauwake}

\subsubsection{Mauwake phonemes}

Table 3.8.1a presents the Mauwake phoneme inventory.

Table 3.8.1a: Mauwake consonant phonemes

\begin{tabular}{|l|c|c|c|c|}
\hline & labial & alveolar & palatal & velar \\
\hline stop & $/ \mathrm{p} /, / \mathrm{b} /$ & $/ \mathrm{t} /, / \mathrm{d} /$ & & $/ \mathrm{k} /, / \mathrm{g} /$ \\
\hline nasal & $/ \mathrm{m} /$ & $/ \mathrm{n} /$ & & \\
\hline fricative & $/ \mathrm{f} /$ & $/ \mathrm{s} /$ & & \\
\hline liquid & & $/ \mathrm{r} /, / \mathrm{l} /$ & & \\
\hline glide & $/ \mathrm{w} /$ & & $/ \mathrm{y} /$ & \\
\hline
\end{tabular}

Voiced stops do not occur word-finally, are much less frequent than voiceless stops, and are not used in derivational or inflectional morphology (Berghäll 2015: 26). This restricted distribution of voiced stops in Mauwake is not surprising, given that Proto-Kumil $* \mathrm{~b},{ }^{*} \mathrm{~d}$ and, ${ }^{*} \mathrm{~g}$ merged with ${ }^{*} \mathrm{p},{ }^{*} \mathrm{t}$, and $* \mathrm{k}$ to become voiceless stops in Mauwake (see Chapter 9). There are no Mauwake words with voiced stops which can be shown to be directly inherited.

Mauwake is the only Kumil-Tibor language that has not merged PNA *r and *1. Mauwake reflexes are critical for disambiguating these two sounds in Proto-Kumil-Tibor reconstructions.

As in many other Northern Adelbert languages, Mauwake glides have voiced fricative allophones. For $/ \mathrm{w} /$, the fricative allophone is more likely to occur adjacent to unrounded vowels, and word-finally. For $/ y /$, there is dialectal variation of $[3 \sim \mathrm{j}]$.

All five Mauwake vowels have a length contrast, although this contrast is found only in wordinitial syllables. Berghäll analyzes long vowels as phonemically a sequence of two of the same vowel. 
In Mauwake, consonant clusters are only found word-medially, and are only found in words that are trisyllabic or longer. According to Berghäll (2015: 41), clusters are usually the result of elision of an unstressed vowel, which can sometimes be perceived in careful pronunciations.

\subsubsection{Mauwake verb morphology}

Mauwake has a three-way distinction between past, present and future tense. Unlike some Tibor languages, Mauwake does not have aspectual markers that precede the tense and subject markers. Instead, aspect is indicated by auxiliary verbs which follow the main verb.

Mauwake verb roots are inflected with tense- and subject-marking affixes. However, these are less fusional than most other Northern Adelbert languages, as they can be segmented into separate tense- and subject-marking morphemes.

Table 3.8.2a: Mauwake TAM-marking morphology

\begin{tabular}{|l|l|l|l|l|l|l|}
\hline & $1 \mathrm{SG}$ & $2 \mathrm{SG}$ & $3 \mathrm{SG}$ & $1 \mathrm{PL}$ & $2 \mathrm{PL}$ & $3 \mathrm{PL}$ \\
\hline Past & $-a-m$ & $-a-n$ & $-a-k$ & $-a-m i k$ & $-a-m a n$ & $-a-m i k$ \\
& $-e-m$ & $-e-n$ & $-e-k$ & $-e-m i k$ & $-e-m a n$ & $-e-m i k$ \\
\hline Present & $-i-y e m$ & $-i-n$ & $-i-y a$ & $-i-m i k$ & $-i-m a n$ & $-i-m i k$ \\
\hline Future & $-i-n e n$ & $-i-n a n$ & $-i-n o n$ & $-i-y e n$ & $-o-$ wen & $-i-k u a n$ \\
\hline Imperative & $-u$ (1dual) & $-e /(-a)$ & $-i n o k$ & $-i k u a$ & $-e k a /(-a k a)$ & $-u k$ \\
\hline
\end{tabular}

Past tense is indicated by the marker $-e /-a$. Which allomorph is used is determined by the verb's class. Verb class is largely, but not entirely, predictable from the phonological shape of the stem, and depends on both the last vowel and the final consonant of a stem ${ }^{58}$. Non-past is indicated by the marker $-i$, and is used in present and future tenses. The set of subject markers used in past and present tense are same, with the exception of the $3 \mathrm{SG}$, which has different forms $-k$ and $-y a$ for the past and present tenses, respectively. Future tense uses an entirely different set of subject-markers. Although the tense-

58 For more details, see Berghäll (2012: 47-49). 
and subject-marking affixes are separate, the subject-markers for the future tense can be considered fusional in the sense that the subject-marker alone is enough to indicate the future tense, since they take a different form than subject markers used in past and present tense. The same can be said of the $3 \mathrm{SG}$ subject markers for past and present. Additionally, the non-past marker for the 2PL future is irregular $o$.

Unlike most Northern Adelbert languages, Mauwake does not have object-marking prefixes. Rather, objects are expressed with pronouns that are independent words that precede the verb stem. However, Berghäll notes that the object pronouns often lose their final vowel, and seem to be undergoing cliticization (2015: 96).

Table 3.8.2a also illustrates the imperative markers for Mauwake. Unlike the imperatives presented for most other languages in this dissertation, different forms are given for each person/number combination, not just 2SG and 2PL. However, this may be simply because of a lack of data in other languages, as some Northern Adelbert languages have at least a 1PL imperative (or 'hortative') as well. Note that there is no 1SG imperative in Mauwake, but there is a contrast between first person dual and plural. The forms for the 2SG and 2PL usually have an initial vowel $e$, but this is irregularly $a$ for a handful of verbs.

\subsubsection{Morphophonological processes in Mauwake}

Berghäll (2015: 25) states, 'Allophonic variation in Mauwake is limited, and there is not much morphophonological complexity either'. This is quite unlike the Tibor languages, where the relationship between the underlying and surface forms of inflected verbs is often obscured by morphophonemic processes. However, there are two morphophonemic processes in Mauwake that have parallels in the Tibor languages. These are the deletion of $e$ following $a$, and $e$-rounding. 
$/ \mathbf{a}+\mathbf{e} / \rightarrow \boldsymbol{a}$

In Mauwake, a sequence of /a+e/ sometimes results in the deletion of $e$. This does not apply universally throughout the language, but is usually triggered by the beneficiary suffix - $a$ followed by any suffix beginning with $e$. This is illustrated in (382), where the initial $e$ in the different subject marker -eya is deleted following the beneficiary suffix $-a$.

(383) /aaw-om-a-eya/ $\rightarrow$ aawomaya get-BEN-BNFY2-2/3.DS

'get it for us, and...'

e-rounding

The past tense suffix $-e$ rounds to $o$ following a labial consonant, however, this is restricted to 2SG and 3SG persons, and does not apply for 1SG or plural person, as illustrated in (384-385).

Naturally, this also does not apply for verbs who take the past-tense marker $-a$.

laaw-e-k/ $\rightarrow$ aawok

get-PST-3SG

'She got it'

/aaw-e-m/ $\rightarrow$ aawem get-PST-1SG

'I got it'

\subsection{Bepour}

Table 3.8a presents the phoneme inventory of Bepour. This inventory is based off my own analysis of Z'graggen's Bepour wordlist (1980b) and recordings (1971b). Since the source of this information is, at most, a few individual speakers, it is not possible to know how representative their speech is of the language as a whole. 
Table 3.8a: Bepour consonant phonemes

\begin{tabular}{|l|c|c|l|c|}
\hline & labial & alveolar & palatal & glottal \\
\hline stop & $/ \mathrm{p} /$ & $/ \mathrm{t} /$ & & $/ \mathrm{r} /$ \\
\hline nasal & $/ \mathrm{m} /$ & $/ \mathrm{n} /$ & & \\
\hline fricative & $/ \mathrm{f} /$ & $/ \mathrm{s} /$ & & $/ \mathrm{h} /$ \\
\hline liquid & & $/ \mathrm{r} /$ & & \\
\hline glide & $/ \mathrm{w} /$ & & $/ \mathrm{y} /$ & \\
\hline
\end{tabular}

Bepour generally lacks voiced stops, but a voiced bilabial is found in burir 'axe', which is an obvious loan, with identical form found in many Northern Adelbert languages. Bepour is notable for having no velar consonants, but instead a glottal stop and fricative, which are derived from PNA * $g$ and $* \mathrm{k}$, respectively.

\subsection{Moere}

Table 3.10a presents the Moere phoneme inventory, based off my own analysis of Z'graggen's wordlist (1980b) and recordings (1971b).

Table 3.10a: Moere consonant phonemes

\begin{tabular}{|l|c|c|l|l|c|}
\hline & labial & alveolar & palatal & velar & glottal \\
\hline stop & $/ \mathrm{p} /, / \mathrm{m} \mathrm{p} /$ & $/ \mathrm{t} /, / \mathrm{n} \mathrm{t} /$ & & $/ \mathrm{k} /, /{ }^{\mathrm{n}} \mathrm{k} /$ & $/ \mathrm{P} /$ \\
\hline nasal & $/ \mathrm{m} /$ & $/ \mathrm{n} /$ & & & \\
\hline fricative & $/ \mathrm{f} /$ & $/ \mathrm{s} /$ & & & \\
\hline liquid & & $/ \mathrm{r} /$ & & & \\
\hline glide & $/ \mathrm{w} /$ & & $/ \mathrm{y} /$ & & \\
\hline
\end{tabular}

Moere has a distinction between voiceless and prenasalized voiceless stops. The latter are the reflexes of PNA voiced stops. Prenasalized voiceless stops are found both intervocalically, and wordinitially in words which historically had an initial vowel, for example mpir 'plate' < Proto-Kumil *ebir. The word-final allophone of $/{ }^{\mathrm{p}} \mathrm{k} /$ is a velar nasal. Some words also have a velar nasal word-medially, for example fungum 'hair' ([fuyum]), and mangen 'right' ([mayen]). I analyze this as an allophone 
of $/{ }^{\mathrm{p}} \mathrm{k} /$, since it only occurs when the following stop is a nasal. ${ }^{59}$ The glottal stop is only found in wordfinal position, and other stops are either rare or unattested word-finally.

59 Only one word, mengkem 'woman', does not follow this pattern, as a nasal is expected instead of a prenasalized stop. 


\section{Numugen languages}

The six Numugen languages (Usan, Yaben, Karian, Parawen, Ukuriguma, and Yarawata), are spoken in a mountainous inland area surrounding the Numugen river, and are the southernmost Northern Adelbert languages. They are mostly surrounded by languages that do not belong to Northern Adelbert, but are likely more distantly related. Pal and Kobol are spoken to their east, and Mabuso languages are spoken to their southwest. The rough terrain of the Adelberts divides the Numugen languages from the coastal Northern Adelbert languages Barem, Malas and Gavak. A trip to the coast takes several days on foot.

Usan is the northernmost Numugen language, and the only one which borders another Northern Adelbert language outside the Numugen subgroup, with Mokati to its north. The largest Usan settlement is Wanuma, which is also the name that Z'graggen uses to refer to the language. Reesink (1987) estimated 1400 speakers of Usan at that time.

To the south of Usan is the closely related Yaben, with an estimated 700 speakers (Eberhard, Simons, \& Fennig 2020). ${ }^{60}$ To the south of Yaben territory is Parawen, with an estimated 430 speakers in 1981, and to the northwest of this are the smaller areas of Yarawata and Ukuriguma, with estimated speaker populations of 130 and 170, respectively, in 2003 (Eberhard, Simons, \& Fennig 2020). To the east of these, is Karian, the smallest Numugen language, which Ethnologue lists as having a speaker population of 30 in 2000 (Eberhard, Simons, \& Fennig 2020). It is bordered by the Mabuso languages Mosimo and Wamas.

While Karian is somewhat geographically removed from Usan and Yaben, it seems to have a closer relationship with these two Numugen languages, as it shares more cognates with them. On the

60 The map in Z'graggen (1980b) also shows a small Yaben exclave on the other side of the mountains, closer to the coast. This is probably meant to represent the village of Yambarik, which is in fact inhabited by speakers of a different language, Yamben, that is similar in name only. Yamben is not a Northern Adelbert language, but is probably distantly related (Pick 2018). 
other hand, there are numerous word sets with cognates only in Parawen, Ukuriguma, and Yarawata. Thus, these may form two subgroups within Numugen (see Chapter 10).

Below, I outline the basics of phonology and verbal morphology for Usan, Karian, and Yaben. The data on Parawen, Ukuriguma, and Yarawata is limited to the wordlist in Z'graggen (1980b), so a description of the verbal morphology of these language is not possible, and I present only a phoneme inventory and some brief observations on their phonologies.

\subsection{Usan}

Usan is the best documented of the Numugen languages. Reesink has produced an Usan grammar (1987) as well as a number of articles which focus on Usan, (Reesink 1981, 1983, 1993). Prior to Reesink's work, Z'graggen $(1975,1980 b)$ were the only publications on Usan. There are also some Usan language materials produced by SIL, including Bible translations and children's books. Lexical data used in this dissertation come from Z'graggen (1980b), Reesink's Usan (1987) grammar, and a wordlist compiled by Reesink (n.d.). All information on Usan phonology and grammar presented here are summarized from Reesink (1987).

\subsubsection{Usan phonemes}

Tables 4.1.1a-b present the Usan phoneme inventory. Major allophones of each phoneme are discussed below. For information on morphophonological processes in Usan, see Chapter 2 of Reesink (1987). 
Table 4.1.1a Usan vowel phonemes

\begin{tabular}{|l|c|c|c|}
\hline & front & central & back \\
\hline high & $/ \mathrm{i} /$ & & $/ \mathrm{u} /$ \\
\hline mid & $/ \mathrm{e} /$ & $/ \mathrm{\partial} /(<\mathrm{a}>)$ & $/ \mathrm{o} /$ \\
\hline low & & $/ \mathrm{a} /$ & \\
\hline
\end{tabular}

Table 4.1.1b: Usan consonant phonemes

\begin{tabular}{|l|c|c|l|l|l|}
\hline & labial & alveolar & palatal & velar & glottal \\
\hline stop & $/ \mathrm{p} /, / \mathrm{b} /, / \mathrm{m} \mathrm{b} /$ & $/ \mathrm{t} / / \mathrm{d} /, / \mathrm{n} \mathrm{d} /$ & & $/ \mathrm{g} /, / \mathrm{g} \mathrm{g} /$ & $/ \mathrm{P} /$ \\
\hline nasal & $/ \mathrm{m} /$ & $/ \mathrm{n} /$ & & & \\
\hline fricative & & $/ \mathrm{s} /$ & & & \\
\hline glide & $/ \mathrm{w} /$ & & $/ \mathrm{y} /$ & & \\
\hline
\end{tabular}

/b/ optionally lenites to a fricative intervocalically, and /g/ optionally lenites to a fricative both intervocalically and word-finally. /d/ is realized as an alveolar flap after a vowel, while [d] is found word-initially. Unlike lenition of $/ \mathrm{b} /$ and $/ \mathrm{g} /$, lenition of $/ \mathrm{d} /$ to a flap is not optional. Prenasalized voiced stops are not found word-initially. They contrast with plain voiced stops word-medially and word-finally. Reesink provides some evidence from morphological alternations that [g] and [d] should be analyzed as word initial allophones of $/{ }^{n} \mathrm{~g} /$ and $/{ }^{\mathrm{n}} \mathrm{d} /$, respectively, at least for some words. As I illustrate in Chapter 10, the regular reflex of Proto-Numugen voiced stops are plain voiced stops in Usan. It is not clear how the distinction between plain voiced and prenasalized voiced stops arose.

The glottal stop (a reflex of Proto-Numugen *k) is only found word initially, and is lost when a word with initial glottal stop is prefixed or found as the second element of a compound (Reesink 1987: 27).

Vowel sequences may be complex nuclei or separate syllables (Reesink 1987: 12). There is a contrast between long and short vowels, for example moon 'wind' vs 'mon' house. This is a result of a loss of medial *k, as in *makwan 'wind' > moon. 
Reesink notes that the mid-central vowel-final $\hat{a}$ is much less frequen than $a$, and the functional load of the contrast between the two is low. However, there are clear minimal pairs, such as mani 'snake' and mâni 'yam'. For more on the development on the contrast between these two vowels, see Chapter 10 .

I follow the orthography for Usan used by Reesnink (1987), which uses the symbol < â $>$ for schwa and $<\mathrm{q}>$ for glottal stop.

\subsubsection{Usan verbal morphology}

The subject/tense markers for final Usan verbs are presented in Table 4.1.2. Forms in parentheses are used by certain verb classes instead of the standard forms.

Table 4.1.2: Usan subject/tense markers

\begin{tabular}{|c|c|c|c|c|c|c|}
\hline & $1 \mathrm{SG}$ & $2 \mathrm{SG}$ & $3 \mathrm{SG}$ & 1PL & $2 \mathrm{PL}$ & $3 \mathrm{PL}$ \\
\hline Present & $\begin{array}{l}\text {-oum } \\
(- \text { aum })\end{array}$ & $-\hat{a} n$ & $-\hat{a}$ & $\begin{array}{l}\text {-oun } \\
(- \text { aun })\end{array}$ & $\begin{array}{l}\text {-oumon } \\
\text { (-aumon) }\end{array}$ & $\begin{array}{l}\text {-our } \\
\text {-aur }\end{array}$ \\
\hline Near Past & $-u m e i$ & -anei & $-a i$ & -unei & -umanei & -urei \\
\hline Far Past ${ }^{61}$ & $-V m e i$ & $\begin{array}{l}\text {-Vnei } \\
(- \text { amonei) }\end{array}$ & $\begin{array}{l}\text {-Vrei } \\
\text { (-amorei) }\end{array}$ & -Vminei & -Vmanei & -Vmirei \\
\hline Future & $-i b-\hat{a} m$ & $-i b-\hat{a} n$ & $-i b-\hat{a}$ & $-u b-$ oun & -ub-oumon & $-u b$-our \\
\hline $\begin{array}{l}\text { Uncertain } \\
\text { Future }\end{array}$ & $-n$ & -nen & $-n e r$ & $-n$ & -non & $-n o r$ \\
\hline
\end{tabular}

Usan has a distinction between present tense, near past (within the current day) and far past (before the current day). The future tense is used for events that are strongly expected to take place, while the uncertain future is used for events that are possible, but not strongly expected. Negated future events also employ the uncertain future affixes.

61 The initial vowel of the far past suffixes changes depending on verb class. 


\section{Usan verb classes}

Reesink analyzes Usan verbs as falling into seven main conjugational classes (with a few smaller subclasses of irregular verbs). The initial vowel in the far past tense suffixes is either $a, e$, or $o$, depending on the verb class, and a number of other affixes (not shown in Table 4.1.2a) also have somewhat different forms for verbs of different classes. Another difference between verb classes is that certain classes have multiple different stems that are related to each other according to different patterns. For example, the class 4 verb 'go up' has the stems ir- and iro-, and the class 6 verb 'hide' has the stems wabi- and wabim-, while the class 2 verb 'spear' has only one invariant stem, gum-. The division of verbs into different classes which have different patterns of stem formation is also seen in Pamosu (see Chapter 3). Some Karian and Yaben verbs also have alternating stems, although there is not enough information to define clear classes for these languages.

Reesink also notes that some verbs, including 'hit' and 'give', have different stems depending on the direct object of the verb. This is seen also in Karian and Yaben, as well as other Northern Adelbert languages. ${ }^{62}$

\subsection{Karian}

The only previously published primary data on Karian comes from Z'graggen (1975, 1980b), who refers to the language as Bilakura. A 49-minute recording of a Karian elicitation session is available on PARADISEC (Z'graggen 1971b). Additional data comes from my own fieldwork with Karian speakers who now live in the Manep-speaking village of Malas, who I met with for a day each in 2017 and 2019. The Karian speakers I worked with come originally from the villages of Boia and Barto, which are a two to three day journey from Malas. These villages are no longer permanently 62 Reesink (1987:108) writes: 'wâb 'to shoot', wârâmb 'to hit', and utâb 'to give' change their stems considerably according to the person-number of their goals.' Unfortunately, he does not make clear what the forms of these stems are. 
inhabited, although the speakers I met make periodic trips to these areas. The Boia and Barto varieties are quite similar, differing mainly in the reflex of PNA*k, which is a velar stop $k$ in Boia, and a glottal stop in Barto. Both varieties have very few speakers, and Anton Ake, my main Karian consultant, is probably the only fluent speaker of the Boia variety. The analysis of Karian I present is based mainly on his speech. The Karian speaker in Z'graggen's (1971b) recording uses a variety that is closer to the Boia dialect, as he has $k$ rather than glottal stop.

\subsubsection{Karian phonemes}

Tables 4.2.1a-b present the Karian phoneme inventory.

Table 4.2.1a Karian vowel phonemes

\begin{tabular}{|l|c|l|c|}
\hline & front & central & back \\
\hline high & $/ \mathrm{i} /$ & & $/ \mathrm{u} /$ \\
\hline mid & & $/ \mathrm{\jmath} /$ & \\
\hline low & & & $/ \mathrm{a} /$ \\
\hline
\end{tabular}

Table 4.2.1b: Karian consonant phonemes

\begin{tabular}{|l|c|c|l|l|c|}
\hline & labial & alveolar & palatal & velar & glottal \\
\hline stop & $(/ \mathrm{p} /), / \mathrm{b} /$ & $/ \mathrm{t} /, / \mathrm{d} /$ & & $/ \mathrm{k} /, / \mathrm{g} /$ & $(/ \mathrm{\gamma} /)$ \\
\hline nasal & $/ \mathrm{m} /$ & $/ \mathrm{n} /$ & $/ \mathrm{ny} /$ & & \\
\hline fricative & & $/ \mathrm{s} /$ & $/ \mathrm{j} / 63$ & & \\
\hline liquid & & $/ \mathrm{l} /$ & & & \\
\hline glide & $/ \mathrm{w} /$ & & $/ \mathrm{y} /$ & & \\
\hline
\end{tabular}

The phoneme inventories of the Boia and Barto varieties are slightly different, as Boia has $/ \mathrm{k} /$ where Barto has $/ \mathrm{R} /$. /p/ is a loan phoneme found in a small number of words, such a papur 'rotten'.

In Karian, voiced stops are typically realized without prenasalization. However, nasal-stop sequences are found in some morphemes, including several which mark a direct object in some way. This includes object-marking prefixes, such as $i m b$ - 'PL.IDO', as well as verb stems for 'give', in which

63 While I have listed $j$ as a palatal fricative in Table $4.2 .1 \mathrm{~b}$, phonetically it seems to be closest to a postalveolar fricative [3]. 
the person/number of the direct object is included in the meaning, for example aind- 'give to $2 \mathrm{PL}$ '. I do not analyze these as prenasalized-voiced phonemes, as Reesink (1987) does for Usan, but rather as nasal-stop sequences, since in Karian there is little reason to consider them any different from nasalstop sequences which occur across morpheme boundaries, as in /worum+bə/ > worumbə 'kill-SS', for example.

Voiced alveolar stops are in complementary distribution with an alveolar tap $r$, as a result of a change from $* \mathrm{~d}>r$ after a vowel (see Chapter 10). Therefore $d$ and $r$ are analyzed as allophones of $/ \mathrm{d} /$.

The palatals $j$ and $n y$ contrast with their alveolar counterparts, for example gunyari 'black cockatoo' and unar 'mother', and juwur 'thigh' and durun 'root'. However, $j$ and ny are often realizations of underlying $/ \mathrm{d} /$ and $/ \mathrm{n} /$, which palatalize before $i$ (see morphonology section below). In some words, it is clear that a historic *i triggered palatalization and was later lost, as in *niaw 'breast' > nyuə, or *dibur 'shin' > juwur, which has undergone a sporadic change of $*_{i}$ to $u$ in the first syllable.

The alveolar fricative $/ \mathrm{s} / \mathrm{is}$ in near complementary distribution with $/ \mathrm{t} /$ and $/ \mathrm{k} /$, as $/ \mathrm{s} /$ almost always appears adjacent to a high front vowel, while /t/ and /k/ do not/ This is the result of a change of $*_{\mathrm{t}}$ and $* \mathrm{k}$ to $s$ in this environment. However, there are a small number of words which break this pattern, such as sukwa- 'to cut' and kiki 'crooked', resulting in a phonemic contrast between /s/ and /t/ and $/ \mathrm{k} / .^{64}$

The four-vowel system found in Karian (as well as the other Numugen languages described below) is atypical of a Northern Adelbert language, which, other than the Numugen languages, all have five-vowel systems. Although Karian lacks phonemic /e/ and /o/, these vowels are found as allophones of /a/ in surface forms (see below). /a/ sometimes reduces to [ə] in rapid speech.

$64 s u k w$ - is from Proto-Numugen *kikwa-, with a regular change of $* \mathrm{k}>\mathrm{s} \mathrm{i}$, followed by a sporadic change of $* \mathrm{i}>\mathrm{u}$. The origin of kiki 'crooked' is not know, and there are no cognates in the other Numugen languages. 


\subsubsection{Morphophonological processes in Karian}

\section{Palatalization}

The alveolars $/ \mathrm{d} /$ and $/ \mathrm{n} /$ become palatals $j$ and $n y$ before $i .^{65}$ This is illustrated in (401-402), where the past tense suffix $-i$ triggers palatalization of a final alveolar on the preceding subject marker. Compare this with the present tense conjugations in (403-404), where the final alveolars on the subject markers are followed by /a/, which does not trigger palatalization.

(401) /sukwa-min-i/ $\rightarrow$ sukwaminyi cut-1PL.NFUT-PST

'we cut it'

(402) /sukwa-ad-i/ $\rightarrow$ sukwaji cut-3SG.NFUT-PST

'he cut it'

(403) /sukwa-aku-min/ $\rightarrow$ sukwokumin cut-PRG-1PL.NFUT

'we're cutting it'

(404) /sukwa-ak-ad/ $\rightarrow$ sukwokar cut-PRG-3SG.NFUT

'he's cutting it'

$/ \mathbf{a} / \rightarrow \boldsymbol{o} / \mathbf{w}_{-}$

Underlying /a/ can be realized as $o$ following $w$.

(405) /igw-ak-an/ $\rightarrow$ igwokan be-PRG-1PL

'you are'

$\mid \mathbf{a} / \rightarrow \boldsymbol{e} / \mathbf{i}$

Underlying /a/ usually fronts and raises to $e$ before a high front vowel. This occurs both at morpheme boundaries, as in (406), and within a word, as in /tai/ 'short' $\rightarrow$ tei.

65 The voiceless stop $t$ is never found before $i$, and it is clear that historical $* \mathrm{t}>\mathrm{s} / \mathrm{i}$. However, there is no evidence for palatalization of $t>s$ as a synchronic rule. 
/sukwa-iwin/ $\rightarrow$ sukweivin

cut-SG.FUT

'I/he/she will cut'

\section{Final vowel epenthesis}

According to Z'graggen's recordings and transcripts ${ }^{66}$ of Karian and other Numugen languages, speakers commonly add an epenthetic final vowel to content words (at least in the context of the recorded elicitation sessions). The Karian speaker in his recordings sometimes adds an epenthetic $u$ or schwa to elicited nouns, as in /nuam/ 'tree' $\rightarrow$ nuam nuamu. The Karian speakers I worked with also sometimes added a final epenthetic $u$ or schwa, but much less frequently than the speaker in Z'graggen's recordings.

\subsubsection{Karian verb morphology}

Table 4.2.3a illustrates tense-and subject marking morphology for the Boia dialect of Karian. Some suffixes have two forms, one with initial $a$, and one with initial $ə$. Which suffix is used appears to depend on the verb stem, but more research is needed on this.

Table 4.2.3a: Karian (Boia) TAM markers

\begin{tabular}{|c|c|c|c|c|c|c|}
\hline & $1 \mathrm{SG}$ & $2 \mathrm{SG}$ & $3 \mathrm{SG}$ & $1 \mathrm{PL}$ & $2 \mathrm{PL}$ & $3 \mathrm{PL}$ \\
\hline Present & $-m$ & $\begin{array}{l}-a n \\
-\partial n\end{array}$ & $\begin{array}{l}-a r \\
-\partial r\end{array}$ & $-\min$ & $-m a n$ & $-m i r$ \\
\hline Past & $-m-i$ & $\begin{array}{l}-a n y-i \\
- \text { any- } i\end{array}$ & $\begin{array}{l}-a j-i \\
-\partial j-i\end{array}$ & $-m i n y-i$ & $-m a n y-i$ & $-m i j-i$ \\
\hline $\begin{array}{l}\text { Present } \\
\text { Prog }\end{array}$ & $-a k u-m$ & -ak-an & $-a k-a r$ & $-a k u-\min$ & -aku-man & -aku-mir \\
\hline Future I & \multicolumn{3}{|l|}{-ivin } & \multicolumn{3}{|l|}{$-u v u n$} \\
\hline Future II & $\begin{array}{l}-i n \\
-i n y-i \text { (NEG) }\end{array}$ & -inan inən & $\begin{array}{l}\text {-inar inər } \\
\text {-inəji (NEG) }\end{array}$ & $\begin{array}{l}\text {-un } \\
- \text { uni (NEG) }\end{array}$ & -unan & -unar unar \\
\hline IMP & & $-\varnothing$ & & & $-a r$ & \\
\hline
\end{tabular}

66 These final vowels are most common in isolated elicited forms in the recordings, and less common in running speech. Even for the languages for which Z'graggen's recordings are not available, it is clear that there is variation in this final vowel, as it is often transcribed in parenthesis by Z'graggen, indicating it is only sometimes present. 


\section{Karian past and present tenses}

Unlike its close relative Usan, Karian does not appear to make a tense distinction between recent past and remote past. Nor does it distinguish between hodiernal tense and past tense, as languages such as Pamosu and Barem do. Instead, it has a tense system more like Mauwake, with a distinction between past and present, where the past tense is used for an event at any time in the past. This is illustrated by the pair of sentences in (407-408), where sukwami 'I cut' has the same form when referring to an event the previous day, or on the morning of the current day.

$\begin{array}{lll}\text { bəbalimot } & \text { nuam } & \text { sukwa-m-i } \\ \text { morning 2SG } & \text { tree } & \text { chop-1SG.NFUT-PST }\end{array}$

'I chopped down a tree in the morning.'

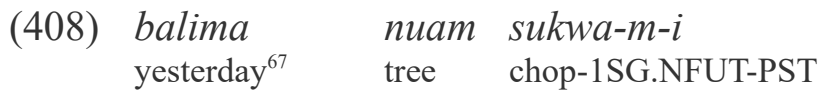

'I chopped down a tree yesterday.'

Karian is also similar to Mauwake in that the subject and tense markers are somewhat less fusional than other Northern Adelbert languages. The Karian past tense conjugations are formed by adding an additional suffix $-i$ to the present tense conjugation. Compare sikamin 'we come up' in (409) with the past tense form sikaminyi 'we came up' in (410). The present tense endings can therefore be analyzed as marking the person/number of the subject, as well as indicating non-future. Past tense is specified with the addition of the past tense marker $-i$.

(409) in sika-min

1PL come_up-1PL.NFUT

'We come.'

(410) in sika-miny-i

1PL come_up-1PL.NFUT-PST

'We came.'

67 This term, and its cognates in other Numugen languages, means both 'tomorrow' and 'yesterday'. 


\section{Karian future tense}

Karian is more similar to Usan when it comes to the future tense. The future tense markers are completely fusional, as it is not possible to further segment them into subject markers and future tense markers. Like Usan, Karian has two sets of future tense endings. The set labeled Future I in Table 4.2.3a is related to Usan's uncertain future markers, while the set labeled Future II is related to Usan's (regular) future tense markers (see Chapter 10). It is not clear if the distinction is Karian is also one of future vs. uncertain future. However, negated future events in Karian always use the Future I set, followed by the affix $-i$, as illustrated in (411). This suggests that Future I is equivalent to Usan's uncertain future, since negated future events in Usan use the uncertain future affixes, followed by -ei (see Chapter 10).

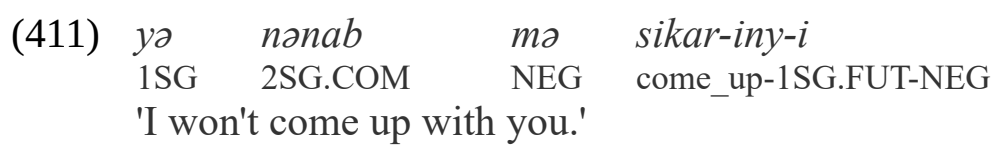

\section{Karian present progressive}

The present progressive is formed by suffixing the present tense markers -aku (before a consonant) and - ak (before a vowel) to the verb root, followed by the subject marker.

argia ij-ak-ar

where go-PRG-3SG.NFUT

'Where is she going?'

inyina munyai amor ij-aku-min
$1 \mathrm{PL}$ house $\quad$ inside go-PRG-1PL.NFUT
'We're going inside the house'

\section{Karian imperatives}

There is no overt marker for the $2 \mathrm{SG}$ imperative. The form of the $2 \mathrm{SG}$ imperative is the same as the bare verb root $^{68}$.

68 Or rather, it is the same as one of the bare verb roots, since many Karian verbs have multiple roots, as discussed below. 
(414) $y a r-\varnothing$

come-2SG.IMP

'Come!'

(415) bigum- $\varnothing$

sit-2SG.IMP

'Come!'

The 2PL imperative is formed with the suffix -ar.

yar-ar

come-2PL.IMP

'Come!'

\section{Karian switch reference}

Karian has a system of switch reference whereby a verb is inflected with a marker indicating whether the verb's subject and the subject of the following clause have the same referent or a different referent. Three switch reference markers have been identified in Karian: same subject marker - bə, and two different subject markers -arz and -inarz. The switch reference markers only occur on medial verbs, while the TAM markers in Table 4.2.3a only occur on final verbs.

The different subject marker -inarz is used when the medial verb has a first person subject (singular or plural), and the subject of the following verb is different, as in (417).

$\begin{array}{llllll}\text { balima } & \text { yə } & \text { totəria worum-inarə } & \text { na } & k a & \text { yam-əj-i } \\ \text { yesterday } & \text { 1SG } & \text { chicken kill-1.DS } & \text { mother } & \text { just } & \text { cook-3SG.NFUT-PST } \\ \text { 'Yesterday } & \text { i killed a chicken and mother cooked it.' }\end{array}$

The different subject marker -arz is used with both second and third person subjects, as in (418) and (419).

(418) balima yesterday $\begin{array}{llll}n a & k a & \text { totəria worum-arə } & \text { bainda ka } \\ \text { mother } & \text { just } & \text { chicken kill-2/3.DS } & \text { sister just }\end{array}$ yam-əj-i 'Yesterday mother killed a chicken and sister cooked it.'

$\begin{array}{llllll}\text { balima } & \text { no } & \text { totoria worum-aro } & \text { na } & k a & \text { yam-əj-i } \\ \text { yesterday } & \text { 2SG } & \text { chicken kill-2/3.DS } & \text { mother } & \text { just } & \text { cook-3SG.NFUT-PST } \\ \text { 'Yesterday you killed a chicken and mother cooked it.' }\end{array}$


When there is no change in subject between clauses, the same subject marker - bo is suffixed to the medial verb. - $b$ o is used with subjects of every person and number.

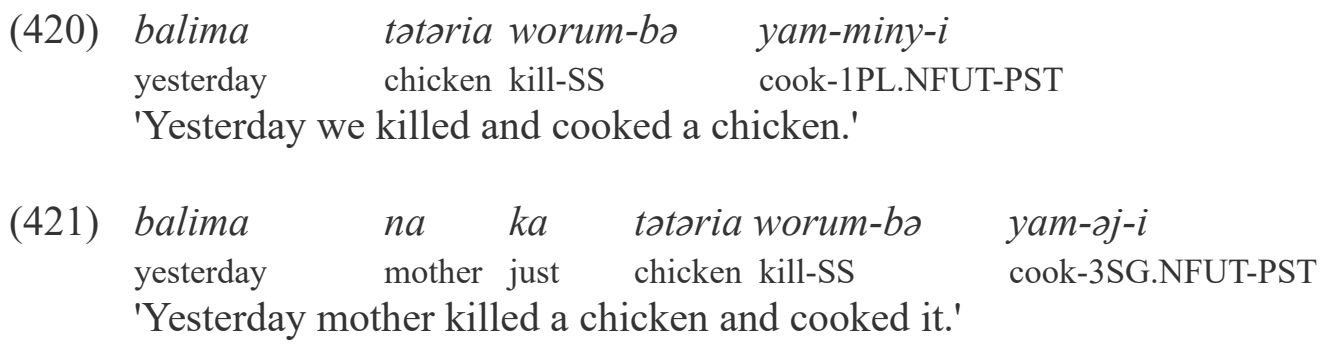

Usan switch reference markers follow a similar pattern. There is one same subject marker used for first, second, and third person subjects, and different subject markers are divided into first person and second/third person markers. However, the Usan different subject markers also distinguish singular and plural (Reesink 1987) ${ }^{69}$. Furthermore, there are also different forms for switch reference markers used with future tense. It is not clear if this distinction exists in Karian, as all the data on switch refernce comes from past tense conjugations.

\section{Karian verbs with multiple stems}

A number of Karian verbs have multiple stems, with different stems being used with different affixes. For example, 'to be' has the stems igwad-, used for future tense and imperative, and igw-, used with other tenses. For 'to call', $a$ - is used for past tense, and $a l$ - is used for all other conjugations. This is similar to the verb classes seen in Usan (see above). There is not enough data on verb paradigms in Karian to develop a clear picture of verb classes, but it is clear that different verbs pattern in different ways with regard to how the verb stems are formed, and which endings each stem pairs with.

69 See Reesink (1987) for a detailed description of Usan switch reference. It is not clear from the available data on other Numugen languages if they have switch reference systems as well. 
As in Usan (and other Northern Adelbert languages), Karian also has some verbs that use different stems depending on the person and number of the direct object. Three such verbs have been identified: 'to see', 'to give', and 'to hit'.

There are six roots for 'to see', one for each person/number combination. These are listed in Table 4.2.3b and illustrated in the examples below.

Table 4.2.3b: Karian verb stems for 'to see'

\section{ya ivaga-m-i \\ 1SG see_3PL-1SG.NFUT-PST}

'I saw them'

\begin{tabular}{|l|l|}
\hline 'see 1SG' & yəga- \\
\hline 'see 2SG' & nəga- \\
\hline 'see '3SG' & ga- \\
\hline 'see 1PL' & inyimbəga- \\
\hline 'see 2PL' & animbaga- \\
\hline 'see 3PL' & ivaga- \\
\hline
\end{tabular}

(423) уә bиә nәga-ivin

1SG again see 2SG-SG.FUT

'I'll see you again'

(424) yə an animbəga-m-i

1SG 2PL see_2PL-1SG.NFUT-PST

'I saw you'

The first syllable of some of the verb stems for 'to see' resembles the pronoun for the corresponding person/number of the object. For example, the first syllable in yəga-'see 1SG' is the same as the $1 \mathrm{SG}$ pronoun $y \partial$, and an '2PL' is the same as the first syllable in animbaga- 'see $2 \mathrm{PL}^{\text {'. }}{ }^{70}$ However, it is clear that the verb stems for 'to see' are not simply pronouns cliticized onto a shorter stem, as the pronoun referring to the object can co-occur with the stem, as in (424) above.

The verb 'to give' similarly has six different stems, shown in Table $4.2 .3 \mathrm{c}$ and illustrated in the examples below.

70 Unlike some other Northern Adelbert languages, Karian has a single set of pronouns for subjects and objects. 
Table 4.2.3c: Karian verb stems for 'to give'

\begin{tabular}{|l|l|}
\hline 'give 1SG' & is- \\
\hline 'give 2SG' & nət- \\
\hline 'give '3SG' & ut- \\
\hline 'give 1PL' & ind- \\
\hline 'give 2PL' & aind- \\
\hline 'give 3PL' & ir- \\
\hline
\end{tabular}

(425)

$\begin{array}{lll}\text { matakur } & \text { maya maya } & \text { ut-any-i? } \\ \text { coconut } & \text { how_many } & \text { give_3SG-2SG.NFUT-PST }\end{array}$

'How many coconuts did you give him?'

$\begin{array}{ll}\text { yuan } & \text { ind-aj-i } \\ \text { betel nut } & \text { give_1PL-3SG.NFUT-PST }\end{array}$

'She gave us betel nut'

The verb 'to hit' is even more elaborate, as it has two separate stems for each person/number combination-- one for future, and another for non-future conjugations. The full set of verb stems for 'to hit' is listed in Table 4.2.3d

Table 4.2.3d: Karian verb stems for 'to hit'

\begin{tabular}{|l|l|l|}
\hline & NFUT & FUT \\
\hline 'hit 1SG' & yən- & yənal- \\
\hline 'hit 2SG' & nən- & nənal- \\
\hline 'hit '3SG' & w- & wal- \\
\hline 'hit 1PL' & iningg- & ininggal- \\
\hline 'hit 2PL' & aningg- & aninggal- \\
\hline 'hit 3PL' & ig- & igal- \\
\hline
\end{tabular}

\subsection{Yaben}

The only published primary data on Yaben is Z'graggen $(1975,1980 b)$. Recordings of Yaben elicitation sessions are available on PARADISEC (Z'graggen 1971b), and provide additional lexical data and verb paradigms. My description of Yaben phonology and verb morphology is based primarily on these recordings. 
The speaker in Z'graggen (1971a) lists the names Kurukuguran and Kamiarum as the only two places that speak his particular language variety, and lists the place names Abia, Ilima 'uman, Balətə, and Magila ${ }^{71}$ as communities whose speech is different from his own dialect, but completely intelligible to everyone in his community.

\subsubsection{Yaben phonemes}

Table 4.3.1a Yaben vowel phonemes

\begin{tabular}{|l|c|c|c|}
\hline & front & central & back \\
\hline high & $/ \mathrm{i} /$ & & $/ \mathrm{u} /$ \\
\hline mid & & $/ \mathrm{a} /$ & \\
\hline low & & & $/ \mathrm{a} /$ \\
\hline
\end{tabular}

Table 4.3.1b Yaben consonant phonemes

\begin{tabular}{|l|c|c|l|l|}
\hline & labial & alveolar & palatal & velar \\
\hline stop & $/ \mathrm{b} /$ & $/ \mathrm{d} /, / \mathrm{t} /$ & & $/ \mathrm{k} /, / \mathrm{g} /$ \\
\hline nasal & $/ \mathrm{m} /$ & $/ \mathrm{n} /$ & & \\
\hline fricative & & $/ \mathrm{s} /$ & $/ \mathrm{j} /$ & \\
\hline liquid & & $/ \mathrm{r} /, / \mathrm{l} /$ & & \\
\hline glide & $/ \mathrm{w} /$ & & $/ \mathrm{y} /$ & \\
\hline
\end{tabular}

The velar stop / $/$ is often realized as a glottal stop, or even deleted entirely. The velar and glottal stop allophones seem to be in free variation, and some words are recorded with both allophones, for example /kuman/ 'nape' $\rightarrow$ kuman 'uman. Intervocalically, /k/ is nearly always realized as a glottal stop. /k/ does not appear word-finally.

There does not appear to be a phonemic distinction between voiced and prenasalized voiced stops, as these are in variation. For example, yagu 'this' has been recorded as [3agu zangu]. This variation is present even in careful pronunciations.

71 According to Reesink (1987), the language of Magila village is mutually intelligible with Usan. Most Magilan men speak fluent Usan, but less Usan men speak Magilan. 
$/ \mathrm{t} /$ and $/ \mathrm{s} /$ are in near complementary distribution, as /t/ never appears before $i$, and almost all instance of $/ \mathrm{s} /$ are before $i$. However, there are a few words where $s$ occurs before other vowels, like sa'il- 'split'.

The realization of intervocalic /b/ varies betwen a stop and a fricative $[\beta]$ or glide $[\mathrm{w}]$. This leads to potential ambiguity between $/ \mathrm{w} /$ and $/ \mathrm{b} /$ in this position. However, intervocalic $/ \mathrm{w} /$ is never realized as a stop. Word-initially and -finally, /b/ is usually voiced, but is sometimes devoiced, even when followed by an epenthetic vowel, as in /imap/ 'bowstring $>$ [imapu].

Yaben has clearly maintained a distinction between $* d$ and $* r$, unlike Usan and Karian. Also unlike Karian, palatalization of /d/ does not apply synchronically in Yaben. However, it did apply historically, as in Proto-Numugen *tadi $\rightarrow$ taji. The realization of the palatal fricative varies between alveolar and palatal.

As in many other Northern Adelbert languages, glides have both fricative and glide allophones. It is not clear what conditions the use of each allophone.

/a/ and /a/ clearly contrast in word-final position, as there are minimal pairs, for example $n a$ 'mother' and nə '2SG', and ya 'who' and yə '1SG'. However, in some words, there is variation between $a \sim$ when followed by a consonant, for example nənəlu nanalu '2SG.POSS'. In careful pronunciations, $a$ is more common. /a/ also has the allophone [e] before /i/, as in /tai/ 'short' $\rightarrow$ [tei]. Word-final /ai/ may also coalesce into [e].

In fast speech, word-final /ə/ is usually realized as [e] when the following word begins with /i/, for example /yə\#igumi/ 'I hear $\rightarrow$ [yeigumi]. 


\section{Epenthetic final vowel}

An epenthetic final $u$ is sometimes added to consonant-final content words, but this does not apply consistently. For example, /awan/ 'white' has been recorded as awan awanu, and /gugum/'all' as gugum gugumu. Epenthetic final vowels are not added to vowel-final words.

\subsubsection{Yaben verbal morphology}

Table 4.3.2a present Yaben TAM-marking morphology.

Table 4.3.2a Yaben TAM markers ${ }^{72}$

\begin{tabular}{|l|l|l|l|l|l|l|}
\hline & $1 \mathrm{SG}$ & $2 \mathrm{SG}$ & $3 \mathrm{SG}$ & $1 \mathrm{PL}$ & 2PL & $3 \mathrm{PL}$ \\
\hline Present & $-m$ & $-a n$ & $-a d$ & - min & - man & -mid \\
\hline Past & $-m-i$ & $-a n-i$ & $-a d-i$ & - min- $i$ & - man- $i$ & - mid-i \\
\hline $\begin{array}{l}\text { Present } \\
\text { Prog }\end{array}$ & $-a^{\prime}$ 'um & & $-a^{\prime} a d$ & $-a^{\prime}$ umin & & $-a^{\prime}$ umid \\
\hline Future & $-i n$ & - inan & - inad & - un & -unan & -unad \\
\hline IMP & & $-\varnothing$ & & & $-a d$ & \\
\hline
\end{tabular}

The Yaben TAM markers are very similar to the Karian TAM markers, both in form and

function. A major difference is that only one set of future tense endings is attested for Yaben. Like Karian, Yaben forms the past tense by suffixing $-i$ to the present tense conjugations, as illustrated by the pair of examples in (427-428). As with Karian, I analyze the present tense endings as nonfuture/subject markers. ${ }^{74}$

$$
\begin{aligned}
& \text { wo iju-ad } \\
& \text { 3SG go-3SG.NFUT } \\
& \text { 'He goes' }
\end{aligned}
$$

72 The TAM markers presented here should be considered tentative, as they are based on limited data. This is especially true of the present progressive forms, which are found only a few times in the Yaben recordings.

73 Conjugations in the 2SG and 2PL present progressive are not found in Z'graggen's Yaben recordings.

74 For both Karian and Yaben, it is not clear if the nonfuture/subject markers can felicitously be used for a past event without the addition of the past-tense marker $-i$. Since the analysis of these suffixes is based on elicited sentences with little context, it is not possible to define their precise semantics. It could also be possible that what I call the past tense marker is actually a perfective marker, for example. 
balima wo iju-ad-i

yesterday $\quad$ SSG go-3SG.NFUT-PST

'He went'

\subsection{Parawen}

The Parawen phoneme inventory is presented in Tables 4.4.a-b.

Table 4.4a Parawen vowel phonemes

\begin{tabular}{|l|c|c|}
\hline & front & back \\
\hline high & $/ \mathrm{i} /$ & $/ \mathrm{u} /$ \\
\hline low & & $/ \mathrm{a} /$ \\
\hline
\end{tabular}

Table 4.4b: Parawen consonant phonemes

\begin{tabular}{|l|c|c|l|l|}
\hline & labial & alveolar & palatal & velar \\
\hline stop & $/ \mathrm{b} /$ & $/ \mathrm{t} /, / \mathrm{d} /$ & & $/ \mathrm{k} /, \mathrm{g} /$ \\
\hline nasal & $/ \mathrm{m} /$ & $/ \mathrm{n} /$ & & \\
\hline glide & $/ \mathrm{w} /$ & & $/ \mathrm{y} /$ & \\
\hline
\end{tabular}

/b/ devoices word-finally, including before an epenthetic final vowel. $/ \mathrm{t} /$ is realized as a fricative [s] adjacent to $i$. While Karian and Yaben have at least at handful of words that illustrate a phonemic distinction between /t/ and /s/, there is no clear case for phonemic /s/ in Parawen.

/d/ has allophones [d] and [r], with the liquid allophone found postvocalically.

Parawen, along with its sister language Yarawata, has the smallest vowel phoneme inventory of any Northern Adelbert language, with only three vowels.

Most Parawen consonant-final words are recorded with a final vowel added. This epenthetic vowel is usually $a$, as in *ginam 'village' $>$ ginama, and *binat 'heavy $>$ binata. However, if the preceding vowel is $u$, then the final epenthetic vowel is $u$, as in *gugum 'cold' $>$ gugumu, and *gun 'louse' > gunu. Although most of Z'graggen's transcriptions have this final vowel, some words are recorded without a final vowel added, as in ilam 'belly' <*ilam, or with variation, as in unim(a) 'name' $<*$ unim. 


\subsection{Ukuriguma}

Table 4.5a Ukuriguma vowel phonemes

\begin{tabular}{|l|c|c|}
\hline & front & back \\
\hline high & /i/ & /u/ \\
\hline mid & & /o/ \\
\hline low & & /a/ \\
\hline
\end{tabular}

Table 4.5b: Ukuriguma consonant phonemes

\begin{tabular}{|l|c|c|l|l|}
\hline & labial & alveolar & palatal & velar \\
\hline stop & $/ \mathrm{b} /$ & $/ \mathrm{t} /, / \mathrm{d} /$ & & $/ \mathrm{k} /, / \mathrm{g} /$ \\
\hline nasal & $/ \mathrm{m} /$ & $/ \mathrm{n} /$ & & \\
\hline liquid & & $/ \mathrm{r} /$ & & \\
\hline glide & $/ \mathrm{w} /$ & & $/ \mathrm{y} /$ & \\
\hline
\end{tabular}

In Ukuriguma /b/ devoices word-finally. As in Parawen, [s] appears as an allophone of /t/ adjacent to a high front vowel.

Ukuriguma has a vowel phoneme inventory that is unique among the Northern Adelbert languages, which is the result of an unconditioned change of *e to $o$ (see Chapter 10). Unlike Parawen and Yarawata, there are not usually epenthetic final vowels in Ukuriguma.

\subsection{Yarawata}

Table 4.6a Yarawata vowel phonemes

\begin{tabular}{|l|c|c|}
\hline & front & back \\
\hline high & /i/ & $/ \mathrm{u} /$ \\
\hline low & & $/ \mathrm{a} /$ \\
\hline
\end{tabular}

Table 4.6b: Yarawata consonant phonemes

\begin{tabular}{|l|c|c|l|l|}
\hline & labial & alveolar & palatal & velar \\
\hline stop & $/ \mathrm{b} /$ & $/ \mathrm{t} /, / \mathrm{d} /$ & & $/ \mathrm{k} /, / \mathrm{g} /$ \\
\hline nasal & $/ \mathrm{m} /$ & $/ \mathrm{n} /$ & & \\
\hline liquid & & $/ \mathrm{l} /$ & & \\
\hline glide & $/ \mathrm{w} /$ & & $/ \mathrm{y} /$ & \\
\hline
\end{tabular}


Yarawata /b/ sometimes devoices word-finally, including when followed by an epenthetic final vowel. As in Parawen, [s] appears is an allophone of /t/ adjacent to a high front vowel.

Like Yaben and Parawen, Yarawata adds an epenthetic final vowel. This final vowel is usually $a$, as in *guan 'skin' > guana and *ilam 'belly' > ilama. If the preceding vowel is $u$, the epenthetic vowel can be $a$, as in *gugum 'cold' > guguma, but can also be $u$, as in *kum 'brain' > kumu. This is similar to the pattern seen in Parawen. In Yarawata, unlike Yaben and Parawen, final vowel epenthesis is not restricted to consonant final-words, but applies to vowel final words as well, as in *ununu 'dirty' $>$ ununua, and *ibi 'feces' > ibia. As with Parawen, in Z'graggen's transcriptions there is sometimes no final vowel, or variation is recorded, as in *gun 'louse' > gun, and *unim 'name' > unim(a). 


\section{Kaukombar languages}

The Kaukombar languages are the northernmost Northern Adelbert languages, spoken in coastal and inland areas to the northwest of the Kumil languages. The Kaukombar subgroup is a dialect continuum, and different authors have grouped Kaukombar varieties into different languages along different lines. Capell (1962) and Schebesta (1940) make no clear distinction between language and dialect in the group. Z'graggen divides the Kaukombar varieties into four languages on the basis of lexical similarity (or dissimilarity). He assigns these languages the names Pay, Pila, Saki and Tani, based off the word for 'word, speech' (1971a: 47) in each variety. May \& Loeweke (1982a, 1982b) identify four Kaukombar languages: Miani, Maiani, Mala, and Maia. These names come from the word for 'what' in each variety, and are the labels that speakers themselves use. May \& Loweke do not state how they arrived at this classification into four languages, but presumably they are simply following the labels used by speakers. However, this division is somewhat arbitrary, as it simply reflects speakers' practice of referring to their language by the word for "what", which is not an objective measure of similarity. Two varieties could have the same word for "what", but have other important differences. On the other hand, two varieites could have different words for "what", but otherwise be quite similar. As a case in point, Maia and Mala only have different words for "what" by virtue of Mala having undergone a conditioned sound change of intervocalic *y > l/ (Proto-Kaukombar *maya $>$ mala).

According to May \& Loweke (1982a, 1982b), Z'graggen's Pila and Saki are equivalent to inland and coastal varieties of Maia, and Z'graggen's Tani corresponds with two different languages, Miani and Maiani. Table 5a shows the correspondence that May \& Loeweke give for Z'graggen's labels and their own. 
Table 5a

\begin{tabular}{|l|l|}
\hline Z'graggen & May \& Loeweke \\
\hline Pay & Mala \\
\hline Pila & Maia (coastal) \\
\hline Saki & Maia (inland) \\
\hline Tani & Miani \\
\hline Tani & Maiani \\
\hline
\end{tabular}

Comparison of Z'graggen's recordings and wordlists with the data in May \& Loeweke (1982a, 1982b) make it clear that the variety Z'graggen calls Pay is in fact equivalent to the variety that May and Loeweke call Mala. It is also clear that Z'graggen's (1980b) Tani wordlist is based off of a speaker of Miani. ${ }^{75}$

However, the Kaukombar varieties that Z'graggen labels as Pila and Saki are not quite equivalent to the variety called Maia in SIL manuscripts. First of all, Z'graggen's Pila and Saki wordlists have words with initial $k$ which correspond with no initial consonant in the forms found in Hardin et al's (2007) Maia dictionary (as well as other SIL manuscripts), which is based on the speech of Wagedav village. For example, the words for 'mosquito' are Pila kasi, Saki kasi, and Maia asi. Second, Hardin's (2002) list of Maia-speaking villages largely corresponds with Z'graggen's (1975) list of Saki-speaking villages, but includes none of the names in his list of Pila-speaking villages. This suggests that Z'graggen's Saki and Hardin's Maia more or less overlap, but it is unclear whether the Pila villages are part of the same speech community.

75 Z'graggen's (1971b) recordings include sessions with a Maiani speaker as well, but this variety is not included in any of his published (1980b) wordlists. The consultant in these recording is from Simbine village, which May (1994) lists as one of the main Maiani-speaking villages. Miani and Maiani are lexically very similar, but easily distinguishable, since Maiani has no voicing distinction in the stops, while Miani does. Since the published wordlist is clearly from a Miani speaker, but a Maiani speaker is found in the archived recordings, it is clear that Z'graggen worked with speakers of both varieties. He apparantly deemed them sufficiently similar to include both under the label "Tani". 
Although Saki and Pila are both considered to be "Maia" by May \& Loewke (1982a, 1982b), they are just as distinct from each other as they are from any of the other Kaukombar varieties, at least according to Z'graggen's (1971a) lexicostatistical analysis of the Kaukombar varieties. He finds that $58 \%$ of the items on his wordlists for Pila (AKA coastal Maia) and Saki (AKA inland Maia) appear to be related to each other. This does not indicate a particularly closer resemblance between these two varieties as compared to others, since the percentages calculated for other pairings are in roughly the same range, as shown in Table $5 b$.

Table 5b: lexicostatistical similarity of Kaukombar varieties (Z'graggen 1971a)

\begin{tabular}{|l|l|}
\hline Pay-Pila (Mala-coastal Maia) & $58 \%$ \\
\hline Pay-Saki (Mala-inland Maia) & $50 \%$ \\
\hline Pay-Tani (Mala-Miani) & $61 \%$ \\
\hline Pila-Saki (coastal Maia-inland Maia) & $58 \%$ \\
\hline Pila-Tani (coastal Maia-Miani) & $44 \%$ \\
\hline Saki-Tani (inland Maia-Miani) & $52 \%$ \\
\hline
\end{tabular}

Despite the lexical differences between Saki, Pila, and Wagedav Maia, their phonologies are for the most part quite similar. However, in my reconstruction of Proto-Kaukombar (Chapter 11), I consider Z'graggen's Saki and Pila data separately from the Maia data in Hardin (2002) and other SIL works. The most important reason for this is that Saki and Pila retain reflexes of word-initial PNA *k, while the Maia variety recorded by Hardin usually does not. Table 5c summarizes the sources I have consulted for the following descriptions Kaukombar languages, and the labels used for that variety in each source. 
Table 5c: Sources of Kaukombar lexical data

\begin{tabular}{|l|l|}
\hline Language & Sources of data \\
\hline Maia (Pila) & Z'graggen (1980b) ("Pila" wordlist) \\
\hline Maia (Saki) & Z'graggen (1980b) ("Saki" wordlist) \\
\hline $\begin{array}{l}\text { Maia } \\
\text { (Wagedav) }\end{array}$ & Hardin et al (2007), Hardin (2002), May \& Loeweke (1982a-b) \\
\hline Miani & $\begin{array}{l}\text { Z'graggen (1980b) ("Tani" wordlist) } \\
\text { May \& Loeweke (1982a-b), May (1994b), "Miani" (1975), Capell (1952) ("Banar") }\end{array}$ \\
\hline Maiani & $\begin{array}{l}\text { Z'graggen (1971b) ("Tani" recordings) } \\
\text { May \& Loeweke (1982a-b), May (1994a), "Maiani" (1975) }\end{array}$ \\
\hline Mala & Z'graggen (1980b) ("Pay" wordlist), May \& Loeweke (1982a-b) \\
\hline
\end{tabular}

\subsection{Maia}

In this section I cover all three varieties which fall under the label "Maia". Where necessary, I distinguish between Maia (Pila), Maia (Saki), and Maia (Wagedav) (the variety found in Hardin 2002).

\subsubsection{Maia phonology}

Table 5.1.1a presents the Maia consonant phoneme inventory, which is the same for all three varieties. All Kaukombar varieties have the same five vowel system /i, u, e, o, a/.

Table 5.1a: Maia consonant phonemes

\begin{tabular}{|l|c|c|l|l|}
\hline & labial & alveolar & palatal & velar \\
\hline stop & $/ \mathrm{p} /, / \mathrm{b} /$ & $/ \mathrm{t} /, / \mathrm{d} /$ & & $/ \mathrm{k} /, / \mathrm{g} /$ \\
\hline nasal & $/ \mathrm{m} /$ & $/ \mathrm{n} /$ & & \\
\hline fricative & & $/ \mathrm{s} /$ & & \\
\hline liquid & & $/ \mathrm{r} /, / \mathrm{l} /$ & & \\
\hline glide & $/ \mathrm{w} /$ & & $/ \mathrm{y} /$ & \\
\hline
\end{tabular}

As mentioned above, Saki and Pila often have word-initial $k$ where Wagedav does not. However, $k$ is found word-initially in some Wagedav words, such as kabu 'short' (Pila koambu). 
In the Wagedav variety, voiced stops do not have prenasalization. For Pila and Saki, there appears to be variation between plain voiced and prenasalized voice stops, as Z'graggen transcribes both, but these do not correspond between the dialects in any regular way. Prenasalization is more common in his Pila transcriptions.

May and Loewke (1982a) include alveopalatal and labiovelar fricatives in their phoneme inventories of the Kaukombar languages. I have replaced these with glides $/ \mathrm{w} /$ and $/ \mathrm{y} /$ in the phoneme inventories I present for these languages.

Hardin outlines several morphophonological processess in Maia, some of which are general processes, and some of which are specific to particular morphemes. One salient process is the assimilation of morpheme-final /e/ to the following vowel within the same word.

/dame+mi/ $\rightarrow$ damimi

hear+1SG.PST

'I heard'

Assimilation does not apply within a morpheme, as in /egan/ $\rightarrow$ egan 'path'.

\subsubsection{Maia verb morphology}

Hardin (2002) analyzes the final suffixes on Maia verbs as fusional affixes marking subject and realis or irrealis mood, rather than subject and tense as in most other Northern Adelbert languages. The subject/mood markers are shown in Table 5.1.2a.

Table 5.1.2a: Maia (Wagedav) subject mood markers ${ }^{76}$

\begin{tabular}{|l|l|l|l|l|l|l|}
\hline & $1 \mathrm{SG}$ & $2 \mathrm{SG}$ & $3 \mathrm{SG}$ & $1 \mathrm{PL}$ & $2 \mathrm{PL}$ & $3 \mathrm{PL}$ \\
\hline $\mathrm{R}$ & $-m o$ & $-i a$ & $-a$ & $-m i$ & $-m e$ & $-m o$ \\
\hline IRR & $-i o$ & $-i n i$ & $-i d o$ & $-a r a v$ & $-i w e$ & - ito \\
\hline
\end{tabular}

76 There are also imperative and desiderative mood markers, not listed in Table 5.1.2a. 
According to Hardin, Maia verbs are also marked for aspect, with aspectual suffixes following the verb stem and preceding the subject/mood markers. Aspect markers include a null perfective marker $-\varnothing$, imperfective $-g \mathrm{~V}$, and prospective $-s \mathrm{~V}^{77}$. An example of a verb marked for realis mood and perfective aspect illustrated in (502), and realis mood with imperfective aspect is illustrated in (503).

$y a g=r a \quad$ gadi- $\varnothing-m i$

water=LOC come_down-PFV-1PL.R

'we came down to the water'

(503) gete-g-a

wait-IPFV-3SG.R

'she was waiting'

Verbs marked for realis mood and prospective aspect indicate future events that are expected to

occur.

(504) irebue-su- $a^{78}$

come-PROS-3SG.R

'she was waiting'

\subsection{Maiani}

\subsubsection{Maiani phonology}

Table 5.2.1a: Maiani consonant phonemes

\begin{tabular}{|l|c|c|l|c|}
\hline & labial & alveolar & palatal & velar \\
\hline stop & $/ \mathrm{p} /$ & $/ \mathrm{t} /$ & & $/ \mathrm{k} /$ \\
\hline nasal & $/ \mathrm{m} /$ & $/ \mathrm{n} /$ & & $(/ \mathrm{y} /)$ \\
\hline fricative & & $/ \mathrm{s} /$ & & \\
\hline liquid & & $/ \mathrm{r} /, / \mathrm{l} /$ & & \\
\hline glide & $/ \mathrm{w} /$ & & $/ \mathrm{y} /$ & \\
\hline
\end{tabular}


Maiani is one of the few Northern Adelbert languages which has only a single (voiceless) stop series. May and Loeweke (1982a) note that the velar nasal phoneme is rare, only found in a few words and names.

$\mathbf{t} \rightarrow \mathbf{s} / \mathbf{V}[+\mathbf{h i g h}]_{-}$

Morpheme-final /t/ is realized as s before high vowels, as in (505), and as $t$ before non-high

vowels, as in (506).

(505)

/it-ikemo/ $\rightarrow$ isikemo

bathe-1SG.PRS

'I bathe'

When /t/ is followed by any other vowel, it is realized as a stop.

(506) $/$ it-omo/ $\rightarrow$ itomo

bathe-1SG.PST

'I bathed'

Lenition of / $\mathrm{t} /$ is not triggered by following /i/ within the same morpheme, as in /uti/ $\rightarrow u t i$ 'banana'.

\subsubsection{Maiani verbal phonology}

Table 5.2.1a illustrates the Maiani subject/tense verb suffixes, as analyzed by May and Loeweke (1982b).

Table 5.2.2a: Maiani subject/tense markers

\begin{tabular}{|c|c|c|c|c|c|c|}
\hline & $1 \mathrm{SG}$ & 2SG & 3SG & 1PL & 2PL & 3PL \\
\hline PST & $-(i)$ kemo & $-(i) k i$ & $-(i) k e$ & $-(i)$ kemi & -(i)kemet & -(i)kemot \\
\hline PRS & $-a m o$ & $-a r o$ & $-a t$ & $-a m i$ & -amet & -amot \\
\hline FUT & - -emo & $-i a$ & $-a$ & $-e m i$ & -emet & -emot \\
\hline
\end{tabular}

May and Loeweke (1982b) analyze Maiani, Miani, and Mala as having a distinction between past, present, and future tense. The Maiani past tense affixes have initial $-i$ when suffixed to consonantfinal verb roots, which May \& Loeweke (1982b) analyze as an epenthetic vowel. These epenthetic 
vowels are also seen in the Miani and Mala subject/tense endings. The forms for the past tense and present tense suffixes are cognate with the Maia perfective+realis and imperfective + realis, respectively, and the future tense ending are possibly cognate with the Maia prospective+realis (see Chapter 11). It therefore seems possible that Miani, Maiani, and Mala could be analyzed along the same lines as Maia, with verb suffixes marking aspect and mood, rather than tense. At present, there is insufficient data on these languages to meaningfully compare the merits of either analysis.

The distinction between past, present, and future tense in Maiani is illustrated with (507-509) below.

(507) /ituw-kemo/ $\rightarrow$ ituwikemo go-1SG.PST

'I went'

(508) /ituw-amo/ $\rightarrow$ ituwamo

go-1SG.PRS

'I go'

(509) /ituw-emo/ $\rightarrow$ ituwemo

go-1SG.FUT

'I will go'

\subsection{Miani}

\subsubsection{Miani phonology}

Table 5.3.1a: Miani consonant phonemes

\begin{tabular}{|l|c|c|l|l|}
\hline & labial & alveolar & palatal & velar \\
\hline stop & $/ \mathrm{p} /, / \mathrm{b} /$ & $/ \mathrm{t} /, / \mathrm{d} /$ & & $/ \mathrm{k} /, \mathrm{g} /$ \\
\hline nasal & $/ \mathrm{m} /$ & $/ \mathrm{n} /$ & & \\
\hline fricative & & $/ \mathrm{s} /$ & & \\
\hline liquid & & $/ \mathrm{r} /$ & & \\
\hline glide & $/ \mathrm{w} /$ & & $/ \mathrm{y} /$ & \\
\hline
\end{tabular}

Miani voiced stops are realized without prenasalization. 
$\mathbf{t} \rightarrow \boldsymbol{t} \sim \boldsymbol{S}$

As in Maiani, $t$ and $s$ alternate, depending on the quality of the following vowel as illustrated by the pair of verbs below.

(510) /it-egemo/ $\rightarrow$ isegemo

bathe-1SG.PRS

'I bathe'

/it-amo/ $\rightarrow$ itamo

bathe-1SG.PST

'I bathed'

May and Loeweke (1982a) claim that the $t$ allomorph occurs befor low vowel /a/, while $s$ occurs before mid and high vowels. However, they present some alternations where $t$ is found before $o$-initial affixes. It is more likely that front vowels or high vowels, rather than non-high vowels, trigger lenition of $t$ to $s$, but this is not clear from the data in May and Loweke (1982a, 1982b)

\subsubsection{Miani verb morphology}

Table 5.3.2a illustrates the Miani subject/tense markers. These forms closely resemble the Maiani subject/tense markers, and they pattern in the same way. The initial vowel of the past tense suffixes only appears when attached to consonant-final stems. Whereas in Maiani this vowel is always $i$, in Miani it mirrors the quality of the following vowel.

Table 5.3.2a: Miani subject/tense markers

\begin{tabular}{|c|c|c|c|c|c|c|}
\hline & $1 \mathrm{SG}$ & 2SG & 3SG & 1PL & 2PL & 3PL \\
\hline PST & $-(e)$ gemo & $-(i)$ gia & $-(e)$ gea & $-(i)$ gimi & $-(e)$ geme & -(e)gemod \\
\hline PRS & $-a m o$ & $-a$ & $-a n$ & $-a m i$ & $-a m e$ & -amod \\
\hline FUT & $-e m o$ & $-i a$ & $-e a$ & $-i m i$ & $-e m e$ & -emod \\
\hline
\end{tabular}




\subsection{Mala}

\subsubsection{Mala phonology}

Table 5.4a: Mala consonant phonemes

\begin{tabular}{|l|c|c|c|}
\hline & labial & alveolar & velar \\
\hline stop & $/ \mathrm{p} /, / \mathrm{b} /$ & $/ \mathrm{t} /, / \mathrm{d} /$ & $/ \mathrm{k} /, / \mathrm{g} /$ \\
\hline nasal & $/ \mathrm{m} /$ & $/ \mathrm{n} /$ & $/ \mathrm{y} /$ \\
\hline liquid & & $/ \mathrm{r} /, / \mathrm{l} /$ & \\
\hline glide & $/ \mathrm{w} /$ & & \\
\hline
\end{tabular}

My phoneme inventory for Mala differs from that proposed by May and Loeweke (1982a) in a few ways. First, they include an alveolar fricative /s/, which I analyze as an allophone of /t/. They state that $/ \mathrm{s} /$ and $/ \mathrm{t} /$ are in complementary distribution prevocalically, with /s/ occuring before high vowels, and /t/ occuring before low and mid vowels. They claim /s/ contrasts with /t/ only wordfinally. However, the examples they give for word-final /s/ are in fact all verb roots, which are obligatorily suffixed. In this position, a root-final $/ \mathrm{t} /$ is realized as $[\mathrm{s}]$ when the following suffix begins with a high vowel. Second, I include /w/, while they have a bilabial fricative instead. This is largely a matter of preference, since this phoneme has both glide and fricative allophones. Third, they include a prenasalized voiced stop series in addition the plain voiced stops. An editor's footnote states: The vast majority of voiced and prenasalized stops in Mala appear to follow this rule: Voiced stops appear realised with prenasalisation unless another voiced stop appears in the immediate environment. May and Loeweke decided agains this analysis on the basis that it does not seem to have a phonological basis' (May \& Loeweke 1982a: 4). As discussed in Chapter 1, this same pattern is found in other Northern Adelbert languages, such as Barem and Manep, and should not be discounted. Furthermore, in Z'graggen's Mala recordings, there is variation in the pronunciation of voiced stops. Some speakers tended to pronounce them with prenasalization, while others tended to pronounce them without, even when no other voiced stops were in the environment. 
Mala is unique among Northern Adelbert languages in lacking a palatal glide phoneme. This is the result of two changes, deletion of word-initial glides and a change of $* y>l$ intervocalically (see Chapter 11). Mala is also one of only a few Northern Adelbert languages which allow word-initial $n g$. In Mala, this is a reflex of PNA *k. However, it seems to be in the process of merging with $/ \mathrm{n} /$, as some words reflecting word-initial *k are recorded with $n$, not $n g$, for example, *kamar 'sago' > namar.

\subsubsection{Mala verb morphology}

Table 5.4.2a illustrates the Mala subject/tense markers. Mala has the same past, present, and futture tense distinction found in Maiani and Miani. As in these languages, an epenthetic $i$ is added before the past tense suffixes when they follow a consonant-final stem.

Table 5.4.2a: Mala subject/tense markers

\begin{tabular}{|c|c|c|c|c|c|c|}
\hline & $1 \mathrm{SG}$ & $2 \mathrm{SG}$ & $3 \mathrm{SG}$ & $1 \mathrm{PL}$ & $2 \mathrm{PL}$ & 3PL \\
\hline PST & $-(i) k e m$ & $-(i) k i a$ & $-(i) k a$ & $-(i) k e m i$ & $-(i) k a m a$ & $-(i) k o m$ \\
\hline PRS & $-e m$ & $-i a$ & $-a$ & $-e m i$ & $-a m a$ & - om \\
\hline FUT & $-e k$ & $-i$ & $-o k$ & $-u n e$ & $-u a$ & - ue \\
\hline
\end{tabular}




\section{Gavak}

Gavak is spoken southeast of the Gilagi river, which separates it from the Waskia-speaking area. The Gavak-speaking area extends about five miles southeast of the Gilagi, and several miles inland toward the northern Adelbert Mountains. It is bordered to the southeast by the Papuan languages Garus and Bargam, as well speakers of the Austronesian language Takia who live along the coast. According to Ethnologue's 2000 census, there were 3,820 Gavak speakers at the time (Eberhard, Simons \& Fennig 2020). According to this same census, all adults used Gavak at the time, while some children were unable to speak. In my own brief visits to Gavak-speaking areas in 2017-2018, I gained the impression that Gavak was the primary language for adults older than around thirty. It is also not uncommon to encounter Waskia speakers who were conversant in Gavak.

This chapter is based primarily on my own fieldwork in the summers of 2017-2018. In 2017, I visited the Gavak-speaking community of Dimir for one day, when I met with community leaders and collected a Gavak wordlist. I did not work with Gavak speakers again until the following summer, when I worked with Gabriel Lamuk Sr., Gabriel Lamuk Jr., and Valentine Laut, who would visit me in the home I was staying in on the Waskia side of the Gilagi river. Gabriel Lamuk Jr. spent many hours with me translating my Tok Pisin prompts into Gavak words and sentences. We recorded Gabriel Lamuk Sr. and Valentine Laut telling Gavak narratives, which Gabriel Lamuk Jr. worked with me to transcribe and translate. Prior to my own work, the only published data on Gavak was the wordlist in Z'graggen (1980b).

This chapter aims to provide an overview of the basics of Gavak phonology and morphology, with two broader goals in mind. First, to provide a deeper description of this language than was previously available, despite the fact that this chapter only describes the very essentials of Gavak 
phonology and morphology. Second, to provide the background necessary to understand my classification of Gavak as a primary branch of Northern Adelbert, and understanding the sound changes which have taken place. The structure of the rest of this chapter is as follows. Section 6.1 discusses the Gavak phonemes and their major allophones. Section 6.2 discusses Gavak syllable and word structure, and section 6.3 outlines Gavak morphophonological processes. Section 6.4 presents an overview of Gavak morphology.

\subsection{Gavak phonemes}

Table 6.1a: Gavak vowel phonemes

\begin{tabular}{|l|c|c|}
\hline & front & back \\
\hline high & $/ \mathrm{i} /$ & $/ \mathrm{u} /$ \\
\hline mid & $/ \mathrm{e} /$ & $/ \mathrm{o} /$ \\
\hline low & & $/ \mathrm{a} /$ \\
\hline
\end{tabular}

Table 6.2b: Gavak consonant phonemes

\begin{tabular}{|c|c|c|c|c|}
\hline & labial & alveolar & palatal & velar \\
\hline stop & $/ \mathrm{p} / / \mathrm{b} /$ & $/ \mathrm{t} / / \mathrm{d} /$ & & $/ \mathrm{k} / / \mathrm{g} /$ \\
\hline nasal & $/ \mathrm{m} /$ & $/ \mathrm{n} /$ & & $/ \mathrm{y} /$ \\
\hline fricative & & $/ \mathrm{s} /$ & & \\
\hline trill & & $/ \mathrm{r} / / \mathrm{l} /$ & & \\
\hline glide & $/ \mathrm{w} /$ & & $/ \mathrm{y} /$ & \\
\hline
\end{tabular}

\section{Vowels}

Gavak has five vowels /i, u, e, o, a/ The most common vowel sequences are /ai/ and /au/.

\section{Obstruents}

Gavak has voiced and voiceless labial, alveolar, and velar stops. In general, voiced stops do not contrast with homorganic nasal-stop sequences. The realization of /g/ varies between plain voiced and 
prenasalized voiced, as in /nag+er/ 'he went' $\rightarrow$ [nager $\sim$ nanger]. Voiced labial and alveolar stops generally do not occur intervocalically or word-finally, as PNA *b and *d lenited to $w$ and $r$, respectively, in these positions (see Chapter 7). However, in the few words that do have intervocalic voiced labial or alveolar stops, these are always prenasalized, and are therefore analyzed as underlyingly a single phoneme $/ \mathrm{b} /$ and $/ \mathrm{d} /$, rather than clusters $/ \mathrm{mb} /$ or $/ \mathrm{nd} /$.

\section{Nasals}

Gavak has three nasals, $/ \mathrm{m} /, / \mathrm{n} /$, and $/ \mathrm{y} /$. Gavak is one of the few Northern Adelbert languages, along with Mala, which allows /y/ word-initially. It is also the only Northern Adelbert language to regularly retain a distinction between $\mathrm{PNA} * \mathrm{n}$ and $*_{\mathrm{y}}$.

\section{Liquids}

Gavak has two liquids, $/ \mathrm{r} /$ and $/ 1 /$. Although these are phonemically distinct, underlying /r/ surfaces as [1] in some environments (see Section 6.3). The realization of final $/ \mathrm{r} /$ is sometimes realized as [t] on some affixes, for example -mer 'SG' [mer met] and -kut 'SG' [kur $\sim \mathrm{kut}]$.

\section{Glides}

Gavak has a labiovelar glide /w/ and a palatal glide /y/. The phonetic realization of the labiovelar glide varies from a glide to a bilabial fricative $[\beta]$.

\section{Orthography}

Gavak has no standard orthography. I adopt the same general orthography I have used for most of the Northern Adelbert languages throughout this dissertation. Where phonemic distinctions are neutralized, the surface form is represented in the orthography. For example, underlying /g/ devoices 
before $/ \mathrm{t} /$, as in $/$ nag + to $/ \rightarrow$ [nakto], and this is written as $<$ nakto $>$. Prenasalization on intervocalic $/ \mathrm{b} /$ and $/ \mathrm{d} /$ is also represented with $<\mathrm{mb}>$ and $<$ nd $>$.

\subsection{Gavak syllable and word structure}

Gavak syllables have the structure $(\mathrm{C}) \mathrm{V}(\mathrm{C})$. The large majority of Gavak monomorphemic words are one or two syllables. However there a few apparantly monomorphemic words of three syllables, such as kurumo 'tomorrow', and umutkom 'husband'. Polymorphemic words of three and four syllables are common for both nouns and verbs.

While there are many Gavak words beginning with /i/, /u/, and /a/, words generally cannot begin with mid vowels /e/ or /o/. The single documented exception is okoyo 'five'. The liquid /r/ is also not found in word-initial position.

The voiced stops /b/, /d/, and /g/, as well as the fricative /s/ and the glides /w/ and /y/, are not found in coda position, either word-finally or word-medially.

Several types of consonant clusters are allowed word-medially, including heterorganic stop clusters, as in lapding 'cockatoo' and aptiken 'clouds', heterorganic nasal-stop and stop-nasal clusters, as in kamdim 'old' and yepne 'branch', as well as heterorganic nasal clusters, as in wengne 'village' and gamnak 'middle'. There are also clusters with /s/ as the second element, as in kelsup 'body' and amsor'to break'. Although both liquids are allowed as syllable onsets (although $/ \mathrm{r} /$ is not found wordinitially), they do not appear as onsets if there is a coda in the previous syllable (in other words, as the second element of a consonant cluster). Liquids can, however, appear as the first element in a consonant cluster, as in bargot 'caretaker' and kelsup 'body.

Vowel hiatus is permitted, but generally only occurs at morpheme boundairies, as in /wani+am/ 'net_bag+PL' $\rightarrow$ [wa.ni.am]. 


\subsection{Morphophonoligical processes in Gavak}

This section outlines some of the morphophonological processes that apply in Gavak word formation.

\section{Vowel insertion}

An epenthetic vowel is inserted between a consonant-final verb stem and a consonant-initial past tense suffix (-ngeng, -nger, -min, -men, or -mit). The quality of the epenthetic vowel is determined by two factors: the quality of the preceding vowel in the verb stem, and the number of consonants at the end of the verb stem. If the preceding vowel in the verb stem is a high vowel $(/ \mathrm{i} / \mathrm{or} / \mathrm{u} /)$ followed by a single consonant, then the epenthtic vowel has the same quality as the preceding vowel.

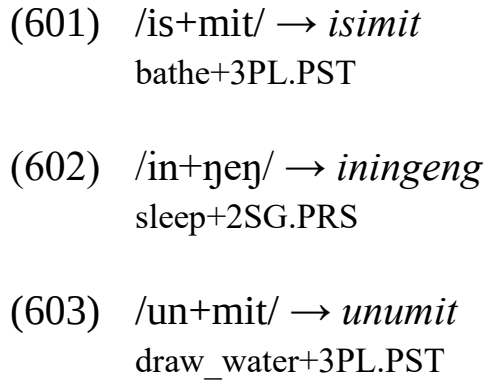

If the preceding vowel is a low or mid vowel (/a/, /e/, or /o/), then $a$ is inserted, as in (604-607).

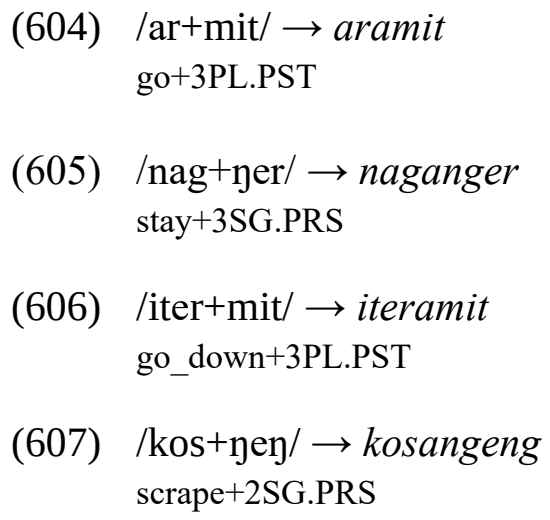

If the verb stem ends in more with one consonant segment, then $a$ is inserted, no matter what the quality of the preceding vowel is. 
(608) $\quad$ /ins + mit/ $\rightarrow$ insamit

shoot+3PL.PST

(609) $/ \mathrm{kapt}+\mathrm{min} / \rightarrow$ kaptamin

cut+1PL.PST

An exception to vowel insertion occurs when -ngeng '2SG.PRS' and -nger '3SG.PRS' are suffixed to a $w$-final polysyllabic verb-root ${ }^{79}$. In this case, root-final $w$ deletes and there is no epenthetic vowel (e-rounding, described below, also applies to the vowel in the suffix).

(610) $/$ saraw+yey/ $\rightarrow$ sarangong

ache+2SG.PRS

(611) $/$ dirow + ner/ $\rightarrow$ dirongor

carry+3SG.PRS

If the verb stem does not contain any vowels, then $a$ is inserted.

(612) $/ \mathrm{g}+\mathrm{min} / \rightarrow$ gamin

see+1PL.PST

(613) /n+ney/ nangeng

eat+2SG.PRS

As a result of vowel insertion, the surface forms for the $2 \mathrm{PL}$ and $3 \mathrm{PL}$ past tense conjugations are homophonous with the 2PL and 3PL future tense conjugations for those verb stems that trigger the insertion of $a$, as illustrated in (614-615). These conjugations are not homophonous in verbs whose rightmost vowel is high, as illustrated in (616-617).

$/ \mathrm{n}+\mathrm{men} / \rightarrow$ namen

eat+2PL.PST

(615) $/ \mathrm{n}+$ amen/ $\rightarrow$ namen

eat +2 PL.FUT

(616) $/$ in + men $/ \rightarrow$ inimen

sleep+2PL.PST

(617) /in+amen/ $\rightarrow$ inamen sleep+2PL.FUT

79 Monosyllabic $w$-final roots either undergo vowel insertion, as in /uw+ner/ 'build+3SG.PRS $\rightarrow$ [uwuyor], or have irregular forms, as in dungor 'he comes' (daw- 'to come'). 
$e$-rounding: $\mathrm{e} \rightarrow \mathbf{0} / \mathbf{w}+(\mathrm{y})$

In some suffixes with underlying/e/, this rounds to [o] when suffixed to a $w$-final stem. Rounding applies to all of the present tense suffixes, including those with initial $e$ (-em '1SG.PRS',

-emin '1PL.PRS', -emen '2PL.PRS' and -emit '3PL.PRS'), but also applies to the medial $e$ in -ngeng

'2SG.PRS' and -nger '3SG.PRS', as in (617) below, and (610-611) above.

(615) $/$ isiw + em/ $\rightarrow$ isiwom

dislike+1SG.PRS

(616) $/$ dirow + emit/ $\rightarrow$ dirowomit

carry+3PL.PRS

(617) $/$ uw +ner/ $\rightarrow$ uwuyor

build+3PL.PRS

The e-rounding rule also applies to -ei '2PL.IMP'.

(618) $/ \mathrm{kew}+\mathrm{ei} / \rightarrow$ kewoi

speak+2PL.IMP

Rounding does not apply to the past tense suffixes -eng '2SG.PST', -er '3SG.PST', and -ewe

'3SG.PST.SS'.

(619) /uw+ey/ $\rightarrow$ uweng

plant+2SG.PST

(620) $/$ kew + er/ $\rightarrow$ kewer

say+3SG.PST

(621) /dirow + ewe/ $\rightarrow$ dirowewe

carry+3SG.PST.SS

$\mathbf{g} \rightarrow \mathbf{k} / \mathbf{t}, \mathbf{w} \rightarrow \mathbf{p} / \mathbf{t}, \mathbf{r} \rightarrow \mathbf{l} / \mathbf{t}$

There are a few phonemes which undergo changes before $/ \mathrm{t} /{ }^{80}$. Underlying voiced velar stops are realized as voiceless before /t/, as in (622-623).

80 It is not clear if other voiced stops would also trigger these processes, as the relevent combinations do not arise in inflected Gavak verbs. 
(622) $/$ tag+to/ $\rightarrow$ takto

see+IPFV

(623) $/$ nag+to/ $\rightarrow$ nakto

be_at + IPFV

An underlying $/ \mathrm{w} /$ is realized as a voiceless bilabial stop [p] before $/ \mathrm{t} /$.

(624) /iw+to/ $\rightarrow$ ipto

come+IPFV

(625) $/$ uw + to/ $\rightarrow$ upto

hold+IPFV

Finally, $/ \mathrm{r} /$ is realized as a lateral approximant /1/ before /t/.

(626) $/$ ar+to/ $\rightarrow$ alto

go+IPFV

(627) $/$ iter+to/ $\rightarrow$ itelto

go_down+IPFV

\subsection{Gavak morphology}

This section outlines the basics of Gavak nominal and verbal morphology. Gavak has somewhat richer nominal morphology than other Northern Adelbert languages, as it marks number on nouns.

\subsubsection{Gavak number marking}

The inflection of number on nouns is rare in TNG languages as a whole (Pawley \& Hammarström 2018: 97), and Gavak is the only Northern Adelbert language which inflects nouns for number. Gavak nouns may be marked for singular or plural, or unmarked for number.

According to Corbett (2000: 9-19), in many languages which explicitly mark number, there are also noun forms which can express the meaning of the noun without specificying number. This is 
called 'general number'. In some languages, general number is expressed with a unique form different from the singular or plural forms (or other number distinctions). Corbett gives an example from the Cushitic language Bayso, where lúban 'lion(s)' is the general form, and the singular and plural are marked with affixes: lubán-titi 'lion-SG', luban-jool 'lion-PL'. However, it is crosslinguistically more common for the forms which express general number to also be used for one of the restricted number meanings (such as singular or plural). For languages with a singular vs. plural distinction, this provides two possible patterns: one form is used for general/singular, while another is used for plural, or general/plural share a form, while a separate form is used for singular. In Gavak, three different patterns are found in the inflection of number on nouns. Some nouns share a form for general/singular, and have another form for plural. A smaller number of nouns share a form for general/plural, and have another form for singular. Finally, some nouns mark both singular and plural with suffixes, and an unmarked form is rare or unattested.

\section{Unmarked singular/general, marked plural}

For some Gavak nouns, an unmarked form is used to express singular or general number (the number of the noun is not specified). For these nouns, the plural is formed with the suffixes -am and -im (which of these suffixes is used is lexically determined). This is the case for all nouns denoting people and most animals, for example nipmur 'person(/people)' vs. nipmuram 'people', bur 'pig(s)' vs. burim 'pigs, and yaret 'bird(s) of paradise' vs. yaretam 'birds of paradise'. Nouns denoting objects that are easily differentiated and frequently manipulated as individual items also behave this way, for example wani 'net bag(s)' vs. waniam 'net bags', and ungam 'egg(s)' vs. ungamam 'eggs'. Compare the unmarked noun forms kangap 'dog' and mulap 'child' in (628) and (629), which refer to singular entities, with the plural-marked kangapam 'dogs' and mulapam 'children' in (630) and (631). 
'The dog took it and ran away'

(629) mulap kung g-er.

child NEG see-3SG.PST

'He didn't see the child.

\begin{tabular}{|c|c|c|}
\hline $\begin{array}{l}\text { kangap-am } \\
\text { dog-PL }\end{array}$ & $\begin{array}{l}u \text {-mit-be } \\
\text { take-3PL.PST-SS }\end{array}$ & $\begin{array}{l}\text { iwar-amit } \\
\text { flee-3PL.PST }\end{array}$ \\
\hline
\end{tabular}

$\begin{array}{llll}\text { kurumo } & k a & \text { mulap-am } & \text { irug-am. } \\ \text { tomorrow } & k a & \text { child-PL } & \text { see_PL-1SG.FUT }\end{array}$

'I'll see the children tomorrow.'

The unmarked form is used to refer to singular entities in the examples above, but it can also be used to refer to a noun without specifying number. In (632), bur is used with the general number meaning 'pig(s)'. It is clear that is is used with the general meaning, not the singular, since it is modified by kapal, 'many', which is incompatible with the singular. However, the speaker is talking about pigs as a general entity, not a specific countable amount, so doesn't use the plural affix.

$\begin{array}{llllll}\text { bur } & \text { kapal } & \text { g-amit } & \text { katung gip } & \text { kung } & \text { ins-imit. } \\ \text { pigs } & \text { many } & \text { see-3PL.PST but one } & \text { NEG } & \text { shoot-3PL.PST }\end{array}$

'They saw many pigs but didn't shoot any.'

It is unacceptable to mark nouns in this group with a singular affix mer, for example **bur-mer 'pigSG', **mulap-mer 'child-SG', and **liweng-mer 'bird-SG' are all unacceptable forms.

\section{Unmarked plural/general, marked singular}

Only a few nouns have been identified which mark number according to the opposite pattern, in which there is a marked form for the singular, and the unmarked form is used for both the plural and general. All of the nouns so far identified which follow this pattern are foods that are typically cooked 
or consumed in multiples, such as kep 'bananas', bong 'betel nut', and sarur 'betelpepper vine ${ }^{\prime 81}$. To indicate a single item, the singular suffix -mer is used, as in kepmer 'banana' and bongmer 'betel nut'. Unmarked kep 'bananas' in (633) and (634) refers to multiple bananas. This is clear in (634) from the use of kinengki 'all' to modify kep 'bananas'.

komkom ge muri-yak itel-to always garden-LOC go_down.IPFV banana banana.sp 'He would always go down to the garden and steal mapdor bananas.'

$\begin{array}{llllll}\text { kep mapdor } & \text { gongkel } & \text { kinengki } & u w \text {-ui } & \text { kait } & \text { kinengki } \\ \text { banana banana.sp } & \text { moon } & \text { all } & \text { plant-1PL.FUT this } & \text { all } \\ \text { sik-ar-et. } & & & & \\ \text { stay-3SG.FUT-et } & & & \end{array}$

'All of the 'moon mapdor' bananas that we'll plant will stay there.'

For these nouns, the plural suffix is unacceptable, for example **sarur-am 'betelpepper vines'.

\section{Marked singular and plural}

Some Gavak nouns can be inflected with either the singular affix -mer/-met or the plural affix -am/-im. For these nouns, a form that is uninflected for number is either rare or unattested. Some of these singular- and plural-marked noun pairs are illustrated in Table 6.4.1a.

Table 6.4.1a: Gavak nouns with both singular and plural marking

\begin{tabular}{|l|l|}
\hline kasinmer 'mosquito' & kasinam 'mosquitos' \\
\hline kitengmer 'flea' & kitengim 'fleas' \\
\hline uninmer 'bee' & uninam 'bees' \\
\hline kingermet 'red ant' & kingeram 'red ants' \\
\hline karermet 'fly' & kareram 'flies' \\
\hline aipmer 'leaf' & aipam 'leaves' \\
\hline muremer 'vein' & mumuremam 'veins' \\
\hline manemet 'aibika leaf & manemam 'aibika greens' \\
\hline
\end{tabular}

81 This is a small vine that is chewed along with betel nut.

82 This plural form also has reduplication of the first syllable, which is common for words for 'vein' in NA languages.

83 This is a leafy green vegetable, called aibika in Tok Pisin that is ubquitous throughout the area. 
This list includes items such as leaves and stars, which are often treated as a unitary group, but whose individual entities can easily be singled out in the appropriate context. Compare (635), in which the speaker uses the plural form aipam when describing the leaves of the tree as a whole, with (636), in which the speaker uses aipmer when describing a picking a single leaf.

$\begin{array}{llll}\text { ngom } & \text { kait } & \text { aip-am } & \text { lalaket. } \\ \text { tree } & \text { this } & \text { leaf-PL } & \text { red }\end{array}$

'This tree's leaves are red.'

\begin{tabular}{|c|c|c|c|c|c|c|c|}
\hline $\begin{array}{l}\text { mangar- } \\
\text { bend-3SG. }\end{array}$ & & $\begin{array}{l}\text { ar-ewe } \\
\text { go-3SG.PST.SS }\end{array}$ & $\begin{array}{l}k a \\
k a\end{array}$ & $\begin{array}{l}\text { sareng aip-mer } \\
\text { tree_sp leaf-SG }\end{array}$ & $\begin{array}{l}\text { kait } \\
\text { this }\end{array}$ & $\begin{array}{l}w \text {-ewe, } \\
\text { get-3SG.PST.SS }\end{array}$ & $\begin{array}{l}n g o m \\
\text { tree }\end{array}$ \\
\hline aip-mer & kait & $w$-ewe & g-ato & & & & \\
\hline leaf-SG & this & get-3SG.PST.SS & see-IPF & & & & \\
\hline
\end{tabular}

This group of nouns also includes swarming insects, which are typically seen in groups, but can also act (or be acted on) individually, for example uninmer 'bee' in (637), and uninam 'bees' in (638).

\begin{tabular}{|c|c|c|}
\hline unin-mer & aung & $g u s-e r$ \\
\hline bee-SG & $3 \mathrm{SG}$ & sting-3SG.PST \\
\hline \multicolumn{3}{|c|}{ 'The bee stung him.' } \\
\hline unin-am & aung & gus-umit \\
\hline bee-PL & $3 \mathrm{SG}$ & sting-3PL.PST \\
\hline
\end{tabular}

An unmarked form **unin would be unacceptable in either (637) or (638). Compare this with nouns denoting insects that are larger, and do not typically appear in groups. These have unmarked forms for the singular, for example lasivu 'butterfly', user 'centipede', kalopi 'snail', and uta 'grasshopper'.

A small number of nouns have been identified for which the addition of a number-marking affix changes the meaning of the noun, for example awen 'hand' vs. awenam 'arm'. Another example is magep 'star', which follows the general/singular vs. plural pattern, illustrated by (639) and (640). However, when suffixed with -mer, the meaning changes to 'year(s)', illustrated in (641). Although it is 
marked with -mer, magepmer can be singular or plural, as is clear in (641), where is it modified by eighteen pela ${ }^{84}$.

(639) magep uvuks-anger.

star shine-3SG.PRS

'The star is shining'

(640) magep-am uvuks-emit.

star-PL shine-3PL.PRS

'The stars are shining'

$\begin{array}{lllllll}\text { [eighteen-pela] } & \text { magep-mer } & \text { miningak } & k a & \text { mulap aung } & \text { mur } & \text { bar-er. } \\ \text { eighteen-ADJ } & \text { star-SG } & \text { later } & k a & \text { child } 3 \mathrm{SG} & \text { man } & \text { finish-3SG.PST }\end{array}$

'Eighteen years later, the child became a man.'

Some nouns use number-marking affixes other than the standard singular -mer and plural -am/ -im. As shown in Table $6.4 .1 \mathrm{~b}$, these are mostly body parts, and especially body parts that come in pairs. The singular-marked nouns mekmer 'eye' and gepmer 'rib' use the standard singular suffix -mer, but mark the plural with -mareng. Other body part nouns use -kut/-kur for the singular, and -teng for the plural. The only words on the list that do not denote a body part are inepkur 'tobacco' and inepteng 'smoke', which provide another example where number-marking morphology changes the meaning of the noun.

Table 6.4.1b: Irregular Gavak number-marking affixes

\begin{tabular}{|l|l|}
\hline mekmer 'eye & mekmareng 'eyes' \\
\hline gepmer 'rib' & gepmareng 'ribs' \\
\hline diningkut 'knee' & diningteng 'knees' \\
\hline porkut 'thigh' & polteng 'thighs' \\
\hline matepkut 'buttock' & matepteng 'buttocks' \\
\hline inepkur 'tobacco, cigarette' & inepteng 'smoke' \\
\hline
\end{tabular}

There is also a plural suffix -en, which is used for a smaller number of nouns than -am/-im, and is typically used for things that are not easily differentiated as individual entities, such itungen 'roots', 84 This is mixed Tok Pisin/English, and means 'eighteen'. 
and dilengen 'scales', and garwanen 'gills'. For some of these nouns, a singular counterpart is not attested.

Table 6.4c.1: Gavak nouns inflected with -en

\begin{tabular}{|l|l|}
\hline gong 'skin, banana peel' & gongen 'skin, banana peels' \\
\hline mareng 'seed' & marengen 'seeds' \\
\hline dileng 'ringworm' & dilengen 'scales' \\
\hline mepkanggel 'nail' & mepkanggelen 'nails' \\
\hline-- & garwanen 'gills' \\
\hline -- & damboren 'gums' \\
\hline itung 'root' & itungen 'roots' \\
\hline aweng 'branch' & awengen 'branches' \\
\hline
\end{tabular}

For some nouns, the plural can be marked with either -am or -en. For example, masarung 'firefly' has the plural forms masarungen and masarungam 'fireflies', and both dilengen and dilengam are attested for 'scales'. More research is needed on whether there are semantic or grammatical differences between these forms. For example, it's possible that the forms inflected with -am are countable, while the forms inflected with -en are mass nouns. Note that there are mass nouns which do not take any number marking affixes, such as me 'food', mail 'saltwater, salt' and ivot 'feces'.

\subsubsection{Gavak verb morphology}

\section{Subject/tense affixes}

Gavak has fusional tense/subject markers that indicate the person and number of the subject, as well as present, past, or future tense. As can be seen in Table 6.4.2a, several of the tense/subject markers have similar forms across the three tenses. For example, for plural subject, the difference between the tenses is indicated only by the initial vowel, or lack thereof (except for - $u i$ '1PL.FUT'). 
Table 6.4.2a: Gavak subject/tense suffixes

\begin{tabular}{|c|c|c|c|}
\hline & PRS & PAST & FUT \\
\hline $1 \mathrm{SG}$ & -em & $-u m$ & $-a m$ \\
\hline $2 \mathrm{SG}$ & -ngeng & -eng & -ang \\
\hline $3 \mathrm{SG}$ & -nger & $-e r$ & $-a r$ \\
\hline 1PL & -emin & $-\min$ & $-u i$ \\
\hline $2 \mathrm{PL}$ & -emen & $-m e n$ & -amen \\
\hline 3PL & -emit & $-m i t$ & -amit \\
\hline
\end{tabular}

Gavak present tense is used for events that are currently happening, as in (642-643), or habitual, as in (644-645).
ning amse g-angeng?
2 what see-2SG.PRS
'what are you looking at?'
mulap-am kep n-emit
child-PL banana eat-3PL.PRS
'the children are eating bananas'

$\begin{array}{llll}\text { kom kinengki } & \text { bekom } & \text { kamnak } & \text { nag-anger } \\ \text { time all } & \text { grandfather } & \text { inside } & \text { be_at-3SG.PL } \\ \text { 'grandfather always stays inside.' } & & \end{array}$

$\begin{array}{lllllll}\begin{array}{l}\text { mulap-am } \\ \text { child-PL }\end{array} & \text { kinengki } & k a & \text { Igarom } & \text { be } & \text { yek } & \text { is-emit } \\ & \text { all } & \text { DEM } & \text { Gilagi } & \text { LOC } & \text { water } & \text { bathe-3PL.PRS }\end{array}$
'the children bathe in the Gilagi river.'

Unlike some other Northern Adelbert languages, Gavak does not have a distinction between remote past and recent past. Gavak has a single past tense that is used to refer to events in both the remote past, as in (646), and recent past, as in (647).

$\begin{array}{lll}\text { kakomne } & \text { nakom } & \text { unggur-er } \\ \text { long_ago } & \text { grandmother } & \text { die-3SG.PST } \\ \text { 'Grandmother died long ago.' }\end{array}$

$\begin{array}{lll}\text { awunki } & \text { nakom } & \text { unggur-er } \\ \text { morning } & \text { grandmother } & \text { die-3SG.PST } \\ \text { 'Grandmother died this morning.' }\end{array}$


The future tense is used for future events, as in (648-649).

(648)

$\begin{array}{lllll}\text { bar } & \text { kait } & \text { tauk } & k a & u w-a m \\ \text { song } & \text { this } & \text { now } & \text { just } & \text { sing-1SG.FUT }\end{array}$

'I'm going to sing this song now.'

(649) ning kurumo aripe nag-ang?

2 tomorrow where be_at-2SG.FUT

'Where will you be tomorrow?'

\section{Imperatives}

The imperative suffixes $-a k$ '2SG.IMP' and $-e i$ '2PL.IMP' are used for commands.

(650) gaver iter-ak

quickly come_down-2SG.IMP

'Hurry and come down!'

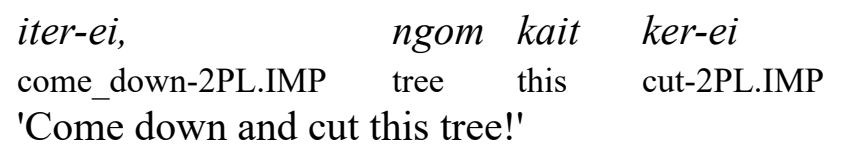

\section{Imperfective -to}

The suffix -to is used to mark imperfective aspect. In some other Northern Adelbert languages, like Pamosu and Barem, aspectual markers are used in only conjunction with tense/subject markers. This is not the case in Gavak, where imperfective -to can be used in conjunction with a tense/subject marker, as in the final verb in (652), but also without, as in (653). The Gavak imperfective marker does not indicate person/number of the subject.
nipmur-am al-to go-IPFV
ga-to-mit.
person-PL look-IPFV-3PL.PST

'The people went and watched.'

\begin{tabular}{|c|c|c|c|c|c|}
\hline $\begin{array}{l}\text { komkom ge } \\
\text { always }\end{array}$ & $\begin{array}{l}\text { muri-yak } \\
\text { garden-LOC }\end{array}$ & $\begin{array}{l}\text { itel-to } \\
\text { go_down-IPFV }\end{array}$ & $\begin{array}{l}\text { kep } \\
\text { banana }\end{array}$ & $\begin{array}{l}\text { mapdor } \\
\text { banana.sp }\end{array}$ & $\begin{array}{l}\text { saru } \\
\text { theft }\end{array}$ \\
\hline
\end{tabular}
'He would always go down to the garden and steal mapdor bananas.' 


\section{Desiderative -oyem}

The suffix -oyem indicates intention or purpose. This suffix is used for all person and number combinations. In (654) sili baroyem 'tell a story' has a $1 \mathrm{SG}$ subject, while 3PL subjects are seen in (655) uroyem 'kill him' and (656) duwayoyem 'sing and dance'.

(654) ying gongkel-em sili bar-oyem.

1 moon-POSS story make-DES

'I'm going to tell the story of the moon.'

$\begin{array}{lllll}\text { di-mit-be, } & \begin{array}{l}\text { kawen pings-amit-be, } \\ \text { come-3PL.PST-SS }\end{array} & \begin{array}{l}\text { nipmur-am } \\ \text { house surround-3PL.PST-SS }\end{array} & \begin{array}{l}\text { kuropkariki } \\ \text { three }\end{array} & \begin{array}{l}\text { kamnak } \\ \text { inside }\end{array} \\ \text { wongar-amit-be } & \text { ur-oyem. } & & \\ \text { ascend-3PL.PST-SS } & \text { kill-DES } & & \\ \text { 'They came and surrounded the house and three people went up inside to kill him.' }\end{array}$

$\begin{array}{llll}\begin{array}{l}\text { nipmuram } \\ \text { person-PL }\end{array} & \text { all } & \text { duway-oyem } & d u \text {-mit } \\ \text { sing_and_dance-DES } & \text { come-3PL.PST }\end{array}$

'The people all came to sing and dance.'

\section{Direct-object marking}

Gavak does not mark direct objects on most transitive verbs. However, there are a number of irregular verbs which have different stems depending on the person and number of the object, as is common in Northern Adelbert languages (see Chapter 1). One such verb is 'to see', which has different verb roots for $1 \mathrm{SG}, 2 \mathrm{SG}, 3 \mathrm{SG}$ and plural direct objects. The use of ipg- 'see $1 \mathrm{SG}$ ' and napg- 'see $2 \mathrm{SG}$ ' is illustrated in (657), and irug- 'see PL' is illustrated in (658). The verb $g$ - 'see' is used for 3SG objects, illustrated in $(659)^{85}$.

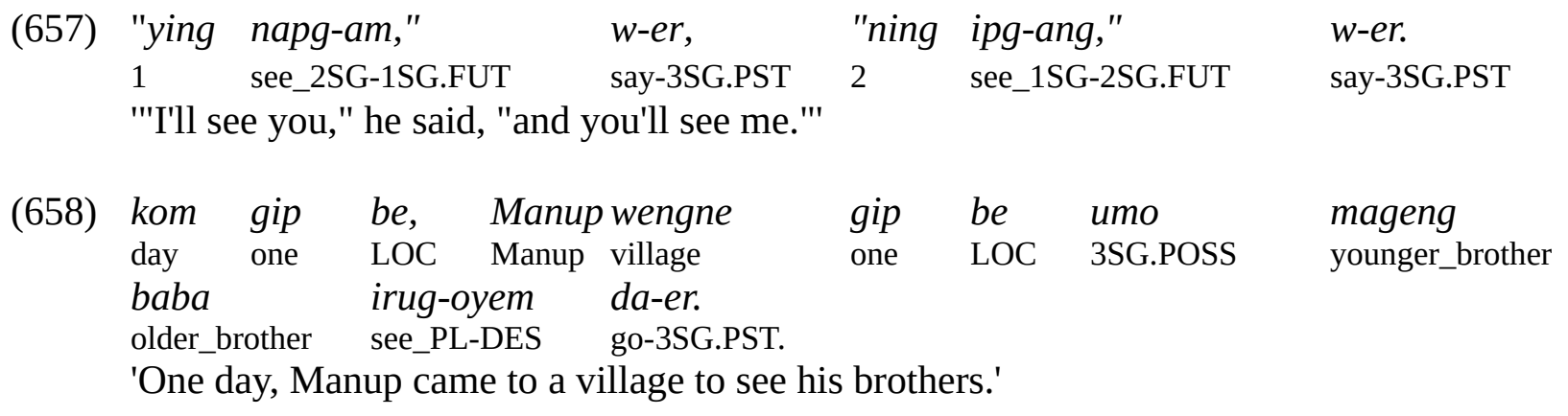

$85 \mathrm{~g}$ - is also used for non-human general number direct objects, as in (632) in section 6.4.1. 
(659) mulap kung g-er.

child NEG see-3SG.PST

'He didn't see the child.'

The verb 'to hit/kill' patterns similarly to 'see', with separate roots for 1SG (inggar-), 2SG (nanggar-), 3SG (ur-), and plural (gar-) direct objects. A direct object pronoun may be used to disambiguate between plural direct objects, as in (662).

$\begin{array}{lll}\text { "Kuluwop } & \text { ur-oi," } & \text { w-er. } \\ \text { Kuluwop } & \text { kill_3SG-2PL.IMP } & \text { say-3SG.PST } \\ \text { '"Kill Kuluwop!" he said.' } & \end{array}$

(661) nanggar-er.

hit 2SG-3SG.PST

'He hit you.'

(662) ingku gar-er.

1PL.OBJ hit_PL-3SG.PST

'He hit us.'

Gavak uses different verb stems for 'to give', depending on the person and number of the recipient. These are is- 'give to $1 \mathrm{SG}$ ', nas- 'give to $2 \mathrm{Sg}$ ', $u s$ - 'give to $3 \mathrm{SG}$ ', and $i r$ - 'give to PL.'

(663) warereki ning nas-um.

yesterday 2SG give_2SG-1SG.PST

'I gave it to you yesterday.'

(664) ying nip kait meme gip us-am.

1 woman this thing one give_3SG-1SG.FUT

'I'm going to give something to this woman.'

(665) me ir-er.

food give_PL-3SG.PST

'He gave them food. 
The verbs 'to ask' and 'to tell/teach' follow the same pattern. They both have one root for $1 / 2 \mathrm{SG}$ direct objects, one for 3SG, and another for plural: yalsis- 'ask 1/2SG, yals- 'ask 3SG', and yaltar- 'ask PL', and sagis- 'tell 1/2SG', sas- 'tell 3SG', and tagar 'tell PL'. ${ }^{86}$

\section{Gavak switch reference}

Gavak has two basic switch reference markers -be 'SS' and -e 'DS'. These follow the subject/tense marker, and indicate whether there is a change in the referent of the subject between two clauses. The same subject marker - be indicates that referent of the subject of a clause is the same as the referent of the subject of the following clause, as in (666), where the subject of the verb iterum 'I went down' has the same referent as the subject of the following verb irowarem 'I'm coming back.' The sentence in (667) shows a clause chain where every verb has the same 3PL subject, mulapam 'children', and the same subject marker -be is seen on both medial verbs iteramitbe 'they went down' and dumitbe 'they went'.

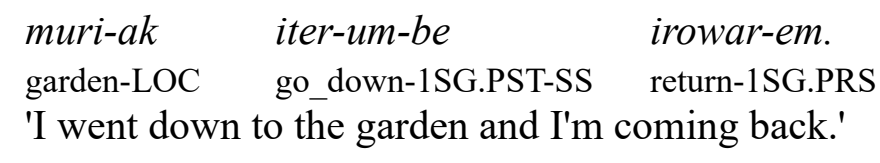

$\begin{aligned} & \text { mulap-am argenki } \quad \begin{array}{l}\text { kait } \\ \text { child-PL two }\end{array} \text { this behind } \\ & \text { wongar-amit. }\end{aligned}$
climb-3PL.PST
'The two children went down behind her and climbed up'

86 Unlike the roots for 'to see' and 'to hit/kill', which differ from each other at the left edge of the stem, 'to ask' and 'to tell/teach' differ at the right edge of the stem. For both 'to see' and 'to kill/hit', the root for the 3SG object is historically the basic form, while the 1SG, 2SG, and plural roots have fossilized direct object affixes. For 'to ask' and 'to tell/teach', the element -is on the 1/2SG stems is historically derived from is- 'give to 1SG', and the element -ar on the roots for plural objects is perhaps historically related to iru- 'give to plural'. 
Same subject is marked differently for verbs in the third person singular past tense. These do not use the 3SG.PST marker -er or the same subject marker -be, but are instead affixed with -ewe, which indicates both 3SG.PST and SS. ${ }^{87}$

\begin{tabular}{|c|c|c|c|c|c|}
\hline Мапир-ет & & aung & irem-ewe & unak & da-er. \\
\hline
\end{tabular}

'Manup's wife got up and went home.'

The different subject marker $-e$ indicates that the subject of the following clause has a different referent, as in (669), where bekom 'grandfather' is the subject of first verb unggurere 'he died', and nakom 'grandmother' is subject of the final verb.

$\begin{array}{llll}\text { bekom } & \text { unggur-er-e } & \text { miningak } & \text { nakom unggur-er } \\ \text { grandfather } & \text { die-3SG.PST-DS } & \text { after } & \text { grandmother die-3SG.PST } \\ \text { 'grandfather died and grandmother died after.' } & \end{array}$

\section{Overlapping reference}

If there is overlapping reference in the subject of two clauses, then the same subject marker may be used. The example in (670) describes a situation in which a group of women go to the beach, and then one woman breaks away and leaves the others. The subject of unumitbe 'they drew water' is all the women, while the subject of the following verb isiwer 'she left (them)' is only one of the group of women. Nonetheless, the same subject marker -be is used on unumitbe 'they drew water'.

$\begin{array}{lllll}\begin{array}{l}\text { nivam-am } \\ \text { wife-PL }\end{array} & \text { kinengki... } & \text { ar-amit-be, } & \text { iter-amit-be, } & \text { mail } \\ \text { all } & & \text { go-3PL.PST-SS } & \text { go_down-3PL.PST-SS salt_water } \\ \begin{array}{l}\text { un-umit-be, } \\ \text { draw-3PL.PST-SS }\end{array} & \begin{array}{l}\text { nivam-am } \\ \text { wife-PL }\end{array} & \text { kait } & \text { ungku } & \text { isiw-er. }\end{array}$

'All the wives... went, they went down, they drew salt water, and she left these wives.'

The sentence in (671) shows another example where there is overlapping reference of the subject of two clauses, but the same subject marker is used. The first two verbs in the clause chain have a 3PL subject whose referent is a large group of people. At wongaramitbe 'they went up', the

87 Some evidence that -ewe drives from -er+-be '3SG.PST+SS' comes from the verb 'to flee', which has two variants, irbar- and iwar-. This suggests that, at one point, the cluster $r b$ may have also alternated with $w$ in the sequence -er-be. 
referent of the subject narrows to only three of the group. Nonetheless, the preceding verb pingsamitbe 'they surrounded' is marked with the same subject marker -be.

$\begin{array}{lllll}\text { umo } & \text { unak } & \text { kawen-be } & \text { di-mit-be, } & \text { kawen pings-amit-be, } \\ \text { 3PL.POSS } & \text { village.DAT } & \text { house-LOC } & \text { come-3PL.PST-SS } & \text { house surround-3PL.PST-SS } \\ \text { nipmur-am } & \text { kuropkariki } & \text { kamnak } & \text { wongar-amit-be } & \text { ur-oyem. } \\ \text { person-PL } & \text { three } & \text { inside } & \text { go_up-3PL.PST-SS } & \text { kill-DES }\end{array}$

'They came to the houses in their village, they surrounded the house, and three people went up inside to kill him.' 


\section{Proto-Northern Adelbert}

In this chapter, I present my classification of Northern Adelbert languages and a Proto-Northern Adelbert phoneme inventory and lexicon. Section 7.1 gives a brief background on Papuan historical linguistics and discusses some previous classifications of Madang languages. In section 7.2, I present my own classification of Northern Adelbert languages and compare it with previous classifications. In 7.3, I present my PNA phoneme inventory, and list the reflexes of each proto-phoneme in individual Northern Adelbert languages. More detailed sound correspondences and discussion of the changes in each subgroup and individual languages are found in Chapters 7-11, except for the Gavak sound changes, which are outlined in section 7.4. Section 7.5 presents the Proto-Northern Adelbert reconstructed vocabulary.

\subsection{Papuan historical linguistics}

The New Guinea region is home to around 1200 languages (Foley 2000), around seventeen percent of the world's total. While about 300 of these languages belong to the Austronesian language family, the other 900 or so are non-Austronesian, or Papuan. The label "Papuan" does not presuppose that these language are all genetically related; it is simply a convenient label for the non-Austronesian languages of the region. As the large majority of Papuan languages are poorly documented, little is understood about their history and classification. Based on lexical resemblances in core vocabulary, McElhanon and Voorhoeve (1970) proposed the Trans New Guinea (TNG) phylum, encompassing a large portion of the languages of New Guinea. Later work on the TNG hypothesis (Wurm et al. 1975) expanded TNG to include a group of around 80 languages in Madang Province. If this hypothesis is 
correct, this would make the Madang group the largest branch of the putative TNG phylum, which is currently supposed to include around 300 or so languages (Pawley \& Hammarström 2018). See Pawley (2005) and Pawley \& Hammarström (2018) for a more detailed history of the TNG hypothesis. The most detailed comparative work on Madang languages so far is that of Daniels (2020) on the Sogeram languages, which border the Northern Adelbert languages to the southwest. I discuss potential connections with Sogeram and other Madang languages in Chapter 12.

\section{Previous classifications of Madang languages:}

The first detailed classification of Madang languages appears in Z'graggen (1971a) and is expanded upon in Z'graggen (1975a). Z'graggen applies lexicostatistical methods to classify the languages of Madang into several phyla, two of which he calls the Madang phylum and the Adelbert Range phylum ${ }^{88}$. In later publications (1980a-d), he renames these two phyla "superstocks" and links them as sister groups that together comprise the "Madang subphylum" of TNG. His classification of the Madang subphylum languages is presented in Figure 7.1a. Languages that are included in my Northern Adelbert group are italicized.

88 Z'graggen's other phyla are the Ramu phylum, composed of languages around the Ramu valley, the Torricelli phylum, and the East New Guinea Highlands phylum, whose membership is composed mostly of languages outside the Madang area. 
Figure 7.1a: Z'graggen's (1980a-d) classification of the Madang subphylum

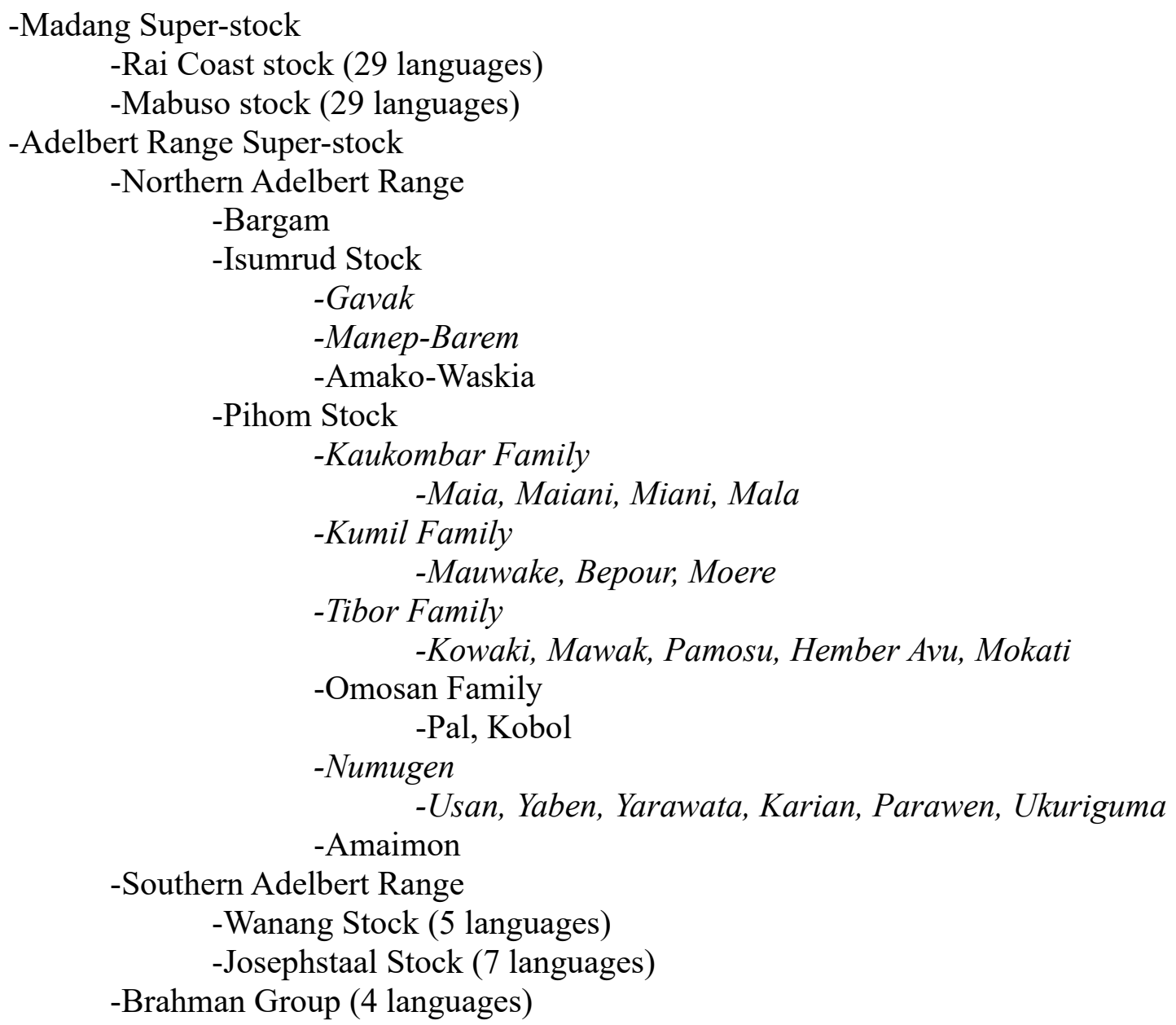

The languages in my Northern Adelbert group all fall into either Z'graggen's Isumrud Stock or the Pihom stock, which, together with Bargam, form Z'graggen's Northern Adelbert Range group. Z'graggen's Northern Adelbert Range includes a few other languages that I do not include in my Northern Adelbert. However, the membership of my Northern Adelbert and Z'graggen's Northern Adelbert Range largely overlaps, although there are significant differences in their internal structures.

Another classification of Madang languages is presented in Ross (2000). Ross's classification is based on the comparison of pronoun forms. His classification includes a group of languages he names the Croisilles linkage, which includes around fifty languages, and is comprised of languages from both 
Z'graggen's Northern Adelbert Range group (from his Adelbert Range superstock) and his Mabuso group (from his Madang superstock). Figure 7.1b illustrates Ross' classification, with languages from my Northern Adelbert italicized.

Figure 7.1b: Ross's (2000) classification of Madang languages

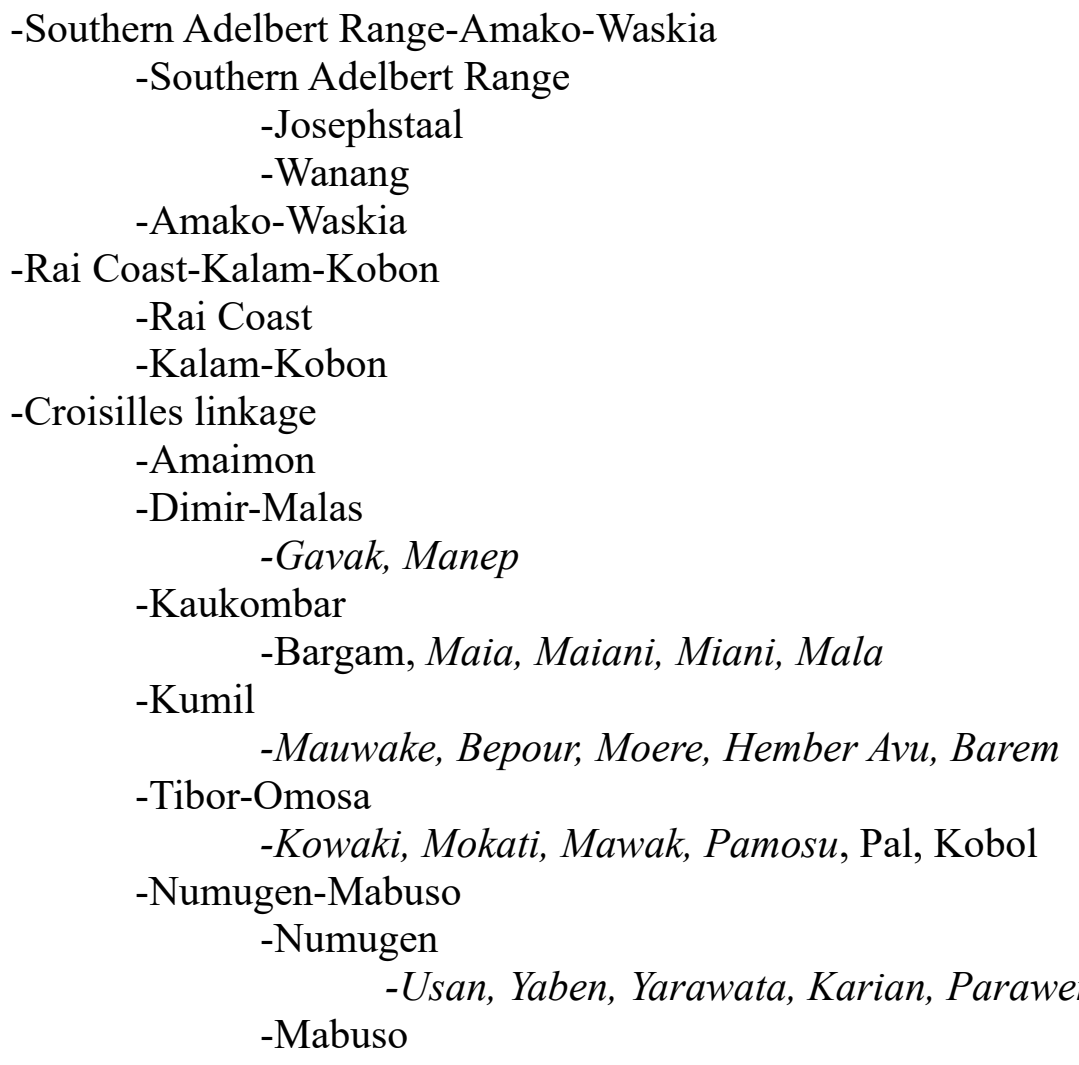

The Northern Adelbert languages all fall within Ross's Croisilles linkage. However, Ross also includes the large group of Mabuso languages, as well as Pal and Kobol.

One limitation of both Z'graggen's and Ross' classifications is that they do not establish regular sound correspondences to determine cognacy, but assume cognacy based on subjective judgments of similarity. Both Z'graggen and Ross state that their classifications are preliminary, and Ross emphasizes that his classification is intended to be a starting point for a more traditional approach based upon the comparative method. 
A more recent classification of Madang languages appears in Pawley and Hammarström (2018). The classification they present is based on Ross's, but includes some changes mostly related to languages outside Northern Adelbert ${ }^{89}$. The only changes in the classification which directly concern Northern Adelbert languages are that the Mabuso group is no longer paired with the Numugen languages, and some refinements to the internal structure of the Numugen subgroup are proposed. Figure 7.1c shows Pawley and Hammarström's (2018) classification of the languages of the Croisilles linkage (other languages in the Madang branch are not shown).

Figure 7.1c: Pawley and Hammarström's (2018) classification of Croisilles linkage

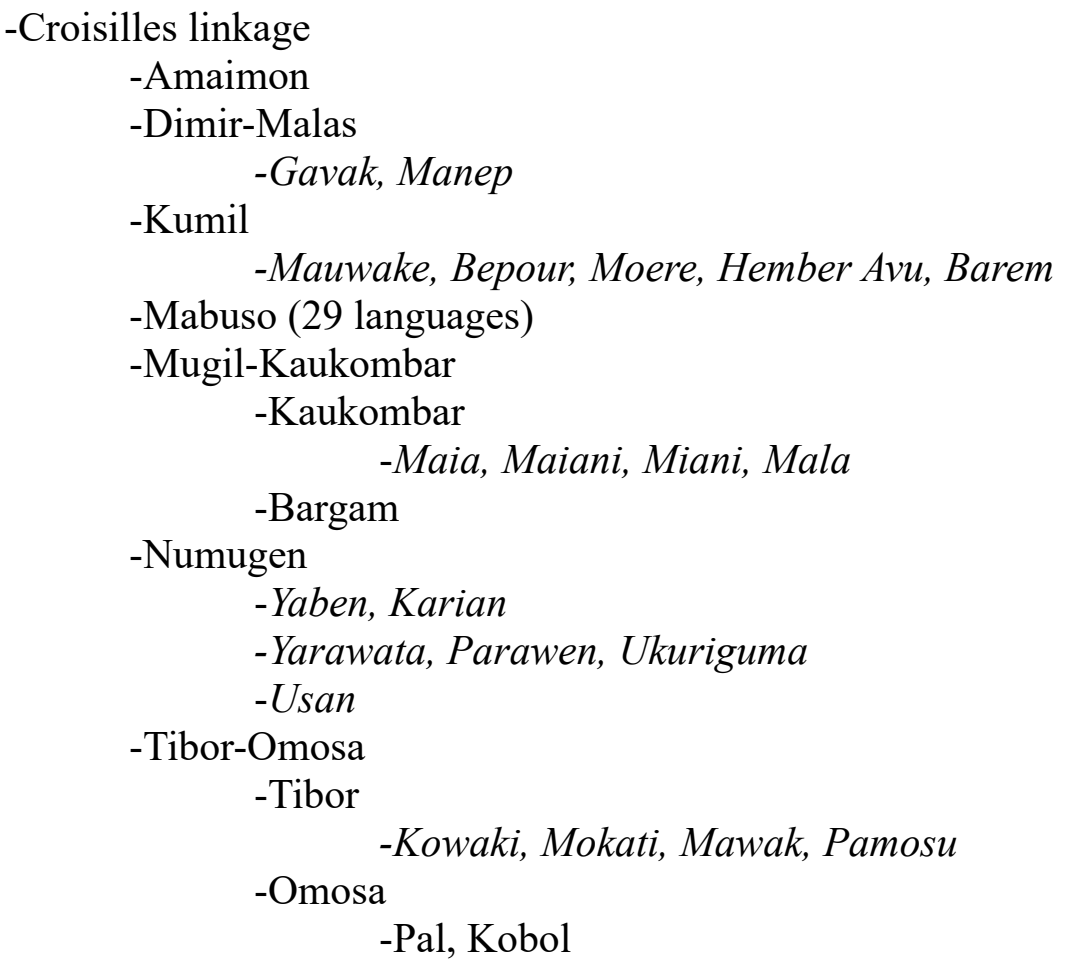

89 These changes include Amako-Waskia and Kalam-Kobon both being moved out of their respective subgroups and classified as primary branches of Madang, and changes to the internal structure of the South Adelbert group, following Daniels $(2010,2015)$ work on the Sogeram languages. 


\subsection{A new classification of Northern Adelbert languages}

For my classification of Northern Adelbert languages I took Ross's Croisilles linkage as a starting point. I examined data from Z'graggen's wordlists and other sources (listed in Table 1.4a in Chapter 1) for each of the Croisilles languages and attempted to establish regular sound correspondences between them, starting from each of Ross's subgroups and working outward.

This study benefits from a larger pool of data than was available to Z'graggen or Ross, including dictionaries and other materials made available in recent years, as well as primary data from my own fieldwork. This improved data has allowed me to apply the comparative method more effectively than would have been possible even ten years ago. However, for a number of languages, Z'graggen's wordlists are unfortunately still the only published data available, making the establishment of regular sound correspondences for some languages difficult. As discussed in Chapter 1, Z'graggen's wordlists are phonetic transcriptions, and it has been necessary to make some assumptions about what linguistic forms these transcriptions represent.

The classification I arrive at is presented below in Figure 7.2a. The phonological innovations defining each subgroup are listed in Table 7.2a. The innovations for each subgroup are discussed in more detail in Chapters 8-11, with the exception of the Gavak changes, which are discussed at the end of this chapter.

Figure 7.1d My classification of Northern Adelbert languages

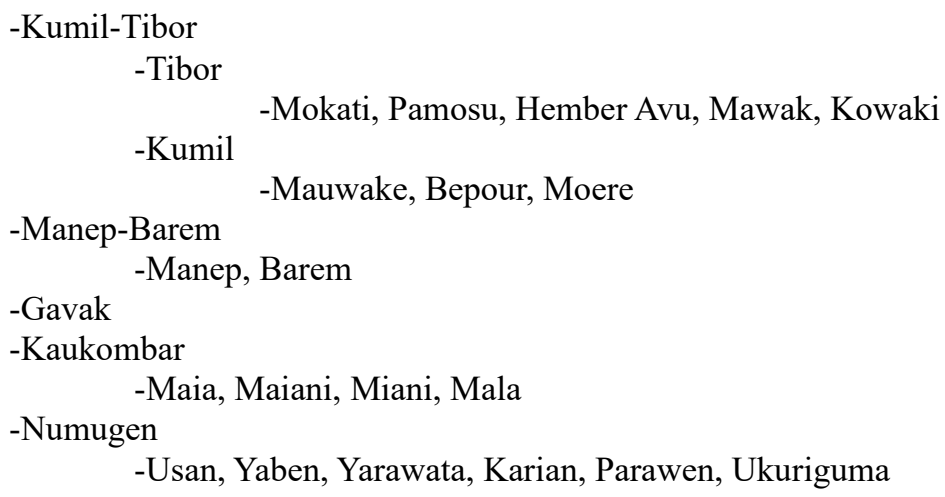


Table 7.2a: Phonological innovations in Northern Adelbert subgroups

Subgroup

Phonological innovations

Kumil-Tibor $* \mathrm{p}>\mathrm{f}$

$* \eta>\varnothing$

Kumil final $a$ added to monosyllables

$* \mathrm{k}, * \mathrm{t}>\varnothing / \#$

$* \mathrm{k}, * \mathrm{t}>\mathrm{r} / \ldots$

$* \mathrm{t}>\mathrm{k}$

$* \mathrm{~d}>\mathrm{g}$

$* \mathrm{~b}>\mathrm{p}$

$*$ ua $>$ o

$* \mathrm{a}>\mathrm{e} / \mathrm{CH}$

Tibor final $u$ added to monosyllables

$* \mathrm{a}>\mathrm{e} / \#$

$* \mathrm{t}>\mathrm{s} / \#$

$* \mathrm{n}>\varnothing^{-} \#$

$*_{\mathrm{f}}>\mathrm{w} / \overline{\#}$

$* \mathrm{r}, * 1>\mathrm{r}$

Manep-Barem $* \eta>n$

$* \mathrm{e}>\mathrm{a} / \mathrm{Ca}$

$* \mathrm{~g}>\mathrm{y} / \#$

$* \mathrm{~d}>\mathrm{j} / \mathrm{i}_{1}$

$* \mathrm{p}>\mathrm{w} / \mathrm{V}$

Kaukombar $*_{\eta}, *_{n}>\bar{\varnothing} / \#$

$* \mathrm{p}>\mathrm{w}$

$* \mathrm{e}>\mathrm{o}$

Numugen $\quad * \mathrm{n}>\mathrm{n}$

$* \mathrm{p}>\varnothing / \#$

$* \mathrm{p}>\mathrm{w} / \mathrm{V}_{-} \overline{\mathrm{V}}$

$* \mathrm{~s}>\varnothing$

$* 1>\mathrm{r}$

Gavak $\quad *$ a,$*$ e $>\varnothing \#$

$* \mathrm{~d}>\mathrm{r} / \mathrm{V}$

$* \mathrm{k}>\varnothing / \#$

$* \mathrm{~V}>\varnothing \bar{I} \#$

$* \mathrm{~g}>\mathrm{k}$

$* \mathrm{~b}>\mathrm{w} / \mathrm{V} \mathrm{V}$

$*_{\mathrm{a}}>\mathrm{e} / \mathrm{C}$

$* \mathrm{a}>\mathrm{o} / \mathrm{m}$

$*$ ua $>$ o

Although I used Ross's Croisilles linkage as a starting point for attempting to establish sound correspondences, my resulting classification is somewhat closer to Z'graggen's than Ross's. My 
Northern Adelbert essentially unites Z'graggen's Isumrud and Pihom stocks, with the difference that the Omosan languages (Pal and Kobol), Amaimon, and Amako-Waskia have been excluded. The most important difference between my classification and Ross's is that his Croisilles linkage includes the Mabuso group, composed of around 30 fairly closely related languages. Although there are a number of promising lexical resemblances between the Mabuso and Northern Adelbert groups, these have as yet not proven sufficient to be able to establish regular sound correspondences. In other details, too, my classification is closer to Z'graggen's: Hember Avu is grouped with Tibor languages, rather than Kumil; Barem is paired with Manep, rather than placed in Kumil; Bargam has been removed from Kaukombar. My classification differs from both Z'graggen's and Ross's in that I exclude Bargam, Pal, Kobol, and Amaimon.

It is not surprising that there are numerous differences between these classifications and my own, given that each one is based on different methods. Taking our different methods into account can explain some differences in our results. For example, Z'graggen proposes a relatively close relationship between Manep-Barem, Gavak, and Amako-Waskia, while I find no evidence for subgrouping There is no evidence for grouping Manep-Barem and Gavak together based on shared sound changes, and I have excluded Amako-Waskia from Northern Adelbert. These languages are all located in a contiguous area, and their speakers are in frequent contact with each other. ${ }^{90}$ Some shared lexical items among these languages are likely to have spread through contact, rather than independent direct inheritance. This would increase the percentage of resemblant lexical items, and result in a closer relationship via the lexicostatistics method Z'graggen employs. Nonetheless, the results of Z'graggen's lexicostatistical classification align fairly closely with my classification based on shared phonological innovations. The membership of each of his lowest-level branches aligns exactly with mine.

90 On any given market day in Tokain, the main Waskia village, there will be many speakers of Manep, Barem, and Gavak present. It is less clear how much contact these language groups had in pre-modern times. 
Comparing Ross' classification to mine, there are more differences in the placement of individual languages. Again, this can be accounted for by our differing methods. A good example is the Kumil group, which I define as Mauwake, Bepour and Moere, to which Ross adds Hember Avu and Barem. In Ross's classification based on pronoun forms, he writes: "the Kumil languages are characterised by the insertion of a reflex of $*_{-} \mathrm{fa}^{9}{ }^{91}$ between the prefixed $1 S$ and $2 S$ object pronoun and the verb stem" (2000: 23). Ross claims that the similarity in these forms (shown in Table 7.2b) is not shared by other languages, and suggests this resemblance is a shared innovation.

Table 7.2b: $1 \mathrm{SG}$ and 2SG object pronouns in Ross's Kumil group ${ }^{92}$

\begin{tabular}{|l|l|l|}
\hline & 1SG.OBJ & 2SG.OBJ \\
\hline Mauwake & e-fa & nefa \\
\hline Bepour & e-fe- & ne-fe- \\
\hline Moere & e-we- & ne-we- \\
\hline Hember Avu & e-we- & (ne-) \\
\hline Barem & e-we- & na-we- \\
\hline
\end{tabular}

However, cognate forms are actually found in at least three additional languages (Manep, Gavak, and Karian) not identified by Ross. The cognate forms in these languages are restricted to use with the verb 'to see', and therefore are not found in Z'graggen (1980b), which provides Ross's data. The Barem prefixes are in fact only used with two verbs, 'to see' and 'to show' (which is derived from 'see'). Direct objects are otherwise not marked on Barem verbs. ${ }^{93}$ Barem's sister language Manep also has these forms as fossilized elements only on 'to see' as well, as in nawengg- 'to see 2SG'. Fossilized forms are also found in Karian and Gavak: Karian yaga-, Gavak ipg- 'see 1SG' < PNA *ip+*ag'1SG.OBJ+see'; Karian nəga-, Gavak napg- 'see 2SG' < PNA *nap+*ag- '2SG.OBJ+see'. Since cognate forms for these prefixes are in fact more widespread throughout Northern Adelbert languages

91 In my reconstruction, these forms reflect PNA *p, which corresponds with Proto-Kumil *f.

92 The forms shown in this table are as presented by Ross. I analyze the Barem affixes as 1SG iv- and 2SG nav-, and Berghäll (2015) analyzes the Mauwake forms as free pronouns, not prefixes. See section 7.5 on the reconstruction of PNA *ip '1SG.OBJ' and *nap '2SG.OBJ'.

93 However, Barem does have object pronouns that are independent words derived from the same forms (ivo 1SG, navo 2SG, uvo 3SG). 
(having reflexes in every subgroup except Kaukombar), they do not provide evidence for the Kumil subgroup proposed by Ross. However, these forms may possibly be a shared innovation exclusive to Northern Adelbert, as similar forms have not yet been identified in other Madang or TNG languages.

\section{Languages excluded from Northern Adelbert}

As noted above, my classification of the Northern Adelbert languages excludes many languages that were included in Ross's and Z'graggen's groupings. The most notable are the Mabuso languages, the Omosan languages, Bargam, Amaimon, and Amako-Waskia, as either Ross or Z'graggen has proposed a close relationship between these and at least some of my Northern Adelbert languages. I have not excluded these languages because I don't believe they are related to Northern Adelbert. They likely are related, and there are promising potential cognates between the Northern Adelbert languages and other languages in the area. Further research may show that the boundaries of Northern Adelbert need to be adjusted.

As I illustrate in section 7.5, the languages I include in Northern Adelbert all share cognate subject/tense verb endings, which are a core part of the grammar. The languages I have excluded either don't have reflexes of these PNA verb endings, or there is insufficient data to show that they do. It is by no means clear that these shared verb endings are an innovation unique to Northern Adelbert languages. They may in fact be a retention from a higher-order proto-language, and they may also be found in other languages outside those I have included in NA, but for which there is currently insufficient data. However, I have used these verb endings as a convenient (and somewhat arbitrary) diagnostic for which languages to include in Northern Adelbert, since at the current level of knowledge of Papuan historical linguistics it is not possible to define Northern Adelbert by shared innovations relative to a higher-order proto-language. 
In previous iterations of this research (Pick, forthcoming), I included Amako and Waskia in Northern Adelbert since I was able to demonstrate regular sound correspondences between AmakoWaskia and the rest of the Northern Adelbert languages. However, Amako and Waskia share none of the verbal morphology that is reconstructible to PNA, so although they are clearly related, they are not part of core Northern Adelbert. There is also probably sufficient data available on Bargam (Hepner 2006, 2007) to establish at least some regular sound correspondences with my Northern Adelbert group. Again, I have excluded Bargam because the Bargam subject/tense inflections presented in Hepner (2006) show no obvious relationship to the PNA endings. The same is true of the verb morphology of Amele (Roberts 1987), the most well-documented Mabuso language. If it is representative of the Mabuso group, these languages can be excluded as well.

Another language I have excluded is Yamben, spoken in Yambarik village, not far from the Manep-speaking community of Simbukanam. Yamben was not included in Z'graggen's survey of Madang languages. Yamben is possibly distantly related to Northern Adelbert, but has no obvious close relatives. Its verb endings are also non-cognate with Northern Adelbert languages. See Pick (2018) for a discussion of the potential relationship between Yamben and Northern Adelbert.

That leaves three languages which either Ross or Z'graggen considered to have a close relationship with Northern Adelbert languages: Amaimon, and the Omosan languages Pal and Kobol. The available data on these languages is very limited, but there are many words which appear to be cognate with Northern Adelbert languages. However, these resemblant forms are not numerous enough to establish regular sound correspondences with any degree of confidence. A brief Amaimon phonology sketch completed by SIL researchers (Lillie 2001) includes some short sentences with inflected verb forms that appear possibly cognate with Northern Adelbert languages, but more data is needed. Z'graggen's (1980b) wordlists for Pal and Kobol show a number of promising resemblences between these languages and Northern Adelbert languages, but again, these resemblances are 
insufficient for establishing regular sound correspondences. I therefore do not classify Amaimon, Pal, and Kobol as Northern Adelbert languages, but additional data may provide evidence for their inclusion in the future.

\subsection{Northern Adelbert phonemes}

In this section, I present the sound correspondences which have been used to reconstruct PNA phonemes. The reconstructed PNA phoneme inventory is presented in Tables 7.3a and 7.3b.

Table 7.3a: PNA vowel phonemes

\begin{tabular}{|c|c|c|}
\hline & front & back \\
\hline high & $*_{\mathrm{i}}$ & $*_{\mathrm{u}}$ \\
\hline mid & $*_{\mathrm{e}}$ & \\
\hline low & & $*_{\mathrm{a}}$ \\
\hline
\end{tabular}

Table 7.3b: PNA consonant phonemes

\begin{tabular}{|l|c|c|c|c|}
\hline & labial & alveolar & palatal & velar \\
\hline stops & ${ }^{\mathrm{p}},{ }^{*} \mathrm{~b}$ & $*_{\mathrm{t}},{ }_{\mathrm{d}}$ & & $*_{\mathrm{k},}{ }_{\mathrm{g}}$ \\
\hline nasals & $*_{\mathrm{m}}$ & $*_{\mathrm{n}}$ & & $*_{\mathrm{g}}$ \\
\hline fricatives & & $*_{\mathrm{s}}$ & & \\
\hline liquids & & ${ }_{\mathrm{r}},{ }_{\mathrm{l}}$ & & \\
\hline glides & ${ }_{\mathrm{w}}$ & & $*_{\mathrm{y}}$ & \\
\hline
\end{tabular}

\section{PNA Vowels}

Northern Adelbert languages typically have a five-vowel system /i, u, e, o, a/, with the exception of the Numugen languages. However, only four vowels are reconstructed for Proto-Northern Adelbert: $*_{i},{ }^{*} \mathrm{u},{ }^{*} \mathrm{e},{ }^{*}$ a. There is no strong evidence for PNA *o.

There are a few word sets where $o$ is found in a number of Northern Adelbert languages, shown in Table 7.3c, but each of these has problems. PNA *n usually deletes word-finally in Kumil, but in 'stone', both Kumil languages unexpectedly retain a reflex of the final nasal, possibly indicating 
borrowing. Pamosu and Mawak, the two Tibor languages which lack a final nasal, also have final $-e$ rather than $-o$.

The consonant correspondences for 'net trap for pigs' do not present a problem, but as this is a cultural item, it is the type of word where borrowing is likely. Furthermore, both Manep and Mauwake historically added final $a$ to content words ${ }^{94}$, but this is lacking in Mauwake top and Manep dop.

The terms for 'sea turtle' are easily identified as borrowings, for several reasons. First, the words for 'sea turtle' in these languages are clearly related to Proto-Oceanic *poñu. Being borrowed from Austronesian is not enough to reject a reconstruction outright, as PNA *buruk 'pig' is also a borrowing from Austronesian, but was nonetheless likely present in PNA before it split into its daughter groups. However, pon can be clearly identified as a borrowing in most of the Northern Adelbert languages. In both Barem or the Kaukombar languages, initial $p$ - is not found in native vocabulary. Again, Mauwake lacks an expected final vowel. Only Gavak pon could possibly be a native word based on the phonotactics of that language.

Table 7.3c. Word sets with recurrent $o$

\begin{tabular}{|c|c|c|c|c|c|c|}
\hline gloss & Numugen & $\begin{array}{l}\text { Manep- } \\
\text { Barem }\end{array}$ & Tibor & Kumil & Kaukombar & Gavak \\
\hline 'stone' & $\begin{array}{l}\text { YAB: } \\
\text { namanu } \\
\text { USA: nomon } \\
\text { KAR: naman } \\
\text { UKU: namon } \\
\text { PAR: numon } \\
\text { YAR: naman }\end{array}$ & $\begin{array}{l}\text { BAR: nimon, } \\
\text { namon }\end{array}$ & $\begin{array}{l}\text { MOK: nomon } \\
\text { PAM: nome } \\
\text { HA: nomon } \\
\text { MAW: nome } \\
\text { KOW: nomon }\end{array}$ & $\begin{array}{l}\text { *nomon } \\
\text { BEP: nomon } \\
\text { MAU: } \\
\text { nomona }\end{array}$ & Miani: nomo & namon \\
\hline $\begin{array}{l}\text { 'net trap } \\
\text { for pigs' }\end{array}$ & & $\begin{array}{l}\text { BAR: } d o v \\
\text { MAN: } d o p\end{array}$ & MoK: $d e p$ & MOE: top & & $d o p$ \\
\hline 'sea turtle' & & BAR: pon & & MAU: pon & $\begin{array}{l}\text { Maia: pon } \\
\text { Mala: pon }\end{array}$ & pon \\
\hline $\begin{array}{l}\text { down, } \\
\text { coastward }\end{array}$ & USA: umo & $\begin{array}{l}\text { BAR: umuo } \\
\text { MAN: umo }\end{array}$ & & & & \\
\hline
\end{tabular}

94 In Manep, this only applied to monosyllabic content words (see Chapter 8). 
PNA *i

PNA $* \mathrm{i}$ is almost invariantly reflected as $i$ throughout all Northern Adelbert languages. Most changes to $* \mathrm{i}$ are either reduction of $*_{\mathrm{i}}>e$ preceding a consonant, or sporadic changes of $* \mathrm{i}>u$. Table $7.3 \mathrm{~d}$ presents the regular reflexes of $\mathrm{PNA} * i$.

Table 7.3d. Reflexes of PNA $* i$

\begin{tabular}{|l|l|l|l|l|l|}
\hline Numugen & $\begin{array}{l}\text { Manep- } \\
\text { Barem }\end{array}$ & Tibor & Kumil & Kaukombar & Gavak \\
\hline$*_{\mathrm{i}}$ & $*_{\mathrm{i}}$ & $*_{\mathrm{i}}$ & $*_{\mathrm{i}}$ & $*_{\mathrm{i}}$ & $i$ \\
YAB: $i$ & BAR: $i, e$ & MOK: $i$ & BEP: $i$ & Maia: $i$ & \\
USA $: i$ & MAN: $i$ & PAM: $i$ & MOE: $i$ & Maiani: $i$ & \\
KAR: $i$ & & HA: $i$ & MAU: $i$ & Miani: $i$ & \\
UKU: $i$ & & MAW: $i$ & & Mala: $i$ & \\
PAR: $i$ & & KOW: $i, u$ & & & \\
YAR: $i$ & & & & & \\
\hline
\end{tabular}

PNA * u

As with $* i$, most changes to $*_{\mathrm{u}}$ involve sporadic change of $* \mathrm{u}>i$. The sporadic fronting of $u$ to $i$ has also been observed in Australian languages (O'Grady 1998), and sporadic change of both $*_{\mathrm{i}}>u$ and $* \mathrm{u}>i$ in individual lexical items is widespread in the Austronesian language family as well (Blust 1970). Many of the changes of $*_{\mathrm{i}}>u$ and $*_{\mathrm{u}}>i$ in Northern Adelbert languages appear to be driven by assimilation to another high vowel, as in Bepour unum and Mauwake unuma 'name' < PNA *unim. Occasionally a language will have two reflexes, one with $*_{\mathrm{i}}>u$, and another with $*_{\mathrm{u}}>\mathrm{i}$, for example Mauwake irip-, urup- 'to come up' <*irub-. There is also a conditioned change in Bepour word-initial $*_{u}>i$ preceding a labial consonant (observed in 'to plant', 'to dance', and 'to sing'). 
Table 7.3e: Reflexes of PNA *u

\begin{tabular}{|c|c|c|c|c|c|}
\hline Numugen & $\begin{array}{l}\text { Manep- } \\
\text { Barem }\end{array}$ & Tibor & Kumil & Kaukombar & Gavak \\
\hline $\begin{array}{l}{ }^{*} \mathrm{u} \\
\text { YAB: } u \\
\text { USA: } u \\
\text { KARBO: } u \\
\text { KARBA: } u \\
\text { UKU: } u \\
\text { PAR: } u \\
\text { YAR: } u\end{array}$ & $\begin{array}{l}{ }^{*} \mathrm{u} \\
\text { BAR: } u \\
\text { MAN: } u\end{array}$ & $\begin{array}{l}{ }^{*} \mathrm{u} \\
\text { MOK: } u \\
\text { PAM: } u \\
\text { HA: } u \\
\text { MAW: } u \\
\text { KOW: } u\end{array}$ & $\begin{array}{l}* \mathrm{u} \\
\text { BEP: } u, i \\
\text { MOE: } u \\
\text { MAU: } u\end{array}$ & $\begin{array}{l}\text { *u } \\
\text { Maia: } u, a \\
\text { Maiani: } u \\
\text { Miani: } u \\
\text { Mala: } u\end{array}$ & $u$ \\
\hline
\end{tabular}

PNA *a

The reflexes of PNA *a are more varied than for $* i$ and $* u$, and unexplained irregular reflexes are more numerous. In the Tibor and Kumil subgroups, *a has merged with *e in some environments.

Table 7.4f: Reflexes of PNA *a

\begin{tabular}{|c|c|c|c|c|c|}
\hline Numugen & $\begin{array}{l}\text { Manep- } \\
\text { Barem }\end{array}$ & Tibor & Kumil & Kaukombar & Gavak \\
\hline $\begin{array}{l}* \mathrm{a} \\
\text { YAB: } a \\
\text { USA: } a, \hat{a}, o \\
\text { KAR: } a, a \\
\text { UKU: } a \\
\text { PAR: } a \\
\text { YAR: } a\end{array}$ & $\begin{array}{l}* \mathrm{a} \\
\mathrm{BAR}: a, i a, \\
u a \\
\text { MAN: } a, u\end{array}$ & $\begin{array}{l}* \mathrm{a},{ }^{*} \mathrm{e} \\
\text { MOK: } a, e, o \\
\text { PAM: } a, e \\
\text { HA: } a, e \\
\text { MAW: } a, e \\
\text { Kow: } a, e, o\end{array}$ & $\begin{array}{l}* \mathrm{a}, * \mathrm{e} \\
\text { BEP: } a, e, o \\
\text { MOE: } a, e, o \\
\text { MAU: } a, e, o\end{array}$ & $\begin{array}{l}* \mathrm{a} \\
\text { Maia: } a, \text { ua } \\
\text { Maiani: } a \\
\text { Miani: } a \\
\text { Mala: } a\end{array}$ & $a, e, o$ \\
\hline
\end{tabular}

PNA *e

The reflexes of *e also vary widely, having undergone conditioned changes in a number of languages. Common changes to $*$ e are rounding to $o$, often in the environment of a labial, and $* \mathrm{e}>a$ when the preceding or following consonant is *a. 
Table 7.3g: Reflexes of PNA *e

\begin{tabular}{|l|l|l|l|l|l|}
\hline Numugen & Manep-Barem & Tibor & Kumil & Kaukombar & Gavak \\
\hline$* \mathrm{e}, * \mathrm{a}$ & $* \mathrm{e}, * \mathrm{a}$, & $* \mathrm{e}, * \mathrm{a}$ & $* \mathrm{e}, * \mathrm{a}, * \mathrm{o}$ & $* \mathrm{e}, * \mathrm{o}$ & $e$ \\
YAB: $a, \partial$ & BAR: $e, i, a, o$, & MOK: $a, e, o$ & BEP: $a, e, o$ & Maia: $e, a, o$ & \\
$\mathrm{USA}: e, o, \hat{a}$ & $i e$ & PAM: $a, e$ & MOE: $a, e, o$ & Maiani: $e$ & \\
KAR: $a, \partial$ & MAN: $e, a, i$ & HA: $a, e$ & MAU: $a, e, o$ & Miani: $e, o$ & \\
$\mathrm{UKU}: o$ & & MAW: $a, e$ & & Mala: $e, a$ & \\
PAR: $a$ & & KOW: $a, e, o$ & & & \\
YAR: $a$ & & & & & \\
\hline
\end{tabular}

The only vowel sequence which is fairly frequent in PNA reconstructions is *ua. There are also a handful of reconstructions with *ai or *ia. It is not always clear whether these should be considered diphthongs, a sequence of two vowels, or glide-vowel sequence.

\section{PNA * $w$ and *y}

Two glides, $* w$ and $* y$, have been reconstructed for PNA. In most Northern Adelbert languages, glides have fricative allophones, sometimes in free variation, sometimes conditioned by adjacent vowels, as in Barem, where $/ \mathrm{w} /$ is realized as $[\beta]$ adjacent to $/ \mathrm{i} /$. Reflexes of word-final $*_{\mathrm{w}}$ often vary widely within individual languages. Z'graggen's transcriptions of final $<\mathrm{w}>$ and $<\mathrm{b}>$ do not regularly correspond across languages, and I have assumed in most cases that these represent underlying $/ \mathrm{w} /$.

Table 7.3h: reflexes of PNA * $\mathrm{w}$

\begin{tabular}{|l|l|l|l|l|l|}
\hline Numugen & Manep-Barem & Tibor & Kumil & Kaukombar & Gavak \\
\hline${ }_{\mathrm{W}}$ & ${ }_{\mathrm{W}}$ & ${ }_{\mathrm{W}}$ & ${ }_{\mathrm{W}}$ & ${ }_{\mathrm{W}}$ & $w, p$ \\
YAB: $w$ & BAR: $w, u, o$ & MOK: $w, v, \varnothing$ & BEP: $w$ & Maia: $w$ & \\
USA $w$ & MAN: $w, u, p$ & PAM: $w, v, \varnothing$ & MOE: $w, \varnothing$ & Maiani: $w$ & \\
KARBO: $w$ & & HA: $w$ & MAU: $w$ & Miani: $w$ & \\
KARBA: $w$ & & MAw: $w$ & & Mala: $w, \varnothing$ & \\
UKU: $w$ & & KOw: $w$ & & & \\
PAR: $w$ & & & & & \\
YAR: $w$ & & & & & \\
\hline
\end{tabular}


Table 7.3i: reflexes of PNA *y

\begin{tabular}{|l|l|l|l|l|l|}
\hline Numugen & Manep-Barem & Tibor & Kumil & Kaukombar & Gavak \\
\hline *y & *y & FY $_{\text {Y }}$ & *y & *y & $y$ \\
YAB: $y$ & BAR: $y$ & MOK: $y, \varnothing$ & BEP: $y$ & Maia: $y$ & \\
UsA: $y$ & MAN: $y$ & PAM: $y, \varnothing$ & MOE: $y, \varnothing$ & Maiani: $y$ & \\
KARBO: $y$ & & HA: $y, \varnothing$ & MAU: $y$ & Miani: $y$ & \\
KARBA: $y$ & & MAw: $y, \varnothing$ & & Mala: $l, \varnothing$ & \\
UKU: $y$ & & KOw: $y, \varnothing$ & & & \\
PAR: $y$ & & & & & \\
YAR: $y$ & & & & & \\
\hline
\end{tabular}

\section{PNA oral stops}

Voiced and voiceless stops at three places of articulation are reconstructed in word-initial, -medial, and -final positions. As discussed in chapter one, voiced stops in Northern Adelbert languages often have plain voiced and prenasalized voiced allophones. In some languages, prenasalization or lack thereof is determined by the position of the stop in the word, as well as if there is another voiced stop in the environment. Plain voiced and prenasalized voiced allophones likely date to PNA, with the plain voiced allophone occurring word-initially and in the environment of another voiced stop, and the prenasalized voiced allophone intervocalically and word-finally (when no other voiced stop is in the environment). In some languages, there have been phonemic splits between the plain and prenasalized allophones due to a particular change affecting one or the other. In the Wanambre dialect of Mokati, for example, the plain voiced allophones merged with their voiceless counterparts intervocalically, while prenasalized voiced allophones did not. For example, PNA $* d$ was prenasalized $*\left[{ }^{n} d\right]$ in *kuduruk 'fly', and is reflected as $n d$ in Wanambre Mokati kunduruk. PNA *d was plain voiced *[d] in *gedaw 'strong' due to the preceding * $\mathrm{g}$, and is reflected as $t$ in Wanambre Mokati getav (see section 9.2.3 for more on these changes in Mokati). 


\section{PNA *b and *p}

Table 7.3j shows the reflexes of PNA *b. There are few PNA reconstructions with word-final *b, and *ib 'feces' is the only one with widespread reflexes.

Table 7.3j: reflexes of PNA*b

\begin{tabular}{|l|l|l|l|l|l|}
\hline Numugen & Manep-Barem & Tibor & Kumil & Kaukombar & Gavak \\
\hline *b & *b & $* \mathrm{~b}$ & *p & *b & $b$ \\
YAB: $b \sim p$ & BAR: $b, m b$ & MOK: $b, p, w$ & BEP: $p$ & Maia: $b$ & \\
UsA: $b$ & MAN: $b, m b$ & PAM: $p$ & MOE: $p, m p$ & Maiani: $b$ & \\
KARBO: $b, w$ & & HA: $b, p, m b$ & MAU: $p$ & Miani: $b$ & \\
KARBA: $b, w$ & & MAW: $p$ & & Mala: $b$ & \\
UKU: $b$ & & KOw: $p$ & & & \\
PAR: $b$ & & & & & \\
YAR: $b$ & & & & & \\
\hline
\end{tabular}

Table 7.3k: reflexes of PNA *p

\begin{tabular}{|l|l|l|l|l|l|}
\hline Numugen & Manep-Barem & Tibor & Kumil & Kaukombar & Gavak \\
\hline$\varnothing, * \mathrm{w}$ & ${ }_{\mathrm{p}}$ & ${ }_{\mathrm{f},}{ }_{\mathrm{w}}$ & ${ }_{\mathrm{f}}$ & ${ }_{\mathrm{f}}$ & $w, p$ \\
YAB: $\varnothing, w$ & BAR: $f, w$ & MOK: $\varnothing, f$ & BEP: $f$ & Maia: $w$ & \\
UsA: $\varnothing, w$ & MAN: $p, w$ & PAM: $f, v$ & MOE: $f, w$ & Maiani: $w$ & \\
KARBO: $\varnothing, w$ & & HA: $f, w$ & Mau: $f$ & Miani: $w$ & \\
KARBA: $\varnothing, w$ & & MAW: $f, w$ & & Mala: $w$ & \\
UKU: $\varnothing, w$ & & KOw: $f, w$ & & & \\
PAR: $\varnothing, w$ & & & & & \\
Yar: $\varnothing, w$ & & & & & \\
\hline
\end{tabular}

PNA *p is also found in word-initial, -medial, and -final positions. However, Mauwake, Bepour, and possibly Mokati are the only languages which retain the distinction between PNA *p and ${ }^{*} \mathrm{w}$ after a vowel. In the Kumil languages, ${ }^{*} \mathrm{p}$ shifted to $f[\phi]$, while ${ }^{*} \mathrm{w}$ is reflected as $w$. In Mokati, the difference between the reflexes is more subtle. PNA *p deleted after a vowel, while ${ }^{*} \mathrm{w}$ is reflected as a glide. However, distinguishing a glide between two vowels from no segment between to vowels is not always easy given the limited Mokati data. In all other languages, PNA *p and ${ }^{*} \mathrm{w}$ have merged after a vowel. I use PNA ${ }^{*}$ for this phoneme, though in some languages, this is realized on the surface as a stop or fricative in certain cases, especially word-finally. 
I have said that Mauwake is one of the few languages to preserve a distinction between postvocalic ${ }^{*} \mathrm{p}$ and ${ }^{*} \mathrm{~W}$, but Berghäll (2015) suggests the opposite, that in Mauwake historic ${ }^{*} \mathrm{~W}$ (with allophones $[\mathrm{w}]$ and $[\beta])$ devoiced to $f[\phi]$ in some positions. However, there are both $w: f$ and $w: w$ correspondences in similar positions, as exemplified by Mauwake and Barem in Table 7.31.

Table 7.31: correspondences for ${ }^{*} \mathrm{p}$ and ${ }^{*} \mathrm{w}$ in Mauwake and Barem

\begin{tabular}{|l|l|l|}
\hline PNA & Mauwake & Barem \\
\hline *mup- 'pull' & muf- & muw- \\
\hline *kapur 'lime' & afura & kawur \\
\hline *up- 'sing' & uf- & uw- \\
\hline *ip 'leaf' & ifa & iv \\
\hline *iduw- 'go' & itiw-, ikiw- & induw- \\
\hline *aw- 'get, do' & aaw- & aw- \\
\hline *mekiw 'land' & miiwa & mikiv \\
\hline
\end{tabular}

If Mauwake $f$ derives from historic ${ }^{*} \mathrm{w}$, this leaves unexplained why it devoiced in ifa 'leaf', for example, but not miiwa 'land'. For this reason, I reconstruct PNA *p and *w for these two correspondences. For cognate sets without a Bepour, Mauwake, or Mokati reflex to disambiguate between PNA $* \mathrm{p}$ and ${ }^{*} \mathrm{w}, \mathrm{I}$ have assumed it to be ${ }^{*} \mathrm{w}$.

An argument could be made to reconstruct a bilabial fricative *f for this correspondence, rather than a stop *p, given that stop reflexes are found only in Manep and Gavak. I have reconstructed PNA ${ }^{*} \mathrm{p}$, rather than $*_{\mathrm{f}}$, since the lenition or deletion of stops is a common process in Northern Adelbert languages. Tibor and Kaukombar languages lenited *t to $s$ in at least some environments, and PNA *k deleted or lenited to $h$ in several languages as well. It is therefore not surprising that lenition or deletion of $*_{p}$ is widespread. On the other hand, reconstructing $*_{f}$ for this correspondence would require positing a fortition of $*_{\mathrm{f}}>p$ in Manep and Gavak, and there are no parallel fortitions of PNA * $\mathrm{s}$ in these or other Northern Adelbert languages. 
The choice of reconstructing PNA *p rather than $* \mathrm{f}$ has consequences for classification of Northern Adelbert languages, as ${ }^{*} \mathrm{p}>*_{\mathrm{f}}$ is one of the two shared changes uniting the Kumil and Tibor subgroups. If PNA $* \mathrm{f}$ is reconstructed rather than $* \mathrm{p}$, this would leave $* \mathrm{y}>\varnothing$ as the only change uniting Kumil and Tibor.

\section{PNA *d, *t, and *s}

PNA had two alveolar stops $*$ t and $*$ d, and an alveolar fricative *s. Major changes to these phonemes in individual subgroups include the merger of $*_{t}$ and $* d$ with their corresponding velars in Proto-Kumil, and the merger of initial $*_{t}$ and $*_{s}$ as $*_{s}$ in Proto-Tibor.

Table 7.3m: reflexes of PNA *d

\begin{tabular}{|l|l|l|l|l|l|}
\hline Numugen & Manep-Barem & Tibor & Kumil & Kaukombar & Gavak \\
\hline$*_{\mathrm{d}}$ & ${ }_{\mathrm{d}}$ & $*_{\mathrm{d}}$ & *g, $_{\mathrm{g}}{ }_{\mathrm{t}}$ & ${ }_{\mathrm{d}}$ & $d, r$ \\
YAB: $d, j$ & BAR: $d, n d, j, n j$ & MOK: $d, t, n$ & BEP: $?, \varnothing$ & Maia: $d$ & \\
$\mathrm{USA}: d, r$ & MAN: $d, n d, j, n j$ & PAM: $t, n d$ & MOE: $k, n g k, t$ & Maiani: $t$ & \\
KARBO: $d, j, r$ & & HA: $t, n d, n$ & MAU: $k, t$ & Miani: $d$ & \\
KARBA: $d, j, r$ & & MAW: T, $n t, t$ & & Mala: $d$ & \\
UKU: $d$ & & KOw: $t, n d, n t$ & & & \\
PAR: $d$ & & & & & \\
YAR: $d$ & & & & & \\
\hline
\end{tabular}

Table 7.3n: reflexes of PNA *t

\begin{tabular}{|l|l|l|l|l|l|}
\hline Numugen & Manep-Barem & Tibor & Kumil & Kaukombar & Gavak \\
\hline$*_{\mathrm{t}}$ & $*_{\mathrm{t}}$ & ${ }_{\mathrm{t}}, *_{\mathrm{s}}$ & *k $_{\mathrm{k}}$ & $*_{\mathrm{t}}$ & $t$ \\
YAB: $t$ & BAR: $t, s$ & MOK: $s, t$ & BEP: $h, \varnothing$ & Maia: $t, s$ & \\
USA $t$ & MAN: $t$ & PAM: $s, t$ & MOE: $k, \varnothing$ & Maiani: $t, s$ & \\
KARBO: $t$ & & HA: $s, t$ & Mau: $\varnothing$ & Miani: $t, s$ & \\
KARBA: $t$ & & MAW: $s, t$ & & Mala: $t, s$ & \\
UKU: $t$ & & KOW: $s, t$ & & & \\
PAR: $t$ & & & & & \\
YAR: $t$ & & & & & \\
\hline
\end{tabular}

$*_{\mathrm{s}}$ is the only fricative in the PNA phoneme inventory. PNA *s is found in relatively few reconstructions, and usually occurs before $*$ i. Since $* t$ does not occur before $* i$, it may be possible to 
analyze them as two instantiations of the same proto-phoneme, with *[s] as the allophone of *t when it occurs before $*_{i}$. However, there are a few reconstructions where $*_{s}$ occurs before other vowels, such as *suw- 'push', *selew 'sand', and *sewaw 'sword grass'. Before these vowels, *s and *t are contrastive.

Table 7.3o: reflexes of PNA *s

\begin{tabular}{|c|c|c|c|c|c|}
\hline Numugen & Manep-Barem & Tibor & Kumil & Kaukombar & Gavak \\
\hline $\begin{array}{l}\varnothing \\
\text { YAB: } \varnothing \\
\text { USA: } \varnothing \\
\text { KARBO: } \varnothing \\
\text { KARBA: } \varnothing \\
\text { UKU: } \varnothing \\
\text { PAR: } \varnothing \\
\text { YAR: } \varnothing\end{array}$ & $\begin{array}{l}*_{\mathrm{S}} \\
\text { BAR: } \varnothing, s \\
\text { MAN } s\end{array}$ & $\begin{array}{l}*_{\mathrm{S}} \\
\text { MOK: } s \\
\text { PAM: } s \\
\text { HA: } s \\
\text { MAW: } s \\
\text { KOW: } s\end{array}$ & $\begin{array}{l}*_{\mathrm{S}} \\
\text { BEP: } s \\
\text { MOE: } s \\
\text { Mau } s:\end{array}$ & $\begin{array}{l}* \mathrm{t}^{95} \\
\text { Maia: } s \\
\text { Maiani: } s \\
\text { Miani: } s \\
\text { Mala: } s\end{array}$ & $S$ \\
\hline
\end{tabular}

\section{PNA *g and *k}

Correspondences for PNA $* \mathrm{~g}$ and $* \mathrm{k}$ are illustrated in Table $7.3 \mathrm{p}-\mathrm{q}$. Notable changes to $* \mathrm{k}$ are its lenition or deletion in most contexts in many Tibor, Kumil, and Kaukombar languages. In a few Numugen languages, $* \mathrm{k}$ has become $s$ before $* \mathrm{i}$.

Table 7.3p: reflexes of PNA *g

\begin{tabular}{|l|l|l|l|l|l|}
\hline Numugen & Manep-Barem & Tibor & Kumil & Kaukombar & Gavak \\
\hline${ }_{\mathrm{g}}$ & ${ }_{\mathrm{g}}$ & ${ }_{\mathrm{g}} \mathrm{g}$ & $* \mathrm{~d}$ & ${ }_{\mathrm{g}}$ & $\mathrm{g}$ \\
YAB: $g, \varnothing$ & BAR: $g, n g g, n g$ & MOK: $g \sim k$ & BEP:,$\varnothing$ & Maia: $g, \varnothing$ & Maiani: $k, \varnothing$ \\
USA: $g, \varnothing$ & MAN: $g, n g g, n g$ & PAM: $k$ & MoE: $k, n g k$ & Miani: $g, \varnothing$ & \\
KARBO: $g$ & & HA: $k$ & MAU: $k$ & Mala: $k$ & \\
KARBA: $g$ & & MAW: $k$ & & & \\
UKU: $g, \varnothing$ & & KOW: $?$ & & & \\
PAR: $g$ & & & & \\
YAR: $g, \varnothing$ & & & & & \\
\hline
\end{tabular}

95 Although the reflex of PNA *s is $s$ in all Kaukombar languages, this correspondence is reconstructed as ProtoKaukombar *t. $t$ and $s$ are in complementary distribution in all Kaukombar languages, and were in Proto-Kaukombar as well, so that Proto-Kaukombar *t had allophones *[t] and *[s] (see Chapter 11). 
Table 7.3q: reflexes of PNA *k

\begin{tabular}{|c|c|c|c|c|c|}
\hline Numugen & Manep-Barem & Tibor & Kumil & Kaukombar & Gavak \\
\hline $\begin{array}{l}\text { *k- } \\
\text { YAB: } k \sim 2, s, \varnothing \\
\text { UsA: } \sim \varnothing, s, \varnothing \\
\text { KARBO: } k, s, \\
\varnothing \\
\text { KARBA: } ?, s, \\
\varnothing \\
\text { UKU: } k, \varnothing \\
\text { PAR: } k \\
\text { YAR: } k, \varnothing\end{array}$ & $\begin{array}{l}{ }^{*} \mathrm{k} \\
\text { BAR: } k, q k, \\
\text { MAN: } k, g, \varnothing\end{array}$ & $\begin{array}{l}\text { *k- } \\
\text { MOK: } k \\
\text { PAM: } \varnothing, h, k \\
\text { HA: } h, k \\
\text { MAW: } \varnothing, h, k \\
\text { Kow: } h, ?\end{array}$ & $\begin{array}{l}{ }_{\mathrm{k}} \\
\text { BEP: } h, \varnothing \\
\text { MOE: } k, \varnothing \\
\text { Mau: } \varnothing\end{array}$ & $\begin{array}{l}{ }^{*} \mathrm{k} \\
\text { Maia: } \varnothing, k \\
\text { Maiani: } \varnothing \\
\text { Miani: } \varnothing- \\
\text { Mala: } n g, \varnothing\end{array}$ & $k, \varnothing$ \\
\hline
\end{tabular}

\section{PNA *m, *n, and * $\mathbf{y}$}

PNA had labial, alveolar, and velar nasals. PNA *m has undergone few changes, deleting only in some instances in Tibor languages. PNA *n has deleted word-finally in Tibor and Kaukombar. PNA $*_{y}$ is found almost exclusively in word-final position, with the single exception of *yam 'tree'. Most languages have either deleted $*^{\prime}$ or merged it with $*_{n}$.

Table 7.3r: reflexes of PNA *m

\begin{tabular}{|l|l|l|l|l|l|}
\hline Numugen & Manep-Barem & Tibor & Kumil & Kaukombar & Gavak \\
\hline$*_{\mathrm{m}}$ & ${ }_{\mathrm{m}}$ & *m, $_{\mathrm{m}}$ & ${ }_{\mathrm{m}}$ & ${ }_{\mathrm{m}}$ & $m$ \\
YAB $m$ & BAR: $m$ & MOK: $m, \varnothing$ & BEP: $m$ & Maia: $m$ & \\
USA $m$ & MAN: $m$ & PAM: $m, \varnothing$ & MOE: $m$ & Maiani: $m$ & \\
KARBO: $m$ & & HA: $m, \varnothing$ & MAU: $m$ & Miani: $m$ & \\
KARBA: $m$ & & MAW: $m, \varnothing$ & & Mala: $m$ & \\
UKU: $m$ & & KOW: $m, \varnothing$ & & & \\
PAR: $m$ & & & & & \\
YAR: $m$ & & & & & \\
\hline
\end{tabular}

Table 7.3s: reflexes of PNA *n

\begin{tabular}{|l|l|l|l|l|l|}
\hline Numugen & Manep-Barem & Tibor & Kumil & Kaukombar & Gavak \\
\hline$*_{\mathrm{n}}$ & $*_{\mathrm{n}}$ & $*_{\mathrm{n}}, \varnothing$ & $*_{\mathrm{n}}$ & $*_{\mathrm{n}}$ & $n$ \\
YAB: $n$ & BAR: $n$ & MOK: $n, \varnothing$ & BEP: $n$ & Maia: $n, \varnothing$ & \\
USA: $n$ & MAN: $n$ & PAN: $n, \varnothing$ & MoE: $n$ & Maiani: $n, \varnothing$ \\
KARBO: $n$ & & HA: $n, \varnothing$ & MAU: $n$ & Miani: $n, \varnothing$ \\
KARBA: $n$ & & MAW: $n, \varnothing$ & & Mala: $n, \varnothing$ \\
UKU: $n$ & & Kow: $n, \varnothing$ & & & \\
PAR: $n$ & & & & \\
YAR: $n$ & & & & & \\
\hline
\end{tabular}


Table 7.3t: reflexes of PNA * $\eta$

\begin{tabular}{|l|l|l|l|l|l|}
\hline Numugen & Manep-Barem & Tibor & Kumil & Kaukombar & Gavak \\
\hline$*_{\mathrm{n}}$ & $*_{\mathrm{n}}$ & $* \varnothing$ & $* \varnothing$ & $* \varnothing$ & $n g$ \\
YAB: $n$ & BAR: $n$ & MOK: $\varnothing$ & BEP: $\varnothing$ & Maia: $\varnothing$ & \\
USA: $n$ & MAN: $n$ & PAN: $\varnothing$ & MOE: $\varnothing$ & Maiani: $\varnothing$ & \\
KARBO: $n$ & & HA: $\varnothing$ & MAU: $\varnothing$ & Miani: $\varnothing$ & \\
KARBA: $n$ & & MAw: $\varnothing$ & & Mala: $\varnothing$ & \\
UKU: $n$ & & KOw: $\varnothing$ & & & \\
PAR: $n$ & & & & & \\
YAR: $n$ & & & & & \\
\hline
\end{tabular}

Gavak is the only language which retains $*^{\prime} y$ as a distinct phoneme. However, it is possible in some cases to reconstruct ${ }^{*} \eta$ without a Gavak reflex, based on the nasal correspondences in other languages. For example, $*_{\eta}$ is reflected as $n$ in Barem, and $\varnothing$ in Moere and Bepour, while $*_{n}$ is reflected as $n$ in both. These correspondences are illustrated in Table 7.3t.

Table 7.3t: correspondences for $* n$ and $* \eta$ in Moere and Barem

\begin{tabular}{|l|l|l|l|}
\hline PNA & Moere & Bepour & Barem \\
\hline *gemay 'liver' & kema & ema & gaman \\
\hline *madey 'man' & mangke & -- & mamunden \\
\hline *bugay 'post' & -- & pu'a & bugan \\
\hline *wapen 'hand' & ampen & wapen & omben \\
\hline *iben 'vagina & impen & ipen & imbien \\
\hline *demin 'how many' & kemin & emin & dimin \\
\hline
\end{tabular}

For some reconstructions, I have relied on Waskia, a related language outside Northern Adelbert, to decide between $* \eta$ and $* n$. For example, Proto-Manep Barem *wayan and ProtoKaukombar *waya 'white' could point to either PNA *wayan or *wayan. However, Waskia uyang 'white' points to *wayay. 


\section{PNA *r and *1}

Two liquid phonemes, *r and *1, are reconstructed for PNA. PNA *r much more frequent in the reconstructed vocabulary than $* 1$, which is only in a handful of reconstructions. Many Northern Adelbert languages have merged $* \mathrm{r}$ and $* 1$ into a single liquid phoneme, either $/ \mathrm{r} /$ or $/ 1 /$. In my fieldwork I have found that there is often great variation in the realization of this phoneme both within and between speakers, with some realizations more $r$-like and some more $l$-like. In the source materials for some of the more poorly-documented languages, such as Hember Avu, both $<\mathrm{r}>$ and $<1>$ are used in transcriptions, but it is unclear whether they are phonemically contrastive. However, for a few languages, including, Mauwake and Manep, a distinction between $/ \mathrm{r} /$ and $/ \mathrm{l} /$ can be clearly demonstrated. Neither *r nor $* 1$ are found word-initially in any reconstructions, and in most Northern Adelbert languages they are either rare or unattested in word-initial position. This likely represents a phonotactic restriction of Proto-Northern Adelbert.

Table 7.3u: reflexes of PNA *r

\begin{tabular}{|c|c|c|c|c|c|}
\hline Numugen & Manep-Barem & Tibor & Kumil & Kaukombar & Gavak \\
\hline $\begin{array}{l}* \mathrm{r} \\
\text { YAB: } l \\
\text { USA: } r \\
\text { KARBO: } r \\
\text { KARBA: } l \\
\text { UKU: } l \\
\text { PAR: } r \\
\text { YAR: } l\end{array}$ & $\begin{array}{l}*_{\mathrm{r}} \\
\text { BAR: } r \\
\text { MAN: } r\end{array}$ & $\begin{array}{l}*_{\mathrm{r}} \\
\text { MOK: } l \\
\text { PAM: } l \\
\text { HA: } r \\
\text { MAW: } r \\
\text { KOW: } r\end{array}$ & $\begin{array}{l}{ }^{*} \mathrm{r} \\
\text { BEP: } r \\
\text { MOE: } r \\
\text { MAU: } r\end{array}$ & $\begin{array}{l}{ }^{*} \mathrm{r} \\
\text { Maia: } r \\
\text { Maiani: } r \\
\text { Miani: } r \\
\text { Mala: } r\end{array}$ & $r$ \\
\hline
\end{tabular}

Table 7.3v: reflexes of PNA *1

\begin{tabular}{|l|l|l|l|l|l|}
\hline Numugen & Manep-Barem & Tibor & Kumil & Kaukombar & Gavak $^{96}$ \\
\hline$*_{r}$ & $* 1$ & $*_{\mathrm{r}}$ & $* 1$ & $* 1$ & $r, l$ \\
YAB $: l$ & Bar: $r$ & MOK: $l$ & BEP: $l$ & Maia: $l$ & \\
USA $: r$ & Man: $l$ & PAM: $l$ & MoE: $r$ & Maiani: $l$ & \\
KARBo: $r$ & & HA: $r$ & MAU: $l$ & Miani: $r$ & \\
KARBA: $l$ & & MAW $: r$ & & & \\
UKU: $l$ & & KOW: $r$ & & & \\
PAR: $r$ & & & & & \\
Yar: $l$ & & & & & \\
\hline
\end{tabular}

96 Only two PNA reconstructions with *l have reflexes in Gavak. *kapil 'lime' is reflected as Gavak kivir, while *selew 'sand' is reflected as selep. 


\subsection{Sound changes in Gavak}

Chapters 7-11 outline the changes that have taken place in each branch of Northern Adelbert and their daughter languages, and reconstruct vocabularies for the proto-languages of each group. Gavak is a single-member primary branch of Northern Adelbert, however, and as such there is no proto-language to reconstruct for this branch. I outline the sound changes which took place in ProtoGavak relative to PNA below.

$* \mathbf{a}, * \mathbf{e}>\varnothing / \#$

Initial vowels $*$ a and $*$ e deleted in verb stems, as in *ag- 'to see' $>g_{-}, *^{*}$ an- 'to eat', $n-$, *aw- 'to

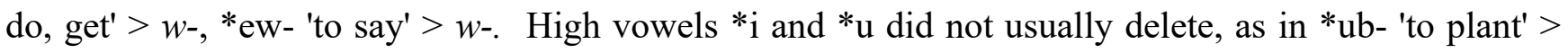
$u w-,{ }^{*}$ un- 'draw water' $>$ un-, $*$ in- 'sleep' $>$ in-, and $*$ id- 'give to plural' $>i r-$.

$* \mathbf{d}>\mathbf{r} / \mathbf{V}_{-}$

PNA *d lenited to $r$ after a vowel, as in *id- 'give to PL' > ir-, *wediem 'sun' > urume, *dul 'tail' $>\operatorname{arur}^{97}$ and the 3SG.PST suffix *-Vd $>-e r$.

$* \mathbf{k}>\varnothing / \# \mathbf{\&} * \mathbf{V}>/$ \#

Final $*^{*} \mathrm{k}$ deleted, as in *buruk 'pig' $>$ bur, ${ }^{*}$ merik $>$ mel, and *t(e/i)bik 'rain' $>$ tepik. These forms also illustrate the deletion of final vowels, which was fed by final *k deletion.

97 The initial $a$ in arur tail is likely a fossilized possessor morpheme, seen also in aip 'leaf' < PNA *ip, and anek 'tooth' < *nag. 
$* \mathbf{g}>\mathbf{k}$

Word-final *g devoiced to $\mathrm{k}$, as in *duag 'snake' > dok, *mag 'eye' > mek, *nag 'tooth' > anek, and *yag 'water' > yek.

$* \mathbf{b}>\mathbf{w} / \mathbf{V}_{-} \mathbf{V}$

PNA *b lenited to a glide $w$ intervocalically, resulting in a merger with ${ }^{*} \mathrm{~W}$ in this position. Examples are *ub- 'to plant' > uw-, *waben 'arm' > aven *kebuar 'mouth' > kawor.

$* \mathbf{a}>\mathbf{e} /$ C.

*a became $e$ in closed syllables, as in *yag > yek, *mag 'eye' > mek, *nag 'tooth' > anek, *magaw 'star' > magep, and *gar 'platform' > ger.

$* \mathbf{a}>\mathbf{0} / \mathbf{m}$

Before *m, *a become $o$, as in *mam 'taro' > mom, and *kam 'day' > kom. PNA *yam 'tree' has two reflexes: ngom 'tree' (singular) and $n g a m$ 'tree(s)' (general/plural).

${ }^{*} \mathbf{u a}>\mathbf{0}$

PNA *ua coalesced into $o$, as in *duag 'snake' > dok, *guang 'skin' > gong, and *kebuar 'mouth' $>$ kawor.

\section{Relative chronology of Gavak sound changes}

Deletion of final $* \mathrm{k}$ took place before devoicing of final stops and final vowel deletion, as illustrated in Table 7.4a. 
Table 7.4a: relative chronology of Gavak sound changes

\begin{tabular}{|l|l|l|l|l|}
\hline & *duag 'snake' & *yag 'water' & *buruk 'pig' & *merik 'eel' \\
\hline 1$) * \mathrm{k}>\varnothing / \#$ & -- & -- & buru & meri \\
\hline 2$) * \mathrm{~g}>\mathrm{k} / \#$ & duak & yak & -- & -- \\
\hline$* \mathrm{~V}>\varnothing / \# \#$ & -- & -- & bur & mer \\
\hline & dok & yek & bur & mer \\
\hline
\end{tabular}

If devoicing of final $* \mathrm{~g}$ had taken place first, it would have fed loss of final $* \mathrm{k}$, giving $*$ do for 'snake' and *ye for 'water'. Since the final consonant was not deleted in dok and yek, this indicates that * $\mathrm{k}$ deletion was already completed at the time ${ }^{\mathrm{g}} \mathrm{g}$ devoicing took place.

\subsection{Proto-Northern Adelbert lexical reconstructions}

In this section, I present the reconstructed Proto-Northern Adelbert vocabulary. First, I discuss Proto-Northern Adelbert pronouns and verb morphology. I then present my PNA reconstructions and supporting cognate sets.

\subsubsection{PNA pronouns}

I reconstruct three sets of PNA pronouns: free pronouns, possessive pronouns, and direct objectmarking prefixes ${ }^{98}$. The free pronouns are independent words whose reflexes in all languages refer to the subject of a clause. In some languages, such as Tibor and Kaukombar languages, they can be used to refer to any other kind of argument as well. In other languages, more pronouns for other kinds of arguments, such as possessors and direct objects, have been formed by suffixing the free pronouns

98 Reconstruction of the pronouns for individual subgroups' proto-languages are discussed in Chapters 8-11. 
forms. For example, Barem has formed dative pronouns by adding the element -tuk to the reflexes of the free pronouns (ituk 1SG.DAT, natuk 2SG.DAT, utuk 3SG.DAT, etc).

Table 7.5a shows the reconstructed free pronouns for PNA and for each Northern Adelbert subgroup (or in the case of Gavak, the attested forms). Reconstruction of the pronoun forms in each subgroup's proto-language is discussed in Chapters 8-11.

Table 7.5a: reconstructed free pronouns in PNA and subgroups

\begin{tabular}{|c|c|c|c|c|c|c|}
\hline PNA & P. Tibor & P. Kumil & P. M-B & P.Numugen & P.Kaukombar & Gavak \\
\hline *ye 1SG & $*$ ye & $*$ ye & $*_{\mathrm{i}}$ & $*$ ye & *yo & ying \\
\hline *ne $2 \mathrm{SG}$ & *ne & *ne & $*$ ne & $*$ ne & *no & ning \\
\hline${ }^{*}$ we $3 \mathrm{SG}$ & $*_{\mathrm{wO}}$ & *wo & $* \mathrm{u}$ & *we & *wo & aung \\
\hline *yin 1PL & *yik & *ik & $*$ in & $*$ in & *yi & yin \\
\hline$*_{\operatorname{nin}} 2 \mathrm{PL}$ & *nik & *nik & *nan & $*$ an & $*_{\text {nai, }}^{*}$ ni & $\operatorname{nin}$ \\
\hline$*_{\text {win }} 3 \mathrm{PL}$ & $*_{\text {wuk }}$ & ${ }^{*}$ wik & *un & $*_{\text {wed }}$ & $*_{\mathrm{wi}}$ & aun \\
\hline
\end{tabular}

Most subgroups reflect the PNA forms quite faithfully. Kumil-Tibor has rounded PNA *e to $\mathrm{PKT} *_{\mathrm{o}}$ in the $3 \mathrm{SG}$, which is not a regular change. However, it is not surprising, given that many Kumil-Tibor languages have undergone diachronic changes or have synchronic processes which round $e$ to $o$ adjacent to a labial consonant. Proto-Kaukombar also rounded PNA *e in the singular forms, but this was a regular sound change. Gavak added the suffix $-n g$.

For the plural forms, the Tibor and Kumil groups share the innovation of final *k which replaces PNA final $*$ n. Proto-Numugen has also innovated $2 \mathrm{PL} *$ an and $3 \mathrm{PL} *$ wed. The loss of final $*_{\mathrm{n}}$ in Proto-Kaukombar is regular. There are some discrepancies in the vowel for the $2 \mathrm{PL}$, which is *a in Proto-Manep-Barem and Proto-Numugen, but *i in the other languages.

Table $7.5 \mathrm{~b}$ shows reflexes of the PNA free pronouns in a representative language from each subgroup. Forms which have undergone irregular innovations are in parentheses. 
Table 7.5b: reflexes of PNA free pronouns

\begin{tabular}{|c|c|c|c|c|c|c|}
\hline PNA & P. Tibor & Bep. & Manep & Karian & Miani & Gavak \\
\hline *ye 1SG & ye & ye & $i$ & yo & yo & (ying) \\
\hline$*_{\text {ne }} 2 \mathrm{SG}$ & ne & ne & ne & no & no & (ning) \\
\hline${ }^{*}$ we $3 \mathrm{SG}$ & wo & wo & $u$ & wa & $O$ & (aung) \\
\hline *yin 1PL & (yik) & $i$ & in & in & $y i$ & yin \\
\hline$*_{\operatorname{nin}} 2 \mathrm{PL}$ & $(n i k)$ & $(n i)$ & nan & (an) & $n i$ & $\operatorname{nin}$ \\
\hline${ }^{*}$ win $3 \mathrm{PL}$ & $(w u k)$ & (wi) & un & $(w \partial r)$ & $w i$ & aun \\
\hline
\end{tabular}

PNA possessive pronouns are formed with affixation of the suffix *-ner to the free pronouns. Reflexes of *-ner are found in Manep-Barem, Numugen, Kaukombar, and the Kumil language Moere, but are not found in the Tibor languages or Gavak. The reconstructed PNA possessive pronouns and the reconstructions for individual subgroups are shown in Table 7.5c.

Table 7.5c: reconstructed possessive pronouns in PNA and subgroups

\begin{tabular}{|l|l|l|l|l|l|}
\hline PNA & Moere & P. M-B & P.Numugen & P.Kaukombar & Gavak \\
\hline 1SG *ye-ner & ener & $*_{\text {i-ner }}$ & $*_{\text {ye-ner }}$ & $*_{\text {yo-nor }}$ & $($ yem $)$ \\
\hline 2SG *ne-ner & nener & $*_{\text {na-ner }}$ & $*_{\text {ne-ner }}$ & $*_{\text {no-nor }}$ & $($ neme $)$ \\
\hline 3SG *u-ner & onor & $*_{\text {u-ner }}$ & $*_{\text {we-ner }}$ & $*_{\text {o-nor }}$ & $($ umo $)$ \\
\hline 1PL *yi-ner & $($ ikier $)$ & $*_{\text {in-ner }}$ & $*_{\text {i-ner }}$ & $*_{\text {yi-nor }}$ & $($ indime $)$ \\
\hline 2PL *ni-ner & nikiner & $*_{\text {nan-ner }}$ & $*_{\text {a-ner }}$ & $*_{\text {ni-nor }}$ & $($ nendime $)$ \\
\hline 3PL *wi-ner & wikiner & $*_{\text {un-ner }}$ & $*_{\text {wed-iner }}$ & $*_{\text {wi-nor }}$ & $($ undumo $)$ \\
\hline
\end{tabular}

Reflexes of *-ner are not found in Tibor, which does not have separate forms for the possessive pronouns. A reflex of *-ner is not found in Gavak either. Instead, Gavak possessive pronouns are formed with the suffix -me for the singular forms and -dime for the plurals. Moere is the only Kumil language with reflexes of the PNA forms, so it is listed in the place of Proto-Kumil in Table 7.5c.

The reflexes of the PNA possessive pronouns in Moere, Proto-Manep-Barem, Proto-Numugen, and Proto-Kaukombar are for the most part straightforward, following regular sound changes, including a change of PNA *e to Proto-Kaukombar *o. Affixation of possessive *-ner to the Proto-Numugen free 
pronouns *in '1PL' and *an '2PL' resulted in a sequence of two adjacent *n's, one of which deleted. An epenthetic *i was inserted between the Proto-Numugen free pronoun *wed '3PL' and *-ner, resulting in ${ }^{*}$ wediner. Moere ikier '1PL' is irregular, lacking the expected nasal reflex of *n.

Table 7.5d illustrates reflexes of the PNA possessive pronouns with a representative language from each subgroup (except Gavak and Tibor, which do not have reflexes).

Table 7.5d: reflexes of PNA Possessive pronouns

\begin{tabular}{|c|c|c|c|c|}
\hline PNA & Moere & Manep & $\begin{array}{l}\text { Yaben } \\
\text { (Numugen) }\end{array}$ & $\begin{array}{l}\text { Maia } \\
\text { (Kaukombar) }\end{array}$ \\
\hline $\begin{array}{l}\text { *ye-ner } \\
\text { 1SG }\end{array}$ & ener & $i-n e r$ & yənalu & yonor \\
\hline $\begin{array}{l}* \text { ne-ner } \\
2 \mathrm{SG}\end{array}$ & (ikier) & na-ner & nənalu & nonor \\
\hline $\begin{array}{l}{ }^{*} \text { we-ner } \\
3 \mathrm{SG}\end{array}$ & ne-ner & $u$-ner & wonalu & onor \\
\hline $\begin{array}{l}* \text { in-ner } \\
1 \mathrm{PL}\end{array}$ & niki-ner & ini-ner & inyinalu & inor \\
\hline $\begin{array}{l}* \text { an-ner } \\
2 \mathrm{PL}\end{array}$ & onor & nani-ner & anyinalu & ninor \\
\hline $\begin{array}{l}* \text { win-ner } \\
\text { 3PL }\end{array}$ & niki-ner & uni-ner & wajinalu & winor \\
\hline
\end{tabular}

Some Northern Adelbert languages have object-marking prefixes which are essentially the same in form as the free pronouns, sometimes with slight alterations to the vowel. This is the case in Maia for example, where the forms of the object prefixes differ from the free pronouns only in changes to the vowel, as illustrated in Table 7.6d. 
Table 7.6d Maia free pronouns and object prefixes

\begin{tabular}{|l|l|l|}
\hline & free pronouns & obj. prefixes \\
\hline 1SG & yo & $i$ \\
\hline 2SG & no & $n i-/$ no- \\
\hline 3SG & $o$ & $u-/ o-$ \\
\hline $1 \mathrm{PL}$ & $i$ & $i-$ \\
\hline 2PL & $n a e$ & $n i-$ \\
\hline 3PL & $w i$ & $w i-$ \\
\hline
\end{tabular}

As discussed in section 7.2, some Northern Adelbert languages have 1SG and 2SG singular object pronouns which are formed by addition a reflex of PNA *p to the free pronouns, resulting in PNA *ip- 1SG.OBJ and *nap- 2SG.OBJ ${ }^{99}$. In Mauwake, these are free standing pronouns. In Manep, Karian, and Gavak, the reflexes are prefixes ${ }^{100}$ that are used only with the verb 'to see'. Barem has both free standing pronouns and prefixes reflecting PNA *ip- and *nap-. In Barem as well, the prefixes are used only with 'to see'. Plural objects of 'to see' are marked with reflexes of the prefix *ib- in Barem, Manep, and Karian. Gavak also has a specialized plural object prefix used only with 'to see', but it is not cognate. Table 7.6e illustrates the reflexes of PNA object pronouns in individual languages.

Table 7.6e: reflexes of PNA object pronouns

\begin{tabular}{|l|l|l|l|l|l|}
\hline PNA & Mauwake & Barem $(\mathrm{QK})$ & Manep & Karian & Gavak \\
\hline *ip- 1SG & efa & iv-, ivo & -- & yo- & ip- \\
\hline *nap- 2SG & nefa & $n a v-$, nawo & $n a v-$ & $n$ - $^{-}$ & nap- \\
\hline 3SG & $\varnothing \varnothing$ & $\varnothing-$, uwo & $\varnothing-$ & $\varnothing-$ & $\varnothing-$ \\
\hline *ib- PL & -- & imb- & imb- & ivo- $^{101}$ & (iru-) \\
\hline
\end{tabular}

Although both Mauwake and Barem have free-standing object pronouns, they are not entirely cognate. The final $a$ in Mauwake ifa $1 \mathrm{SG} . \mathrm{OBJ}$ and nefa 2SG.OBJ is not cognate with the final $o$ in

$99 *$ *nap 2SG.OBJ also differs from the corresponding free pronoun *ne in the vowel.

100 Synchronically, they may be better analyzed as fossilized prefixes that are now part of the verb stem.

101 Karian actually has three plural object prefixes for 'to see': 1PL inyimbə-, 2PL anyimbə-, and 3PL ivə-. The 1PL and 2PL forms are derived historically from the corresponding pronouns plus *ib-. 
Barem ivo 1SG.OBJ and navo 2SG.OBJ. For this reason, I reconstruct PNA *ip- and *nap- as prefixes. Their use was possibly restricted to 'see', as in Manep, Karian and Gavak, with a later innovation for use as free standing pronouns in Mauwake and Barem.

\subsubsection{PNA subject/tense marking}

As outlined in the descriptions of individual languages in Chapters 1-6, most Northern Adelbert languages have verb endings that mark subject and tense. Under Hardin's (2002) analysis of Maia, verb endings mark subject and aspect/mood, not tense, and this analysis may apply to other Kaukombar languages as well. For the purposes of reconstructing PNA subject/tense endings ${ }^{102}$, I treat the Maia perfective-realis endings as equivalent to past tense in other languages, and imperfective-realis endings as equivalent to present or hodiernal tense in other languages.

Table 7.6f shows past tense endings from each Northern Adelbert subgroup, and the forms reconstructed for PNA. For Tibor, Numugen, and Kaukombar languages, the reconstructed forms are shown. Dashes in a cell indicate no form has been reconstructed. Mauwake represents the Kumil languages, and both Manep and Barem are included, as they each retain different parts of the PNA paradigm. Proto-Kaukombar endings are composed of the perfective aspect marker *-g(e), followed by a subject/realis mood marker. Proto-Numugen has added past tense marker *-i to the PNA endings.

102 In this section I refer to endings which occur on final verbs. The endings on medial verbs are much more diverse in both form and function across Northern Adelbert languages. The only reconstructed medial verb endings are the same subject markers *-be and *-eb. 
Table 7.6f: past tense/subject markers

\begin{tabular}{|c|c|c|c|c|c|c|c|}
\hline PNA & Mauwake & PTibor & Manep & Barem & PNum. & PKauk. & Gavak \\
\hline $\begin{array}{l}*-\mathrm{Vm} \\
1 \mathrm{SG}\end{array}$ & $\begin{array}{l}-a-m \\
-e-m\end{array}$ & *-em & $-u m i$ & $-m e$ & *_Vm(-i) & $*(-g e)-m o$ & $-u m$ \\
\hline $\begin{array}{l}*_{-a}(\mathrm{n} / \mathrm{\eta}) \\
*_{-} \mathrm{e}(\mathrm{n} / \mathrm{\eta}) \\
2 \mathrm{SG}\end{array}$ & $\begin{array}{l}-a-n \\
-e-n\end{array}$ & *-en & $\begin{array}{l}-a n \\
-e n\end{array}$ & $\begin{array}{l}-a n \\
-e n\end{array}$ & $* \operatorname{Vn}(-\mathrm{i})$ & $*(-g)$-ia & -eng \\
\hline $\begin{array}{l}* \text {-ad } \\
* \text {-ed } \\
3 \mathrm{SG}\end{array}$ & $\begin{array}{l}-a-k \\
-e-k\end{array}$ & *-et & -- & $\begin{array}{l}-a d,-e d,- \\
o d\end{array}$ & $*-\operatorname{Vr}(-\mathrm{i})$ & $*(-g e)-a$ & $-e r$ \\
\hline $\begin{array}{l}*-\min \\
1 \mathrm{PL}\end{array}$ & $\begin{array}{l}-(a-m i k) \\
(-e-m i k)\end{array}$ & *-emin & -umin & $-\min$ & ${ }^{*}-\min (-i)$ & *(-ge)-mi & $-\min$ \\
\hline $\begin{array}{l}* \text {-man } \\
2 \mathrm{PL}\end{array}$ & $\begin{array}{l}-a-m a n \\
-e-m a n\end{array}$ & *-eman & -uman & $(-m a)$ & *-man(-i) & -- & -men \\
\hline $\begin{array}{l}* \text {-mid } \\
3 \mathrm{PL}\end{array}$ & $\begin{array}{l}-a-m i k \\
-e-m i k\end{array}$ & *-emid & (-umin) & -mid & ${ }^{*}-\operatorname{mid}(-\mathrm{i})$ & -- & - mit \\
\hline
\end{tabular}

For the PNA 1SG.PST marker *-Vm, it is only possible to reconstruct the consonant, since the vowel is not consistent across individual subgroups, and it sometimes precedes, and sometimes follows *m.

Two forms are reconstructed for both the 2SG.PST and the 3SG.PST, one with *a, and the other with *e. In Mauwake, Manep, Barem, and possibly Numugen languages, the use $e$ or $a$ in the suffix depends on the verb's class. ${ }^{103}$ For the 2SG.PST, Kumil-Tibor languages indicate final *n, but Gavak indicates final $* \eta$. The other languages are ambiguous.

For the plural endings, both Mauwake and Manep have one form for 1/3PL.PST. Mauwake 1/3PL -mik it is a reflex of the PNA 3PL.PST *-mid, with a regular sound change of $* \mathrm{~d}>k$. Manep 1/3PL -umin is a reflex of PNA 1PL.PST *-min. Manep also uses the same forms for 2/3SG.PST, derived from the PNA 2SG.PST.

Table 7.6g shows the endings for either present tense or hodiernal tense, or in the case of ProtoKaukombar, imperfective/realis. In every subgroup, the forms in Table $7.6 \mathrm{~g}$ are morphologically

103 Two allomorphs with $e$ and $a$ in the 3SG endings are also found in Tibor languages, but in the 3SG hodiernal endings, not the past tense ending. 
related to the past tense forms illustrated in Table $7.6 \mathrm{f}$ for at least some endings. In Numugen and Kaukombar, the past endings simply add an additional suffix to the present endings. In the other subgroups, it is the reverse; the present tense endings are formed by adding morphology to the past tense endings. Mauwake present tense is formed with the addition of the present tense marker $-i$ to the past tense forms, and Manep present tense is formed with the addition of $-i k$. The Proto-Tibor 1SG hodiernal is formed by adding -ek to the 1SG past form (the forms of other Proto-Tibor hodiernal suffixes are not related to their past tense counterparts). For Barem, the hodiernal endings have initial $k$ where the past tense endings have initial $m$ or a vowel. Gavak 2SG and 3SG present are formed by adding -ng to their past tense counterparts. What all these languages have in common is the present/hodiernal tense is related to the past tense through the addition of some kind of velar. A PNA present tense marker *-ik can tentatively be reconstructed based on the Mauwake, Manep, and ProtoTibor 1SG forms, and Barem could also reflect this, with unexplained loss of $* \mathrm{i}$. However, the element -ng used with the Gavak 2SG and 3SG present endings is not the expected reflex of *k.

Table 7.6g: present tense/subject markers

\begin{tabular}{|c|c|c|c|c|c|c|c|}
\hline & Mauwake & $\begin{array}{l}\text { PTibor } \\
\text { HOD }\end{array}$ & $\begin{array}{l}\text { Manep } \\
\text { PRS }\end{array}$ & $\begin{array}{l}\text { Barem } \\
\text { HOD }\end{array}$ & PNum. & PKauk. & $\begin{array}{l}\text { Gavak } \\
\text { PRS }\end{array}$ \\
\hline $1 \mathrm{SG}$ & $-i-y e m$ & *-ekem & -ikimi & $-k e$ & $*-\mathrm{Vm}$ & *-mo & -em \\
\hline $2 \mathrm{SG}$ & $-i-n$ & $*$-ik & -ian & $-k a n$ & *-Vn & *-ia & -ng-eng \\
\hline $3 \mathrm{SG}$ & $-i-y a$ & * -ak/-ek & -egan & $-k o,-k a$ & $*_{-} \mathrm{Vr}$ & *-ad & -ng-er \\
\hline 1PL & $-i-m i k$ & *-emig & -ikimin & $-k i n$ & *-min & *-mi & -emin \\
\hline $2 \mathrm{PL}$ & $-i-m a n$ & *-emag & -ikaman & $-k a$ & *-man & -- & -emen \\
\hline $3 P L$ & $-i-m i k$ & -- & -ikimin & $-k i d$ & $*_{\text {-mid }}$ & -- & -emit \\
\hline
\end{tabular}

It is not clear if the reconstructed PNA verb endings in Table $76 \mathrm{f}$ marked subject as well as tense, or only the subject. Since reflexes of these endings are used in both past and present tense conjugations in most languages, and also are used in future tense endings in languages like Gavak, I only assign the meaning of person/number of the subject to these endings. 


\subsubsection{PNA vocabulary}

Below I present the reconstructed PNA vocabulary with supporting cognate sets. I reconstruct a PNA form if there are reflexes with regular sound correspondences in at least two languages belonging to different branches of PNA. This includes cases where a reconstruction is based only on two adjacent or nearby languages. For example, PNA *ten 'branch' is based only on Manep and Gavak reflexes. As Manep and Gavak are adjacent and speakers of these languages are in regular contact, there is a possibility that this lexical item spread from one language to the other through borrowing, rather than both languages inheriting it from PNA.

If resemblant forms are found in two languages, but the sound correspondences are not regular, I do not reconstruct a PNA form. For example, Manep karerak and Gavak karerang 'parrot' resemble each other, but final $k$ in Manep and final $n g$ in Gavak are not a regular correspondence, so I do not reconstruct a PNA form based on these words.

When the reflexes are ambiguous between the presence or absence of a segment in PNA, that segment is listed in parenthesis in the reconstruction. For example, reflexes of *gabe(k) 'bone' are ambiguous between *gabe and *gabek. When reflexes are ambiguous between two segments, both segments are listed in parentheses with a slash between them, as in *muga(n/y) 'bird'. When a lexical item for a particular language is listed in parentheses, this indicates that, although the item resembles forms in other languages, it is not cognate. These forms are included for the sake of completeness, to indicate that they have been identified as non-cognate. 


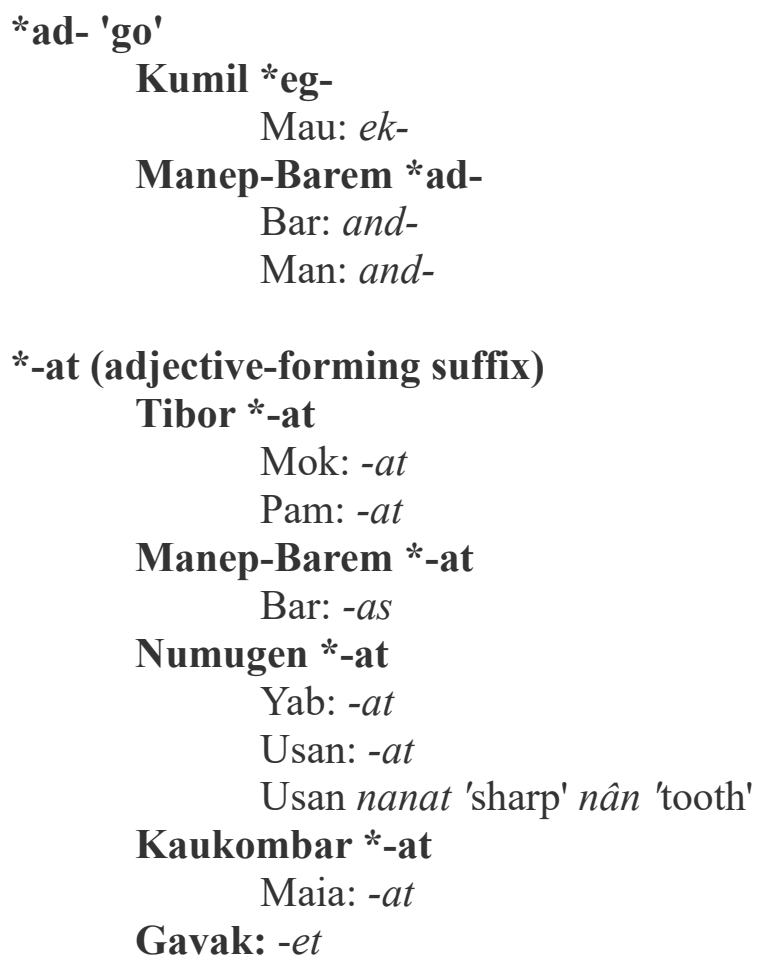

Gavak: -et

In all languages but Gavak, the reflexes of *-at appear to be fossilized morphology that is no longer productive. It derives an adjective from a noun, for example Pamosu kupil 'saliva' and kupilat slippery, or Proto-Kaukombar *yag 'water' and *yag-at 'wet'. Two derived adjectives with this suffix have been constructed for PNA: *bin-at 'heavy' from *bin 'weight', and *ked-at 'red' from *ked 'blood'.

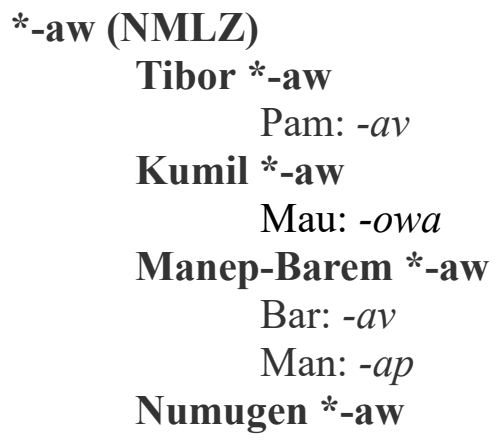

Reflexes of *-aw are used to form gerunds and derived nouns.

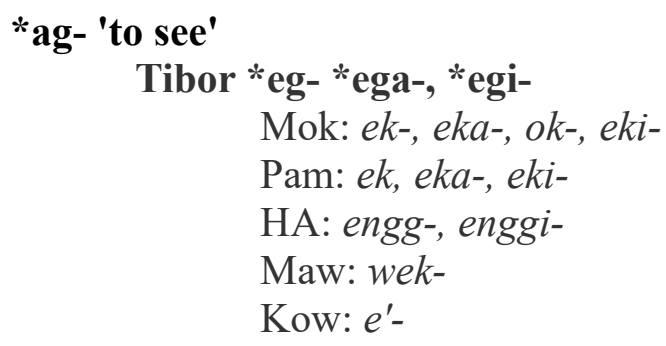




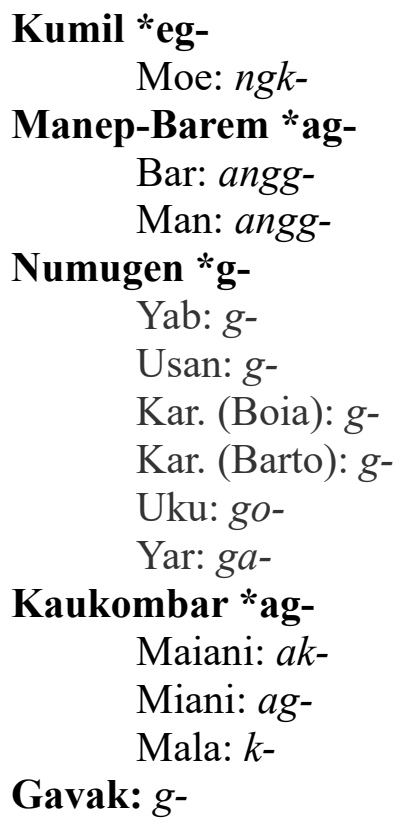

In the Tibor languages with multiple roots, reflexes of *ega- is used with past tense, *eki- is used with imperatives, and *ek- is used with other conjugations (see section 3.1 on multiple stems in Tibor languages).

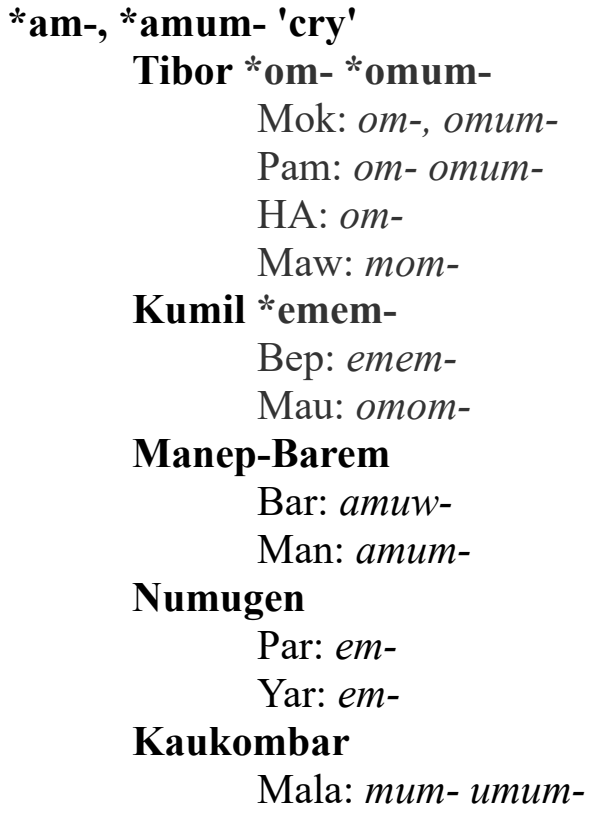

Par: em-

Yar: em-

Kaukombar

Mala: mum- umum-

\section{Gavak: $m$ -}

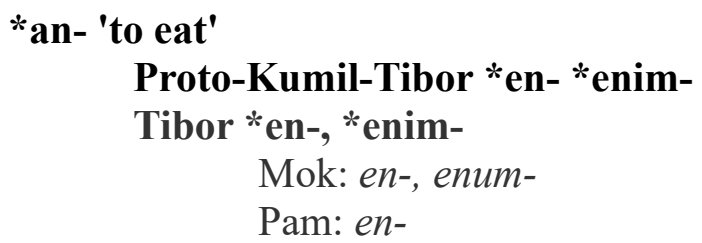


HA: en-, enum-, onum-

Maw: enim-

Kow: en-

Kumil *en-, *enim-

Bep: en-

Moe: nem-

Mau: enim-

Manep-Barem *an-

Bar: an-

Man: an-

Gavak: $n$ -

Proto-Numugen *ni- is likely related.

*ar- 'become'

Tibor: *al-, *el-, *a-

Mok: el-

Pam: al-, el-, a-

HA: al-, el-, a-

Kumil *ar-

Mau: ar-

Numugen

Usan: $-r$

Manep-Barem *ar-

Bar: ar-

Man: ar-

Usan $-r$ is a derivational suffix used to turn an adjective into a process verb (Reesink 1987: 46). The reflex of *ar- has a similar use in Manep, for example gadap 'strong' and gadawar- 'strengthen'.

*arakai 'road'

Tibor *ereke

Pam: elehe

HA: erehe

Kow: erihe

Kumil

Mau: era

Numugen *alakai 'road'

Yab: ala'i

Kar. (Boia): alakai

Kar. (Barto): ala'ai

Par: alakei

Uku: ([yake])

*arek 'trunk, piece'

Tibor *arek 'trunk'

Mok: alek 


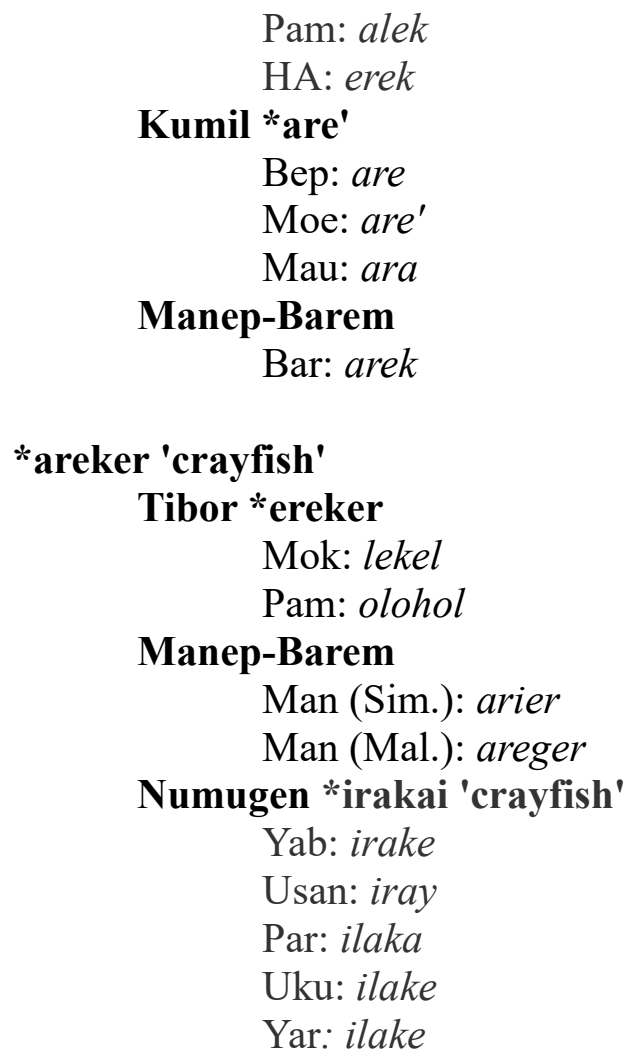

The Manep reflexes suggest that this reconstruction is bimorphemic *arek(e)-er, since the correspondence between Simbukanam $\varnothing$ and Malas $g$ is usually due to a morpheme boundary. The initial vowel in the Numugen forms does not correspond with Tibor and Manep-Barem.

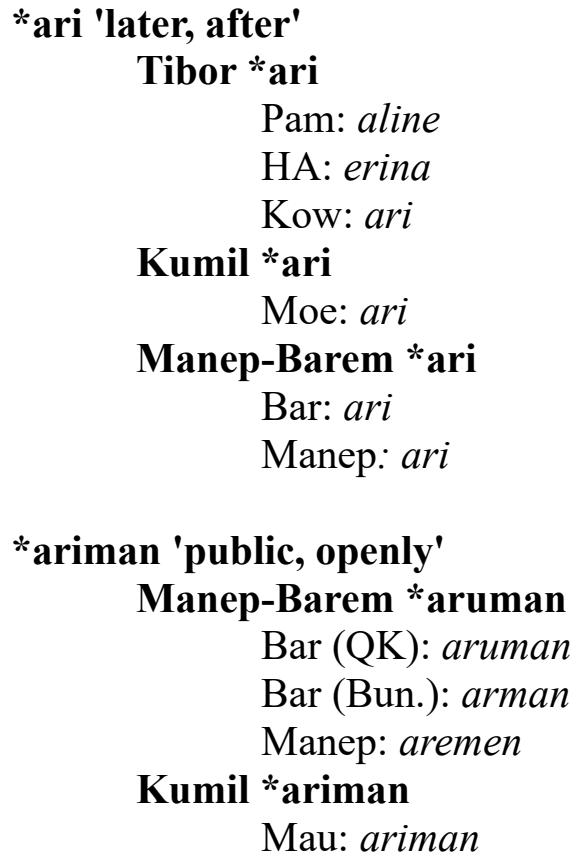

Mau: ariman 


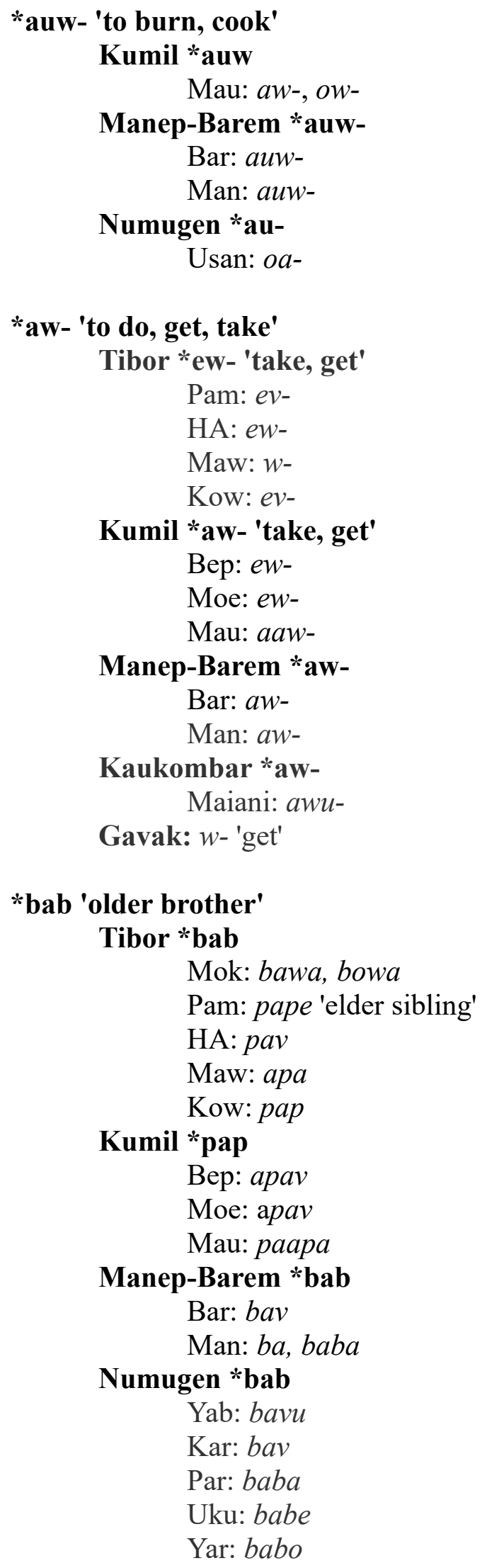



Kaukombar *-bab
Maia: $-b a v$
Maiani: - pap
Miani: $-b a b$
Mala: $-b a v, b a b a$

Gavak: $b a$

*babad- 'break, cut'

Manep-Barem *babad-

Bar: babad- 'break up, cut up'

Man: bamband- 'cut up'

Numugen *babad-

Kar: bəbər- 'break'

Kaukombar *bad-, *babad-

Maia: buad- 'cut', bua-buad- 'break into pieces'

Maia (Saki): bad- 'cut'

PNA *babad- may have been a reduplicated form (*ba-bad-), since both reduplicated and nonreduplicated forms are found in Kaukombar languages. However, it is not possible to reconstruct nonreduplicated *bad- for PNA, since reflexes are only found in Kaukombar.

*baner 'signal drum, ironwood tree'

Tibor *baner

Mok: banel

Pam: panol 'ironwood tree'

HA: banel

Manep-Barem *baner

$\operatorname{Bar}(\mathrm{QK})$ : banor

Bar (Bun.): banar

The ironwood tree (Tok Pisin kwila) is used to carve signal drums. Usan banderi 'signal drum' is similar but not cognate.

*badim 'platform, bed'

Manep-Barem *badim

Man: bandim

Kaukombar *badim

Mala: badim

*bak- 'carve, sharpen'

Tibor *bak-

Pam: pah-, pa-, pav-

Kow: apah-

Numugen *bak- *bakat-

Yab: ba'at-

Kar (Boia): bak-, bakat- 
Pamosu and Karian both have allomorphic variants of the same stem, but only one variant *bakis reconstructable to PNA. Barem $f k$ - 'carve' is similar, but would reflect initial *p, not *b.

*barat, *babarat 'year'

Manep-Barem

Bar: babaras

Kaukombar

Maia (Wagedav): barat

Mala: babarat

May be related to Proto-Numugen *bebel 'star'.

*baram 'hornbill'

Tibor

Mok: balom

Pam: kumbalom

HA: param

Manep-Barem *baram

Bar: baram

Man: buram

Numugen *baram

Kar: balam

Gavak: navuram

In Gavak $n a$ - is not an independent word, but is found on many bird names. This is possibly a loanword in at least some languages, as the change of $* \mathrm{a}>o$ in Mokati and Pamosu, and $* \mathrm{a}>u$ in Gavak are irregular.

*-be, -eb SS

Tibor

Kumil

Mok: $-e p$, be

Pam: -op (SS sequential), embe (SS coordinator)

Numugen

Mau: -ap/-ep (SS sequential)

Usan: $-\hat{a} b,-u b$

Kar: $-\boldsymbol{b} \boldsymbol{\partial}$

Gavak: -be

These suffixes and coordinators all mark same subject on a medial verb.

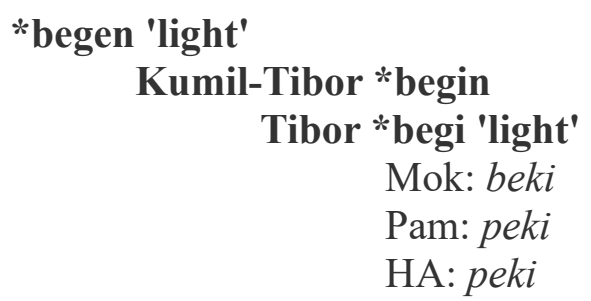




\section{Kumil}

Mau: paakina

Manep-Barem *begen

Bar: bagen, bigen

Man: bangen

Numugen *begen 'light'

Usan: begen

Kar: bagan

Kaukombar *bogo

Maia (Saki): bogo

$*_{\mathrm{e}}>i$ in Kumil-Tibor is irregular.

*ben 'adze/axe'

Kumil-Tibor *ben

Tibor *be

Pam: pe 'axe'

HA: be 'stone 'axe'

Kumil *pen

Mau: pena 'adze'

Manep-Barem *ben

Bar: ben 'axe'

Man: banu 'axe'

Numugen *ben

Usan: ben

Kar: bian

Par: $b a$

Uku: bon

Gavak: panu

*beren 'road'

Kumil-Tibor *beren 'road'

Tibor *bere 'road' (PNA *baren)

Mok: bele

$\mathrm{HA}$ : bele

Kumil *peren

Bep: peren

Moe: permua

Manep-Barem *baren

Bar: baren

Man: baren

Moere permua is 'road+man', with lenition of the medial syllable.

\section{*bik 'bamboo'}

Kumil *pika

Bep: piha 
Mau: pia

Manep-Barem *bik

Bar: bik

*bin *bin-at 'heavy, weight'

Tibor *bin-at

Mok: binat, binan

Pam: pinand

HA: binan

Maw: pinan

Kow: pinant

Kumil *pine'

Bep: pine

Moe: pine'

Mau: pina 'heavy, weight'

Manep-Barem *bin, *binat

Bar: bin

Man: binat

Numugen *binat

Yab: binatu

Usan: binat

Kar: binuat

Par: binata

Uku: binat

Yar: binata

Kaukombar *ubi 'heavy'

Maia (Wagedav): $u b i$ 'heavy, weight', ubin- 'be heavy'

Maiani: upi

Miani: $u b i$

Mala: $u m b i$

\section{Gavak}

binet

The initial $u$ in Kaukombar *ubi is likely the 3SG possessor prefix, at least historically. While in Maia $u b i$ both a noun 'weight' and an adjective 'heavy', the other languages are only glossed as 'heavy'. While PNA final *n deleted in Proto-Kaukombar, it is preserved in Maia ubin- 'be heavy', where it is not word-final.

*bug- *bugum- 'to sit'

Tibor *bug- *bugum-

Mok: buk-, bugum-

Pam: pukem-, puk-

HA: pukum, bug-, buk-

Maw: pok-

Kow: $p u^{\prime}-$, $p u^{\prime} u m-$

\section{Kumil *puk-}

Mau: pok- 


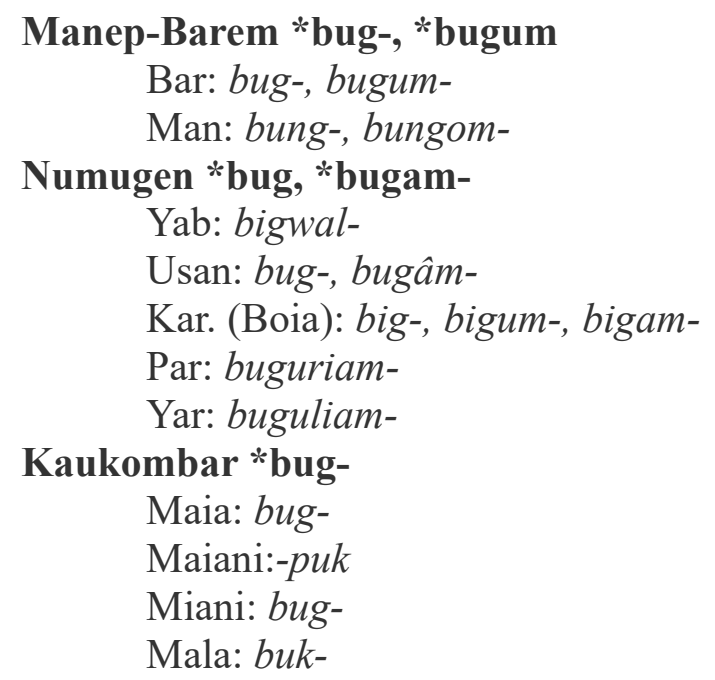

In Tibor, the reflexes of *bugum- are used with most past tense conjugations, present progressive, irrrealis/future, and imperatives. Tibor reflexes of *bug are used with hodiernal conjugations. In Manep-Barem, reflexes of *bug- are used with past and present tense, and *bugumwith future tense and imperatives. The pattern of distribution of the two forms in Numugen languages is not clear.

\author{
*bugan 'house post' \\ Tibor *boka, bokan \\ Mok: bokan \\ Pam: poka \\ HA: pokan \\ Kow: pu'an \\ Kumil *puga \\ Bep: $p u^{\prime} a$ \\ Mau: poka \\ Manep-Barem *bugan \\ Bar: bugan \\ Kaukombar *buga \\ Maia: buga \\ Mala: buka
}

Gavak: bugong

Final *y usually deleted in Kumil-Tibor, so the nasals in Mokati, Hember Avu, and Kowaki are unexplained.

\author{
*buruk 'pig' \\ Manep-Barem *buruk \\ Bar: buruk \\ Man (Sim.): buruk \\ Man (Mal.): buru \\ Numugen *buruk 'pig' \\ Yab: bulu
}


Usan: bur

Kar. (Boia): buru

Kar. (Barto): buru

Par: bulu

Uku: buruk

Yar: bulua

Gavak: bur

This is a borrowing from Austonesian (Proto-Oceanic *boRok 'pig').

*debik 'dirty'

Tibor *debik

Mok: dewik

HA: tembik

Kumil

Moe: tempi

Manep-Barem *debik

Man: jimbik

The expected Moere reflex is kempi.

\section{*degen 'straight'}

Kumil-Tibor *dagen

Tibor *degen 'straight'

Mok: degenat

Pam: teke

Kumil *gegen 'straight'

Bep: 'e'en

Moe: kengen

Mau: kakena

Manep-Barem *degen

Bar: digen

Man: dangen

Numugen *degen 'long', right (hand)'

Yab: daganu

Usan: degen

Kar: dagan

Par: (d^gasiki)

Uku: dogon

Yar: $\operatorname{dog} \Lambda$ na

Kaukombar *dogo 'straight', *dogon- 'stand'

Maia (Wagedav): dogo 'straight', dogon- 'stand'

Maia (Saki): dogon- 'stand'

Maiani: tokon- 'stand'

Miani: $\operatorname{dog} o$ 'straight', dogon- 'stand'

Mala: dokodoko 'straight' 
The expected Mauwake reflex is kekena. Rounding of *e in Yarawata is unexplained.

*darem- 'to stand'

Manep-Barem *darem-

Barem: darem-

Manep: darem-

Numugen *daram-

Yar: daram-

Kaukombar *derem-

Mala: terem- 'stand up'

*demin 'how many'

Kumil *gemin

Bep: emin

Moe: kemin

Mau: kamin

Manep-Barem *demin

Bar: dimin

The expectied Mauwake reflex is **kemin

*didum 'bottom'

Kumil *gugum

Mau: kukuma

Manep-Barem *didum

Bar: didum

*diruw 'buttress roots, roots above ground'

Tibor *diruw

HA: diluv

Kaukombar *-duruw

Maia (Wagedav): -durub 'roots above ground'

See also *durun 'roots'.

*duag 'snake'

Manep-Barem *duag

Bar: duang

Man: duang

Numugen *duag

Yab: dua

Kar . (Boia): duəg

Kar (Barto): duək

$\mathrm{Uku}$ : dua

Gavak: dok 


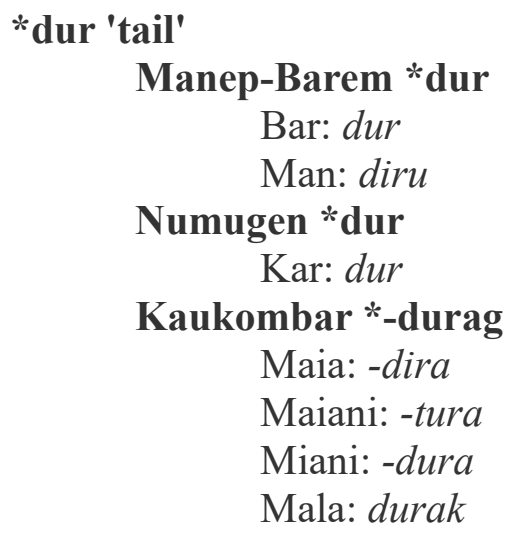

Gavak: arur

Proto-Kaukombar *-durag may be cognate, but the final syllable is unexplained.

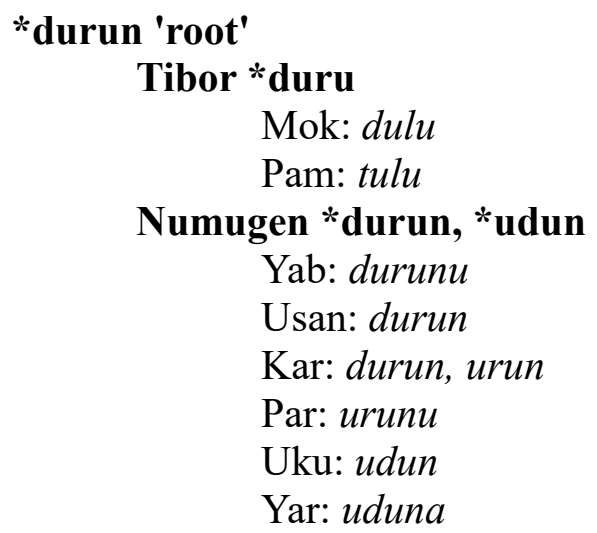

The similar form *diluw has the specific meaning of 'buttress roots', 'above ground roots'

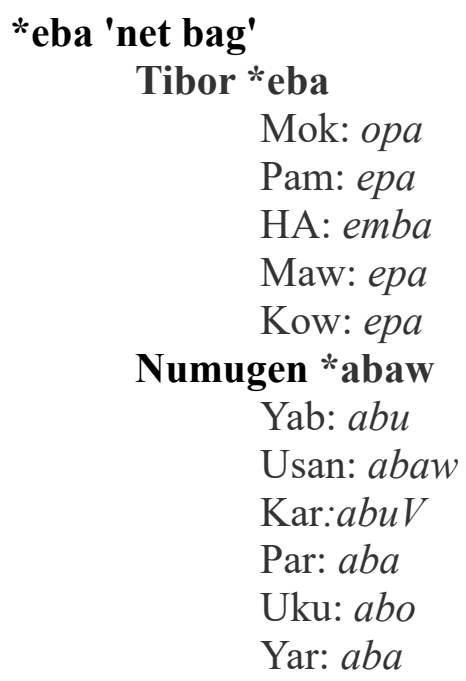




\section{Manep-Barem}

Man: $w$ -

Kaukombar *ew-

Mala: ew-

Gavak: $w$ -

The loss of the initial vowel in Manep is unexplained.

*gabe(k) 'rib'

Manep-Barem *gabe(k)

Bar: gabegarem

Gavak: gep

See *garem 'bone'

*gar 'platform'

Manep-Barem *gar

Bar: gar

Numugen *gar

Usan: gâr 'bed'

Gavak: $g e r$

*garem 'bone'

Manep-Barem *garem

Bar (QK): irigarem'face', gabegarem 'ribs'

Bar (Bun.): irigrem

Man: gamangarem 'chest' kumangarem 'nape'

Kaukombar *-garem 'bone'

Maia (Wagadev): -garum

Maia (Saki): -garum

Maia (Pila): -nggarum

Maiani: -karum

Miani: -garom

Mala: -garem

Reflexes of *garem are not attested as independent words in Manep and Barem, but are found only in compounds. Barem irigarem is a compound of irik 'face' and garem (irik 'face' is attested as an independent word). In Manep, kumangarem is a compound of kuman 'nape' and garem, and gamangarem 'chest' is a compound of gaman 'liver' and garem. It is therefore not clear that garem has the meaning 'bone' in Manep-Barem. However, the Barem expression for chest is gaman ksen 'liverbone', which suggests that the corresponding Manep expression could be bone-liver. The Maia varieties are expected to have the reflex **-garom, and Maiani is expected to be **-karom.

*gedaw 'strong'

Tibor *gedaw

Mok: getav

Pam: ketav 
HA: ketav

Manep-Barem *gadaw

Bar: gadav

Man: gadap

*gemay 'liver'

Kumil-Tibor *gema

Tibor *gema

Pam: kema

HA: gema fua 'lungs'

Maw: kema

Kow: 'ema

Kumil *gema

Bep: ema

Moe: kema

Mau: kema

Manep-Barem *gaman

Bar: gaman

Man: gaman

Kaukombar *-gema

Maia (Wagadev): -gama 'inside'

Maia (Saki): goama 'inside'

Maia (Pila): goama 'inside'

Maiani: -kema

Miani: -gema

Mala: -kama 'inside'

Gavak: gamemang

*girik- 'turn'

Tibor *giri, *giri fer-

Mok: gili

Pam: kili fel 'turn over (trns)', kili fuv- 'turn over (intrs), turn around'

HA: gilembik-

Maw: kiri fer-

Kumil *gir-

Bep: ir-

Moe- kir-

Mau: kir-

Manep-Barem

Bar: girik-

Man (Sim.): girig-, girug-

Man: (Mal.): giri-

Kaukombar

Maia (Wagedav): (kirik 'turn a log')

Gavak: gigiris- 'become, turn into' 
Maia kirik found in May \& Loewke (1982) and glossed as 'turn a log'. Presumably it is a verb stem. However, the expected reflex of PNA * $\mathrm{g}$ in Maia is $g$. In Pamosu and other Tibor languages, reflexes of * giri are coverbs used in conjunction with a light verb.

*guay 'skin'

Manep-Barem *gun

Man: gunu

Numugen *guan 'skin'

Yab: gwanu

Usan: goan

Kar: guən

Par: goana

Uku: guan

Yar: guana

Gavak: gong

The loss of *a in Manep gunu is unexplained.

*gun 'louse'

Kumil *guna

Bep: una

Moe: kuna

Mau: (kua)

Manep-Barem *gun

Bar: gun

Man: gunu

Numugen *gun

Yab: gunu

Usan: gun

Kar: gun

Par: gunu

Uku: gun

Yar: gun

Kaukombar *-gu

Maia (Wagadev): nagu

Maiani: aku

Miani: $a g u$

Mala: $-k u$

Gavak: igun

The expected Mauwake form is **kuna. The initial $n$ in Maia nagu is unexpected.

*gurum 'thick'

Tibor *gurum

Mok: gulum

Pam: kulum 


\section{Kumil *gurum}

Mau: kuruma

Manep-Barem *gurum

Bar: gurum

Man: gurum

\section{Numugen *gurum}

Kar: gurum

Gavak: gurum

*ib 'feces'

Tibor *ibu

Mok: ipu

Pam: ipu

HA: imbu

Maw: ipu

Kow: ipu

Kumil *ipa

Bep: ipa

Moe: триа

Mau: ipa

Manep-Barem *ib

Bar: imb

Man: imbu

Numugen *ibi 'feces'

Yab: $i b i$

Usan: $i b i$

Kar: ivi

Par: ibi

Uku: $i b i$

Yar: ibia

Kaukombar *-ib 'feces'

Maia (Wagadev): $-i b$

Maia (Saki): -im

Maia (Pila): -im

Miani: -ip

Mala: $-i b$

Gavak: $i v-o t$

Gavak ivot is a compound of $i v$ 'feces'+ vot 'fruit,seed'.

*iben 'vagina'

Kumil-Tibor *iben

Tibor *ibe

Mok: upe

Pam: upe

HA: imbe

Kow: ipe 


\author{
Kumil *ipen \\ Bep: ipen \\ Moe: impen \\ Mau: ipena \\ Manep-Barem *iben \\ Bar: imbien \\ Kaukombar *-ube 'vagina' \\ Maia (Saki): -be \\ Maia (Pila): -mbe \\ Miani: -ube
}

*id- 'give to $P L^{\prime}$

Manep-Barem *id-

Bar: -ind

Man: und-

\title{
Numugen
}

Usan: ind- 'give 1PL'

Kar: ind- 'give 1PL', aind- 'give to 2PL', ir- 'give to 3PL'

Kaukombar *yiet-, *niet-, *wiet-

Maia (Wagedav): i-es (give to 1PL), ni-es- (2PL) wi-es-3PL)

Mala: et- (give to 1PL), net- (2PL) ot-3PL)

\section{Gavak: $i r-$}

The Manep-Barem, Gavak, and Usan reflexes are used for any person plural object. In Karian and the Kaukombar languages, additional elements are added to distinguish person. However, these elements are not cognate between Karian and Kaukombar, so are not reconstructible to PNA. There has been an irregular change of PNA *d to Proto Kaukombar *t.

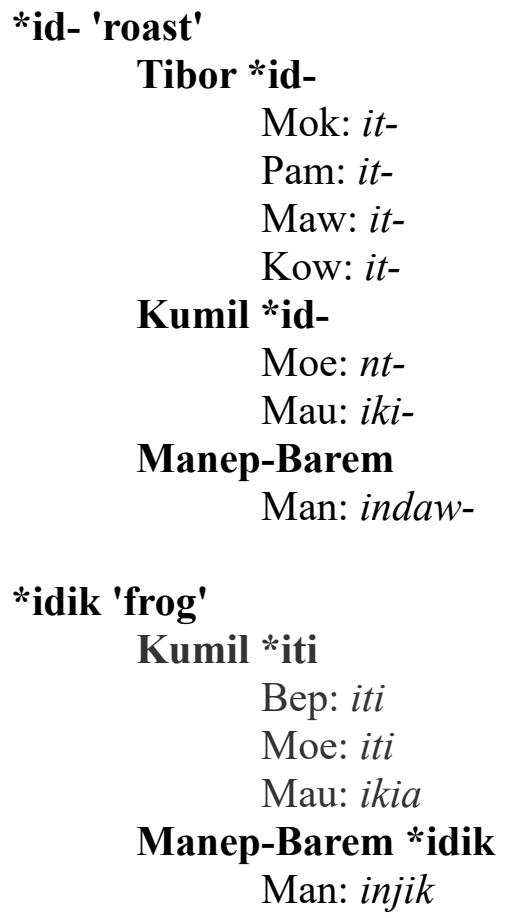

Moe: $n t-$

Mau: iki-

Manep-Barem

Man: indaw- 
*idin 'smell'

Tibor *idu

Pam: itu 'aroma'

HA: induw-

Kumil *ikin

Bep: itinew-

Moe: intinew-

Mau: ikina

Manep-Barem *idin

Bar: injin

This form seems to have been originally a noun or a coverb, which was reanalyzed as a verb stem in Hember Avu, and with a change of $* \mathrm{i}>$ Proto-Tibor $* u$.

*iduw- 'to go'

Tibor *idiw- to go' (see PNA *iduw)

Mok: iti- (itak)

Pam: itiv-

HA: indiw-

Kow: tiw-

Kumil *itiw-

Bep: itiv-

Mow: ntiv-

Mau: itiw-, ikiw-

Manep-Barem *iduw-

Bar: induw-

Man: injiw-

Numugen *idu-

Yab: ijuw-

Usan: $i j-$

Kar: $i j-$

Uku: id-

Yar: $i d-$

Kaukombar *iduw

Maiani: ituw-

Mala: induw-

Gavak: $d a w-, d u$ -

*ig-, *igVd- *igam- to be'

Tibor *ig-, *iga-, *igu-, *igam-, *igud-

Mok: ik-, ikua-, ikuam-, ikut-

Pam: ik-, ika, iku-, ikam-, ikal-

HA: ingga-, inggu-, inggam-, inggor-

Kow: 'a-, 'u-, 'am-, 'ot-

Kumil *ig-

Bep: $i^{\prime}-$ 
Mau: ik-, ika-

Manep-Barem *ig-, igid-

Bar: ingg-, inggid-

Man: ingg-, inggind-

Numugen *igw-, *igwad-

Yab: igw-

Usan: igo-, igâm-, igwar-

Kar (Boia): igw-, igwad-

Par: igu-

Uku: igw-

Yar: igwa-

Kaukombar *ig-

Maia: ig-

Maiani: ik-

Miani: ge-

Mala: ik-, iket-

In most languages, 'to be' has more stems than any other verb. Three of these stems can be reconstructed for PNA. In Tibor languages, *ikam- is used with past tense singular conjugations, *ikawith past tense plural, *ik- and *iku- are used with hodiernal, and *igud- is used with irrealis and imperatives.

\section{*igar- 'hit PL'}

Manep-Barem *inggar-

Man: inggar- 'hit PL'

Kaukombar *igar-

Kar: ig-, igal 'hit 3PL'

Gavak: gar- 'hit PL'

*iguar 'penis'

Kumil-Tibor *iguar 'penis'

Tibor *iguar 'penis'

Mok: ikal, ikual

Pam: ikual

HA: ingguar

Maw: ikual

Kow: u'ar

Kumil *igor

Bep: i'or

Moe: ingkor

Mau: ikora

Manep-Barem *iguar

Bar: ingguar

Man: unggwar

Numugen *iguar 'penis'

Yaben: igwalu

Usan: igoar 


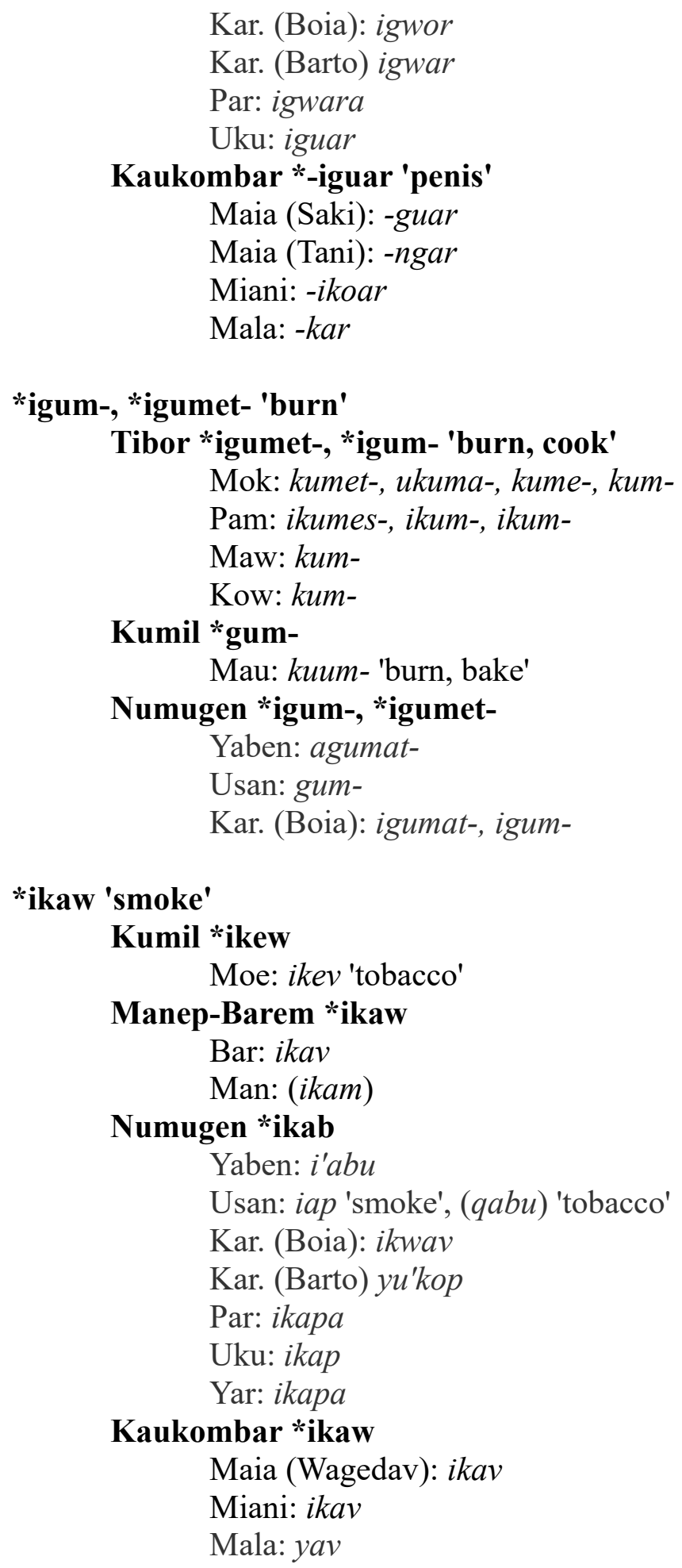

With the exception of Usan, the same form is used for 'smoke' and 'tobacco' in the Numugen languages. Usan qabu 'tobacco', is probably a borrowing, since Usan does not usually epenthesize a final vowel. The final $* b$ in Proto-Numugen does not correspond with reflexes of ${ }^{*} \mathrm{w}$ in other languages. 
*im 'hair'

Tibor *imi

Mok: imi

Pam: imi

HA: $i m i$

Maw: imi

Kow: imi

Numugen *im

Yaben: imu

Usan: $i m$

Kar: im

Uku: im

*im- 'boil, cook in pot'

Tibor *im-

Mok: im-

Pam: im-

HA: im-

Maw: im-

Kow: im-

Kaukombar *im-

Mala: im-

\section{*in- 'to sleep' \\ Tibor *in- \\ Mok: in- \\ Pam: in- \\ HA: in- \\ Maw: in- \\ Kow: in- \\ Kumil *in- \\ Bep: in- \\ Moe: in- \\ Mau: in-}

Manep-Barem *in-

Bar: in-

Man: in-

Numugen *in-

Yab: in-

Usan: in-

Kar: in-

Par: in-

Uku: in-

Yar: in-

Kaukombar *in-

Maia (Wagedav): in-

Mainia: in- 
Miani: in-

Mala: in-

Gavak: in-

*inigirik- 'to turn in one's sleep'

Kumil *inigirik-

Mau: inikiri-

Manep-Barem *inigirik-

Bar: ininggirik-

Derived from *in- 'sleep' and *girik- 'turn'.

*ip 'hair, leaf'

Kumil *ifa

Mau: ifa 'leaf'

Manep-Barem *iw 'leaf'

Bar: $i v$

Man: $i w u$

Kaukombar *-iw

Maia (Wagadev): wiv 'leaf'

Maiani: wuiv 'leaf'

Miani: wiv 'hair'

Mala: -iv 'hair'

Gavak: aip 'leaf'

*iper 'salt, ocean'

Tibor *ifer 'salt'

Mok: yel

Pam: ivol

HA: iver

Maw: ivir

Kow: iver

Kumil *ifer 'salt, ocean'

Bep: ifer

Mau: ifera

Manep-Barem

Bar (QK): ivor 'rain'

Numugen *iwer 'salt' (see also *yer 'ocean')

Yab: iwalu

Kar: yuar

Par: iwara

Uku: iwol

Yar: iwala

Kaukombar *iwer 'salt, sea'

Maia (Wagadev): ivor

Maia (Saki): ivor

Maia (Pila): iwor 
Miani: iwor

Mala: iver

QK ivor 'rain' is likely related. Polysemy between 'water' and 'rain' is found in Usan, Parawen and Yarawata.

*ir-, *iru- 'go up'

Tibor *ir-, *ira-, *iru-

Mok: il-ila-, ilu-

Pam: il-, ila-, ilu-

HA: ilak-

Maw: ir-

Kow: ir-, iru-

Kumil *ir-

Bep: ir-, iriw-

Moe: ir-, iraw-

Mau: ir-

Manep-Barem *ir-

Bar: ir-, iru-

Man: ir-

Numugen *ir-

Yaben: il-

Usan: ir-, iro-

Kar: ila-

Kaukombar *ir-

Maia (Wagedav): ir-

Miani: ir-

The velar in Hember Avu is unexplained.

*irin 'all'

Kumil-Tibor *irin

Tibor *irin

Mok: ilin

Pam: ilin

HA: irin

Kumil *irin

Mau: irina

Manep-Barem *irin

Bar: irinka

Man: irin

*iruar 'aibika greens'

Tibor *iruar

Mok: ilual

Pam: ilual

HA: iruar 


\section{Manep-Barem *iruar}

Bar: iruar 'aibika; megapode fowl'

Man: uruar 'megapode fowl'

Names of vegetables are often used as codewords for meat when guests are present, leading to the polysemy in Manep-Barem.

*irub- 'come up'

Tibor *irub-

Mok: ilov-

Pam: ilup-

HA: irumb-

Kumil *irup-

Mau: irip-, urup-

Manep-Barem *irub-

Bar: irumb-

Man: irumb-

\section{Kaukombar}

Mala: romb-

Z'graggen also gives iromb- for Mala 'go up'.

*irub- 'fill'

Manep-Barem *irub-

Bar: irumb-

Man: irumb-

Gavak: $i r b$ -

*isiw- 'leave behind'

Manep-Barem

Bar: $i v-$

Gavak: $i$ siw-

*it- *yag *it- 'bathe'

Tibor *is-

Mok: is-

Pam: is-

HA: $s i-$

Maw: is-

Kow: is-

Kumil *yagi-

Bep: yahi-

Moe: engkai-

Mau: yaki-

Manep-Barem *yag *is- 'bathe'

Bar: yanggu-

Man: yanggu is- 


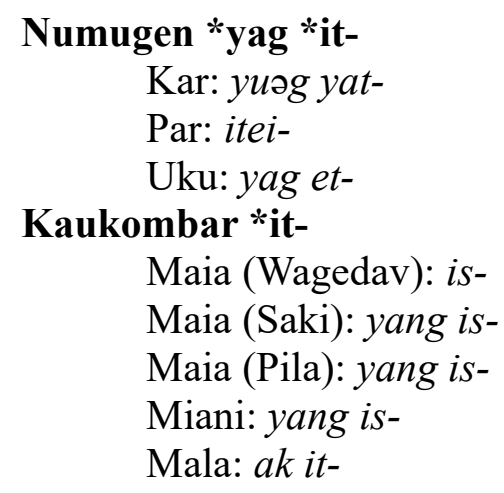

Gavak: yek is-

Reflexes of *it- do not always necessarily refer to bathing with water. For example Pamosu mundu famung is-u-ek [fire ash bathe-PRG-3.HOD] 'he is painting himself with fire ash' (Tupper 2012: 408). In Barem, yanggu- 'bathe' has formed from *yag *is- 'water bathe' with regular loss of *s. yanggu- can be used for bathing in things other than water, for example fumuang te yanggu-am-ko [dust LOC bathe-IPFV-R] 'he (a bird) bathing in dust'.

*ituw- 'take out'

Tibor *suw-

Pam: siv- 'detach, take out'

Manep-Barem *ituw-, *utuw- 'take out, take off'

Bar: ituw-, utuw-

Man: ituw-, utuw-

Kaukombar *tuw-

Maia (Wagedav) suv- 'pull out'

Gavak: uwit-

If Gavak is cognate it has undergone metathesis.

*iw- 'put'

Kumil *wi- 'put, place, set'

Moe: wi-

Mau: $w u-$

Manep-Barem *iw- 'put inside'

Bar: $i v-$

Man: iw-

*kai 'sugarcane'

Numugen * kai

Usan: qai

Par: $k a$

Uku: ke

Yar: kaya

Kaukombar *kai

Maia (Wagedave): $a i$

Maia (Saki): kai 
Maia (Pila): kai

Maiani: $a i$

Miani: $a i$

Mala: ngai

*kam 'day, sun'

Tibor *kamu

Mok (Wan.): kam beki 'daylight')

Pam: pekinamu (daytime)

HA: hamu 'sun'

Maw: (hemari)

Kow: (hemari)

Kumil *ama 'sun'

Bep: ama

Moe: $m$ иа

Mau: ama

Manep-Barem *kam 'sunlight, day, daytime'

Bar: kam

Man: kamu

Kaukombar *kam

Maia (Wagedav): (koiam)

Gavak: kom 'day, time, season'

* Kamar 'sago'

Numugen *kamar

Yab: 'amalu

Usan: amar

Kar. (Boia): 'amalu

Par: kamaru

Yar: komaru

Kaukombar *kamar 'sago' (<PNA *kamar)

Maia (Wagedave): amar

Maia (Saki): kamar

Maia (Pila): kamar

Miani: amar

Mala: namar

PNA *k regularly became $n g \sim n$ in Mala, but has only been recorded with $n$ for namar 'sago' (see Chapter 11).

*kamun 'pan'

Tibor *kamuna

HA: hamuna

Kowaki: hamuna

Kumil *amin

Bep: omin

Moe: muin 
Mau: amina

\section{Manep-Barem}

Man: kumun 'pot'

Kaukombar *kamun

Maia (Wagedave): wamun

Maia (Saki): kamung

Maia (Pila): kwamun

Miani: amun

Mala: ngamun, namun

Gavak: kamin 'pot'

Final $a$ in Tibor languages is unexplained. The expected Manep reflex is **kamun.

\section{*kanam 'later'}

Numugen *kanem

Yaben: 'anam

Usan: qanam

Kaukombar *kanam

Maia (Wagedav): anam

Maia (Pila): kanam

Miani: anam

*kapil 'grease, fat'

Tibor *kafir

Mok: (yal)

Pam: eval

HA: havil

Maw: awir

Kow: havir

Kumil *afil

Bep: afir

Moe: wisawir

Mau: afila

Manep-Barem *kawil

Bar: kavir

Manep: kavil

Kaukombar *kawil 'fat'

Maia (Wagedave): wavil

Maia (Saki): koawir

Maia (Pila): kuawir

Maiani: uwavil

Miani: awir

Mala: avir

Gavak: kivir

The Maiani form appears to have 3SG inalienable possessor prefix $u$-. Moere is a compound with wisa 'meat' as the first element. 
*kapur 'lime'

Kumil *afur

Bep: afur

Moe: fur

Mau: afura

Manep-Barem *kawur

Bar: kavur

Man: kavur

Gavak: kor

*kar 'skin'

Manep-Barem *kar

Bar: kar

Kaukombar *-kar

Mala: -ngar

Moere kar 'skin' looks similar but is not cognate, as the expected reflex for Moere would be **ara.

*karim- 'swell'

Tibor *kirim-

Mok: kilim-

HA: hirim-

Kumil *arim-

Mau: arim-

Manep-Barem *karim-

Bar (QK): karum-

Bar (Bun.): karm-

Man: karim-

Numugen *karim- 'to swell'

Yab: alim-

Usan: arim-

Kar. (Boia): karim-

Yar: karim-

Kaukombar *karim- 'swell'

Maia (Wagedave): arim-

Maia (Saki): karim-

Maia (Pila): karim-

Mala: ngarim-

The change of $* \mathrm{a}>i$ in Tibor languages is irregular.

*kasik 'wild'

Tibor

Pam: wasik

HA: esik 


\section{Kumil *asi}

Mau: asia

Manep-Barem *kasik

Bar: ksik

Man (Sim): kasik 'very'

Man (Mal.): kasi 'very'

\section{Kaukombar}

Maia: katok

Mala: ato

Gavak: kusik

'Wild' is used as a modifier meaning 'very' in Waskia, so Manep kasik 'very' is not surprising. The change of $*_{\mathrm{i}}>o$ in Kaukombar languages is irregular.

\section{*kasin 'mosquito'}

Kumil

\section{Mau: iina}

Manep-Barem *kasin

Bar: kain

Man: kasin

Numugen *kain

Par: kaina

Yar: kaina

Kaukombar *kasi

Maia (Wagedave): asi

Maia (Saki): kasi

Maia (Pila): kasi

Maiani: asi

Miani: asi

Mala: ngasi

Gavak: kasin

Mauwake iina may not be cognate, since ${ }^{*} \mathrm{~s}$ is usually retained.

*keb 'speech'

Tibor*kopu

Pam: opu

Kow: hopu

Numugen*keb 'speech'

Yab: 'avu

Usan: $q o b$

Kar. (Boia): kavu

Kar. (Barto) 'avu

Gavak: kep 


\section{*kebuar 'mouth'}

Tibor*kebar 'mouth'

Mok: koval

HA: hember

Maw: apar

Kow: hopar

Kumil *opor 'speech'

Bep: opor

Mau: opora

Manep-Barem *kabuar

Bar: kambuar

Man: kambar

Numugen *kabar

Yab: kabal, kabali

Usan: abar, abari

Kar (Boia): kava-ilu

Kar (Barto) 'ava-ilu

Kaukombar *-kebuar 'mouth'

Maia (Wagadev): -wabuar

Maia (Saki): -kamnoar

Maia (Pila): -kambuar

Maiani: -epuar

Miani: -obuar

Mala: - ambar

Gavak: kawor

The vowel reflexes have irregularities in several languages. Karian kavailu is 'mouth' + 'hole'

*kew- 'say'

Tibor *kew-

Mok: kow-

Gavak: kew-

*ked 'blood'

Kumil-Tibor*ked 'blood'

Tibor *ketu 'blood'

HA: hetu

Kow: hetu

Kumil *ega 'blood'

Bep: $e^{\prime} a$

Moe: engka

Mau: aka

Numugen *ked 'blood'

Yab: 'adu

Usan: qeru

Kar. (Boia): kar

Kar. (Barto) 'ar 
Par: kara

Uku: kod

Yar: kada

Kaukombar *(k)od 'blood'

Maiani: ot

Miani: od

Mala: od, ond

Gavak: kakat

*ked-at 'red'

Kumil-Tibor *kedat

Tibor *ketat 'red'

Mok: ketat 'red'

Pam: etat 'red'

HA: hetat

Maw: etat

Kow: etat

Kumil *ege'

Moe: $n g k e^{\prime}$

Manep-Barem *kadat

Bar: karas

Man: kandat

Numugen *kadat 'red'

Yab: karatu

Kar. (Boia): karzt

Kar. (Barto) 'arat

Par: (kara)

Uku: (urat)

Kaukombar *kedat

Maia (Wagedav): kedat

Maia (Saki): kedat

Expected Kowaki reflex is hetat.

*k(a/e)kawin 'palm cockatoo'

Tibor *kVkawin

Mok: kakavin

HA: kekavin

Kumil

Mau: aawina

Manep-Barem

Bar: qkavin

It is not clear what vowel to reconstruct in the initial syllable, as the Mokati and HA reflexes do not fit a regular correspondence, and both the Mauwake and Barem reflexes are ambiguous between PNA $*$ a and $*$ e. 
*kemi 'bow'

Manep-Barem

Man: kimu

Kumil *ami

Bep: omi

Moe: $m u i$

Mau: amia

Numugen *kemi

Yab: 'ami

Usan: emi

Kar. (Boia): kami

Par: kami

Uku: komi

Yar: kamia

Kaukombar *kumui

Maia (Wagadev): umu

Maia (Saki): kumu

Maia (Pila): kumui

Miani: umui

Mala: mui

The vowel correspondences in the initial syllable are irregular.

*kenam 'base'

Tibor *kena

Mok: kena

Pam: ena

HA: ena

Maw: ena

Kow: hena

Kumil *kenem

Bep: enem

Moe: nem

Mau: onoma

Manep-Barem *kanam

Bar: kanam

Man: kanam

Numugen

Usan: qanam 'base' (of a tree)

Kaukombar *kenam 'base'

Maia (Wagadev): otowanam 'source, base, reason'

Maia (Saki): koanam

Maia (Pila): koanam

Miani: enam

Gavak: kenmang 
Gavak is kenmang 'base' is formed from the reflex of *kenam plus mang 'place, piece'. The source of oto- in Maia (Wagedav) is unclear. The most literal meaning of *kenam is the base of a tree, but it is used metaphorically for bases and origins of all kinds.

\section{*kepak flying fox}

\section{Prot Kumil-Tibor *kefak}

Tibor *kewak

HA: hevak

Maw: ewak

Kow: heva'

Kumil *efe' 'flying fox'

Bep: efe

Mau: $a f a$

\section{Kaukombar}

Maia kavakavak 'small bat'

Although the sound correspondences are perfect, Maia kavakavak should possibly be excluded. Flying foxes are quite large and are a food source. They are generally not considered to be the same kind of animal as small bats. Other reconstructions for 'flying fox' are PNA *malabuy, Proto-Numugan *nunai

*keta 'coconut'

Kumil-Tibor *keta

Tibor *keta

Mok: keta

Pam: eta

HA: heta

Maw: eta

Kow: heta

Kumil *eka

Moe: $k a$

Manep-Barem *kata

Bar: kta

Kaukombar *kata 'coconut'

Maia (Wagedave): ata

Maia (Saki): kata

Maia (Pila): kataw

Maiani: ata

Miani: ata

Mala: nata

\section{*ki Question particle}

Manep-Barem *ki

Bar: $k i$

Man: $i$

Numugen *ki

Usan: $q i$ 
Kar: $k i$

Kaukombar *i

Maini: $i$

Miani: $i$

Mala: $i$

In Barem and Karian, reflexes of *ki are used for polar questions. The expected Manep reflex is $* * k i$.

*kibem 'kundu drum'

Tibor *kibem

Mok: kivom

Kumil *ibem

Moe: mpem

Manep-Barem *kibem

Bar (QK): kimbem

Bar (Bun.): kimbiem

Man: kimbem

Numugen *kibem

Yab: siwamu

Usan: sibemi

Kar. (Boia): sivam

Par: kiboama

Uku: kibem

Yar: kibama

The expected Ukuriguma reflex is **kibom.

*kidar 'breadfruit'

Kumil *iger

Mau: ikera

Manep-Barem *kidar

Bar: kindar

Numugen: *kidar

Kar (Boia): kijar

*kilal 'night bird of prey'

Kumil *ilel

Mau: ilela 'owlet nightjar'

Numugen *kirar

Kar. (Boia): kiruar 'bird sp, night bird of prey'

Manep sirar 'night bird of prey' may be cognate with irregular change of ${ }^{*} \mathrm{k}>\mathrm{s} / \mathrm{i}$

*kima- 'tell'

Manep-Barem *kima-

Bar: kima 


\section{Numugen *kima-}

Kar (Boia): kima-

*kit 'meat'

Manep-Barem *kit

Bar: kit

Man: kitu

Numugen

Par: kitunea

Uku: kit

Yar: kitunia

The extra material in Parawen and Yarawata is unexplained.

*kuaken 'old'

Manep-Barem *kuken

Bar: qkon

Man: kuken

Numugen *kwakan 'old'

Yab: wa'anu

Usan: qoan

Kar. (Boia): kwakan

Kar. (Barto): 'wa'ən

The vowel correspondences do not match.

*kuar, *kakuar 'hot'

Manep-Barem

Man: kuar- 'be hot'

Bar: qkuar 'hot'

Gavak: kor, kakor

Both base and reduplicated forms can be reconstructed for PNA, but it is not clear if there is a difference in meaning.

\section{*kuari 'tulip tree'}

Kumil

Mau: (arina)

Numugen *kwari

Kar (Boia): kwari

Kar (Barto): 'wali

Kaukombar *wari

Maia (Wagedav): wari

Maiani: wari

Gnetum gnemon, called tulip in Tok Pisin, is a tree whose leaves are commonly cooked and eaten. 
*k(u/a)bum 'stinging nettle (Tok Pisin salat)'

Kumil *apuma

Mau: apuma

Manep-Barem *kubum

Bar: kumbum

Man: kumbum

Kaukombar:

Maia (Wagedav): wabum

The vowel in the first syllable in Manep-Barem indicates *kubum, but the Mauwake reflex indicates *kabum. Maia is ambiguous.

*kudi 'banana'

Manep-Barem *kudi

Bar: kundi

Man: kunju

Numugen *kwedi 'banana'

Yab: 'waji

Usan: qori

Kar. (Boia): kwaji

Par: kwari kwn:ri

Uku: kodi

Yar: kodia

Kaukombar *kudi 'banana'

Maia (Wagadev): idi

Maia (Saki): kidi

Maia (Pila): kindi

Maiani: $u t i$

Miani: $u d i$

Expected Barem reflex is kunji. The vowel in the first syllable of Proto-Numugen *kwedi is not cognate with other languages.

*kuduruk 'fly' (insect)

Tibor*kuduruk

Mok: kunduruk

Pam: unduruk

HA: hondoruk

Maw: unduruk

Kow: tiruk

Kumil *uguru

Bep: mu'uru

Moe: mukuru

Mau: kuura

Manep-Barem *kuduruk

Bar (QK): kunduruk 
Bar (Bun.): kunruk

Man (Sim.): kunduruk

Man (Mal.): kunduru

Numugen *kuduruk

Yab: udulu

Usan: urur

Kar. (Boia): kururu

Kar. (Barto): ululu

Uku: kuduruk

Yar: kudulu

Kaukombar *kuduru

Maia (Wagadev): aduru

Maia (Saki): kaduru

Miani: udiru

Mala: uduru

Gavak: (karer)

Bepour mu'uru and Moere mukuru 'fly' probaby reflect PKT *ma 'small flying insect' plus *kuduruk 'fly'. The expected Mauwake reflex is **ukura, rather than the attested kuura. The consonants in Gavak karer 'fly' fit the expected reflexes, but the vowels do not, so it is probably not cognate.

\section{*(k/g)ugu(t/d) 'shadow' \\ Tibor *gugut \\ Mok: gukut \\ Pam: kukut \\ HA: mukukut \\ Maw: kukut \\ Kow: 'o' $u$}

\section{Kumil}

Bep: (o'ut)

Moe: ngkuku

Mau: (kukusa)

\section{Manep-Barem}

Bar: (kinggur)

Numugen *kugud

Yab: 'ugudu

Usan: qugur

Kar: kugur

Kaukombar *-gugud

Maia (Wagadev): -gugud

Miani: -gugun

Mala: -gugut

This reconstruction is problematic, as the voicing of the initial and final stops don't correspond across the subgroups. However, given that voiced stops undergo conditioned changes, in the 
enviroment of other voiced stops, and this reconstruction potentially has three voiced stops, these could possibly be regular reflexes following as yet unidentified patterns.

*kukum 'dumb'

Kumil-Tibor *kukum

Tibor *kukum

Pam: uhum 'foolish, stupid'

Kumil *ukum

Numugen *kukum

Mauwake: opaimik uuma 'dumb'

Usan: quum 'deaf, dumb'

*kum 'brain'

Tibor *kum

Mok: kokum

Pam: mendekumu

HA: munumu

Maw: mundu kumu

Kow: munti'imu

Manep-Barem *kum

Man: kumu jinu, kumu kavil

Numugen *kum

Yab: akakum

Usan: qoum

Kar. (Boia): kakakum 'brain, marrow', taji kakakum 'brain'

Kar. (Barto): 'a'aum

Par: kumu

Uku: tarikum

Yar: kumu

Kaukombar *-kum

Maia (Wagedav): -kum

Miani: um

Mala: (umun)

Ukuriguma is 'head'+'brain'. Manep jinu also means 'brain', so it is not clear what the distinction between kumu and jinu is. Manep kumu kavil is 'brain'+'fat, grease'. It is not clear what the first element of the compound is in Tibor languaegs, but Pamosu mendekumu is apparantly monomorphemic now.

*kumay 'nape'

Tibor *kuma, kuma *genav

Mok: danggel kuma, kumanggena

Pam: uma ilu- 'raise head'

HA: uma

Maw: uma, uma kenav

Kow: huma'enap 


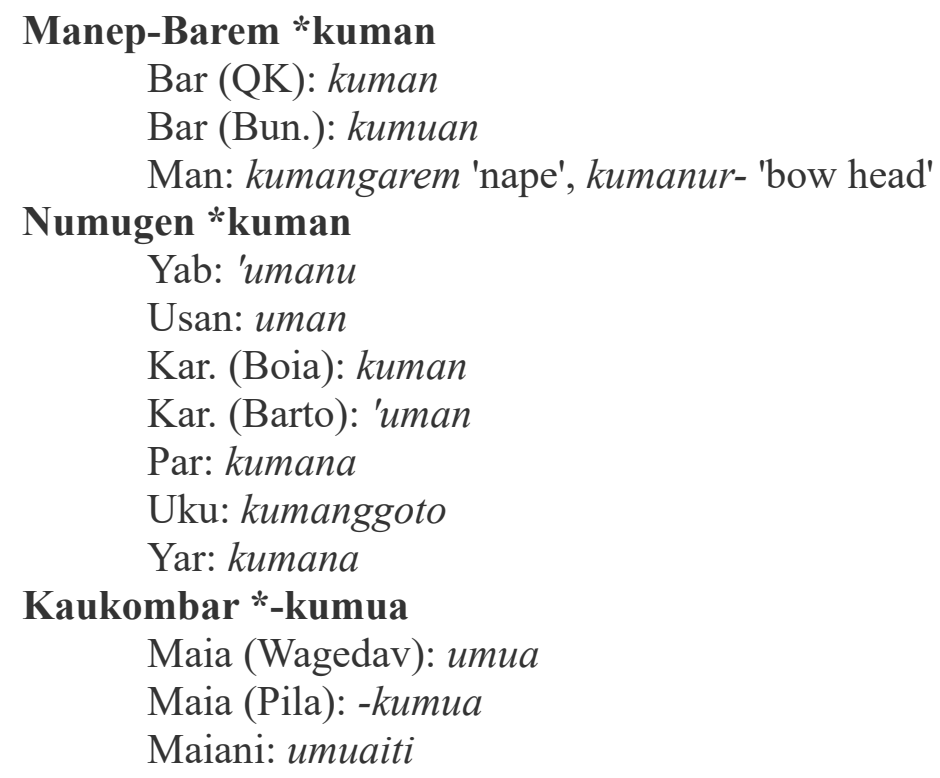

Waskia komang indicates this had a velar nasal. Mokati, Mawak, Kowaki, Manep, and Ukuriguma are 'nape'+'bone'

*kupi 'betelpepper vine'

Kumil *ufi

Bep: $u f i$

Mau: ufia

Manep-Barem *kuwi

Bar: kuvi

Kaukombar * kuwi

Miani: kuwi

Mala: $u w i$

\author{
*kurun 'black' \\ Manep-Barem *kurun \\ Bar: kurun \\ Man: kurun \\ *kurun 'black' (see also PN *umaw) \\ Yab: 'ulunu \\ Usan: urun \\ Kar. (Boia): kurun \\ Kar. (Barto): 'urun \\ *kurum 'valley' \\ Tibor *kurum \\ Mok: kakurum \\ HA: fakurum \\ Kumil *urum \\ Mau: epa uruma
}




\section{Manep-Barem *kurum}

Bar: kurum

Man: kurum

Numugen *kurum 'valley'

Usan: qurum

Kar. (Boia): kurum

Gavak: kurume

Mokati and HA are compounds, with the word for 'place' as the first element. The word for 'place is also seen in the Mauwake phrase.

*kumag, *kamug 'testicles'

Tibor *kumag

Mok: ikakumak

Pam: umang

HA: inggumang

Kumil *imeg

Moe: (kumang)

Mau: imeka

Manep-Barem *kumag

Man: kumang

Kaukombar *kamu

Maia (Wagedav): (-wamu)

Gavak: kamogot

Mokati and Hember Avu are compounds with 'penis' as the first element. Moere is likely a borrowing, as the expected reflex is **(i/u)meng. Gavak has is a compound with -ot 'fruit, seed'. Maia and Gavak also have swapped the places of the vowels.

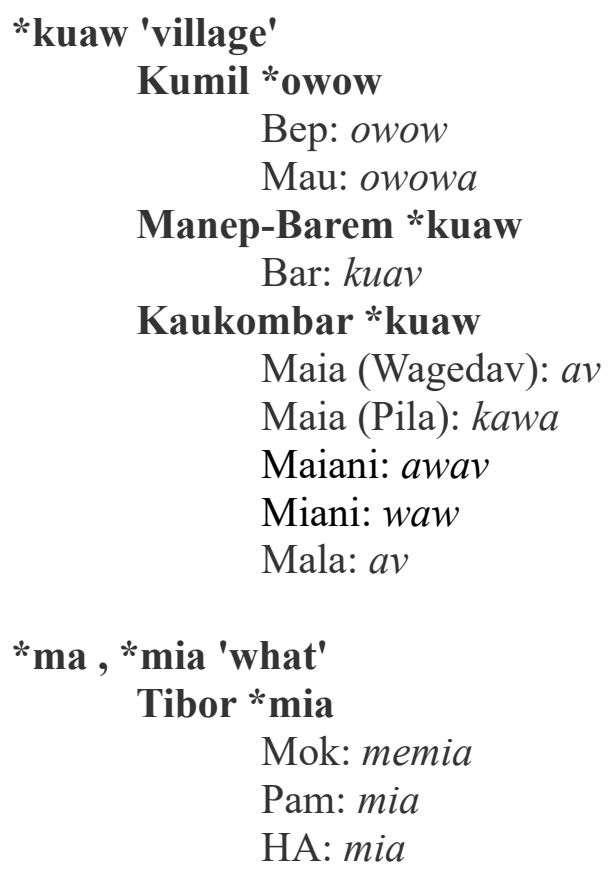

Bep: owow

Mau: owowa

Manep-Barem *kuaw

Bar: kuav

Kaukombar *kuaw

Maia (Wagedav): $a v$

Maia (Pila): kawa

Maiani: awav

Miani: waw

Mala: $a v$

*ma , *mia 'what'

Tibor *mia

Mok: memia

Pam: mia

HA: mia 
Maw: mamea

Kow: mea

Kumil

Bep: mia

Mau: mauwa

Manep-Barem *ma

Bar: $m a$

Man: masi

Numugen *ma

Yab: $m a$

Usan: mâi, meimi

Kar: məma, ma

Par: $m a$

Uku: $m a$

Yar: mama

Kaukombar *maia

Maia: maia

Maiani: maia

Miani: mia

Mala: mala

*ma- 'talk, say'

Kumil *ma-

Mau: $m a-$

Manep-Barem *ma-

Bar: $m a-$

*madey 'man'

Kumil-Tibor *made 'person'

Tibor *made

Mok: mande

Pam: mande

HA: mande

Maw: mande

Kow: mande

Kumil *mage

Moe: mangke

Manep-Barem *RED-maden

$\operatorname{Bar}(\mathrm{QK})$ : mamunden

Bar (Bun): mumdien

Numugen *made

Uku: mado, madon

Kaukombar *muade 'man'

Maia: muado

Maiani: muato

Miani: muado

Mala: muande 
The change of *a to $u a$ in the initial syllable of Proto-Kaukombar is irregular. The only indication of final $* y$ rather than $* n$ is the lack of final nasal on the Mauwake reflex, as word-final ${ }^{*} n$ is reflected as $n$ in Mauwake, but final *y was deleted.m

*mak 'behind, back'

Tibor

Pam: mahu 'behind'

Manep-Barem *mak

Bar: mak te, muak te 'behind, later' makten 'back'

Man: mak 'after' (mukur 'back')

*main 'weak, soft'

Tibor *men

Pam: men

Manep-Barem * main

Bar: main

Man: main

Numugen *mein

Usan: mein

Waskia maingar- 'weaken' indicates a velar nasal.

*maiw 'aibika greens'

Manep-Barem *maiw

Bar: maiv

Man: maip

\section{Numugen}

Kar: mai igəm

\section{*mam 'taro' \\ Tibor *ma \\ Mok: $m a$ \\ Pam: $m a$ \\ HA: $m a$ \\ Maw: $m a$ \\ Kow: $m a$}

Kumil

Moe: $m a$

Mau: moma

Manep-Barem *mam

Bar: mam

Man: mamu

Numugen *mam

Yab: mamu

Kar: mam

Par: mama 
Uku: mam

Yar: mamo

Kaukombar *mam

Maia (Wagadev): mam

Maia (Saki): mam

Maia (Pila): mam

Maiani: mam

Miani: mam

Mala: mam

Gavak: mom

Loss of final $* \mathrm{~m}$ in Moere is irregular.

*malabuy 'flying fox'

Kaukombar *marabu

Maia (Pila): marambo

Miani: marapu

Mala: marabu

Gavak: malewong

See also *kepak 'flying fox'

*mar 'wing'

Manep-Barem *mar

Bar: mar

Man: maru

Gavak: amer

*maur 'Victoria crowned pigeon'

Kumil *maur

Mau: muura

Manep-Barem *maur

Bar: maur

Numugen *maur

Karian: maur

*me 'NEG'

Tibor *me

Mok: $m \mathrm{~V}$ -

Pam: me-

Kumil *me

Bep: me

Moe: me

Mau: me

Manep-Barem *me

Bar: me 


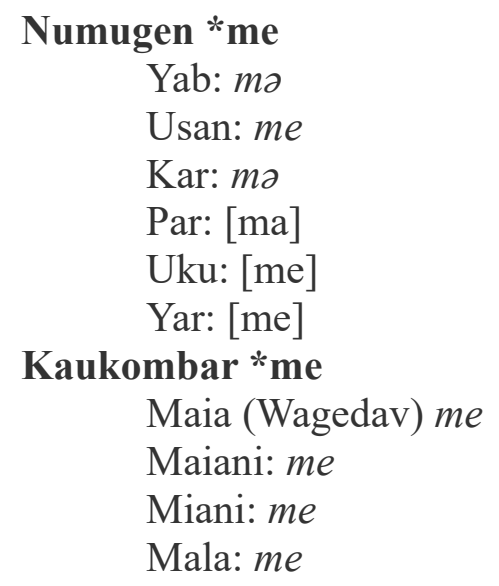

In all languages, reflexes of me precede the negated verb. In the Tibor languages, it is a prefix. The forms listed Parawen, Ukuriguma, and Yarawata are what Z'graggen transcribed, but these may not be accurately represent the vowel, as he transcribes [me] for Yaben and [ma] for Karian, but both of these in actuality have mo. If the Ukuriguma form is actually me, then it would be necessary to reanalyze the vowel phoneme inventory, as Ukuriguma does not have /e/ under my analysis,

*megam, *magaw 'star, year'

Kumil-Tibor*megam 'star, year'

Tibor *megam

Mok: menggam 'year'

HA: menggam 'star'

Maw: menggam 'star'

Kow: me'am 'star'

Kumil *megem

Moe: mengkem

Mau: mokoma

Manep-Barem *magam 'firefly'

Bar: manggam

Man: manggam

\section{Numugen}

Kar. (Barto): mwan'an

Kaukombar*magaw 'star'

Maia (Wagadev): magav

Maia (Saki): manggap

Maiani: makav

Miani: magav

\section{Gavak: magep}

Polysemy in Pamosu sepena 'star, year, firefly' supports the inclusion of Proto-Manep-Barem *magam 'firefly'. Kumil-Tibor and Manep-Barem suggest PNA *megam, but Gavak and Kaukombar suggest *m(e/a)gaw. 
*meger- 'look for'

Tibor *mager-

Pam: mangelev-

Kumil *meger-

Moe: mengker-

Manep-Barem * meger-

$\operatorname{Bar}(\mathrm{QK})$ : munggor-

Bar (Bun.): manggar-

Kaukombar *migar-

Maia: mik-, mikar-

The expected QK Barem reflex is **minggor-. The vowel reflexes in Maia are not regular.

*mekiw 'land, ground'

Tibor *meki 'garden'

Mok: meki

Pam: mehi 'garden', imehiv 'ground level'

HA: mekiv

Maw: imhi

Kow: emehi

Kumil *mekiw

Bep: mehiw

Mau: miiwa

Manep-Barem *mekiw

Bar $(\mathrm{QK})$ : mikiv

Bar (Bun.): makiv

Man: mikip

Kaukombar

Mala: misiv

Gavak: mai

The loss of final ${ }^{*} \mathrm{w}$ in Tibor languages is irregular.

*men 'breast'

Proto-Kumil-Tibor *men

Tibor *me

Pam: $m e$

$\mathrm{HA}: m e$

Kow: $m e$

Kumil *mena

Bep: mena

Moe: mena

Manep-Barem *men

Man: manu

Gavak: menam

See also Proto-Kaukombar -mek. 
*merir- 'vomit'

Kumil-Tibor *merir-, *merirew- 'vomit'

Tibor *merire-, *merirew- 'vomit'

Mok: melile- melilew-

Pam: melile-, melilev-

HA: milil-

Maw: mirir-

Kow: mirir-, miriraw-

Kumil *merir- 'vomit'

Bep: merir-, merirew-

Moe: merir-

Manep-Barem *mil-

Bar: mir-

Man: mil-

Numugen *me?ir-

Gavak: (mingal-)

The Manep reflexes suggest that PNA contains *1, but Bepour indicates *merir-. Since the Manep form irregularly loses the final syllable, I have based the PNA form on Bepour. Tibor *melileis used with past and hodiernal tenses, while *melilev is used with other conjugations. Manep-Barem irregularly contracted to *mil-

*melik 'eel'

Tibor *melik

Mok: melik

Pam: melik

Manep-Barem *merik

Bar (Bun.): marik

Man: mirik

Gavak: $m e l$

*mid-, midet- 'pierce, shoot'

Proto-Kumil-Tibor *mid-

Tibor *mud-

Pam: mund- mundet-, mundes- munda-

Maw: mund-

Kow: munt-

Kumil * mig-

Bep: $m i^{\prime}-$

Moe: mingka-

Mau: $m i k$ -

Kaukombar *medet-

Maia (Saki): mendet-

Maia (Pila): mendes- 
The vowel correspondence is not regular, but Maia $e$ and Proto-Kumil $*_{\mathrm{i}}$ suggest PNA *i, which became ${ }^{*} u$ in Proto-Tibor.

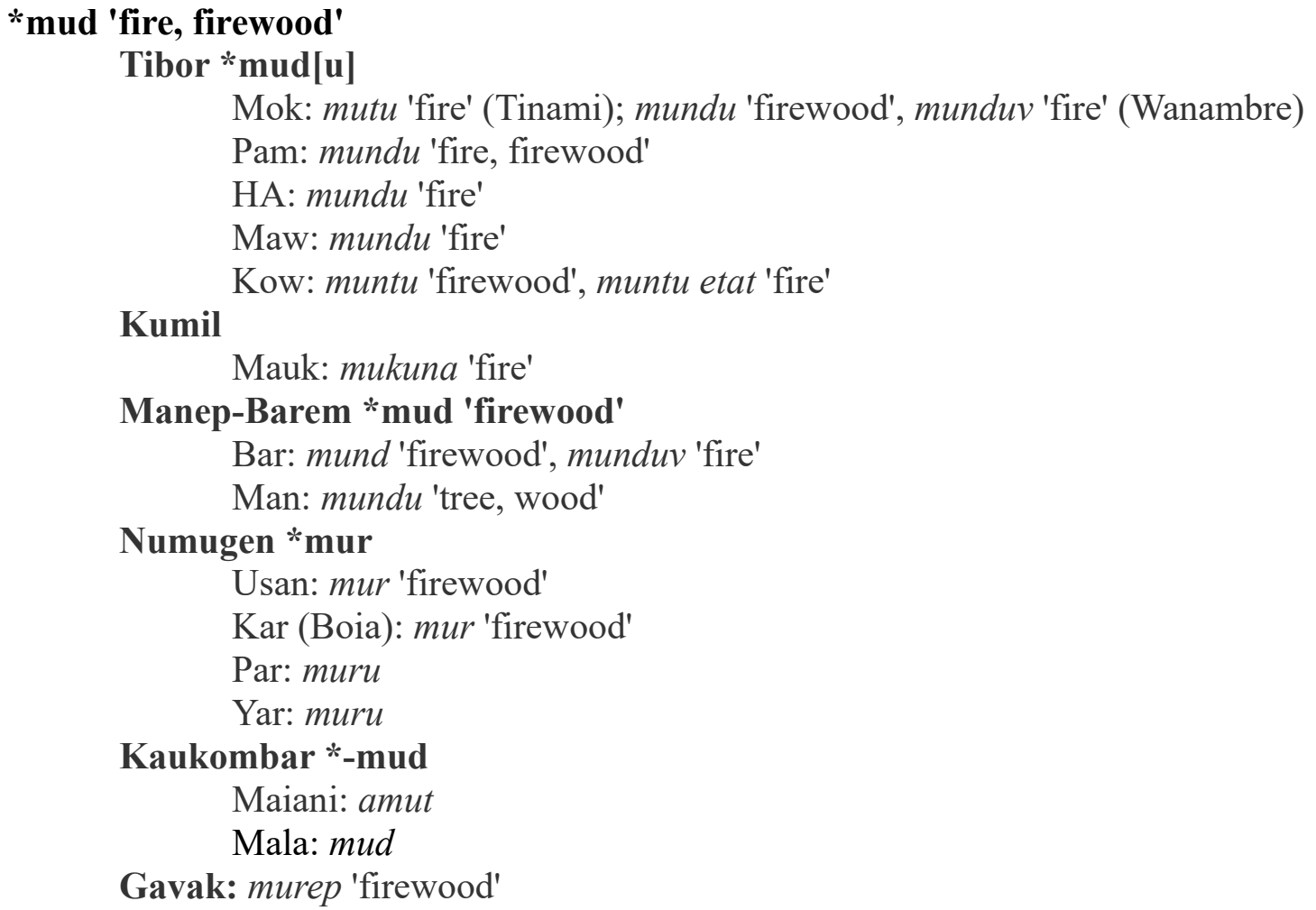

The Wanambre dialect of Tinami usually deletes the stop portion of final prenasalized stops. Wanambre does not treat the $* d$ in Proto-Tibor $* \operatorname{mud}[\mathrm{u}]$, with epenthetic final $*[\mathrm{u}]$, as word-final. Mauwake mukuna appears cognate other than the unexplained final nasal. However, Mokati and Barem also have added material at the right edge, which gives the meaning 'fire' from the shorter base from with the meaning 'firewood'

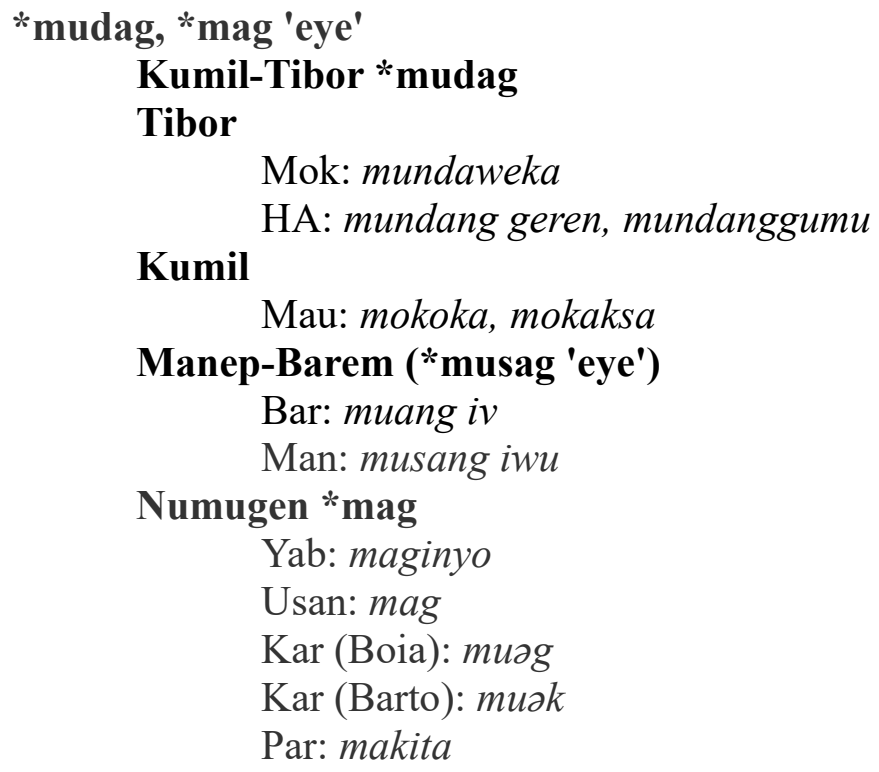


Uku: mag

Yar: makita

Kaukombar *mudag

Maia (Wagedav): umuda

Maia (Pila): -mundua

Maiani: -muta

Miani: - muda

Mala: -mutak

Gavak: mek

Kaukombar *mudag and Kumil-Tibor indicate *mudag, while Gavak and Numugen indicate *mag. Manep-Barem *musag is similar, but PMB *s does not correspond with PNA*d. Many languages compound 'eye' with 'fruit'/'seed'.

*mudir 'ant'

Tibor *mudir

Mok: mundil

Was: mudidir

Manep-Barem *RED-mudir

Bar (QK): mamunjir

Bar (Bun.): mumjir

Man: mumunjir

*muduru 'type of greens'

Tibor * muduru

Mok: muturu

Kaukombar *muduru

Miani: muduru

$* \operatorname{muga}(\mathbf{n} / \mathrm{\eta})$ 'bird'

Tibor *muga 'bird'

Mok: mungga

Pam: mungga

HA: mungga

Mawak: mungga

Kow: $m u^{\prime} a$

Manep-Barem (*mununggan)

Bar (QK): (mununggan)

Bar (Bun.): (mun-guan)

Kaukombar *muga 'bird'

Maia: muga

Maiani: $m u k a$

Miani: muga

Mala: $m u k a$

See also Proto-Numugen *maragwan and PNA *nebek. The Barem forms are similar, but contain an additional unexplained syllable. 


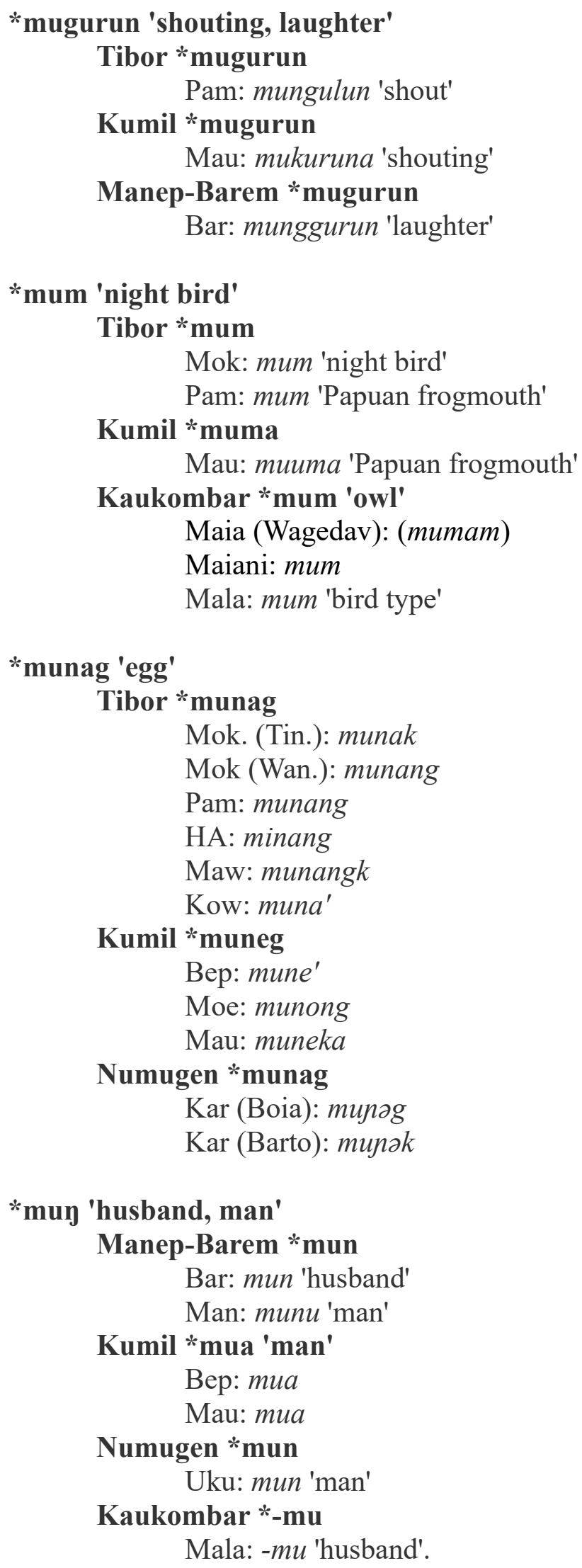


The lack of final nasal in Kumil indicates final * $y$, rather than *n. Resembles Proto-Sogeram *-mum 'husband'

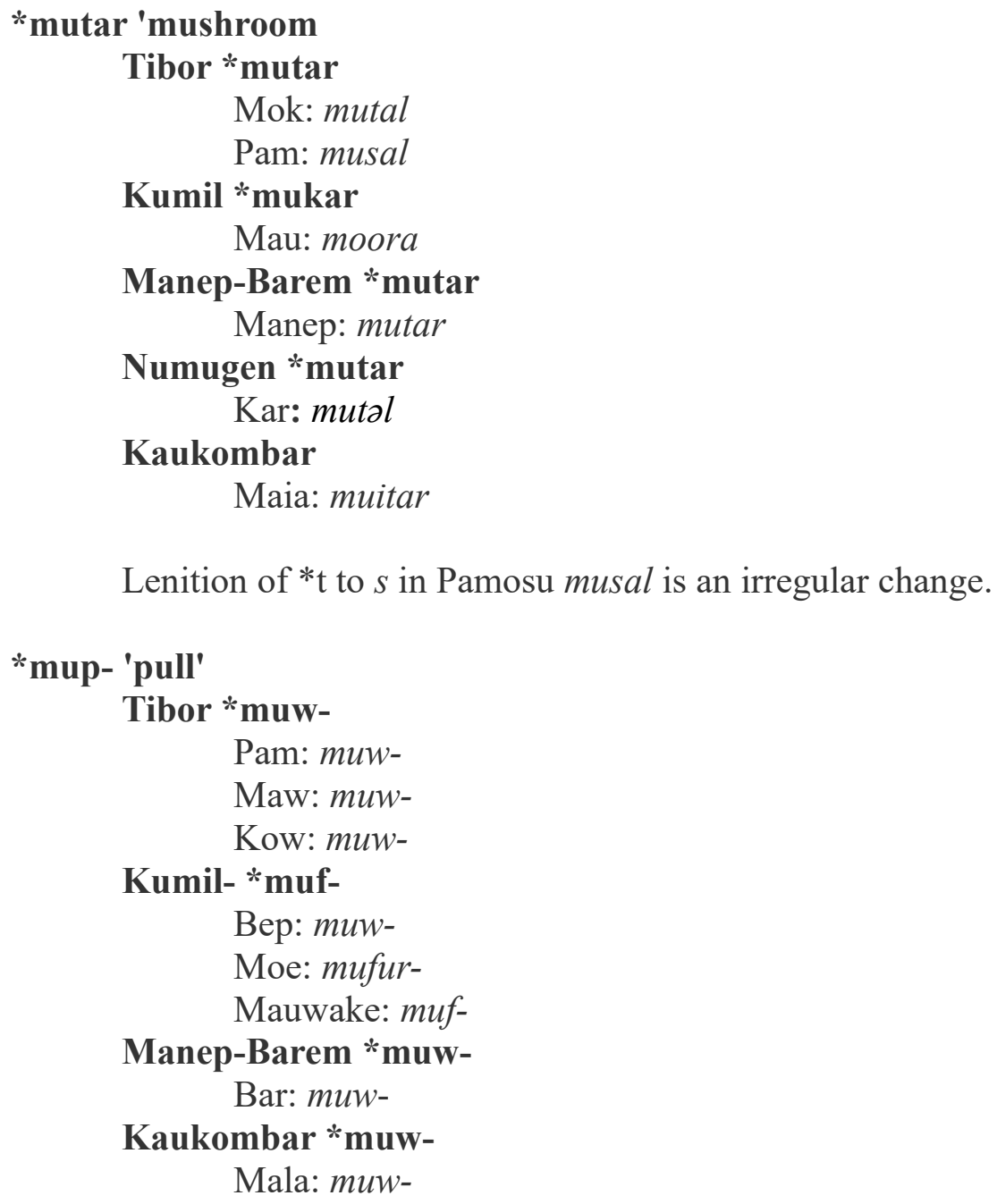

Bepour and Moere both have unexpected reflexes, as medial *p is usually reflected as $f$ in Bepour and $w$ in Moere, but the reverse is seen here. This is important since the Kumil languages Bepour and Mauwake are the only group which distinguishes distinct reflexes of intervocalic * $p$ and ${ }^{*}$ w. Since Mauwake is the best documented Kumil language, I base PNA *mup- off of Mauwake muf-

*nasin 'spirit'

Tibor *nenasin

Mok: nenasin, nanasin

Pam: nenasin

HA: nenasin

Kow: nenasin

Kumil *inasin

Moe: inasin

Mau: inasina 


\section{Manep-Barem}

Bar: (nasin)

\section{Numugen}

Kar: nanasin

Reflexes of *nasin also have the sense 'foreign, foreigner, white person' in every language' Barem nasin is probably a loan, since *s usually deleted.

*nat- 'give to $2 \mathrm{SG}$ '

Tibor

Mok: nat- 'give to $1 / 2 \mathrm{SG}^{\prime}$

Manep-Barem *nas-

Bar: $-n$

Man: nas-

Numugen

Kar: not-

Kaukombar

Maia (Wagedav): ine-s-

Mala: nit-

Gavak: nas-

*nebek 'bird'

Kumil *nebe' 'bird'

Bep: nepe

Moe: nempe'

Mau: nepa

Manep-Barem *nebek

Man: nambe

Kaukombar

Mala: nembe pai 'Tok Pisin'

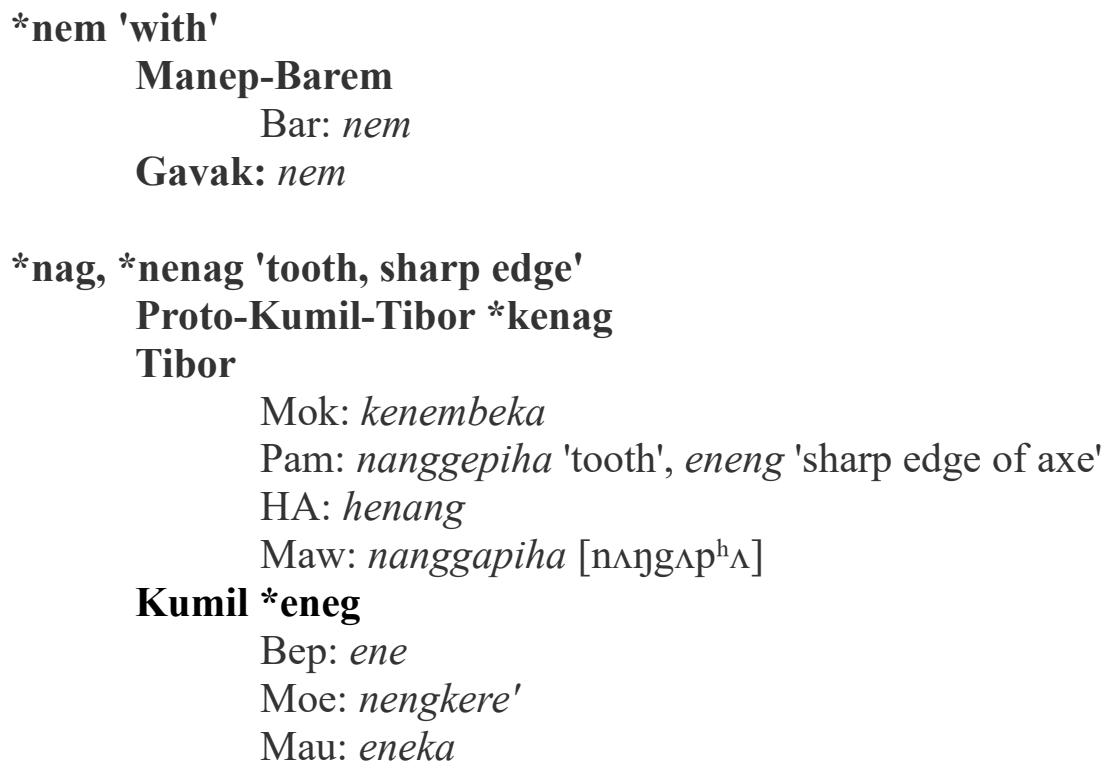

Gavak: nem

*nag, *nenag 'tooth, sharp edge'

Proto-Kumil-Tibor *kenag

Tibor

Mok: kenembeka

Pam: nanggepiha 'tooth', eneng 'sharp edge of axe'

HA: henang

Maw: nanggapiha $\left[\mathrm{n} \Lambda \mathrm{gg} \Lambda \mathrm{p}^{\mathrm{h}} \Lambda\right.$ ]

\section{Kumil *eneg}

Bep: ene

Moe: nengkere'

Mau: eneka 


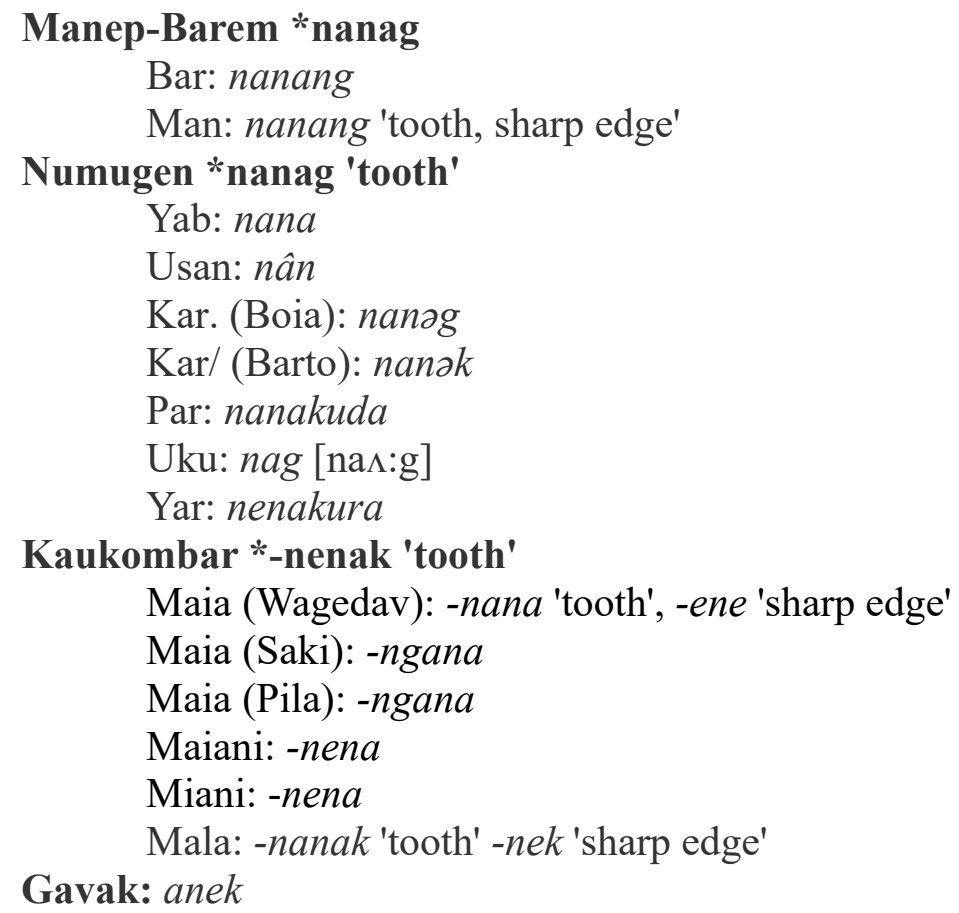

Proto-Kumil-Tibor *kenag 'tooth' does not match in the initial syllable with other languages, which mostly point to PNA *nenag. The original form is probably *nag, which was combined with unidentified elemets $k e$ - in Kumil-Tibor and $n e$ - in the other subroups. Proto-Kaukombar *-nenak 'tooth' reflects PNA *nag, while Proto-Kaukombar*-nek 'sharp edge' reflects PNA *nag. Gavak anek reflects *nag with a fossilized possessor affix, seen also in arur 'tail' $<*$ dur and aip 'leaf $<*$ ip. *nag also seems to be reflected by Ukuriguma nag.

Mokati, Pamosu, and Mawak are compounds with 'liver/heart', which also refers to fruit pits, which may be the sense it has here. A similar compound is found in Parawen and Yarawata ('tooth'+'fruit'). Moere is a compound with are' 'trunk, piece', which is similar to Manep-Barem 'tooth'+'trunk/base' for 'molar'.

\section{*nenar- 'hit 2SG'}

Kumil *nenar-

Mau: nenar-

Manep-Barem *nanar-

Man: nanar-

Kaukombar *nanar-

Kar: nən-, nənal-

*yam 'tree'
Tibor *na
Mok: $n a$
Pam: $n a$
HA: $n a$
Maw: $n a$
Kow: $n a$




\section{Kumil *nama \\ Bep: nama \\ Moe: nama \\ Mau: (nomokowa) \\ Manep-Barem}

Bar: wam

Numugen *nam 'tree'

Yab: namu

Usan: nam

Kar: пиәт

Par: nama

Yar: nama

Kaukombar *nam

Maia (Wagedav): nanam

Maiani: nam

Miani: nam

Mala: nanam

Gavak: ngam, ngom

This is the only reconstructed PNA form with initial * $y$, which otherwise is only found wordfinally. As such, it is speculative, since a regular correspondence for initial ${ }^{*} \eta$ has not been established. Word-initial $n g$ is allowed, but infrequent, in Gavak, identified only in a handful of words. This may have been the case in PNA as well.

*pai 'mango'

Manep-Barem *pai

Bar: fai

Man: pui

Kaukombar *wai

Maia (Wagedav): vai

This probably originally referred to Mangifera minor, rather than the introduced Mangifera indica, which was introduced to PNG after 1870, but is currently more popular (Bourke 2010). Mauwake fiiwua 'mango' may also be related.

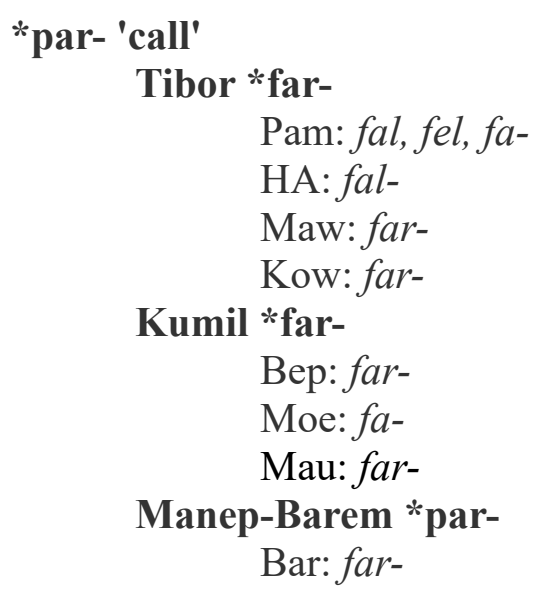




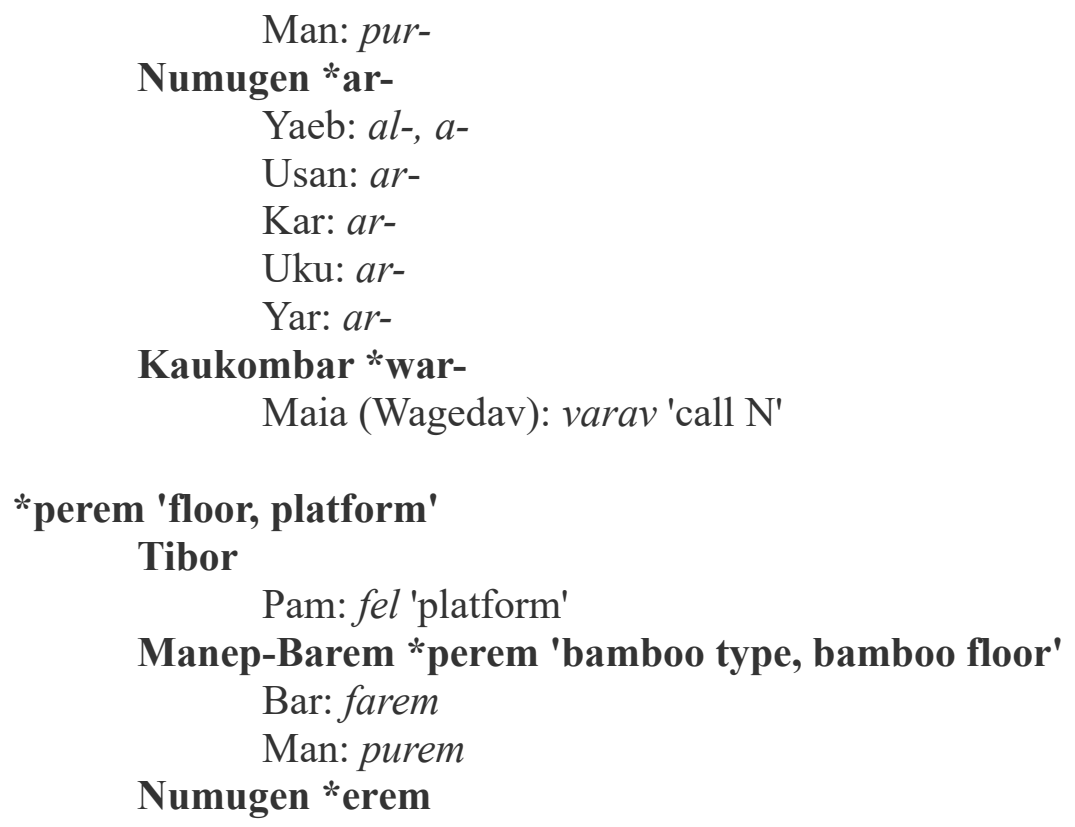

Barem also has par 'platform, loft, bench', but this is certainly borrowed, as Barem lacks initial $p$ in native vocabulary.

*pi 'bad'

Tibor *fifi 'bad'

Mok: yat

Pam: fivi

Maw: fivi

Kow: fivi

\section{Kumil *fia}

Moe: fia

Manep-Barem *pi

Man: $p i$

Kaukombar

Pila: wiwi

Mokati yat is the reflex of *pi with the adjective suffix -at. Tibor and Kaukombar languages reduplicate the stem.

\section{*pia 'pitpit' \\ Tibor \\ Pam: fia \\ HA: fia}

Kaukombar

Maia: wiya 


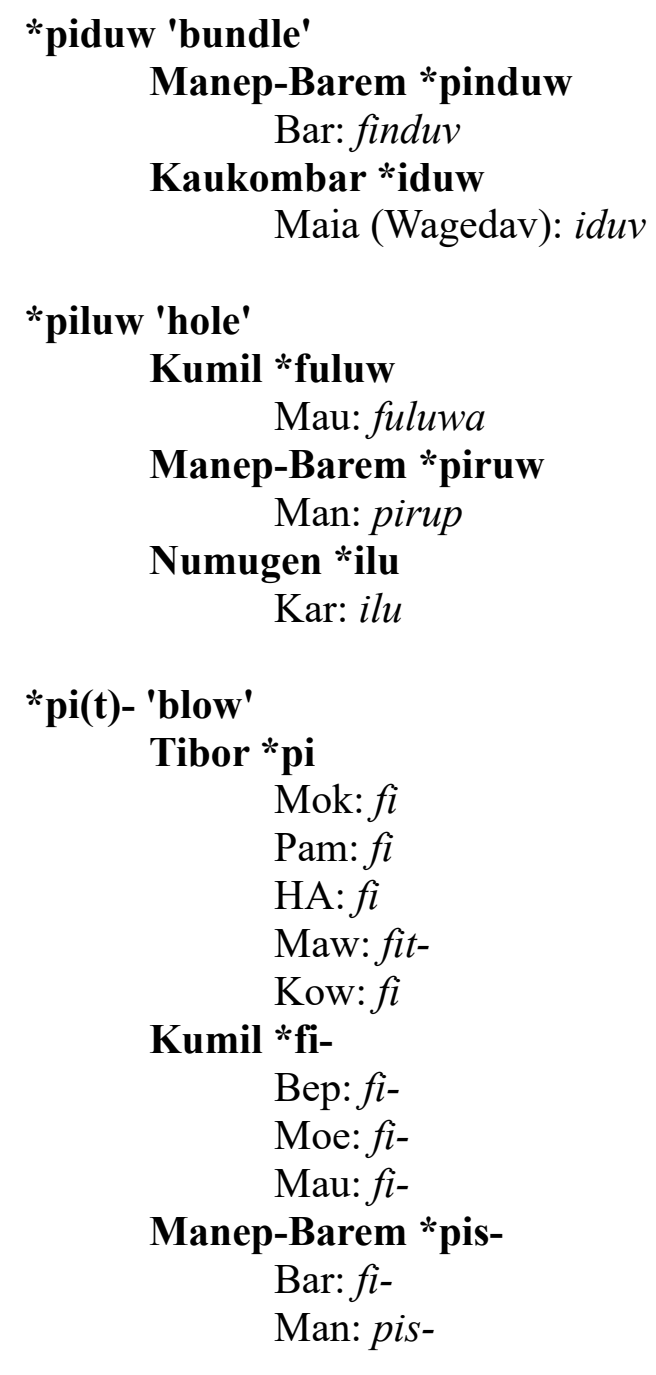

In Mokati and Pamosu, $f i$ is a coverb that pairs with a light verb. A light verb may be the source of the Mawak and Manep alveolars.

*puk 'skin, body'

Tibor *fuk[u]

Mok: $u k u$

Pam: fuku

HA: fuku

Maw: $f u k u$

Kow: fu'u

Manep-Barem *puk

Bar: fuk 'body'

Polysemy between 'skin' and 'body' is widespread in languages in the area, including Tok Pisin.

*puruk 'smell, hear, perceieve'

Tibor *furuk

Mok: luk- 
Pam: fuluk ov-

HA: huluw-

Maw: furukew-

Kow: furu'ev-

Manep-Barem *puruk

Bar: furuk

*selew 'sand, beach'

Tibor *serew

Mok: selew

Pam: selev

HA: selep

Maw: sereb

Kow: sereb

Kumil *selew

Bep: sereb

Manep-Barem *selew

Man: silep

Numugen *erew

Yab: alo

Usan: oro sow

Kar. (Boia): araw

Par: arorowa

Uku: ole

Yar: alowa

Kaukombar *solow

Maia (Wagedav): solov

Gavak: silep, selep

The meaning of the element sow in Usan oro sow is not known.

*sewaw 'sand, beach'

Tibor *sewaw

Mok: sowav

HA: sewav

Maw: sewav

Kow: sewav

Kumil *sewew

Bep: sewew

Moe: sewew

Manep-Barem *sewaw

Bar: siwav

Barem *s usually deleted, but is preserved in siwav. 


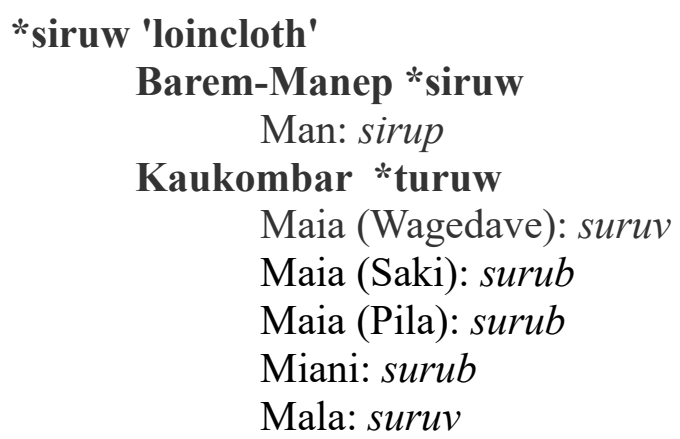

May be related to Proto-Kumil *iruw 'loincloth'.

\section{*sisimur 'sunfly'}

Tibor *ma *sisimur

Mok: misisimur, mususumur

Pam: masisimul

Manep-Barem *sisimur

Man: kasisimur

Mauwake maa samora 'mosquito' looks similar. samora means 'bad'. See also Proto KumilTibor *ma 'small flying insect'.

*susur 'ant sp.'

Tibor *sisur

Pam: sisul

Kumil *susur

Mau: susura

Kaukombar *tutur

Maia (Wagedav): susul

Maini: tutul

Miani: tutur

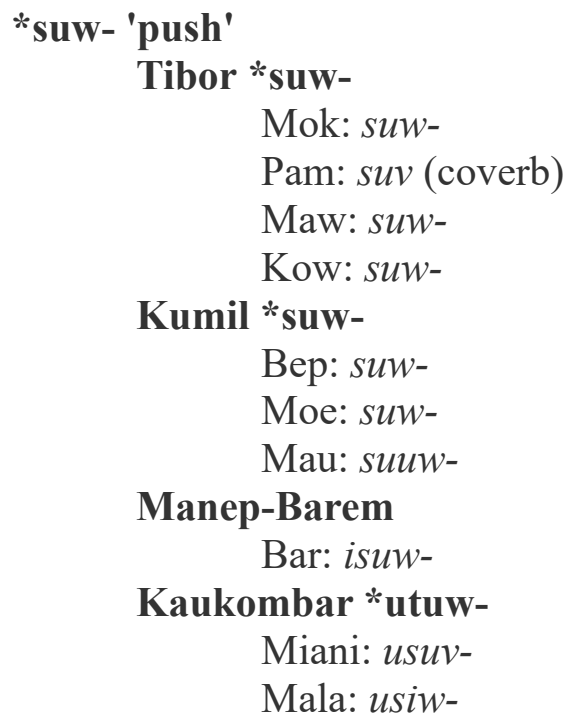


Barem *s usually deleted, but was retained in isuw-.

*taban 'mountain'

Numugen *taban 'mountain'

Yab: tabanu

Kar. Boia: tavən

Kar. Barto: tavan

Par: tatapa

Uku: tatpan

Yar: tatapa

Kaukombar *tapa 'mountain'

Maia (Wagedav): tapapa 'steep place, mountainous'

Maiani: tapa

Miani: tapa

Mala: tapa

The usually reflex of PNA *b in is Proto-Kaukombar *b, not*p.

*tabir 'plate'

Tibor *sabir

Mok: savil

Pam: sapil

HA: sambir

Maw: sapir

Kow: sapir

Kumil *epir

Bep: epir

Moe: mpir

Mau: epira

Numugen (*tabin 'plate')

Yab: tawinu

Kar: tavin

Kaukombar *tabir 'plate'

Maiani: tapir

Miani: tabir

Mala: tambir

Kumil *a $>e$ is irregular. Proto-Numugen *tabin does not correspond with other languages in the final segment.

*tak 'leaf'

Tibor *saku

Mok: saku

Pam: saku

HA: saku 


\section{Manep-Barem *tak}

Bar: tak

Man: taku

*tak refers to a flat, broad leaf, while *ip is long and thin. Kowaki doesn't have a reflex with the meaning 'leaf', but has sa'u in ape sa'u 'palm' < Proto-Tibor *abe saku.

*takaw 'grasshopper'

Kumil

Mau: aawa

Manep-Barem *takaw

Bar: skav

Man: takap

Kaukombar *takaw

Maia (Wagedav): takav

*taw 'piece of wood'

Manep-Barem *taw

Bar: tav

Man: tawu

Numugen *taw

Yaben: taw

*te LOC

Tibor *te

HA: te

Manep-Barem *te LOC, INST

Bar: te

Man: te

Numugen *te

Yab: to

Usan: $-t$

Kar: to

*teber 'tree sp.' (Tok Pisin: mangas)

Tibor *seber 'today'

Mok: sembel

Pam: sembel

HA: sember

Manep-Barem *teber

Bar (QK): timbor

Bar (Bun.): tambar

Manep: tamber

Numugen

Kar. (Boia): tambar

Kaukombar

Mala: tambar 
Possibly Hibiscus tileaceus. The expected Mokati and Pamosu reflexes are sepel.

*temen 'now'

Tibor *seme 'today'

Pam: seme

Maw: seme

Kow: seme

Numugen *temen

Yab: tamanu

Usan: temen

Kar. (Boia): taman

Uku: tomon

Yar: tamana

*teteri 'chicken

Tibor *teteri

Mok: teteli

Kumil *ekeri

Bep: eheri

Moe: keri

Mau: (aara)

Manep-Barem *teteri

Bar (QK): stiri

Bar. (Bun): stari

Man:tatiri

Numugen *teteri

Yab: talia

Usan: teteri

Kar. Boia: tətəria

Par: tatari

Uku: tatari

Yar: tatalia

Kaukombar *tatar 'chicken'

Maia (Saki): tatar

Maia (Pila): tatar

Miani: tatar

Gavak: tater

*t(e/i)bik 'rain'

Kumil-Tibor *tebik 'rain'

Tibor *sebik 'rain

Mok: siwik

Pam: sepik

HA: simbik

Maw: sepik

Kow: sepi' 


Kumil *ipi'
Bep: ipi
Moe: $m p i^{\prime}$
Mau: ipia
Manep-Barem *tebik
Man: timbik

\section{Gavak: tep}

It is not clear whether the vowel in the initial syllable should be reconstructed as $*_{\mathrm{i}}$ or $*_{\mathrm{e}}$.

Manep is ambiguous between the two, and Mokati, Hember Avu and Kumil languages suggest *i, while other languages suggest $*$ e.

\section{*ten 'branch'}

\section{Manep-Barem *ten}

Manep: tanu

Gavak: tengken

In Gavak, -ken is found as the second element in many words for long, thin objects, for example sambingken 'broom', and kundengken 'earthworm'.

\section{*tuar 'crocodile'}

Tibor *tuar

Mok: tual

HA: (tuan)

Maw: (duar)

Kow: tuar

Manep-Barem *tuar

Bar: tuar

Man: tuar

\section{Numugen *tuar}

Kar (Boia): tuar

Kaukombar *tuar

Mala: $\operatorname{tar}$

The Kumil languages also have tuar but this is certainly a borrowing. Inconsistencies in the Tibor forms also suggest these are borrowings. A possible source is Waskia tuar.

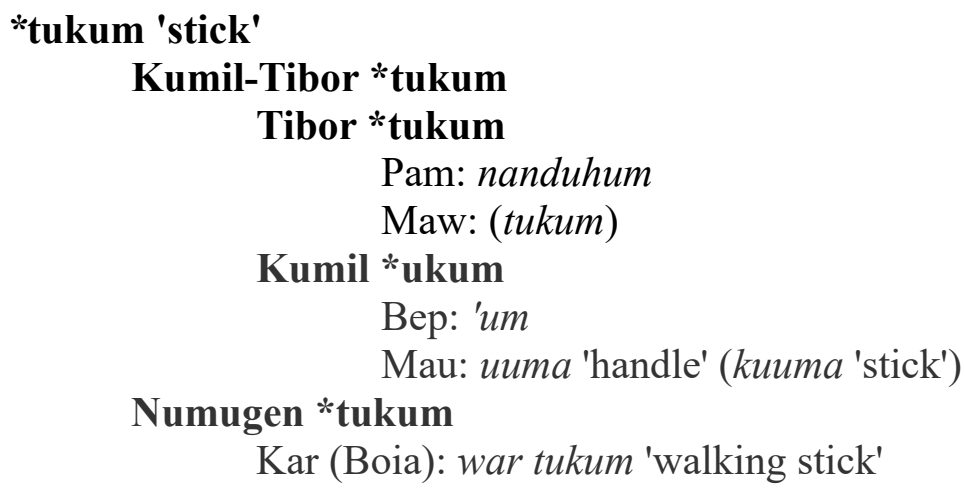


*ub- 'to plant'

Kumil-Tibor *ub-

Tibor *ub-

Mok: $u w$ -

Pam: up-

HA: $u m b-$

Kow: $o p-$

Kumil *up-

Bep: $i p-$

Moe: $m p u-$

Mau: up-

Manep-Barem *ub-

Bar: $u m b-$

Man: umb-

Numugen *ub-

Yab: $u b-$

Usan: $u b-$

Kar: $u w$ -

Uku: $u w-$

Gavak: $u w-$

*ub- 'boil'

Manep-Barem

Bar: umbaw-

Kumil *up-

Mau: uиp-

Kaukombare *ub-

Maia: $u v-$

*ubar 'branch'

Tibor *ubar

HA: umbar

Kow: opar

Kaukombar *ubar

Maia: ubar

*udir(a/e)m 'leech'

Tibor *udila

Mok: utila

Pam: itila

Manep-Barem *iderem

Bar: inderem

Man: inderem

Karian *udilam

Kar: ujilam 
Mauwake kadilam 'leech' is a loan, probably from Amako katilam.

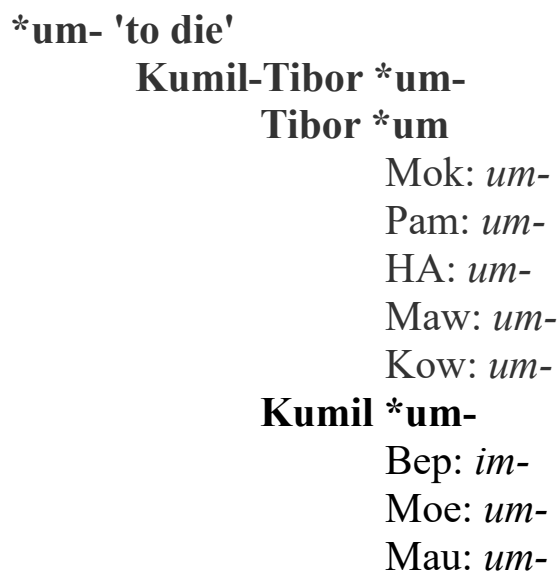

Bar: um-

Man: um-

Numugen *um-

Yab: um-

Usan: um-

Kar: um-

Par: um-

Uku: um-

Yar: um-

Kaukombar *um-

Maia (Wagedav): um-

Miani: um-

Mala: um-

\section{*un- 'to draw water'}

Kumil-Tibor *un-

Tibor *un-

Mok: un-

Pam: un-

HA: un-

Maw: un-

Kow: un-

Kumil *un-

Bep: un-

Moe: un-

Mau: un-

\section{Manep-Barem *un-}

Bar: un-

Man: un-, unew-

Numugen *un-

Yab: un-

Usan: un- 
Kar: un-

Par: un-

Uku: un-

Yar: un-

Kaukombar *un-

Maia (Wagedav): un-

Miani: un-

Mala: un-

Gavak: un-

*un-at 'female'

Kumil-Tibor *unet

Tibor *unet

Mok: unen

Pam: unend

HA: unen

Maw: unend

Kow: unent

Kumil *une'

Bep: une

Numugen *unad

Yab: unad

Usan: unor

Kar: unar

Par: unara

Uku: unar

Yar: unad

Nasal spreading in the Tibor reflexes indicate this was two morphemes.

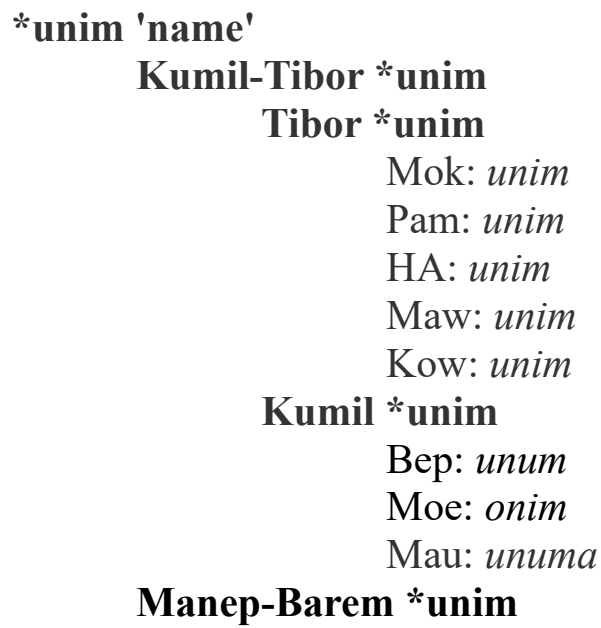

Bar: unim

Man: unim

Numugen *unim

Yab: unyimu 
Usan: unum

Kar: unyim

Par: unima

Uku: unim

Yar: unima

Kaukombar *-unim

Maia (Wagedav): unim

Miani: -inum

Mala: -num

*unin 'bee'

Tibor *uni

Mok: uni

HA: uni

Kumil

Mau: (ununka)

Manep-Barem *unin

Bar: unin

Man: unin

Gavak: unin

Mauwake ununka may not be cognate, as it contains an additional unexplained syllable.

\section{*up- 'dance'}

Kumil-Tibor*uf-

Tibor *uw-

HA: $u w-$

Maw: $u w-$

Kow: $u w-$

Kumil *uf-

Bep: if-

Mau: $u f-$

Manep-Barem *uw-

Bar: $u w$ -

Man: $u w-$

Numugen *uw-

Yab: uya-

Kar: $u y$ -

Uku: $u w$ -

Yar: $w$ -

Kaukombar *uw-

Maia: $u v-$

Maiani: $u w$ -

Miani: $u w-$

Mala: $u w-$

Gavak: $u w$ - 


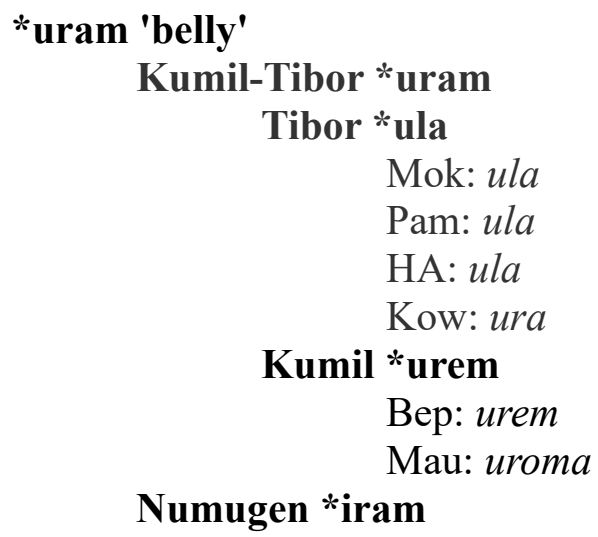

The first syllable in Ukuriguma odilam is unaccounted for, but is perhaps relate to kod

\section{*usa 'grasshopper'}

\section{Tibor}

Mok: usa

\section{Numugen}

Kar: usa

Gavak: (uta)

Mokati and Karian reflexes suggest PNA *usa, but Gavak uta suggests PNA *uta, so may not be cognate.

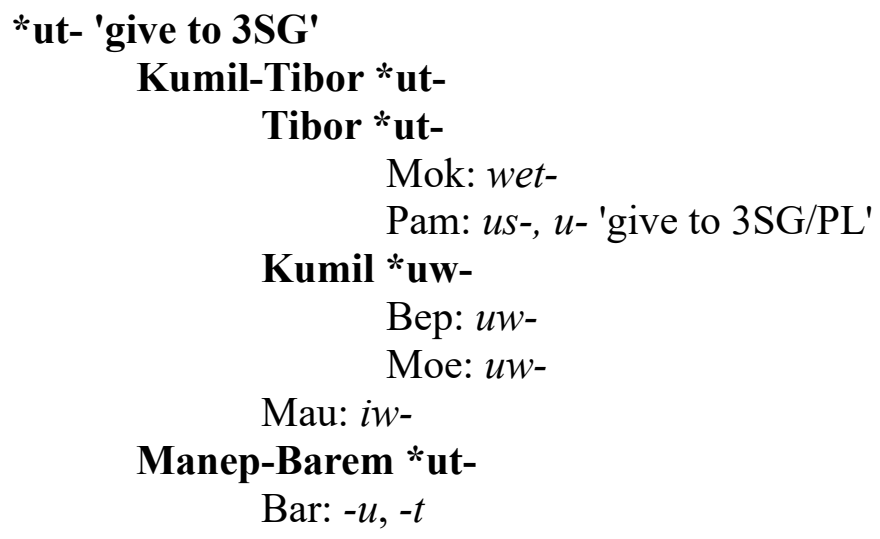


Man: $u s-$

Numugen *ut-

Yab: $u t$ - 'give SG"

Usan: $u t$ -

Kar:ut-

Kaukombar *ut-

Maia: $u s-$

Mala: $u t-$

Gavak: $u s$ -

*uyaw 'spear'

Kumil-Tibor *uyaw

Tibor *uyaw 'spear'

Mok: uya

Pam: yua

HA: uyap

Maw: uya

Kow: uyeb

Kumil *uyew

Bep: uyeb

Mau: wiowa

Manep-Barem: *uyaw

Bar: uyaw

Man: uyap

Kaukombar *uyaw

Maia (Wagedav): wiav

Maia (Saki): wiab

Maia (Pila): wiab

Maiani: uyav

Miani: uyav

Mala: (umav)

*wa 'pig, marsupial game animal'

Kumil-Tibor *wa

Tibor *wa

Pam: wa 'pig, marsupial'

HA: $w a$

Mawak: wa

Kowaki: wa

Kumil *wa 'pig'

Bep: wa

Moe: $w a$

Mau: waaya

\section{Manep-Barem}

Bar: wagi 'cuscus'

Man: wayi 'cuscus' 


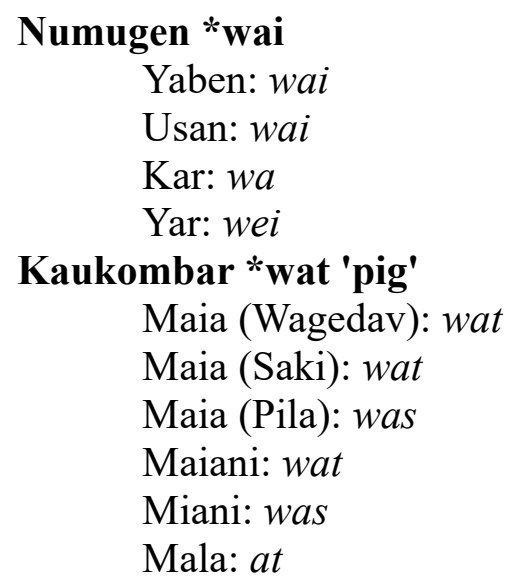

When referring to marsupials, reflexes of *wa are followed by a modifier specifying a more specific animal. For example, Karian wa tawarz and wa 'avin are two types of wallaby, and Mokati wa meleke and wa bikise are two types of cuscus. When used without a modifier, Tibor *wa and Numugen *wat simply mean 'pig'. The final Proto-Numugen *t is unexplained.

*waben 'arm, hand'

Kumil-Tibor *waben

Tibor *abe

Mok: ape

Pam: ape

HA: embe

Maw: ape

Kow: ape

Kumil *wapen

Bep: wapen

Moe: ampen

Mau: wapena

Manep-Barem *waben

Bar: omben

Man: imben

Numugen *uben

Usan: $u b e n$

Kar: uvan

Uku: ubon

Kaukombar *-wab(e/o) 'hand, arm'

Maia: -wabo

Maiani: -wapu

Miani: -uabo

Mala: -nambe

Gavak: aven

*waben kenam 'shoulder, tricep, deltoid'

Tibor *abe kenam 'wrist'

Mok: ape kena 'shoulder' 
Pam: ape na 'tricep/delt'

HA: embe hena 'tricep/delt'

Kow: ape hena 'shoulder'

Manep-Barem

Man: imben kanam 'part of arm'

Manep imben kanam is pulled from Z'graggen's Manep recordings. It is not clear from the audio which part of the arm the speaker is referring to.

*waben kumay 'wrist, shoulder'

Kumil-Tibor *wapen kuma

Tibor *abe *kuma 'wrist'

Mok: ape kuma 'wrist', abukuma 'shoulder'

Pam: apuma

HA: embe huma 'upper arm'

Kumil *wapen *uma

Mauwake:wapen uma

Manep-Barem *waben kuman 'wrist'

Bar: omben kumuan

Man: imben kuman

Numugen

Kar (Bar): uman

May be related to Proto-Sogeram *kuman 'arm, hand'

*wak- 'break'

Tibor *wak-

Pam: wah-

Manep-Barem *wak-

Bar: ok-

Man: uk-, ukew-

*wag 'hand drum'

Kumil *waga

Bep: $w a^{\prime} a$

Mau: oka

Kaukombar *wag

Maia (Wagedav): wag

Maia (Saki): wang

Maia (Pila): wang

Mala: $a k$

If Mauwake $o k a$ is cognate, then the change of *wa $>o$ is irregular.

*wag 'canoe'

Manep-Barem *wag

Manep: unggu 


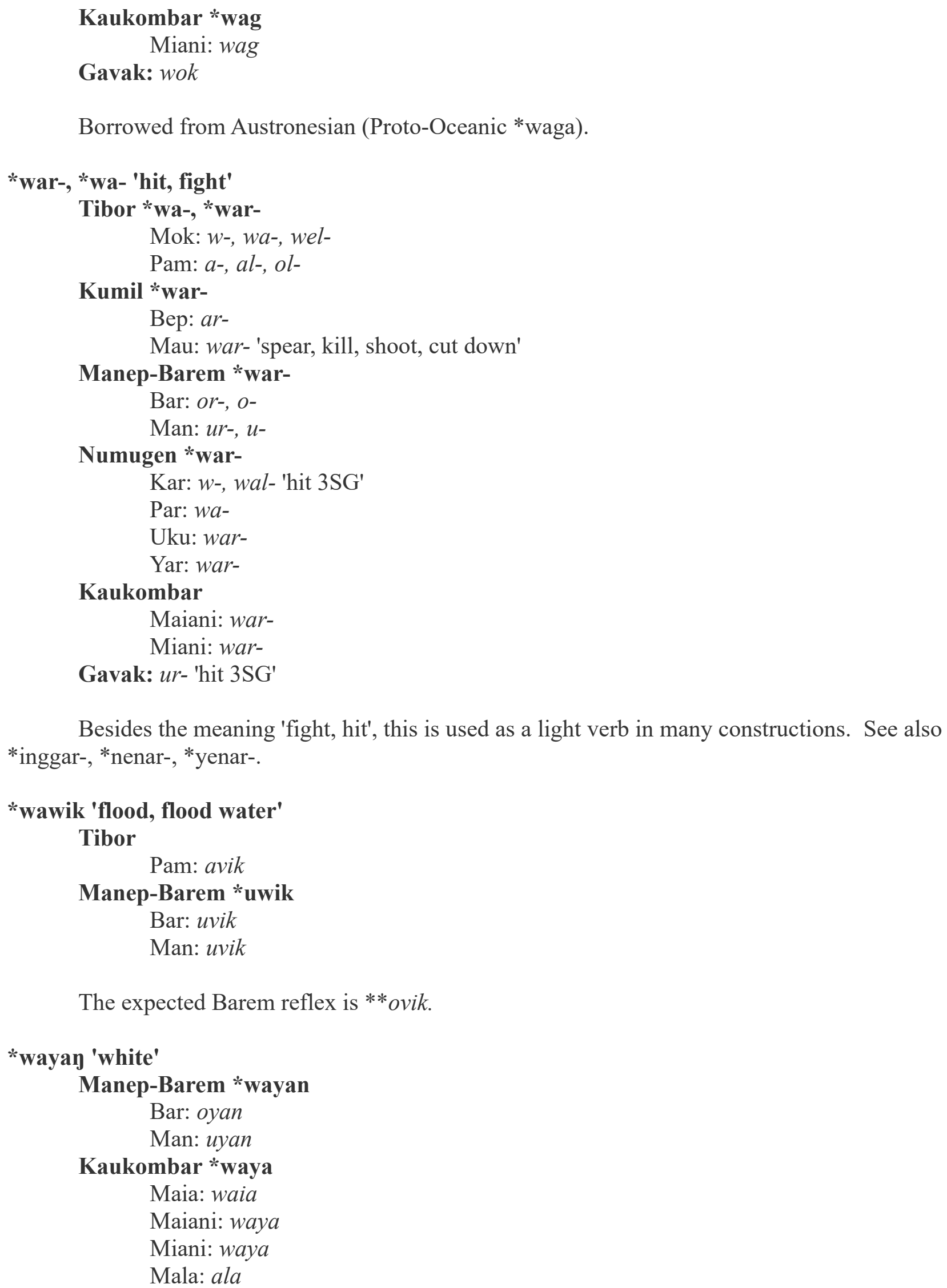

Besides the meaning 'fight, hit', this is used as a light verb in many constructions. See also *inggar-, *nenar-, *yenar-.

*wawik 'flood, flood water'

Tibor

Pam: avik

Manep-Barem *uwik

Bar: uvik

Man: uvik

The expected Barem reflex is **ovik. 
Proto-Numugen *iwan 'lime' is possibly also cognate.

*wediem 'sun'

Manep-Barem *wedem

$\operatorname{Bar}(\mathrm{QK})$ : undem

Bar (Bun): undiem

Numugen *wediem

Yab: wayamu

Usan: worom

Kar. Boia: wəjam

Par: wareama

Uku: odemo

Yar: udeama

Kaukombar *wedem

Maia: wedem

Maiani: witem

Miani: idem

Mala otem

Gavak: urume

In Ukuriguma, which does not have phonemic /e/, *e usually became $o$, but is reflected as $e$ in the second syllable of odemo, probably due to the preceeding *i. The final vowel in Gavak urume is unaccounted for.

*wayek NEG

Tibor *waik

Mok: wakat, wahat

Pam: waik, wahik

HA: aik

Maw: waik

Kow: wai

Kumil *wia

Bep: oya

Moe: we

Mau: wia

Manep-Barem *wiek

Bar: uyek

Man: we, weget

Numugen *uyek

Yab: uwo

Usan: uwe

Kar: uyo

Par: wak

Uku: woyak

Yar: wek

Kaukombar *weyek 
Maia (Wagedav): weie, we

Maia (Saki): we

Maia (Pila): we

Maiani: we

Miani: we, weyek

Mala: ila

*uyak

Yab: uwo

Usan: uwe, ue

Kar: uya

Par: wak

Uku: woyak

Yar: wek

Gavak: waik

The form I reconstruct for *wayek is simply a best guess, since it is not possible to trace the exact changes affecting the vowels and semivowels. *wayek comes after a verb or negated predicate. The retention of final * $\mathrm{k}$ in the Numugen languages Yarawata and Parawen is irregular.

*wisir 'centipede'

Tibor *wir

Mok: wil

Pam: wil

Manep-Barem *usir

Bar: vir

Man: usir

Numugen *waya

Maia: wisir

Kaukombar *witir

Maia (Wagedav): wisir

Maiani: $i$ sir

Miani: isir

Gavak: user

\author{
*wud 'song', *wud *war- 'to sing and dance' \\ Tibor *udu \\ Mok: utu, utu wa- 'dance' \\ Pam: itu, itu ol- 'sing' \\ HA: indu wal- \\ Kow: itu w- \\ Kumil *ugu \\ Moe: ngkua wa- 'sing' \\ Manep-Barem \\ Bar: undar- 'sing' \\ Man: undundu 'drum beat'
}




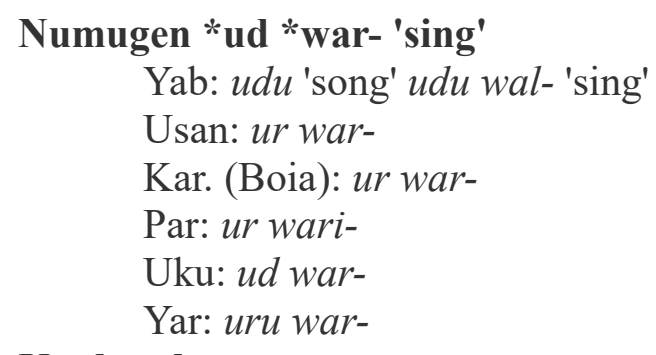

\section{Kaukombar}

Maiani: wur 'singsing type'

$*_{\text {wud }}^{*}$ war- 'to sing' is literally 'hit a song'. Initial *w is also suggested by Waskia wut 'song'.

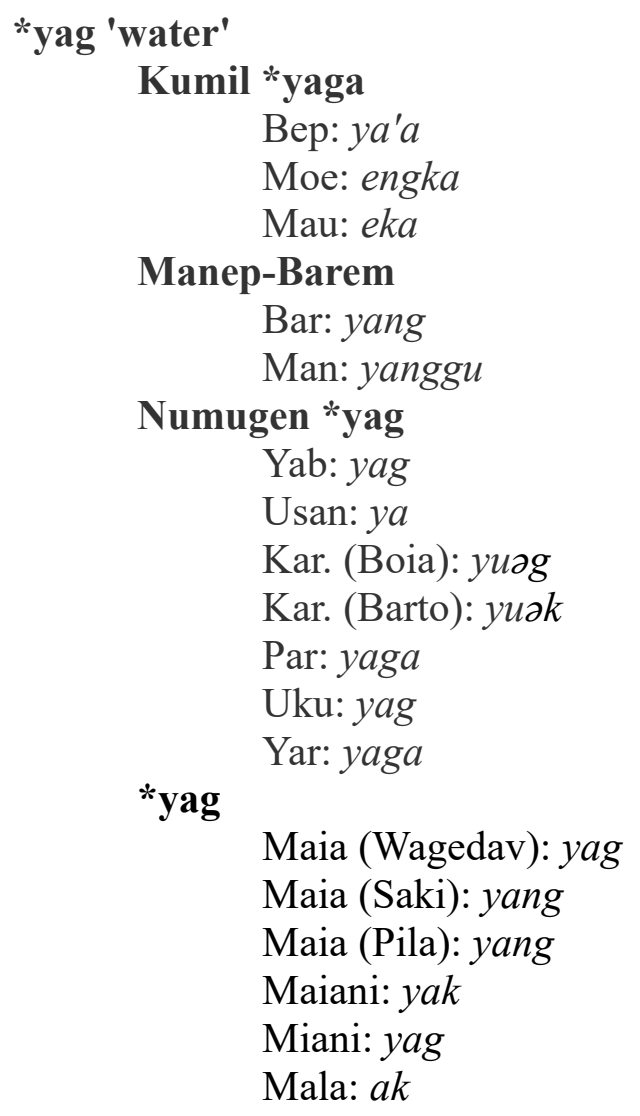


Gavak: yap-am (footprint-PL)

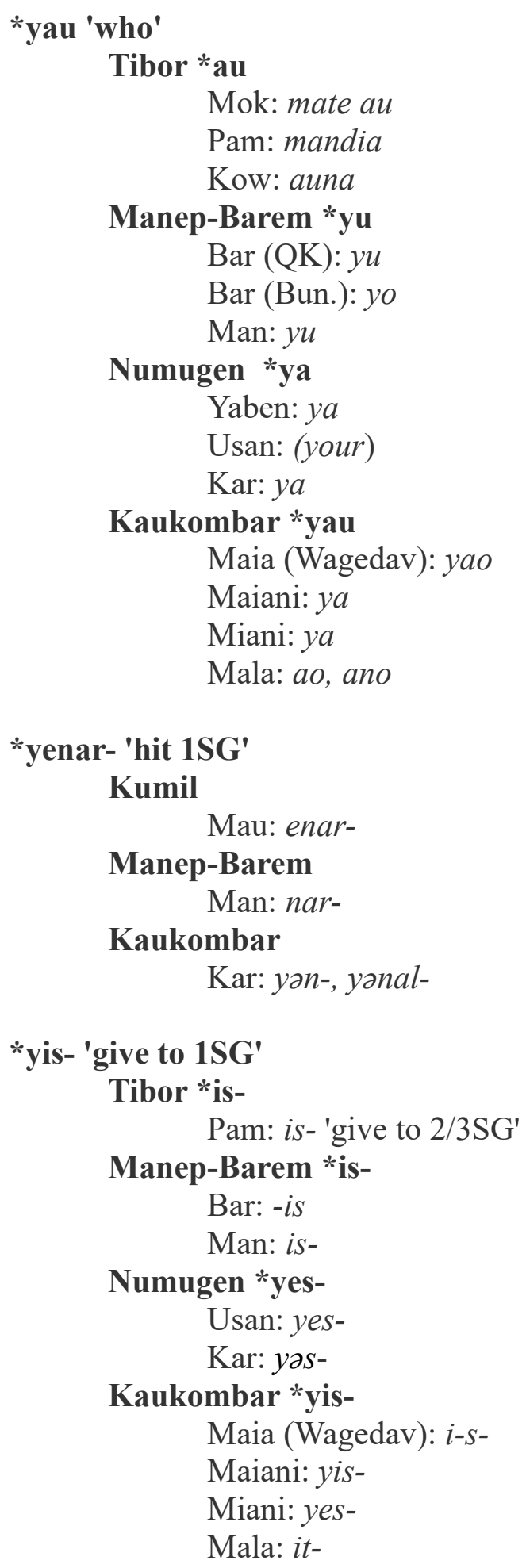

Gavak: is- 


\section{Proto-Manep-Barem}

In this chapter, I illustrate the changes that have taken place in Barem and Manep respective to Proto-Northern Adelbert, and reconstruct Proto-Manep-Barem lexical items. In Section 8.1, I present the sound correspondences used to reconstruct the Proto-Manep-Barem phoneme inventory, and discuss the distribution and allophones of the reconstructed PMB phonemes. Section 8.2 discusses sound changes that took place in Proto-Manep-Barem respective to Proto-Northern Adelbert (in other words, those that are shared by Manep and Barem). In Sections 8.3 and 8.4 , I discuss the changes that took place in Barem and Manep respective to PMB. Section 8.5 discusses the grammatical morphemes that have been reconstructed for PMB, including verb affixes, pronouns, adpositions, and other function words. Section 8.6 presents the reconstructed PMB vocabulary.

\subsection{Proto-Manep-Barem phonemes}

The tables below illustrate the reconstructed Proto-Manep-Barem phoneme inventory.

Table 8.1a: Reconstructed PMB vowel phonemes

\begin{tabular}{|l|l|l|}
\hline & front & back \\
\hline high & $*_{\mathrm{i}}$ & $*_{\mathrm{u}}$ \\
\hline mid & $*_{\mathrm{e}}$ & $*_{\mathrm{o}}$ \\
\hline low & $*_{\mathrm{a}}$ & \\
\hline
\end{tabular}

Table 8.1b: Reconstructed PMB consonant phonemes

\begin{tabular}{|c|c|c|c|c|}
\hline & labial & alveolar & palatal & velar \\
\hline stop & $* \mathrm{p}, * \mathrm{~b}$ & $*_{\mathrm{t},}, \mathrm{d}$ & & $* \mathrm{k}, *_{\mathrm{g}}$ \\
\hline nasal & $*_{\mathrm{m}}$ & $* \mathrm{n}$ & & \\
\hline \multicolumn{5}{|l|}{ affricate } \\
\hline fricative & & $*_{\mathrm{S}}$ & & \\
\hline trill & & ${ }^{*} \mathrm{r}, * 1$ & & \\
\hline glide & ${ }^{*} \mathrm{~W}$ & & $* \mathrm{y}$ & \\
\hline
\end{tabular}




\section{Vowels}

Table 8.1f shows the vowel correspondences used to reconstruct PMB vowels, and the conditioning environments in which those correspondences are found.

Table 8.1f: PMB vowel correspondences

\begin{tabular}{|c|c|c|c|c|c|}
\hline PMB & environment & $\begin{array}{l}\text { Barem } \\
(\mathrm{QK})\end{array}$ & $\begin{array}{l}\text { Barem } \\
\text { (Bun.) }\end{array}$ & $\begin{array}{l}\text { Manep } \\
\text { (Sim.) }\end{array}$ & $\begin{array}{l}\text { Manep } \\
\text { (Mal.) }\end{array}$ \\
\hline$*_{\mathrm{i}}$ & & $i$ & $i$ & $i$ & $i$ \\
\hline$* \mathrm{u}$ & & $u$ & $u$ & $u$ & $u$ \\
\hline \multirow[t]{5}{*}{$* \mathrm{e}$} & & $e$ & $e$ & $e$ & $e$ \\
\hline & /_r\# & $o$ & $a$ & $e$ & $e$ \\
\hline & $/ \mathrm{V}[+$ high $] \mathrm{C}_{-}$ & $e$ & ie & $e$ & $e$ \\
\hline & /\#C_CV & $i$ & $a$ & $a$ & $a$ \\
\hline & $/ \mathrm{C}_{-} \mathrm{Ci}$ & $i$ & $a$ & $i$ & $i$ \\
\hline \multirow[t]{2}{*}{$*_{0}$} & & $o$ & $o$ & $o$ & $o$ \\
\hline & $/ \mathrm{uC}$ & $o$ & uo & $o$ & $o$ \\
\hline \multirow[t]{4}{*}{$* \mathrm{a}$} & & $a$ & $a$ & $a$ & $a$ \\
\hline & $/ \# \mathrm{p}$ & $a$ & $a$ & $u$ & $u$ \\
\hline & $/ \mathrm{iC}$ & $a$ & $i a$ & $a$ & $a$ \\
\hline & $/ \mathrm{uC}$ & $a$ & ua & $a$ & $a$ \\
\hline \multirow[t]{2}{*}{ *ai } & & $a i$ & $a i$ & $a i$ & $a i$ \\
\hline & $/ \# p_{-}$ & $a i$ & $a i$ & $a i$ & $u i$ \\
\hline *au & & $a u$ & $a u$ & $a u$ & $a u$ \\
\hline *ua & & $u a$ & $u a$ & $u a$ & ua \\
\hline$* \mathrm{~V}$ & /VC_CV & $\mathrm{V}$ & $\varnothing$ & $\mathrm{V}$ & $\mathrm{V}$ \\
\hline$* \varnothing$ & /\#CV(C)\#_ & $\varnothing$ & $\varnothing$ & $\mathrm{u}$ & $\mathrm{u}$ \\
\hline
\end{tabular}

PMB * o can only be tentatively reconstructed based on four word sets in which Barem $o$ corresponds to Manep $o$. One of these, the conjunction ${ }^{*} \mathrm{o}$, may very well be a borrowing of Tok Pisin $o$ 'or' in both languages. 
Table 8.1e: evidence for PMB $*_{\mathrm{O}}$

\begin{tabular}{|l|l|l|}
\hline PMB & Barem & Manep \\
\hline *bok 'grandfather' & bok & bok \\
\hline *mos 3SG.COM & mo & mos \\
\hline *o CONJ & o & o \\
\hline *umo 'coastward' & uтиo (Bun.) & umo \\
\hline
\end{tabular}

\section{Stops}

Table 8.1f: PMB stop correspondences

\begin{tabular}{|c|c|c|c|c|c|}
\hline PMB & environment & $\begin{array}{l}\text { Barem } \\
(\mathrm{QK})\end{array}$ & $\begin{array}{l}\text { Barem } \\
\text { (Bun.) }\end{array}$ & $\begin{array}{l}\text { Manep } \\
\text { (Sim.) }\end{array}$ & $\begin{array}{l}\text { Manep } \\
\text { (Mal.) }\end{array}$ \\
\hline$* \mathrm{p}$ & & $f$ & $f$ & $p$ & $p$ \\
\hline \multirow[t]{3}{*}{$* b$} & /\#_ & $b$ & $b$ & $b$ & $b$ \\
\hline & $/ \mathrm{V}_{-}$ & $m b$ & $m b$ & $m b$ & $m b$ \\
\hline & $/ \mathrm{DV}_{-}, \mathrm{VD}$ & $b$ & $b$ & $m b$ & $m b$ \\
\hline \multirow[t]{2}{*}{$* \mathrm{t}$} & & $t$ & $t$ & $t$ & $t$ \\
\hline & $/ \mathrm{VT}$ & $s$ & $s$ & $t$ & $t$ \\
\hline \multirow[t]{4}{*}{$* \mathrm{~d}$} & $\begin{array}{l}/ \# \\
/ \mathrm{DV}\end{array}, \ldots \mathrm{VD}$ & $d$ & $d$ & $d$ & $d$ \\
\hline & $/ \mathrm{V}_{-}$ & nd & nd & nd & nd \\
\hline & /\#_i & $j$ & $j$ & $j$ & $j$ \\
\hline & $/ \mathrm{V}_{-} \mathrm{i}$ & $n d$ & nd & $n j$ & $n j$ \\
\hline \multirow[t]{4}{*}{$* \mathrm{k}$} & & $k$ & $k$ & $k$ & $k$ \\
\hline & 1_\# & $k$ & $k$ & $k$ & $\varnothing$ \\
\hline & $1+$ & $k$ & $k$ & $g$ & $\varnothing$ \\
\hline & /_Vk & $x$ & $x$ & $k$ & $k$ \\
\hline \multirow[t]{5}{*}{$* g$} & /\# & $g$ & $g$ & $g$ & $g$ \\
\hline & $/ \mathrm{V}_{-}$ & $n g g$ & $n g g$ & $n g g$ & $n g g$ \\
\hline & $/ \mathrm{DV}_{-}, \mathrm{VD}$ & $g$ & $g$ & $n g$ & $n g$ \\
\hline & /_\# & $n g$ & $n g$ & $n g$ & $n g$ \\
\hline & /_\#(monosyllables) & $n g$ & $n g$ & $n g g$ & $n g g$ \\
\hline
\end{tabular}


Proto-Manep-Barem had three voiceless stops ${ }^{*} \mathrm{p},{ }^{*} \mathrm{t}$, and ${ }^{*} \mathrm{k}$, and three voiced stops $* \mathrm{~b}$, ${ }^{*} \mathrm{~d}$, and $*_{\mathrm{g}}$. In reconstructed vocabulary, $*_{\mathrm{t}}$ and $*_{\mathrm{k}}$ are found in all possible positions, but $*_{\mathrm{p}}$ is only found word-initally. The three voiced stops are found in all possible positions, although there is only one reconstruction with final $* b$.

For Proto-Manep-Barem voiced stops, it is possible to reconstruct plain voiced and prenasalized-voiced allophones. PMB word-initial voiced stops are reflected as plain voiced stops in both Manep and Barem, while PMB intervocalic voiced stops are reflected as nasal-stop sequences in both languages. Since plain voiced stops and nasal-stop sequences are in complementary distribution in directly-inherited vocabulary, we can reconstruct the same pattern of complentary distribution to PMB, with a plain voiced allophone word-initially, and a prenasalized voiced allophone intervocalically.

Word-final voiced stops were also likely realized as prenasalized-voiced in Proto-ManepBarem. In both Barem and Manep, voiced stops are typically realized as nasal-stop sequences. However, word-final $* \mathrm{~g}$ is reflected as a velar nasal in both languages, as in *musag 'eye' $>$ Barem muang [muay], Manep musang [musay]. Thus word-final $*_{\mathrm{g}}$ may have also been realized as a nasal in PMB. However, this is not entirely clear, since there are also instances in both Manep and Barem where word-final PMB *g is reflected as a nasal stop sequence after subsequent changes led to the addition of a following vowel. For example, PMB *yag 'water' > Manep yanggu, following a change in Manep where monosyllabic words added final $-u$.

Table 8.1g illustrates the reflexes of $\mathrm{PMB} * \mathrm{~b}, * \mathrm{~d}$, and $* \mathrm{~g}$ in Manep and Barem in word-initial, intervocalic, and word-final positions, along with the reconstructed PMB voiced stop allophone for each position. 
Table 8.1g: voiced stop allophones in Proto-Manep-Barem

\begin{tabular}{|l|l|l|l|l|}
\hline position & PMB & PMB allophone & Barem & Manep \\
\hline \multirow{2}{*}{$\begin{array}{l}\text { word-initial: } \\
\text { plain voiced }\end{array}$} & $*$ baren 'road' & $*[\mathrm{~b}]$ & baren & baren \\
\cline { 2 - 5 } & $*$ dur 'tail' & $*[\mathrm{~d}]$ & dur & diru \\
\cline { 2 - 5 } & *gaman 'liver' & $*[\mathrm{~g}]$ & gaman & gaman \\
\hline \multirow{2}{*}{$\begin{array}{l}\text { intervocalic: } \\
\text { prenasalized-voiced }\end{array}$} & $*$ kibem 'hand drum' & $*[\mathrm{mb}]$ & kimbem & kimbem \\
\cline { 2 - 5 } & $*$ widar- 'draw bow' & $*[\mathrm{nd}]$ & windar- & windar- \\
\cline { 2 - 5 } & $*$ iguar 'penis' & $*[\mathrm{gg}]$ & ingguar & ungguar \\
\hline \multirow{2}{*}{$\begin{array}{l}\text { word-final: } \\
\text { prenasalized-voiced }\end{array}$} & $*$ ib 'feces' & $*[\mathrm{mb}]$ & imb & imbu \\
\cline { 2 - 5 } & $*$ mud 'firewood' & $*[\mathrm{nd}]$ & mund 'firewood' & mundu 'wood' \\
\cline { 2 - 5 } & $*$ musag 'eye' & $*[\mathrm{~g}(\mathrm{~g})]$ & muang & musang \\
\hline
\end{tabular}

In both Manep and Barem, the reflex of a voiced stop is also affected by whether there is another voiced stop in the environment. In Barem, if the consonant preceding or following a voiced stop is another voiced stop, both are realized as plain voiced. For example, PMB *gadaw 'strength' > gadav, and *bagen 'light' > bagen. The only exception to this is that final $*^{\mathrm{g}}$ is reflected as a nasal regardless, as in *duag 'snake' > duang. In Manep, the pattern is similar, but more complicated, as stops at each place of articulation behave differently. Alveolar stops behave the same as in Barem: they are realized as plain voiced in the environment of another voiced stop, as in PMB *gadaw 'strength' > gadap, and *gaid 'sky' > gaid. Velar stops are realized as a velar nasal under the same conditions, as in *bagen 'light' > bangen, and *dagen 'straight' > dangen. Labial stops are unaffected by another voiced stop in the environment, and are realized as prenasalized, as in PMB *babad- 'to cut up' > bambandand PNA *debik 'dirty' > jimbik. Since these patterns are different between Manep and Barem, it is not clear how a voied stop in PMB would have been affected by another voiced stop in the environment. 


\section{Fricative *s}

Proto-Manep Barem had one fricative, ${ }^{*}$, which was deleted in most environments in Barem (see section 8.2)

Table 8.1h: correspondences for $\mathrm{PMB} * \mathrm{~s}$

\begin{tabular}{|l|l|l|l|l|}
\hline PMB & $\begin{array}{l}\text { Barem } \\
(\mathrm{QK})\end{array}$ & $\begin{array}{l}\text { Barem } \\
\text { (Bun.) }\end{array}$ & $\begin{array}{l}\text { Manep } \\
\text { (Sim.) }\end{array}$ & $\begin{array}{l}\text { Manep } \\
\text { (Mal.) }\end{array}$ \\
\hline$*_{\mathrm{s}}$ & $\varnothing$ & $\varnothing$ & $s$ & $s$ \\
\cline { 2 - 5 } & $s$ & $s$ & $s$ & $s$ \\
\hline
\end{tabular}

\section{Nasals}

Proto-Manep-Barem had two nasals, ${ }^{*}$ m and ${ }^{*} n$, which were found in all phonotactic positions. While both Manep and Barem have a velar nasal, there is no phonemic velar nasal reconstructed for Proto-Manep-Barem, although a velar nasal was possibly an allophone of *g (see above).

Table 8.1i: PMB nasal correspondences

\begin{tabular}{|l|l|l|l|l|}
\hline PMB & $\begin{array}{l}\text { Barem } \\
(\mathrm{QK})\end{array}$ & $\begin{array}{l}\text { Barem } \\
(\text { Bun. })\end{array}$ & $\begin{array}{l}\text { Manep } \\
(\text { Sim. })\end{array}$ & $\begin{array}{l}\text { Manep } \\
(\text { Mal. })\end{array}$ \\
\hline$*_{\mathrm{m}}$ & $m$ & $m$ & $m$ & $m$ \\
\hline$*_{\mathrm{n}}$ & $n$ & $n$ & $n$ & $n$ \\
\hline
\end{tabular}

\section{Liquids}

Proto-Manep-Barem had two liquids, ${ }^{*} \mathrm{r}$ and $* 1$. PMB *1 is rare, found in only three reconstructed forms. Both *r and $* 1$ are not found in word-initial position.

In both Barem and Manep verb roots ending in $r, r$ deletes before certain affixes. For example PMB *war-min 'we hit' > (Bun.) omin, Manep wamin; *war-mi 'I hit' > Barem ome, (Sim.) wami. Since this deletion occurs in a similar way in both languages, it likely applied in Proto-Manep-Barem as well. 
Table 8.1j: PMB liquid correspondences

\begin{tabular}{|l|l|l|l|l|}
\hline PMB & $\begin{array}{l}\text { Barem } \\
(\mathrm{QK})\end{array}$ & $\begin{array}{l}\text { Barem } \\
(\text { Bun.) }\end{array}$ & $\begin{array}{l}\text { Manep } \\
(\text { Sim. })\end{array}$ & $\begin{array}{l}\text { Manep } \\
\text { (Mal.) }\end{array}$ \\
\hline$*_{r}$ & $r$ & $r$ & $r$ & $r$ \\
\hline$*_{1}$ & $r$ & $r$ & $l$ & $l$ \\
\hline
\end{tabular}

\section{Glides}

Proto-Manep-Barem had two glides, ${ }^{*} \mathrm{w}$ and ${ }^{*} \mathrm{y} .{ }^{*} \mathrm{w}$ appears in all phonotactic positions, but ${ }^{*} \mathrm{y}$ does not appear word-finally. Word-final reflexes of ${ }^{*} \mathrm{w}$ are realized as a bilabial fricative $[\beta]$ (an allophone of /w/) in Barem, and as $p$ in Manep, which suggests it was a fricative in this position in Proto-Manep-Barem. It is clear that we should reconstruct PMB ${ }^{*} \mathrm{w}$ for this correspondence, rather than ${ }^{*} \mathrm{p}$, since when a Manep word with final $p$ is the first element in a compound, it has $w$ instead. For example, *PMB *gadaw 'strong' > Manep gadap, (Barem gadav) but Manep gadawar- 'strengthen', derives from PMB *gadaw and *ar- 'become'. The same alternation is seen in Manep bumbup 'ripe, red' and the compounds bumbuwar- 'be red' and bumbuwuyan 'baby' ('ripe'+'white').

Table 8.1j: PMB glide correspondences

\begin{tabular}{|l|l|l|l|l|l|}
\hline PMB & environment & $\begin{array}{l}\text { Barem } \\
(\mathrm{QK})\end{array}$ & $\begin{array}{l}\text { Barem } \\
(\text { Bun.) }\end{array}$ & $\begin{array}{l}\text { Manep } \\
\text { (Sim.) }\end{array}$ & $\begin{array}{l}\text { Manep } \\
\text { (Mal.) }\end{array}$ \\
\hline \multirow{2}{*}{$* \mathrm{~W}$} & /_V & $w$ & $w$ & $w$ & $w$ \\
\cline { 2 - 6 } & /_\#,_C & $v$ & $v$ & $p$ & $p$ \\
\hline *wa & & $o$ & $u$ & $u$ & $u$ \\
\hline *y & & $y$ & $y$ & $y$ & $y$ \\
\hline
\end{tabular}

\section{Word and syllable structure}

Proto-Manep-Barem words were of one, two, or three syllables. Initial syllables did not require an onset, and final syllables could lack a coda. Consonant clusters were not allowed. Verb roots were of one or two syllables, and always ended in a consonant. 


\subsection{Manep-Barem innovations}

Manep and Barem share four sound changes with respect to Proto-Northern Adelbert: two mergers and two subphonemic shifts. In addition to these shared phonological innovations, there are numerous PMB reconstructions for which cognates have not been identified in other Northern Adelbert languages. It is likely that some of these are shared lexical innovations.

Table 8.2a: Manep-Barem sound changes

PNA* $\boldsymbol{y}>\boldsymbol{n}$

\begin{tabular}{|l|l|}
\hline innovation & type of change \\
\hline$*_{\mathrm{g}}>\mathrm{n}$ & merger \\
\hline$*_{\mathrm{e}}>\mathrm{a} / \mathrm{Ca}$ & merger \\
\hline${ }^{\mathrm{p}} \mathrm{p}>\mathrm{w} / \mathrm{V}$ & \\
\hline$*_{\mathrm{g}}>\mathrm{y}$ & shift \\
\hline$*_{\mathrm{d}}>\mathrm{j} / \mathrm{i}$ & shift \\
\hline
\end{tabular}

In Manep-Barem, PNA *y and ${ }^{*} n$ merged as $n$, a change that took place in most other Northern Adelbert subgroups as well.

Table 8.2b: Manep Barem wordsets with * $y>n$

\begin{tabular}{|l|l|l|l|l|l|}
\hline PNA & PMB & $\begin{array}{l}\text { Barem } \\
(\mathrm{QK})\end{array}$ & Barem (Bun.) & $\begin{array}{l}\text { Manep } \\
\text { (Sim.) }\end{array}$ & $\begin{array}{l}\text { Manep } \\
\text { (Mal.) }\end{array}$ \\
\hline *guay 'skin' & & -- & -- & gunu & gunu \\
\hline *wayan 'white' & *wayan & oyan & uyan & uyan & uyan \\
\hline *geman 'liver' & *gaman & gaman & gaman & gaman & gaman \\
\hline *kumay 'nape' & *kuman & kuman & kumuan & -- & kumangarem $^{104}$ \\
\hline *bugay 'post' & *bugan & bugan & buguan & -- & - \\
\hline
\end{tabular}

However, there is one piece of evidence that this change may have taken independently in Manep and Barem. In the Kimbu Kambuar dialect of Barem, which is no longer spoken (see Chapter

104 Manep kumangarem is from *kuman 'nape' + *garem 'bone'. The velar nasal in kumangarem is the regular reflex of ${ }^{*} \mathrm{n}+\mathrm{g}$, which became $\mathrm{ng}$ (see section 8.4 ). 
2), the word for 'liver' is in gamang, from PNA *gamay. If this reflects the regular reflex of $*_{y}$ in Kimbua Kambuar, then the change of $* y>n$ must have taken place separately in Manep and Barem.

\section{PNA *e $>$ a/_Ca}

PNA *e became PMB *a when it was an initial syllable and the following vowel was *a. This change also occurred in Numugen languages and some Kaukombar languages

Table 8.2c: Manep Barem wordsets with *e $>\mathrm{a} / \mathrm{Ca}$

\begin{tabular}{|c|c|c|c|c|c|}
\hline PNA & PMB & $\begin{array}{l}\text { Barem } \\
(\mathrm{QK})\end{array}$ & Barem (Bun.) & $\begin{array}{l}\text { Manep } \\
\text { (Sim.) }\end{array}$ & $\begin{array}{l}\text { Manep } \\
\text { (Mal.) }\end{array}$ \\
\hline *kenam 'base' & *kanam & kanam & kanam & kanam & kanam \\
\hline *nenag 'tooth' & *nanag & nanang & nanang & nanang & nanang \\
\hline *gedaw 'strong' & *gadaw & gadav & gadav & gadap & gadap \\
\hline *kebuar 'mouth' & *kabuar & kambuar & kambuar & kambar & kambar \\
\hline *geman 'liver' & *gaman & gaman & gaman & gaman & gaman \\
\hline *megam 'star' & *magam & manggam & manggam & manggam & manggam \\
\hline *ked-at 'red' & *kadat & karas & karas & kandat & kandat \\
\hline
\end{tabular}

PNA *p $>w / \mathbf{V}_{-}$

PNA *p merged with ${ }^{*} \mathrm{w}$ as $w$ after a vowel. In Manep, it has the allophones [p] and [w].

Table 8.2d: Manep Barem wordsets with $* \mathrm{p}>\mathrm{w} / \mathrm{V}$

\begin{tabular}{|c|c|c|c|c|c|}
\hline PNA & PMB & $\begin{array}{l}\text { Barem } \\
(\mathrm{QK})\end{array}$ & Barem (Bun.) & $\begin{array}{l}\text { Manep } \\
\text { (Sim.) }\end{array}$ & $\begin{array}{l}\text { Manep } \\
\text { (Mal.) }\end{array}$ \\
\hline *up- 'dance' & *uw- & $u w-$ & $u w-$ & $u w-$ & $u w-$ \\
\hline *ip- '1SG.OBJ' & *iw- & $i v-$ & $i v-$ & $i p-$ & $i p-$ \\
\hline *ip 'leaf' & $* \mathrm{iw}$ & $i v$ & $i v$ & $i v u$ & $i v u$ \\
\hline *kapur 'lime' & *kawur & kawur & kawur & kawur & kawur \\
\hline *kapil 'fat' & *kawil & kavir & kavir & kawil & kawil \\
\hline $\begin{array}{l}\text { *kupi } \\
\text { 'betelpepper vine' }\end{array}$ & -- & $k u v i$ & $k u v i$ & -- & -- \\
\hline *iper 'salt, ocean' & $*_{\text {iwer }}$ & ivor 'rain' & -- & iver & iver \\
\hline
\end{tabular}


PNA *g $>y / \#, * d>j /$ i

Word-final PNA * $\mathrm{g}$ shifted to $\eta$ in Manep-Barem, but this change is submorphemic. In both modern languages, $/ \mathrm{y} /$ and $/ \mathrm{g} /$ still do not contrast in word-final position. Another submorphemic shift in Manep-Barem is that $* \mathrm{~d}$ became an affricate $j$ before $* \mathrm{i}$.

\section{Reflexes of PNA *wa-}

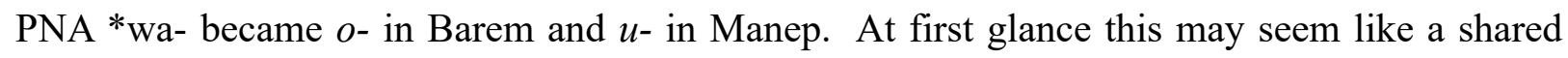
innovation that took place in Proto-Manep-Barem, with PNA *wa- becoming PMB *u-, which later lowered to $o$ in Barem. However, this path of change can be ruled out, since PNA *u- is retained as $u$ in both Barem and Manep, which means that PNA *wa- and *u- were kept distinct in Proto-ManepBarem. I therefore assume that the change from PNA *wa- to a monophthong vowel took place independently in the two languages after they split.

\section{Reduplication}

A number of Manep and Barem forms have undergone reduplication. In many cases, reduplication applied to words for things which are often found in groups (ants, roots, people), but the reduplicated form generally is used for both singular and plural. In only one case ('child') is does a reduplicated form for the plural contrast with a non-reduplicated form for the singular. Reduplicated forms also undergo vowel changes in the reduplicated syllable for which I have been unable to establish a pattern, and which behave differently in the Bunabun and Qkuan Kambuar dialects of Barem Some Barem reduplicated forms have non-reduplicated counterparts, while others do not.

Two of the forms which have undergone reduplication in Barem ('root' and 'ant') also reduplicated in Manep. However, since no clear pattern for reduplication has been established for each 
individual language or dialect, it is not yet possible to reconstruct how reduplication may have worked in Proto-Manep-Barem. Some examples of Barem and Manep reduplication are listed in Table 8.2e.

Table 8.2de reduplication in Manep-Barem

\begin{tabular}{|l|l|l|l|l|}
\hline proto-form & $\begin{array}{l}\text { non-reduplicated } \\
\text { Barem }\end{array}$ & QK & Barem & Manep \\
\hline PMB *dawir 'child' & davir 'child' & davidavir 'children' & deduir 'children' & - - \\
\hline $\begin{array}{l}\text { PNA *maden } \\
\text { person' }\end{array}$ & -- & mamunden & mumdiem & -- \\
\hline PNA *mudir 'ant' & -- & mamunjir & mumjir & mumunjir \\
\hline PMB *murin 'root' & -- & mamurin & mumurin & mururin, muririn \\
\hline $\begin{array}{l}\text { PNA *degen } \\
\text { 'straight' }\end{array}$ & digen & didigen & digidien & dangen \\
\hline
\end{tabular}

\subsection{Sound changes in Barem}

In this section, I outline the sound changes which have taken place in Barem, respective to PMB.

\section{$* \mathbf{V}>\varnothing / \# \mathbf{T}+\mathbf{T}$}

When the first two consonants of a polysyllabic word were voiceless obstruents $\left({ }^{*} \mathrm{p},{ }^{*} \mathrm{t},{ }^{*} \mathrm{k}\right.$, or

*s), the intervening vowel deleted, resulting in a consonant cluster. For example, PNA *keta 'coconut' $>k t a$, and *pataw- 'lift, raise' $>$ ptaw-.

In many cases, the initial consonant in a cluster created via vowel deletion subsequently lenited to a fricative, as detailed below.

\section{$* \mathbf{t}>\mathbf{s} / \#+\mathbf{T}$}

When vowel deletion created a sequence of word-initial $t$ followed immediately by another voiceless obstruent, $t$ lenited to $s$, as in *takap 'grasshopper' > skav, and *tatirik > 'chicken' stiri (QK), 
stari (Bun.). There is, however, some variation between a fricative and stop in the pronunciation of some words, for example skat tkat 'orphan', and skun tkun 'moon' (see Chapter 2).

$* \mathbf{k}>\mathbf{x} / \#+\mathbf{k}$

In a cluster of underlying $/ \mathrm{kk} /$, the first velar stop shifted to a voiceless velar fricative $[\mathrm{x}](<\mathrm{q}>$ in the Barem orthography). This occurs word-initially in clusters created by historic vowel deletion, for example PMB *kakas 'dog'> $>k a$, and *kuken 'old'> qkon. This change was not phonological, as the fricative is best analyzed as an allophone of $/ \mathrm{k} /$ (see Chapter 2).

$* \mathbf{p}>\mathbf{f}$

PMB * p became $f$ (a bilabial fricative) before a vowel in Barem, as in *par- 'to call' $>$ far-. This would have been a subphonemic shift, but innovative vocabulary such as pon 'sea turtle' and par 'bench' (both loans from Waskia) has reintroduced $p$ in word-initial position, so that modern Barem has a distinction between $/ \mathrm{p} /$ and $/ \mathrm{f} /$. Before another obstruent, the phonetic realization of the reflex of $* \mathrm{p}$ varies between a fricative and a stop (see Chapter 2).

${ }^{*} \mathbf{s}>\varnothing$

$\mathrm{PMB} *_{\mathrm{s}}$ was deleted in several environments, including word-initially (*sinem 'unripe' > (QK) inem, (Bun.) iniem), intervocalically (*musag 'eye' > muang), and word-finally (*kakas 'dog' > qka). $\mathrm{PMB} *_{\mathrm{s}}$ is only preserved in consonant clusters that resulted from vowel deletion, as in *kasik 'wild' > $k s i k$, although it was lost in others, as in PMB *umuns- 'to tie' $>$ umun-. This indicates that the $*_{\mathrm{s}}>\varnothing$ took placed after $* \mathrm{~V}>\varnothing / \# \mathrm{~T}_{-} \mathrm{T}$. 
$* \mathbf{t}>\mathbf{s} / \mathbf{a}$

Word final *t became $s$ after *a, as in PMB *ked+at 'red'> karas, *pur+at 'rotten' > furas, and PNA *barat 'year' $>$ babaras. Since word-final $s$ derived from *t did not subsequently delete, this change must have taken place after $*_{s}>\varnothing$.

*I $>$ r

PMB *1 merged with *r in Barem: *tawal 'island' > tawar, *mil- 'vomit' > mir-.

$* \mathrm{e}>\mathbf{0} /$ r $\#(\mathbf{Q K}) * \mathrm{e}>\mathrm{a} /$ r $\#$ (Bun)

*e changed its quality before word-final $r$, becoming $o$ in Qkuan Kambuar, and $a$ in Bunabun. For example, PMB *taiwer 'cassowary' $>$ QK taiwor, Bun. taiwar, PNA *baner 'signal drum' $>$ QK banor, Bun. banar.

Although there is no obvious phonetic motivation for a change of $*_{\mathrm{e}}>o$ or $* \mathrm{e}>a$ in this context, cognates in Manep and other Northern Adelbert languages clearly indicate this was PNA *e. We can therefore also reconstruct Proto-Barem *e for the o:e correspondence between the Barem dialects, even where there are not cognate terms outside of Barem. For example, QK kiror and Bun. kiriar 'men's house' point to Proto-Barem *kirer.

An apparent exception to the change is the sequence -rer, in which *e continued as $e$ in both Barem dialects: PMB *arer 'two' > arer, Proto-Barem *bagarer 'terminalia tree sp.' > QK bagarer, Bun. bagrer.

*e $>$ i/\#C_CV(C) (QK), *e > a/\#C_CV(C) (Bun)

When *e was the first syllable in a polysyllabic word, it changed to $i$ in Qkuan Kambuar and $a$ in Bunabun. For example, PNA *teber 'mangas plant' $>\mathrm{QK}$ timbor, Bun. tamber, *bagen 'light' $>\mathrm{QK}$ 
bigen, Bun. bagen, *mekiw 'ground, garden' > QK mikiv, Bun. makiv, and *dagen 'straight' > Bun. digen. An exception to this change is when the following vowel is *a, in which case *e $>a$ in both $\mathrm{QK}$ and Bunabun, a change shared with Manep, as outlined above.

There are a number of words in which Qkuan Kambuar $i$ corresponds with Bunabun $a$, but there are no cognates outside Barem. For these, I reconstruct Proto-Barem *e. Proto-Barem *nembek 'big' >

QK nimbek, Bun. nambek, *meser 'betel nut' > QK misor, Bun. masar, *bew- 'wait' > QK biw-, Bun. baw-.

$* V>\varnothing / V C \_C V$ (Bun.)

In Bunabun, medial vowels were sometimes lost in words that are trisyllabic or longer, as in Proto-Barem *urumik 'fish' > (QK) urumik, (Bun.) urmik; Proto-Barem *gigiruk 'crooked' > (QK) gigiruk, (Bun.) gigruk.

When vowel loss created a cluster with a prenasalized voiced stop, this stop lost the prenasalization if it came second in the cluster, as in Proto-Barem *kamandim 'bow' > (QK) kamandim, (Bun.) kamdim. If the prenasalized stop was the first segment in the cluster, it lost the oral portion to become a nasal: PNA *kuduruk 'fly' (QK) > kunduruk, (Bun.) kunruk.

There are a few unexplained exceptions to this rule: PMB *yawarap 'again' > (Bun.) yawarav, PMB *kiwinem 'yam' > (Bun.) kivinem, PMB *iderem 'leech' > (Bun.) enderem, and Proto-Barem *kuragat 'frog' > (Bun.) kuruanggat.

\section{High vowel insertion: $\mathrm{V}[-\mathrm{high}]>\mathrm{iV} / \mathrm{iC} \_, \mathrm{V}[-\mathrm{high}]>\mathrm{uV} / \mathrm{uC} \_(\text {Bun.) }$}

In Bunabun, a high vowel was inserted before a non-high vowel when the previous vowel was high. For example, PMB *kibem 'hand drum' > (QK) kimbem, (Bun.) kimbiem; PNA *kumay 'nape' > 
(QK) kuman, (Bun.) kumuan; *sinem 'green, unripe' > (QK) inem, (Bun.) iniem. This rule also applies productively in Bunabun inflected verbs (see Chapter 2).

In some instances, the conditioning high vowel was subsequently lost due to the change $* \mathrm{~V}>$ $\varnothing / \# \mathrm{~T}_{-} \mathrm{T}$. From the inserted vowel in Bunabun, it is possible to reconstruct the conditioning vowel that was deleted. For example, from QK ftam-, Bun. ftiam- 'to serve', it is possible to reconstruct ProtoBarem *pitam-.

*wa- > o/\#

Word initial *wa- became $o$ in Barem. PMB *waben 'arm, hand' > omben, *war- 'to hit' > or-, *wayan 'white' > oyan. This initial $o$ in Barem corresponds with $u$ in Manep, and derives from ProtoNorthern Adelbert *wa-. Since word-initial PNA *u continued as $u$ in both Manep and Barem, I retain $\mathrm{PMB} *$ wa for the $o: u$ correspondence.

\section{Relative chronology of Barem sound changes}

Table $8.2 \mathrm{~d}$ presents the Barem sound changes for which there is evidence of having applied in a particular order. First, it is clear that Bunabun high vowel insertion applied before $* \mathrm{~V}>\varnothing / \# \mathrm{~T} \_$, since vowels which deleted according to this rule first triggered the insertion of a high vowel. Second, *V > $\varnothing / \# \mathrm{~T}_{-} \mathrm{T}$ applied before deletion of $*_{\mathrm{s}}$, since $s$ is preserved immediately following another voiceless obstruent. Third, $* \mathrm{t}>\mathrm{s} / \mathrm{a} \_\#$ applied after deletion of $*_{\mathrm{s}}$, since word-final $s$ did not delete when it is a reflex of $* \mathrm{t}$. 
Table 8.3a: relative chronology of Barem sound changes

\begin{tabular}{|c|c|c|c|c|c|c|}
\hline & & $\begin{array}{l}\text { Proto-Barem } \\
{ }^{*} \mathrm{k}(\mathrm{i} / \mathrm{u}) \text { sen 'bone' }\end{array}$ & $\begin{array}{l}\text { Proto-Barem } \\
\text { *pitam- 'serve' }\end{array}$ & $\begin{array}{l}\text { *kasik } \\
\text { 'wild' }\end{array}$ & $\begin{array}{l}\text { *barat } \\
\text { 'year' }\end{array}$ & $\begin{array}{l}\text { *usir } \\
\text { 'centipede' }\end{array}$ \\
\hline & vowel insertion & $\mathrm{k}(\mathrm{i} / \mathrm{u})$ sien & pitiam & -- & -- & -- \\
\hline 2) & $* \mathrm{~V}>\varnothing / \# \mathrm{~T}_{-} \mathrm{T}$ & ksien & ptiam & ksik & -- & -- \\
\hline 3) & ${ }^{*} \mathrm{~s}>\varnothing / \mathrm{V}_{-}, \#_{-} \mathrm{V}$ & -- & -- & -- & -- & uir \\
\hline 4) & $*_{\mathrm{t}}>\mathrm{s} / \mathrm{a} \_\#$ & -- & -- & -- & baras & -- \\
\hline & & ksien & ptiam- & ksik & baras & vir \\
\hline
\end{tabular}

\subsection{Sound changes in Manep}

Below I outline the sound changes which took place in Manep relative to PMB.

$* \mathbf{i}>\mathbf{u}, * \mathbf{u}>\mathbf{i}$

A common change in Manep is that $*_{i}$ became $u$ when the preceding or following vowel was

${ }^{*} \mathrm{u}$. The opposite change occurred as well, with *u becoming $i$ in the environment of $i$. Neither of these changes appears to be regular, and it does not seem possible to predict which vowel, if any, will assimilate to the other. For example, a change of $*_{\mathrm{i}}>u$ is seen in $*_{\text {iguar }}$ 'penis' $>$ ungguar, ${ }^{*}$ kudi 'banana' > kunju, and *ikus 'to shoot' > ukus-. The opposite change of *u to $i$ is seen in *dur 'tail' > diru and *iduw- 'go' > injiw-. In many cases, both vowels have remained the same, for example *irub 'come up' > irub- and *unim 'name' > unim. In other cases there is variation, as in *ituw- 'pull out, take off, > ituw utuw, and *murin 'root' > mururin muririn. Sporadic change between high vowels is common in Northern Adelbert languages. 
$* \mathbf{a}>\mathbf{u} / \mathbf{p}_{-}$

PMB *a became $u$ in Manep after $p$, for example *par- 'to call' > pur-, and *panar 'village' > punar. This applied also to the sequence /ai/ in *pai 'mango' > pui. For unclear reasons, the change did not occur in *pataw- 'to lift' > pataw-. This vowel change also took place in *baram 'hornbill' > buram, but not in the similarly shaped *baren 'road' > baren and *barek 'uncle/nephew' > barek.

${ }^{*} \mathrm{e}>\mathrm{a} / \# \mathrm{C}_{-} \mathrm{C}, * \mathrm{e}>\mathrm{i} / \mathrm{C}_{-} \mathrm{Ci}$

*e became $a$ in initial syllables when followed by a consonant, as in PNA *ben 'axe' > banu, *men 'breast' > manu 'breast', and *nebek 'bird' > nambek. If the following vowel was *i, then *e raised to $i$ instead, as in *mekiw 'ground'> mikip, PNA *tebik 'rain'> timbik, *merik 'eel' > mirik, and *debik 'dirty' jimbik. In monosyllabic open syllables, *e is reflected $e$, as in *me 'NEG' $>m e$ and *te 'LOC'> te.

$* \varnothing>\mathbf{u} /(\mathbf{C}) \mathbf{V}(\mathbf{C}) \_\#$

Monosyllabic content words with added a final $u$ in Manep. For example, PMB *kit 'meat' > kitu, and *mur 'short' > muru. This change did not apply to words of the shape *CVVC, such as *tuar 'crocodile' > tuar, or *ain 'foot' > ain, suggesting that these are bisyllabic in PMB, rather than monosyllables with phonological diphthongs. This change also did not apply to function words, including monosyllabic pronouns, as well as the locative/instrumental adposition *te, *mak 'after, behind', and *yam 'nothing'.

The change also did not apply to kinship terms: *ya 'uncle' > yaya, *baw 'older brother' > baba, $b a,{ }^{*}$ bok 'grandfather' > bok, and possibly *gar > gar 'clan, extended family', assuming that these words are directly inherited. 
${ }^{*} \mathbf{g}>\mathbf{\eta} / V_{-}$VD, DV_V

As mentioned in Section 1, the realization of voiced stops in Manep-Barem can be affected by another voiced stop in the environment. In Manep, a velar stop *g became a nasal $n g$ when the preceding or following consonant was also a voiced stop, as in *dagen 'straight' $>$ dangen and *bugum'sit' > bungom-. While [g] and [y] would have originally been in complementary distribution, there are now words in Manep (of unknown origin) with intervocalic [y] not in the environment of a voiced stop, such as yangi 'yellow', which makes this distinction phonemic.

${ }^{*} \mathbf{n}+{ }^{*} \mathbf{g}>\mathbf{y}$

When compounding resulted in a sequence of $*^{n}+* g$, this became a velar nasal. Examples are *ain+gaman 'sole of foot' $>$ aingaman, and *waben+*gaman 'palm of hand' $>$ imbengaman, *kuman+*garem > kumangarem 'back of head', and *gaman+*garem.'chest cavity' > gamangarem.

$* k>\varnothing /+$ (Malas only)

Final *k deleted in the Malas dialect, as in *buruk 'pig' > buru, and *kuduruk 'fly' > kunduru. Monosyllabic *PMB words ending in $*_{\mathrm{k}}$ were not affected by this change, as final $/ \mathrm{u} /$ was added to these words first, as in *yik 'sore' > iku. This change also affected morpheme-final *k in compound words and $k$-final verb roots, such as *wabek- 'to hold' > imbe-, and *girik 'to hold' > giri-.

\section{*k $>$ g/_+V (Simbukanam only)}

Word-final $* \mathrm{k}$ did not undergo any changes in the Simbukanam dialect, but morpheme-final $* \mathrm{k}$ became voiced (without prenasalization) word-medially, for example on verb roots, such as *wabek- 'to hold' > imbeg-, and *girik 'to hold' > girig-, but also other suffixed morphemes, such as the negator weget $<\mathrm{PMB} *$ uiek, with the fossilized suffix - et. 
${ }^{*} \mathbf{w}>\mathbf{p} / \#$

Word-final ${ }^{*} \mathrm{w}$ became $p$ in Manep. For example, PMB *yawaraw 'again' > yawarap, and *pitiw 'sago' > pitip. This change applied after the addition of $u$ to monosyllabic words, as it did not apply to forms such as $i w u$ 'hair' < PMB *iw.

${ }^{*} \mathbf{w a}->\mathbf{u} / \#$

Word-initial *wa- merged with $*^{*} \mathrm{u}$ - in Manep, becoming $u$. PMB *war- 'to hit' $>$ ur-, *wayan 'white' > uyan, *waben 'arm, hand' > imben (with later fronting of $u>i$ ).

\section{Relative chronology of Manep sound changes}

For three of the Manep sound changes, it is possible to determine the order they happened in relative to another change. Since the changes that applied to word-final ${ }^{*} \mathrm{k}$ and $*_{\mathrm{W}}$ did not apply to monosyllabic words, it is clear that these changes happened after the addition of final $u$ to monosyllabic words.

Table 8.4a: Relative chronology of Manep sound changes

\begin{tabular}{|ll|l|l|l|l|}
\hline & & $\begin{array}{l}* \text { tak } \\
\text { 'broad leaf' }\end{array}$ & $\begin{array}{l}* \text { taw } \\
\text { 'some' }\end{array}$ & $\begin{array}{l}* \text { buruk } \\
\text { 'pig' }\end{array}$ & $\begin{array}{l}\text { *uyaw } \\
\text { 'spear' }\end{array}$ \\
\hline 1$)$ & $* \varnothing>\mathrm{u} / \#(\mathrm{C}) \mathrm{VC} \_$ & taku & tawu & -- & - -- \\
\hline 2$)$ & $\begin{array}{l}* \mathrm{k}>\varnothing /+(\text { Malas }) \\
* \mathrm{w}>\mathrm{p} / \# \text { _\# }\end{array}$ & -- & -- & buru & uyap \\
\hline & & taku & tawu & buru & uyap \\
\hline
\end{tabular}




\subsection{Proto-Manep-Barem grammatical morphemes}

\section{Verb template}

The following verb template can be reconstructed for Proto-Manep-Barem.

Table 8.5a: Proto-Manep-Barem affix ordering

\begin{tabular}{|l|l|l|l|l|}
\hline OBJ & root & R-markers & IPFV & $\begin{array}{l}\text { subject }+ \text { tense } / \text { mood } \\
\text { SER } \\
\text { NMLZ }\end{array}$ \\
\hline
\end{tabular}

The ordering of verb root and affixes in Table 8.5a is nearly the same in both Manep and Barem, with one caveat: Manep synchronically does not have direct object prefixes, but it does have fossilized elements at the beginning of some verb stems, which derive from PMB object-marking prefixes. Forms for the direct object-marking prefixes, R-markers, the nominative affix $(*$-aw) and the serial verb affix $(*-\mathrm{V})$ are reconstructible for PMB, as are several subject+tense/mood affixes (see below). Of the cells in Table 8.5a, it is not possible to reconstruct any forms only for the imperfective slot. Where the verb root and affixes are all cognate in Manep and Barem, it is possible to reconstruct as fully inflected PMB verb, as in *par-id-ak 'call-PL-2SG.IMP' > Barem far-ind-iak, Manep pur-end-a.

\section{Direct object prefixes}

It is possible to reconstruct a set of Proto-Manep-Barem direct object-marking prefixes, which were only used on a small number of verbs. In Barem, direct object prefixes are attested only on two verbs, angg- 'to see', and anggar- 'to teach, show'. In Manep, there are several sets of verb stems that have the person/number of the direct object included in the meaning of the stem. Some of these Manep verbs have elements that, while not synchronically separate morphemes, are clearly related to the Barem direct object prefixes. 
Table 8.5b: PMB direct object-marking prefixes and their reflexes

\begin{tabular}{|l|l|l|l|}
\hline & PMB & Barem & Manep \\
\hline 1SG & *iw- & $i v-$ & iwansar- 'teach/show 1SG' \\
\hline 2SG & *naw- & $n a w-$ & $\begin{array}{l}\text { nawansar- 'teach/show 2SG' } \\
\text { naweng- 'see 2SG' }\end{array}$ \\
\hline PL & *uw- & $u w-$ & $\begin{array}{l}\text { uwansar- 'teach/show 3SG' } \\
\text { uworum- 'follow/chase SG' }\end{array}$ \\
\hline imb- & $i m b-$ & $\begin{array}{l}\text { imbandar- 'teach/show.PL' } \\
\text { imbensim- 'see.PL' } \\
\text { imberum- 'follow/chase.PL' }\end{array}$ \\
\hline
\end{tabular}

The reflexes of the PMB direct object prefixes are used on only the verbs 'to see' and 'to teach/show' in both Manep and Barem, so we can reconstruct their use on these two verbs in PMB. There are also reflexes of on the Manep verbs for 'to chase/follow', but as no cognate term has been identified in Barem, their use on this verb in PMB cannot be reconstructed. Cognate prefixes in Karian and Gavak are also restricted to 'to see', while the cognate pronouns in Kumil languages are general direct object pronouns (see Chapter 7).

\section{R-markers}

Both Manep and Barem have a set of verb suffixes I call R-markers, which are used to mark indirect objects, beneficiaries, maleficiaries, and experiencers in bodily and mental state verbs. In Manep, these R-markers are similar in form to the verb roots with the meaning 'to give', which have different forms depending on the person/number of the recipient. ${ }^{105}$

The Manep and Barem R-markers and the Manep 'give' verbs are used to reconstruct the PMB forms in Table $8.5 \mathrm{c}$, which function both as verb roots with the meaning 'to give', as well as affixes in other constructions, such as bodily and mental state verbs.

105 I have analyzed 'to give' in Barem as being composed of the R-markers affixed to a phonologically empty root, whereas in Manep I have analyzed the R-markers and verb roots as separate morphemes, since they are not homophonous. An alternate analysis for 'to give' in Barem would be a set of verb stems that are (mostly) homophonous with the R-markers. 
Table 8.5c: PMB R-markers and their reflexes

\begin{tabular}{|l|l|l|l|l|}
\hline & PMB & Barem R-markers & Manep R-markers & Manep 'to give' \\
\hline 1SG & *is & $-i$ & $-i s$ & is- \\
\hline 2SG & *nas & $-n$ & $-a n s$ & nas- \\
\hline 3SG & *us & $-w$ (for 'to give') & $-a s$ & us- \\
\hline PL & *ind & - for other verbs) & & und- 'give to 3PL' \\
\hline
\end{tabular}

Some explanation is necessary for some of the Manep and Barem forms used for the PMB reconstructions. First, the Barem 3SG R-markers $-w$ is used only for the verb 'to give', while other verbs use the form $-t$. PMB ${ }^{*}$ s regularly deleted in Barem, which is reflected in $-w$ (as well $1 \mathrm{SG}-i$ and $2 \mathrm{SG}-n)$. It is possible that $3 \mathrm{SG}-t$ also reflects $\mathrm{PMB} * \mathrm{us}$, with irregular fortition of $*$ s. Second, in addition to und- 'give to 3PL', Manep also has the verbs inind- 'give to 1PL' and nanind-'give to 2PL' which may also reflect PMB *ind, with additional material added. Alternately, it is possible that PMB also distinguished 1/2/3PL, and that this distinction was lost in Barem. However, since the Manep plural R-marker - and is used for all plurals without a person distinction, I have reconstructed PMB *ind as the R-marker for all plurals, rather than 3PL specifically. Third, some Manep R-markers have undergone irregular vowel changes, which is not surprising in grammatical morphemes. Furthermore, some verb stems affect the vowel quality in Manep R-markers. For example, bim-ond-in 'he tricked them' and bim-ons-in 'he tricked you', rather than expected *bim-and-in and *bim-ans-in.

\section{Subject+tense/mood affixes}

Table $8.5 \mathrm{~d}$ shows the reconstructed PMB subject and tense/mood suffixes. 
Table 8.5d: PMB subject+tense/mood suffixes

\begin{tabular}{|l|l|l|}
\hline PMB & Barem & Manep \\
\hline *-mi & -me & $\begin{array}{l}\text { Sim: -umi } \\
\text { 1SG.REM }\end{array}$ \\
\hline $\begin{array}{l}\text { *-min } \\
\text { 1PL.REM }\end{array}$ & Bun: -min & -umin \\
\hline $\begin{array}{l}\text { *-Vn } \\
\text { 2SG.REM }\end{array}$ & -Vn & $-\mathrm{V} n$ \\
\hline $\begin{array}{l}\text { *-ak } \\
\text { 2SG.IMP }\end{array}$ & -ak & $-a$ \\
\hline
\end{tabular}

\section{SG.REM *-mi}

Barem -me $e^{106}$ and Manep -umi (Sim.) and -umoi (Malas) '1SG.PST' are used to reconstruct PMB *-mi '1SG.REM'. Although the usual reflex of final *i in Barem is $i$, not $e$, it also applied in the only other grammatical morpheme with final $*_{i}$ that has been reconstructed, the question particle $*_{i}$ (Barem e). The insertion of $o$ in Malas -umoi is also not a regular change.

\section{PL.REM *-min}

Bunabun -min '1PL.REM' and Manep -umin '1/3PL.PST' are used to reconstruct PMB *-min 1PL.REM. Although both Manep and the Qkuan Kambuar dialect of Barem have combined the 1PL and 3PL past, these were distinct in Proto-Manep-Barem, and the distinction in maintained in the Bunabun dialect of Barem with -min '1PL.REM' and -mid '3PL.REM'. Qkuan Kambuar -mind '1/3PL.R' is derived from PNA *-mid '3PL.REM', while Manep -umin '1/3PL.PST' is derived from *_ mid '1PL.REM'. The merger of the 1PL and 3PL remote past markers is probably due in part to their similarity in form, and has occurred in other Northern Adelbert languages as well, including Hember Avu and Mauwake.

106 In Bunabun, this marker is used for 1SG.REM, while in QK it is 1SG.R (see section 9.2.3). 


\section{SG.REM *-Vn}

The PMB 2SG past marker *-Vn is reconstructed based on Barem -Vn '2SG.REM' and Manep Vn '2/3SG.PST'. Since PNA had both *-Vn '2SG.REM' and *-Vd '3SG.REM', a distinction that Barem maintains, it is clear that the meaning of the PMB marker was $2 \mathrm{SG}$, and not 2/3SG. Manep extended $\mathrm{V} n$ to cover both the $2 \mathrm{SG}$ and $3 \mathrm{SG}$ past, a change that also took place in the Tiboran language Hember Avu.

In Barem, the form of the vowel in $-\mathrm{V} n$ is determined by the preceding consonant. The allomorph -an is used after velars and $r$, -en is used after alveolars (except $r$ ), and -on is used after labials. In Manep, which allomorph is used depends on the verb's class, which only roughly correlates with its final consonant (see Chapter 2). However, if we look only at Manep verbs which are inherited from PMB, they follow a similar pattern to Barem, with some small differences ${ }^{107}$. We can therefore reconstruct the following allomorphs of Proto-Manep-Barem *-Vn: *-en is used after an alveolar (except $*$ r), *-an is used after velars and ${ }^{*}$, and $*_{\text {-on }}$ is used after labials. This pattern is illustrated in Table 8.e.

Table 8.5e: allomorphs of $*_{-} \mathrm{Vn}$

\begin{tabular}{|l|l|l|}
\hline PMB & Barem (Bunabun) & Manep \\
\hline *an-en 'eat-2SG.REM' & anen & anen \\
\hline *in-en & inien & inen \\
\hline *is-en 'give_1SG-2SG.REM' & yen & isen \\
\hline *ag-an 'see-2SG.REM' & anggan & angan \\
\hline *iduw-on 'go-2SG.REM' & induwon & injiwon \\
\hline *aw-on 'take-2SG.REM' & awon & awon \\
\hline
\end{tabular}

Table 8.5f illustrates how in both Manep and Barem, a final $r$ on a verb stem deletes before the reflex of *-Vn. ${ }^{108}$ This $r$-deletion is not a regular phonological process in both Manep and Barem, but

107 Some Manep $s$-final verbs, pis- 'blow' < *pis- and $u k u s$ - 'shoot' < *ikus- take the 2/3SG.REM form -in, rather than -en (pisin 'he blow, ukusin 'he shot'). The -in allomorph is also used on historically *k-final verbs, which are now vowel-final in the Malas dialect, and $g$-final in Simbukanam (imbegin 'he held' $<*$ wabek-, girigin 'he turned' < *girik-).

108 Manep verbs ending in -ar have an irregular 2/3SG.PST suffix -mun (see Chapter 2). 
is only triggered by specific suffixes. Since it is triggered by the reflexes of $*$-Vn in both languages, I reconstruct inflected forms without *r for PMB.

Table 8.5f: deletion of $r$ before $*$-Vn

\begin{tabular}{|l|l|l|l|}
\hline PMB verb step & PMB inflected form & Barem (Bunabun) & Manep \\
\hline *war- 'to hit' & *wa-an 'hit-2SG.REM' & wan (/or-an/) & wan (/ur-an/) \\
\hline *par- 'to call' & *pa-an 'call-2SG.REM' & fan (/far-an/) & puan (/pur-an/) \\
\hline
\end{tabular}

2SG.IMP *-ak

The Barem 2SG imperative affix - $a k$ and corresponding Manep - $a$ are used to reconstruct PM *ak '2SG.IMP'. The Malas dialect of Manep regularly lost final *k, but the Simbukanam dialect did not. However, both dialects have lost the final *k in - a '2SG.IMP'.

\section{Nominative *-aw}

Barem $-a v$ and Manep $-a p /-e p^{109}$ are suffixed to a verb stem to create a noun or a gerund. In both languages, this suffix is the final suffix on a verb, and does not co-occur with a subject/tense suffix, although it can co-occur with R-markers. The most common use of the nominative affix in both languages is to form a gerund, illustrated in (801) for Barem, and (802) for Manep.

banar mata onor ptunggu-av mata nem. signal_drum method 3.POSS cut-NMLZ method with

(Barem) 'Signal drums have their method for carving them.'

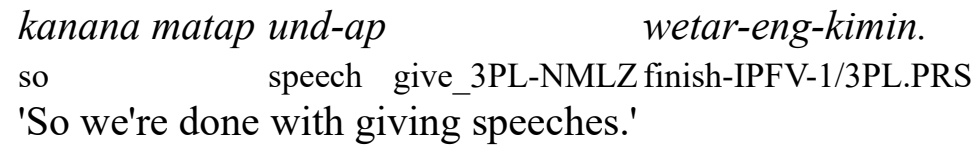

These suffixes are also used in both languages to form nouns with a fixed meaning, as in Barem umav 'death' and Manep umap 'death' < PMB *um- 'die'. These nouns do not always have equivalent meanings in the two languages, for example Barem anav 'food' and Manep anap 'crops' < PMB *an-

109 Manep has two forms of the nominative suffix, used on different verb classes. 
'eat', or Barem inggidiav 'residents' and Manep ingindep 'way of life', from PMB *igid- 'to live at, be at'.

\section{PMB pronouns}

Two pronoun paradigms are reconstructible to Proto-Manep-Barem. These are subject pronouns and possessive pronouns.

The reconstructed PMB subject pronouns are identical in form to the Manep pronouns. Barem has added the ending -ne to the singular subject pronouns, and - $o$ to the plural subject pronouns. Furthermore, the Qkuan Kambuar and Bunabun dialects have markedly different paradigms from each other, and both dialects have idiosyncratic changes for some of the forms. QK has 2SG nane instead of expected *nene, and Bunabun has idiosyncratic changes in the 2SG and 3rd person pronouns, including the extension of the historically 3PL to plural and singular. Table $8.5 \mathrm{~g}$ lists the reconstructed PMB subject pronouns, with their reflexes in Barem and Manep. Forms which have undergone irregular changes are in parentheses.

Table 8.5g: PMB subject pronouns

\begin{tabular}{|l|l|l|l|l|}
\hline & PMB & QK & Bunabun & Manep \\
\hline 1SG & $*_{\mathrm{i}}$ & ine & inie & i \\
\hline 2SG & $*_{\text {ne }}$ & (nane) & nene & ne \\
\hline 3SG & $*_{\mathrm{u}}$ & une & (ono) & u \\
\hline 1PL & $*$ in & ino & inuo & in \\
\hline 2PL & $*$ nan & nano & (ane) & nan \\
\hline 3PL & $*$ un & uno & (ono) & un \\
\hline
\end{tabular}

An argument could be made to reconstruct *na for the $2 \mathrm{SG}$ form, rather than *ne, since this would make the PMB singular and plural pronoun forms completely symmetrical, as they are in Qkuan Kambuar, with the PMB plural being formed with the addition of final *n to the singular. However, 
other Northern Adelbert languages, including the Kumil-Tibor languages, Usan, and Gavak, point to *ne for the PNA 2SG.

Possessive pronouns are forme with the addition of the suffix *-ner $(<\mathrm{PNA} *$-ner $)$ to the subject pronouns. As with the subject pronouns, the reconstructed PMB singular possessive pronouns are again identical to Manep. An epenthetic vowel is inserted in QK and Manep between the final *n of the plural subject pronouns and *-ner. QK inserts a copy of the preceding vowel, while Manep inserts i. The changes of *-er to -or in $\mathrm{QK}$ and -ar in Bunabun are regular. Bunabun onor is not cognate, and like the Bunabun subject pronouns, it is used for both 3rd person singular and plural.

Table 8.5h:PMB possessive pronouns

\begin{tabular}{|l|l|l|l|l|}
\hline & PMB & QK & Bunabun & Manep \\
\hline 1SG & *i-ner & inor & iniar & iner \\
\hline 2SG & *na-ner & nanor & nanar & naner \\
\hline 3SG & *u-ner & unor & (onor) & uner \\
\hline 1PL & *in-ner & ininor & inior & ininer \\
\hline 2PL & *nan-ner & nananor & anar & naniner \\
\hline 3PL & $*$ un-ner & ununor & (onor) & uniner \\
\hline
\end{tabular}

\section{SG.COM *mos}

The Barem 3SG comitative pronoun mo and its Manep counterpart mos are used to reconstruct PMB *mos '3SG.COM'. ${ }^{110}$ The 3SG.COM pronoun is used to indicate accompaniment, as in the Barem example in (803) and the Manep example in (804).

Ukir faret-di kodi water_rat call-3SG-3PL.PFV.SS come- 3PL.PFV.SS mo
3SG.COM bugum-mid. 'They called to Water Rat and came and sat down with him.' sit-3PL.REM (Barem) pirup kambar te mos inj-umin si sag-in. hole mouth LOC 3SG.COM go-1/3PL.PST DS go_down-2/3SG.PST 'They went with her to the mouth of the hole, and she went down.'

(Manep)

110 Although Barem has a full paradigm of comitative pronouns, only two comitative pronouns are attested for Manep: mos and a plural comitative pronoun munang, which is not cognate with Barem's plural comitative pronoun mainde. 


\section{LOC and INST *te}

The PMB postposition *te is reconstructed based on Barem te and Manep te. In both languages, te can be used to indicate location, time and instrument. As a locative postposition, it has a broad range of meanings, including 'to', 'in', 'on' and 'at'. The use of te as a locative postposition is illustrated for Barem in (805-806), and for Manep in (807-808)

(805) biga te induw-od.

ocean LOC go-3SG.REM

'He went to the ocean.'

(806) duadup te ivom.

basket LOC put_inside-2PL.IMP

'Put them in the basket.'

(807) umansi dinggop te injiw-on

husband forest LOC go-2/3SG.PST

'the husband went to the forest'

\begin{tabular}{|c|c|c|c|}
\hline $\begin{array}{l}\text { kivinem } \\
\text { yam }\end{array}$ & $\begin{array}{l}g e \\
\text { one }\end{array}$ & $\begin{array}{l}\text { ang-amin, } \\
\text { see-1/3PL.PRS }\end{array}$ & $\begin{array}{l}\text { suap } \\
\text { bamboo }\end{array}$ \\
\hline
\end{tabular}

'They saw a yam, at the foot of a bamboo.'

The temporal use of te is illustrated in (809) for Barem and (810) for Manep.

$\begin{array}{ll}\text { [April] te Bunabun } & \text { amun tu-mid. } \\ \text { April in } & \text { Bunabun }\end{array}$

'In April, they burned houses in Bunabun.'

$\begin{aligned} & \text { menda bok } \\ & \text { before grandfather }\end{aligned} \quad \begin{aligned} & \text { sese } \\ & \text { grandmother }\end{aligned}$
$\begin{aligned} & \text { wetar-eng-kimin. } \\ & \text { 3PL.POSS }\end{aligned}$

The use of te as an instrumental postposition is illustrated in (811) for Qkuan Kambuar Barem and (812) for Manep.

(811) ine sawen te umun-ume.

1SG cane.sp INST tie-1SG.R

'I tied it with sawen cane.' 
$\begin{array}{llll}u & \text { kimu } & \text { te } & \text { w-an. } \\ \text { 3SG } & \text { bow } & \text { INST } & \text { hit-2/3SG.PST }\end{array}$

'He shot it with a bow.'

\section{*urite 'inside'}

Although the locative postposition te can include the meaning of 'in' or 'inside' in both Barem and Manep, as in the Barem example in (806), both languages have another postposition, urite $(<\mathrm{PMB}$ * urite $^{111}$ ), with the more specific meaning of 'inside'. In the Barem example in (813), compare the use of te biga te 'to the ocean' with biga urite 'in the ocean'. The use of urite makes it clear that the character in the narrative, who is a sea turtle, was living inside the ocean, rather than on the beach, for example.

$\begin{array}{lllll}\text { biga } & \text { te } & \text { and-a dokm-od. } & \text { inggid-iomada, } & \text { biga } \\ \text { ocean LOC } & \text { go-SER run-3SG.REM } & \text { live-SG.IPFV.SS } & \text { ocean inside }\end{array}$

'She ran away to the ocean. She lived there, in the ocean...'

The example in (814) illustrates the use of urite in Manep, where it again expresses a more specific notion of 'inside' compared to the general locative postposition te.

\begin{tabular}{|c|c|c|c|c|c|c|c|}
\hline $\begin{array}{l}\text { bumu } \\
\text { neck }\end{array}$ & $\begin{array}{l}\text { butug-umin } \\
\text { cut-1/3PL.PST }\end{array}$ & $\begin{array}{l}\text { ne } \\
\text { 3.SS }\end{array}$ & $\begin{array}{l}\text { uner } \\
\text { 3SG.POSS }\end{array}$ & $\begin{array}{l}\text { kumu } \\
\text { head }\end{array}$ & $\begin{array}{l}k a \\
\text { DET }\end{array}$ & $\begin{array}{l}\text { kumun } \\
\text { pot }\end{array}$ & $\begin{array}{l}\text { banumin. } \\
\text { put-1/3PL.PST }\end{array}$ \\
\hline
\end{tabular}

\section{Question marker *i}

Barem $e$ and Manep $i$ are used to reconstruct the PMB question particle $*_{\mathrm{i}}$. Barem $e$ is used at the end of a yes/no question (815), as is Manep $i(816)$. As noted above, the lowering of $*_{\mathrm{i}}$ to $e$ in Barem is not a regular change, but only applied grammatical morphemes.

$\begin{array}{llll}\text { ain } & \text { te } & \text { kur-kan } & \text { ? } \\ \text { leg INST } & \text { come-2SG.HOD Q }\end{array}$

'Did you come on foot?'

111 *urite is likely derived from *urir 'belly' + *te 'LOC'. 
(816) ka katuk begar-eng-kimin ne ambor ar-eng-kimin i? DET thus do-IPFV-1/3PL.PRES 3.SS good become-IPFV-1/3PL.PRES Q 'When they do it like that does it get better?'

WH-questions in Barem (817) and Manep (818) do not use the question particle.

$\begin{array}{lll}\text { (817) } & \text { go ma babaras te? } \\ \text { DEM what year } & \text { LOC } \\ & \text { 'What year was that?' } \\ \text { (818) } & \text { ne masi umb-ian? } \\ & \text { 2SG what plant-2SG.PRS } \\ \text { 'What are you planting?' }\end{array}$

\section{The conjunction *o}

The conjuction $o$ in both Barem and Manep is used to link items in a list, especially when those items are intended as examples, rather than an exhaustive list. (819) and (820) illustrate the use of $o$ in Barem.

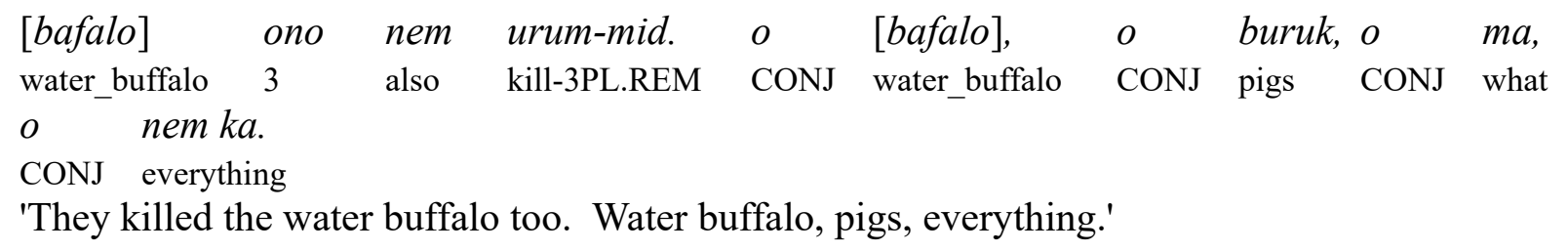

(820) ktakanam, o kuvikanam, o buakkanam, iwak opk-av ka coconut CONJ betelpepper_vine CONJ betel nut theft hold-NMLZ just nambek.

big

'Coconuts, betelpepper vine, betelpepper, it's just a lot of theft' (these things are being stolen)

The examples in (821) and (822) illustrate similar use of $o$ in Manep, where it is used to link illustrative items in a list.

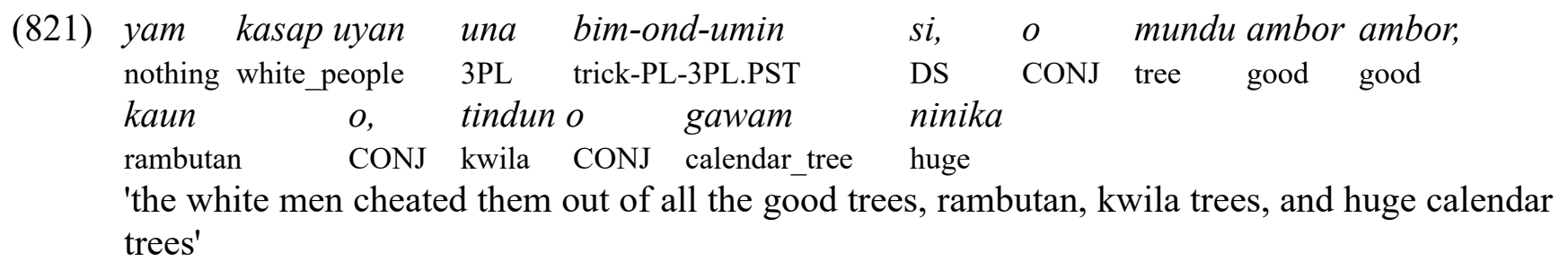




$\begin{array}{llllllll}\text { menda } & \text { bok } & \text { un } & \text { dimbingam } & \text { o } & \text { karu } & \text { masi masi pakin-and-eng-an } \\ \text { past } & \text { grandfather } & \text { 3PL } & \text { knee } & \text { CONJ } & \text { body } & \text { whatever } & \text { hurt-PL-IPFV2/3SG.PST } \\ \text { ka } & \text { kumbum } & \text { ke } & \text { aw-eng-kimin } & \text { ne } & \text { karu } & \text { te } & \text { usuaw-eng-kimin. } \\ \text { COMP } & \text { stinging_nettle } & \text { this } & \text { get-IPFV-1/3PL } & \text { 3.SS } & \text { body } & \text { LOC burn-IPFV-1/3PL }\end{array}$
'in the past, when their knees or whatever body part hurt, our grandfathers would get this stinging nettle and sting their body with it.'

Although the form and function of $o$ are are identical in Manep and Barem, I only tentatively reconstruct the $\mathrm{PMB}$ conjunction $*_{\mathrm{o}}$, for two reasons. First, the PMB phoneme $*_{0}$ can only be tentatively reconstructed based on a handful of word sets. Second, it is possible that in both Manep and Barem $o$ is a loanword, coming from Tok Pisin $o$ 'or'.

\subsection{Proto-Manep-Barem vocabulary lexical reconstructions}

*-aw 'NMLZ'

Barem: $-a v$

Manep: -ap, -ep

*abar- 'come'

Bar: ambar-

Man: ambar-

*ad- 'go'(<PNA *ad)

*an- 'eat' (<PNA *an-)

*ag- 'see' (<PNA *ag-)

*ain 'foot'

Bar: ain

Man: ain

May be related to Gavak angin 'foot'.

*ain *gaman 'sole of foot'

Bar: ain gaman

Man: aingaman

*ain *kit 'calf'

Bar: ain kit

Man: ain kitu 
*ain *yaw 'footprint' (<PNA *yap)

*amin 'mind'

Bar: amin

Man: amin

*amun 'house'

Bar: amun

Man: amun

*amun *mar 'awning'

Bar: amun mar

Man: amun maru

This pharse is composed of 'house+wing'.

*ar- 'become' (PNA *ar-)

*arer 'two'

Bar: arer

Man: arer

*arer *arer 'four'

Bar: ararer ararer

Man: arer arer

*ari 'later' (<PNA *ari)

*arub- 'fall'

Bar: arumb-

Man: arumb-

*-aw NMLZ (<PNA *-aw)

*auw- 'burn' (<PNA *auw-)

*aw- 'do, get, take ( $<$ PNA *aw-)

*ayak 'paternal aunt'

Bar: ayak

Man: ayak

*babad- 'cut up, break up' (<PNA *babad-)

*baram 'hornbill' (<PNA *baram)

*barek 'nephew, uncle'

Bar: barek

Man: barek

This resembles Pamosu melek 'sister's child', but the initial consonants do not correspond.

*baren 'road' (<PNA *beren)

*begen 'light' (<PNA *begen)

*bim-, *yam *bim- 'lie, cheat, trick

Bar: bim-, yam bim- 
Man: bim-, yam bim-

*bin 'heavy' (<PNA *bin)

*bok 'grandfather'

Bar: bok

Man: bok

This resembles Gavak bekom 'grandfather', which is probably bimorphemic (nakom grandmother' wom 'ancestor).

*bug-, *bugum- 'sit' (<PNA *bug-)

*buruk 'pig' (<PNA *buruk)

*degen 'straight' (<PNA*degen)

*din 'brain'

Bar: jin

Man: jinu, kumu jinu

*duag 'snake' (<PNA *duag)

*dur 'tail' (<PNA *dur)

*gadaw 'strong' (<PNA *gedaw)

* gaid 'sky'

Bar: gaid

Man: gaid

*gaman 'liver' (<PNA *gemay)

*garem 'bone' (<PNA *garem)

* ge 'one'

Bar (QK): ge

Bar (Bun.) gie

Man: ge

*ge *ar- 'change'

Bar (QK): ge ar-

Bar (Bun.): gie ar-

Man: ge ar-

This verb is composed of *ge 'one' + *ar- 'become'.

*girik- 'turn' (<PNA * girik-)

* gun 'louse' (<PNA *gun)

*gur- 'bite'

Bar: gur-

Man: gur-, gurew-

*gurum 'thick' (<PNA * gurum)

$*$ ib 'feces' (<PNA *ib)

*id- 'give to PL' (<PNA *id-) 
*iduw- 'go' (<PNA *iduw-)

*ig-, *igid- 'to be' (<PNA *ig-)

*iguar 'penis' (<PNA *iguar)

*ikus- 'shoot'

Bar: ikuw-

Man: ukus-

*in- 'sleep' (<PNA *in-)

*iner 1SG.POSS (<PNA *ye-ner)

*ir- 'go up' (<PNA *ir-)

*irin 'all, everyone' (<PNA *irin)

*iruar 'aibika greens, megapode fowl' (<PNA *iruar)

*irub- 'come up' (<PNA *irub-)

*irub- 'fill' (<PNA *irub)

*is- 'give to 1SG' (<PNA *yis-)

*ituw- 'take out, take off' (<PNA*ituw-)

*iw- '1SG.OBJ' (<PNA *ip-)

*iw 'leaf' (<PNA *ip)

*iwer 'salt, ocean' (<PNA *iper)

*kabem 'knowledge'

Bar: kambem

Man: kambem

*kab(u)ar 'mouth' (<PNA *kebuar)

*kadat 'red' (<PNA *ked-at)

*kakas 'dog'

Bar: $q k a$

Man: kakas

*kam 'sunlight, day, daytime' (<PNA *kam)

*kanam 'base, source' (<PNA *kenam)

*kar 'skin' (PNA *kar)

*karen 'new garden'

Bar: karen

Man: karen

*karim- 'swell' (<PNA *karim-)

*kasik 'wild' (<PNA *kasik)

*kaun 'rambutan'

Bar: kaun

Man: kaun

*kawet 'fishing net

Bar: kawet

Man: kawet 
*kawil 'fat, grease' (<PNA *kapil)

*kawur 'lime' (PNA<*kapur)

*kibem 'hand drum' (<PNA *kibem)

*kit 'meat' (<PNA *kit)

*kuken 'old' (<PNA *kuaken)

*kubum 'stinging nettle' (<PNA *kubum)

*kudek 'earthworm'

Bar (QK): kundek

Bar (Bun.): kundiek

Man: kundekunu

The extra material at the right edge of Manep kundekunu is unexplained, but this is almost certainly a separate morpheme, as monomorphemic words are rarely longer than three syllables in Manep.

*kudi 'banana' (<PNA *kudi)

*kuduruk 'fly' (<PNA *kuduruk)

*kuman 'nape' (< PNA *kuman)

*kumerum 'heron'

Bar: kumerum

Man: kumerum

*kurum 'valley' (<PNA *kurum)

*kurun 'black' (<PNA *kurun)

*kuwi 'betelpepper vine' (PNA *kupi)

*magam 'firefly' (<PNA *megam)

*mak 'later, after' (<PNA *mak)

*main 'weak, soft (<PNA *main)

*maiw 'abika greens' (<PNA *maiw)

*mam 'taro' (<PNA *mam)

*mar 'wing' (<PNA *mar)

*mekiw 'ground' (<PNA *mekiw)

*mil- 'vomit' (<PNA *meril-)

*mos '3SG.COM'

Bar: mo

Man: mos

*mud 'firewood' (<PNA *mud)

*mudir 'ant' (<PNA *mudir)

*mun 'husband' (<PNA *mun)

*munugur 'nose'

$\operatorname{Bar}(\mathrm{QK})$ : mununggur

Bar (Bun.): (mun-gun)

Man: mununggur

The final $r$ on the Bunabun form does not correspond. 
*mur 'short'

Bar: mur

Man: muru

*mur *wiek 'long'

Bar: muriek

Man: muruwek

In both languages, 'long' is derived from 'short+NEG'. Barem also has dirur 'long' (for spatial or temporal length) but muriek is more frequent.

*murin 'veins, root's

Bar (QK): mamurin 'roots'

Bar (Bun.): mumurin 'roots'

Man: mururin, muririn

This resembles Gavak mumurem-am 'vein-PL', as well as the terms for 'vein' in Numugen, Kaukombar, and Kumil-Tibor languages, but there are problems with the sound correspondences.

*musag 'eye' (<PNA *mudag)

*musag *iw 'eyebrow'

Bar: muang iv

Man: musang iwu

*musag *tuk 'blind'

Bar: muang tuk

Man: musang tiku

*na 'egg'

Bar: $n a$

Man: $n a u$

This resemebles Proto-Numugen *niaw 'egg'.

*nanag 'tooth' (<PNA *nanag)

*nanag *kanam 'molar'

Bar: nanang kanam

Man: nanakanam

*naner 2SG.POSS (<PNA *ne-ner)

*nas- 'give to 2SG' (<PNA *nat-)

*naw- '2SG.OBJ' (<PNA *nap-)

*pai 'mango' (PNA * pai)

*panar 'village'

Bar: fanar 'village area'

Man: punar 'village' 
*par- 'call' ( $<$ PNA *par-)

*pataw- 'raise, lift'

Bar: ptaw-

Man: pataw-

The expected Manep reflex is **putaw-. This looks similar to Maia patak 'lift up'.

*perem 'bamboo sp, bamboo floor' ( $<$ PNA *perem)

*pis- 'blow' (<PNA *pit-)

*pitiw 'sago'

Bar: ptiv

Man: pitip

*sinem 'green, unripe'

Bar (QK): inem

Bar (Bun.): iniem

Man: sinem

*tabem 'brown crow'

Bar: tambem

Man: tambem

*taiwer 'cassowary'

Bar (QK): taiwor

Bar (Bun.): taiwer

Man: taiwer

This may be related to Proto-Kaukombar *kusuwar.

*tak 'leaf' (<PNA *tak)

*takaw 'grasshopper' (<PNA *takaw)

*tar-

Bar: tar-

Man: tar-

This is a light verb whose meaning is unclear.

*taw 'some'

Bar: $\operatorname{tav}$

Man: tawu

*taw 'piece of wood' (<PNA *taw)

*tawal 'island'

Bar: tawar

Man: tawal 
*te LOC, INST (<PNA *te)

*teber 'mangas plant' (<PNA *teber)

*tuar 'crocodile' (<PNA *tuar)

*ub- 'plant' (<PNA*ub-)

*um- 'die' (<PNA *um-)

*umo 'coastward'

Bar (Bun.): umuo

Man: umo

Probably related to Usan umo 'down there'. However, a correspondence between Manep-Barem

$*_{0}$ and Usan $o$ is not seen in other word sets.

*un- 'draw water' (<PNA *un-)

*uner 3SG.POSS (<PNA *we-ner)

*unim 'name' (<PNA*unim)

*unin 'bee' (<PNA *unin)

*urik 'digging stick'

Bar: urik

Man (Sim.): urik

This is gardening tool used for planting root crops.

*urir 'belly

Bar: urir

Man: urir

*urite 'inside'

Bar: urite

Man: urite

Likely derived from *urir 'belly' + *te LOC.

*us- 'give to 3SG' (<PNA *ut-)

*usir 'centipede' (<PNA *wisir)

*uw- 'dance' (<PNA *up-)

*uwik 'flood' (<PNA *wawik)

*uyaw 'spearp (<PNA * uyaw)

*waben 'arm, hand. (<PNA *waben)

*waben gaman 'palm of hand'

Bar: omben gaman

Man: imbengaman

*waben kuman 'wrist' (<PNA *waben kumay)

*wabek- 'hold'

Bar: ombek-

Man (Sim): imbeg- 
Man (Mal): imbe-

*wak- 'break' (<PNA *wak-)

*wayan 'white' (<PNA *wayay)

*wiek NEG (<PNA *wayek)

*windar- 'draw bow'

Bar: windar-

Man: windar-

*ya 'uncle'

Bar: ya

Man: yaya

*yag 'water' (<PNA*yag)

*yag *is- 'bathe' (<PNA *it-)

*yam 'nothing'

Bar: yam

Man: yam

*yawar 'wind'

Bar: yawar

Man: yawar

*yawaraw 'again'

Bar: yawarav

Man: yawarap

*yatar- 'hunt, look for'

Bar: yatar-

Man: yatar-

*yik 'sore'

Bar: yik, ik

Man: $i k u$

Possibly related to Proto-Numugen *ikamag.

*yu 'who' (<PNA *yau) 


\section{Proto-Kumil-Tibor}

This chapter outlines the sound changes which have taken place in the Kumil-Tibor languages, and presents reconstructed Proto-Kumil, Proto-Tibor, and Proto-Kumil-Tibor vocabulary. Section 9.1 discusses the sound changes which took place in Proto-Kumil-Tibor relative to Proto-Northern Adelbert. Section 9.2 outlines the sound changes which took place in the Tibor languages after the break up of Kumil-Tibor, including the shared innovations which define the subgroup, as well as innovations in individual languages. This section also presents the Proto-Tibor reconstructed vocabulary. Section 9.3 does the same for the Kumil languages. Section 9.4 presents the reconstructed Proto-Kumil-Tibor vocabulary.

\subsection{Kumil-Tibor}

\subsubsection{Proto-Kumil-Tibor phonemes}

Tables 9.2a-b show the reconstructed Proto-Kumilt-Tibor (PKT) phoneme inventory. Two changes from PNA are the loss of $* \eta$ and a shift of $* p$ to $* f$.

Table 9.2a: PKT vowel phonemes

\begin{tabular}{|c|c|c|}
\hline & front & back \\
\hline high & $*_{\mathrm{i}}$ & ${ }^{*} \mathrm{u}$ \\
\hline mid & $*_{\mathrm{e}}$ & \\
\hline low & & $*_{\mathrm{a}}$ \\
\hline
\end{tabular}


Table 9.2b: PKT consonant phonemes

\begin{tabular}{|l|c|c|l|l|}
\hline & labial & alveolar & palatal & velar \\
\hline stop & $*_{\mathrm{b}}$ & $*_{\mathrm{t},} *_{\mathrm{d}}$ & & $*_{\mathrm{k},}{ }_{\mathrm{g}}$ \\
\hline nasal & $*_{\mathrm{m}}$ & $*_{\mathrm{n}}$ & & \\
\hline affricate & $*_{\mathrm{f}}$ & & & \\
\hline fricative & & $*_{\mathrm{s}}$ & & \\
\hline trill & & ${ }^{\mathrm{r}},{ }^{*} \mathrm{l}$ & & \\
\hline glide & $*_{\mathrm{w}}$ & & $\mathrm{y}$ & \\
\hline
\end{tabular}

The sound correspondences for the Tibor and Kumil groups are presented in sections 9.2 and 9.3

\subsubsection{Sound changes in Proto-Kumil-Tibor}

The Kumil-Tibor subgroup of Northern Adelbert consists of eight languages, three in the Kumil branch, and five in the Tibor branch. These languages share two phonological innovations. The first of these is the shift of PNA *p to $f[\phi]$. This can be seen in the reflexes of PNA *par- 'to call', and *pis- 'to blow', which are widespread throughout the subgroup.

Table 9.1.2a: Kumil-Tibor reflexes of PNA *p

\begin{tabular}{|l|l|l|l|l|l|l|l|l|}
\hline PNA & Mokati & Pamosu & $\begin{array}{l}\text { Hember } \\
\text { Avu }\end{array}$ & Mawak & Kowaki & Bepour & Moere & Mauwake \\
\hline $\begin{array}{l}\text { *par- } \\
\text { 'to call' }\end{array}$ & -- & fel- & fal- & far- & far- & far- & $f a-$ & far- \\
\hline $\begin{array}{l}\text { *pis- } \\
\text { 'to blow' }\end{array}$ & fi- & fi- & -- & fit- & $f i-$ & $f i-$ & $f i-$ & far- \\
\hline
\end{tabular}

The second change defining Kumil-Tibor is the loss of final *y, as illustrated in Table 9.1.2b. As there are few PNA reconstructions with final $*$ y, the evidence for this change is limited, especially for the Kumil languages, which lack reflexes of *mugan 'bird', and *kuman 'nape'. 
Table 9.1.2b: loss of PNA *n in Kumil-Tibor

\begin{tabular}{|l|l|l|l|l|l|l|l|l|}
\hline & Mokati & Pamosu & $\begin{array}{l}\text { Hember } \\
\text { Avu }\end{array}$ & Mawak & Kowaki & Bepour & Moere & Mauwake \\
\hline $\begin{array}{l}\text { *gaman } \\
\text { 'liver' }\end{array}$ & $\begin{array}{l}\text { (gumanin } \\
\text { g) }\end{array}$ & kema & gema & $\begin{array}{l}\text { kema fua } \\
\text { 'lungs' }\end{array}$ & 'ema & ema & kema & kema \\
\hline $\begin{array}{l}\text { *kuman } \\
\text { 'nape' }\end{array}$ & kuma & uma & huma & uma & huma & & & \\
\hline $\begin{array}{l}\text { *bugan - } \\
\text { 'post' }\end{array}$ & bokan & poka & pokan & & po'an & pu'a & & poka \\
\hline 'bird' & mungga & munga & mungga & mungga & mu'a & & & \\
\hline
\end{tabular}

The Tibor languages Mokati, Hember Avu, and Kowaki have a final nasal in reflexes of *bugay. As discussed below, other nasals deleted in Proto-Tibor as well. While the deletion of final $*^{n}$ is regular in Tibor, the deletion of final ${ }^{*}$ m did not apply consistently to all lexical items. The final $n$ in the Tibor reflexes of *bugan 'house post' suggests that deletion of final * ${ }^{*}$ may be inconsistent as well. In this case, final $*^{*}$ may have applied separately in Kumil and Tibor, and this should not be considered a shared change.

\subsection{Proto-Tibor}

In this section, I first present the reconstructed Proto-Tibor phoneme inventory and outline the sound changes which took place in Proto-Tibor respective to Proto-Kumil-Tibor. Following this are sections discussing the sound changes that took place in individual Tibor languages. Following this, I present the Proto-Tibor reconstructions 


\subsubsection{Proto-Tibor phonemes}

Table 9.2a presents the Proto-Tibor consonant phoneme inventory. The only change from the Proto-Kumil-Tibor consonant phoneme inventory is the loss of $* 1$. The reconstructed vowel phoneme inventory is the same as Proto-Kumil-Tibor $\left(*_{\mathrm{i}},{ }^{*} \mathrm{u},{ }^{*} \mathrm{e},{ }^{*} \mathrm{o}\right.$, and $\left.{ }^{*} \mathrm{a}\right)$.

Table 9.2.1a: Reconstructed Proto-Tibor consonant phonemes

\begin{tabular}{|l|c|c|c|c|}
\hline & labial & alveolar & palatal & velar \\
\hline stop & $*_{\mathrm{b}}$ & $*_{\mathrm{t},} *_{\mathrm{d}}$ & & $*_{\mathrm{k},}{ }^{\mathrm{g}}$ \\
\hline nasal & ${ }_{\mathrm{m}} \mathrm{m}$ & ${ }_{\mathrm{n}} \mathrm{n}$ & & \\
\hline affricate & $*_{\mathrm{f}}$ & & & \\
\hline fricative & & $*_{\mathrm{s}}$ & & \\
\hline trill & & $*_{\mathrm{r}}$ & & \\
\hline glide & $*_{\mathrm{W}}$ & & $*_{\mathrm{y}}$ & \\
\hline
\end{tabular}

Table 9.2.1b-f show the sound correspondences used to reconstruct Proto-Tibor phonemes along with the environment that conditions each correspondence.

\section{Vowels}

Table 9.2.1b: Tibor vowel correspondences

\begin{tabular}{|l|l|l|l|l|l|l|}
\hline PTibor & environment & Mokati & Pamosu & HA & Mawak & Kowaki \\
\hline$*_{\mathrm{i}}$ & $i$ & $i$ & $i$ & $i$ & $i$ \\
\hline$*_{\mathrm{u}}$ & & $u$ & $u$ & $u$ & $u$ & $u$ \\
\hline$*_{\mathrm{e}}$ & & $e$ & $e$ & $e$ & $e$ & $e$ \\
\hline$*_{\mathrm{o}}$ & & $o$ & $o$ & $o$ & $o$ & $o$ \\
\hline$*_{\mathrm{a}}$ & & $a$ & $a$ & $a$ & $a$ & $a$ \\
\cline { 2 - 7 } & $\#+$ & $e$ & $e$ & $e$ & $e$ & $e$ \\
\cline { 2 - 7 } & /\# & $a$ & $a$ & $e$ & $a$ & $a$ \\
\hline
\end{tabular}


Stops

Table 9.2.1c: Tibor stop correspondences

\begin{tabular}{|c|c|c|c|c|c|c|}
\hline PTibor & environment & Mokati & Pamosu & HA & Mawak & Kowaki \\
\hline \multirow[t]{3}{*}{$* b$} & /\# & $b \sim p$ & $p$ & $b \sim p$ & $p$ & $p$ \\
\hline & $/ \# \mathrm{~V}_{2}$ & $p$ & $p$ & $m b$ & $p$ & $p$ \\
\hline & $/ \mathrm{CV}$ & $w$ & $p$ & $m b$ & $p$ & $p$ \\
\hline \multirow[t]{4}{*}{$* d$} & /\# & $d$ & $t$ & $t$ & $t$ & $t$ \\
\hline & $/ \# \mathrm{~V}_{2}$ & $t$ & $t$ & $n d$ & $t$ & $t$ \\
\hline & $\# C V_{-} \mathrm{V}$ & $t \sim d$ & nd & nd & nd & nd \\
\hline & /_\# & $n \sim t$ & nd & $n$ & $n t$ & $n t$ \\
\hline$* \mathrm{t}$ & & $t$ & $t$ & $t$ & $t$ & $t$ \\
\hline \multirow[t]{3}{*}{$* \mathrm{k}$} & /\# & $k$ & $\varnothing$ & $h$ & $\varnothing$ & $h$ \\
\hline & $/ V_{-} V_{1}$ & $k$ & $h$ & $k$ & $h$ & $h$ \\
\hline & I_\# & $k$ & $k$ & $k$ & $k$ & $?$ \\
\hline \multirow[t]{5}{*}{$* g$} & /\# & $g \sim k$ & $k$ & $g \sim k$ & $k$ & $?$ \\
\hline & $/ \# \mathrm{~V}_{2}$ & $k$ & $k$ & $n g g$ & $k$ & $?$ \\
\hline & $/ \mathrm{D}_{-}$ & $k$ & $k$ & $k$ & $k$ & $?$ \\
\hline & $/ \mathrm{CV}_{-} \mathrm{V}$ & $n g g \sim k$ & $n g g$ & $n g g$ & $n g g$ & $?$ \\
\hline & / \# & $n g \sim k$ & $n g$ & $n g$ & $n g$ & $?$ \\
\hline
\end{tabular}

\section{Fricatives}

Table 9.2.1d: Tibor fricative correspondences

\begin{tabular}{|l|l|l|l|l|l|l|}
\hline PTibor & & Mokati & Pamosu & HA & Mawak & Kowaki \\
\hline$*_{\mathrm{f}}$ & /\#_ & $\varnothing \sim f$ & $f$ & $f$ & $f$ & $f$ \\
\cline { 2 - 7 } & /V_V & $\varnothing$ & $v$ & $w$ & $w$ & $w$ \\
\hline$*_{\mathrm{s}}$ & & $s$ & $s$ & $s$ & $s$ & $s$ \\
\hline
\end{tabular}

\section{Nasals}

Table 9.2.1e: Tibor nasal and sonorant correspondences

\begin{tabular}{|l|l|l|l|l|l|}
\hline PTibor & Mokati & Pamosu & HA & Mawak & Kowaki \\
\hline$*_{\mathrm{m}}$ & $m$ & $m$ & $m$ & $m$ & $m$ \\
\hline$*_{\mathrm{n}}$ & $n$ & $n$ & $n$ & $n$ & $n$ \\
\hline$*_{\mathrm{r}}$ & $l$ & $l$ & $r$ & $r$ & $r$ \\
\hline
\end{tabular}




\section{Glides}

Table 9.2.1f: Tibor vowel correspondences

\begin{tabular}{|l|l|l|l|l|l|l|}
\hline PTibor & environment & Mokati & Pamosu & HA & Mawak & Kowaki \\
\hline${ }^{*} \mathrm{w}$ & /\#_ & $w$ & $w$ & $w \sim \varnothing$ & $w$ & $w$ \\
\cline { 2 - 7 } & $/ \mathrm{V}$ V & & $v$ & $w$ & $w$ & $w$ \\
\cline { 2 - 7 } & $/ \#$ & $\varnothing \sim w$ & $v$ & $v$ & $b$ & $v \sim b$ \\
\hline \multirow{2}{*}{$*_{\mathrm{y}}$} & $/ \#+$ & $y$ & $\varnothing, y$ & $\varnothing, y$ & $\varnothing, y$ & $\varnothing, y$ \\
\cline { 2 - 7 } & & $y$ & $y$ & $y$ & $y$ & $y$ \\
\hline
\end{tabular}

\subsubsection{Proto-Tibor Innovations}

Below, I outline the sound changes shared by all Tibor languages. These are changes which took place in Proto-Tibor after it split from Proto-Kumil-Tibor, and before it broke up into individual Tibor languages.

1) Epenthetic $-u$ on monosyllabic words

2) $*$ a $>$ e/\#_ in verb stems

3) $* \mathrm{t}>\mathrm{s} / \#$

4) $* \mathrm{~N}>\varnothing / \#$

5) $* \mathrm{f}>\mathrm{w} / \#$

6) $* \mathrm{r}, * 1>\overline{\mathrm{r}}$

\section{Epenthetic $-u$ on monosyllabic words}

Proto-Tibor added a final $u$ to the end of monosyllablic content words which end in a consonant. This final $u$ is present in all Tibor languages. Table 9.2.2a illustrates this change with PNA reconstructions of monosyllabic words, the Proto-Tibor form, and the reflexes in Tibor languages. 
Table 9.2.2a: addition of final $u$ to Proto-Tibor monosyllables

\begin{tabular}{|l|l|l|l|l|l|l|}
\hline PNA & Proto-Tibor & Mokati & Pamosu & Hember Avu & Mawak & Kowaki \\
\hline *tak 'leaf' & *saku & saku & saku & saku & & sa'u \\
\hline *ib 'feces' & *ibu & ipu & ipu & imbu & ipu & ipu \\
\hline *mud 'fire' & *mudu & mundu & mundu & mundu & mundu & muntu \\
\hline *puk 'skin' & *fuku & uku & fuku & fuku & fuku & fu'u \\
\hline *kam 'sun' & *kamu & kambeki & pekinamu & hamu & & \\
\hline *ud 'song' & *udu & utu & itu & indu & & \\
\hline *yap & 'footprint' & yau & avu & & & \\
\hline $\begin{array}{l}\text { *k(e/a)d } \\
\text { 'blood' }\end{array}$ & *ketu & & & hetu & & hetu \\
\hline
\end{tabular}

Although the addition of final $u$ is shared by all Tibor languages, and can therefore be reconstructed for Proto-Tibor, it seems that Proto-Tibor still considered these words to be phonologically monosyllabic. Later changes in individual Tibor languages 'ignore' the final $u$ added to monosyllables in this way. For example, in Pamosu, ${ }^{*} \mathrm{k}$ lenited to $h$ intervocalically, while the reflex of word-final $* \mathrm{k}$ is $k$. Pamosu treats $* \mathrm{k}$ as if it were word-final in words that added final $* \mathrm{u}$ in ProtoTibor, as in *saku 'leaf'>saku, and *fuku 'skin' fuku, and not *sahu and *fuhu, which are the expected reflexes for intervocalic *k. Later Mawak and Kowaki also treat the *k in *fuku and *saku as wordfinal. Mawak has the same reflexes of intervocalic and word-final *k as Pamosu, with $k$ word-finally and $h$ intervocallicaly. The Mawak reflex of *fuku 'skin' is fuku 'skin', which has the usual reflex of final $* \mathrm{k}$. In Mawak, final $* \mathrm{k}$ became a glottal stop, nad intervocalic *k lenited to $h$. In Kowaki $s a^{\prime} u$ and $f u^{\prime} u$, we again see the reflexes of *k behaving as if they were word-final.

A possible explanation is that all the individual Tibor languages added final $u$ to monosyllables individually. It is also possible that final $u$ was added at the Proto-Tibor stage, but only at the phonetic level. For example, 'skin' would have the underlying form */fuk/ and the surface form *[fuku] in ProtoTiber. At the time of the breakup of Proto-Tibor, these were phonologically monosyllabic words, and 
were treated as such by later changes in individual languages. I nonetheless include this final $* u$ in Proto-Tibor reconstructions.

$*_{\mathbf{a}}>e_{\text {/\#_ in verbs }}$

PNA initial *a raised to $e$ in verb stems in the Tibor languages, as illustrated in Table 9.2.2.b. Note that this change also took place in the Kumil languages Bepour and Moere. Since it did not take place in the third Kumil language, Mauwake, it does not date to Proto-Kumil-Tibor. It is not clear why this change is restricted to verb stems, but it likely is related to the vowel assimilation rules that are found in many Tibor languages. Furthermore, the change did not apply uniformly to all verb stems, as some verbs retain initial $a$ in one or more of their stem variants (see Chapter 3).

Table 9.2.2b: *a > e/\#

\begin{tabular}{|l|l|l|l|l|l|l|}
\hline PNA & Proto-Tibor & Mokati & Pamosu & Hember Avu & Mawak & Kowaki \\
\hline *ag- & $*_{\text {eg- }}$ & $e k-$ & $e k-$ & $e n g g-$ & $e k-$ & $e^{\prime}-$ \\
\hline *an- & $*_{\text {en- }}$ & $e n-$ & $e n-$ & $e n-$ & $($ enem- $)$ & $e n-$ \\
\hline *ar- & er- $_{\text {er- }}$ & & $e l-$ & $e l-$ & & \\
\hline *aw- & *ew- & & $e v-$ & $e w-$ & $(w-)$ & $e v-$ \\
\hline
\end{tabular}

$* \mathbf{t}>\mathbf{s} / \#$

Word-initial PNA *t lenited to $s$ in several words in Proto-Tibor, as illustrated in Table 9.2.2c. This resulted in a merger of PNA $*_{\mathrm{t}}$ and ${ }^{*} \mathrm{~s}$ word-initially.

Table 9.2.2c: $* t>s / \#$ in Proto-Tibor

\begin{tabular}{|c|c|c|c|c|c|c|}
\hline PNA & Proto-Tibor & Mokati & Pamosu & Hember Avu & Mawak & Kowaki \\
\hline *tak 'leaf' & $*_{\text {saku }}$ & saku & saku & saku & -- & $s a^{\prime} u$ \\
\hline *tabir 'plate' & $*_{\text {sabir }}$ & savil & sapil & sambir & sapir & sapir \\
\hline $\begin{array}{l}* \mathrm{t}(\mathrm{e} / \mathrm{i}) \mathrm{bik} \\
\text { 'rain' }\end{array}$ & $*_{\text {sibik }}$ & sivik & sepik & simbik & sepik & sepi' \\
\hline $\begin{array}{l}\text { *t(a/e)men }(\mathrm{a}) \\
\text { 'now' }\end{array}$ & *seme & & seme & & seme & seme \\
\hline
\end{tabular}


There are also a number of word sets, illustrated in Table 9.2.2d, where some Tibor languages have initial $t$, while others have initial $s$, although there is no regular correspondence. In the words sets in Table 9.2.2c, where PNA *t became $s$ in all Tibor languages, it is before a non-back vowel, while in Table 9.2.2d, all of the word sets but one, have $o$ or $u$ as the following vowel. It is therefore possible that the lenition of PNA $* \mathrm{t}>s$ depends on the quality of the following vowel.

Table 9.2.2d: Tibor words sets with initial $t$ and $s$

\begin{tabular}{|l|l|l|l|l|l|l|}
\hline PNA & Proto-Tibor & Mokati & Pamosu & Hember Avu & Mawak & Kowaki \\
\hline *tukuw & 'short' & tuku & tuhuv & sukuw & tuhuw & tuhuw \\
\hline & 'night' & ka tulu & sulu & (ha uru $)$ & ha turu & turu \\
\hline *tukum & 'stick' & & nanduhum ${ }^{112}$ & & $(\text { tukum })^{113}$ & \\
\hline & 'forehead' & tumunggena & somungenav & somangenav & & \\
\hline & 'lightning' & tewelak & sepelak & & & \\
\hline & 'crossbeam' & tomal & somal & & & \\
\hline
\end{tabular}

Of the word sets in Table 2.2d, however, only 'short' is without other complicating factors. The terms for 'night' are possibly related to Proto-Tibor *uru 'dark' with an added element, as 'night' is often related to 'dark' in Northern Adelbert languages. The Hember Avu term ha uru, for example, is 'place' + 'dark'. For 'stick', Pamosu nanduhum is a compound with na 'tree', and could potentially be directly inherited. The Mawak term tukum is likely a borrowing, as the usual reflex of intervocalic *k is $h$. For 'forehead', the Pamosu term is a compound of somu 'mountain' and kenav 'bone', but cognate terms for 'mountain' are not attested for Mokati and Hember Avu. For 'lightning', similarly-shaped words are found in other Northern Adelbert languages, but they often do not follow the regular sound correspondences, and no specific form can be reconstructed for PNA. Finally 'crossbeam' in Mokati and Pamosu are potentially related to each other, but this term could have easily been borrowed in one language from the other.

112 This is a compound na+tuhum 'tree+stick'. In Pamosu, $t>n d$ is a regular morphophonological process in this environment (Tupper).

113 This is likely a borrowing, as the usual reflex of intervocalic $* \mathrm{k}$ is $h$ in Mawak 


\section{Final nasal deletion}

As mentioned above, final $*_{y}$ deleted in Proto-Tibor, although there may be exceptions. Final *n also deleted, as illustrated by the reflexes of PNA reconstructions in Table 9.2.2e.

Table 9.2.2e: deletion of final $* \mathrm{n}$ in Tibor

\begin{tabular}{|c|c|c|c|c|c|c|}
\hline PNA & Proto-Tibor & Mokati & Pamosu & Hember Avu & Mawak & Kowaki \\
\hline *begen 'light' & *beki & beki & peki & peki & & \\
\hline *beren 'road' & $*$ bere & bele & & bere & & \\
\hline $\begin{array}{l}\text { *iben } \\
\text { 'vagina' }\end{array}$ & *ibe & upe & upe & imbe & & ipa \\
\hline $\begin{array}{l}\text { *madey } \\
\text { 'man' }\end{array}$ & *made & mande & mande & mande & mande & mande \\
\hline *men 'breast' & *me & & me & me & & me \\
\hline *temen 'now' & & & seme & & seme & seme \\
\hline *unin 'bee' & *uni & uni & & uni & & \\
\hline $\begin{array}{l}\text { *waben 'arm, } \\
\text { hand' }\end{array}$ & *abe & ape & ape & embe & ape & ape \\
\hline
\end{tabular}

Final *n was retained in suffixed forms, for example the reflexes of Tibor *bin-at 'heavy' from PNA *bin 'heavy, weight. Another example is Mokati degenat 'straight', from PNA *degen 'straight', plus the adjective forming suffix *-at. Compare this with Pamsou teke 'straight', which doesn't include the adjective-forming suffix, and has lost the final $*_{\mathrm{n}}$.

PNA final *m did not usually delete in the Tibor languages. However, in a handful of words, final *m was lost. Compare the word sets of Table 9.2.2f, which have lost final *m, with the remaining word sets, in which final ${ }^{*} \mathrm{~m}$ is retained. There is no obvious conditioning phonological environment for why it should have been lost in the first four word sets. These reconstructions end in *-am, but other reconstructions ending in $*_{\text {-am }}$ have retained final $* \mathrm{~m}$. One commonality between the words which have lost final $*_{m}$ is that they are all highly frequent words in the Tibor languages. Trees and taro are items that dealt with on a daily basis, while 'base' and 'belly' are used metaphorically in many 
expressions. Numerous studies have suggested that high frequency words lead certain types of changes, particularly in processes of lenition, reduction and deletion (Phillips 1984, 2006, Bybee 2002, 2002, Pierrehumbert 2002). It would be worthwhile to investigate whether the words which have lost final ${ }^{*} \mathrm{~m}$ are indeed used more frequently than those that haven't as this could be a potential explanation for the variation in the deletion of ${ }^{*} \mathrm{~m}$.

Table 9.2.2f: Reflexes of final $*_{m}$ in Tibor

\begin{tabular}{|c|c|c|c|c|c|c|}
\hline PNA & Proto-Tibor & Mokati & Pamosu & $\begin{array}{l}\text { Hember } \\
\text { Avu }\end{array}$ & Mawak & Kowaki \\
\hline *kanam 'base' & *kena & kena & ena & hena & ena & hena \\
\hline *mam 'taro' & *ma & $m a$ & $m a$ & $m a$ & $m a$ & $m a$ \\
\hline *nam 'tree' & *na & $n a$ & $n a$ & $n a$ & na & $n a$ \\
\hline *uram 'belly' & *ura & ula & ula & ula & & ura \\
\hline *baram 'hornbill' & *baram & balom & kumbalom & param & & \\
\hline *kam 'sun' & *kamu & kambeki & pekinamu & hamu & & \\
\hline *kurum 'valley' & *kurum & kulum & & kurum & & \\
\hline *gurum 'thick' & *gurum & gulum & kulum & & & \\
\hline $\begin{array}{l}\text { *megam 'star, } \\
\text { year' }\end{array}$ & *megam & menggam & & menggam & menggam & me'am \\
\hline *unim 'name' & *unim & unim & unim & unim & unim & unim \\
\hline
\end{tabular}

Reflexes of Proto-Tibor *ma 'taro' are perhaps not directly inherited from PNA *mam, since 'taro' in the Kumil languages Bepour and Moere is also ma, suggesting Proto-Kumil-Tibor ${ }^{*} \mathrm{ma}^{114}$. Final $*_{\mathrm{m}}$ otherwise never deleted in Kumil languages.

$* \mathbf{f}>\mathbf{w} / \#$

Proto-Tibor merged Proto-Kumil-Tibor *f and *w word-finally as w. In Mokati, Hember Avu, Mawak, and Kowaki, word-final $w$ can be realized as a glide, a voiced fricative, or a voiced or voiceless stop $([\mathrm{w} \sim \beta \sim \mathrm{p} \sim \mathrm{b}])$. In Mokati, word-final $*_{\mathrm{f}}$ and ${ }^{*} \mathrm{w}$ are sometimes deleted entirely. This 114 In Mauwake, the remaining Kumil language, 'taro' is moma, with $m$ followed by final $a$ which was added by a regular sound change. 
variation in the phonetic realizatoin of word-final $w$ does not seem to be predictable, but this is hard to determine based on the limited data available. In Pamosu, word-final ${ }^{*} f$ and ${ }^{*} \mathrm{w}$ are always refleced as $v$, and $w$ does not occur word-finally (Tupper 2012).

All Tibor languages except Mokati have also merged $*_{\mathrm{f}}$ and $*_{\mathrm{w}}$ intervocalically. In Mokati, however, they have distinct reflexes, as *f has deleted intervocalically, as in *ifer 'salt' > yel, but *w has not, as in *sewaw 'sword grass' > sowav.

$* \mathbf{I}>\mathbf{r}$

As with most Northern Adelbert languages, PNA *r and *1 have merged in Tibor. Tupper (2012) describes this sound in Pamosu as a lateral flap, and writes it as $<\mathrm{l}>$. Z'graggen typically transcribes it as either as trill or a lateral in the other languages, although the former is a bit more common. In my own work with Mokati speakers, I found the sound to be consistently a lateral. I use *r to represent the Proto-Tibor phoneme that is resulted from the merger of PNA *r and *1.

In the remaineder of the section, I outline the sound changes which took place in individual languages after the breakup of Proto-Tibor.

\subsubsection{Sound changes in Mokati}

\section{Stop devoicing}

Stops lost prenasalization and devoiced when they were the first consonant in a vowel-initial word $\left(* \mathrm{D}>\mathrm{T} / \# \mathrm{~V}_{-}\right)$, as in Proto-Tibor *abe 'hand' $>$ape, *ibu 'feces' ipu, and *idiw- 'to go' > ituw-. This rule applied differently in the Wanambre and Tinami dialects with respect to *g. In the Wanambre dialect, devoicing applied to ${ }^{*} \mathrm{~g}$ in the same way it did to ${ }^{*} \mathrm{~b}$ and $*^{*} \mathrm{~d}{ }^{*} \mathrm{~g}$ devoiced as well as lost prenasalization, as in *eg- 'to see' $>e k$ - and *ig- 'to be' $>i k$-. In the Tinami dialect, $* \mathrm{~g}$ lost 
prenasalization, but did not devoice, as in *eg- 'to see' $>$ eg- and *ig- 'to be' $>$ ig-. That the Tinami dialect retained voicing in $* \mathrm{~g}$, but not $* \mathrm{~b}$ or $* \mathrm{~d}$, is somewhat surprising, given that it is physiologically more difficult to maintain voicing in velar stops than labials or alveolars (Ohala, 1983). A result of this change is that Wanambre has merged $*^{*} \mathrm{~d}$ and ${ }^{*} \mathrm{~g}$ with $*_{\mathrm{t}}$ and $* \mathrm{k}$ in the environment $\# \mathrm{~V}_{-}$.

Two exceptions to this devoicing rule are *ub- to plant' $>u v_{-}{ }^{115}$, and *wabina 'cordyline' $>$ uvina, in which $* \mathrm{~b}$ became $w$ rather than expected $p$. These are the only Mokati reflexes of reconstructions beginning with ${ }^{*} \mathrm{ub}-{ }^{116}$, so it may that the quality of the vowel conditioned these exceptions.

\section{$* d>t / N_{+}, * g>k / N_{-}($Tinami only)}

In the Tinami dialect, $* \mathrm{~d}$ and $*_{\mathrm{g}}$ devoiced to $t$ and $k$ when the preceding consonant was a nasal, as in *made 'man' > mate, *mudu 'fire' > mutu, and *muga 'bird' > muka. ${ }^{117}$ This change applied to word-final stops as well, as in *munag 'egg' > munak, and *uned 'female' > unet. In all Proto-Tibor reconstructions with a word-final voiced stop, the preceding consonant is a nasal. It may therefore be the case that devoicing of final voiced stops was a separate change, but without reconstructions with a final voiced stop that doesn't follow a nasal, there is no way determine this.

\section{*g > ng/_\# (Wanambre only)}

In the Wanambre dialect, voiced stops following a nasal didn't undergo any change following a nasal, maintaining both prenasalization and voicing, as in mande 'man', and mungga 'bird'. However, word-final *g lost the voiced portion of the stop and became nasals, as is *munag 'egg' $>$ munang, and

115 Z'graggen (1980b) in fact records up- for 'to plant'. However, the Mokati speakers I worked with consistently pronounced it with a bilabial fricative.

116 Proto-Tibor *wabina would have become pre-Mokati *ubina.

117 This change may have applied to all voiced stops following a nasal, but there are no reconstructed words with *b in this position, so there is no evidence for this. 
*ineg 'yesterday > inong. The velar nasal in this position is the word-final allophone of $/ \mathrm{g} /$. There are not many reconstructions with word-final $* \mathrm{~d}$, but it also sometimes loses the stop portion, as in and *bin-ad 'heavy' > binan. However, there does not seem to be a complete merger of word-final $* \mathrm{~d}$ and ${ }^{*} \mathrm{n}$, as there is variation between $n$ and $n d$ in the reflex of the 3PL.PST affix *-mid $>-$ mind -min.

${ }^{* \mathrm{~N}} \mathbf{D}>\mathbf{D} / \mathbf{D V}$

Prenasalized stops following another voiced stop lost nasalization. In the Wanambre dialect, they also devoiced, as illustrated in Table 9.2.3a. In Wanambre, this has resulted in the merger of voiced and voiceless stops in this environment. For example. compare the Wanambre reflexes of *bug'sit' > buk- and *bik- 'put' bik-.

Table 9.2.3a: Loss of prenasalization in Mokati voiced stops

\begin{tabular}{|l|l|l|}
\hline Proto-Tibor & Tinami & Wanambre \\
\hline *bug- 'to sit' & bug- & buk- \\
\hline *begi 'light' & -- & beki \\
\hline *dagul 'snake' & dagul & dakul \\
\hline *gedaw 'strong' & -- & getav \\
\hline *Vgeba 'pot' & igoba & ikopa \\
\hline
\end{tabular}

$* \mathbf{b}>w / V_{-} \mathbf{V}$

Where intervocalic *b was not subject to any of the changes described above, it lenited to $w$, in both dialects, as in Proto-Tibor *sibik > sivik, *tabir > savil, and *irub- 'come up' '> ilov-. When *d and $*^{\mathrm{g}}$ where not subject to any of the above changes, they are reflected as $n d$ and $n g g$.

$* \mathbf{f}>\varnothing / \mathbf{V}_{-}$

In Mokati, *f deleted after a vowel, as in Proto-Tibor *ifer 'salt' $>y e l, *$ ifif 'dry' $>y i$, and *gufu 'thigh' $>g u$. It also deleted word initially in most instances, as in *fuku 'skin, body' $>u k u$, *furu 
'bamboo' > ulu, and *furuk- 'hear, small' > luk-. However, in other lexical items it is either retained or there is variation between $f$ and $\varnothing$, as in *faya 'left' $>$ faya and *fua 'white' $>$ fua wa.

$*$ e $>$ /_[+labial]

*e sometimes rounded to $o$ before the labial consonants ${ }^{*} \mathrm{~b},{ }^{*} \mathrm{w}$, or $*_{\mathrm{f}}$. This change did not apply regularly, and some words are recorded with both $e$ and $o$ in this environment. For example, Proto-Tibor *ketew- 'stand' > ketow-, *eba 'net bag' > opa epa, *bewu 'pus' > bovu, and *ilew 'two' > ilo.

$* \mathbf{e}>\varnothing / \#+\mathbf{r}$

Word-initial mid vowels sometimes delete before *r, as in Proto-Tibor *ereke 'road' > leke, and *ereker 'crayfish' > lekel. This should possibly be considered a synchronic process, as it does not apply consistently to the Proto-Tibor verb *elem- 'go down', which has three roots used for different conjugations, *el-, *elam- and *elem-. The Mokati reflexes recorded for this verb are el-, elam-, and lem-, respectively.

$* \mathbf{e}>$ o/_g\#

Proto-Tibor $*$ e also rounded to $o$ before final $* \mathrm{~g}$, as in $*_{\mathrm{ineg}}$ 'yesterday' > inok (Tinami), inong (Wanambre), and*umeg > umok, (Tinami), umong (Wanambre).

\section{Relative chronology of Mokati sound changes}

Stop devoicing following an initial vowel $\left(* \mathrm{D}>\mathrm{T} / \# \mathrm{~V}_{-}\right)$, and desnasalization of voiced stops following another voiced stop $\left({ }^{* N} \mathrm{D}>\mathrm{D} / \mathrm{DV}_{-}\right)$took place before the change of $* \mathrm{~b}>\mathrm{w} / \mathrm{V}_{-} \mathrm{V}$, as the two 
former rules blocked the application of the latter, as illustrated with the Mokati (Tinami dialect) reflexes in Table 9.2.3b.

Table 9.2.3b: relative chronology of Mokati sound changes

\begin{tabular}{|c|c|c|c|c|c|}
\hline & $\begin{array}{l}\text { *abe } \\
\text { 'arm' }\end{array}$ & $\begin{array}{l}\text { *ibe } \\
\text { 'vagina' }\end{array}$ & $\begin{array}{l}\text { *bibik- } \\
\text { 'be afraid' }\end{array}$ & $\begin{array}{l}\text { *sabir } \\
\text { 'plate' }\end{array}$ & $\begin{array}{l}*_{\text {irub- }} \\
\text { 'come up' }\end{array}$ \\
\hline \multirow{2}{*}{$\begin{array}{l}\text { 1) } * \mathrm{D}>\mathrm{T} / \# \mathrm{~V}_{-} \\
{ }^{* \mathrm{~N}} \mathrm{D}>\mathrm{D} / \mathrm{DV}_{-}\end{array}$} & ape & ipe & -- & -- & -- \\
\hline & & & bibik & & \\
\hline \multirow[t]{2}{*}{ 2) $* \mathrm{~m} b>w / V_{-}$} & -- & -- & -- & sawir & iruw \\
\hline & ape & ipe & bibik & sawir & ilov- \\
\hline
\end{tabular}

\subsubsection{Sound changes in Pamosu}

$* \mathbf{k}>\boldsymbol{h} / \mathbf{V}$

Proto-Tibor *k lenited to $h$ before a vowel, as in *bik- 'to put' > pih-, *bibik- 'be afraid' > pipih-, and *mekiw 'garden' > mehi. Recall that Proto-Tibor added final $u$ to monosyllabic content words, as in PNA *tak 'leaf' > Proto-Tibor *saku, and PNA *puk 'skin, body' > Proto-Tibor *fuku. The change of $* \mathrm{k}>h_{-} \mathrm{V}$ not apply before final $u$ in such words, in Pamosu. Instead, they are treated the same as word-final * $\mathrm{k}$, whose reflex is $k$ in Pamosu, as in PNA *tibik 'rain' > sepik.

$* \mathbf{k}>\varnothing / \#$

Word-initial *k deleted entirely, as in *keta > eta, *kena 'base' > ena, and *kuma 'top' > uma. The deletion of word-initial *k was likely a two-step process, whereby it first lenited to $h$ according to

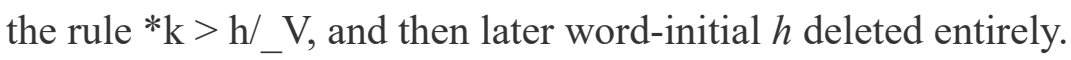

\section{Stop devoicing}

Voiced stops devoiced in several environments in Pamosu. First, voiced stops devoiced when they were the first consonant in a word. This includes word-initial voiced stops, as well as voiced stops 
immediately following a word-initial vowel. These two environments can be covered by the rule ${ }^{*} \mathrm{D}>$ $\mathrm{T} / \#(\mathrm{~V})$, where D represents voiced stops, and T represents voiceless stops. Examples of a voiced stop devoicing word-initially are Proto-Tibor *biliw 'ripe' > piliv, *buruk 'pig' > puruk, *duar 'house' > tual, and *genaw 'bone' > kenav. A voiced stop devoicing immediately after an initial vowel can be seen in Proto-Tibor *abe 'hand' > ape, *iguar 'penis' > ikual, *ig- 'to be' > ik-, and *idiw- 'to go' > itiv-.

Following this, a voiced stop devoiced when the preceding obstruent was voiceless. This applied when the conditioning obstruent was historically voiceless, as in *sibik 'rain' > sepik, and *sabir 'plate' > sapil, as well as to voiced obstruents which had become devoiced, as in Proto-Tibor *gedaw 'strong' > ketav, *begi 'light' > peki, *bibik- 'be afraid' > pipih-, and *bug- 'to sit' > puk-. Tupper (2012) notes that in Pamosu, words with two successive stops that are alike in voicing (either both voiced or both voiceless) seem to be more common than a mixed voicing pattern. The change of voiced stops devoicing after a preceding voiceless obstruent can help to account for this tendency. While these two rules cover most reflexes of voiced stops in Pamosu, there are some unexplained exceptions, such as sangi 'meat.'

$* \mathbf{f}>\boldsymbol{v} / \mathbf{V}_{-}$

Proto-Tibor *f voiced to $v$ after a vowel, as in *ifif 'dry' $>i v i v, *$ ifer 'salt' $>i v o l$, and *gufu 'thigh' guvu.

$* \mathbf{e}>\boldsymbol{o} / \mathbf{r}$ 
Mid front vowels became $o$ before word-final *r, as in Proto-Tibor *ifer 'salt' $>$ ivol and *baner 'signal drum' > panol. A similar change is found in the Qkuan Kambuar dialect of Barem (see Chapter 8).

$* \mathbf{e}>$ o/_Co

As discussed in Chapter 3, Pamosu has a synchronic process of vowel rounding, whereby $e$ rounds to $o$ when the following vowel is $o$, for example /ev-ot/ $\rightarrow$ ovot 'take-3.PST'. In cases where there are no alternating forms to indicate underlying $e$, this had led to the change $* \mathrm{e}>\mathrm{o} /{ }_{-}$Co. This can be seen in words where a final $*_{\mathrm{e}}$ became $o$ before ${ }^{*}$, as outlined above, and this carried over to a preceding *e as well. Examples are *memer 'sap' > momol, *keger 'enemy, warrior' > onggol, and *ereker 'crayfish' > olohol.

\section{Relative chronology of Pamosu sound changes}

In order to derive the attested forms of Pamosu words, the sound changes I propose above must have applied in a particular order. This ordering also requires positing that the deletion of initial $* \mathrm{k}$ took part in two steps: first, word-initial $* \mathrm{k}$ lenited to $h$, then $h$ subsequently deleted after a period of time, during which other changes took place. This assumption is warranted, since the patterning of reflexes of $* \mathrm{k}$ in other Tibor languages suggests that $*_{\mathrm{k}}$ has changed over time in a similar way throughout the group. It is either further along the path of lenition in word-initial position than intervocalically, or the reflex is the same in both environments. Mawak shows the same pattern of Pamosu: *k deleted word-initially and is reflected as $h$ intervocalically. In Kowaki, *k is reflected as $h$ in all positions. In Hember Avu, it is $h$ word-initially, and $k$ intervocalically. 
Table 9.2.4a: reflexes of Proto-Tibor $* \mathrm{k}$ - and $*-\mathrm{k}$ -

\begin{tabular}{|l|l|l|l|l|l|}
\hline & Mokati & Pamosu & Hember Avu & Mawak & Kowaki \\
\hline *k- $_{\mathrm{k}-}$ & $k-$ & $\varnothing$ & $h-$ & $\varnothing$ & $h-$ \\
\hline *-k- & $-k-$ & $-h-$ & $-k-$ & $-h-$ & $-h-$ \\
\hline
\end{tabular}

Table 9.2.4b below illustrates the chronology of four sound changes related to obstruent voicing in Pamosu. The changes I suggest in Table 9.2.4b below necessitate that at the time the changes ${ }^{*} \mathrm{D}>$ $\mathrm{T} / \#(\mathrm{~V})$ _ and $* \mathrm{D}>\mathrm{T} / \mathrm{DV}$ _ took place, Pamosu had the same reflexes of $* \mathrm{k}$ that are currently found in Kowaki, with $h$ both word-initially and word-medially. ${ }^{*} \mathrm{k}>\mathrm{h} /{ }_{-} \mathrm{V}$ must have taken place before $* \mathrm{D}>$ $\mathrm{T} / \#(\mathrm{~V})$, since initial $* \mathrm{~g}$ is reflected as $k$, without further lenition to $h$. At the time $* \mathrm{D}>\mathrm{T} / \mathrm{DV} \_$took place, $h>\varnothing / \#$ _ had not yet taken place, since the presence of initial $*$ h blocked the devoicing of the second stop in words like *kuduruk > unduruk 'fly', whereas devoicing applied in vowel-initial words, such as *idiw > itiw- 'to go'. After these changes were complete, word-initial $h$ deleted, resulting in the forms that are seen in Pamosu today.

Table 9.2.4b: relative chronology of Pamosu sound changes

\begin{tabular}{|c|c|c|c|c|c|c|c|c|c|c|}
\hline & $\begin{array}{l}\text { *kuduruk } \\
\text { 'fly' }\end{array}$ & $\begin{array}{l}\text { *keger } \\
\text { 'enemy' }\end{array}$ & $\begin{array}{l}\text { *gugud } \\
\text { 'shadow' }\end{array}$ & $\begin{array}{l}\text { *gedaw } \\
\text { 'strong' }\end{array}$ & $\begin{array}{l}\text { *genaw } \\
\text { 'bone' }\end{array}$ & $\begin{array}{l}\text { *bik- } \\
\text { 'put' }\end{array}$ & $\begin{array}{l}\text { *bug- } \\
\text { 'sit' }\end{array}$ & $\begin{array}{l}\text { *sabir } \\
\text { 'plate' }\end{array}$ & $\begin{array}{l}\text { *idiw- } \\
\text { 'go' }\end{array}$ & $\begin{array}{l}\text { *ig- } \\
\text { 'be' }\end{array}$ \\
\hline$*_{\mathrm{k}}>\mathrm{h} /{ }_{-} \mathrm{V}$ & hunduruk & hangel & -- & -- & -- & bih- & -- & -- & -- & -- \\
\hline$* \mathrm{D}>\mathrm{T} / \#(\mathrm{~V})$ & -- & -- & kugud & kedav & kenaw & pih & pug- & -- & itiw & ik- \\
\hline \multirow{3}{*}{$\begin{array}{l}{ }^{*} \mathrm{D}>\mathrm{T} / \mathrm{DV} V_{-} \\
\mathrm{h}>\boldsymbol{\varnothing} / \#_{-}\end{array}$} & -- & -- & kukut & ketav & -- & -- & puk- & sapil & -- & -- \\
\hline & unduruk & angel & -- & -- & -- & - & -- & -- & -- & - \\
\hline & unduruk & ongol & kukut & ketav & kenav & pih- & puk- & mehiw & itiv- & $i k-$ \\
\hline
\end{tabular}

First, the change of $* \mathrm{k}>h /{ }_{-} \mathrm{V}$ took place before $* \mathrm{D}>\mathrm{T} / \#(\mathrm{~V})_{-}$, in which voiced stops devoiced word-initially, or immediately following a word-initial vowel. This is clear because $* \mathrm{k}>h$ did not apply to word-initial $k$ resulting from $* \mathrm{D}>\mathrm{T} / \#(\mathrm{~V})$. This is illustrated by the reflexes of $*$ gugud, *gedaw, and *genaw.

Second, $* \mathrm{D}>\mathrm{T} / \#(\mathrm{~V})_{-}$applied before $* \mathrm{D}>\mathrm{T} / \mathrm{D}$, in which voiced stops devoiced when the previous consonant was a voiceless obstruent. This is clear because $* \mathrm{D}>\mathrm{T} / \#(\mathrm{~V})_{\text {_ }}$ feeds $* \mathrm{D}>\mathrm{T} / \mathrm{D}_{-}$. 
Word-initial $k$ which came from $*_{\mathrm{g}}$ triggered devoicing in a following voiced obstruent, as illustrated by *gugud and *gedav.

Third, $* \mathrm{D}>\mathrm{T} / \mathrm{D}_{-}$must have taken place after word-initial $* \mathrm{k}>h$, since word-initial $* \mathrm{k}$ did not trigger devoicing of a following voiced stop in words such as *keger and *kuduruk. At the time *D > T/D_ applied, these words had word-initial $h$, which is not an obstruent, and so would not trigger devoicing.

Finally, $h$ (Proto-Tibor $* \mathrm{k}$ ) deleted entirely in word initial position. Note that the last two rules in Table 9.2.4b, $\mathrm{h}>\varnothing / \#$ _ and $* \mathrm{D}>\mathrm{T} / \mathrm{D}$, could have applied in any order.

One result of these changes is that Pamosu vowel-initial words with a following voiced stop (VD-) point to an earlier form with word-initial *k. This is useful for reconstructing Proto-Kumil-Tibor forms based on Pamosu and Mauwake data alone, since word-initial *k also deleted in Mauwake. For example, from Pamosu umbuk 'bird nest fern' and Mauwake upua 'bird's nest fern', it is possible to recontruct Proto-Kumil-Tibor *kubuk, since voicing on the labial stop in Pamosu indicates initial *k.

\subsubsection{Sound changes in Hember Avu}

${ }^{*} \mathbf{k}>\mathbf{h} / \#_{-}$

Word-initial *k lenited to $h$, as in *kena 'base' > hena, *keta 'coconut' > heta, and *kinam 'basket' > hinam.

$* \mathbf{g}>\mathbf{n g} / \#, * \mathbf{d}>\mathbf{n} / \#$ 
Word-final *g is realized as a velar nasal $n g$, as in *kenag 'tooth' > henang, and *munag 'egg' > minag. This can be analyzed synchronically as the word-final allophone of $/ \mathrm{g} /$.

There are no Proto-Tibor reconstructions with word-final *b, and reconstructions with wordfinal $* \mathrm{~d}$ are rare. However, from the few reconstructions with word-final $* \mathrm{~d}$, which would have historically be realized as a prenasalized voiced stop, it seems that the stop portion of final $* \mathrm{~d}$ was lost in Hember Avu as well. These are *uned 'female; thumb' > unen, and *bin-at 'heavy' > pinan. The latter would have become /d/ via application of nasal spreading (see Chapter 3). Since these are the only two instances of final $* d$ that have been identified, I only tentatively propose a change of $* d>$ $n$ /_\# for Hember Avu. Unlike the shift of word-final $* \mathrm{~g}>n g$, the change of Proto-Tibor word-final $* \mathrm{~d}$ $>n$ results in a merger of final $* \mathrm{n}$ and $* \mathrm{~d}$.

Note that Proto-Tibor *ibu 'feces' (< PNA *ib) and *mudu 'fire, firewood' could potentially be considered an instance of word-final voiced stops, since the epenthetic $u$ added to monosyllables in Proto-Tibor is often treated as if it is not present in later changes in Tibor languages. However, this is not the case here, as the Hember Avu reflexes, imbu 'feces', and mundu 'fire', retain both the nasal and stop portions.

$* \mathbf{f}>\boldsymbol{v} / \mathbf{V}_{-}$

As with all other Tibor languages except Mokati, ${ }^{*} \mathrm{f}$ merged with ${ }^{*} \mathrm{w}$ following a vowel. This is underlying $w$, and is realized variously as a glide $w$ or a voiced bilabial fricative $v[\beta]$. Examples include *ifer 'salt' > iver, *kafir 'fat' > havil, and *uf- 'dance' > uw-.

$* \mathbf{a}>\boldsymbol{e} / \#$ 
Word-initial *a merged with *e as $e$, as in Proto-Tibor *abe 'hand' > embe, *arek 'trunk' > erek, and *ate 'true, right' $>$ ende. This applied to all Proto-Tibor words with initial *a, not just to verbs as in the other Tibor languages.

\subsubsection{Sound changes in Mawak}

${ }^{*} \mathbf{k}>\boldsymbol{h} / \mathbf{V}, * \mathbf{k}>\varnothing / \#$

Proto-Tibor *k became $h$ intervocalically in Mawak, as in *eleke 'road' > elehe, while wordinitial *k deleted entirely, as in *kuma 'top' > uma, and *keta 'coconut' > eta. As I propose for Pamosu above, the deletion of word-initial *k probably took place in two stages: lenition of *k to $h$ preceding a vowel, followed by deletion of $h$ word-initially.

$* \mathbf{b}>\boldsymbol{p}$

Proto-Tibor *b devoiced to $p$ in all environments, as in *bita 'buttocks' pita, *ape $>$ ape 'hand', and *orob- 'come down' > orop-.

$\mathbf{D}>\mathbf{T} \#(\mathbf{V})$

As in Mokati and Pamosu, Mawak voiced stops devoiced word-initially, as well as in vowelinitial words where they were the first consonant. Examples of word-initial devoicing include *gawuk 'smoke' > kawuk, *geri 'cane' keri, *duar 'house' > tuar, and *duag 'girl' > duangg. Examples of voiced stops devoicing as the first consonant in a word include *abe 'hand' > ape, *eba 'net bag' > epa, and *iguar 'penis' > ikual. While this change can be said to have applied to all voiced stops, it is redundant in the case of $* b$, since $* b$ devoiced in all environments.

${ }^{*} \mathbf{D}>\mathbf{T} / \mathbf{D}$ 
Voiced stops also devoiced following a preceding voiced stop, as in *bebur 'cold' > pepur, *begi 'light' > peki, and *bug- 'sit' > pok-.

$* \mathbf{f}>\boldsymbol{v} / \mathbf{V}_{-}$

As with most other Tibor languages, ${ }^{*} \mathrm{f}$ and ${ }^{*} \mathrm{w}$ merged as $w$ after a vowel, as in *kafir 'fat' > awir, and *kefak 'flying fox'> ewak.

\section{Relative chronology of Mawak sound changes}

Deletion of word-initial $* \mathrm{k}$ took place before the change $* \mathrm{D}>\mathrm{T} / \#(\mathrm{~V})$, since word-initial $* \mathrm{~g}$ did not delete after devoicing. This ordering is illustrated in Table 9.2.6a.

Table 9.2.6a: relative chronology of Mawk sound changes

\begin{tabular}{|c|c|c|c|c|}
\hline & *kena 'base' & *keta 'coconut & * genaw 'bone & * gema 'liver' \\
\hline${ }^{*} \mathrm{k}>\varnothing / \#$ & ena & eta & -- & -- \\
\hline \multirow[t]{2}{*}{$* \mathrm{D}>\mathrm{T} / \#(\mathrm{~V})$} & -- & -- & kenaw & kema \\
\hline & ena & eta & kenav & kema \\
\hline
\end{tabular}

\subsubsection{Sound changes in Kowaki}

$* \mathrm{~g}>$ ?

Proto-Tibor $*_{\mathrm{g}}$ became a glottal stop in all environments in Kowaki, as in *gema 'liver' > 'ema, *eg- 'to see' $>e^{\prime}$-, *begi 'light' > pe'i, and *munag 'egg' > muna'.

$*_{\mathbf{k}}>\boldsymbol{h} / \mathbf{V}$

Proto-Tibor *k became $h$ before a vowel in Kowaki, as in *kena 'base' > hena, *keta 'coconut'> heta, and *eleke 'road' > erihe.

$* \mathbf{k}>$ ?/\# 
Word-final *k became a glottal stop, as in *sibik 'rain' > sepi', and *kefak 'flying fox' > hewa'. This resulted in a merger with $* \mathrm{~g}$ word-finally. This change also applied to monosyllables with final $* \mathrm{k}$ followed by epenthetic $u$, for example *fuku 'skin' > fu'u, and *saku 'leaf' > sa'u.

$* \mathbf{b}>\boldsymbol{p}$

As in Mawak, *b devoiced to $p$ in all environments, as in *sabir 'plate $>$ sapir, *ub- 'to plant' > op-, an d *kuba 'leg' > hupa.

$* d>t / \#(V)$

Proto-Tibor $* \mathrm{~d}$ devoiced word-initially, or as the first consonant in a vowel-initial word, as in *duar 'house' > tuar, *duag 'girl' > tua', *ade 'right, true' > ate, and *id- 'roast' > it-. This change may have been more general, but made redundant for $* b$, since *b devoiced in all environments. However, a parallel change did not take place with $*_{\mathrm{g}}$, since $*_{\mathrm{g}}$ is reflected in all environments as a glottal stop. The change $* d>t / \#(\mathrm{~V}) \_$could have been a more general devoicing rule $* \mathrm{D}>\mathrm{T} / \#(\mathrm{~V})$, but this would have necessarily applied after $* \mathrm{~g}>$ ?, since $* \mathrm{~g}$ was not affected.

$* \mathbf{f}>\boldsymbol{v} / \mathbf{V}_{-}$

Proto-Tibor $*$ merged with $* \mathrm{w}$ as $w$ after a vowel. The realization of this phoneme varies between a labiovelar glide and a voiced bilabial fricative.

\subsubsection{Proto-Tibor reconstructions}

Below I present Proto-Tibor reconstructions with their supporting word sets. First, I present the reconstructed Proto-Tibor subject/tense marking morphology, followed by other reconstructed lexical 
items in alphabetical order. As discussed in Chapter 3, some verbs in Tibor languages have multiple stems which are used with different conjugational suffixes. Where more than one stem can be reconstructed for a Proto-Tibor verb, they are listed under the same entry. Proto-Tibor reconstructions which are inherited from a higher-order proto-language (either Proto-Kumil-Tibor or Proto-Northern Adelbert) are listed below, but the supporting word sets are found in the sections for the higher-order proto-language.

\section{Proto-Tibor subject/tense markers}

Tables 9.2.8a-b show the reconstructed Proto-Tibor subject/past tense markers and their reflexes. Mawak is not listed, since there is no data on subject and tense marking for this language.

Pamosu and Kowaki have both combined the 3SG and 3PL past tense markers as a general third person past. In both languages, the 3.PST marker is a reflex of Proto-Tibor 3SG.PST *-et This suggests that Pamosu and Kowaki perhaps form a subgroup of Tibor.

For some Pamosu and Mokati plural subjects, the same markers are used for the past tense and the hodiernal. These appear to be cognate with the hodiernal tense markers in Hember Avu and Kowaki, not the past tense markers.

Another change in Pamosu is that the vowel in the 1SG, 2SG, and 3SG past tense markers has changed from *e to $o$, which is nto a regular sound change. In Hember Avu and Kowaki, this suffix rounds to -ot from underlying /-et/ when attached to a verb root ending in a labial consonant. I suggest that there used to be a similar alternation in Pamosu, and allomorph -ot was reanalyzed as the general form, and then became used for all verbs, not just for labial-final verb roots. This explanation is supported by the fact that labial-final roots are epecially common in Pamosu. The second-largest class of verb roots all end in $v$ (Tupper 2012: 309), and several highly frequent verbs outside this class also end in a labial, such as itiv- 'to go', ilup- 'come up', olop- 'come down', and ev- 'to take'. 
The expected reflex 2PL.PST *-emin in Wanambre Mokati is **-emin, but instead we have eming, perhaps on analogy with the 2PL ending.

Table 9.2.8a: Proto-Tibor subject/past tense markers

\begin{tabular}{|c|c|c|c|c|c|}
\hline & Mokati (Wan) & Mokati (Tin) & Pamosu & $\begin{array}{l}\text { Hember } \\
\text { Avu }\end{array}$ & Kowaki \\
\hline $\begin{array}{l}\text { *-em } \\
\text { 1SG.PST }\end{array}$ & $-e m$ & $-o m$ & $-o m$ & $-e m$ & $-o m$ \\
\hline $\begin{array}{l}\text { *-en } \\
\text { 2SG.PST }\end{array}$ & $-e n$ & $-e n$ & -on & $-e n$ & -uan \\
\hline $\begin{array}{l}\text { *-et } \\
\text { 3SG.PST }\end{array}$ & $-e t$ & $-e t$ & -ot '3.PST' & & $-e t$ \\
\hline $\begin{array}{l}\text { *-emin } \\
\text { 1PL.PST }\end{array}$ & -eming & $\begin{array}{l}(-e m i k) \\
(\mathrm{PST} / \mathrm{HOD})\end{array}$ & $\begin{array}{l}(- \text { eming }) \\
\text { (PST/HOD) }\end{array}$ & -emin & -emin \\
\hline $\begin{array}{l}\text { *-eman } \\
\text { 2PL.PST }\end{array}$ & $\begin{array}{l}(\text {-omang) } \\
(\mathrm{PST} / \mathrm{HOD})\end{array}$ & $\begin{array}{l}(- \text { omak }) \\
(\mathrm{PST} / \mathrm{HOD})\end{array}$ & $\begin{array}{l}(- \text { omong }) \\
(\mathrm{PST} / \mathrm{HOD})\end{array}$ & -eman & -eman \\
\hline $\begin{array}{l}\text { *-emid } \\
\text { 3PL.PST }\end{array}$ & -emind & $\begin{array}{l}\text {-emit } \\
\text { (PST/HOD) }\end{array}$ & $\left(-o t^{\prime} 3 . \mathrm{PST}^{\prime}\right)$ & -emin & $(-e t)$ \\
\hline
\end{tabular}

Table 9.2.8b: Proto-Tibor subject/hodiernal tense markers

\begin{tabular}{|c|c|c|c|c|c|}
\hline & Mokati (Wan) & Mokati (Tin) & Pamosu & Hember Avu & Kowaki \\
\hline $\begin{array}{l}\text { *-ekem } \\
\text { 1SG.HOD }\end{array}$ & -ehem & $-e m$ & -hom & -ekem & -ehem \\
\hline $\begin{array}{l}\text { *-ik } \\
\text { 2SG.HOD }\end{array}$ & $-i k$ & $-i k$ & $-i k$ & $-i k$ & $-i^{\prime}$ \\
\hline $\begin{array}{l}* \text {-ak/-ek } \\
\text { 3SG.HOD }\end{array}$ & $-a k /-o k$ & $-e k /-a k /-a u k$ & $-o k /-e k /-a k$ & $/-e k /-a k$ & $-e^{\prime},-a^{\prime}$ \\
\hline $\begin{array}{l}* \text {-emig } \\
\text { 1PL.HOD }\end{array}$ & -ehing & $\begin{array}{l}\text {-emik } \\
\text { (PST/HOD) }\end{array}$ & $\begin{array}{l}\text {-eming } \\
\text { (PST/HOD) }\end{array}$ & -ekemin & $-e m i^{\prime}$ \\
\hline $\begin{array}{l}\text { *-emag } \\
\text { 2PL.HOD }\end{array}$ & $\begin{array}{l}\text {-omang } \\
\text { (PST/HOD) }\end{array}$ & $\begin{array}{l}\text {-omak } \\
\text { (PST/HOD) }\end{array}$ & -omong & -ekoman & $-e m a^{\prime}$ \\
\hline 3PL.HOD & -ehind & $\begin{array}{l}(- \text { emit }) \\
\text { (PST/HOD) }\end{array}$ & $-o k /-e k /-a k$ & -ekemin & $\left(-e^{\prime},-a^{\prime}\right)$ \\
\hline
\end{tabular}

\section{Proto-Tibor pronouns}

Table 9.28.c shows the reconstructed Proto-Tibor pronouns. Unlike some other Northern Adelbert languages, the Tibor languages do not have multiple sets of case-marked pronouns, but use the same forms for different arguments of the verb, including subject, direct object, and possessor. The 
Pamosu, Mawak, and Kowaki forms for 1PL and 2PL suggest a final *e, with a morpheme boundary indicated by nasal spreading on the $2 \mathrm{PL}$ forms in Pamosu and Mawak (*nik+e $>$ ningge). I do not reconstruct a final *e for Proto-Tibor, since it is absent in Mokati and Hember Avu and also on the 3PL forms. The source of the Pamosu third person pronoun is not clear. Mawak 3PL mande is literally 'people'.

Table 9.2.8c: Proto-Tibor pronouns

\begin{tabular}{|l|l|l|l|l|l|}
\hline Proto-Tibor & Mok & Pam & HA & Maw & Kow \\
\hline *ye 1SG & ye & ye & ye & ye & $y e^{\prime}$ \\
\hline *ne 2SG & ne & $n e$ & $n e$ & $n e$ & $n e$ \\
\hline *wo 3SG & wuk & $($ on $)$ & wo & wo & wo \\
\hline *yik 1PL & yik & $i k e$ & $y i k$ & ike & $i^{\prime} e$ \\
\hline *nik 2PL & nik & ninge & nik & ningge & ni'e \\
\hline *wuk 3PL & wuk & $($ on $)$ & wuk & (mande) & wo \\
\hline
\end{tabular}

\section{Proto-Tibor vocabulary}

In this section I present the reconstructed Proto-Tibor vocabulary. Proto-Tibor reconstructions that date to Proto-Kumil-Tibor (PKT) or PNA are listed here, but the cognates are presented in the section for the higher order proto-language.

*abe 'arm, hand' ( $<$ PKT *waben, PNA *waben)

*abe kuma 'wrist, shoulder' ( < PKT *wapen kuma, PNA *waben *kuman)

*abe *genaw 'forearm'

Mok: apenggena

Pam: ape kenav

HA: embe kenav

Kow: ape 'enav

*abe *genaw *ilew 'forearm'

Mok: apenggena ilov

Pam: ape kenav ilov

Kow: ape 'enav ireb 
It is not clear if there is a difference in meaning between *abe *genaw (literally 'arm+bone') and *abe *genaw *ilew (literally 'arm+bone+two').

*abe kena 'shoulder, tricep, deltoid' (see PNA *waben kenam)

*ade 'right, true' (<PKT *aden)

*ane 'leg'

Mok: ane

Pam: ane

Maw: ane

Possibly related to Proto-Manep Barem *ain and Gavak angin.

*abe 'hand, arm' (<PKT *waben, PNA *waben)

*abe kuma 'wrist (< PNA *waben kumang)

*abe saku 'palm of hand'

Mok: ape saku, ape saku

Pam: ape saku

HA: embe saku

Kow: ape sa'u

*arek 'trunk, piece' (<PKT *arek, PNA *arek)

*awurun 'always' (<PKT *awurun)

*bak- 'carve, sharpen' (<PNA *bak-)

*baner 'signal drum' (< PNA *baner)

*be 'adze/axe' (<PKT *ben, PNA *ben)

*befi 'Papuan owlet nightjar'

Mok: bei

Pam: kumbevi

The element $k u$ - in Pamosu is also seen in 'hornbill' and a number of other bird names.

*begi 'light' (<PKT *begin, PNA *begen)

*bere 'road' (<PKT *beren, PNA *beren)

*betim 'beard'

Mok: betim

Pam: petim

*bibik- 'be afraid' (<PKT *bibik-)

*bik- 'put'

Mok: bik-

Pam: pih-, pi, piv-

HA: bik-

Maw: bih-

This is similar to Proto-Numugen *bigu-, but the velars do not match in voicing.

*binat 'heavy' (<PKT *binat, PNA *bin) 
*biriw 'ripe' (<PKT *biriw)

*bita 'buttocks'

Mok: bita

Pam: pita

Maw: pita

Maia (Saki) -bida is similar in form, but the velars do not correspond in voicing.

*bokan 'post' (<PKT< *buga, PNA *bugan)

*bogom 'spirit'

Mok: pokom 'local spirit'

Kow: po'om

*bug-, bugum- (<PKT *bug-, PNA *bug-)

*dagul 'snake'

Mok: dakul

Pam: takul

May be related to PNA *duag.

*dege 'straight' (<PKT *degen, PNA *degen)

*duar 'house' (<PKT *duar)

*ekik 'palm sp.

Mok: ekik

HA: ehik

*eg- 'to see' (see PNA *ag-)

*en-, *enim- 'to eat' (<PKT *en- *enim-, PNA *an-)

*ena 'banana'

Mok: ena

Pam: ena

Maw: ena

See also Proto-Kumil-Tibor *egi 'banana'.

*kena 'base' (<PKT *kenam, PNA *kenam)

*er- 'become' (PKT *ar-, PNA *ar-)

*ereker 'crayfish' (<PNA *areker)

*ereke 'road' (<PKT *ereke, PNA *areakai)

*erem- *eram-, *er- 'go down'

Mok: lem-, elam-, el-

Pam: elem-, elam, el-, ela-

Kow: erem-, eram-

*ew- 'to do, get, take' (<PKT *aw-, PNA *aw-)

*faya 'left' (see Proto-Kumil-Tibor *fa)

*fia 'pitpit' (<PNA * pia) 
*fifi 'bad' (see PNA *pi)

*fua 'white'

Mok: wa

Pam: fua

HA: fua

Maw: fua

Pam: fua

*fuk 'skin, body' (see PNA *puk)

*furu 'bamboo'

Mok: ulu

Pam: fulu

Maw: furu

*furuk 'smell, hear, perceieve' (see PNA *puruk)

*fuw- 'to come'

Mok: we-, wev-, w-

Pam: $f u-, f u v-$

Kow: fo-, fov-

*gagi 'cassowary'(<PKT *gagi)

*gamu 'rib, side'

Mok: gamu

Pam: kamu

Kow: 'amu

Resembles Mauwake kame 'side', but the final vowels do not correspond.

*gawuk 'smoke'

Mok: gauk

Pam: kavuk

HA: kawuk

Maw: kawuk

Kow: 'avu'

*gedaw 'strong' (<PNA *gedaw)

*gema 'liver' (< PKT *gema, PNA *gemay)

*genaw 'female bird of paradise'

Mok: kakuten gena

Pam: kenav 'female bird of paradise or bowerbird'

*genaw 'bone'

Mok: gena

Pam: kenav

HA: genav

Maw: kenab

Kow: 'enap 


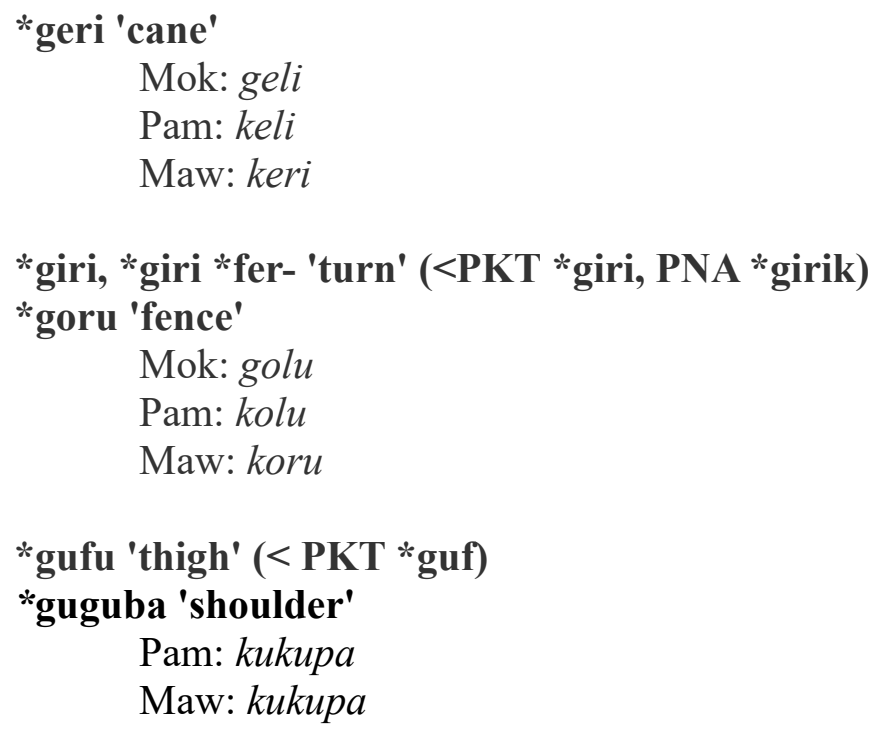

*ifer 'salt, ocean' (<PKT *ifer, PNA *iper)

*ifif 'dry, dry coconut' (<PKT *ifif)

*ig- 'to be' (<PKT *ig-, PNA *ig-

*iguar 'penis' (<PKT *iguar, PNA *iguar)

*ikik 'color'

Mok: ikik

Pam: ihik

*ikuma 'burn, cook' (<PKT *igum-, PNA *igum-)

*im- 'boil, cook in pot' (<PNA *im-)

*imi 'hair' (<PNA *im)

*in- 'sleep' (<PKT *in-, PNA *in-)

*ir- iru- 'go up' (<PKT *ir, PNA *ir-)

*irikir 'many

Mok: ilikil

HA: ilikil

*iruar 'aibika greens' (<PNA *iruar)

*irub- 'come up' (see PNA *irub-)

*irum 'palm sp.'

Mok: irum

HA: irum

*is- 'to bathe' (< PNA *it-) 
*iwu 'urine'

Pam: ivu

Maw: ivu

Kow: ivu

*kafuk 'lightweight'

Mok: kauk

Pam: avu

Kow: havu

*kakuten 'bird of paradise (possible PNA, see Karian)

Mok: kakuten

HA: mungga hakuten

This also resembles Mauwake osaiwa kokosa 'female bird of paradise' and Karian (Boia) kwagatan 'bird of paradise', but there are some problems with the correspondences. The expected Karian form would be ** kwakatan, and Mauwake should preserve the final nasal. On the other hand, Tibor languages usually lost a final nasal, but they are present in this word set.

*kamu 'day, sun' (<PNA *kam)

*kamuna 'pan' (<PNA *kamuna)

*kafir (<PKT *kafil, PNA *kapil)

*kagiw 'village area'

Pam: akiv 'open area', fa akiv 'village'

Kow: ha'iv 'village'

*kagur 'large bee sp.'

Mok: kanggul

HA: uni hanggur

*kariga 'near'

HA: halik

Maw: arika

Kow: hiri'a

*kaw 'tree sp.' (Tok Pisin skin diwai)

Mok: kav

HA: hav

*kamu 'sun' (see PNA *kam)

*kebar 'mouth' (<PKT *kebar, PNA *kebuar)

*keg-, *kegew- 'tell'

Pam: ek-, ekev-

HA: hengg-, henggev-

*keg- was used with past and hodiernal tenses, and *kegew- with other conjugations. 
*kena 'base' (< PKT *kenam, PNA *kenam)

*kenag 'tooth' (<PKT *kenag, see also PNA *nenag)

*ket- *ketew- 'to stand'

Mok: kete-, ketow-

Pam: ete-, etev-

Kow: hete-, hetev-

Reflexes of *ketew- are used with present progressive and irrealis conjugations, while reflexes of *kete- are used with other conjugations.

*keta 'coconut' (<PNA *keta)

*ketat 'red' (<PKT *kedat, PNA *ked-at)

*ketu 'blood' (<PKT *ked, PNA *ked

*kewak 'flying fox' (<PKT *kefak, PNA *kepak)

*kinam 'basket'

Pam: inam

HA: hinam

Maw: inam

Kow: hinam

*kiram- 'laugh'

Mok: kilam-

Pam: ilame-, ilames-, ilamet-, ilama-

Maw: irami-

Kow: hiram-

*kirim-swell' (< PNA *karim-)

*kofu 'child'

Pam: kou

HA: hovu

Kow: hovu

Resembles Moere kofa, but initial *k deleted in Kumil.

*komar 'day before yesterday'

Mok: komal

Pam: omal

Maw: omar

Kow: homar

*kopu 'word, speech' (<PNA *keb)

*kowa 'loincloth'

Pam: ova

Maw: howa

Kow: hova

*kuduruk 'fly' (<PNA *kuduruk) 
*kuma 'top'
Mok: kuma
Pam: uma
HA: huma
Maw: uma
Kow: huma

*kuma 'banana bunch' (< Proto-Kumil-Tibor *kuma)

*kumag 'testicles'(< PKT *kumag, <PNA *kumag)

*kumanum 'palm sp.' (TP:kuranga, Eng: fish-tail palm)

Mok: kumanum

HA: humanum

*kupa 'leg'

HA: humba

Kow: hupa

*kurum 'valley' (< PNA *kurum)

*kutak 'crab' (see PNA *ku?ak)

*ma 'small flying insect' (< Proto-Kumil-Tibor *ma)

*ma-bubu 'butterfly'

Pam: mambupu

Kow: mapupu

*made 'person' (PKT *made, PNA *maden )

*masen 'mosquito' (< Proto-Kumil-Tibor *sen)

*mambusen 'mosquito'

Mok: mambusen

HA: mambusen

This is a compound, with the first syllable a reflex of *ma 'small flying insect'. See also ProtoKumil-Tibor *ma and *masen, and PNA *sisimur.

*masisimur 'sunfly' (< PNA *masisimur)

*me NEG (<PKT *me, PNA *me)

*mekak 'bean'

HA: mekak

Kow: $m e^{\prime} a^{\prime}$

Although Z'graggen (1980b) transcribed the Kowaki word as $n e^{\prime} a$, I transcribed $m e^{\prime} a^{\prime}$ from his recording. This reconstruction is similar in shape to Proto-Kumil *mese', but not cognate.

*meki 'garden' (<PKT *mekiw <PNA *mekiw)

*megam 'star, year'

Mok: menggam 'year'

HA: menggam 'star'

Maw: menggam 'star' 
Kow: $m e^{\prime} a m$ 'star'

*merek 'male bird of paradise'

Mok: kakuten melek

Pam: melek 'male bird of paradise or bowerbird'

*merire-, *merirew- 'vomit' (<PKT *melil-, *melilew-, <PNA *melil-, *melilew-)

*memer 'sap'

Mok: memel

Pam: momol

Maw: memer

Kow: memer

*mimir 'grass'

Mok: mimil

HA: mimir

*molokon 'male (of animal)'

Mok: molokon

Pam: molohon

*mud- 'pierce, shoot' (<PKT *mid-, PNA *mid-, *midet-)

*mud[u] 'fire, firewood' (see PNA *mud)

*mudu ketat 'firelight'

Mok: mundu ketat 'firelight'

Pam: mundu etat 'burning coal'

HA: mundu hetar 'firelight

Kow: muntu etat 'fire'

*muga 'bird' (< PNA *mugan)

*munag 'egg' (<PKT *munag, < PNA *munag)

*na 'tree' (<PKT *nam, PNA * yam)

*nina 'stinging plant' (Tok Pisin salat)

Mok: nina

Pam: nina

HA: nina

*om- *omum- 'cry' (<PNA *am-, *amum-)

*orob- 'come down' (< Proto-Kumil-Tibor *ereb-)

*oru 'palm sp.'

Mok: olu

HA: olu

*oruw, 'pool, lake'

Mok: yapot olu

HA: opet oluv 
The first element in these terms is 'water'.

*sabir 'plate' (< PKT *tabir, < PNA *tabir)

*saku 'leaf' (< PNA *tak)

*sarem 'pandanus' (< Proto-Kumil-Tibor *sarem)

*sawua 'bush fowl'

Mok: savua

Pam: savua

Maw: savua

*sekat 'long'

Pam: sekat

Maw: sekat

Kow: se'at

*seba 'big'

Mok: (somba)

Pam: sepa

Maw: sepa

Kow: sepa

Prenasalization not expected in Mokati.

*sebik 'rain (<PNA *t(e/i)bik)

*seme 'today' (<PNA *temen)

*simu 'tree sp.' (Tok Pisin nar)

Mok: simu

HA: simu

*sisik 'vine tupe'

Mok: sisik

HA: sisik

*suman 'vine'

Mok: suman

Pam: suman

Maw: suman

Kow: suman

*suw 'push' (< PNA *suw)

*ub- 'to plant'(<PKT *ub-, PNA *ub-)

*ubin 'mountain' (<PKT *ubin)

*udu 'song' (<PNA *wud)

*um- 'to die' (<PKT *um-, PNA *um-)

*ume 'knife'

Mok: ume

Pam: ume 
HA: ime

Maw: ume

Kow: ume

*un- 'to draw water' (<PKT *un-, PNA *un-)

*unak- 'to dig'

Mok: unake-, unaket-

Pam: unat-, unah-, una-

Maw: uno-

*uni 'bee' (< PNA *unin)

*unim 'name' (<PKT *unim, PNA *unim)

*ura 'belly' (<PKT *uram, PNA *uram)

*us- 'give to 3SG' (<PNA *ut-)

*uw- dance' (<PKT *uf-, PNA *up-)

*uyaw 'spear' (<PKT *uyaw, PNA *uyaw)

*wagim 'lime'

Mok: wanggim

Pam: wangim

HA: anggim

Maw: wanggim

Kow: a'im

*war- 'hit, fight' (<PNA *war-)

*yak- *ya- 'to go'

Mok: yak-, ya-, yaka-

Pam: $a h-a-, a v-$

HA: ak-, aka-, akev-

Maw: ah-

*yagew 'cockatoo

Mok: yengge, yainge

Pam: enggev

HA: anggiav

*yaniw 'yellow' (<PKT *yaniw)

*yaw 'footprint' (<PNA *yaw) 


\subsection{Proto-Kumil}

The Kumil languages Bepour, Moere, and Mauwake clearly form a subgroup. They share several phonological innovations, and there are many Proto-Kumil reconstructions which do not have cognates in other Northern Adelbert languages.

\subsubsection{Proto-Kumil phonemes}

Table 9.3.1a shows the Proto-Kumil consonant phoneme inventory.

Table 9.3.1a: Reconstructed Proto-Kumil consonant phonemes

\begin{tabular}{|l|c|c|l|l|l|}
\hline & labial & alveolar & palatal & velar & glottal \\
\hline stop & $*_{\mathrm{p}}$ & $*_{\mathrm{t}}$ & & $*_{\mathrm{k},} *_{\mathrm{g}}$ & $(* \mathrm{p})$ \\
\hline nasal & $*_{\mathrm{m}}$ & $*_{\mathrm{n}}$ & & & \\
\hline affricate & ${ }_{\mathrm{f}}$ & & & & \\
\hline fricative & & $*_{\mathrm{s}}$ & & & \\
\hline trill & & ${ }^{\mathrm{r}},{ }^{*} \mathrm{l}$ & & & \\
\hline glide & ${ }_{\mathrm{w}}$ & & $*_{\mathrm{y}}$ & & \\
\hline
\end{tabular}

\section{Vowels and glides}

Like most other Northern Adelbert subgroups, Proto-Kumil had five vowels and two glides.

The correspondences for these phonemes are shown in Tables 9.3.1b-c.

Table 9.3.1b: Proto-Kumil vowel correspondences

\begin{tabular}{|l|l|l|l|l|}
\hline PKumil & environment & Bepour & Moere & Mauwake \\
\hline$*_{\mathrm{i}}$ & & $i$ & $i$ & $i$ \\
\hline$*_{\mathrm{u}}$ & & $u$ & $u$ & $u$ \\
\hline$*_{\mathrm{e}}$ & $e$ & $e, \varnothing$ & $e$ \\
\cline { 2 - 5 } & $?$ & $o$ & $\varnothing$ & $a$ \\
\cline { 2 - 5 } & /_[+labial $]$ & $e$ & $e$ & $o$ \\
\cline { 2 - 5 } & /? & $e$ & $e$ & $a$ \\
\hline$*_{\mathrm{o}}$ & & $o$ & $o$ & $o$ \\
\hline *a $_{\mathrm{a}}$ & & $a$ & $a, \varnothing$ & $a$ \\
\hline & /\# & $e$ & $e, \varnothing$ & $a$ \\
\hline
\end{tabular}


Table 9.3.1c: Proto-Kumil glide correspondences

\begin{tabular}{|c|c|c|c|c|}
\hline PKumil & environment & Bepour & Moere & Mauwake \\
\hline \multirow[t]{2}{*}{$*_{\mathrm{W}}$} & & $w$ & $w$ & $w$ \\
\hline & /\# & $w$ & $\varnothing$ & $w$ \\
\hline \multirow[t]{2}{*}{$* y$} & & $y$ & $y$ & $y$ \\
\hline & /\# & $y$ & $\varnothing$ & $y \sim \varnothing$ \\
\hline
\end{tabular}

\section{Stops}

The correspondences for the reconstructed Proto-Kumil stops are shown in Table 9.3.1d. The glottal stop can be considered an allophone of word-final $*_{\mathrm{k}}$, as they are in complementary distirubtion in Proto-Kumil, and both are reflexes of PNA *k and *t (which merged in Proto-Kumil). Proto-Kumil $*_{\mathrm{t}}$ is found in few reconstructions, as it is the conditioned reflex of PNA $* \mathrm{~d}$ in a restricted environment $(/ * \mathrm{i} i \mathrm{i})$. PNA $* \mathrm{~d}$ otherwise merged with $* \mathrm{~g}$.

Table 9.3.1d: Proto-Kumil stop correspondences

\begin{tabular}{|c|c|c|c|c|}
\hline PKumil & environment & Bepour & Moere & Mauwake \\
\hline \multirow[t]{3}{*}{$* \mathrm{~g}$} & $\#$ & $P \sim \varnothing$ & $k$ & $k$ \\
\hline & $\mathrm{V}_{-} \mathrm{V}$ & ? & $n g k$ & $k$ \\
\hline & \# & $?$ & $n g$ & $k$ \\
\hline$* \mathrm{k}$ & & $h$ & $k$ & $\varnothing$ \\
\hline (*?) & & $\varnothing$ & $?$ & $\varnothing$ \\
\hline$*_{\mathrm{t}}$ & & $t$ & $n t$ & $t \sim k$ \\
\hline \multirow[t]{2}{*}{$* p$} & \# & $p$ & $p$ & $p$ \\
\hline & V_V & $p$ & $m p$ & $p$ \\
\hline
\end{tabular}

\section{Fricatives}

Two fricatives are reconstructed for Proto-Kumil. Proto-Kumil *f $[\phi]$ is from PNA *p.

Table 9.3.1e: Proto-Kumil fricative correspondences

\begin{tabular}{|l|l|l|l|l|}
\hline PKumil & environment & Bepour & Moere & Mauwake \\
\hline \multirow{2}{*}{$*_{\mathrm{f}}$} & $\#_{-}$ & $\mathrm{f}$ & $f$ & $f$ \\
\cline { 2 - 5 } & $\mathrm{V}_{-}$ & $f$ & $w$ & $f$ \\
\hline$*_{\mathrm{s}}$ & & $s$ & $s$ & $\mathrm{~s}$ \\
\hline
\end{tabular}




\section{Nasals and liquids}

The correspondences of nasals and liquids are quite regular in the Kumil languages. The most important change relative to PNA is the loss of the velar nasal.

Table 9.3.1f: Proto-Kumil nasal correspondences

\begin{tabular}{|l|l|l|l|}
\hline PKumil & Bepour & Moere & Mauwake \\
\hline$*_{\mathrm{m}}$ & $m$ & $m$ & $m$ \\
\hline$*_{\mathrm{n}}$ & $n$ & $n$ & $n$ \\
\hline
\end{tabular}

able 9.3.1g: Proto-Kumil liquid correspondences

\begin{tabular}{|l|l|l|l|}
\hline PKumil & Bepour & Moere & Mauwake \\
\hline$* \mathrm{r}$ & $r$ & $r$ & $r$ \\
\hline$* 1$ & $r$ & $r$ & $l$ \\
\hline
\end{tabular}

\subsubsection{Proto-Kumil innovations}

Below I discuss the sound changes shared by the three Kumil languages, but not by the Tibor languages. In other words, these are changes that took place after the Kumil branch split from ProtoKumil-Tibor, but before Proto-Kumil broke up into Bepour, Moere, and Mauwake. The sound changes shared by the Kumil languages are as follows:

1) addition of word-final *a to monosyllables

2) $* \mathrm{a}>* \mathrm{e} / \mathrm{C} \#$

3) $* \mathrm{t}>*_{\mathrm{k}}$

4) $* \mathrm{~d}>* \mathrm{~g}$

5) $* \mathrm{k} * \mathrm{t},>\varnothing / \#$

6) $* \mathrm{k}>*$ ? / \#

7) $* b>* p$

8) $*$ ua $>*_{0}$

The change of PNA *t to Proto-Kumil *k likely happened before deletion of PNA *k wordinitially, since $* \mathrm{t}$ also deletes in this position. Another possibility is that the deletion of $* \mathrm{t}$ and $* \mathrm{k}$ wordinitially took place as separate changes, followed by the change of $* \mathrm{t}>*_{\mathrm{k}}$. 


\section{Addition of final *a monosyllables}

Proto-Kumil added a final *a to all monosyllabic content words, as illustrated in Table 9.3.2a.

Mauwake later added final $a$ to all content words, not just monosyllabic ones.

Table 9.3.2a: addition of final a to Proto-Kumil monosyllables

\begin{tabular}{|l|l|l|l|l|l|}
\hline gloss & PNA & Proto-Kumil & Bepour & Moere & Mauwake \\
\hline 'sun' & *kam & *ama & ama & mua & ama \\
\hline 'water' & *yag & *yaga & ya'a & engka & eka \\
\hline 'feces' & *ib & *iba & ipa & mpua & ipa \\
\hline 'tree' & *yam & *nama & nama & nama & -- \\
\hline 'louse' & *gun & *guna & una & kuna & -- \\
\hline 'hand drum' & *wag & *waga & wa'a & (ngku mpem) & oka \\
\hline 'bamboo' & *bik & *pika & piha & -- & pia \\
\hline
\end{tabular}

As discussed above, Tibor languages also added a final vowel to monosyllabic words, though it was $u$, not $a$. In the Tibor languages, consonants preceding this final vowel still behave as if they are word-final for some changes. This is not the case in Kumil, however, as the reflexes of consonants preceding the added final $a$ pattern in the same way as other intervocalic consonants.

$* \mathbf{a}>* \mathbf{e} / \mathrm{CH}$

PNA *a raised to *e in final closed syllables (which only occur word-finally in Proto-Kumil). This is illustrated with the reflexes in Table 9.3.2b. Note that in the Mauwake reflexes, some words underwent a later change of $\mathrm{PKT} * \mathrm{e}>o$ (see section 9.3.5). 
Table 9.3.2b: *a > e/ C\#

\begin{tabular}{|l|l|l|l|l|l|}
\hline gloss & PNA & Proto-Kumil & Bepour & Moere & Mauwake \\
\hline 'tooth' & PKT *kenag & *ene' & ene & nek-ere' & eneka \\
\hline 'bird' & *munag & *mune' & mune' & monong & muneka \\
\hline 'testicles' & *kumag & -- & -- & -- & imeka \\
\hline 'flying fox' & *kepak & $*$ efe' & efe & -- & afa \\
\hline 'spear' & *uyaw & *uyew & uyew & -- & wiowa \\
\hline 'base' & *kenam & $*$ enem & enem & nem & onoma \\
\hline 'star, year' & *megam & $*$ megem & -- & mengkem & mokoma \\
\hline 'belly' & $*$ uram & $*$ urem & urem & -- & uroma \\
\hline
\end{tabular}

$* \mathbf{k}>\varnothing / \#$

PNA word-initial *k was deleted in Proto-Kumil, as illustrated in Table 9.3.2c.

9.3.2c: *Reflexes of PNA initial *k in Kumil

\begin{tabular}{|l|l|l|l|l|l|}
\hline gloss & PNA & Proto-Kumil & Bepour & Moere & Mauwake \\
\hline 'lime' & *kafur & *afur & afur & fur & afura \\
\hline 'fat' & *kafil & *afir & afir & wisawir & afila \\
\hline 'base' & *kanam & *enem & enem & nem & onoma \\
\hline 'sun' & *kam & *ama & ama & mua & ama \\
\hline 'betelpepper vine' & *kufi & $*$ ufi & ufi & -- & ufia \\
\hline 'bow' & *kVmi & $*$ emi & omi & mui & amia \\
\hline 'pot' & *kamun & $*$ emin & omin & mui & amia \\
\hline 'tail' & PKT *kelew & $*$ elew & erew & erpop & alewa \\
\hline 'flying fox' & PKT *kewak & $*$ efe' & efe & - & afa \\
\hline
\end{tabular}

Although PNA word-initial *k was lost in Proto-Kumil, a small number of Proto-Kumil words with initial *k have been reconstructed, based on the correspondence of Bepour $h$, Moere $k$, and Mauwake $\varnothing$, illustrated in Table 9.3.2d. 
9.3.2d: *Reflexes of Proto-Kumil initial *k

\begin{tabular}{|l|l|l|l|l|}
\hline gloss & Proto-Kumil & Bepour & Moere & Mauwake \\
\hline 'dry' & *kerere- & herere- & kerere & $($ eres- $)$ \\
\hline 'cough' & *kwamer fup- & hamer fup- & kwamer fump- & - -- \\
\hline 'stone' & *kawen & hawen & kawen & -- \\
\hline 'stand' & *kimar- & himar- & -- & iimar- \\
\hline
\end{tabular}

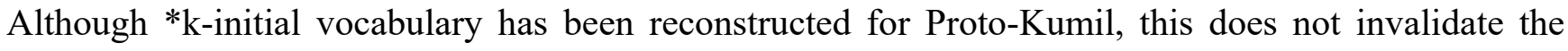
claim that PNA *k was lost in Proto-Kumil. None of the reconstructions with initial *k are inherited from Proto-Northen Adelbert, and therefore could have entered Proto-Kumil after the loss of initial *k.

Although PNA *k was lost word-initially in Proto-Kumil, it is preserved intervocalically, as some Proto-Kumil reconstructions with intervocalic $* \mathrm{k}$ are inherited from PNA, for example PNA *bik 'bamboo' > Proto-Kumil *pika > Bepour piha, Mauwake pia, and PNA *mekiw 'land' : Proto-Kumil *mekiw > Bepour mehiw, Mauwake miiwa.

$* \mathbf{k}>* \mathbf{2}$

Word-final $* \mathrm{k}$ became a glottal stop in Proto-Kumil. It is still reflected as a glottal stop in Moere, but has deleted entirely in Bepour and Mauwake, as illustrated in Table 9.3.2e.

Table 9.3.2e: Reflexes of PNA final *k in Kumil

\begin{tabular}{|l|l|l|l|l|l|}
\hline gloss & PNA & Proto-Kumil & Bepour & Moere & Mauwake \\
\hline 'trunk, piece' & *arek & *are' & are & are' & ara \\
\hline '2PL' & *nik & *ni' & $n i$ & $n i^{\prime}$ & $n i$ \\
\hline 'flying fox' & *kepak & *efe' $^{\text {Pefe }}$ & efe & & afa \\
\hline 'rain' & *tibik & *impi' & ipi & mpi' & ipia \\
\hline 'tongue' & PKT *nawiak & -- & & $n a w e^{\prime}$ & \\
\hline
\end{tabular}


Note that even without a reflex in Moere, which is the only language to retain Proto-Kumil *?, it is still possible to reconstruct a final glottal based on the correspondence of Bepour final $e$ with Mauwake final $a$, as final $e$ does not otherwise occur in Bepour content words (it does occur on some pronouns).

It seems to be the case that Proto-Kumil-Tibor *t merged with final $* \mathrm{k}$ to become Proto-Kumil *?. Final *? in Proto-Kumil *pina? 'heavy' (Bepour pine, Moere pine', Mauwake pina), corresponds final *t in Proto-Tibor *binat. These are derived from PNA *bin 'heavy, weight' plus the PNA adjective-forming suffix *-at. Unfortunately, there are no other clear cases of PNA final *t in Kumil, although there are other word sets that are probably derived from PNA *-at that also show Kumil *?, such as Bepour tane and Moere tane' 'full', from Proto-Kumil-Tibor *dan- 'to be full'.

$* \mathbf{b}>* \mathbf{p}$

PNA *b became Proto-Kumil *p, as illustrated in Table 9.3.2f. While Moere retains prenasalization on reflexes of intervocalic $* \mathrm{~b}$ (as well as $* \mathrm{~d}$ and $* \mathrm{~g}$ ), the stop portion has devoiced. In Bepour and Mauwake, prenasalization has been lost. Phonetically, Proto-Kumil *p was probably a prenasalized voiceless stop.

Table 9.3.2f: Reflexes of PNA *b in Kumil

\begin{tabular}{|l|l|l|l|l|l|}
\hline gloss & PNA & Proto-Kumil & Bepour & Moere & Mauwake \\
\hline 'heavy' & *bin & *pinet & pine & pine' & pina \\
\hline 'bamboo' & *bik & *pika & piha & -- & pia \\
\hline 'sit' & *bug- & -- & -- & -- & pok- \\
\hline 'plate' & *tabir & $*$ epir & epir & mpir & epira \\
\hline 'vagina' & *iben & $*$ ipen & ipen & impen & ipena \\
\hline 'rain' & *tibik & $*$ ipi' & ipi & impi' & ipia \\
\hline 'to plant' & $*$ ub- & $*$ up- & ip- & mpu- & up- \\
\hline 'feces' & $*$ ib & $*$ ipa & ipa & mpua & ipa \\
\hline
\end{tabular}


It is clear that the change of PNA *b to Proto-Kumil *p took place after the shift of PNA *p to ProtoKumil-Tibor $* f$. Had the shift of $* b>*_{p}$ applied first, then it would have fed the shift of $*_{p}$ to $*_{f}$.

$* \mathbf{t}>* \mathbf{k}$

As with *k, word-initial *t deleted in the Kumil languages, as illustrated in Table 9.3.2g

Table 9.3.2g: Reflexes of PNA initial *t in Kumil

\begin{tabular}{|l|l|l|l|l|l|}
\hline gloss & PNA & Proto-Kumil & Bepour & Moere & Mauwake \\
\hline 'plate' & *tabir & *epir & epir & mpir & epira \\
\hline 'rain' & *tibik & *ipi' & ipi & mpi' & ipia \\
\hline 'grasshopper' & *takaw & -- & -- & -- & aawa \\
\hline
\end{tabular}

Although there are fewer PNA reconstructions with medial *t, those with Kumil reflexes indicate that PNA medial *t has also merged with *k, as shown in 9.3.2h.

Table 9.3.2h: Reflexes of PNA medial *t in Kumil

\begin{tabular}{|l|l|l|l|l|l|}
\hline gloss & PNA & Proto-Kumil & Bepour & Moere & Mauwake \\
\hline 'coconut' & PNA *keta & -- & -- & $k a$ & -- \\
\hline 'chicken' & PNA *teteri & *ekeri & eheri & keri & (aara) \\
\hline $\begin{array}{l}\text { 'sky, cloud, } \\
\text { lightning'118 }\end{array}$ & ?atebarek & ?kapere & hapere & kemperem & aapereka \\
\hline
\end{tabular}

The only PNA form with final *t that is reflected in Kumil is *bin-at 'heavy'. Final *t in this word became a glottal stop in PKT * pine', which also the reflex of PNA final *k. Although there are few forms which reflect PNA *t in the Kumil languages, the evidence points to a merger with PNA *k.

118 A precise form for 'sky, cloud, 'lightning' can not be reconstructed, as most languages have irregularities in the correspondences, especially at the right edge of the word (for example $m$ in Moere and $k$ in Mauwake). However, the correspondences for the alveolar consonant are mostly regular (PNA *t $>s$ in Pamosu sepelak, $>t$ in Manep atembarek). 
PNA * $\mathrm{d}$ merged with * $\mathrm{g}$ in Kumil in the reflexes shown in Table 9.3.2i.

Table 9.3.2i: PNA *d $>*^{*}$ in Proto-Kumil

\begin{tabular}{|l|l|l|l|l|l|}
\hline gloss & PNA & Proto-Kumil & Bepour & Moere & Mauwake \\
\hline 'straight' & *degen & *gegen & 'e'en & kengen & kaken \\
\hline 'house' & PKT *duar & *gor & -- & kor & koora \\
\hline 'blood' & *ked & *ega & $e^{\prime} a$ & engka & aka \\
\hline 'shoot, pierce' & *mid- & *mig- & mi'- & mingk- & mik- \\
\hline 'man' & *made & -- & $($ mua $)$ & mangke & $($ mua $)$ \\
\hline 'to sing' & *ud *war- & -- & -- & ngkua wa- & - -- \\
\hline 'breadfruit' & *kidar & -- & -- & -- & ikera \\
\hline 'true' & PKT *aden & -- & -- & -- & akena \\
\hline 3SG.PST & $*$-ad, *-ed & -- & -- & -- & -ek, -ak \\
\hline
\end{tabular}

However, in some word sets, PNA *d is reflected as $t$ in Bepour and $(n) t$ in Moere. The Mauwake reflexes vary from $t \sim k$.

Table 9.3.2j: Reflexes of PNA *d in Kumil ${ }^{119}$

\begin{tabular}{|l|l|l|l|l|l|}
\hline gloss & PNA & PKT & Bepour & Moere & Mauwake \\
\hline 'to go' & $*_{\text {iduw- }}$ & $*_{\text {itiw- }}$ & itiw- & ntiw- & itiw-, ikiw \\
\hline 'roast' & $*_{\text {id- }}$ & $*_{\text {it- }}$ & -- & nt- & iki- \\
\hline 'smell' & $*_{\text {idin }}$ & $*_{\text {itin }}$ & itinew- & intinew- & ikina \\
\hline 'frog' & Manep injik & $*_{\text {iti }}$ & iti & iti & ikia \\
\hline 'dirty' & *debik & -- & -- & tempi & -- \\
\hline 'neck' & Proto-Tibor *dager & -- & -- & tangker & - -- \\
\hline
\end{tabular}

Most of the word sets in Table 9.3.2j have in common that the reflexes of $* \mathrm{~d}$ is found between two high front vowels. This suggests that PNA *d regularly became Proto-Kumil *g, but was retained

119 In addition to the word sets in Table 9.3.2j, there are some Mauwake words with $t$ which resemble terms in other Northern Adelbert languages, but can be discounted as borrowings. Mauwake tapu 'audience, crowd' resembles Waskia daup 'audience, crowd', but the placement of the vowels is problematic, and final - $a$ is expected on all Mauwake content words inherited from PNA. Mauwake top 'pig trap' resembles Waskia dop, as well as similar terms in Amako, Barem, and Manep, but again lacks the expected final - $a$. In form, Mauwake tuula 'top end' matches well with PNA *dur 'tail', but would require positing a change in meaning. 
as an alveolar under the influence of the front vowels. The exception is Mauwake where $* \mathrm{~d}$ merged with $*^{*} \mathrm{~g}$ even in the environment of $* \mathrm{i}$, although there is variation in ikiw- itiw- 'to go'. Moere tempi 'dirty'120 and tangker 'neck' do not have $i$ following *d, but these could very well be borrowings.

${ }^{*} \mathbf{u a}>\mathbf{o}$

Proto-Kumil-Tibor *ua became *o in Proto-Kumil, as illustrated by the reflexes in the table below.

Table 9.3.2k: Reflexes of *ua

\begin{tabular}{|l|l|l|l|l|l|}
\hline gloss & PNA/PKT & Proto-Kumil & Bepour & Moere & Mauwake \\
\hline 'penis' & PNA/PKT *iguar & *igor & i'or & ingkor & ikora \\
\hline 'house' & PKT *duar & *gor & -- & kor & koora \\
\hline 'mouth' & PNA *kebuar & $*$ opor 'speech' & opor & -- & opora \\
\hline
\end{tabular}

\subsubsection{Sound changes in Bepour}

In this section I outline the sound changes which took place in Bepour after the break up of Proto-Kumil.

$* \mathbf{k}>\boldsymbol{h}$

As discussed above, word-initial PNA *k deleted in all Kumil languages, as did word-final *k in Bepour and Mauwake. Intervocalic Proto-Kumil *k became $h$ in Bepour, as in PNA *mekiw 'land' > mehiw, and *bik 'bamboo' > piha. In Proto-Kumil words with initial *k (not derived from PNA *k), this also became $h$ in Bepour, as in *kawen 'stone' > hawen, and *kimar- 'stand' > himar-.

120 Z'graggen did not transcribe a final glottal stop on Moere tempi 'dirty, but one is expected if this is a directly inherited word. However, this should not rule it out as a possibly legitimate cognate, as Z'graggen did not reliably transcribe glottal stops. 
$* p>\varnothing$

Proto-Kumil final glottals deleted in Bepour, as in *pine' 'heavy' > pine, and *ni' '2pl' > ni, and *wi' '3pl' > wi.

${ }^{*} \mathrm{~g}>\mathrm{P},{ }^{*} \mathrm{~g}>\varnothing$

Proto-Kumil *g became a glottal stop intervocalically and word-finally in Bepour, as in *yag 'water' > ya'a, *iguar 'penis' > i'or, *ig- 'to be' > i'-, and Proto-Kumil-Tibor *munag 'egg' $>$ mune'. Word-initially, PNA *g somtimes deletes entirely, as in *gema 'liver' > ema, *gir- 'turn' > ir- and *gun 'louse' > una. However, there are a few words which appear with an initial glottal in Z'graggen's transcriptions, such as Proto-Kumil-Tibor *gagi 'cassowary' > 'ahi.

$* \mathbf{f}>\boldsymbol{w} / \#$

Proto-Kumil $*_{\mathrm{f}}$ appears to have merged with ${ }^{*} \mathrm{~W}$ as $w$ in word final position. Only two Proto-

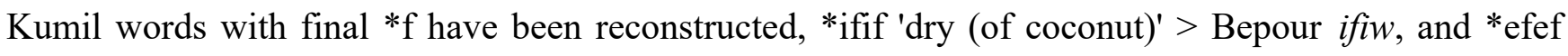
'lightweight' $>$ few.

$* I>r$

Proto-Kumil *1 merged with *r to become Bepour $r$, as in *afil 'fat' > afir, and *elew 'tail' > erew.

${ }^{*} \mathbf{u}>\boldsymbol{i} / \# \_[+ \text {labial] }$

Word-initial $* \mathrm{u}$ fronted to $\mathrm{i}$ when followed by a labial consonant, as in PNA *um 'die' > im-, *ub- 'to plant' > ip-, and *up- 'sing and dance' to if-. This change also applied to both vowels in *urup- 
'see' > irif-. This change seems to only have applied to verbs, as it did not apply to Proto-Kumil *ufi 'betelpepper vine' > ufi, or to Proto-Kumil *ufu 'cane' > ufu.

$* \mathrm{e}>a, * \mathrm{e}>\mathrm{o}$

In some words, word-initial *a has become $e$ or $o$. It is not clear what has conditioned this change. Examples are PNA *aw-' to do, and take' $>e w-$ *an- $>$ en-. In other words, Bepour $e$ corresponds with Mauwake $a$, for which I have reconstructed Proto-Kumil *e or *a, through comparison with languages outside Kumil. It is not clear what has conditioned the change of vowel in these Kumil words. Examples are PNA *kamun $>$ Proto-Kumil *amun 'pan' > omin, and PNA *kemi $>$ Proto-Kumil *emi 'bow' $>$ omi. ${ }^{121}$

\section{Relative chronology of Bepour sound changes}

For some of the changes which applied to velars, it is possible to determine the order in which they take place. The deletion of Proto-Kumil *? took place before the shift of Proto-Kumil $* \mathrm{~g}>$ ?, as the glottals derived from * $\mathrm{g}$ did not subsequently delete, as illustrated in Table 9.3.3a.

Table 9.3.3a: relative chronology of Bepour sound changes

\begin{tabular}{|l|l|l|l|l|}
\hline & $*$ irirag 'sweat' & $*^{\prime}$ muneg 'egg' & *wi? '3PL' & *pine ? 'heavy' \\
\hline 1$) * ?>\varnothing$ & -- & - & wi & pine \\
\hline 2$) * g>?$ & irira? & mune? & -- & -- \\
\hline & irira' & mune' & wi & pine \\
\hline
\end{tabular}

Although there is no direct evidence, it is possible that the change of *g $>$ ? went through a medial stage of where ${ }^{*} \mathrm{~g}$ first devoiced to $k$ before shifting to a glottal. If so, then this change must have taken place after the shift of $* \mathrm{k}$ to $h$, since $* \mathrm{~g}$ and $* \mathrm{k}$ did not merge, as illustrated in Table 9.3.3b.

121 Similar irregular changes also applied in Maia, where to PNA *a > ua/\#k_ in some words. 
Table 9.3.3b: relative chronology of Bepour sound changes

\begin{tabular}{|l|l|l|l|l|}
\hline & *mekiw 'land' & *pika 'bamboo' & *igor 'penis' & *pug- 'break' \\
\hline 1$) * \mathrm{k}>h$ & mehiw & piha & -- & -- \\
\hline 2$) * \mathrm{~g}>$ ? & -- & -- & i?or & pu?- \\
\hline & mehiw & piha & i'or & pu'- \\
\hline
\end{tabular}

\subsubsection{Sound changes in Moere}

$* a, * e>\varnothing / \#$

Word-initial *a and *e deleted in most instances in Moere, as illustrated in Table 9.3.4a. There are a few words where initial *e, *a did not delete, as in *ega 'blood' > engka, and *aw- 'to take' > ew-.

Table 9.3.4a: Deletion of initial *a, *e in Moere

\begin{tabular}{|l|l|l|l|}
\hline Proto-Kumil & Bepour & Moere & Mauwake \\
\hline *awon 'old' & awon & won & awona \\
\hline *afur 'lime' & afur & fur & afura \\
\hline *ama 'sun' & ama & mua & ama \\
\hline *epir 'plate' & epir & mpir & epira \\
\hline *epi 'fire' & epi & mpi 'firewood' & epia \\
\hline *eger 'sago' & -- & ngker & ekera \\
\hline
\end{tabular}

Although initial vowel deletion did not typically apply to $*_{\mathrm{i}},{ }^{*} \mathrm{u}$, or ${ }^{*} \mathrm{o}$, it also applied to these vowels in a few cases, as in *itiw- 'to go' $>$ ntiw-, and *okon 'leg' $>$ kon. Although there is no clear condition for why it applied in these words, the deletion of initial high vowels is common in conjunction with $u$ insertion (described below), as in *ipa 'feces' > mpua, *um- 'die' > mu-, and *up- 'to plant' > mpu-. 


\section{$u$-insertion}

In many words begining with a vowel followed by a labial consonant, $u$ was inserted after the labial $(* \# \mathrm{VC}[+$ labial $]>\mathrm{VCu})$. Word sets illustrating this change are shown in Table 9.3.4b.

Table 9.3.4b: $u$-insertion in Moere

\begin{tabular}{|l|l|l|l|}
\hline Proto-Kumil & Bepour & Moere & Mauwake \\
\hline *ipa 'feces' & ipa & mpua & ipa \\
\hline *ifa 'snake' & ifa & iwua & ifa \\
\hline *ama 'sun' & ama & mua & ama \\
\hline *um- 'die' & im- & mu- & um- \\
\hline *up 'to plant' & ip- & mpu- & up- \\
\hline *ami 'bow' & omi & mui & amia \\
\hline *amin 'pot' & omin & muin & amina \\
\hline
\end{tabular}

There are, however, a number of words in which this change apparantly did not apply, such as *ipen 'vagina' > impen, *ifan 'ear' > iwan, and *epir 'plate' > mpir. It is not clear if there is a conditioning factor which determined when the change applied.

$*_{\mathbf{f}}>\boldsymbol{w} / \mathbf{V}_{-}$

Proto-Kumil $*_{\mathrm{f}}$ and ${ }^{*} \mathrm{w}$ merged as $w$ following a vowel, as in $*_{\text {ifan }}$ 'ear' $>i w a n, *^{\text {nefe }}$ '2SG.OBJ' > newe, and *ifif 'dry (of coconut)' > iwiw.

$* \mathbf{I}>\boldsymbol{r}$

As in Bepour, Proto-Kumil *1 merged with $* \mathrm{r}$ to become $r$ in Moere. However, this change is less clear in Moere, as the reflexes of the only two Proto-Kumil reconstructions with *1 are compounds. Proto-Kumil *afil 'fat' is reflected in Moere wisawir, a compound whose first element is wisa 'fat'. The second Proto-Kumil reconstruction with *1 is *erew 'tail', for which Z'graggen transcribes erpop. The origin of the additional final syllable is not clear. 


\section{Changes to Proto-Kumil *g}

Proto-Kumil * $\mathrm{g}$ merged with $*_{\mathrm{k}}$ in word-initial position in Moere, where both are reflected as $k$, as in Proto-Kumil *gema 'liver' > kema, *gir- 'turn' > kir- and *guna 'louse' > kuna. Intervocalic PNA *g became $n g k$ in Moere, as in PNA *yag 'water' > Proto-Kumil *yaga > engka, PNA *iguar 'penis' > ingkor, and Proto-Kumil-Tibor *egi 'banana' $>$ ngki. This contrasts with reflexes of medial $*^{*}$, which do not have prenasalization, as in the medial consonant in *gaki 'cassowary' > kaki. Word-finally, *g is reflected as a nasal $n g$, as in Proto-Kumil-Tibor *muneg 'egg' > munong.

\section{Relative chronology of Moere sound changes}

The Moere reflex of *afur 'lime' indicates that the deletion of initial *a took place before the change of $* \mathrm{f}>\mathrm{w} / \mathrm{V}_{-}$. The ordering of these changes is illusrated in Table 9.3.4c.

Table 9.3.4c: relative chronology of Moere sound changes

\begin{tabular}{|c|c|c|c|}
\hline & *afur 'lime' & *ifif 'dry' & *ifan 'ear' \\
\hline 1) $* a>\varnothing / \#$ & fur & -- & -- \\
\hline \multirow[t]{2}{*}{ 2) $* \mathrm{f}>\mathrm{w} / \mathrm{V}_{\mathrm{V}}$} & -- & iwiw & iwan \\
\hline & fur & $i w i w$ & iwan \\
\hline
\end{tabular}

\subsubsection{Sound changes in Mauwake}

\section{Addition of final $a$ to content words}

A notable change in Mauwake is that final $a$ has been added to the end of all open-class words, for example Proto-Kumil *ifan 'ear' > ifana, *ufi 'betelpepper vine' > ufia. Although open-class words without final $a$ exist in Mauwake, these are recent innovations. Lack of final $a$ can help to identify loanwords. For example, Maia lol 'sand, shore' and Gavak lul 'shore' can be used to reconstruct PNA

*lul. Mauwake luul 'black sand' should not be taken as evidence supporting this reconstruction, as 
there is no clear reason why final $a$ would not have been added if it were directly inherited. Instead, it can be identified as a recent innovation, likely a borrowing from Maia.

According to Berghäll (2015: 44), final $-a$ is often dropped in fast speech, especially when unstressed and followed by a vowel-initial word. It is also never found on the first constituent of a compound. However, final $-a$ cannot be considered synchronically to be an epenthetic vowel, as there are a number of conent words which do not have final $-a$. Lack of final $-a$ is therefore a reliable diagnostic for identifying loanwords.

$* \mathbf{e}>\boldsymbol{o} / \mathbf{m}$

Proto-Kumil *e rounded to $o$ before $* \mathrm{~m}$, as illustrated in Table 9.3.5a. When the vowel in the preceding syllable was also *e, this rounded to $o$ as well, as in *enem 'base' > onoma, and *megem 'star' > mokoma.

Table 9.3.5a: *e $>o$ in Mauwake

\begin{tabular}{|l|l|l|l|}
\hline Proto-Kumil & Bepour & Moere & Mauwake \\
\hline *semar- 'walk' & semar- & -- & soomar- \\
\hline *urem 'stomach' & urem & urem & uroma, iroma \\
\hline *emem- 'cry' & emem- & -- & omom- \\
\hline *enem 'base' & enem & nem & onoma \\
\hline *megem 'star' & -- & mengkem & mokoma \\
\hline
\end{tabular}

This change did not apply in *gema 'liver' > kema. It is not clear why this is an exception, but it is notable that in most nouns in which $*_{\mathrm{e}}$ did round, it is before coda $*_{\mathrm{m}}\left(*^{\mathrm{urem}},{ }^{*} \mathrm{enem}, *^{\mathrm{megem}}\right)$, while in $*_{\text {gema, }}^{*} \mathrm{~m}$ is the onset of the following syllable. 
$* \mathbf{e}>\boldsymbol{a} / \#$

Word-final *e lowered to $a$ in Mauwake, as in Proto-Kumil *are' 'trunk' > ara, *pine' 'heavy' > pina, *mese' 'wing bean' > mesa, and *nefe '2SG.OBJ' > nefa.

$* \mathbf{k}>\varnothing$

Proto-Kumil *k deleted in all environments in Mauwake, as in *kimar- 'stand' > iimar-, *mekiw 'land' > miiwa, and *muk- 'swallow' > mu-.

$* \mathbf{g}>\boldsymbol{k}$

Proto-Kumil *g devoiced to $k$, as in *gir- 'turn' > kir-, *yaga 'water' > eka, and *pug- 'cut, break' $>$ puuk-.

$* 2>\varnothing$

Proto-Kumil final glottal stops deleted in Mauwake, as in *pine? 'heavy' ' pine, and *ni? '2PL' > $n i$, and *wi? '3PL'> wi.

\section{Vowel assimilation $V_{1} V_{2}>V_{2}$ :}

Although there are few Proto-Kumil words to which this rule could have applied, it seems that if the deletion of an intervocalic * $\mathrm{k}$ (see above) resulted in a sequence of two different vowels in Mauwake, then the first vowel assimilated in quality to the second vowel, as in *mekiw 'land' > miiwa, and *gaki 'cassowary' > kiiya. 


\section{Relative chronology of Mauwake sound changes}

It is possible to deterrmine the order in which some sound changes applied in Mauwake. The deletion of Proto-Kumil * $\mathrm{k}$ took place before the change of $*_{\mathrm{g}}>k$, since the latter rule did not feed the former, as illustrated in Table 9.3.5b.

Table 9.3.5b: relative chronology of Mauwake sound changes

\begin{tabular}{|l|l|l|l|l|}
\hline & *kimar- 'stand' & *mekiw 'land' & *gema 'liver & *igor 'penis' \\
\hline 1$) * \mathrm{k}>\varnothing$ & imar- & meiw & -- & -- \\
\hline 2$){ }^{*} \mathrm{~g}>\mathrm{k}$ & -- & -- & kema & ikor \\
\hline & iimar- & miiwa & kema & ikora \\
\hline
\end{tabular}

The deletion of *k also clearly took place before vowel assimilation $\left(V_{1} V_{2}>V_{2}\right)$, since the deletion of *k created the conditions necessary for vowel assimilation to apply.

The deletion of final glottal stop feeds the lowering of word-final *e to $a$, as illustrated in Table $9.3 .5 \mathrm{c}$.

Table 9.3.5c: relative chronology of Mauawke sound changes

\begin{tabular}{|l|l|l|l|}
\hline & *are' - 'trunk' & *pine' 'heavy' & *mese' 'bean' \\
\hline 1$) * \mathrm{p}>\varnothing$ & are & pine & mese \\
\hline 2$) * \mathrm{e}>\mathrm{a} / \#$ \# & ara & pina & mesa \\
\hline & ara- & pina & mesa \\
\hline
\end{tabular}

\subsection{Proto-Kumil reconstructions}

Table 9.4a compares the Kumil free pronouns, and shows the Proto-Kumil forms I have reconstructed. The reflexes of the Proto-Kumil forms are completely regular in Bepour. Moere adds $n V$ to the end of the singular forms, where the vowel copies the quality of the preceding vowel. Moere also adds additional material in ikie 1PL. In Mauwake, 1SG *ye and 2SG *ne have changed their vowels to $o$ on analogy with $3 \mathrm{SG} *$ wo. 
Table 9.4a: Proto-Kumil free pronouns

\begin{tabular}{|l|l|l|l|}
\hline Proto-Kumil & Bepour & Moere & Mauwake \\
\hline *ye 1SG $^{\text {*ne 2SG }}$ & ne & ene & yo \\
\hline *wo 3SG $^{\text {wik 1PL }}$ & wo & nene & no \\
\hline *nik 2PL & $n i$ & $i k i e$ & wo \\
\hline *wik 3PL & $w i$ & $n i^{\prime}$ & ni \\
\hline
\end{tabular}

The Kumil direct object pronouns (which are independent words in Mauwake, but considered prefixes for Bepour and Moere by Z'graggen) are shown in Table 9.4b. The singular pronouns are formed with the addition of *-fe to the free pronouns, except for the $3 \mathrm{SG}$, which is a null form. Bepour and Mauwake form the plural direct object pronouns by suffixing $-a$ to the free pronounds. Moere adds -iwi, which is perhaps all from *-fe, but with assimiliation to the preceding vowel.

Table 9.4b: Proto-Kumil object pronouns

\begin{tabular}{|c|c|c|c|}
\hline Proto-Tibor & Bepour & Moere & Mauwake \\
\hline *ye-fe 1SG & efe- & ewe & efa \\
\hline *ne-fe 2SG & nefe- & newe & nefa \\
\hline$* \varnothing 3 \mathrm{SG}$ & $\varnothing$ & $\varnothing$ & $\varnothing$ \\
\hline *yik-a 1PL & $y a-$ & $i k i--w i$ & yia \\
\hline *nik-a 2PL & nia- & nik-iwi- & nia \\
\hline *wik-a 3PL & wia- & wik-i- & wia \\
\hline
\end{tabular}

The Kumil possessive pronouns are shown in Table 9.4c. Possessieve pronouns are not reconstructed for Proto-Kumil, since each language forms them using a different strategy. Mauwake adds - ena to the free pronoun forms. Bepour adds -em to the plurals and -Cem to the singulars, where 
$\mathrm{C}$ is a copy of the preceding consonant. Moere addes the suffix -ner, which is inherited from PNA *ner.

Table9.4c: Proto-Kumil possessive pronouns

\begin{tabular}{|l|l|l|l|}
\hline & Bepour & Moere & Mauwake \\
\hline $1 \mathrm{SG}$ & yiyem & ener & yena \\
\hline 2SG & nenem & nener & nena \\
\hline 3SG & wuwem & onor & ona \\
\hline $1 \mathrm{PL}$ & ihem & ikier & yiena \\
\hline 2PL & ninihem & nikiner & niena \\
\hline 3PL & wiwihem & wikiner & wiena \\
\hline
\end{tabular}

\section{Proto-Kumil reconstructed vocabulary}

Below I present the Proto-Kumil vocabulary. Cognate sets for reconstructions dating to ProtoKumil-Tibor or PNA are listed in the sections for those proto-languages.

*afil 'fat, grease' ( < PNA *kapil)

*afur 'lime' (< PNA *kapur)

*ama 'day, sun' (< PNA *kam)

*aw- 'to get, take' (< PNA *aw-)

*awon 'old'

Bep: awon

Moe: won

Mau: awona

*arek 'trunk, piece' (< PNA *arek)

*efe' 'flying fox' ( < Proto-Kumil-TIbor *kepak)

*egi 'banana' ( < Proto-Kumil-Tibor *egi)

*ega 'blood' (<PNA *ked)

*ema 'mountain'

Bep: amere

Moe: mare'

Mau: ema

Bepour and Moere are assumed to be compounds of *ema +*are' 'piece'. The reflex of *arek is also used to refer to landscape in Barem, for examples biga arek 'a piece of ocean'.

*emi 'bow' ( < PNA *kemi) 
*ekeri 'chicken' (<PNA *teteri)

*eneg (< Proto-Kumil-Tibor *kenag)

*ema 'mountain'

*emem-'cry' (<PNA *am-, *amum-)

*enow 'food'

Bep: enow

Mau: enowa

*enum 'green'

Bep: enum

Mau: enuma

*epi 'fire, firewood'

Bep: epi 'fire'

Moe: $m p i$ 'firewood'

Mau: epia 'firewood, fire'

*epir 'plate' (< PNA *tabir)

*erep- 'fall' (< Proto-Kumil-Tibor *ereb-)

*eyep 'new'

Bep: еуер

Moe: yemp

*fa 'left' (< Proto-Kumil-Tibor *fa)

*fere 'few'

Bep: fere

Moe: fere

*fugum 'hair'

Bep: fu'um

Moe: fungum

The usual reflex of intervocalic * $\mathrm{g}$ is a prenasalized stop in Moere, but the speaker in Z'graggen's recordings pronounces only a velar nasal in all tokens of this word. A velar nasal $n g$ [ $\mathrm{y}]$ is possibly a conditioned reflex of ${ }^{*} \mathrm{~g}$ when the following consonant is nasal (see section 3.10 ).

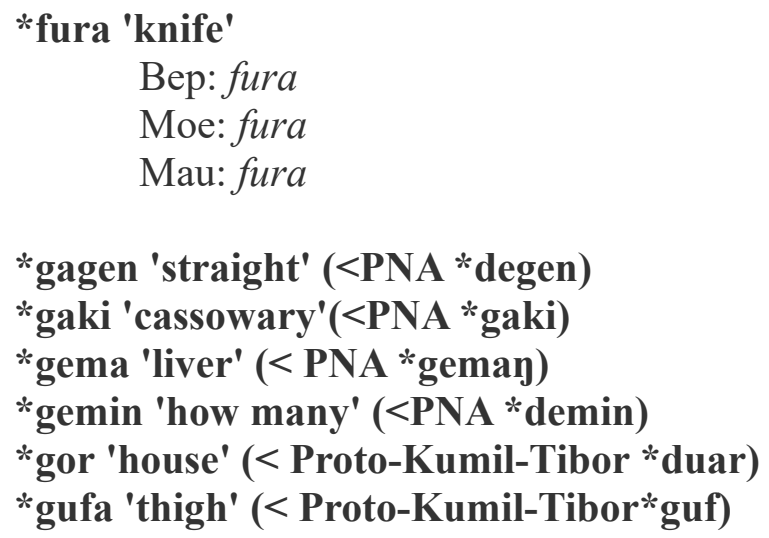


*guna 'louse' (< PNA *gun)

*ifan 'ear'

Bep: ifan

Moe: iwan

Mau: ifana

*ifan- 'to listen'

Bep: ifan-

Moe: iwan-

*ifer 'salt, ocean' (< PNA *iper)

*ifif 'dry, dry coconut' (< Proto-Kumil-Tibor *ifif)

*ig- 'to be' (<PNA *ig-)

*igor 'penis' (< PNA *iguar)

*ipa 'feces' (< PNA *ib)

*ipen 'vagina (< PNA *iben)

*ipi' 'rain' (< PNA *tibik)

*ineg 'back'

Moe: ineng

Mau: ineka

*iruw 'loincloth'

Bep: iruw

Moe: iruw

Mau: uruwa

May be related to PNA * siruw.

*isiwe' 'black (of skin)'

Bep: isiwe

Moe: isiwe'

*kawen 'stone'

Bep: hawen

Moe: kawen

*kenem 'base' (<PNA *kenam)

*kerere 'dry'

Bep: herere-

Moe: kerere-

*ma 'small flying insect' (< Proto-Kumil-Tibor *ma)

*mekiw 'land' (< PNA *mekiw)

*megem 'woman' (< Proto-Kumil-Tibor *megem)

*megem 'star, year' (PNA *megem)

*mena 'breast' ( < PNA *men)

*mera 'fish' 
Bep: mera

Moe: mera

Mau: mera

*merir- 'vomit' (<PNA *merir-)

*mese' 'wing bean'

Bep: mese

Moe: mese'

Mau: mesa

*mosa 'saliva'

Bep: mosa

Moe: mosa

Mau: mosa

*mua 'man' (<PNA *mun 'husband)

*muneg 'egg' (< PNA *munag)

*nama 'tree' (<PNA * nam)

*nebe' 'bird' (<PNA *nebek)

*okon 'leg'

Bep: ohon 'leg'

Moe: kon 'bone, leg'

Mau: oona 'bone'

Polysemy between 'bone' and 'leg' is also found in Numugen *guaten. Proto-Kumil *okon may be cognate with Proto-Numugen *gwaten. This would suggest PNA* $(\mathrm{g} / \mathrm{k})$ uaten, with one group having an irregular change in the initial voicing of the velar.

*opor 'speech' ( < PNA kebuar 'mouth')

*oram 'nothing'

Bep: oram

Mau: oram

*oriw 'vine'

Bep: oriw

Moe: oriw

*owow 'village' ( < PNA *kuwaw)

*perper 'bush fowl'

Bep: perper

Moe: perper

*pika 'bamboo' ( < PNA*bik)

*pine' 'heavy' (< PNA *bin)

*piriw 'ripe' ( < PKT *biriw

*pug- 'break'

Bep: $p u-$ 


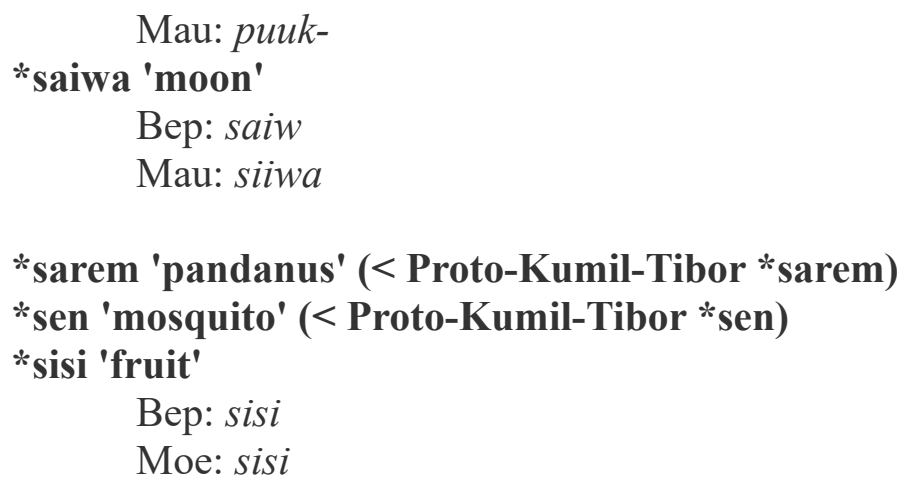

\subsection{Proto-Kumil-Tibor reconstructions}

Table 9.4a shows the reconstructed Proto-Kumil-Tibor pronouns and their reflexes. The Tibor reflexes are used for subjects, objects, and possessors, while the Kumil reflexes are typically used for 
subjects, and have different forms for those used with other kinds of arguments. The reconstructed Proto-Tibor and Proto-Kumil forms have only two small differences. First, the lack of *y in the 1PL in Kumil, and a difference in the vowel in the 3PL Proto-Tibor *wuk and corresponding Proto-Kumil *wik. I reconstruct *wik for Proto-Kumil-Tibor.

Table 9.4a: Proto-Kumil-Tibor pronouns

\begin{tabular}{|c|c|c|c|c|c|c|c|c|c|c|}
\hline PKT & $\begin{array}{l}\text { Proto- } \\
\text { Tibor }\end{array}$ & Mok. & Pam. & HA & Maw. & Kow. & $\begin{array}{l}\text { Proto- } \\
\text { Kumil }\end{array}$ & Bep. & Moe. & Mauw. \\
\hline *ye $1 \mathrm{SG}$ & *ye & ye & ye & ye & ye & ye & *ye & ye & ene & yo \\
\hline$*^{*}$ ne $2 \mathrm{SG}$ & *ne & ne & ne & ne & ne & ne & *ne & ne & nene & no \\
\hline *wo 3SG & *wo & wuk & on & wo & wo & wo & ${ }^{*}$ wo & wo & ono & wo \\
\hline *yik 1PL & *yik & yik & ike & yik & ike & $i^{\prime} e$ & $* \mathrm{ik}$ & $i$ & ikie & $y i$ \\
\hline *nik 2PL & *nik & nik & ningge & $n i k$ & ninge & $n i^{\prime} e$ & *nik & $n i$ & $n i^{\prime}$ & $n i$ \\
\hline *wik 3PL & *wuk & wuk & on & wuk & (mande) & wo & $*_{\text {wik }}$ & $w i$ & $w i^{\prime}$ & $w i$ \\
\hline
\end{tabular}

Table 9.4b shows the Tibor past tense markers, along side the Mauwake past tense markers (not enough is known about Bepour and Moere to include them). The Mauwake past tense markers begin with $e$, or $a$, depending on the class of verb they are suffixed on (see Chapter 3 ). The correspondences between the final consonants of the Proto-Tibor past tense markers and the Mauwake past tense endings are regular, with two exceptions. First, the correspondence with between Proto-Tibor final $*_{\mathrm{t}}$ and Mauwake final $k$ in the 3SG.PST forms is not regular. However, from other Northern Adelbert languages, it is clear that the $3 \mathrm{SG}$ past tense marker was *-Vd. It is likely that *-Vd was found in Proto-Kumil-Tibor as well, and that it devoiced to $t$ in Proto-Tibor.

The second set marker which does not correspond is the 1PL.PST, since Mauwake 3PL -(e/a)mik extended to cover the 1PL as well. 
Table 9.4b: Proto-Kumil-Tibor subject/past tense markers

\begin{tabular}{|c|c|c|c|c|c|c|c|}
\hline PKT & Proto-Tibor & Mok. (Wan) & Mok. (Tin) & Pam. & HA & Kow. & Mau. \\
\hline *-Vm & $\begin{array}{l}* \text {-em } \\
\text { 1SG.PST }\end{array}$ & $-e m$ & -om & -om & $-e m$ & -om & $-(e / a) m$ \\
\hline$*_{-} \mathrm{Vn}$ & $\begin{array}{l}* \text {-en } \\
\text { 2SG.PST }\end{array}$ & $-e n$ & $-e n$ & -on & $-e n$ & -uan & $-(e / a) n$ \\
\hline *-Vd & $\begin{array}{l}* \text {-et } \\
\text { 3SG.PST }\end{array}$ & $-e t$ & $-e t$ & -ot '3.PST' & & $-e t$ & $-(e / a) k$ \\
\hline-- & $\begin{array}{l}\text { *-emin } \\
\text { 1PL.PST }\end{array}$ & -eming & $\begin{array}{l}(-e m i k) \\
\text { (PST/HOD) }\end{array}$ & $\begin{array}{l}\text { (-eming) } \\
\text { (PST/HOD) }\end{array}$ & -emin & -emin & -(e/a)mik \\
\hline *-Vman & $\begin{array}{l}* \text {-eman } \\
\text { 2PL.PST }\end{array}$ & $\begin{array}{l}(- \text { omang) } \\
\text { (PST/HOD) }\end{array}$ & $\begin{array}{l}(-o m a k) \\
(\mathrm{PST} / \mathrm{HOD})\end{array}$ & $\begin{array}{l}(- \text { omong }) \\
\text { (PST/HOD) }\end{array}$ & -eman & -eman & $-(e / a) m a n$ \\
\hline *-Vmid & $\begin{array}{l}\text { *-emid } \\
\text { 3PL.PST }\end{array}$ & -emind & $\begin{array}{l}\text {-emit } \\
\text { (PST/HOD) }\end{array}$ & $\left(-o t^{\prime} 3 . \mathrm{PST}^{\prime}\right)$ & -emin & $(-e t)$ & -(e/a)mik \\
\hline
\end{tabular}

There are no obvious cognates between the Tibor hodiernal markers and the Mauwake present tense endings. First, hodiernal tense is not exactly the equivalent of Mauwake present tense. Second the Mauwake forms are more clearly segmentable into a subject marker and a present tense marker $-i$. This is clearest in the plurals, since the subject markers are the same as those for the past tense. In Proto-Tibor, some languages form the hodiernal through the addition of reflexes of $* \mathrm{k}$ to the beginning of the past tense stem However, this is now fossilized in all languages, and the Tibor endings are not segmentable into separate subject-marking and tense-marking morphemes.

Proto-Tibor 2SG.HOD *-ik and Mauwake 2SG - $i-n$ do not correspond, and it is not possible to reconstruct the plural endings either. For the $1 \mathrm{SG}$ present/hodieranl, I reconstruct Proto-Kumil-Tibor *ikem, which has fairly regular reflexes in all the languages. From Proto-Tibor *a/ek and Mauwake $-y a$, it is possible to reconstruct Proto-Kumil-Tibor 3SG *-Vk. At first glance Proto-Tibor 3SG.HOD *-a/ek would appear to be cognate with Mauwake 3SG.PST -(e/a)k instead. However, although these forms are identical, including the vowel alternation, they do not fit the regular sound correspondences. 
Table 9.2.8c: Proto-Tibor subject/hodiernal tense markers

\begin{tabular}{|c|c|c|c|c|c|c|c|}
\hline PKT & Proto-Tibor & Mok. (Wan) & Mok. (Tin) & Pam. & HA & Kow. & Mau. \\
\hline *-ikem & $\begin{array}{l}\text { *-ekem } \\
1 \mathrm{SG} . H O D\end{array}$ & -ehem & $-e m$ & -hom & -ekem & -ehem & $-i$-yem \\
\hline-- & $\begin{array}{l}* \text {-ik } \\
\text { 2SG.HOD }\end{array}$ & $-i k$ & $-i k$ & $-i k$ & $-i k$ & $-i^{\prime}$ & $-i-n$ \\
\hline *-Vk & $\begin{array}{l}* \text {-ak/-ek } \\
\text { 3SG.HOD }\end{array}$ & $-a k /-o k$ & $-e k /-a k /-a u k$ & -ok/-ek/-ak & $/-e k /-a k$ & $-e^{\prime},-a^{\prime}$ & $-i-y a$ \\
\hline-- & $\begin{array}{l}* \text {-emig } \\
\text { 1PL.HOD }\end{array}$ & -ehing & $\begin{array}{l}\text {-emik } \\
\text { (PST/HOD) }\end{array}$ & $\begin{array}{l}\text {-eming } \\
\text { (PST/HOD) }\end{array}$ & -ekemin & -emi' & $-i-m i k$ \\
\hline-- & $\begin{array}{l}\text { *-emag } \\
\text { 2PL.HOD }\end{array}$ & $\begin{array}{l}\text {-omang } \\
\text { (PST/HOD) }\end{array}$ & $\begin{array}{l}\text {-omak } \\
\text { (PST/HOD) }\end{array}$ & -omong & -ekoman & $-e m a^{\prime}$ & $-i-m a n$ \\
\hline-- & 3PL.HOD & -ehind & $\begin{array}{l}(-e m i t) \\
(\mathrm{PST} / \mathrm{HOD})\end{array}$ & -ok/-ek/-ak & -ekemin & $\left(-e^{\prime},-a^{\prime}\right)$ & $-i-m i k$ \\
\hline
\end{tabular}

\section{Prot Kumil-Tibor reconstructed vocabulary}

Below I list the reconstructed Proto-Kumil-Tibor vocabulary. The supporting cognate sets for reconstructions that date to PNA are found in Chapter 7.

*aden 'true, real, right'

Tibor *ade

Mok: ate

Pam: ate

HA: ende

Maw: ate

Kow: ate

\section{Kumil}

Mau: akena

This is possibly cognate with Gavak areng 'true', which would suggest PNA *aden. However, final $*$ y usually deleted in Mauwake, whereas final *n was retained.

*ag- 'to see' (<PNA *ag-)

*ar- 'become' (<PNA *ar-)

*arek 'trunk, piece' (< PNA *arek)

*ari 'later' (< PNA *ari)

*ariwak 'arrow'

*aw- 'to do, get, take' (see PNA *aw-)

*awurun 'always'

Tibor *awurun

Mok: owurun 
Pam: avulun

HA: awurun

Kow: awurun'a

Kumil *awurun

Bep: awurun

Mau: aawurun

$*_{a}>0$ in Mokati unexplained. Kowaki has suffixed unknown element.

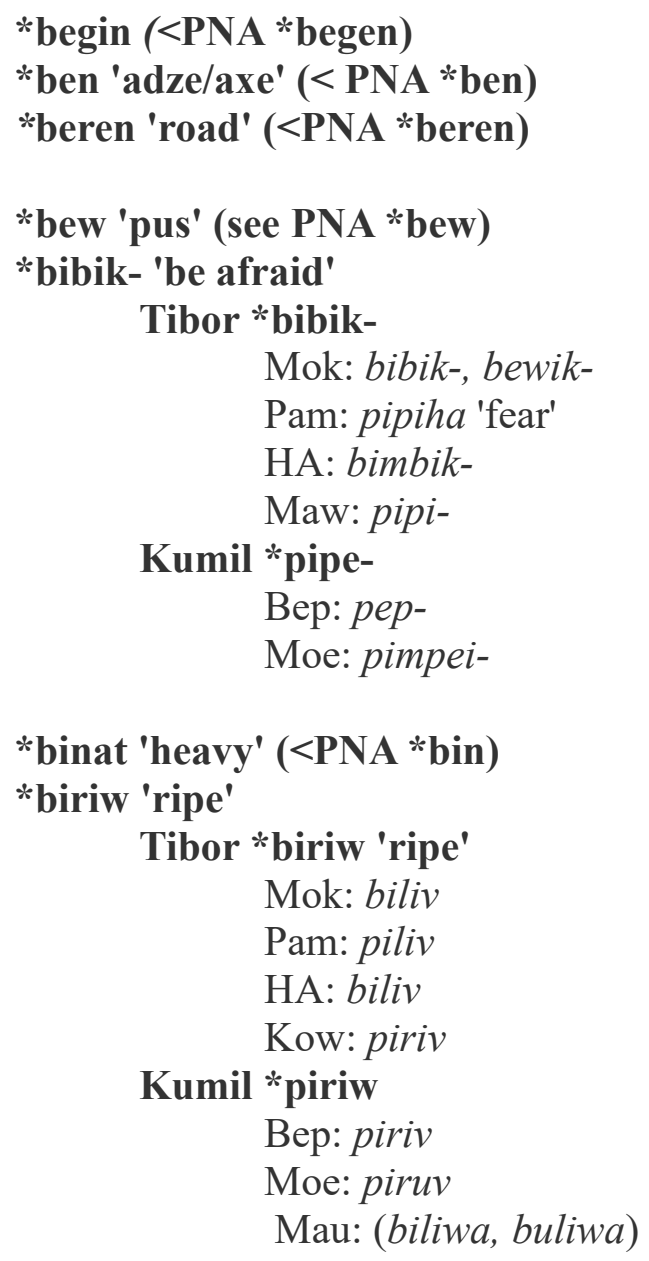

Mauwake terms are borrowings, as voiced stops are not found in directly inherited Mauwake words.

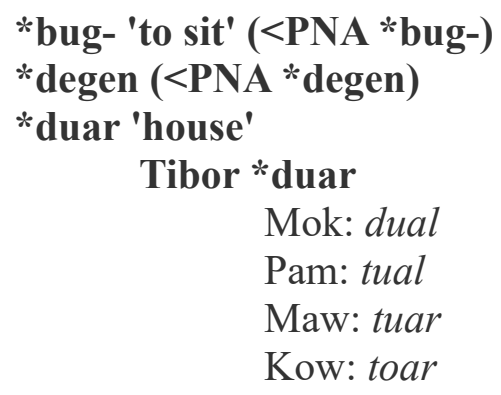




\section{Kumil *gor}

Moe: $k o r$

Mau: koora

This may be related to Proto-Kaukombar *dawa.

*eba 'net bag (< PNA *eba)

* ebak 'underneath

Kow: empa'

Bep: $е p a^{\prime}$

*egi

Tibor *egi

HA: enggi

Kow: ' $e$ 'i, $e^{\prime} i$

Kumil *egi 'banana'

Bep: $e^{\prime} i$

Moe: $n k g i$

Mau: akia

See also Proto-Tibor *ena 'banana'

*eg- 'to see' (see PNA *ag-)

*emawe 'namesake'

Pam: emawe

Mau: -mawa

*en-, *enim- 'to eat' (see PNA *an-)

*ereb- 'come down'

Tibor *orob- 'descend'

Mok: lev- 'come down'

PAM: olop- 'come down'

HA: olomb- 'go down'

Maw: orop- 'go down'

Kumil *erep- 'fall, drop'

Bep: erep-

Moe: erp-

Mau: (orowow-)

Mauwake **orop-. PKT *ereb- resembles Manep-Barem *arub- 'fall', but the vowels aren't cognate.

*ereke 'road' (<PNA *arake)

*fa, *ape *fa, 'left'

Tibor *faya, *ape *faya

Mok: ape faya 


$$
\begin{aligned}
& \text { Pam: ape faiya } \\
& \text { HA: faya } \\
& \text { Maw: feya } \\
& \text { Kow: faya } \\
& \text { Kumil }
\end{aligned}
$$

Bep: $f a$

Moe: ampe fa

*ape *fa is 'hand+left'.

*gagi 'cassowary'

Tibor *gagi

HA: kaki

Maw: kaki

Kow: ' $a$ 'i

Kumil *gaki

Bep: 'ahi

Moe: kaki

Mau: kiiya

*ganua 'fern type' (edible)

Tibor

HA: ganeng ganua

Kumil

Mau: kanua

*gema 'liver' (<PNA *geman)

*giri 'turn' (<PNA *girik-)

*g(a/e)mug 'string'

Tibor

Pam: kamung

Kumil

Mau: kemuka

*gogor 'gorge, valley'

Tibor

Kumil

Pam: fa kokol 'valley'

Mau: kokora 'ravine, gorge'

According to Tupper (2012: 194) kokol also has the extended metaphorical meaning of 'space between conversation partners'. Berghäll's Mauwake dictionary does not list a similar meaning for kokora, but does have an entry kokoreriya (root: kokorer-) which means 'to become stuck in a narrow place' which may be derived from the addition of *ar- 'become'. PKT *gogor may therefore also have had an extended meaning of 'space between'. 
*gub 'plant shoot'

Tibor

Pam: kupu 'shoot, any protrusion'

Kumil

Mau: kupa 'seedling'

*guf 'thigh'

Tibor *gufu

Mok: gu, anenggu

Pam: guvu, anenguvu

HA: humba nanggovu

Maw: nggubu

Kow: hupan'uvu

Kumil *gufa

Bep: uf enem

Moe: kuwere'

Mau: kufa

Mokati and Pamosu have compounds with reflexes of Proto-Tibor *ane 'leg' as the first element. Hember Avu and Kowaki include reflexes of *kupa 'leg', and reflexes of *ane as well. Bepour is a compound with enem < PNA *kanam 'base, source' as the second element. Moere is a compound with are $^{\prime}<$ PNA *arek 'trunk, piece' as the second element.

*ib 'feces' (< PNA *ib)

*iben 'vagina' (< PNA *iben)

*idiw- 'go' (PNA *iduw-)

*ifa 'snake'

Tibor

Maw: iwa

Kumil

Bep: ifa

Moe: iwua

Mau: ifa

*ifer 'salt, ocean' (< PNA *iper)

*ifif 'dry, dry coconut'

Tibor *ifif

Mok: $y i$

Pam: iviv

Maw: iwib

Kow: iwib

Kumil *ifif

Bep: ifiw

Moe: iwiw

Mau: ififa 
*ig- 'to be' (<PNA *ig-)

*iguar 'penis'(<PNA *iguar)

*igum- 'burn, cook' (<PNA *igum-)

*igum 'theft'

Tibor

Pam: ikum ela 'steal', mande ikum 'thief'

Kumil

Mau: ikuma 'theft', ikum 'illicitly', ikum aaw-. steal, ikumar-'steal'

*igum *ar- 'steal'

Tibor

Pam: ikum ela 'steal'

Kumil

Mau: ikumar-'steal'

*imena *ar- 'appear'

Tibor

Pam: imena el-

Kumil:

Mau: imenar-

*in- 'sleep' (<PNA *in-)

*ir- 'go up' (<PNA *ir-)

$*$ irin 'all' (< PNA *irin)

*irub- 'come up' (< PNA *irub-)

*kafil 'fat, grease' (<PNA *kapil)

*k(a/o)guwa 'knot'

Tibor

Pam: ongguv

Kumil

Mau: akuwa

This reconstruction may not be valid, as the vowels in the first syllable don't correspond.

*kam 'sun, day'(<PNA *kam)

*kamun 'pan' (<PNA *kamun)

*karim- 'swell' (<PNA *karim-)

*kebar 'mouth' (<PNA *kebuar)

*ked 'blood' (<PNA *ked)

*kedat 'red' (<PNA *ked-at)

*kefak 'flying fox' (<PNA *kepak)

*kelew 'tail'

Tibor *kerew

Mok: kele

Pam: elev

HA: helep

Maw: erep

Kow: hereb 


\section{Kumil *erew}

Bep: erew

Mau: alewa

*kenag 'tooth' (<PNA*-nag, *nenag)

*kenam 'base' (< PNA *kenam)

*kenag 'tooth'

*kubuk 'bird's nest fern'

Tibor

Pam: umbuk

Kumil

Mau: ириа

Prenasalization in Pamosu indicates an initial *k. If the PKT form were *ubuk then the expected Pamosu reflex would be upuk.

*kuma 'banana bunch'

Tibor *kuma

Mok: kuma

Pam: uma

\section{Kumil}

Mau: uma

*kumag 'testicles' (<PNA *kumag)

*kurum 'valley' (< PNA *kurum)

*ol 'thin'

Tibor

Pam: olol

Kumil

Mau: ola

It is not uncommon in Pamosu for words for qualities to be reduplications, with no equivalent unreduplicated base, as in emem 'sourness' okok 'state of being cold' (Tupper 2012: 197). This is seen also in Proto-Tibor *fivi 'bad' (Pamosu fivi), from reduplicated PNA *pi.

$*_{\text {-omad (distributive suffix) }}$

Tibor

Pam: -omand

Kumil

Mau: -omak

\section{*ma 'small flying insect'}

Tibor

Mok: mambusen 'mosquito', misisimur, mususumur 'sunfly', masen 'mosquito' 
Pam: masisimul 'sunfly', masen 'mosquito' mangol ongol 'stalk-eyed fly' mayakipu 'fly sp.', mambupu 'butterfly'

HA: mambusen 'mosquito', masen 'mosquito' mafifur 'fly sp.'

Maw: masen 'mosquito'

Kow: masen 'mosquito', mapupu 'butterfly'

\section{Kumil}

Bep: mu'uru 'fly'

Moe: masen 'mosquito', mukuru 'fly'

Mau: maa samora 'mosquito'

Reflexes of PKT *ma are found in the names of several small flying insects, especially in the Tibor languages. Nasalization of *b in Mokati and Hember Avu mambusen 'mosquito' and Pamosu mambuрu 'butterfly' indicates that $m a$ - is a separate morpheme in this words, which triggers nasalization on the stop (see Chapter 3 for an explanation of nasal spreading in Tibor languages).

Reflexes of *ma are not as apparent in the Kumil languages. It is probably seen in Moere masen 'mosquito', since the corresponding Bepour form is simply sen. Bepour mu'uru and Moere mukuru 'fly' probaby reflect *ma plus *kuduruk 'fly'.

*made 'person' (<PNA *maden)

*me NEG (<PNA *me)

*mekiw 'land, ground' (<PNA (mekiw)

*men 'breast' (<PNA *men)

*megam 'star, year' (<PNA *megam)

*megem 'woman'

Tibor *made *megem

HA: mande menggem

Kow: mande me'em

Kumil *megem

Bep: $m e^{\prime} e m$

Moe: mengkem

*merew NEG

Tibor

HA: melep

Kumil *merew

Bep: merev

Moe: merev

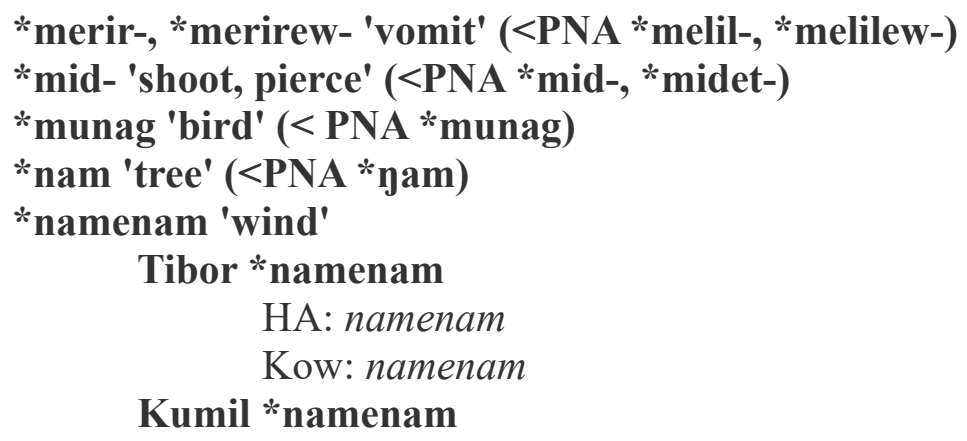


Bep: namnam

Moe: namenam

*nawiak 'tongue'

Tibor *nawiak

HA: nawiak

Maw: nawiak

Kow: nawia'

Kumil *nawe'

Moe: nawe'

*sarem 'pandanus'

Tibor 'pandanus'

HA: sarem

Kow: sarem

Kumil

Bep: sarem

Moe: serem

Mau: (sarema) 'grass'

The expected Moere reflex is **sarem. Mauwake sarema 'grass' is similar in form, but the meaning is different.

*selew 'sand, shore' (<PNA *selew)

*sen 'mosquito', *ma-sen

Tibor

Mok: masen

Pam: masen

HA: masen

Maw: masen

Kow: masen

Kumil

Bep: sen

Moe: masen

In every language but Bepour, *sen has combined with *ma 'small flying insect'. It is not clear if Bepour sen is an independent word, but we would expect addition of final $-a$ if it is.

*susur 'ant sp.' (< PNA *tutur)

*tabir 'plate' (<PNA *tabir)

*tebik 'rain' (<PNA*t(e/i)bik)

*ub- 'to plant' (<PNA *ub-)

*ubin 'mountain'

Tibor *ka upin

Mok: kambin 


\section{HA: hambin \\ Kow: haupin \\ Kumil}

\section{Bep: upin}

Tibor is a compound with *ka 'place'.

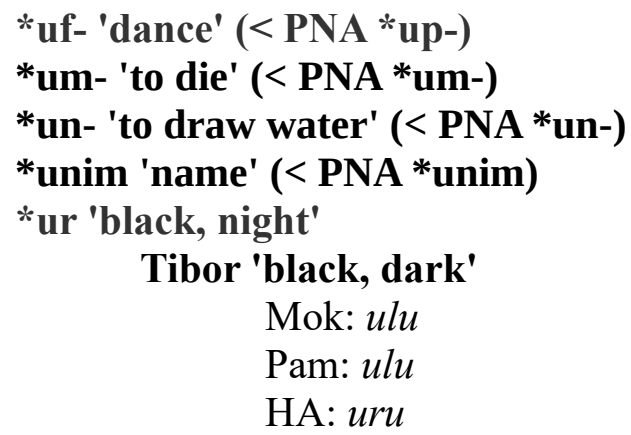




\section{Proto-Numugen}

In this Chapter, I outline sound correspondences between the Numugen languages, and reconstruct Proto-Numugen phonemes and lexical items. I also discuss the sound changes that took place in Proto-Numugen relative to Proto-Northern Adelbert, and later in individual Numugen languages.

As noted in Chapter 5, there are some indications of a closer relationship between Usan, Yaben, and Karian, on one hand, and Parawen, Ukuriguma, and Yarawata, on the other. Usan, Yaben, and Karian share the innovation of $* \mathrm{k}>s_{-} \mathrm{i}$, and Ukurgiuma, and Yarawata all share the loss of final ${ }^{*} \mathrm{w} .{ }^{122}$ Additionally, there are numerous word sets which have cognates only in one group or the other. Cognates shared exlusively between Parawen, Ukuriguma, and Yarawata may be due to close contact rather than shared inheritance, since their territories are contiguous. This explanation is less applicable to Karian, Usan and Yaben, since Karian territory is not near Usan and Yaben. Although Karian, Usan, and Yaben may be more closely related, the number of exclusively shared cognates could also be due to the fact that these three language have the most lexical data available. Cognates shared only by these three languages could very well be found in other Numugen languages as well, but are not found in Z'graggen's wordlists. For the purposes of reconstruction, I treat a comparison of any two Numugen languages as reflecting Proto-Numugen, so that a reconstruction based on Usan and Karian, for example, is reconstructed to Proto-Numugen, not Proto-Usan-Karian-Yaben.

122 A possible exception is the Yarawata reflex of *niaw 'egg, breast', which Z'graggen records as nia for 'egg' and niaw for 'breast'. 


\subsection{Proto-Numugen phonemes}

Tables 10.1a-b show the reconstructed Proto-Numugen phonemes. Proto-Numugen is the only branch of PNA which retains the four-vowel system found in PNA, although the vowel systems of the individual languages all underwent further changes which depart from this. Proto-Numugen $*_{\mathrm{s}}$ and $*_{\mathrm{t}}$ are in complementary distribution, and can be considered as belonging to the same proto-phoneme.

Table 10.1a: Proto-Numugen vowel phonemes

\begin{tabular}{|l|c|c|}
\hline & front & back \\
\hline high & $*_{\mathrm{i}}$ & $*_{\mathrm{u}}$ \\
\hline mid & $*_{\mathrm{e}}$ & \\
\hline lwo & & $*_{\mathrm{a}}$ \\
\hline
\end{tabular}

Table 10.1b: Proto-Numugen consonant phonemes

\begin{tabular}{|l|c|c|l|l|}
\hline & labial & alveolar & palatal & velar \\
\hline stop & ${ }^{\mathrm{b}}$ & ${ }^{*} \mathrm{~d},{ }_{\mathrm{t}}$ & & ${ }^{*} \mathrm{k},{ }^{*} \mathrm{~g}$ \\
\hline nasal & ${ }^{*} \mathrm{~m}$ & ${ }_{\mathrm{n}}$ & & \\
\hline liquid & & ${ }^{*} \mathrm{r}$ & & \\
\hline glide & ${ }^{*} \mathrm{~W}$ & & $*_{\mathrm{y}}$ & \\
\hline
\end{tabular}

\section{Numugen sound correspondences}

Tables 10.1c-f illustrate the sound correspondences used to reconstruct Proto-Numugen phonemes.

Table 10.1c: Numugen vowel correspondences

\begin{tabular}{|c|c|c|c|c|c|c|c|}
\hline $\begin{array}{l}\text { Proto- } \\
\text { Num. }\end{array}$ & environment & Yab & Usan & Kar. & Par. & Uku. & Yar. \\
\hline$*_{\mathrm{i}}$ & & $i$ & $i$ & $i$ & $i$ & $i$ & $i$ \\
\hline$* \mathrm{u}$ & & $u$ & $u$ & $u$ & $u$ & $u$ & $u$ \\
\hline \multirow[t]{3}{*}{$*_{\mathrm{e}}$} & & $a$ & $e$ & $a$ & $a$ & $o$ & $a$ \\
\hline & [+labial]_ & $a$ & $o$ & $a$ & $a$ & $o$ & $a$ \\
\hline & _\# & $\partial$ & $e$ & $\partial$ & $a$ & $o$ & $a$ \\
\hline \multirow[t]{2}{*}{$* a$} & & $a$ & $a$ & $a$ & $a$ & $a$ & $a$ \\
\hline & - $\mathrm{C \#}$ & $a$ & $a, \hat{a}$ & $a$, ə & $a$ & $a$ & $a$ \\
\hline
\end{tabular}


Table 10.1d: Numugen glide correspondences

\begin{tabular}{|l|l|l|l|l|l|l|}
\hline $\begin{array}{l}\text { Proto- } \\
\text { Num. }\end{array}$ & Yab & Usan & Kar. & Par. & Uku. & Yar. \\
\hline$*_{\mathrm{W}}$ & $w$ & $w$ & $w$ & $w$ & $w$ & $w$ \\
\hline$*_{\mathrm{y}}$ & $y$ & $y$ & $y$ & $y$ & $y$ & $y$ \\
\hline
\end{tabular}

In Proto-Numugen reconstructions, $*$ t and $*_{s}$ are in complementary distribution, with $*_{s}$ found adjacent to $* \mathrm{i}$, and $*$ t elsewhere.

Table 10.1e: Numugen obstruent correspondences

\begin{tabular}{|c|c|c|c|c|c|c|c|}
\hline Proto-Num. & environment & Yab & Usan & Kar. & Par. & Uku. & Yar. \\
\hline \multirow[t]{2}{*}{ *b } & & $b \sim p$ & $b$ & $b$ & $b$ & $b$ & $b$ \\
\hline & V_V & $b$ & $b$ & $w$ & $b$ & $b$ & $b$ \\
\hline \multirow[t]{3}{*}{$* d$} & & $d$ & $d$ & $d$ & $d$ & $d$ & $d$ \\
\hline & ${ }_{-}^{\mathrm{i}}$ & $j$ & $r$ & $j$ & $d \sim r$ & $d$ & $d$ \\
\hline & $\mathrm{V}_{-}$ & $d$ & $r$ & $r$ & $d \sim r$ & $d$ & $d$ \\
\hline$*_{\mathrm{t}}$ & & $t$ & $t$ & $t$ & $t$ & $t$ & $t$ \\
\hline$*_{\mathrm{s}}$ & ${ }_{-} \mathrm{i}, \mathrm{i}_{-}$ & $s$ & $s$ & $s$ & $s$ & $s$ & $s$ \\
\hline \multirow[t]{2}{*}{$* g$} & & $\mathrm{~g}$ & $\mathrm{~g}$ & $g$ & $g$ & $g$ & $g$ \\
\hline & -\# & $\varnothing$ & $\varnothing$ & $g \sim k$ & $\varnothing$ & $\mathrm{g}$ & $\varnothing$ \\
\hline \multirow[t]{3}{*}{$* \mathrm{k}$} & & $k \sim ?$ & $P \sim \varnothing$ & $k \sim ?$ & $k$ & $k$ & $k$ \\
\hline & _i & $s$ & $s$ & $s$ & $k$ & $k$ & $k$ \\
\hline & _\# & $\varnothing$ & $\varnothing$ & $\varnothing$ & $\varnothing$ & $k$ & $\varnothing$ \\
\hline
\end{tabular}

Table 10.1f: Numugen nasal and liquid correspondences

\begin{tabular}{|l|l|l|l|l|l|l|}
\hline${ }^{*} \mathrm{~m}$ & $m$ & $m$ & $m$ & $m$ & $m$ & $m$ \\
\hline${ }^{\mathrm{n}}$ & $n$ & $n$ & $n, n y$ & $n$ & $n$ & $n$ \\
\hline${ }^{\mathrm{r}}$ & $l$ & $r$ & $r \sim l$ & $l$ & $r$ & $l$ \\
\hline
\end{tabular}

\subsection{Proto-Numugen innovations}

In this section, I outline the changes which took place in Proto-Numugen relative to Proto-

Northern Adelbert. The Numugen languages share four ${ }^{123}$ changes:

123 A probable fifth change is the merger of PNA *r and *l. All Numugen languages only have one liquid in their phoneme inventories, and it's realization varies as $r \sim l$. However, the only PNA reconstruction with *l that has reflexes in 
1) $* \mathrm{y}>\mathrm{n}$

2) $* p>\varnothing / \#$

3) ${ }^{*} \mathrm{p}>\mathrm{w} / \mathrm{V}-\mathrm{V}$

4) $*_{\mathrm{s}}>\varnothing$

$* \mathbf{y}>*_{\mathbf{n}}$

PNA *guay 'skin' and *kumay 'nape' reconstructions with final *y show have widespread reflexes in the Numugen languages, which show that $*_{\eta}$ merged with $*_{n}$ in Numugen. Isolated Ukuriguma and Usan reflexes of other PNA reconstructions also show this merger.

Table 10.2a: Numugen word sets with reflexes of PNA $* \eta$

\begin{tabular}{|c|c|c|c|c|c|c|c|}
\hline PNA & Proto-Num. & Yab. & Usan & Kar. Boia & Par. & Uku. & Yar. \\
\hline *guay 'skin' & *guan & gwanu & goan & guәn & goana & guan & guana \\
\hline *kumay 'nape' & *kuman & 'umanu & uman & kuman & kumana & kumanggot & kumana \\
\hline *madey 'man' & -- & -- & -- & -- & -- & madon & -- \\
\hline *muy 'husband' & -- & -- & -- & -- & -- & mun & -- \\
\hline *main 'weak' & -- & - & mein & -- & -- & -- & -- \\
\hline
\end{tabular}

$* \mathbf{p}>\varnothing / \#$

There are few Proto-Numugen words with reflex of PNA initial *p. However, they all show that it $* \mathrm{p}$ - deleted in all Numugen languages, as illustrated in Table 10.2b.

Table 10.2b: Deletion of PNA initial *p in Numugen

\begin{tabular}{|l|l|l|l|l|l|l|l|}
\hline PNA & Proto-Num. & Yab. & Usan & Kar. Boia & Par. & Uku. & Yar. \\
\hline *par- 'call' & *ar- & al- & ar- & al- & -- & ar- & ar- \\
\hline *perem 'floor' & *erem & -- & orom & alam & -- & -- & -- \\
\hline *piruw 'hole' & -- & -- & -- & ilu & -- & -- & -- \\
\hline
\end{tabular}

${ }^{*} \mathbf{p}>{ }^{*} \mathbf{w} / \mathbf{V}_{-} \mathbf{V}$

Intervocalically, PNA *p merged with $*_{\mathrm{w}}$ as Proto-Numugen ${ }^{\mathrm{w}}$.

Table 10.2c: Deletion of PNA initial *p in Numugen

\begin{tabular}{|l|l|l|l|l|l|l|l|}
\hline PNA & Proto-Num. & Yab. & Usan & Kar. Boia & Par. & Uku. & Yar. \\
\hline *iper 'salt, ocean' & *iwer & iwalu & -- & yuar & iwara & iwol & iwala \\
\hline *up- 'dance' & *uw & uya- & -- & uy- & -- & uw- & w- \\
\hline
\end{tabular}

Numugen languages is *selew 'sand'. These liquids in these reflexes have the same correspondence as for *r. 
$* \mathbf{s}>\varnothing$

Only two PNA reconstructions with *s have reflexes in Numugen languages, but these indicate that $*$ s deleted in Proto-Numugen.

Table 10.2d: Deletion of PNA *s

\begin{tabular}{|l|l|l|l|l|l|l|l|}
\hline PNA & Proto-Num. & Yab. & Usan & Kar. Boia & Par. & Uku. & Yar. \\
\hline *selew 'sand' & *elew & alo & oro sow $w^{124}$ & araw & arorowa & ole & alowa \\
\hline *kasin & *kain & -- & -- & -- & kaina & -- & kaina \\
'mosquito' & & & & & & & \\
\hline
\end{tabular}

\subsection{Sound changes in Usan}

$* \mathbf{k}>\mathbf{P} / \#$

Proto-Numugen $* \mathrm{k}$ has become a glottal stop $(<\mathrm{q}>$ in Usan orthography) word-initially, as in

*kwedi 'banana'> qori, *kuda 'belly' > qur, and, *kemi 'bow'> qemi.

$* \mathbf{k}>\varnothing / \mathbf{V}_{-}$

*k deleted in non-initial position, as in *ikaw 'dog' > iau, and *dukun 'cough' tuun, and *gutuk 'vagina' > kut.

$* \mathbf{k}>\mathbf{s} / \mathbf{i}$

*k became $s$ before a high front vowel, as in *kibem 'hand drum' > sibem, and *kikwa 'chop' > $S u-.{ }^{125}$

124 The meaning of the element sow in Usan oro sow is not known.

125 su- 'chop' also entail a subsequent change of $* \mathrm{i}>u$, also seen in Yaben and Karian. 
$* \mathrm{~g}>\varnothing / \#$

Final *g deleted, as in *nanag 'tooth' > nân, and *ikamag 'sore' > iâm 'wound'.

$* \mathbf{d}>\boldsymbol{r} / \mathbf{V}_{-}$

*d lenited to $r$ after a vowel, as in Proto-Numugen *kuduruk 'fly' > urur, *kudag 'fruit' > qur, and *kugud 'shadow' $>$ ugur. Since *r is not found word-initially, the result of this change is that $* \mathrm{~d}$ and $* \mathrm{r}$ are now in complementary distribution, with $d$ word-initially, and $r$ post-vocalically. This has resulted in a merger of $* \mathrm{~d}$ and $* \mathrm{r}$ as $/ \mathrm{d} /$.

$* \mathbf{d}>n d / \mathbf{N V}_{-}$

A possible exception to the change of $* \mathrm{~d}>\mathrm{r}$ is that in some word sets, $* \mathrm{~d}$, as well as $*$ r, appears to have become prenasalized $n d$ when the preceding consonant was a nasal, as in *merir- 'vomit' > mendir-, *mudiram 'vein' > mindirom, and *madilam 'neck' > mindiram. However, *r is reflected as $r$, not $n d$, in *maragwan > morogoan 'bird'.

$* \mathbf{e}>\boldsymbol{o}, * \mathbf{a}>\boldsymbol{o}$

Proto-Numugen *e and *a have rounded to $o$ in some words, for example, *memer 'cordyline' > momor, *igem 'green, new' > igom, and *kagam 'smell' > qogom. Although this rounding always occurs in the environment of a labial consonant, it is not clear if it is sporadic, or triggered by a particular condition, as *a and *e have not rounded in similar words, such as *kemi 'bow' $>$ qemi, and *mamur 'frog' > mamur. 


\section{Final vowel deletion}

Word-final *u and *a deleted, as in Proto-Numugen *ununu 'dirty' > unun, *barima 'tomorrow' $>$ barim, and *kuda 'belly' > qur. Word-final *i did not delete: *ibi 'feces' > ibi, and *tadi 'head' > tari.

Word-final ${ }^{*} \mathrm{e}$ is only found in some pronouns and other function words. It did not delete in Usan pronouns, such as *ye ' $1 \mathrm{SG}$ ' > ye $y \hat{a}$, but did in the locative adposition *te, which became an affix $-t$.

\section{Development of $\hat{a}$}

It is not clear how Usan developed $\hat{a}$. In some cases, it seems to have developed from wordfinal *e as in the pronouns *ye ' $1 \mathrm{SG}$ ' $>y e \sim y \hat{a}$, and *ne '2SG' > ne $n \hat{a}$, or from *e which became word final in Usan, as in *imek 'younger brother' > imâ. In other cases, it has developed from *a in a closed syllable, as in *nanag 'tooth' > nân and *ikamag 'sore' > iâm 'wound'. However, *a is reflected as $a$ in closed syllables in other words, such as *ginam 'village' > ginam. Stress, which is phonemic in Usan, may play a role, and this possibility warrants further investigation.

\section{Relative chronology of Usan sound changes}

Deletion of final $* \mathrm{k}$ and $* \mathrm{~g}$ feed final vowel deletion. This is clear because words with final ${ }^{*} \mathrm{k}$ and $*_{\mathrm{g}}$ deleted the previous vowel as well (unless it was $* \mathrm{i}$, which didn't delete word finally). This is illustrated in Table 10.3a.

Table 10.3a: relative chronology of Usan sound changes

\begin{tabular}{|l|l|l|l|l|l|}
\hline & $*_{\text {gutuk }}$ & $*$ buruk & $*_{\text {nanag }}$ & $*_{\text {ikamag }}$ & *kuduruk \\
\hline $\begin{array}{l}* \mathrm{k}>\varnothing / \mathrm{V} \\
* \mathrm{~g}>\varnothing / \ldots\end{array}$ & gutu & buru & nana & iama & uduru \\
\hline$* \mathrm{~V}>$ /_\# & gut & bur & nan & iam & udur \\
\hline & gut & bur & nân & iâm & urur \\
\hline
\end{tabular}




\subsection{Sound changes in Karian}

$* \mathbf{k}>\varnothing / \#$

Word-final *k deleted, as in *kuduruk 'fly' > Boia kururu, Barto ururu, *buruk 'pig' > buru, and * gutuk 'vagina' > gutu.

$* \mathbf{k}>s_{-} \mathbf{i}$

As in Usan, *k became $s$ before $* \mathrm{i}$, as in *kibem 'hand drum' > sivam, and *kikwa- 'chop' > sukwa.

$* \mathrm{~g}>\boldsymbol{k} /$ \# (Barto)

Word-final *g devoiced to $k$ in the Barto dialect, as in *duag 'snake' > Barto: $d u ə k$, and *yag 'water' > Barto: yuək. Voicing was retained in the Boia dialect (duəg 'snake', yuəg 'water')

$* \mathbf{d}>\boldsymbol{r} / \mathbf{V}_{-}$

Proto-Numugen *d became $r$ after a vowel, as in *ked 'blood' $>$ kar and *kuduruk 'fly' > Boia kururu, Barto ururu. Since *r is not found word-finally, the result is that $* \mathrm{~d}$ and $*_{\mathrm{r}}$ have merged in nearly every environment. The exception is before $* \mathrm{i}$, where $* \mathrm{~d}$ is became $j$, as in *kuadi 'banana' > Boia kwaji, and *r is reflected as $r$, as in *karim- 'swell' > Boia karim-.

$* \mathbf{e}>\boldsymbol{a}{ }_{-}+$

Proto-Numugen $*$ e became a morpheme-finally. Final $*$ e occurs only in pronouns in other function words. This applied in the independent pronouns *ye '1SG'> yə, *ne '2SG' > nə, and *we 
'3SG' > wə, as well as the object marking prefixes *ye- '1SG.OBJ" > yə and *ne- '2SG.OBJ' > nə-. It also applied in the locative $*_{\text {te }}>$ to and negator $*$ me $>$ ma.

$* \mathrm{e}>$ al_C

Non-final *e became $a$, as in Proto-Numugen *kemi $>$ kami, *uben $>$ uvan, and *ked 'blood' > kar. An exception to this rule is the 3PL pronoun war $<*$ wer, which irregularly has a schwa, developed on analogy with the other pronouns.

$* a>$ ol_C.

Proto-Numugen *a became $ə$ in closed syllables, as in *ginam 'village' $>$ ginəm and *kudag 'fruit' > Barto 'urək. In monosyllabes, *a is sometimes reflected as a diphthong uə, such as *nam 'tree' $>$ nuəm, and *yag 'water' > yuəg.

\section{Relative chronology of Karian sound changes}

In the Barto dialect, which underwent devoicing of final $* \mathrm{~g}$, this happened after the deletion of final $* \mathrm{k}$. $*_{\mathrm{g}}$ devoicing must have been complete by the time $* \mathrm{k}$ deletion took place. Otherwise, we would find **dua 'snake', and **nana 'tooth', with a reflex of $\varnothing$ for final $* \mathrm{~g}$, rather than the attested reflex of $k$.

Table 10.4a: relative chronology of Karian (Barto) sound changes

\begin{tabular}{|l|l|l|l|l|}
\hline & *gutuk 'vagina' & *buruk 'pig & *duag & *nanag 'tooth' \\
\hline$* \mathrm{k}>\varnothing$ & gutu & buru & -- & -- \\
\hline$* \mathrm{~g}>\mathrm{k} / \#$ & -- & -- & duak & nanak \\
\hline & gutu & buru & duək & nanək \\
\hline
\end{tabular}




\subsection{Sound changes in Yaben}

$* \mathbf{k}, * \mathbf{g}>\varnothing / \#$

Word-final $* \mathrm{k}$ deleted, as in *buruk 'pig' $>$ bulu and *gutuk 'vagina' $>$ gutu. As mentioned in Chapter 5, Proto-Numugen *k is optionally realized as a glottal stop word-initially and intervocalically, suggesting that there is a change in progress to prevocalic $* \mathrm{k}$ as well.

Word-final $* \mathrm{~g}$ also deleted, as in *nanag 'tooth' $>$ nana, and *kudag 'fruit' $>$ kuda. Two exceptions to this rule are *yag 'water' > yagu and *yeg 'this' > yegu. These are the only monosyllabic reconstructions ending in ${ }^{*} \mathrm{~g}$, so this may have been a conditioned change that did not apply to monosyllables.

$* \mathbf{k}>s / \mathbf{i}$

${ }^{*} \mathrm{k}$ palatalized to $s$ before $*_{\mathrm{i}}$ in *kibem 'hand drum' > siwamu, and *kikwa- 'chop' > so'o-. ${ }^{126}$

$* \mathbf{e}>\boldsymbol{\partial} / \#$

Word-final *e shifted to $\partial$, as in *ye '1SG' > yə, *ne '2SG', and *weyek NEG > uwə.

$* \mathbf{e}>$ a/_C

Proto-Numugen *e merged with *a as $a$, as in *ked 'blood' > 'adu, and *iwer 'salt' > iwalu.

However, as mentioned in Chapter 5, there is variation between $a$ and $a$ in some words, possibly indicating that this change is still in progress. Additionally, the 3PL pronoun wad retains a, likely influenced by $3 \mathrm{SG}$ wə.

126 Like in Usan and Karian *kikwa also underwent a vowel change which changed the conditioning *i to a back vowel. 
$* a u>o, * a w>o$

Proto-Numugen $*$ a followed by a back vowel ${ }^{*} \mathrm{u}$ or a glide ${ }^{*} \mathrm{~W}$ sometimes coalesced into $o$, as in *ikaw 'dog' > i'o, and and *kurunaw 'liver' > kuluno. However, coalescence is not seen in some other words, such as *niau 'breast' $>$ nyau. It is not clear whether au and $o$ are in free variation synchronically.

\subsection{Sound changes in Parawen}

$* \mathbf{k}, * \mathbf{g}>\varnothing / \#$

Word-final *k deleted, as in *buruk 'pig' > bulu, and *ibituk 'tail feathers' $>$ ibita. Word-final $*_{\mathrm{g}}$ also deleted, as in *ikamag 'sore' > ikama, and *kudag 'fruit' > kura. As in Yaben, this did not apply to monosyllabic *yag 'water' > yaga.

${ }^{*} \mathbf{w}>\varnothing / \#$

Parawen deleted word-final ${ }^{*} \mathrm{w}$, as in *umaw 'black' $>u m a$, *niaw 'breast' $>$ nia, and *ikaw 'dog'>ika.

$* \mathrm{e}>\boldsymbol{a}$

Proto-Numugen *e became $a$, as in *kemi 'bow' $>$ kami, *iwer 'salt' $>i w a r a$, and the pronouns *ye > '1SG' > ya-na, *ne '2sg' > na-na. 


\subsection{Sound changes in Ukuriguma}

Ukuriguma has undergone fewer sound changes than the other Numugen languages. It is an important language for reconstructing Proto-Numugen for two reasons. First, it is the only language to retain final *k, as in *buruk 'pig' > buruk, and *kuduruk 'fly' > kuduruk. It is also, along with Usan, one of the two Numugen languages which did not merge *e and *a.

$* \mathbf{w}>\varnothing / \#$

Like Parawen, Ukuriguma has lost word-final *w, as in *ikaw 'dog' > ika, and *nanaw 'hot' > nana.

$* \mathbf{e}>\boldsymbol{o}$

Proto-Numugen *e has shifted to $o$, as in *uben 'hand, arm' $>$ ubon, *iwer 'salt' $>i w o l$, and *ked 'blood' > kod.

\subsection{Sound changes in Yarawata}

$* \mathbf{k}, * \mathbf{g}>\varnothing / \ldots$

Word-final velar stops *k and *g deleted, as in *buruk 'pig' > bulua and *kuduruk 'fly' > kudulu,

*ikamag 'sore' > ikama, and *kudag 'fruit' > kuda. As with other languages, monosyllabic *yag 'water' $>$ yaga is an exception. 
${ }^{*} \mathbf{w}>\varnothing / \#$

Word-final ${ }^{*}$ w deleted, as in *ikaw 'dog' > ika, *umaw 'black' > uma, and *nanaw 'hot' > nana. There are a couple of words were final ${ }^{*} \mathrm{~W}$ is retained, with no apparant conditioning factor. For example, *waw 'child' > waw, and *niaw 'breast, egg' has the reflexes nia 'egg' and niaw 'breast'.

$* \mathbf{e}>\boldsymbol{a}$

Yarawata merged *e and *a as $a$, as in *iwer 'salt' > iwala, *kesi 'sap' > kasia, and *kemi 'bow' $>$ kamia.

\subsection{Proto-Numugen Reconstructions}

In this section, I list the cognate sets supporting my Proto-Numugen reconstructions. ProtoNumugen reconstructions which have cognates outside of Numugen are listed here, but the cognate sets are only preseneted in Chapter 7 under the relevant PNA reconstruction. Before presenting the cognate sets, I first discuss the reconstruction of Proto-Numugen pronouns and verb suffixes, as well as kinship terms with multiple different stems.

Tables 10.9a-b present free pronouns and possessive pronouns in the Numugen languages, alongside the Proto-Numugen pronoun reconstructions. The free pronouns can be used for both subjects and objects in Yaben and Karian. The corresponces between the free pronouns are straightforward, with only a few irregular changes. Parawen, Ukuriguma, and Yarawata have suffixed the base forms with -na. 


\section{Proto-Numugen pronouns}

Table 10.9a: Proto-Numugen free pronouns

\begin{tabular}{|l|l|l|l|l|l|l|}
\hline Proto-Num. & Yaben & Usan & Karian & Parawen & Ukuriguma & Yarawata \\
\hline *ye 1SG & ye yə & ye & yə & ya-na & e-na & ya-na \\
\hline *ne 2SG & ne $\sim$ yə & ne & nə & na-na & ne-na & na-na \\
\hline *we 3SG & wə wo & wo & wə & wa-na & wo-na & wa-na \\
\hline *in 1PL & in & in & in & ina-na & ino & in-ana \\
\hline *an 2PL & an & an & an & aina & ani & an-ana \\
\hline *wed 3PL & war wor & wuri & war & warina & wodo & wad-ana \\
\hline
\end{tabular}

The Yaben, Parawen, Ukuriguma and Yarawata possessive pronouns are formed by suffixing the reflex of PNA *-ner to the free pronouns. The addition of epenthetic $u$ or $a$ in Yaben, Parawen, and Yarawata is a regular sound change, as is the change of Ukuriguma *e to $o$. The change retention of $* \mathrm{e}$ as $e$ in Ukuriguma 1SG.POSS enor is irregular, but is found also in the 1SG free pronoun and object suffix.

Table 109.b: Proto-Numugen Possessive pronouns

\begin{tabular}{|l|l|l|l|l|l|l|}
\hline $\begin{array}{l}\text { Proto- } \\
\text { Numugen }\end{array}$ & Yaben & Usan & Karian & Parawen & Ukuriguma & Yarawata \\
\hline *yener 1SG & yənalu & yonou & yəna & enara & enor & enara \\
\hline *nener2SG & nənalu & ininou & nəna & nanara & nonor & nanara \\
\hline *wener3SG & wanalu & nonou & wana & wanara & wonor & wanara \\
\hline *iner 1PL & inyinalu & aninou & inyina & inara & inor & inara \\
\hline *aner 2PL & anyinalu & wonou & anyina & ainara & anor & anara \\
\hline *wediner 3PL & wajinalu & wurinou & wajina & warinara & wodor & wadara \\
\hline
\end{tabular}

Yaben and Karian do not mark direct objects on most verbs, but have a special set of objectmarking pronouns used only on the verb 'see'. The $1 \mathrm{SG}$ and $2 \mathrm{SG}$ forms resemble the free pronouns, but are distinct. Free pronouns occur before the negator no, while the object-marking prefix attaches directly to the verb. 

(1001) na nə ma nə-g-ad-i
mother 2SG NEG 2SG.OBJ-see-3SG.NFUT-PST
'Mother didn't see you'

(Yaben)

Furthermore, 3SG objects are not marked, and the plural object prefixes are derived from the free forms plus the additional element *ibə-, which has cognates in other Northern Adelbert languages (PNA *ib-)

Table 10.9c: Proto-Numugen object prefixes for *g
\begin{tabular}{|l|l|l|}
\hline & Yaben & Karian \\
\hline *ye- 1SG & yə- & yə- \\
\hline *ne- 2SG & nə- & nə- \\
\hline$* \varnothing-3 \mathrm{SG}$ & $\varnothing-$ & $\varnothing-$ \\
\hline *inibe- 1PL & inibə- & inyimbə- \\
\hline *anibe- 2PL & anjibə- & anyimbə- \\
\hline *ibe- 3PL & ibə- & ivə- \\
\hline
\end{tabular}

\section{Proto-Numugen subject/tense markers}

Table 10.9d compares the Yaben and Karien non-future/subject markers with the Usan remote past markers ${ }^{127}$, which can be segmented into a subject marker, followed by the past tense marker $-e i$. When the Yaben and Karian non-future markers are used alone, they indicate present tense. If they are followed by the past tense marker $-i$, they indicate past tense. The Usan, Yaben, and Karian forms are used to reconstruct Proto-Numugen past tense/subject markers. ${ }^{128}$

Based on Usan -ei and Yaben and Karien $-i$, it is also possible to reconstruct a Proto-Numugen past tense marekr*-(e)i.

127 Usan also has present and near past markers, whose forms are related to the remote past markers in most cases. I compare the remote past markers here because they are most clearly cognate with Yaben and Karian (as well as other Northern Adelbert languages).

128 Although none of these three languages uses these markers alone to indicate past tense, strictly speaking, but since they are cognate with past tense markers in other Northern Adelbert languages, I assign this meaning to the Proto-Numugen markers as well. 
Table 10.9d: Proto-Numugen tense/subject markers

\begin{tabular}{|l|l|l|l|}
\hline Proto-Num. & Usan (REM) & Yaben (NFUT) & Karian (NFUT) \\
\hline 1SG.PST $*$-Vm & $-V m-e i$ & $-m$ & $-m$ \\
\hline 2SG.PST $*$ Vn & $-V n-e i$ & $-a n$ & $-a n,-ə n$ \\
\hline 3SG.PST $*$-Vr & $-V r-e i$ & $-a d$ & $-a r,-\partial r$ \\
\hline 1PL.PST $*$-min & - Vmin-ei & - min & - min \\
\hline 2PL.PST $*$-man & - Vman-ei & - man & - man \\
\hline 3PL.PST $*$-mid & - Vmir-ei & - mid & - mir \\
\hline
\end{tabular}

\section{Future Tense}

Two sets of future tense/subject markers can be reconstructed for Proto-Numugen, based on the future tense endings in Usan, Yaben and Karian. As discussed in Chapter 4, both Usan and Karian have two sets of markers for future tense. In Usan, the distinction is between future and uncertain future. The semantic distinction between the two sets in Karian is not clear. The first set of Proto-Numugen future tense markers, illustrated in Table 10.9e, is reconstructed based on the Usan future tense markers and the Karian Future I markers. Reflexes are not attested in the Yaben data. There are only two forms reconstructed for this set, *-ib 'SG.FUT', and *-ub 'PL.FUT'.

Table 10.9e: Proto-Numugen future tense/subject markers (set I)

\begin{tabular}{|c|c|c|c|}
\hline ProtoNum & & Usan (Fut) & Karian (Fut I) \\
\hline $1 \mathrm{SG}$ & \multirow{3}{*}{$\begin{array}{l}\text { *-ib }^{\text {'SG.FUT' }}\end{array}$} & $-i b-\hat{a} m$ & \multirow{3}{*}{-ivin } \\
\hline $2 \mathrm{SG}$ & & $-i b-\hat{a} n$ & \\
\hline $3 \mathrm{SG}$ & & $-i b-\hat{a}$ & \\
\hline 1PL & \multirow{3}{*}{$\begin{array}{l}\text { *-ub } \\
\text { 'PL.FUT' }\end{array}$} & -ub-oun & \multirow{3}{*}{-uvun } \\
\hline $2 \mathrm{PL}$ & & -ub-oumon & \\
\hline 3PL & & -ub-our & \\
\hline
\end{tabular}

The Usan (regular) future tense markers shown in Table10.9e are clearly related to the Karian Future I markers, although the paradigms in the two languages have two large differences. First, the 
Usan future tense has a different marker for every person/number combination, while Karian Future I only distinguishes singular and plural. Second, the Usan future tense markers $-i b$ and $-u b$ are followed by the present tense endings, which together form the future tense conjugation. Karian -ivin and -ivun are formed from the elements $-i v$ and $-u v$, followed by Future II markers '1SG.FUT' -in, and '1PL.FUT' -un, respectively. It is not clear whether a Karian speaker would consider -ivin and -uvun to be composed of two morphemes, but this was clearly the case historically, as the first syllables correspond perfectly with Usan $-i b$ and $-u b$.

Table 10.9f shows the second set of reconstructed Proto-Numugen future tense markers, based on the Yaben future markers, the Usan uncertain future markers, and the Karian future II markers. Two irregularities in the correspondence are the loss of the Usan initial vowel, and the change of *e to $o$ in Usan -non '2PL.FUT', and -nor '3PL.FUT'. This rounding was likely influenced by the preceding *u, which has now been lost in Usan. The Proto-Numugen forms (as well as the Yaben and Karian forms) can be further segmented into an initial vowel $*_{-i}$ for singular and $*_{-} \mathrm{u}$ for plural (resembling the

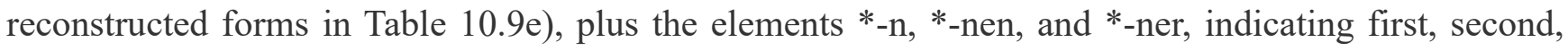
and third person, respectively.

Table 10.9f: Proto-Numugen future tense/subject markers (set II)

\begin{tabular}{|l|l|l|l|}
\hline ProtoNum & Yaben (Fut) & Usan (UF) & Karian (Fut II) \\
\hline $1 \mathrm{SG} *$-i-n & -in & $-n$ & -in \\
\hline 2SG *-i-nen & -inan & -nen & -inan inən \\
\hline 3SG *-i-ner & -inəd & $-n e r$ & -inar inər \\
\hline $1 \mathrm{PL} *$-u-n & -un & $-n$ & -un \\
\hline 2PL *-u-nen & -unan & $-n o n$ & -unan \\
\hline 3PL *-u-ner & -unad & -nor & -unar unər \\
\hline
\end{tabular}


In Usan, negated future events use the uncertain future markers, followed by the suffix -ei, as in the sentence in (1002). In Karian, negated future events use the cognate Future I markers, followed the suffix $-i$, illustrated in (1003). Reflexes of the usual negator *me also precede the verb.

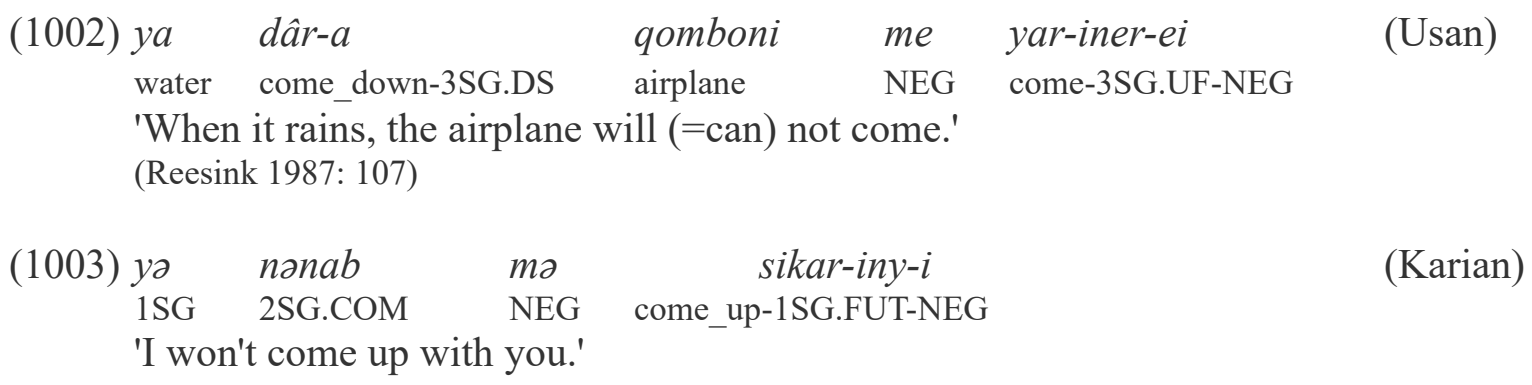

Reesink (1987) writes, "This construction has overtones of ontological impossibility or moral prohibition". It is by no means clear that the equivalent construction in Karian has the same implications, although it is compatible with the Karian data. From the Usan and Karian constructions for negated future events, I reconstruct Proto-Numugen *-(e)i. ${ }^{129}$ This suffix happens to be identical in form with the reconstructed past tense suffix *-(e)i

\section{Kinship terms}

Some kinship terms in Numugen languages have multiple different forms depending on the person and number of the possessor. For example, Usan nani 'mother' is used for first and second person possessors, and unor 'mother' is used for third person possessors. Table 10.9g shows ProtoNumugen reconstructions and supporting word sets for different forms for 'mother', 'father' and 'older brother'.

129 It is not clear if *e should be included in the reconstruction. Word final *-ai is usually reflected as -ai in Usan and -ei in Karian (phonemically /-ai/ with raising of $a$ before $i$ ). However, there are no other reconstructed words which give an indication what the reflex of *-ei would be in the Numugen languages. 
Table 10.9g: Proto-Numugen kinship terms with multiple forms

\begin{tabular}{|l|l|l|l|l|l|l|l|}
\hline & Proto-Numugen & Yaben & Usan & Karian & Parawen & Ukuriguma & Yarawata \\
\hline mother (1) & *na & na & -- & na & - -- & nan & - -- \\
\hline mother (2) & *nain & ninya & nani & ninya & nain, naini & nanine & nai, naini \\
\hline mother (3) & *unad & unadu & unor & unar & unara & unara & unad \\
\hline father (1) & *ta & ta & -- & ta & - - & ta & - -- \\
\hline father (2) & *tain & tinya & tain & tinya & tain, teinie & taino & tai, teini \\
\hline father (3) & *ud & uda & ur & uda & uru & ude & uda \\
\hline older bro (1) & *bab & bavu & -- & bavu & bab & pabe & babo \\
\hline older bro (2) & *bain & bainya & bain & bainya & baini & paina & baini \\
\hline older bro (3) & *umam & umam & umom & umam & uman & umam & umom \\
\hline
\end{tabular}

The sets labeled 'mother/father/older brother' (2) are used for first and second person possessors, while the (3) sets are for third person possessors. Z'graggen does not explicitly label the three forms for Parawen, Ukuriguma, and Yarawata, but I assume that they correspond to first, second, and third person possessors. It is not entirely clear what the distinction between the forms in the (1) and (2) sets are, as the forms in the (1) set are also used with first and second persons in Yaben and Karian.

There are a number of irregularities in the correspondences for *naina 'mother' and *taina 'father'. The Yaben, Usan, and Karian reflexes suggest final segments of the Parawen, Ukuriguma, and Yarawata forms do not fit any regular sound correspondence. Additionally, medial *a has been lost in Yaben and Karian reflexes, and Usan has metathesize *-in to $-n i$ in *nain $>$ nani. ${ }^{130}$ Since there is less information on Parawen, Ukuriguma, and Yarawata, the Proto-Numugen forms are based on Yaben, Usan, and Karian, where the correspondences are more regular.

130 Metathesis of the same segments is seen in Usan inaw < *niaw 'egg, breast' 


\section{Proto-Numugen vocabulary}

Below I present the reconstructed Proto-Numugen vocabulary and supporting cognate sets. For those Proto-Numugen reconstructions which are inherited from PNA, I list the form of the reconstruction below, but the cognate sets are not shown. They can be under the corresponding reconstructed PNA item in Chapter 7. For some body parts and other nouns, Numugen languages have inalienably possessed stem that require a possessor prefix. Thos forms are indicated with a dash before the stem.

*abaw 'net bag' (<PNA *eba)

*ar- 'call' (PNA $<$ *par-)

*arakai 'road' (<PNA *arake)

*awan 'white'

Yab: awanu

Usan: oan

Kar: awan

*bab 'older brother' (<PNA *bab)

*bak-, *bakat- 'carve, sharpen' (<PNA *bak-)

*baina 'older brother (1/2.POSS) (see also *bab, *umam)

Yab: bainya

Usan: bain

Kar: bainya

Yar: baini

Uku: baina

Yar: baini

*barima 'tomorrow, yesterday'

Yaben: balima

Usan: barim

Kar: balima

Par: barimu 'tomorrow'

Uku: barima 'tomorrow'

Yar: balimu balimo 'tomorrow'

*beber 'star'

Par: babara

Uku: bobor

Yar: babala 
Possibly related to PNA *barat 'star, year'

*begen 'light' (<PNA *begen)

*ben 'axe' (<PNA *ben)

*bigu- 'put inside'

Yab: bigw-

Usan: big-

Kar. (Boia): bigu-

Par: bigi-

Uku: $b i-$

Yar: bigi-

Resembles Proto-Tibor *bik- 'put' but the velars don't match in voicing.

*binat (<PNA *bin-at)

*bu 'wing'

Yab: $b u$

Usan: $b u$

Kar. (Boia): $b u$

Par: bua

Uku: $b u$

Yar: bua

*buruk 'pig' (PNA *buruk)

*degen 'long'; right (hand)' (<PNA *degen)

*dibur 'calf'

Yab: jibulu

Usan: dibur

Kar. juwur

*dukun 'cough'

Yab: $d u$ 'un

Usan: duun

Kar. (Boia): dukun

Par: dukan

Uku: dukun

Yar: dukun

The change of $* \mathrm{u}>\mathrm{a}$ in Parawen is unexplained. Resembles Gavak dangun 'cough'.

*egi , *igi'pot'

Usan: egi

Kar: agi

Par: igi

Uku: igi

Yar: igia 
Usan and Karian reflect *egi, while Parawen, Ukuriguma and Yarawata reflect igi.

*erew 'sand' (<PNA *selew)

* git 'body'

Usan: git

Kar: git

*guaten 'leg, bone'

Yab: gwatanu

Usan: goten

Kar: guatan

Par: kuata ([kwat $\Lambda]$ 'bone', [kot $\Lambda]$ 'leg')

Uku: kwoton ([koton] 'bone', [kwoton] 'leg')

Yar: kota ([kwotc] 'bone', [kota] 'leg')

Loss of the final nasal in Parawen and Yarawata is irregular. This could potentially be cognate with Proto-Kumil *okon. This would suggest PNA * $(\mathrm{g} / \mathrm{k})$ uaten, with one group having an irregular change in the initial voicing of the velar.

\section{*gugum 'all'}

Yab: gugum

Usan: gugum

Kar: gugum

\section{*gutuk 'vagina'}

Yab: gutu

Usan: kut

Kar: gutu

Uku: kutuk

Manep kutuk 'vagina' is similar, but the initial velars are not cognate.

*ibi 'feces' (<PNA *ib)

*ikamag 'sore'

Yab: i'ama

Usan: iâm

Kar (Boia): ikaməg

Par: ikama

Uku: ikamak

Yar: ikama

*igem 'green, new' (see also *temen, *gawal)

Usan: igom nob 'green'

Kar: nomim igam 'green'

Par: igama 'new'

Uku: igom 'green' 
Yar: igama

Usan igom is used in other color terms, such as mian nob 'red' (lit: ripe color)

\author{
*igw- 'to be' (<PNA *ig-) \\ *iguar 'penis' (<PNA *iguar) \\ *igum- 'burn' (<PNA *igum-) \\ *ikab 'smoke' (<PNA *ikaw) \\ *ikaw 'dog' \\ Yaben: $i^{\prime} u$ \\ Usan: iau \\ Kar. (Boia): ikuə \\ Kar. (Barto) yi'uə \\ Par: ika \\ Uku: ika \\ Yar: ika
}

*im 'hair' (<PNA *im)

*imeka 'younger brother' (see also *umukuda, *bab)

Yab: ima'a 'younger brother' (all person)

Usan: imâ 'younger brother (1/2 Poss.)'

Kar: imaka 'same sex younger sibling'

Par: imakini 'same sex younger sibling'

Uku: emakina 'same sex younger sibling'

In Usan, the term for 'younger brother' is imâ for a 1/2 person possessoer, and umour for a 3rd person possesor. Yaben $i m a^{\prime} a$ is used for all persons in Z'graggen's (1971b) recording, but an additional term umo'oda, corresponding with Usan umour, is recorded in Z'graggen's (1981b) Yaben wordlist. It is not clear if there is a distinction for person of the possessor for this term in other languages. The Parawen and Ukuriguma terms have an added element of unknown meaning. For the terms for siblings recorded in Z'graggen (1980b), he assumes a semantic distinction between same/opposite sex and older/younger for every language. However, in some languages, such as Usan, the Ego's gender is not, in fact, a relevant factor. Usan imâ is 'younger brother', not 'opposite sex younger sibling'.

\title{
*imekami 'younger sister'
}

Yab: ima'am

Usan: imemi 'younger sister (1/2 Poss), umemi 'younger sister ( $3 \quad$ Poss)

Kar: imakami 'sister'

Karian imakami is used with any person possessor. I also recorded Karian imakira 'younger sister'.

*inukwan 'yesterday'

Par: inukun

Uku: inukwan

Yar: inukun 
*ir- 'go up, ascend' (<PNA *ir-)

*irakai 'crayfish' ( $<$ PNA *areker)

*iram 'stomach' (<PNA *uram)

*it- 'bathe' (<PNA *it-)

*itum 'night'

Yab: itumu

Usan: itum

Kar: itum

Par: itumu

Uku: itum

Yar: itumo

*iwan 'lime'

Yab: iwanu

Usan: uyan

Kar: yuənivi

Par: iwana

Uku: iwan

Yar: iwana

This is likely cognate with PNA *wayay. If so, then Karian is 'white'+'feces'.

*iwer 'salt' (<PNA *iper, see also *yer 'ocean')

*kagam 'smell', *kagam *ig- 'to smell (trs)'

Yab: agamu igu-

Usan: qogom ig-

Uku: kagam okwa-, kagam id-

Yar: [kagan igu-]

The final nasal in Yarawata kagan is not cognate.

*kagi 'left'

Yab: kagiatu

Usan: agi

Kar. (Boia): kagiat

The Yaben and Karian terms also have reflexes of the PNA adjective-forming suffix *-at.

*kai 'sugarcane' (<PNA *kai)

*kamar 'sago' (<PNA *kamar)

*kanam 'sky, cloud'

Yab: kanamu 'sky, cloud'

Kar. (Boia): kanam 'sky, cloud'

Kar. (Barto): 'anam

Yar: ekanama 'cloud'

*karim- 'to swell' (<PNA *karim-) 
* kaur 'top'

Yab: kaulu

Kar (Boia): kaul

*keb 'speech' (<PNA *keb)

*ked 'blood' (<PNA *ked)

*kadat 'red' (PNA *ked-at)

*kei 'some'

Usan: qei

Kar. (Boia): kai

Par: merikauru

Uku: kaur

Yar: kauro

The meaning of the first part of Parawen merikauru is not clear.

*kemer- *kema- 'to speak'

Yab: 'amal-, 'ama-

Usan: qemer-

Kar: kamar-, kam-

Par: kam-

In Yaben and Karian, reflexes of *kemer- are used with future tense and imperatives, and reflexes of *kema- are used for other conjugations.

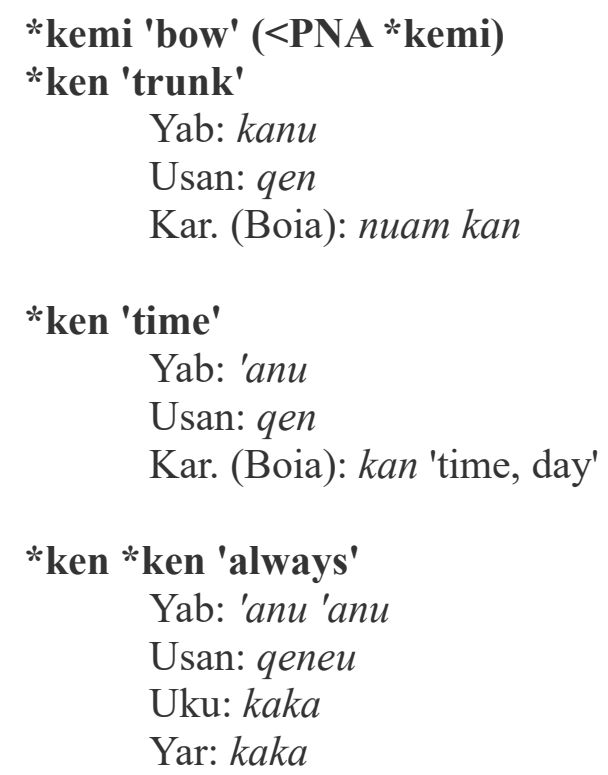

In all languages but Karian, reduplicated reflexes of *kan are used to express the meaning 'always', whereas in Karian it is modified with gugum 'all'. The meaning of *kan is 'time', and reduplicating it gives the meaning 'always'. In Yaben, Ukuriguma, and Yarawata, it is clear that 
reduplicated *kan is two separate words, as Yaben adds word-final $u$ to both syllables, and Ukuriguma and Yarawata, which lost $*_{n}$ word-finally, lost $*_{n}$ in both syllables.

*ken *gugum 'always'

Yab: 'anu gugumu

Kar. Boia: kan gugum

*kereg 'bone'

Yab: 'ala

Usan: qer

Kar. (Boia): karag

Kar. (Barto): 'arak

*kesi 'sap

Yab: 'asi

Usan: esi

Kar: kasi

Par: kasi

Uku: ([kadi])

Yar: kasia

*kibem 'hand drum' (<PNA *kibem)

*kikwa- 'to chop'

Yab: su'uw- [zo?ow-]

Usan: $s u$ -

Kar. (Boia): sukwa-

Par: kikwa-

Uku: kikwa-

Yar: kikw-

Yaben, Usan, and Karian all share the sporadic change of $*_{\mathrm{i}}>\mathrm{u}$.

*kuda, *kudawur 'belly'

Yab: 'udavulu

Usan: qur

Kar. (Barto): 'uravur

Par: kura

Uku: kuda

Yar: kuda

The meaning of the second element in *kudavur is not clear.

*kuda, *nam *kuda 'tree shoot'

Yab: namu 'uda

Kar: nam kuda

*kudag 'fruit' 
Yab: kuda

Usan: qur

Kar. (Boia): kurag

Kar. (Barto): 'urək

Par: kura

Yar: kuda

*kuduruk 'fly' (<PNA *kuduruk)

*kuman 'nape' (<PNA *kumay)

*kuraw 'loincloth'

Usan: qorau

Par: kura

Yar: kula

*kurum 'valley' (<PNA *kurum)

*kurun 'black' (<PNA *kurun, see also PNA *umaw)

*kurunaw 'liver'

Yab: 'uluno

Usan: urunau

Kar. (Boia): kuruna (lungs)

Kar. (Barto): 'urun

It is not uncommon in Northern Adelbert languages to use the same term for 'liver' and 'lungs', although 'lungs is sometimes qualified in some way. For example, Gavak gamemang 'liver, lungs', Moere kema 'liver', kema fon 'lungs' (lit: 'white liver').

*kwari 'tulip tree' (<PNA *kuari)

*kwedi 'banana' (< PNA *kudi)

*kwakan 'old' (<PNA *kuaken)

*kwaiter 'bean'

Par: kwitara

Uku: kwaitor

Yar: kwaitala

*g(a/e)di 'one'

Usan: ger, gari

Kar: geji

*ginam 'village'

Yab: ginamu

Usan: ginam

Kar: ginom

Par: ginama

Uku: ginam

Yar: ginama

*git 'body' 
Yab: gitu

Usan: git

Kar: git

*guan 'skin' (<PNA *guan)

*gwan- 'dig'

*gugum 'all'

Yab: gugumu

Usan: gugum

Kar. (Boia): gugum

*gunei 'yellow'

Yab: gune

Usan: gunai

Kar: gunei

Par: gunei [gun $\Lambda$ :]

Uku: gunei [gune]

*mag 'eye' (<PNA *mudag, *mag)

*mam 'taro' (<PNA *mam)

*mamur 'frog'

Usan: mamur

Kar: mamul

Uku: mamur

*maragwan 'bird' (see also *ibara)

Yab: malVgwanu

Usan: morogoan

Kar. (Boia): maragwən

Kar. (Barto): maragwan

*maymay 'how many'

Yab: maymay

Usan: maymay

Kar. (Boia): mayəmayə

*memer 'tanket'

Yab: mamalu

Usan: momor

Kar: mamal

Uku: momor

*mugam 'forehead'

Yab: mugamu

Kar. Boia: mugəm

Kar. Barto: mugam 
*munen 'man'

Yab: munanu

Usan: munon

Kar: munan

*nam 'tree' (<PNA * yam)

*nanag 'tooth'

Yab: nana

Usan: nân

Kar. (Boia): nanag

Kar/ (Barto): nanək

Par: nanakura

Uku: [nas:g]

Yar: nenakura

Parawen and Yarawata are compounds 'tooth'+'fruit'.

*nanaw 'hot'

Yab: nana

Usan: nanaw

Kar: nano

Par: nana

Uku: nana

Yar: nana

*niaw 'breast, egg'

Yab: nyau

Usan: inaw

Kar: nyuə 'breast'

Par: nia

Uku: $n a$

Yar: nia, niaw

Usan inaw underwent metathesis of the first two segments. Similar metathesis is seen in *nain 'mother' > nani. The Karian speakers I worked with provided munyəg (Boia) and munyək (Barto) for 'egg' (from PNA *munag), and nyuə for 'breast'. Z'graggen records [ñoa] for both.

*nunai 'flying fox'

Yab: nuni

Usan: nunei

Kar: nunei

Par: nuni

Uku: nune

Manep nune nuni may also be related.

*sisir 'mosquito' 
Yab: 'asisilu

Usan: misisir

Kar. Boia: kasisil

Kar. Barto: 'asisil

*tadi 'head'

Yab: taji

Kar. Boia: taji

Kar. Barto: taji

Usan: tari

Par: tarikari

Uku: tarikar

The meaning of the additional element in Parawen and Ukuriguma is unknown.

*taban 'mountain' (<PNA *taban)

*tabin 'plate'

Yab: tawinu

Kar: tavin

Resembles PNA *tabir, but the final consonants are not cognate.

*takwar *war- 'be sick'

Yab: to'wal

Kar. Boia: takwal wal-

Par: takor war-

Uku: tokwala war-

*tat 'sky' (see also (*kanam 'sky')

Usan: tât

Par: tata

*te LOC ( $<$ PNA *te)

*temen 'now' (<temen)

*tuduba 'old'

Yab: tunduva

Kar: tənduba

*tumun 'hole'

Usan: tumun

Kar. Boia: tumun

*ubed, *bed 'good'

Yar: ubada

Usan: uber

Kar: uvar, buər 
Par: buara [boara]

Uku: bor

Yar: bala

*uben 'arm, hand' (<PNA *waben)

Usan: uben

Kar: uvan

Uku: ubon

*ud *war- 'sing' (<PNA *wud, *wud *war-)

*um- 'die' (see PNA *um-)

*um(a/e)kw(a/e)n 'wind'

Yab: uma'wan

Usan: moon

Kar. (Boia): umakwan

Kar. (Barto): umo'on

*umam 'older brother (3.POSS) (see also *bab, *baina)

Yab: umam

Usan: umom

Kar. (Barto): umam

Par: (uman)

Uku: umam

Yar: umom

*umaw 'black'

Usan: umaw

Par: uma

Uku: uma

Yar: uma

*umukuda 'younger brother (3.POSS)

Yab: umu'uda umo?oda

Usan: umour

Kar. (Barto) umuura

*un- 'draw water' (<PNA *un-)

*unad 'female, mother' (PNA *unad)

*urukaur 'buttocks

Yab: urukaulu

Kar. Boia: urukaur

Kar. Barto: uru'aur

*ut- 'give to 3SG' (<PNA *ut-)

*uyak ( $<$ PNA *wayek)

*uw- 'dance' (<PNA *up-)

*uwe NEG (<PNA *wayek) 


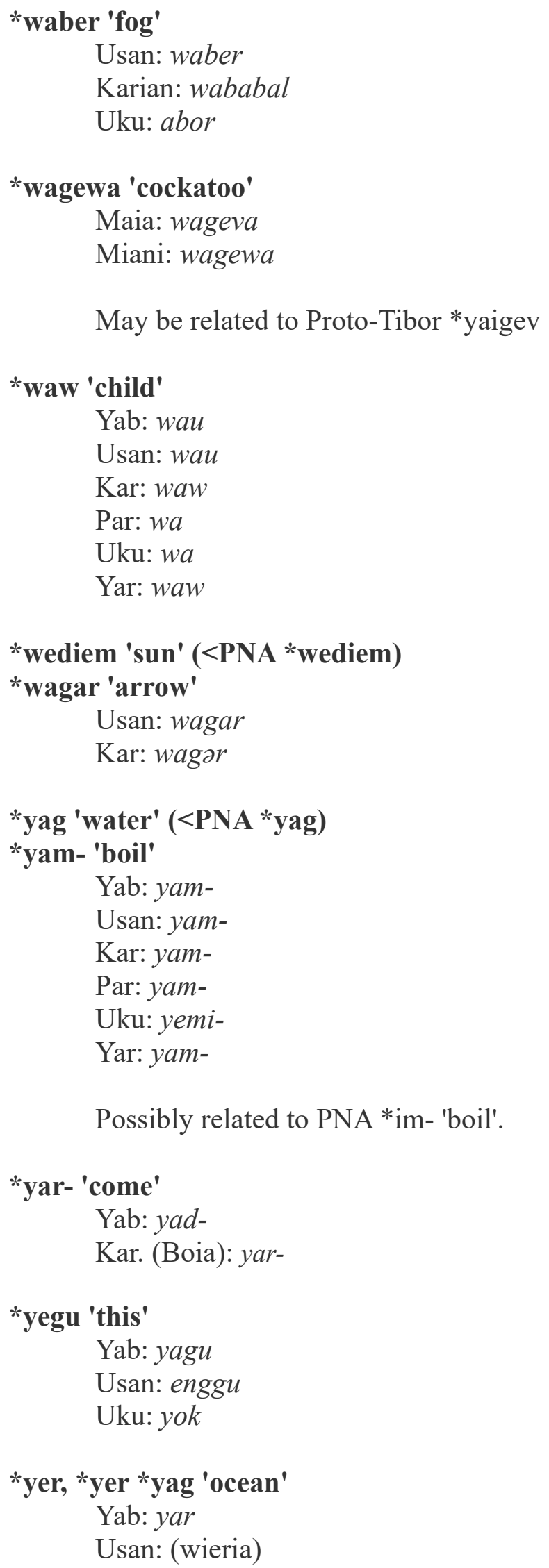


Kar: yar

Par: yar yaga

Uku: yol yag

Yar: yol yaga

Most Northern Adelbert have reflexes of *iper for both 'salt' and 'ocean'. In Numugen, 'ocean' is formed with *yer plus *yag 'water'. Proto-Numugen *yer is similar to *iwer 'salt', the only difference being the lack of medial ${ }^{*} \mathrm{w}$.

\section{*yesi 'navel'}

Yab: yaji

Usan: esi

Kar. (Barto): yasi

Par: yasi

Uku: esi

Yar: yesia 


\section{Proto-Kaukombar}

In this chapter, I reconstruct the Proto-Kaukombar phoneme inventory and lexical items, and discuss sound changes in Kaukombar languages. In section 11.1, I outline the sound correspondences used to reconstruct Proto-Kaukombar phonemes. In section 11.2, I discuss the shared sound changes in the Kaukombar languages relative to Proto-Northern Adelbert. In sections 11.3-11.7, I discuss sound changes that took place in individual Kaukombar languages, and in section 11.8 I present the reconstructed Proto-Kaukombar vocabulary.

\subsection{Proto-Kaukombar phonemes}

Tables 11.1a-b show the Proto-Kaukombar phonemes. Proto-Kaukombar *t has the allophone *[s] before high front vowels, and $*[\mathrm{t}]$ elsewhere. ${ }^{131}$ In the Proto-Kaukombar reconstructions, I have used *t and to represent both these variants, but it should be kept in mind that in some items, this was a fricative.

Table 11.1a: Proto-Kaukombar vowel phonemes

\begin{tabular}{|l|c|c|}
\hline & front & back \\
\hline high & $*_{\mathrm{i}}$ & $*_{\mathrm{u}}$ \\
\hline mid & $*_{\mathrm{e}}$ & $*_{\mathrm{o}}$ \\
\hline lwo & & $*_{\mathrm{a}}$ \\
\hline
\end{tabular}

Table 11.1b: Proto-Kaukombar consonant phonemes

\begin{tabular}{|l|c|c|l|l|}
\hline & labial & alveolar & palatal & velar \\
\hline stop & ${ }^{*} \mathrm{~b}$ & ${ }^{*} \mathrm{~d},{ }^{\mathrm{t}}$ & & $*_{\mathrm{k},}{ }^{\mathrm{g}}$ \\
\hline nasal & $*_{\mathrm{m}}$ & ${ }_{\mathrm{n}}$ & & \\
\hline liquid & & ${ }^{*} \mathrm{r},{ }^{*} \mathrm{l}$ & & \\
\hline glide & ${ }^{*} \mathrm{w}$ & & $*_{\mathrm{y}}$ & \\
\hline
\end{tabular}

$131 *$ also lenited to $s$ in additional environments in some individual Kaukombar languages. 


\section{Kaukombar sound correspondences}

Tables 11.c-f show the sound correspondenes used to reconstruct Proto-Kaukombar phonemes.

Table 11.1c: Kaukombar vowel correspondences

\begin{tabular}{|l|l|l|l|l|l|}
\hline Proto-Kau. & environment & Maia & Maiani & Miani & Mala \\
\hline$*_{\mathrm{i}}$ & & $i$ & $i$ & $i$ & $i$ \\
\hline$*_{\mathrm{u}}$ & & $u$ & $u$ & $u$ & $u$ \\
\cline { 2 - 6 } & $\mathrm{k}_{-}$ & $a, u a$ & $u$ & $u$ & $u$ \\
\hline \multirow{2}{*}{$*_{\mathrm{o}}$} & & $e$ & $e$ & $e$ & $e$ \\
\hline$*_{\mathrm{a}}$ & & $o$ & $o$ & $o$ & $e$ \\
\hline & & $o$ & $o$ & $o$ & $o$ \\
\cline { 2 - 6 } & & $a$ & $a$ & $a$ & $a$ \\
\hline
\end{tabular}

Table 11.1d: Kaukombar glide correspondences

\begin{tabular}{|l|l|l|l|l|l|}
\hline Proto-Kau. & environment & Maia & Maiani & Miani & Mala \\
\hline \multirow{2}{*}{$*_{\mathrm{W}}$} & $\#_{-}$ & $w$ & $w$ & $w$ & $\varnothing$ \\
\cline { 2 - 6 } & $\mathrm{V}_{-}$ & $w$ & $w$ & $w$ & $w$ \\
\hline \multirow{2}{*}{$*_{\mathrm{y}}$} & $\#_{-}$ & $y$ & $y$ & $y$ & $\varnothing$ \\
\cline { 2 - 5 } & $\mathrm{V}_{-} \mathrm{V}$ & $y$ & $y$ & $y$ & $l$ \\
\hline
\end{tabular}

As mentioned above, $*[\mathrm{t}]$ and $*[\mathrm{~s}]$ belong to the same proto-phoneme, with $*[\mathrm{~s}]$ occuring before

high front vowels. *t commonly lenites to $s$ in individual Kaukombar languages adjacent to $e$ and $u$, but this does not seem to follow a strict pattern (see Chapter 5)

There is no clear correspondence for reflexes of medial ${ }^{*} \mathrm{k}$. It tends to delete in Maiani and Miani, but in some cases it it retained. *p does not corresponed with any PNA phoneme, and is only found in one form with apparant cognates outside Kaukombar (Proto-Kaukombar *tapa 'mountain', and Proto-Numugen *taban). 
Table 11.1e: Kaukombar obstruent correspondences

\begin{tabular}{|l|l|l|l|l|l|}
\hline Proto-Kau. & environment & Maia & Maiani & Miani & Mala \\
\hline \multirow{2}{*}{$\mathrm{g}$} & & $g$ & $k$ & $g$ & $k$ \\
\cline { 2 - 6 } & $-\#$ & $\varnothing$ & $\varnothing$ & $\varnothing$ & $k$ \\
\hline$* \mathrm{k}$ & & $k, \varnothing$ & $\varnothing$ & $\varnothing$ & $n g \sim n, \varnothing$ \\
\hline$* \mathrm{~d}$ & $d$ & $t$ & $d$ & $d$ \\
\hline$*_{\mathrm{t}}$ & & $t$ & $t$ & $t$ & $t$ \\
\hline$*_{\mathrm{s}}$ & $s$ & $s$ & $s$ & $s$ \\
\hline$*_{\mathrm{b}}$ & & $b$ & $p$ & $b$ & $b$ \\
\hline$*_{\mathrm{p}}$ & & $p$ & $p$ & $p$ & $p$ \\
\hline
\end{tabular}

Table 11.1f: Kaukombar nasal and liquid correspondences

\begin{tabular}{|l|l|l|l|l|}
\hline Proto-Kau. & Maia & Maiani & Miani & Mala \\
\hline$*_{\mathrm{m}}$ & $m$ & $m$ & $m$ & $m$ \\
\hline$*_{\mathrm{n}}$ & $n$ & $n$ & $n$ & $n$ \\
\hline$*_{\mathrm{r}}$ & $r$ & $r$ & $r$ & $r$ \\
\hline$*_{1}$ & $l$ & $l$ & $r$ & $l$ \\
\hline
\end{tabular}

\subsection{Proto-Kaukombar innovations}

The Kaukombar languages form a clear subgroup, as they closely resemble each other in their lexicons and grammars. May \& Loewecke (1982) state that Maiani speakers are able to understand both Miani and Mala to some degree. The Kaukombar languages share three phonological inovations with respect to Proto-Northern Adelbert:

1) $\mathrm{PNA}^{*} \mathrm{n}, *_{\eta}>\varnothing / \#$

2) $* \mathrm{p}>\mathrm{w} / \mathrm{V}$

3) $* \mathrm{e}>\mathrm{o}$

PNA *n, *n> $\boldsymbol{\gamma} /$ \#

All Kaukombar languages lost $* n$ and $*_{\eta}$ in word-final position, as illustrated in Table 11.2a. 
Table 11.2a: ${ }^{*}$ n, ${ }^{*} \eta>\varnothing / \#$

\begin{tabular}{|l|l|l|l|l|l|}
\hline PNA & $\begin{array}{l}\text { Proto- } \\
\text { Kaukombar }\end{array}$ & Maia & Maiani & Miani & Mala \\
\hline *madey 'man' & *muado & muado & muato & muado & muande \\
\hline *geman 'liver' & *-gema & -gama & -kema & -gema & -kama \\
\hline *kasin 'mosquito & *kasi & asi & asi & asi & ngasi \\
\hline *iben 'vagina' & *-ube & -be & -- & -ube & -- \\
\hline *waben 'hand' & *-wabe & -wabo & -wapu & -wabo & -nambe \\
\hline *bin 'heavy' & *ubi & ubi & upi & ubi & umbi \\
\hline
\end{tabular}

${ }^{*} \mathbf{p}>\mathbf{w} / \mathbf{V}_{-}$

All Kaukombar languages lenited PNA *p to $w$ after a vowel, as illustrated by the reflexes of 'salt', 'fat', 'dance', and 'leaf, hair' in Table 11.2b. Maia lenited *p to $w$ in word-initial position as well. No clear reflexes of reconstructions with word-initial *p have been found Maiani, Miani, or Mala.

Table 11.2b: PNA *p $>$ w/V_V in Kaukombar

\begin{tabular}{|l|l|l|l|l|l|}
\hline PNA & $\begin{array}{l}\text { Proto- } \\
\text { Kaukombar }\end{array}$ & Maia & Maiani & Miani & Mala \\
\hline *iper 'salt, ocean' & *iwer & ivor & -- & iwor & iwer \\
\hline *kapil 'fat' & *kawil & wavil & uwavil & awir & avir \\
\hline *up- 'dance' & *uw- & uv- & $u w-$ & $u w w-$ & $u w-$ \\
\hline *ip 'hair, leaf' & *-iw & wiv 'leaf' & wuiv 'leaf' & wiv 'leaf' & -iv 'hair' \\
\hline $\begin{array}{l}* \text { kupi 'betelpepper } \\
\text { vine' }\end{array}$ & *kuwi & -- & -- & $u w i$ & $u w i$ \\
\hline *pia 'pitpit & -- & wia & -- & -- & -- \\
\hline *par- 'call' & -- & varav 'a call' & -- & -- & -- \\
\hline *pi 'bad' & -- & wiwi & -- & -- & -- \\
\hline *pai 'mango' & -- & vai & -- & -- & -- \\
\hline
\end{tabular}

$* \mathbf{e}>\mathbf{0}$ 
In some words, the Kaukombar languages all underwent a change of $* \mathrm{e}>o$, as seen in the reflexes of PNA *ked 'blood', 'ocean, salt', and *degen 'straight' in Table 11.2c In reflexes of *madey 'man' and *waben 'hand', Mala retains PNA *e.

Table 11.2c: PNA *e $>o$ in Kaukombar

\begin{tabular}{|l|l|l|l|l|l|}
\hline PNA & $\begin{array}{l}\text { Proto- } \\
\text { Kaukombar }\end{array}$ & Maia & Maiani & Miani & Mala \\
\hline *ked 'blood' & *od & -- & ot & od & od \\
\hline *degen 'straight' & *dogo & dogo & tokon- & dogo & doko \\
\hline *begen 'light' & -- & bogo & -- & -- & -- \\
\hline *madey 'man' & *muade & muado & muato & muado & muande \\
\hline *waben 'hand' & *wabe & -wabo & - wapu & -wabo & -nambe \\
\hline *iper 'salt, ocean' & *iwor & ivor & -- & iwor & iwer \\
\hline
\end{tabular}

The change of $* \mathrm{e}>\mathrm{o}$ was not an unconditioned change, as other words retain PNA $* \mathrm{e}$ as $e$, as shown in Table 11.2d. I have not been able to find a clear conditioning factor which causes PNA *e to become $o$ in some words, and retained as Proto-Kaukombar *e in others. However, it may be related to the quality of the following vowel. In the clear cases where PNA *e became Proto-Numugen *e, the following vowel was *a. PNA *a is not found as the following vowel in any of the words where PNA *e became Proto-Kaukombar *o. It is clear that a can have an effect on the quality of preceding vowels in Kaukombar languages, since in Maia and Mala, there was a change of $* \mathrm{e}>a /$ Ca.

Table 11.2d: PNA *e $>e$ in Kaukombar

\begin{tabular}{|l|l|l|l|l|l|}
\hline PNA & $\begin{array}{l}\text { Proto- } \\
\text { Kaukombar }\end{array}$ & Maia & Maiani & Miani & Mala \\
\hline *kenam 'base' & *kenem & $\begin{array}{l}\text { otowanam, } \\
\text { koanam }\end{array}$ & & enam & od \\
\hline *gemay 'liver' & *gema & -gama & -kema & -gema & -kama \\
\hline *nenag 'tooth & *-nenak & -nana & -nena & -nena & -nanak \\
\hline
\end{tabular}




\subsection{Sound changes in Maia}

This section outlines the sound changes that took place in the three Maia varieties Wagedav Maia, Pila, and Saki.

$* k>\varnothing / \# \_$(Wagedav)

In the Wagedav dialect, word-initial *k deleted, as in *kasi 'mosquito' $>$ asi, and *kai 'sugarcane' > ai. Initial *k is usually retained in Saki and Pila (kasi 'mosquito' kai 'sugarcane')

$* \mathbf{g}>\varnothing / \mathrm{VC}_{-} \#$

Word-final *g deleted in polysyllabic words in all Maia varieites, as in *-mudag 'eye' > -muda (Wagedav), -mundua (Pila, Saki), and *-durag 'tail' > -dira (Wagedav, Saki), -dura (Pila). Final *g is retained in monosyllabic words ${ }^{132}$. In Wagedav, this is reflected as $g:{ }^{*}$ yag 'water' $>y a g$, *wag 'hand drum' > wag. In Saki and Pila, final *g has is reflected as a nasal: *yag 'water' > yang, *wag 'hand drum' $>$ wang.

$* \mathbf{e}>\boldsymbol{a} / \mathbf{C a}$

Proto-Numugen *e became $a$ when the following vowel was *a. Examples are *rebam 'four' > rabam (Wagedav), *-gema 'liver' > -gama (Wagedav), goama (Saki, Pila), and *kenam 'base' > koanam (Saki, Pila).

$* \mathbf{a}>u a / k, g_{-}$

Vowels following initial velars have undergone some irregular changes. Proto-Numugen *a sometimes became $u a$ after a velar. This also applied to *e which first became $a$ according to the 132 Monosyllabic words are also an exception to final *g deletion in Maiani and Miani, as well as Numugen languages. 
change $* \mathrm{e}>\mathrm{a} / \mathrm{Ca}$. As can be seen from the reflexes in Table 11.3a, this change did not apply consistently, sometimes applying in only some of the Maia varieties. There are also some words where the change did not apply in any of the three Maia varieties, such as Proto-Numugen *kata 'coconut'> Wagedav ata, Saki and Pila kata, and *karim- 'swell' > Wagedav arim-, Maia and Pila > karim-.

Table 11.3: *a $>u a / \# \mathrm{k}, \# \mathrm{~g}$ in Maia

\begin{tabular}{|l|l|l|l}
\hline Proto-Kaukombar & Wagedav & Saki & Pila \\
\hline *kawil & wavil & koawir & kuawir \\
\hline *-gema & -gama & goama & goama \\
\hline *kamun & wamun & kamung & kuamun \\
\hline *kenam & otowanam & koanam & koanam \\
\hline *kaw & -- & - -- & koaw \\
\hline
\end{tabular}

$* \mathbf{u}>a / \mathbf{k}_{-}$

In all Maia varieties, ${ }^{*} \mathrm{u}$ has become $a$ after $* \mathrm{k}$ in some words. This change occurred in *kuduru 'fly' > Wagedav aduru, Saki kaduru; *kusuwar 'cassowary' > kasiwar (all varieties), *kuwun 'dog' > Wagedav awun, Pila and Saki kawun; and *lakut- 'pour' > Wagedav lakat-. However, in other forms, the change did not take place, as in *kunam 'egg' > unam (Wagedav), kunam (Saki), or *kumui 'bow' > umu (Wagedav), kumu (Saki), kumi (Pila).

\subsection{Sound changes in Maiani}

\section{Stop devoicing}

Maiani voiced stops devoiced in all positions, as illustrated by the reflexes in Table 11.4a. 
Table 11.4a: reflexes of $* \mathrm{~b}, * \mathrm{~d}$, and $* \mathrm{~g}$ in Maiani

\begin{tabular}{|l|l|}
\hline Proto-Kaukombar & Maiani \\
\hline *bug- 'sit' & puk- \\
\hline *tabir 'plate' & tapir \\
\hline *rab 'basket' & rap \\
\hline *dawa 'house' & tawa \\
\hline *kudi 'banana' & uti \\
\hline *od 'blood' & ot \\
\hline *-gema 'liver' & -kema \\
\hline *muga 'bird' & muka \\
\hline *yag 'water' & yak \\
\hline
\end{tabular}

$* \mathbf{k}>\varnothing$

Proto-Numugen *k deleted in all positions in Maiani, as in *kata 'coconut' > ata, *ikaw 'smoke' $>$ iyav, and *-mek 'breast' > -me.

$* \mathbf{g}>\varnothing / \mathrm{VC}_{-} \#$

Word-final *g deleted in polysyllabic words, as in *-nanag 'tooth' > nena, and *mudag 'eye' > muta. It was retained in monosyllabic *yag 'water' > yak.

\subsection{Sound changes in Miani}

$* \mathbf{k}>\varnothing / \#, * \mathbf{k}>\varnothing \_\#$

*k deleted word-initially in Miani, as in *kata 'coconut' > ata, *kasi 'mosquito' > asi, and *kamar 'sago' > amar. *k also deleted word-finally, as in *katek 'galip nut' > ase, and *katok 'wild' > ato.

${ }^{*} \mathrm{~g}>\varnothing / \mathrm{VC} \#$

Word -final *g deleted in monosyllabic words, as in *durag 'tail' > dura, and *-nenag 'tooth' > 
-nenag, but not in monosyllabic *yag 'water' > yag.

$* \mathbf{b}>\boldsymbol{p} / \#$

Word-final *b devoiced, as shown in *-ib 'feces' > -ip and *-eteb 'shoulder > -otop.

$* \mathbf{l}>\boldsymbol{r}$

*1 merged with *r as $r$, as in *ulum 'cloud' > urum, *malip- 'work' > marip-, and *kawil 'fat' > awir.

\subsection{Sound changes in Mala}

$* \mathbf{k}>n g / \#, * \mathbf{k}>\varnothing / / \#$

Word-initially, Proto-Numugen *k became a velar nasal. In some cases, this further shifted to $n$, or there is variation of $n \sim n g$. In other cases, word-initial $* \mathrm{k}$ deleted. These different reflexes of wordinitial $* \mathrm{k}$ do not follow a strict pattern, but there is a strong tendency for ${ }^{*} \mathrm{k}$ to be reflected as $n g \sim n$ before *a. Only avir 'fat' and $a b u$ 'short' delete *k before *a. On the other hand, in all reconstructions where $* \mathrm{k}$ is followed by a vowel other than $* \mathrm{a},{ }^{*} \mathrm{k}$ deletes. Only Table $11.5 \mathrm{a}$ illustrates reflexes of initial $* \mathrm{k}$ in Mala. 
Table 11.5a: reflexes of initial $* \mathrm{k}$ in Mala

\begin{tabular}{|l|l|}
\hline Proto-Kau. & Mala \\
\hline *kai 'sugar' & ngai \\
\hline *kati 'mosquito' & ngasi \\
\hline *karim- 'swell' & ngarim $\sim$ narim \\
\hline *kamun 'pan' & ngamun namun \\
\hline *kamar 'sago' & namar \\
\hline *kata 'coconut' & nata $\sim$ ata \\
\hline *kawil 'fat' & avir \\
\hline *kabu 'short' & abu \\
\hline *-kebuar 'mouth' & -ambar \\
\hline *kuaw 'village' & av \\
\hline *kuduruk 'fly' & uduru \\
\hline *kutuar 'cassowary' & usuar \\
\hline *kumui & mui \\
\hline
\end{tabular}

$* \mathbf{g}>\boldsymbol{k}$

*g devoiced to $k$, as in *igur 'five' > ikur, *muga 'bird' > muka, and *yag 'water' > ak. Other voiced stops retained voicing.

${ }^{*} \mathbf{y}>\boldsymbol{l} / \mathbf{V}_{-}$

*y became $l$ following a vowel, as illustrated in *maya 'what' > mala, *waya 'white' > ala, and *weyek NEG $>$ ila .

${ }^{*} \mathbf{w},{ }^{*} \mathbf{y}>\varnothing / \#$

Word initial glides *w and *y deleted, as in *wat 'pig' > at, *waya 'white' > ala, *yag 'water', ak, and *yau 'who' > ao. 
$* \mathbf{e}>\boldsymbol{a} / \mathbf{C a}$

As in Maia, *e became $a$ when the next vowel was *a, as in *-nenak 'tooth' $>$-nanak, *-gema 'liver, inside' > akama 'inside, and *megera 'tomorrow' > makara.

$* \mathbf{u a}>\boldsymbol{a}$

Proto-Numugen *ua became Mala $a$, as in *-iguar 'penis' $>-k a r, *$-kebuar 'mouth' $>$-ambar, and *muat 'snake' > mat. An uneplained exception is muande 'man' $<*$ muade ${ }^{133}$.

\subsection{Proto-Kaukombar Reconstructions}

In this section, I present Proto-Numugen reconstructions and supporting cognate sets. For Proto-Numugen reconstructions which are inherited from PNA, I list the reconstruction below, but the supporting cognates are found under the entry of the corresponding PNA reconstruction in Chapter 7.

\section{Proto-Kaukombar pronouns}

Table 11.6a illustrates the form reconstructed for Proto-Kaukombar free pronouns and their reflexes in the Kaukombar languages. The free pronouns can be used for subject, objects, and possessors. There are also suffixed forms which can also be used for possessors, shown in Table 11.6b. The sound correspondences are straightforward, with the exception of whether to include *a in the 1PL and 3PL forms. Maiani has lost number distinction in the third person pronouns, and the historically 3SG forms are used for both singular and plural.

133 However, Proto-Numugen *muade 'man' is unusual, since the sequence *ua is not the expected reflex of *a in PNA *madey 'man'. 
Table 11.6a: Kaukombar free pronouns

\begin{tabular}{|c|c|c|c|c|}
\hline $\begin{array}{l}\text { Proto- } \\
\text { Kaukombar }\end{array}$ & $\begin{array}{l}\text { Maia } \\
\text { (Wagedav) }\end{array}$ & Maiani & Miani & Mala \\
\hline 1SG *yo & yo & yo & yo & yono \\
\hline $2 \mathrm{SG} *$ no & no & no & no & nino \\
\hline $3 \mathrm{SG} * \mathrm{o}$ & $o$ & $o$ & $o$ & ono \\
\hline 1PL *yi & $i$ & $i$ & $y i$ & ino \\
\hline $2 \mathrm{PL} * \mathrm{ni}$ & nae & $n i$ & $n i$ & naino \\
\hline $3 \mathrm{PL} * \mathrm{wi}$ & $w i$ & $(o)$ & $w i$ & aino \\
\hline
\end{tabular}

Table 11.6b shows the reconstructed forms for the possessive pronouns. The Maina and Mala forms are notable for having undergone an irregular change of $* n>n g$ in these forms. Velar nasals are rare in Maiani and are usually only found as a reflex of ${ }^{*} \mathrm{k}$ in Mala.

Table 11.6b: Kaukombar possessive pronouns

\begin{tabular}{|l|l|l|l|l|}
\hline $\begin{array}{l}\text { Proto- } \\
\text { Kaukombar }\end{array}$ & $\begin{array}{l}\text { Maia } \\
\text { (Wagedav) }\end{array}$ & Maiani & Miani & Mala \\
\hline $1 \mathrm{SG} *$ yo-nor & yonor & yongor & yono & yongor \\
\hline $2 \mathrm{SG} *^{\text {no-nor }}$ & nonor & nongor & nono & ningor \\
\hline $3 \mathrm{SG} *_{\text {o-nor }}$ & onor & ongor & ono & ongor \\
\hline $1 \mathrm{PL} *$ yi-nor & inor & ingor & yino & ingor \\
\hline $2 \mathrm{PL} *_{\text {ni-nor }}$ & ninor & ninogr & nino & ningor \\
\hline $3 \mathrm{PL} *$ wi-nor & winor & $($ ongor $)$ & wino & aingor \\
\hline
\end{tabular}

\section{Present tense/subject endings}

Table 11.6c shows the reconstructred present tense endings Proto-Kaukombar and their reflexes.

In Maiani, Miani, and Mala, these forms mark subject and present tense, while the cognate forms in Maia mark subject and realis mood (see Chapter 5) ${ }^{134}$. The 2PL and 3PL forms do not correspond exactly, so I do not reconstruct these endings for Proto-Kaukombar.

134 Maia is better documented than the other Kaukombar varieties, and has been the subject of deeper analysis than the others (Hardin 2002). It may be that Hardin's analysis of a realis/irrealis distinction, rather than a tense distinction, is a better fit for the other Kaukombar languages as well. 
Table 11.6c: Proto-Kaukombar present tense/subject endings

\begin{tabular}{|l|l|l|l|l|}
\hline $\begin{array}{l}\text { Proto- } \\
\text { Kaukombar }\end{array}$ & $\begin{array}{l}\text { Maia } \\
(\text { Wagedav })\end{array}$ & Maiani & Miani & Mala \\
\hline $1 \mathrm{SG} *$-mo & $-m o$ & $-a m o$ & $-a m o$ & $-e m$ \\
\hline $2 \mathrm{SG} *$-ia & $-i a$ & $-a r o$ & $-a$ & $-i a$ \\
\hline $3 \mathrm{SG} *$-ad & $-a$ & $-a t$ & $-a n$ & $-a$ \\
\hline $1 \mathrm{PL} *$-mi & $-m i$ & $-a m i$ & - ami & - emi \\
\hline $2 \mathrm{PL}$ & $-m e$ & $-a m e t$ & -ame & -ama \\
\hline $3 \mathrm{PL}$ & $-m o$ & - amot & -amod & -om \\
\hline
\end{tabular}

\title{
Past tense/subject endings.
}

The past tense endings are formed by adding reflexes of Proto-Kaukombar *ge- preceding the present tense endings. In Maia, $-g \mathrm{~V}$ is analyzed as a perfecitve marker, so these endings do not mark past tense, but rather perfective aspect and realis mood.

Table 11.6d: Proto-Kaukombar past tense/subject endings

\begin{tabular}{|c|c|c|c|c|}
\hline Proto-Kau. & $\begin{array}{l}\text { Maia } \\
\text { (Wagedav) }\end{array}$ & Maiani & Miani & Mala \\
\hline $1 \mathrm{SG} *$-ge-mo & -go-mo & -(i)kemo & -(e)gemo & -(i)kem \\
\hline $2 S G *$-g-ia & $-g-i a$ & $-(i) k i$ & -(i)gia & -(i)kia \\
\hline $3 \mathrm{SG} *$-ge-a & $-g-a$ & -(i)ke & -(e)gea & $-(i) k a$ \\
\hline 1PL *-ge-mi & $-g i-m i$ & -(i)kemi & -(i)gimi & -(i)kemi \\
\hline $2 \mathrm{PL}$ & -ge-me & -(i)kemet & -(e)geme & -(i)kama \\
\hline $3 \mathrm{PL}$ & -go-mo & -(i)kemot & -(e)gemod & -(i)kom \\
\hline
\end{tabular}

\section{ProtoKaukombar vocabulary}

\author{
*bab 'older brother' (<PNA *bab) \\ *buai 'breadfruit' \\ Maia (Wagadev): buae \\ Maiani: puai \\ Miani: buae \\ *buga 'post' (<PNA * bugan) \\ *bum- 'to plant' \\ Maia (Wagedav): bum- \\ Maiani: pum-
}


Miani: bum-

*da 'other'

Miani: $d a$

Mala: $d a$

*dai- 'dig'

Maia (Wagedav): daev-

Maia (Saki): dai-

Miani: dai-

Mala: $d a-$

*dam- 'listen, hear'

Maia (Wagedav): dam-

Maia (Saki): dam-

Maiani: tam

Miani: dam-

*dawa 'house'

Maia (Wagedav): dawa

Maia (Saki): dawa

Maia (Pila): dawa

Maiani: tawa

Miani: dua

*dogo 'straight' (<PNA *degen-)

*dogon- 'stand' (<PNA *degen-)

*dudur 'hibiscus'

Maia (Wagedav): dudur

Mala: dudur

*-duwat 'ear'

Maia (Wagadev): -duwat

Maia (Saki): -nduat

Maia (Pila): -nduwat

Maiani: -siwat

Miani: -diwat

Mala: -suat

*-emuar 'friend'

Maia (Wagadev): -emuar

Maiani: -emuar

*-kebuar 'mouth' (<PNA *kebuar)

*gamai 'wind'

Miani: gamai

Mala: kamai 
*-garem 'bone' (< PNA *garem)

*gawut 'smoke'

Maiani: kavus

Mala: kawus

This resemble Proto-Tibor *gawuk 'smoke', but the final consonants do not correspond. Mauwake also has kawus, but this is identifiable as a borrowing based on the lack of final $a$.

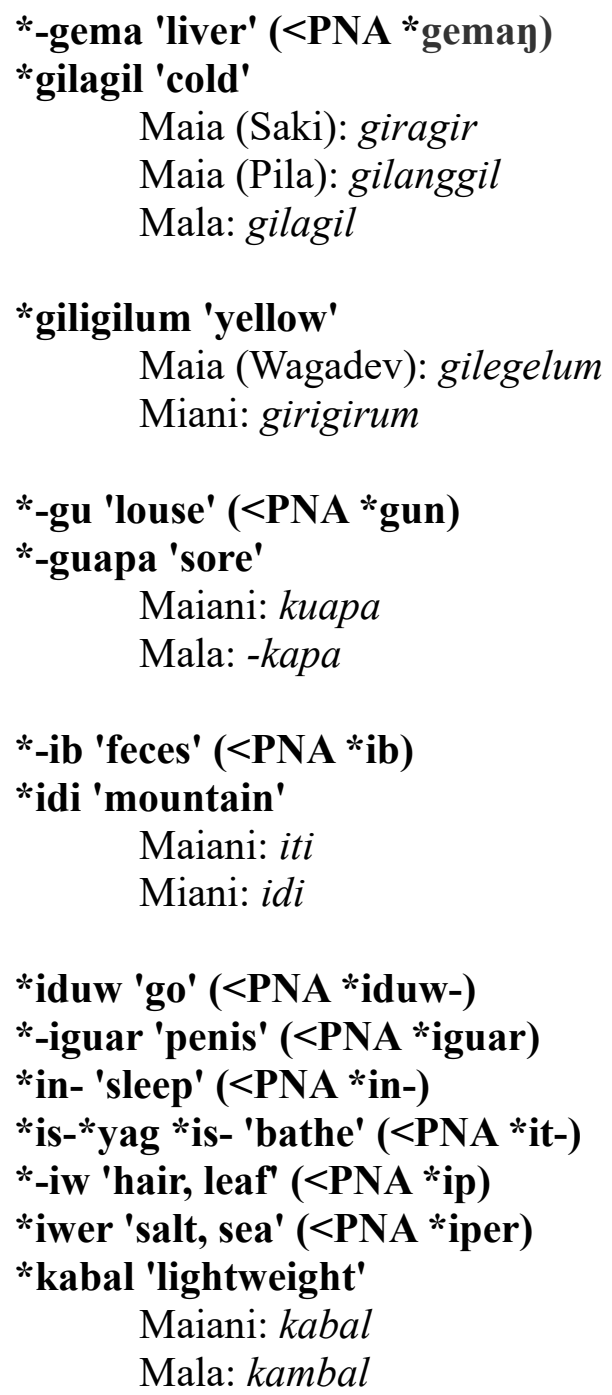

Maiani: at 
Miani: at

Mala: ngat, nat

This resembles Mauwake aasa, but they are not cognate in the final consonant.

*kata 'coconut' (<PNA *keta)

*katek 'galip nut'

Maia (Wagedav): kasek

Mala: ase

*katok 'wild' (<PNA *kasik)

*kawil 'fat' (<PNA *kapil)

*kaw 'black'

Maia (Wagedav): koaw

Maiani: au

Mala: au, ngau

*-kebuar 'mouth' (<PNA *kebuar)

*kenam 'base' (<PNA *kenam)

*kudi 'banana' ( $<$ PNA*kudi)

*kuduru 'fly' (<PNA *kuduruk)

*k(a)ul 'oar'

Maia (Wagedav): kaul

Mala: wol

This also resembles Mauwak wool 'oar', but the lack of final $a$ indicates that it is a loan in Mauwake.

*kumui 'bow' (<PNA *kemi)

*kunam 'egg'

Maia (Wagadev): unam

Maia (Saki): kunam

Miani: unam

Similar in form to Gavak ungam 'egg', but not cognate.

*kuwun 'dog'

Maia (Wagadev): awum

Maia (Saki): kawung

Maia (Pila): kawun

Maiani: uwun

Miani: iwun

*lakut- 'pour'

Maia (Wagadev): lakat-

Miani: rakut-

Mala: lakut- 
*ligam 'yellow'

Maia (Wagadev): aligam

Maia (Saki): karigam

Mala: likam

The initial syllable in Maia is unexpected.

*-made 'body, skin'

Maia (Wagadev): -mado 'body'

Maiani: -mado 'skin'

Miani: -made 'body'

*magaw 'star' (<PNA *megam, *magaw)

*mam 'taro' (<PNA *mam)

*maya 'what' (<PNA *ma)

*me NEG ( $<$ PNA *me)

*-mek 'breast, milk'

Maia (Wagadev): mek

Maia (Saki): -mek

Maiani: ame

Miani: ame

Mala: mek

Similar to PNA *men, but not cognate.

*-mir 'nose'

Maia (Wagedav): -mir

Maia (Saki): -mir

Maini: -mir

*muade 'man' (< PNA *maden)

*muager 'cane'

Miani: moager

Mala: maker

*muala 'wild fowl sp.'

Maia (Pila): moalau

Miani: moara

Mala: mala

There are two similar reconstructions for types of wild fowl, *muala, and *muayaw. Miani is the only language with reflexes attested for both. Miani moara is smaller, and moayaw is larger and has yellow legs.

*muat 'snake'

Maia (Wagedave): muat 
Maia (Saki): moat

Maia (Pila): moat

Maiani: muat

Miani: muat

Mala: mat

*muayaw 'wild fowl sp.' (see *muala)

Maia (Wagedav): maiau

Maia (Saki): moayaw

Miani: moayaw

*mud 'fire' (<PNA *mud)

*muda 'mountain'

Maia (Wagedav): umuda

Maia (Saki): umunda

Maia (Pila): mundoa

Miani: aba muda (lit: 'place mountain')

*mudag 'eye' (<PNA *mudag)

*muga 'bird' (<PNA *mugan)

*mum 'owl' (<PNA *mum)

*nada 'child'

Maia (Wagedav): nada

Maiani: nata

Miani: nada

*nam 'tree' (<PNA * yam)

*-nenag 'tooth' (<PNA *nenag)

*kod 'blood' (PNA *ked)

*orod 'night'

Maiani: orot

Miani: rod

Mala: orod, orond

*pirigan- 'turn'

Maia (Wagedav): pikian-

Miani: pirigan-

*rege 'basket'

Maia (Wagedav): rege

Mala: reke

*tabir 'plate' (<PNA *tabir)

*tabul- 'buy'

Maia (Wagedave): tabul-

Maia (Saki): taboer-

Maia (Pila): tambu- 
Miani: tabur-

Mala: tabul-

*tao 'moon'

Maiani: tao

Miani: tao

Mala: tao

Possibly cognate with Barem tkun 'moon'.

*tapa 'mountain' (<PNA *taban)

*tatar 'chicken' (<PNA *teteri)

*tawa 'fence'

Maia (Wagedave): tava

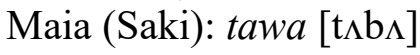

Maia (Pila): tawan

Miani: tawa [tıba]

Final nasal in Pila is unexplained.

*tawur 'ashes'

Maia (Wagedav): tawur

Maia (Saki): tawur

Maia (Pila): ([^bur $])$

Maiani: tawur

Miani: tawur

Mala: (tawuna)

*-tebua 'meat, flesh'

Maia (Wagedave): -sabua

Miani: -sobua

Mala: -tamba

*-tewaw 'egg'

Maia (Pila): sabab

Maiani: utevav

Mala: otovav

*tib, *tibaur 'crayfish'

Maia (Wagadev): sibaur 'lobster'

Maiani: sipaur 'lobster'

Miani: sib 'crayfish'

Mala: simb 'crayfish'

The Maia and Maiani terms are likely bimorphemic, and refer to a specific kind of large crayfish, as they are both glossed 'lobster', while the Miani and Mala terms are glossed 'crayfish'. Mauwake sibaur can be identified as a loanward since it lacks final $a$ and has a voiced stop. 


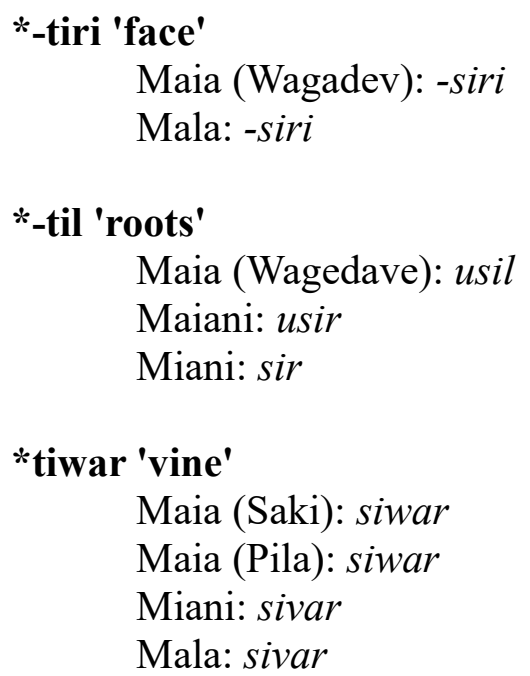

Maia (Wagadev): -siri

Mala: -siri

*-til 'roots'

Maia (Wagedave): usil

Maiani: usir

Miani: sir

*tiwar 'vine'

Maia (Saki): siwar

Maia (Pila): siwar

Miani: sivar

Mala: sivar

*turuw 'loincloth' (<PNA *siruw)

*tutul 'ant sp.'

Maia: susul

Maiaini: tutul

Miani: tutur

*tuwi 'female (of animal)'

Maia (Wagedav): tuvi

Mala: suwi

*-ube 'vagina' (<PNA *iben)

*ubi 'heavy' (<PNA *bin)

*ubueb 'conch'

Maia (Wagedave): ubuev

Maiani: upup

Mala: $u b u b$

*ulum 'cloud, dirty'

Maia (Wagedav): ulum 'dirty' aba ulum 'cloud'

Maia (Pila): ulum 'cloud'

Maiani: ulum

Miani: urum

Mala: ulum

Maia (Wagedav) aba ulum 'cloud' is literally 'place dirty'. The term for cloud in Barem is a similar expression, gaid unun 'sky rubbish'. Reflexes of *ulum are glossed as 'dirty' and 'cloud' in the sources. If they have the sense of 'rubbish' as well, this is not indicated in the sources.

*um- 'to die (<PNA *um-)

*un- 'fill, draw water' (<PNA*un-)

*unu 'ripe' 
Maia (Wagedav): unu

Miani: unu

*utuw- 'push' (<PNA *suw-)

*uw-, *tamag *uw- 'dance' (<PNA *up-)

Maia: uv-, tamang uv-

Maiani: $u w-$

Miani: samag uw-

Mala: $u w$ -

*uyaw 'spear' (<PNA uyaw)

*-wabe 'hand, arm' (PNA *waben)

*wag 'hand drum' (<PNA *wag)

*wage 'crocodile'

Maia (Saki): wake

Maia (Pila): wakei

Miani: wake

*wari 'tulip greens' (<PNA *kuari)

*wat 'pig' (<PNA *wa)

*witir 'centipede' (<PNA *wisir)

*witow 'the bush, forest'

Maia (Saki): wisov

Miani: isov 'deep in the bush'

*yabar 'the bush, forest'

Maia (Wagadev): yabar

Maia (Pila): yambar

Maiani: yapar

*yag 'water'(<PNA *yag)

*yagat 'wet'

Maiani: yakat

Miani: yagat

Mala: akat

This is a combination of *yag 'water' and the PNA adjective-forming suffix *-at. 


\section{Conclusion}

In the preceding chapters, I have reconstructed aspects of Proto-Northern Adelbert, the ancestral language of the 21 modern Northern Adelbert languages, and have presented an internal classification of the group based on shared innovations. I have also reconstructed vocabulary for interstage protolanguages of each Northern Adelbert language subgroup.

So far, I have focused on the relationships of the Northern Adelbert languages with each other. I conclude this work by examining the possible relationships of Northern Adelbert languages with other Papuan languages.

\section{Northern Adelbert and Trans New Guinea}

I have identified regular sound correspondences between the Northern Adelbert languages that establish that they are without a doubt related to one another, and have shown that these languages share verbal morphology that is one of the defining characteristics of the group. However, it is not clear whether this morphology is an innovation of Northern Adelbert or a retention from some higherorder proto-language. Nor has it been possible to establish shared phonological innovations that unite Northern Adelbert as a group, since it does not clearly belong within any higher-order group that has been firmly reconstructed. However, it is widely assumed that the Northern Adelbert languages belong to the Madang branch of the Trans New Guinea phylum. Below I examine this assumption by comparing PNA reconstructions with some of the reconstructions Pawley (Pawley 2011, Pawley \& Hammarström 2018) has proposed for TNG, as well as pronoun reconstructions for Proto-TNG and Proto-Madang proposed by Ross (2000). Table 12.a lists Proto-TNG reconstructions whose forms resemble the corresponding term in PNA. 
Table 12a: Proto-TNG and PNA reconstructions

\begin{tabular}{|c|c|c|}
\hline gloss & Proto-TNG & PNA \\
\hline 'arm, hand' & *mbena & *waben \\
\hline 'older brother' & $*[\mathrm{mb}] \mathrm{amba}$ & *bab \\
\hline 'blood' & *ke(nj,s)a & *ked \\
\hline 'heart' & *kamu & *gemay \\
\hline 'neck, nape' & *kuma(n, $\eta)$ & *kuman \\
\hline 'mosquito' & *kasin & *kasin \\
\hline 'die' & *kumV- & *um- \\
\hline 'sleep' & *kin(i,u)[m]- & *in- \\
\hline 'know, hear, see' & *nVng- & *ag- 'see' \\
\hline NEG & *ma- (+verb) & *me (+verb) \\
\hline 'water' & *ok[V] & *yag \\
\hline 'leaf' & *sasak & *tak \\
\hline
\end{tabular}

Though this list of similar forms isn't long, it contains promising resemblances. There is even some indication of a possible phonological change that could help define northern Adelbert. In 'sleep' and 'die', initial *k has been reconstructed for Proto-TNG, but has been lost in PNA (assuming these are true cognates). However, TNG initial *k corresponds with PNA *k or * $\mathrm{g}$ in other reconstructions. Without more secure TNG reconstructions based on strict sound correspondences, it is not possible to evaluate what could have conditioned the potential change of $* \mathrm{k}>\varnothing$ in these words but not others.

As mentioned above, in previous classifications which have included Northern Adelbert languages, they have all been supposed to belong to the Madang branch of Trans New Guinea. The most important innovations that have been put forward as defining the Madang group are related to pronouns, including the replacement of Proto-TNG *na '1SG', *ga '2SG', *ni '1PL', and *gi '2PL' with Proto-Madang *ya '1SG', *na '2SG', *i- '1PL' and *ni- '2PL' (Ross 2000: 4-5, Pawley \& Hammarström 2018: 59). Table 12.b shows Ross's (2000) reconstructed pronouns for Proto-TNG and Proto-Madang alongside my PNA reconstructions. 
Table 12.b: Reconstructed pronouns for Proto-TNG, Proto-Madang, and PNA

\begin{tabular}{|c|c|c|c|}
\hline & Proto-TNG & Proto-Madang & PNA \\
\hline $1 \mathrm{SG}$ & $*_{\text {na }}$ & *ya & *ye \\
\hline $2 \mathrm{SG}$ & $*_{\mathrm{ga}}$ & *na & *ne \\
\hline $3 \mathrm{SG}$ & $*[\mathrm{y}] \mathrm{a} /{ }^{*} \mathrm{ua}$ & *ua/*nu & *we \\
\hline $1 \mathrm{PL}$ & $*_{\mathrm{ni}}$ & $*_{i-}$ & *yin \\
\hline $2 \mathrm{PL}$ & $*_{\mathrm{gi}}$ & *ni- & *nin \\
\hline 3PL & $*_{\mathrm{i}}$ & -- & *win \\
\hline
\end{tabular}

The PNA pronouns do appear to reflect the Proto-Madang innovations proposed by Ross. The PNA 1SG and 2SG pronouns closely resemble Proto-Madang *ya and *na, as do the 1PL and 2PL pronouns, which differ only in addition of final *n in PNA. Another innovation to Proto-Madang proposed by Ross is the addition of 3SG *nu alongside *ua, which dates back to TNG. PNA does not appear to reflect this innovation. If the proposed innovations to first and second pronouns in ProtoMadang are taken to be one of the defining characteristics of this group, then the case for Northern Adelbert languages' membership in the Madang subgroup is strong.

\section{Northern Adelbert and Sogeram}

Next, I to compare PNA with another potentially related group whose proto-language has been reconstructed in detail. Daniels (2015, 2020) reconstructs numerous lexical items for Proto-Sogeram, based on traditional application of the comparative method. The Sogeram languages are geographically close to the Northern Adelbert languages, and also assumed to belong to the Madang branch of TNG. There is therefore good reason to be optimistic about the prospects of securely establishing a relationship between Sogeram and Northern Adelbert. However, comparison of Daniels's Proto-Sogeram reconstructions and my own PNA reconstructions do not at first glance reveal 
an overwhelmingly obvious connection. However, there are numerous similar-looking forms, some of which are shown in Table 12c.

Table 12c: Proto-Sogeram and PNA reconstructions (Daniels, 2015)

\begin{tabular}{|c|c|}
\hline Proto-Sogeram & PNA \\
\hline *aman 'breast' & *men 'breast' \\
\hline *imu 'put in pot' & *im- 'boil, cook in pot' \\
\hline *inka 'see, perceive' & *ag- 'see' \\
\hline *ir, iri- 'turn, spin' & *girik- 'turn' \\
\hline *kira 'fight' & *war- 'hit, fight' \\
\hline *kimi 'bow' & *kemi 'bow' \\
\hline *kimu 'die' & *um- 'die' \\
\hline *kinta 'walk' & *iduw- 'go' \\
\hline *kintir 'root' & *durun 'root' \\
\hline *kra 'roast' & *id- 'roast' \\
\hline *kuman 'arm, hand' & *waben 'arm, hand' \\
\hline *kuntar 'centipede' & *wisir 'centipede' \\
\hline *mayka 'egg' & *munag 'egg' \\
\hline *-mum 'husband' & *muy 'husband, man' \\
\hline *ña 'eat' & *an- 'eat' \\
\hline *pim 'weight' & *bin 'heavy' \\
\hline *takwi 'snake' & *duag 'snake' \\
\hline *umpay 'heart' & *gemay 'liver' \\
\hline *ura 'call out' & *par- 'call' \\
\hline
\end{tabular}

There is a potential correspondence of Proto-Sogeram initial * $\mathrm{k}$ and PNA $\varnothing$, similar to what is seen in the comparison of PNA and Proto-TNG. However the evidence for this correspondence is somewhat stronger between Sogeram and Northern Adelbert, as the word sets are more numerous. Of the eight *k-initial Proto-Sogeram reconstructions in Table 12c, seven of the corresponding PNA reconstructions have no initial consonant (the exception is Proto-Sogeram *kimi and PNA *kemi 'bow'). However, a good number of the forms in Table 12c are likely due to chance resemblance, and it may not be possible to establish a solid connection between these groups. 


\section{Northern Adelbert and Amako-Waskia}

Now I turn to a group for which it a connection with Northern Adelbert is more secure. This is Amako-Waskia, whose two member languages are spoken on the coast, surrounded by Northern Adelbert languages. Waskia is also spoken on nearby Karkar Island, which it shares with Austronesian Takia speakers.

As mentioned in Chapter 7, I previously included Amako-Waskia as part of Northern Adelbert, as it is possible to establish regular sound correspondences between Amako-Waskia and the Northern Adelbert languages. Table 12d illustrates some stop correspondences between the two groups

Table 12.d: Stop correspondences for Amako-Waskia and PNA

\begin{tabular}{|c|c|c|c|}
\hline gloss & Amako & Waskia & PNA \\
\hline 'hornbill' & bar & baram & *baram \\
\hline 'pig' & bur & buruk & *buruk \\
\hline 'sit' & beng- & -- & *bug- \\
\hline 'year' & -- & barat & *barat \\
\hline 'skin' & -- & guang & *guay \\
\hline 'thick' & uyur & gurum & *gurum \\
\hline 'liver' & gom & gomang & *gemay \\
\hline 'turn' & girka- & gira- & * girik- \\
\hline 'breadfruit' & kid & -- & *kidar \\
\hline 'banana' & kud & -- & *kudi \\
\hline 'lime' & $k a$ & kaur & *kapur \\
\hline 'day, sun' & -- & kam & *kam \\
\hline 'nape' & kumandup $^{135}$ & komang & *kuman \\
\hline 'plate' & taw & tawir & *tabir \\
\hline $\mathrm{LOC}$ & te & te & $*_{\text {te }}$ \\
\hline 'rain' & $t i v$ & tiwik & $* \mathrm{t}(\mathrm{e} / \mathrm{i}) \mathrm{ik}$ \\
\hline
\end{tabular}

From the cognate sets in Table 12.d, it is possible to identify several regular sound correspondences between Amako, Waskia, and PNA. In most cases, stops have the same form across in PNA and Amako-Waskia. PNA initial ${ }^{*} \mathrm{~b},{ }^{*} \mathrm{~g},{ }^{*} \mathrm{k}$, and ${ }^{*} \mathrm{t}$ correspond with $b$-, $g$-, $k$ - and $t$ - in both 
Amako and Waskia. One correspondence where the forms differ is PNA *g to intervocalic $n g$ in Amako. Amako has also notably lost the final syllable of most words.

For the forms in Table 12.d, it is quite straightforward to reconstruct proto-forms for the higher order proto-language that includes Amako-Waskia and PNA. In every case, these reconstructions would in fact be identical to the PNA forms. I exclude Amako-Waskia from Northern Adelbert as they do not share the reconstructed PNA subject endings. However, it may very well be the case that the PNA subject markers are not an innovation exclusive to PNA, but rather a shared retention from the higher-order proto-language which includes the Northern Adelbert languages and Amako-Waskia. In this case Amako-Waskia would be considered another primary branch of PNA. Given the current knowledge of Madang languages, it is not yet possible to determine whether the reconstructed PNA pronouns, as well as other features shared by PNA languages, are retained from a higher-order protolanguage. 


\section{References}

Barker, Fay \& Janet Lee. 1985. Waskia Diksenari: Waskia, Tok Pisin, English. Dictionaries of Papua New Guinea 7. Ukarumpa: Summer Institute of Linguistics.

Berghäll, Liisa. 2015. A grammar of Mauwake. Studies in Diversity Linguistics 4. Berlin: Language Science Press.

Blust, Robert. 1970. i and u in the Austronesian languages. Working Papers in Linguistics 2(6), 113145.

1990. Patterns of sound change in Austronesian languages. In Linguistic change and reconstruction methodology, Trends in Linguistics, Studies and Monographs 45, P. Baldi (ed.) 231-268. Berlin/New York: De Gruyter Mouton.

- 2012. One mark per word? Some patterns of dissimilation in Austronesian and Australian languages. Phonology 29(3), 355-381.

Blust, Robert, and Stephen Trussel. 2020. Austronesian comparative dictionary. www.trussel2.com/ACD.

Bourke, Richard. 2010. Indigenous fruit in Papua New Guinea. In Alan Quartermain and Barbara Tomi (eds.), Fruits and Nuts: Research and Development Issues in Papua New Guinea. Workshop Proceedings No. 9, 39-48. Lae: National Agricultrual Research Institute.

Bowern, Claire, Patience Epps, Russell Gray, Jane Hill, Keith Hunley, Patrick McConvell, \& Jason Zentz. 2011. Does lateral transmission obscure inheritance in hunter-gatherer languages? PLoS ONE 6(9), e25195.

Bybee, Joan. 2000. Lexicalization of sound change and alternating environments. In Michael B. Broe and Janet M. Pierrehumbert (eds.), Laboratory Phonology V: Acquisition and the Lexicon, 250268. Cambridge: Cambridge University Press. 
Bybee, Joan. 2002. Word frequency and context of use in the lexical diffusion of phonetically conditioned sound change. Language Variation and Change 14, 261-290

Capell, Arthur. 1952a. Languages of the Bogia District, New Guinea. Oceania 22(2), 130-147.

—. 1952b. Languages of the Bogia District, New Guinea (Continued). Oceania 22(3), 178-207. . 1962. A Linguistic Survey of the South-Western Pacific. Noumea: South Pacific Commision, Technical Paper No. 70 .

Chinnery, E. 1923. Vocabularies of Native languages: portions of Aitape, Madang and Morobe Districts. New Guinea Annual Report 1923-4, 87-92 (Australia House)

Clayton, Ian. 2010. On the natural history of preaspirated stops. Doctoral dissertation. University of North Carolina: Chapel Hill

Comrie, Bernard. 1985. Tense. Cambridge: Cambridge University Press.

—. 2003. Recipient person suppletion in the verb" give". In T. N. Headland \& R. M. Brend (eds.), Language and life: Essays in memory of Kenneth L. Pike, 265-281. SIL International and the University of Texas at Arlington.

Corbett, Greville G. 2000. Number. Cambridge Textbooks in Linguistics. Cambridge University Press. Daniels, Don. 2010. A preliminary phonological history of the Sogeram languages of Papua New Guinea. Oceanic Linguistics 49(1), 163-193.

- 2015. A Reconstruction of Proto-Sogeram Phonology, Lexicon, and Morphosyntax. Doctoral dissertation. University of California, Santa Barbara.

- 2020. Grammatical reconstruction: The Sogeram languages of New Guinea. Berlin/Boston: De Gruyter.

Durie, M. 1986. The grammaticization of number as a verbal category. In Annual Meeting of the Berkeley Linguistics Society 12, 355-368. 
Eberhard, David M., Gary F. Simons, and Charles D. Fennig, eds. 2020. Ethnologue: Languages of the World. Twenty-third edition. Dallas, Texas: SIL International. Online version: http://wwwethnologue-com

Easton, Catherine. 2000. Amben alphabet development workshop: 4th - 14th December. Unpublished manuscript. Ukarumpa: Summer Institute of Linguistics.

Fam, Jink, Silim R. Jombo, \&Iloi Nembenian. 2000. Upper Amben trial spelling guide. Madang: Summer Institute of Linguistics.

Fedden, Sebastian. 2010. Ditransitives in Mian. In Andrej Malchukov, Martin Haspelmath, and Bernard Comrie (eds.), Studies in Ditransitive Constructions: A Comparative Handbook, 456485. Berlin/New York: De Gruyter Mouton.

Foley, William A. 1986. The Papuan Languages of New Guinea. Cambridge: Cambridge University Press.

- 2000. The Languages of New Guinea. Annual Review of Anthropology 29, 357-404.

Gasaway, Eileen, Patricia M. Lillie, and Heather Sims. 1992. Girawa grammar. Unpublished manuscript, Summer Institute of Linguistics.

Gildipasi Plening Komiti. 2016. Revival of traditional knowledge and revitalization of culture (kastom) within Gildipasi area.

Haantjens, H.A., E. Reiner, R.G. Robbins and J.C. Saunders. 1976. Land systems. In R.G. Robbins, (ed.), Lands of the Ramu - Madang area, Papua New Guinea [Land Research series 37], 18-57. Melbourne: Commonwealth Scientific and Industrial Research Organisation.

Haiman, John and Pamela Munro (eds.). 1983. Switch Reference and Universal Grammar: Proceedings of a Symposium on Switch Reference and Universal Grammar, Winnipeg, May 1981. Amsterdam: John Benjamins. 
Hardin, Barbara. 2002. Maia grammar essentials. Unpublished manuscript, Summer Institute of Linguistics.

Hardin, Barbara, Eunice Loeweke, Jean May, Mavis Price, Susan Richardson, Edwin Richardson, \& Linda Weisenberger. 2007. Maia-English-Tok Pisin Dictionary. Unpublished manuscript, Summer Institute of Linguistics.

Hepner, Mark. 2006. Bargam grammar sketch. Unpublished manuscript. Ukarumpa, PNG: Summer Institute of Linguistics.

—. 2007. Bargam dictionary. Unpublished manuscript. Ukarumpa, PNG: Summer Institute of Linguistics.

Holton, Gary, Marian Klamer, František Kratochvíl, Laura C. Robinson, \& Antoinette Schapper. 2012. The historical relations of the Papuan languages of Alor and Pantar. Oceanic Linguistics 51(1), 86-122.

Hollrung, M. 1887. Erstes Verzeichnis von Wörtern des Dialektes, welcher von der Eingeborenen in den Umgebung von Hatzfeldhafen gesprochen wird. Nachrichten aus dem Kaiser Wilhemsland 3: $85-7$.

Holzknecht, Susanne. 1988. Word taboo and its implications for language change in the Markham family of languages, PNG. Language and Linguistics in Melanesia, 18(1-2), 43-69.

Järvinen, Liisa, Poh San Kwan \& Saror Aduna. 2001. Mauwake dictionary. Unpublished manuscript. SIL archives, Ukarumpa, Papua New Guinea.

Järvinen, Liisa. 1980. Relative constructions in Mauwake. Unpublished manuscript. SIL archives, Ukarumpa, Papua New Guinea.

-1988a. Focus marking in Mauwake. Language and Linguistics in Melanesia 19, 81-96.

—. 1988b. Mauwake dialect survey. Unpublished manuscript. SIL archives, Ukarumpa, Papua New Guinea. 
- 1989. A phonological description of Mauwake. Unpublished manuscript. SIL archives, Ukarumpa, Papua New Guinea.

1990. Mauwake orthography. Unpublished manuscript. SIL archives, Ukarumpa, Papua New Guinea.

— 1991. The pronoun system of Mauwake. In Tom Dutton (ed.), Papers in Papuan linguistics, vol. 1 (Pacific Linguistics A-73), 57-95.

Kenikos, Muks \& Pisen, Jack. Trial Spelling Guide for the Amben Noman language. Madang: Summer Institute of Linguistics.

Kwan, Poh San. 1980. Mauwake (Ulingan) grammar essentials. Unpublished manuscript. SIL archives, Ukarumpa, Papua New Guinea.

— 1983. Transitivity and verb classes in Mauwake. Unpublished manuscript. SIL archives, Ukarumpa, Papua New Guinea.

— 1988. Background study of the Mauwake-speaking people of Madang. Unpublished manuscript. SIL archives, Ukarumpa, Papua New Guinea.

—. 1989. The referential meanings of kema 'liver' in Mauwake. In Karl Franklin (ed.), Studies in componential analysis, vol. 36 (Data papers on Papua New Guinea languages), 4736.

—. 2002. Topicalization in Mauwake. MA thesis. Northern Territory University.

Lillie, Patricia M. 1999. Girawa dictionary. Unpublished manuscript. SIL archives, Ukarumpa, Papua New Guinea.

2001. Amaimon organized phonology data. Unpublished manuscript. SIL archives, Ukarumpa, Papua New Guinea.

Löffler, Ernst. 1977. Geomorphology of Papua New Guinea. Canberra: Australian National University Press. 
MacEachern, Margaret R. 1999. Laryngeal cooccurrence restrictions. New York: Garland.

—. 2002. Ofo co-occurrence restrictions. International Journal of American Linguistics, 68(3), $366-370$.

May, Jean. 1994a. Organised Phonology Data: Maiani (Tani, Miani South) Language [TNH], Madang Province.

—. 1994b. Organised Phonology Data: Miani (Tani, Miani North) Language [PLA], Madang Province.

May, Jean \& Loeweke, Eunice. 1982a. A Recommended Alphabet for Maiani, Miani, Mala and MaiaFour Languages of the Kaukambaran Language Family. Unpublished manuscript. SIL archives, Ukarumpa, Papua New Guinea.

- 1982b. Grammar of Maiani, Miani and Mala-- three languages of the Kaukombaran language family. Unpublished manuscript. SIL archives, Ukarumpa, Papua New Guinea.

"Maiani" 1975. Unpublished manuscript. SIL archives, Ukarumpa, Papua New Guinea.

McElhanon, K. A. \& Voorhoeve, C. L. 1970. The Trans-New Guinea phylum: Explorations in deeplevel genetic relationships. Pacific Linguistics B-16.

Meinerzag, Angella. 2015. Being Mande: Person, Land and Names, Among the Hinihon in the Adelbert Range, Papua New Guinea. Heidelberg Studies in Pacific Anthropology 3. Universitätsverlag Winter: Heidelberg.

"Miani". 1975. Unpublished manuscript. SIL archives, Ukarumpa, Papua New Guinea.

Mühlhäusler, Peter. 1985. 'Syntax of Tok Pisin'. In Wurm, S. A., \& Mühlhäusler, P, eds. Handbook of Tok Pisin (New Guinea Pidgin), 341-421. Pacific Linguistics, The Australian National University.

_. 1996. Linguistic Ecology: Language change and linguistic imperialism in the Pacific region. London and New York: Routledge. 
O'Grady, Geoff N. 1998. Toward a Proto-Pama-Nyungan stem list, Part I: sets J1-J25. Oceanic Linguistics 37(2), 209-33

Ohala, J. I983. The origin of sound patterns in vocal tract constraints. In P.F. MacNeilage (ed.), The production of speech. New York: Springer Verlag. I 8

Palosaari, Naomi and Campbell, Lyle. 2011. Structural aspects of language endangerment. In Peter Austin and Julia Sallabank (eds.), Cambridge handbook of endangered languages, 100-119. Cambridge: Cambridge University Press.

Pawley, Andrew. 2001 The Proto-Trans New Guinea obstruents: arguments from top-down reconstruction. In Andrew Pawley, Malcolm Ross, and Darrell Tryon (eds.), The Boy from Bundaberg: Studies in Melanesian Linguistics in Honour of Tom Dutton. Canberra: Pacific Linguistics, 261-300.

Pawley, Andrew. 2005. 'The chequered career of the Trans New Guinea Hypothesis: recent research and its implications', in Andrew Pawley, Robert Attenborough, Jack Golson and Robin Hide (eds.), Papuan pasts: Cultural, linguistic and biological histories of Papuan-speaking peoples, 67-107. Canberra: Pacific Lingsuistics

2011. Some Trans New Guinea etymologies. Computer file. Department of Linguistics, School of Culture, History and Language, College of Asia and the Pacific, Australian National University.

Pawley, Andrew \& Harald Hammarström. 2018. The Trans New Guinea family. In B. Palmer (ed.), The Languages and Linguistics of the New Guinea Area: a Comprehensive Guide, 21-196. Berlin/Boston: De Gruyter Mouton.

Petir, Amova, Dum Materem, Pakong Yapong, Sakel Mukarek, Moyang Okira, \& Tim Platts-Mills. 1996. Useful Plants of Salembem Village, Madang Province, Papua New Guinea. Madang: Kristen Pres. 
Phillips, Betty. 1984. Word frequency and the actuation of sound change. Language 60, 320-342.

—. 2006. Word frequency and lexical diffusion. New York: Palgrave Macmillan.

Pierrehumbert, Janet. 2002. Word-specific phonetics. In Carlos Gussenhoven \& Natasha Warner (eds.), Laboratory Phonology VII, 101-140. Berlin: Mouton/de Gruyter.

Pick, Andrew. 2018. Yamben: A previously undocumented language of Papua New Guinea. In Mitsuko Suzuki (ed.), Proceeding of the 22nd Annual Graduate Student Conference College of Languages, Linguistics and Literature. National Foreign Language Resource Center, University of Hawaii Manoa.

Pick, Andrew. Forthcoming. A reconstruction of Proto-Northern Adelbert phonology and lexicon. In Patience Epps, Danny Law, and Na’ama Pat-El (eds.), Historical Linguistics and Endangered Languages: Exploring Diversity in Language Change. (Routledge Series in Historical Linguistics.) New York: Routledge.

"Qkuan Kambuar stories," n.d.

Reesink, Ger P. 1981. Grammatical features of cohesion in Usan: Towards a text differential. In Karl J. Franklin (ed.), Syntax and semantics in Papua New Guinea languages, 173-209. Ukarumpa: Summer Institute of Linguistics.

Reesink, Gerard P. 1983. On subordination in Usan and other Papuan languages. In Simon C. Dik (ed.), Advances in functional grammar, 225-243. Dordrecht: Dordrecht/Cinnaminson: Foris.

-1987. Structures and their Functions in Usan: a Papuan Language of Papua New Guinea.

Amsterdam: John Benjamins.

—., n.d. Usan Word List, Madang Province. Unpublished manuscript. SIL archives, Ukarumpa, Papua New Guinea.

—. 1993. "Inner speech" in Papuan Languages. Language and Linguistics in Melanesia, 24(2) $217-225$. 
Roberts, John R. 1987. Amele. London: Croom Helm.

—. 2016. Amele RRG Grammatical Sketch. Unpublished manuscript. SIL archives, Ukarumpa, Papua New Guinea.

Ross, Malcolm. 2000. A preliminary subgrouping of the Madang languages based on pronouns.

Unpublished manuscript, Australian National University.

- 2005. Pronouns as a preliminary diagnostic for grouping Papuan languages. In A. Pawley, R.

Attenbourough, J. Golson, and R. Hide (eds.), Papuan pasts: Cultural, linguistic and biological histories of Papuan-speaking peoples, 15-65. Canberra: Pacific Linguistics.

Ross, Malcolm. \& Paol, John. N. 1978. A Waskia Grammar Sketch and Vocabulary. Canberra: Pacific Linguistics.

Schebesta, J. 1940. Terms expressing relationship in the languages of Dagoi and Bonaputa-Mopu, New Guinea. Anthropos 35-36, 586-92.

Schmidt, W. 1900. Die Sprachlichen Verhältnisse von Deutsch-Neuguinea. Zeitschrift für afrikanische und ozeanische Sprachen 5, 354-84.

Sharp, Timothy L.M. 2012. Following Buai: The highlands betel nut trade, Papua New Guinea. Doctoral dissertation. Australian National University.

Short, Karen. 1976. Climate. In R.G. Robbins (ed.), Lands of the Ramu - Madang area, Papua New Guinea [Land Research series 37]. 58-70. Melbourne: Commonwealth Scientific and Industrial Research Organisation.

Siewierska, A.2003. Person agreement and the determination of alignment. Transactions of the Philological Society, 101(2), 339-370.

Silverman, D. 2003. On the rarity of pre-aspirated stops. Journal of Linguistics, 39(3), 575-598. 
Simons, Gary F. 1982. Word taboo and comparative Austronesian linguistics. In Halim, Carrington and Wurm (eds.), Papers from the Third Annual Conference on Austronesian linguistics, vol 3, 157-226. Camberra: Pacific Linguistics.

Simons, Gary F. \& Fennig, Charles D., eds. 2020. Ethnologue: Languages of the World, Twentysecond edition. Dallas, Texas: SIL International. Online version: http://www.ethnologue.com.

Tadmor, Uri, Martin Haspelmath, and Bradley Taylor. 2010. Borrowability and the notion of basic vocabulary. Diachronica 27(2), 226-246

Tupper, Ian. 2012. A Grammar of Pamosu. Doctoral dissertation. La Trobe University

Wurm, S. A., C. L. Voorhoeve, \& K. A McElhanon. 1975. The trans New Guinea phylum in general. In S.A. Wurm (ed.), Papuan languages and the New Guinea Linguistic Scene. (Pacific Linguistics C-38), 299-322. Canberra: Pacific Linguistics.

Z'graggen, John. A. 1969. Classificatory and Typological Studies in Languages of the Western Madang District, New Guinea. Doctoral dissertation. The Australian National University.

-1971a. Classificatory and Typological Studies in Languages of the Madang District, Papua New Guinea. (Pacific Linguistics C-19). Canberra: Pacific Linguistics.

—. (collector), 1971b. John Z'graggen's recordings. Collection JZ2 at catalog.paradisec.org.au [Open Access]. https://dx.doi.org/10.26278/5b4e128c8ee73

—. 1975a. The Languages of the Madang District, Papua New Guinea. Canberra: Pacific Linguistics.

— 1975b. The Madang-Adelbert Range subphylum. In Papuan Languages and the New Guinea Linguistic Scene. (Pacific Linguistics C-38), ed. by S. A. Wurm, 569-612. Canberra:

Pacific Linguistics.

- 1980a. A comparative word list of the Rai Coast languages, Madang Province, Papua New

Guinea. (Pacific Linguistics D-30). Canberra: Pacific Linguistics. 
1980b. A comparative word list of the Northern Adelbert Range languages, Madang

Province, Papua New Guinea. (Pacific Linguistics D-31). Canberra: Pacific Linguistics.

- 1980c. A comparative word list of the Mabuso languages, Madang Province, Papua New

Guinea. (Pacific Linguistics D-32). Canberra: Pacific Linguistics.

-1980d. A comparative word list of the Southern Adelbert Range languages, Madang Province, Papua New Guinea. (Pacific Linguistics D-33). Canberra: Pacific Linguistics.

Zöller, H. (1890). Untersuchugen über 24 Sprachen aus dem Schutzgebiet der Neuguinea-Compagnie.

A. Petermanns Mitteilungen aus Justus Perthes' Geographischer Anstalt, 36, 122-128. 